Fall 1993

\title{
1993 Miracle Yearbook
}

Cedarville College

Follow this and additional works at: https://digitalcommons.cedarville.edu/yearbooks

Part of the Higher Education Commons, Organizational Communication Commons, and the Public Relations and Advertising Commons

\section{Recommended Citation}

Cedarville College, "1993 Miracle Yearbook" (1993). Yearbooks. 26.

https://digitalcommons.cedarville.edu/yearbooks/26

This Book is brought to you for free and open access by DigitalCommons@Cedarville, a service of the Centennial Library. It has been accepted for inclusion in Yearbooks by an authorized administrator of DigitalCommons@Cedarville. For more information, please contact digitalcommons@cedarville.edu. 


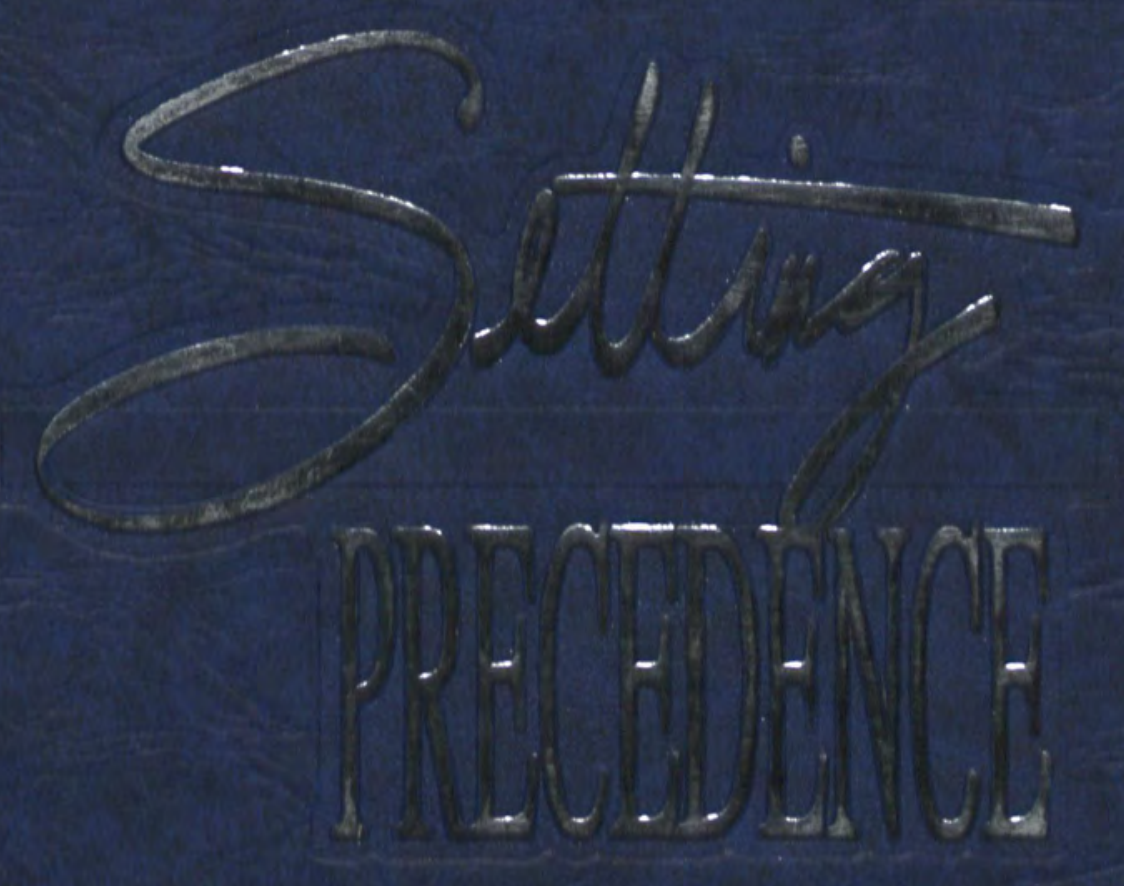





\begin{tabular}{|c|c|}
\hline Opening & 1 \\
\hline Student Life & 10 \\
\hline Faculty/Staff Portraits & 36 \\
\hline Underclass Portraits & 42 \\
\hline Organizations & 72 \\
\hline Christian Ministries & 104 \\
\hline Sports & 134 \\
\hline Fine Arts & 162 \\
\hline Seniors & 184 \\
\hline Patrons & 230 \\
\hline Index & 234 \\
\hline Closing & 238 \\
\hline $\begin{array}{lllll}M & \text { I } & R & A & C\end{array}$ & E \\
\hline
\end{tabular}



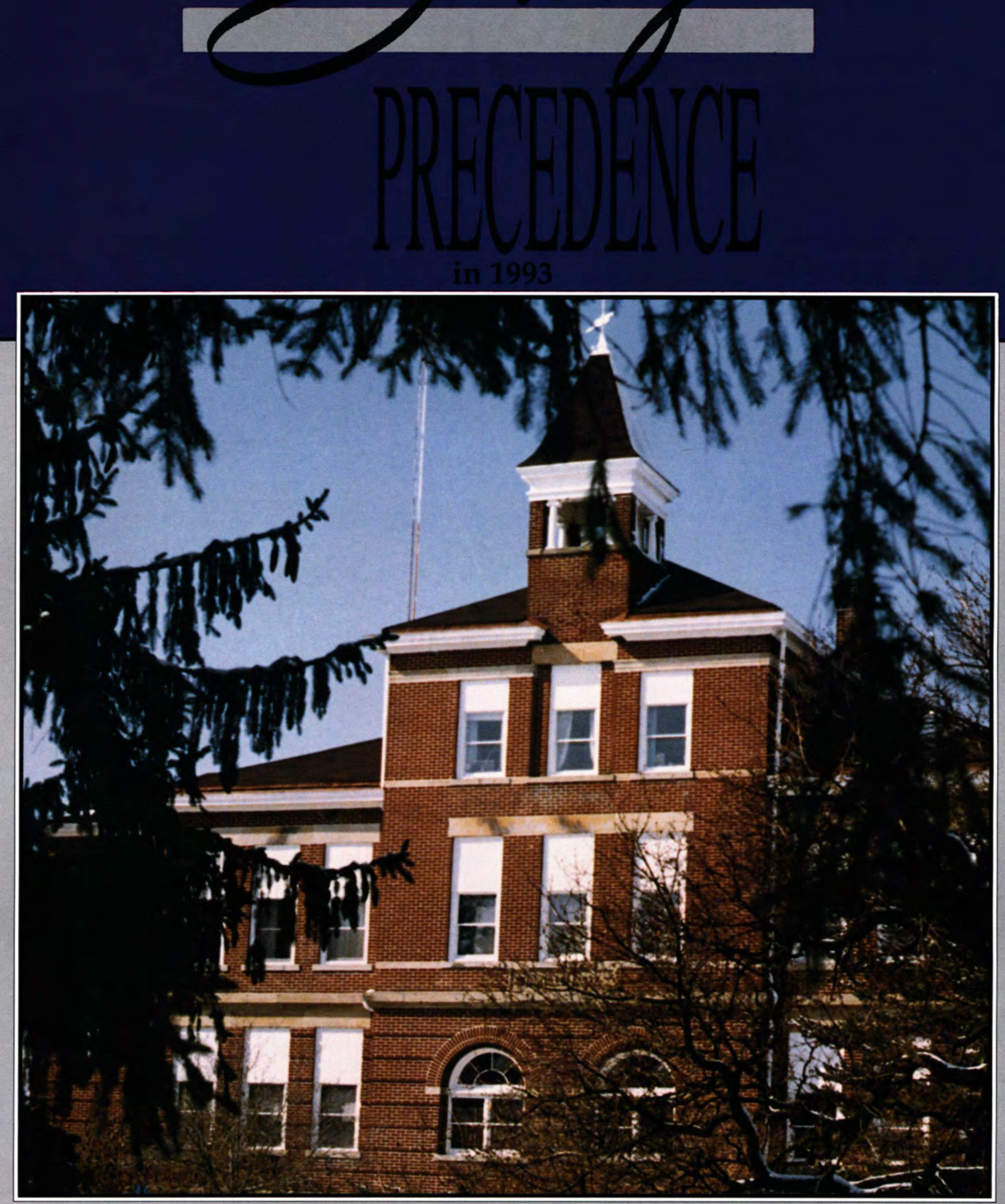

Cedarville College 


\section{A Precedent}
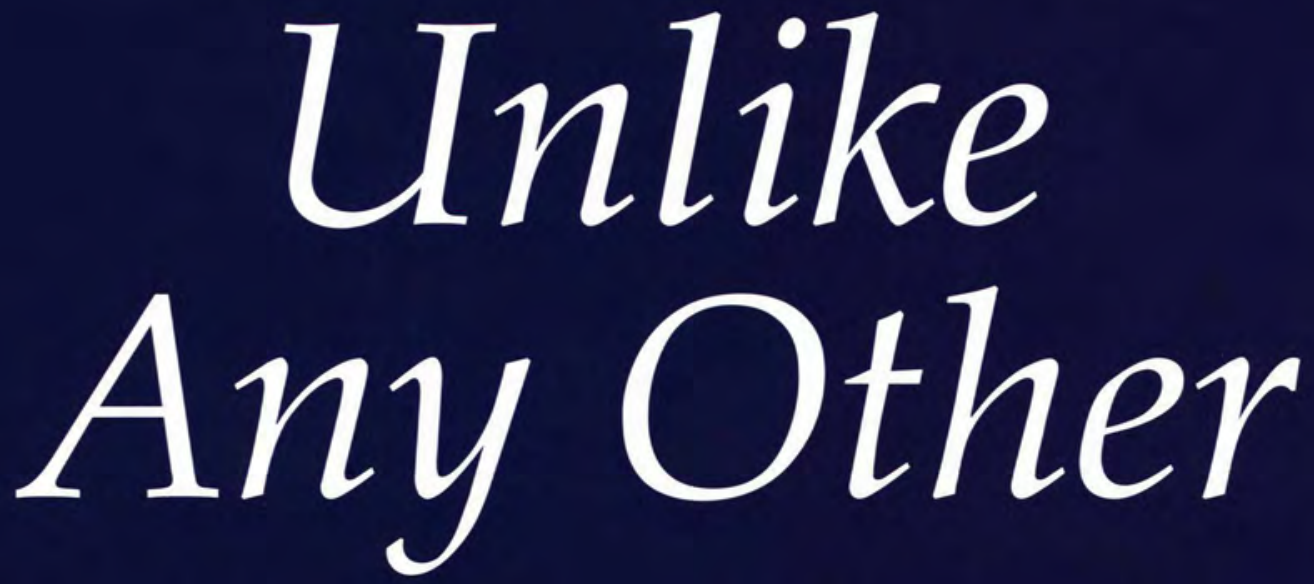

"Setting Precedence" alludes to the importance of establishing priorities in every area of life. A precedent is a rule or example set for others to follow. In all activities as a Christian, one should desire his/her actions and speech to be above reproach. Living a pure life in an otherwise dark world, one can be an example and a light which will draw souls to the Lord Jesus Christ - thus truly "Setting Precedence."

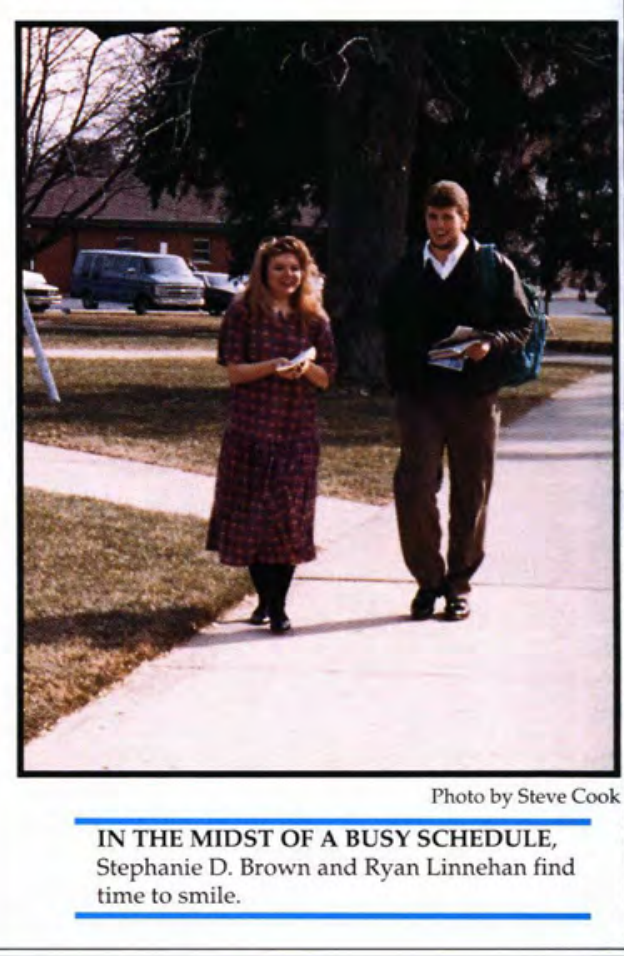



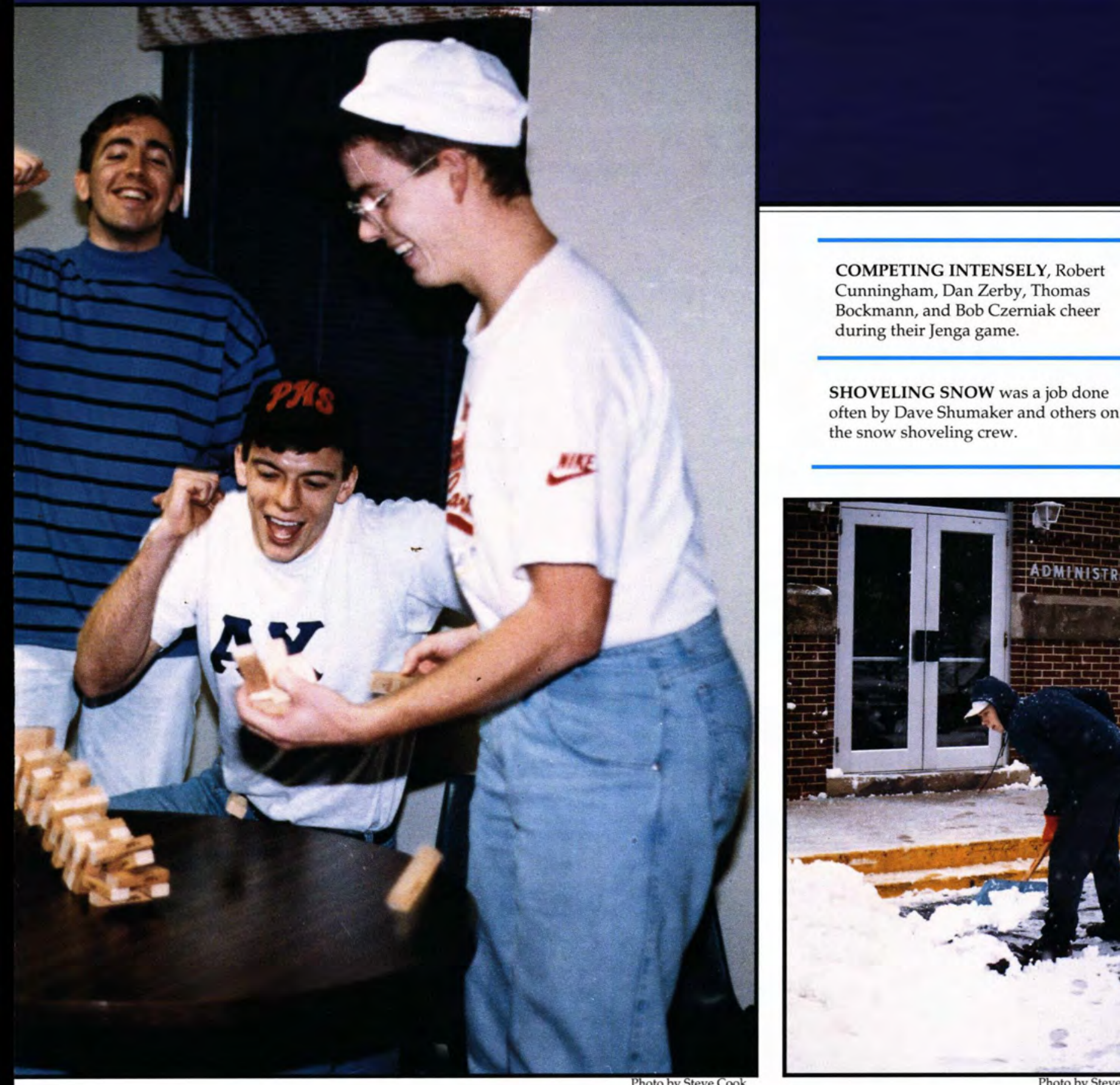

SHOVELING SNOW was a job done often by Dave Shumaker and others on the snow shoveling crew.
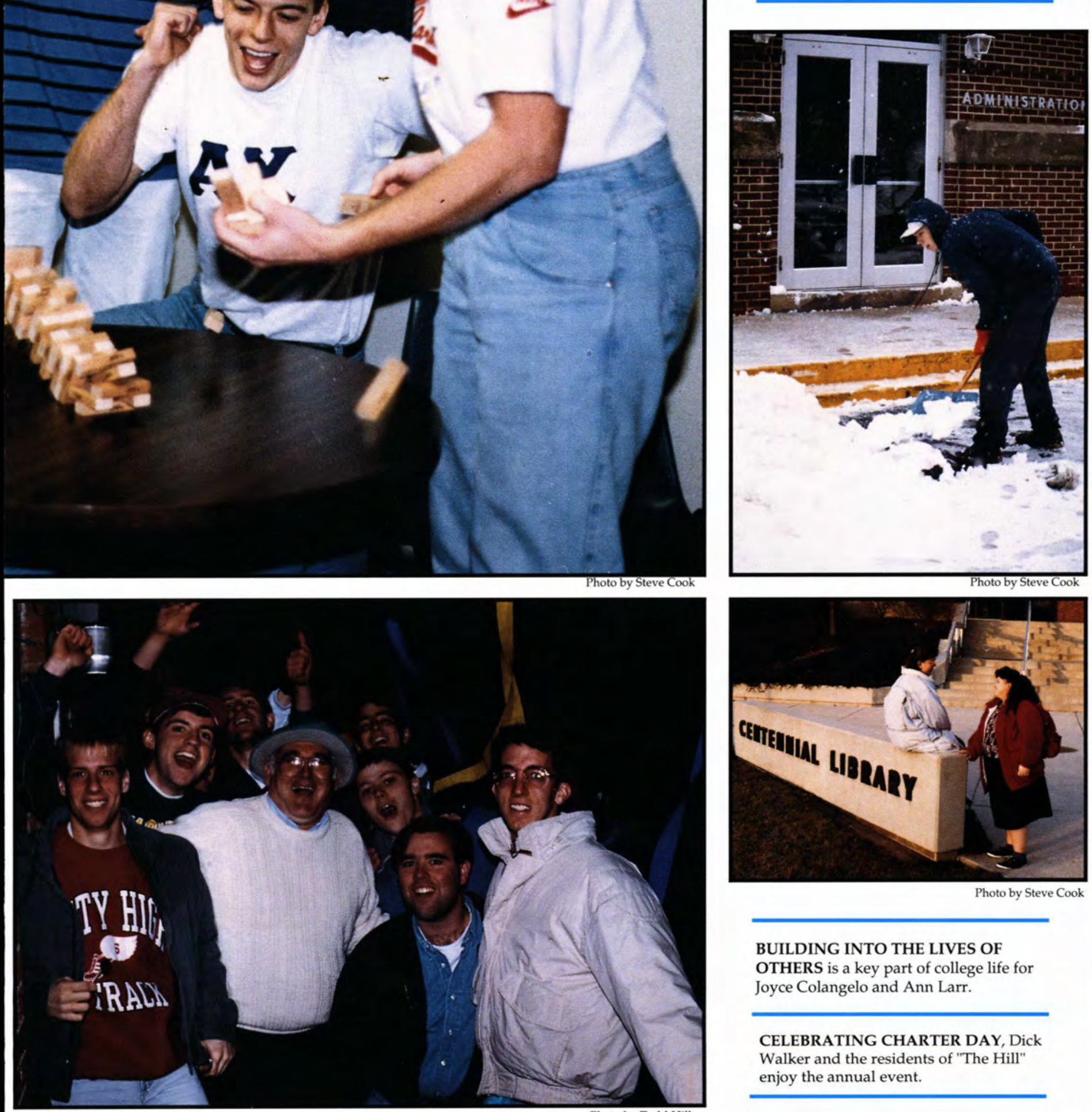

Photo by Steve Cook

BUILDING INTO THE LIVES OF

OTHERS is a key part of college life for

Joyce Colangelo and Ann Larr.

CELEBRATING CHARTER DAY, Dick

Walker and the residents of "The Hill"

enjoy the annual event. 

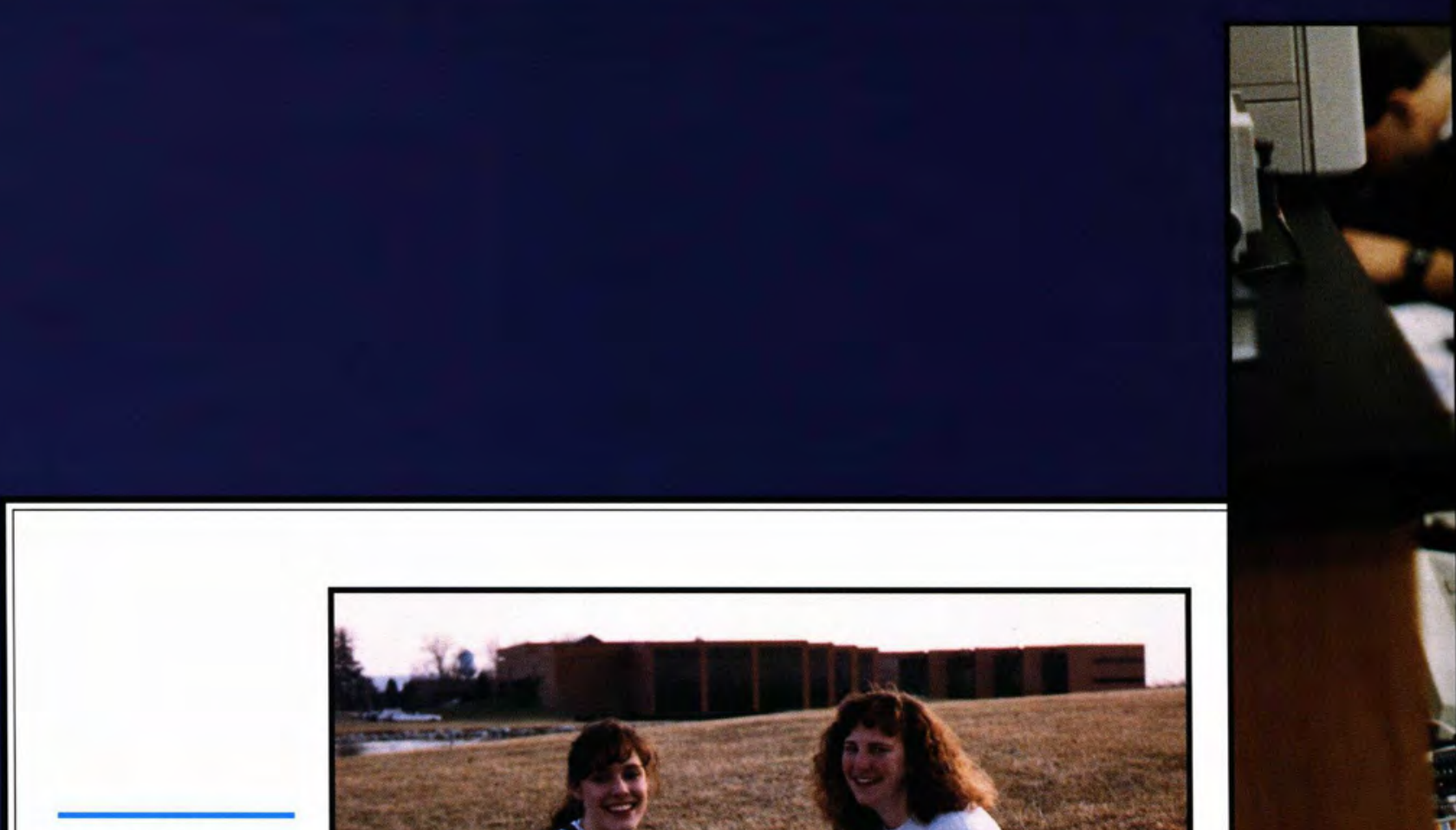

ENJOYING A

PICNIC, Emily

Currall and Beth

Schwind love getting

away from their

busy schedules.

AFTER A COLD

WINTER, these

friends celebrate that

spring has come.

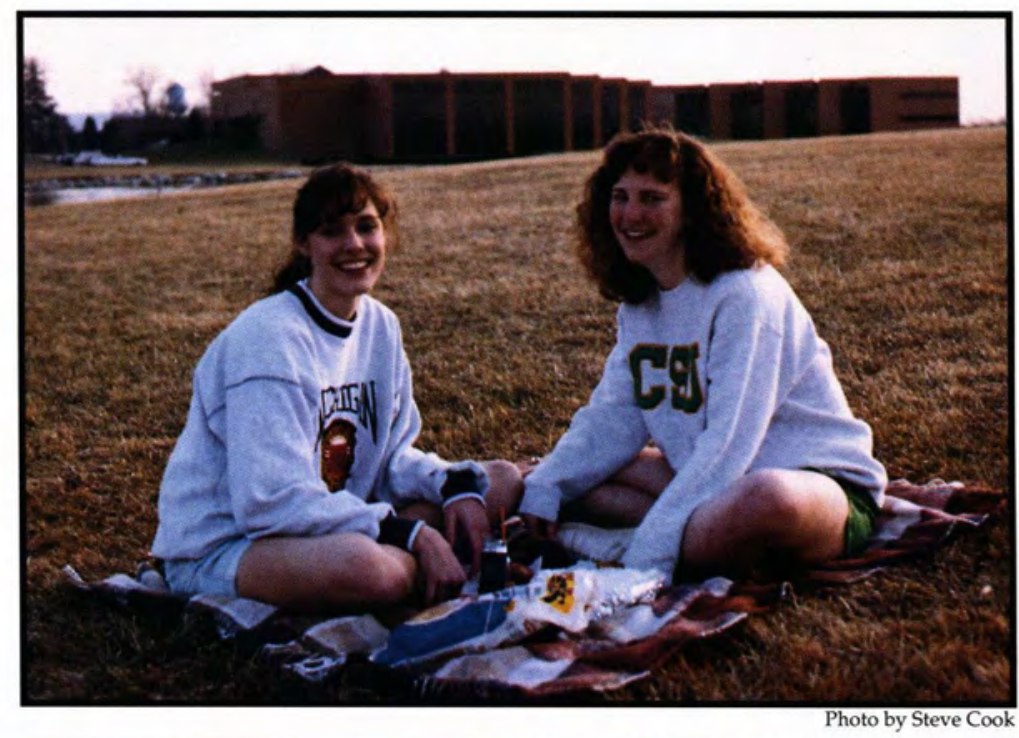

r

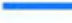
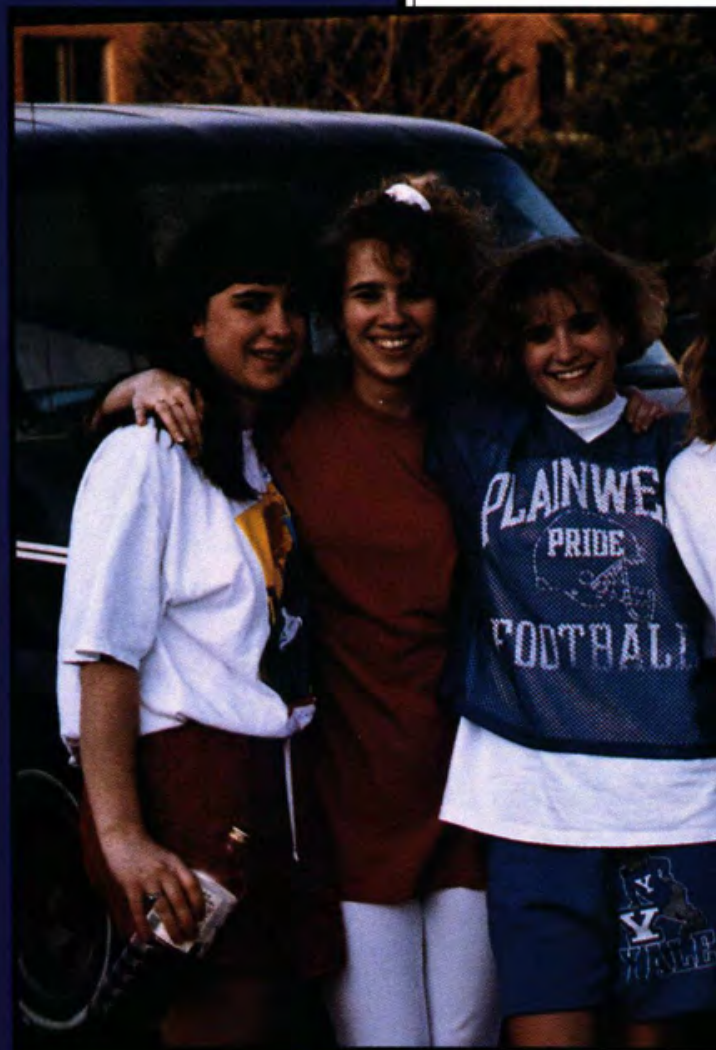

F
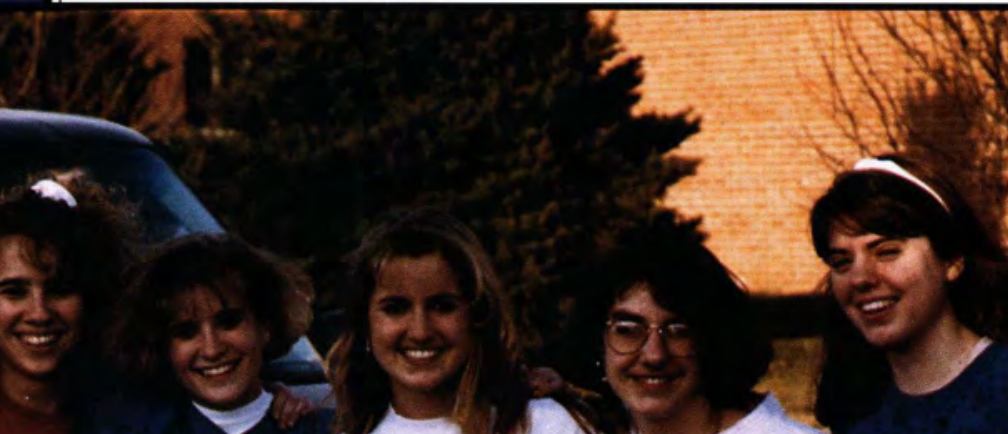

(4)
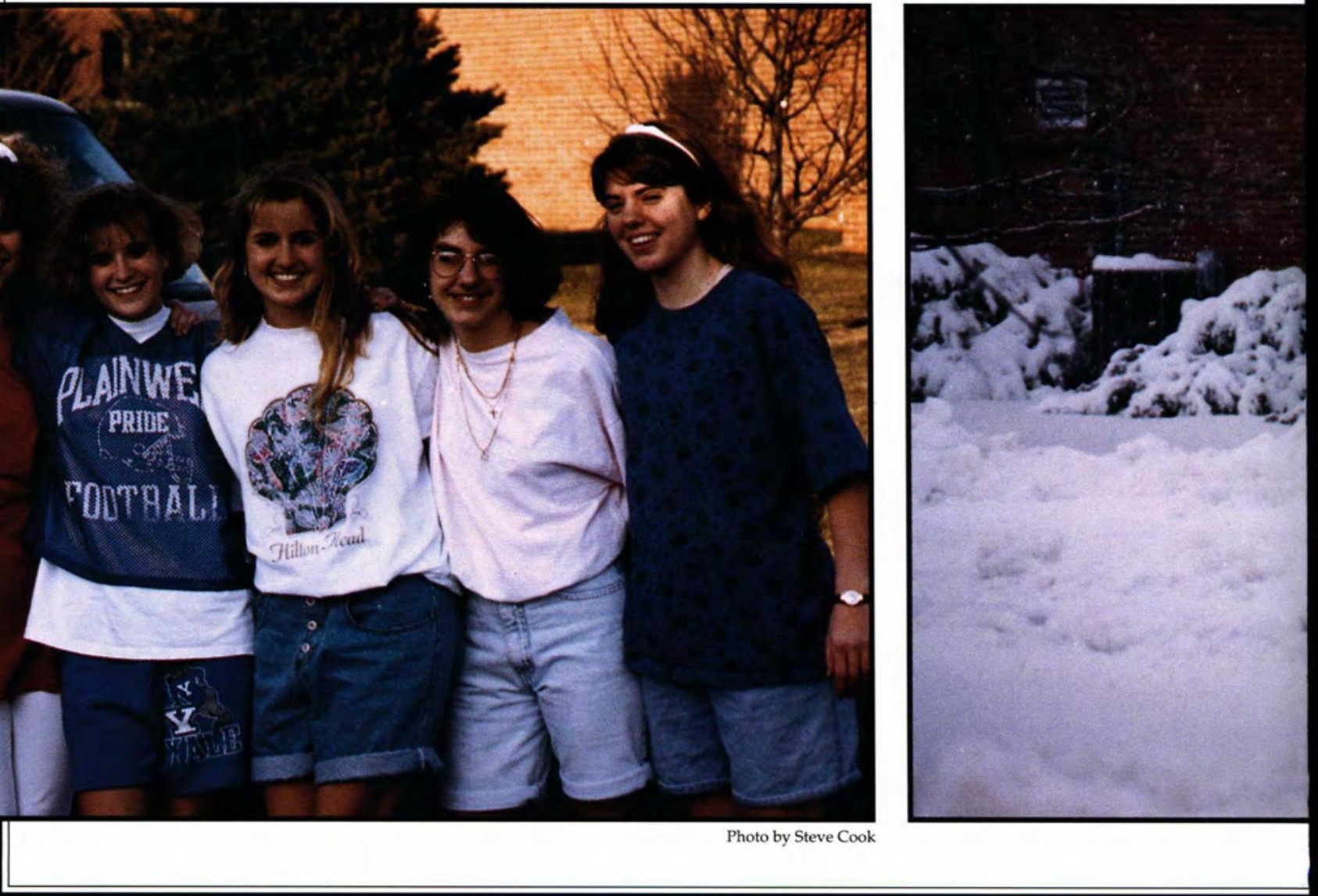


\section{FOLLOWING AN EXAMPLE}

"Therefore, since we are surrounded by such a great cloud of witnesses, let us throw off everything that hinders and the sin that so easily entangles, and let us run with perseverance the race marked out for us. Let us fix our eyes on Jesus, the author and perfector of LET IT SNOW! Jillanne Hunsberger uses her umbrella to protect herself from the

beautiful snow. our faith, who for the joy set before him endured the cross, scorning its shame, and sat down at the right hand of the throne of God." (Hebrewus 12:1 - 3) 


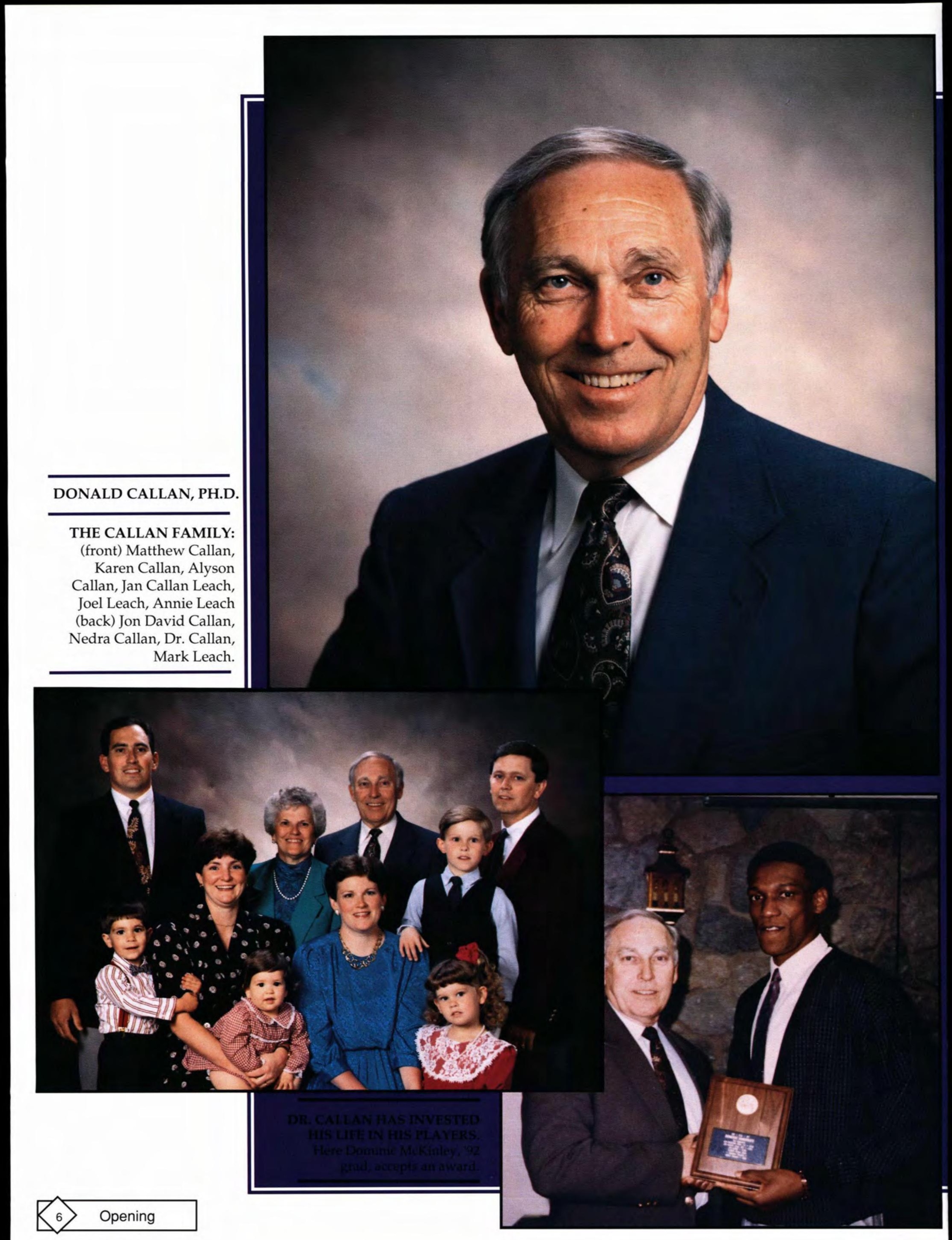




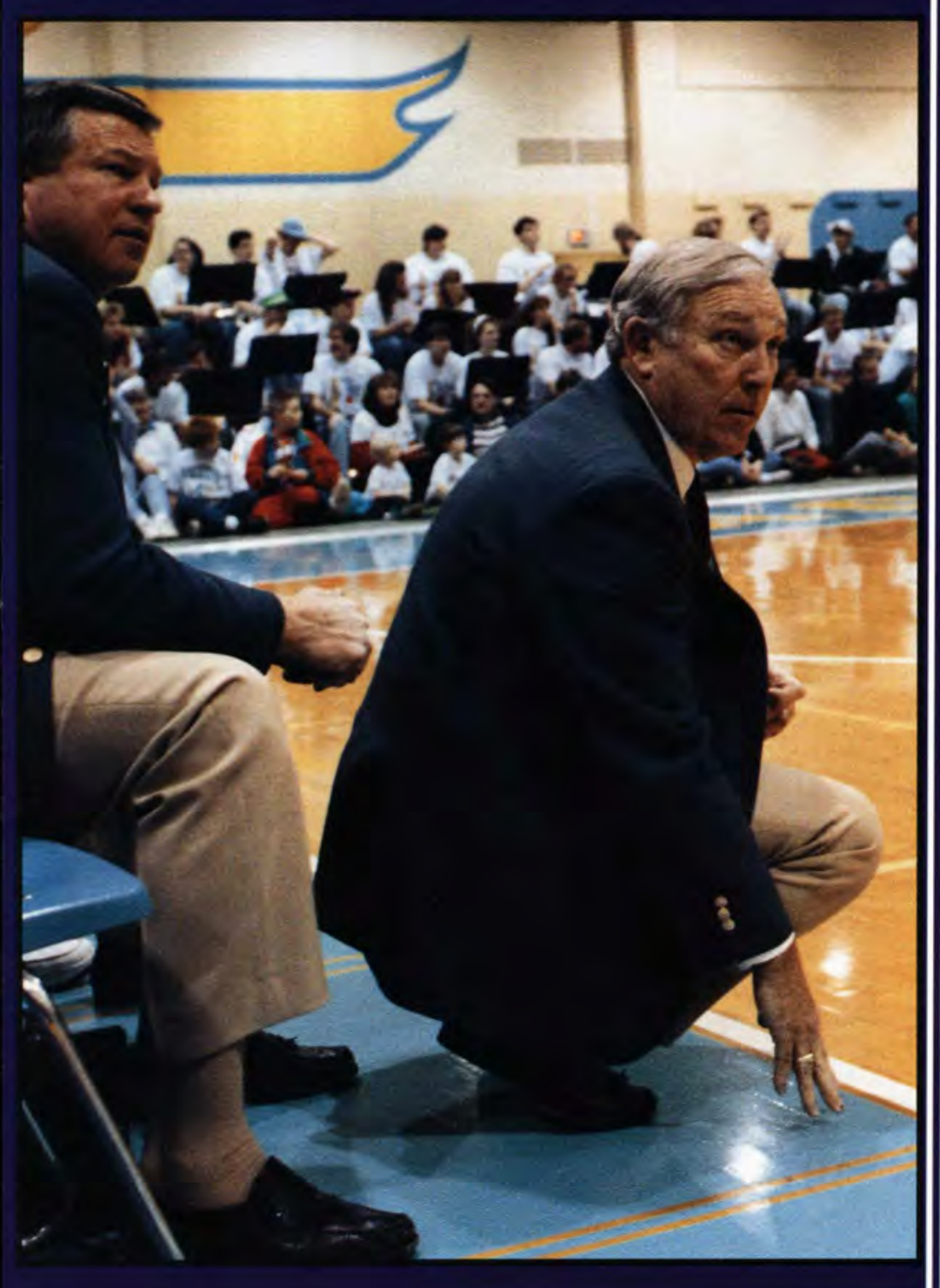

A Precedent of Faithfulness

Dr. Callan sets a precedent for the Cedarville family to follow

When one thinks of a campus individual whose tenure at Cedarville College is an example of the 1993 Miracle theme, "Setting a Precedence," he or she can think only of Donald Callan. He has been a member of the college faculty since 1960: thirty-three years of service as a faculty professor, chairman of the Health and Physical Education Department, Athletic Director, men's varsity basketball coach, and an active member of several college committees. The honorsand records he has achieved in state and national athletics area standard for younger men and women seeking to make their mark in collegiate sports. Of today's active NAIA basketball coaches, Dr. Callan ranks fifth nationally in wins.

Although elected to the Hall of Fame of NAIA, NCCAA, Taylor University, and Cedarville College, his historical contribution to the campus will lie in the birth of the Missionary Internship Service. With a heart for missions, Coach Callan led the first MIS trip to the Philippines in 1970. Since then, his active participation in yearly evangelistic missions trips to various foreign countries has been a model for faculty, staff, and students to emulate.

Paul exhorted Titus to teach young men how to live out the Gospel in their lives: "...in all things showing yourself to be a pattern of good works; ...that one who is an opponent may be ashamed, having nothing evil to say of you" (Titus 2:6-8). This biblical teaching example has occurred through Donald Callan's setting the precedent among the students of Cedarville College. May the precedent that Dr. Callan has set inspire students to "Setting Predcedence" for others to follow.

-Pat Landers Dixon

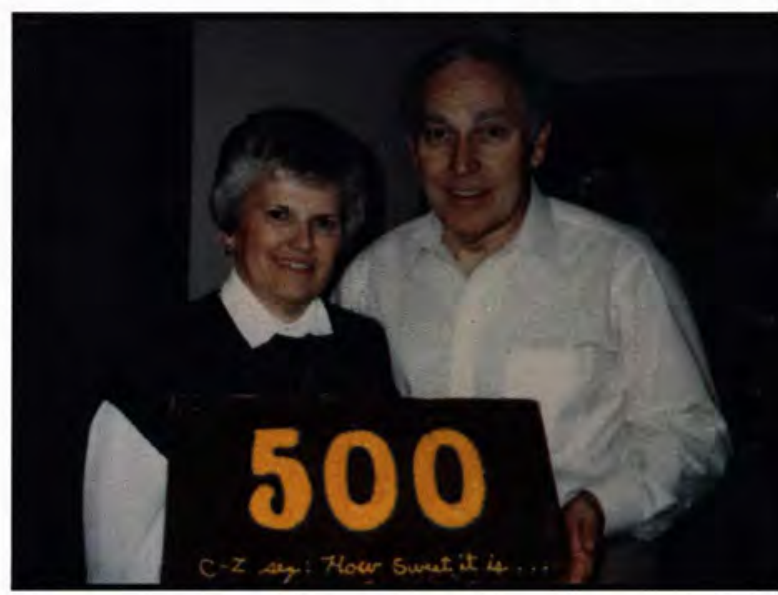

DR. AND MRS. CALLAN celebrate his 500th win in basketball.

ON ONE OF HIS MANY MIS TRIPS, Dr. Callan teaches a class in China. 


\section{Administration}

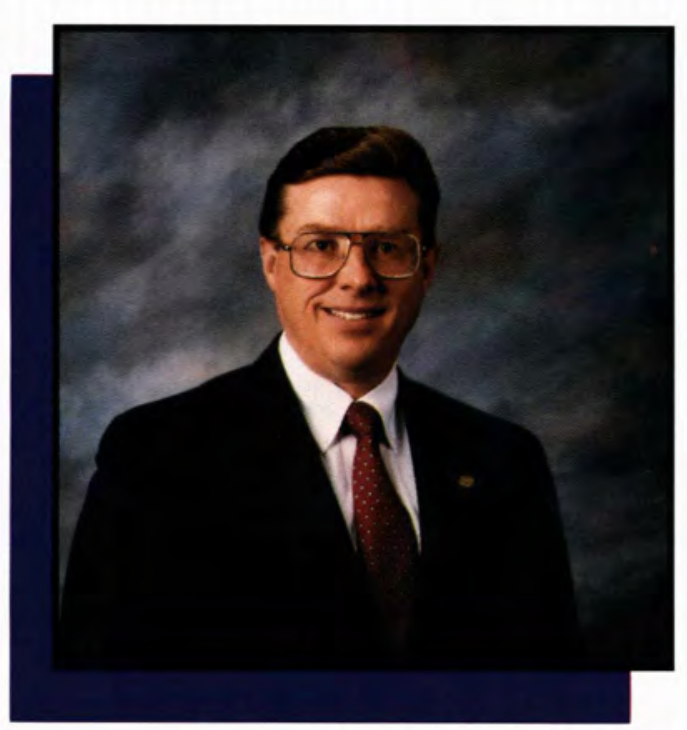

Mr. John Anglea

Vice President for Business

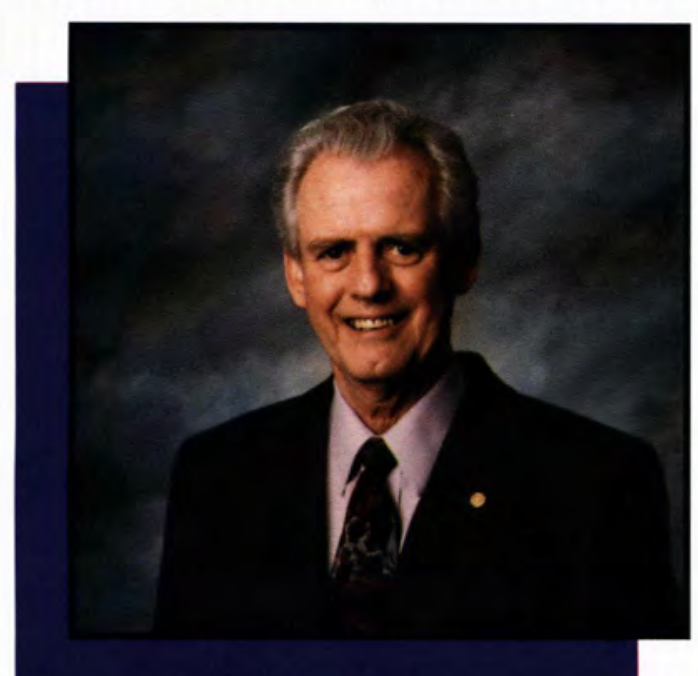

Dr. Harold Green

Vice President for

Christian Ministries

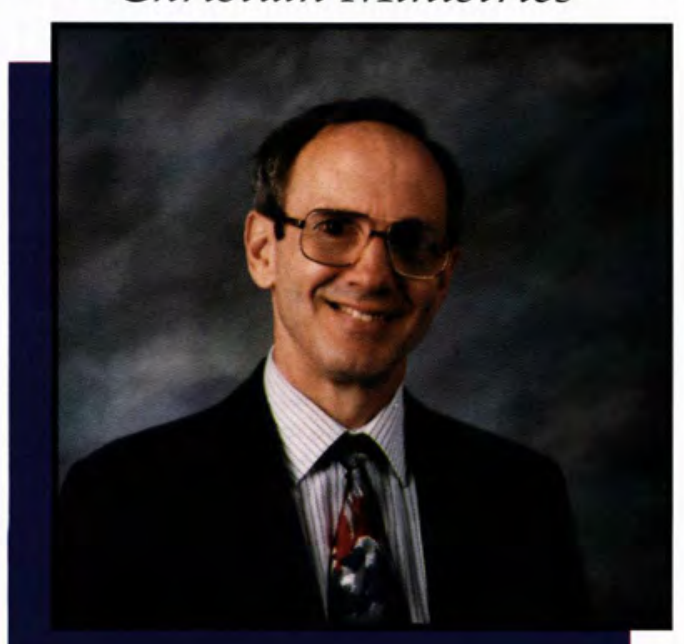

Dr. Duane Wood

Academic Vice President
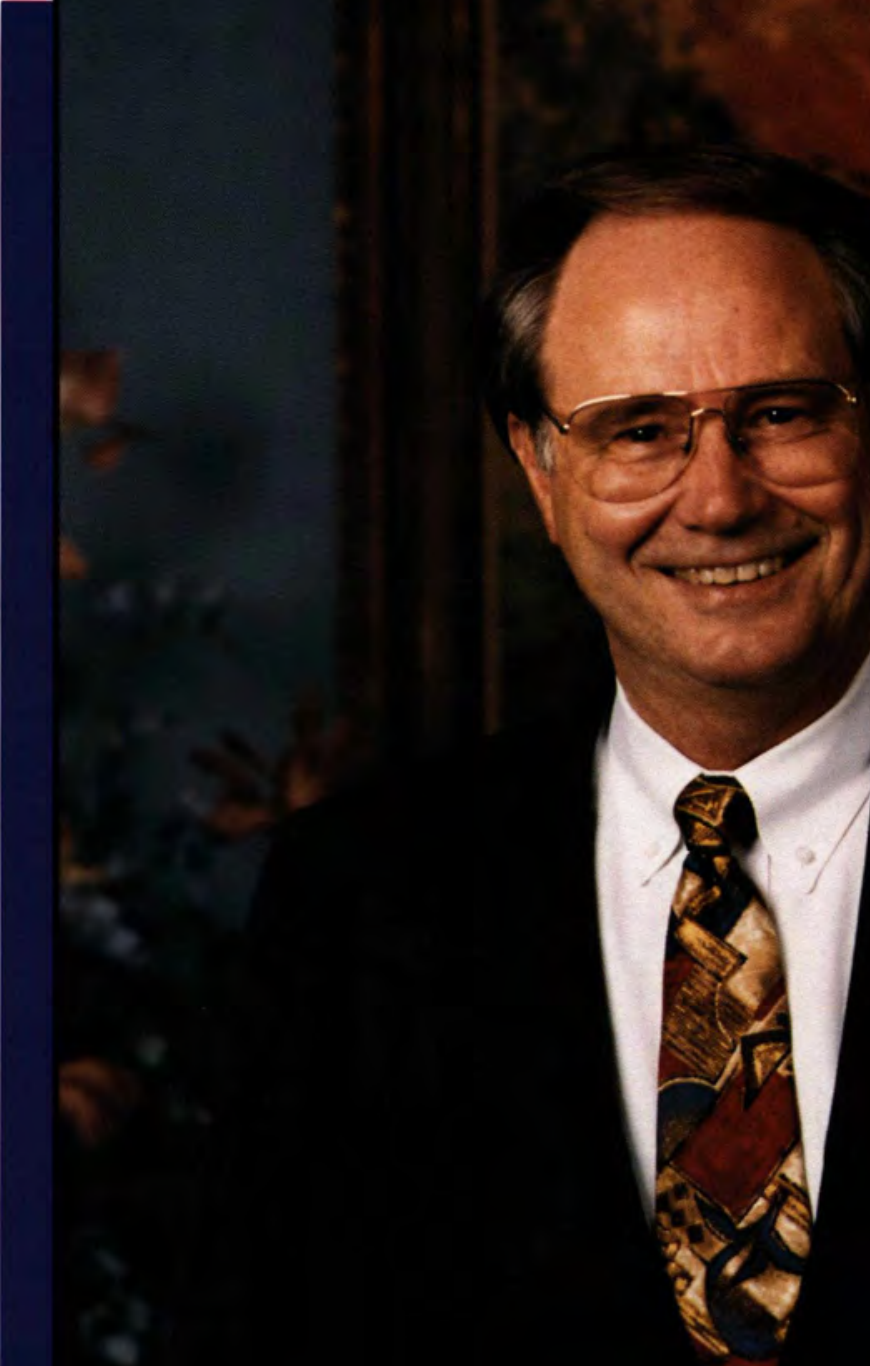

8

\section{Dr. Paul Dixon}

President

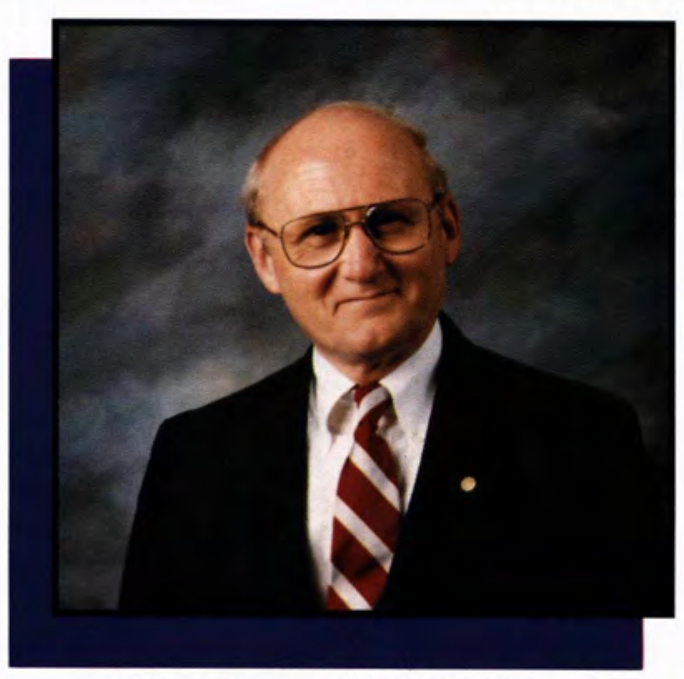

Mr. Donald Rickard

Vice President for Student Services

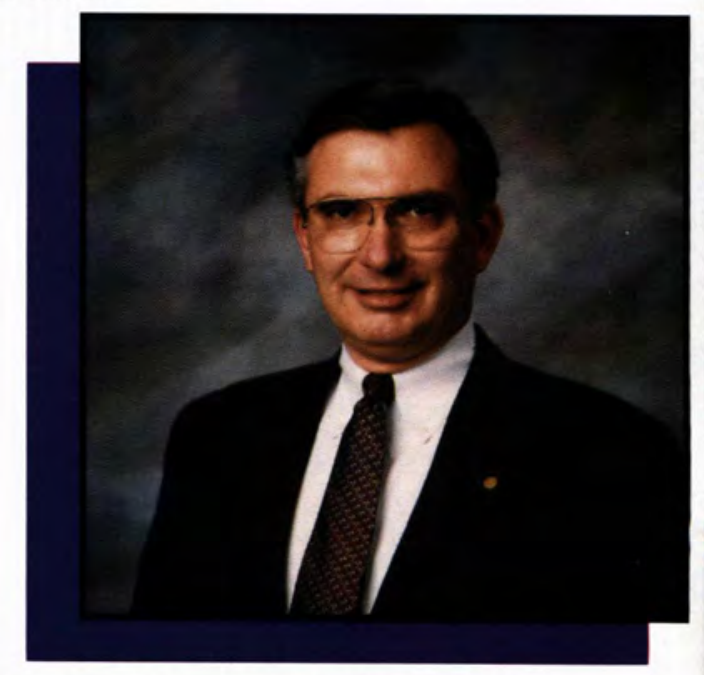

Dr. Martin Clark Vice President for Development 


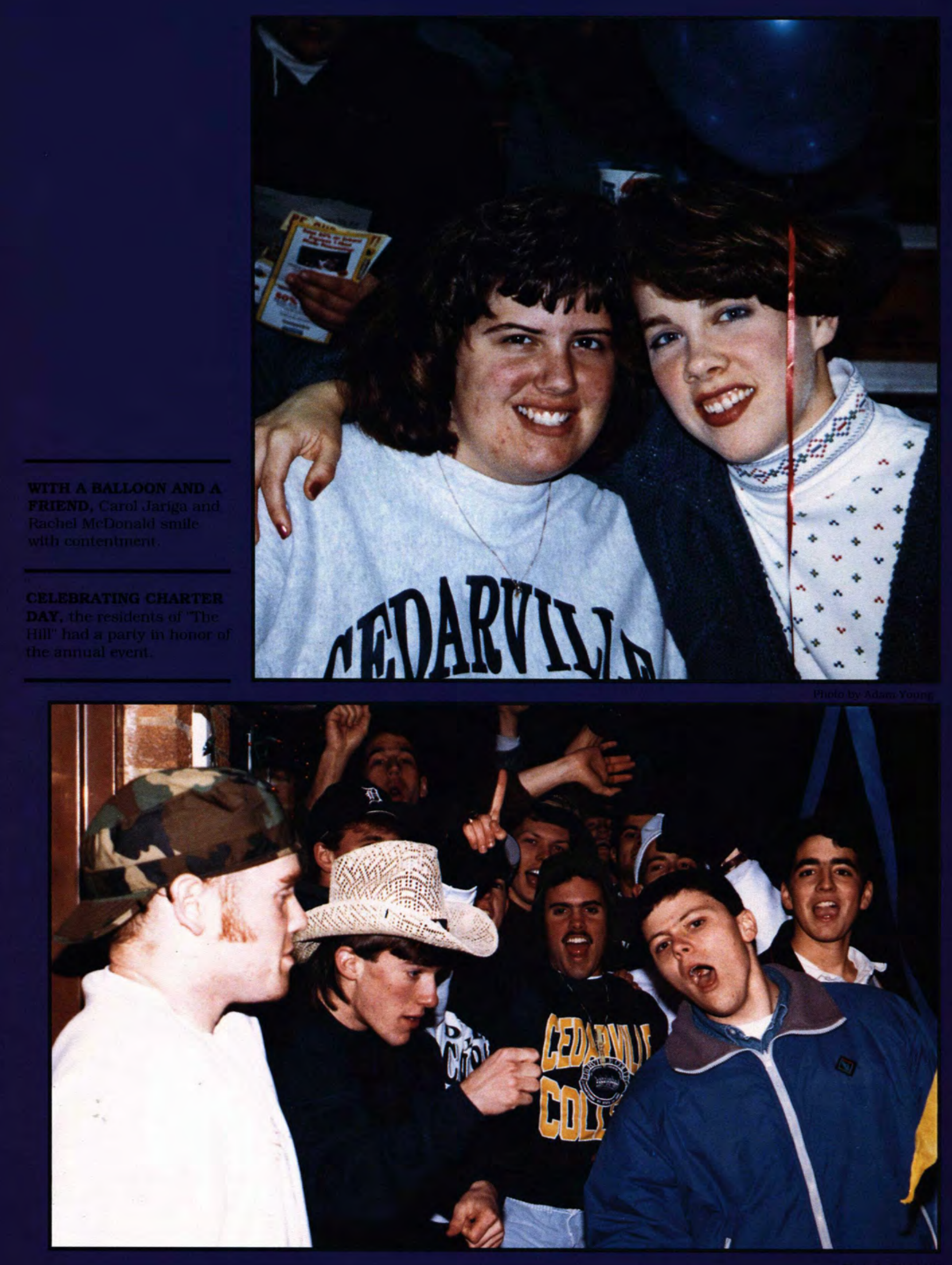




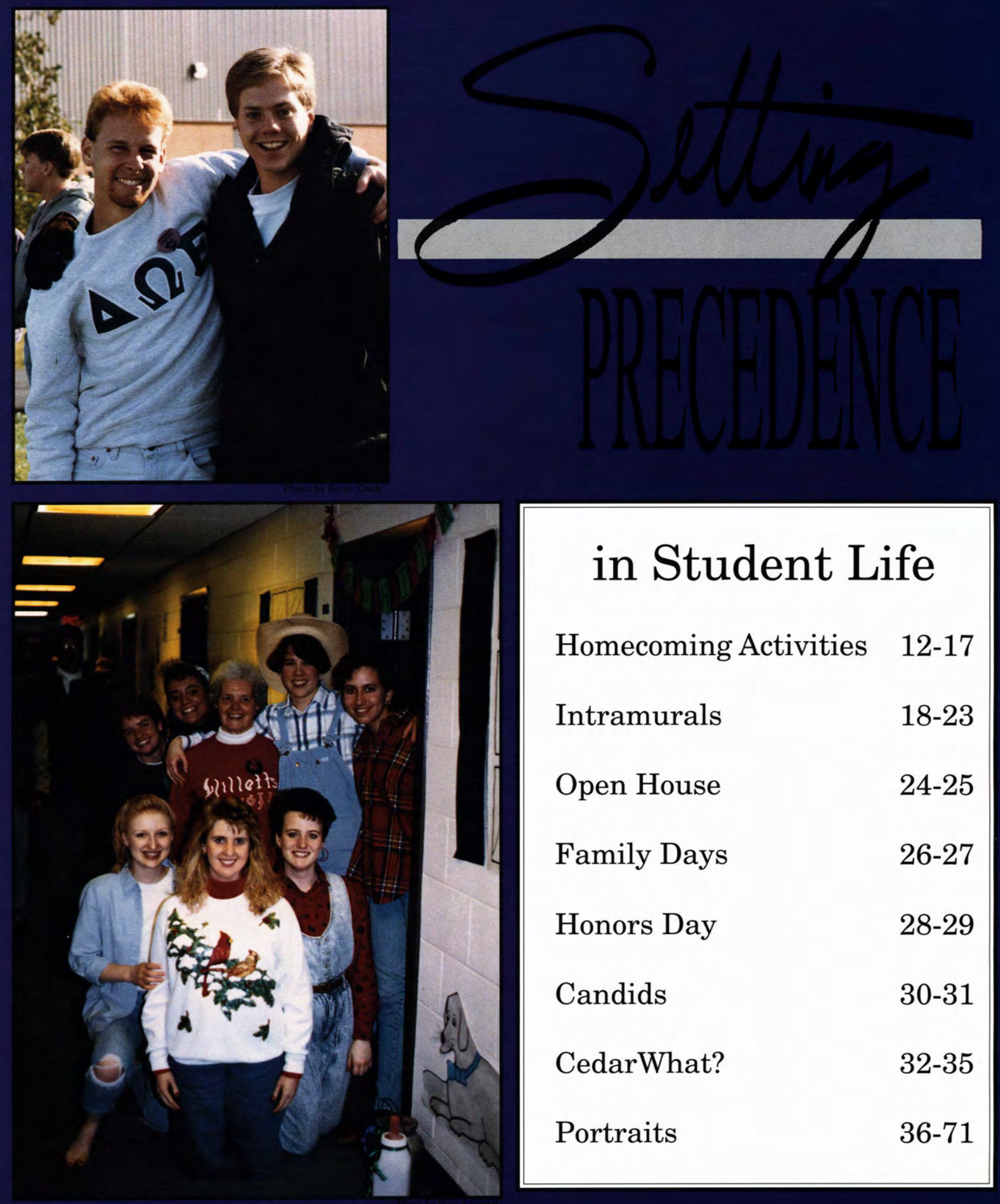


Sheri Leeds Crowned Queen

After spending four years at Cedarville, Sheri Patricia Leeds says that if given one wish, she would ask that graduation not require friends to part.

Life most students, Sheris least fazorite memories of cedarzille are horizontal rain, and whipping wind which destroys even the strongest of umbrellas.

As a nursing major, the rigors of the program made her trust in the Lord completely; Sheri gives all credit for her success to the Lord. 'The support of friends and an incredible amount of coffee and diet coke were her seciondary source of survizal.

After graduation, Sheri plans to work in a hospital in New Yersey. After a year, she plans to seek the Lords direction about possibly going overseas.

Sheri squiet manner and strong tes. timony have been a challenge to all who have met fier. May God continue to use her testimony as she leaves the ville.

- Marsfia Olsen

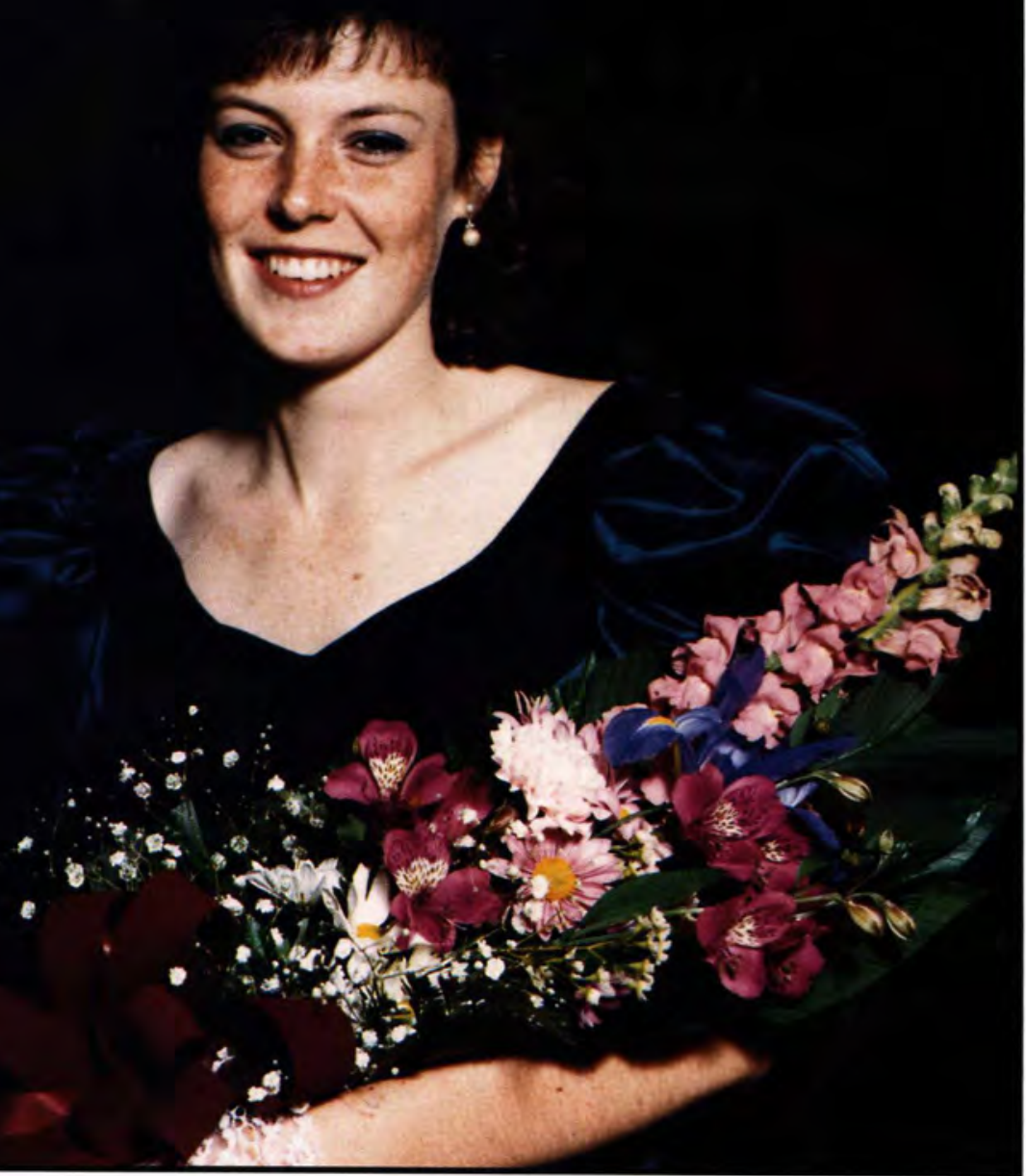

$2 \%$
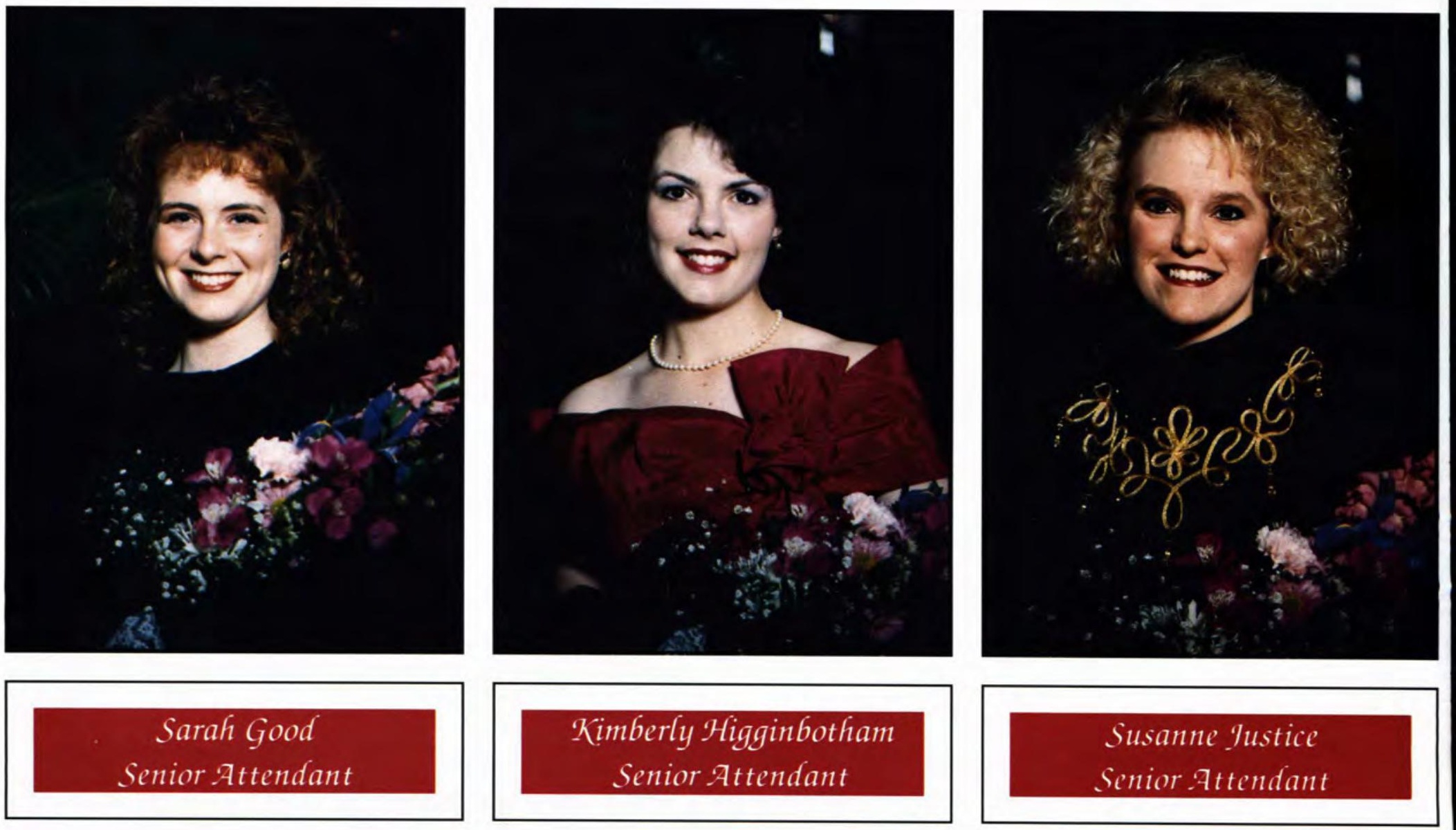

\section{Sarah Good}

Senior Attendant
Kimberly Higginbotham Senior Attendant 


\section{Cinderella Visits}

\section{Windsor Castle}

Just as the magic in the wand ofCinderella's fairy godmother transformed mice into coachmen and her rags into a beautiful gown, so the Homecoming committee magically transformed the dining hall into Windsor Castle for the Homecoming Royalty Banquet.

Castleguards greeted visitors and directed them to their seats for dinner and for the coronation of a new queen, Sheri Leeds.

As well-wishers extended their support to the new queen, they made their way out of the castle onto a torchlit path leading to the
Chapel. There, they enjoyed a concert with Billy and Sarah Gaines. The Gaines sang from their hearts so that all could see their love for God and their love for each other. The highlight of the concert was the encore, a request from the audience, "Love is the Reason." As the last note was played and the applause faded, a Royal Evening at Windsor ended as though a clock had chimed the hour of twelve. Nonetheless, like Cinderella, those present were left with many wonderful memories to think about -- has anyone found the damsel with the other glass slipper?

- Marsha Olsen

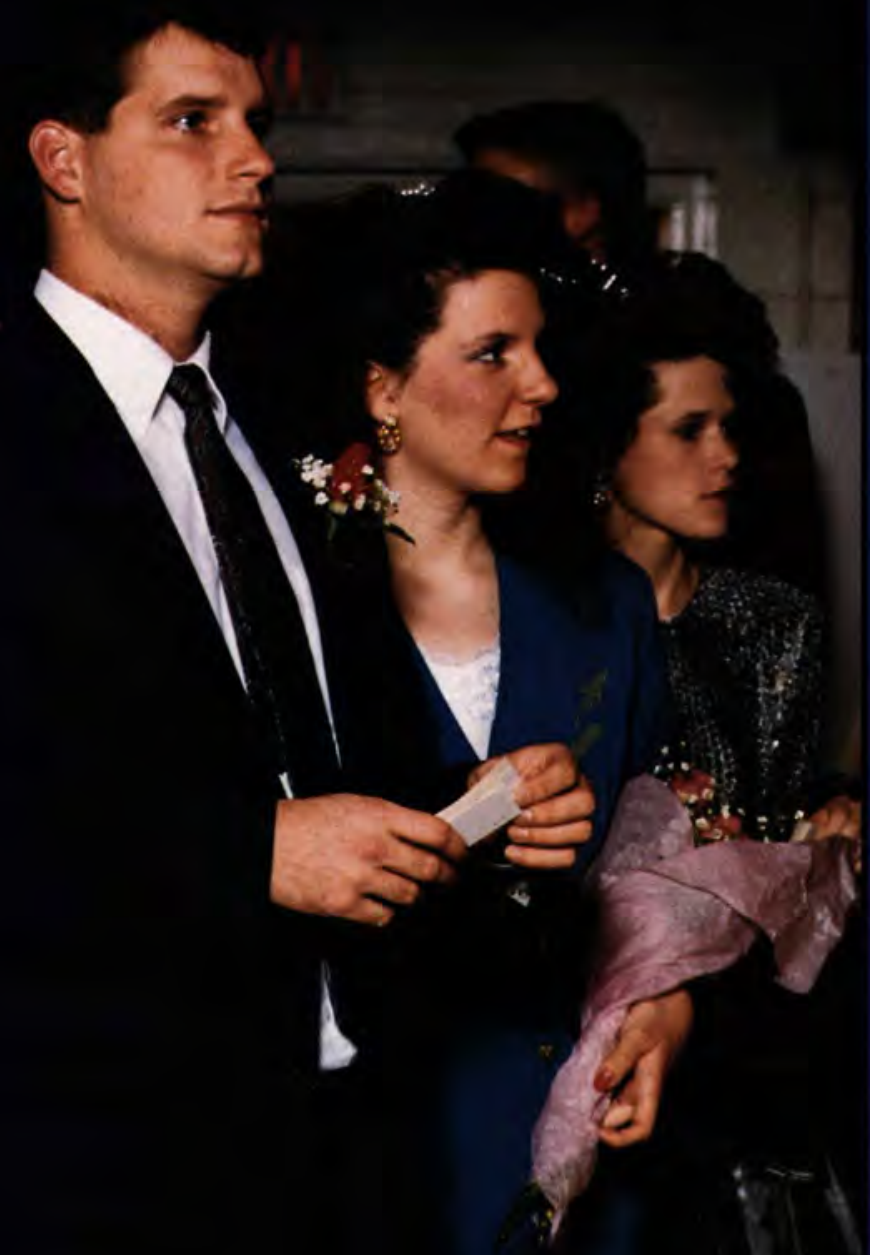

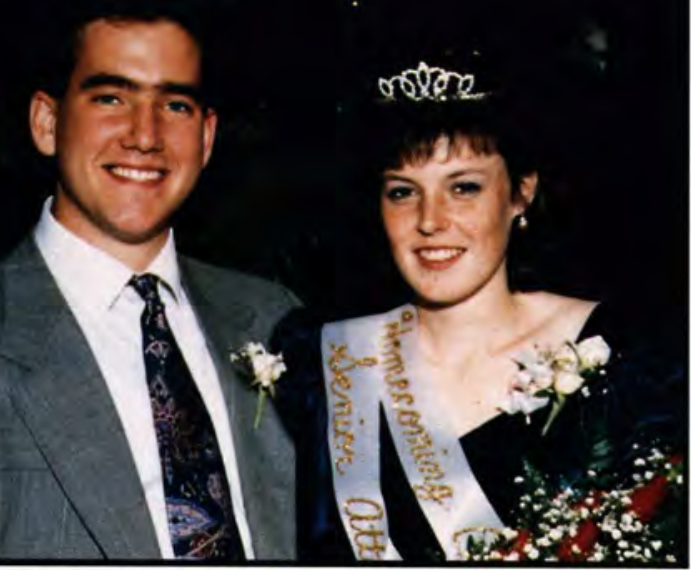

HOMECOMING GUEEN, Sheri Leeds, and her escort Paul Anderson smile after an eventful evening.

IN A MOMENT OF DEEP THOUGHT, Tracy Quinn, Aaron Newcomb, and Bumber Hidalgo stop to discuss the important issues of life.

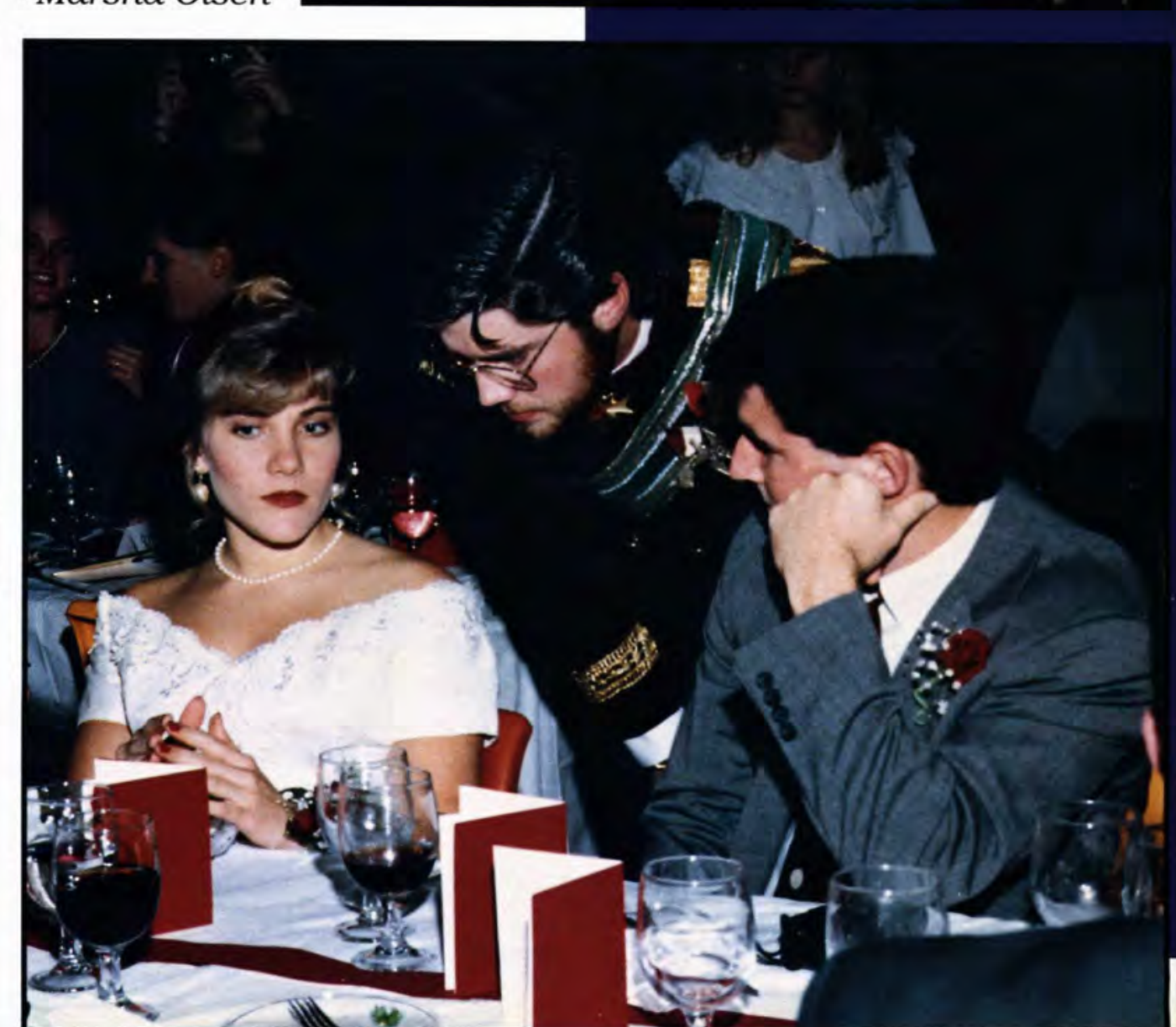



"THE BEST HOMECOMING QUEEN EVER."

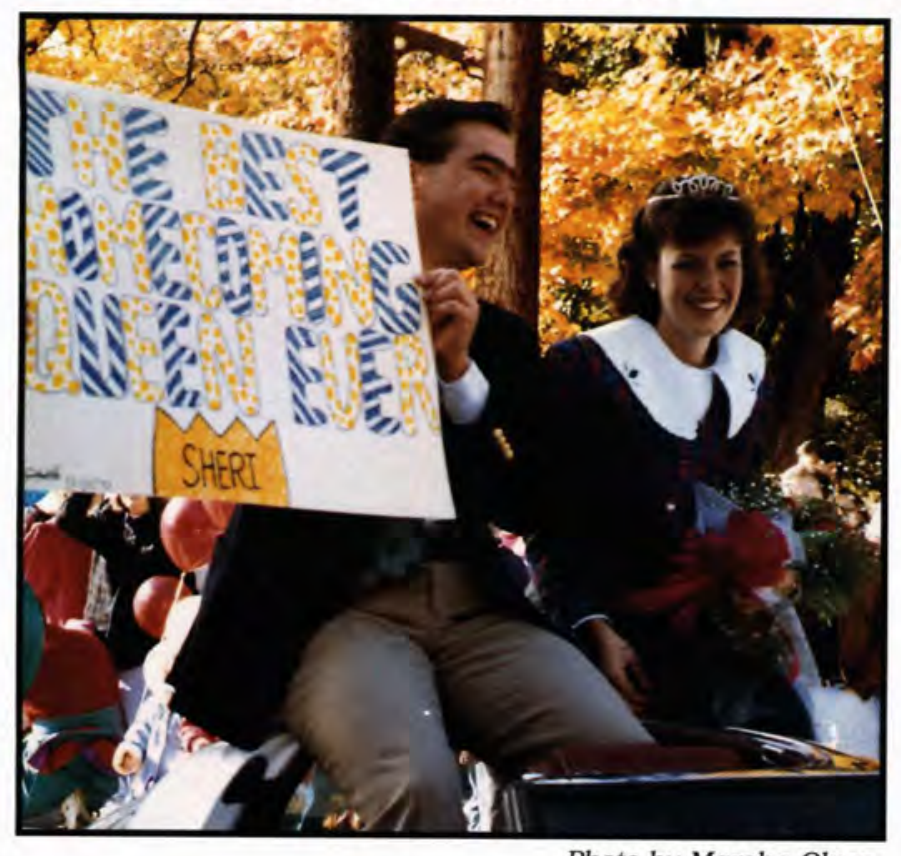

Photo by Marsha Olsen

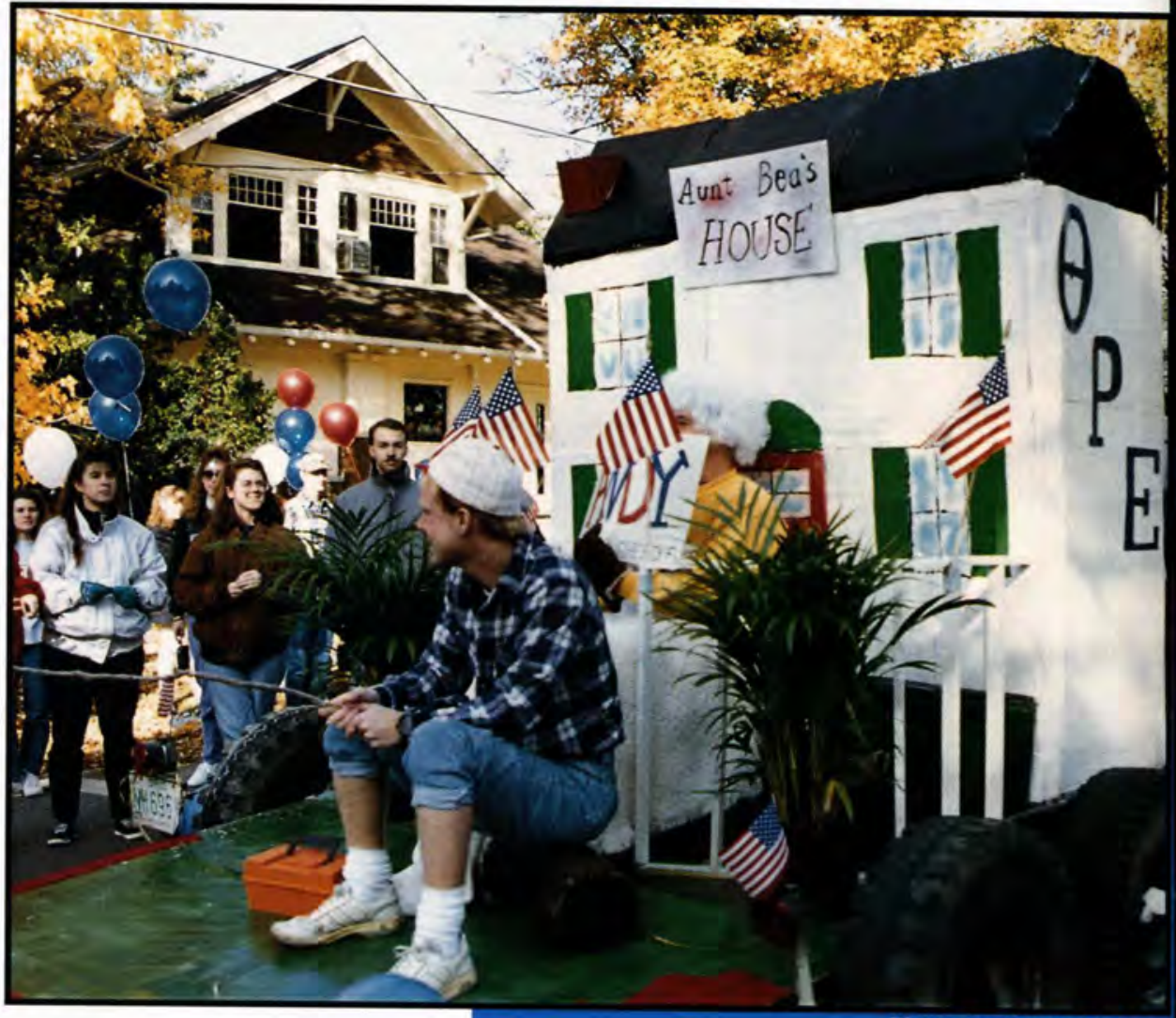

\section{Red, White and Blue Celebration}

Balloons, candy, floats, fire engines, horses, bands, and polished cars caused students, alumni, and children to gather along Main Street for the college Homecoming parade.

Nearing the end of another election year, the parade theme was "Red, White, and Blue." The floats were primarily of a patriotic nature. Organizations and classes recognized various groups of Americansfrom those who served in the Armed Forces to those who lived in the fictional town of Mayberry. The parade

HONOR GUARD -- the only "serious" element in the parade.

caused spectators both to laugh and to reflect on the blessings our nation and our college have enjoyed.

Since it is an election year, the parade could not end without an appearance by the Presidential candidates -- not George Bush and Bill Clinton, but rather Charles Clevenger and Jon Purple, the candidates for President of CedarWhat? With theirappearance, the parade theme seemed to make a sudden change. It was no longer "Red, White, and Blue" but "Green and Purple!" •Marsha Olsen

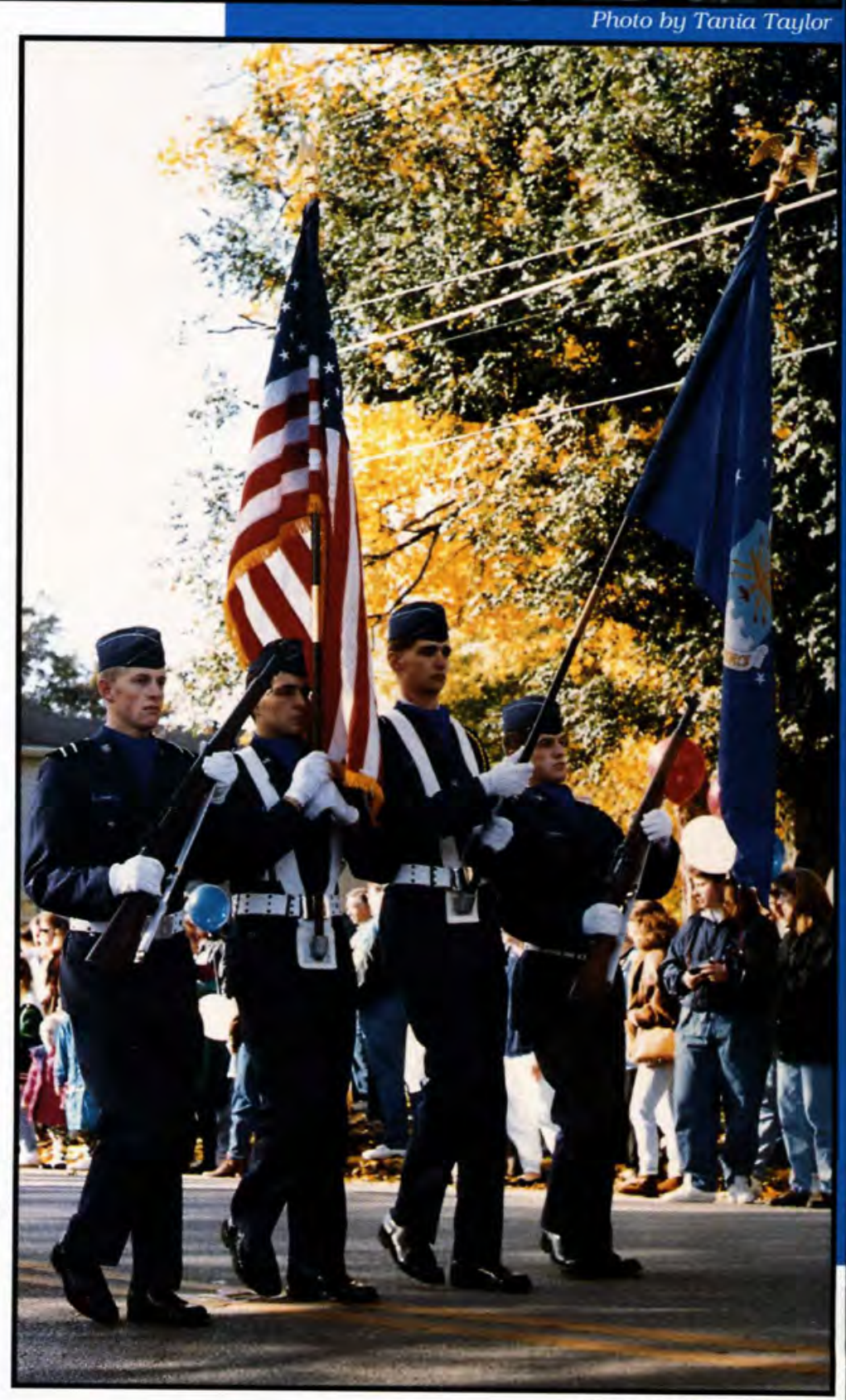



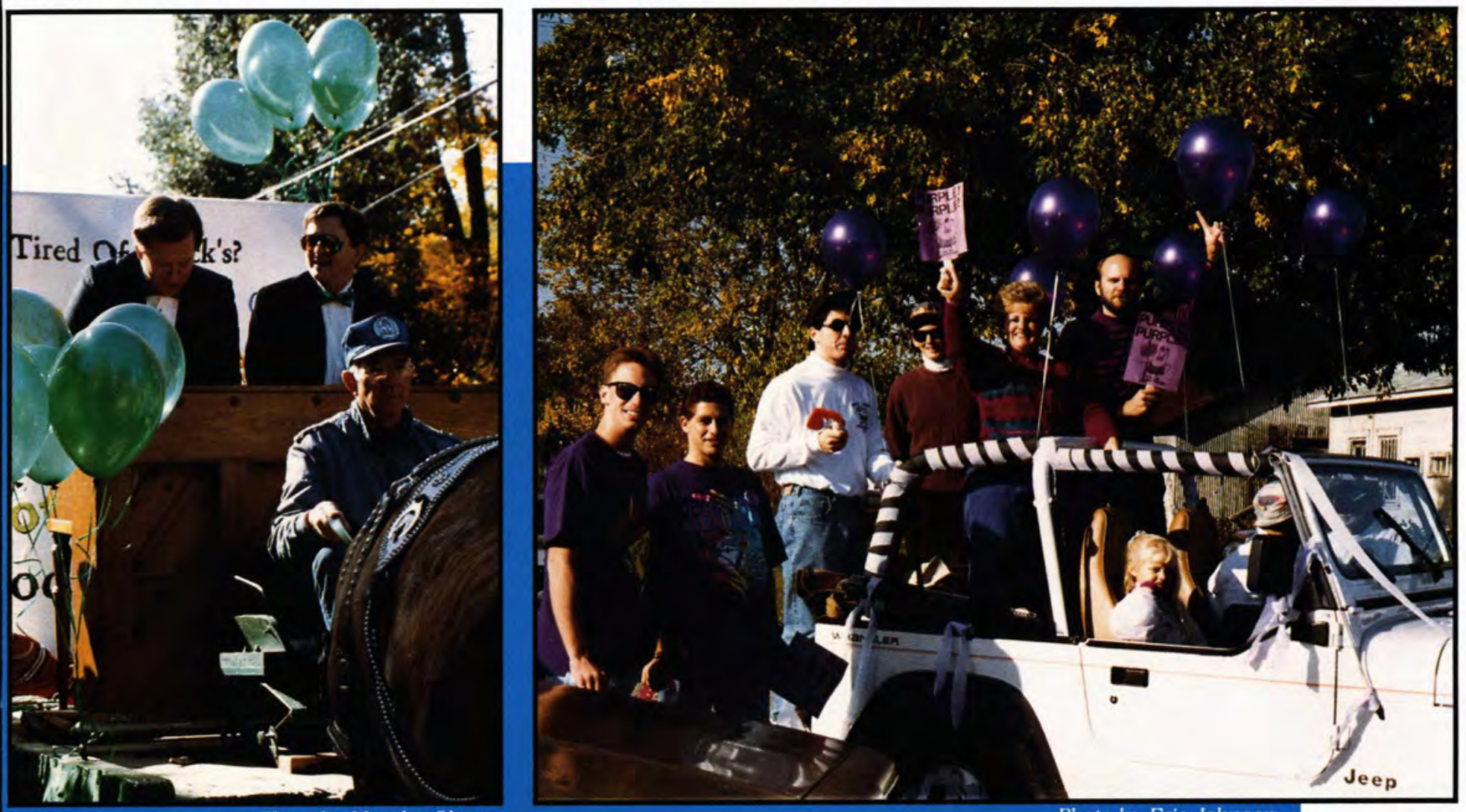

Photo by Marsha Olsen
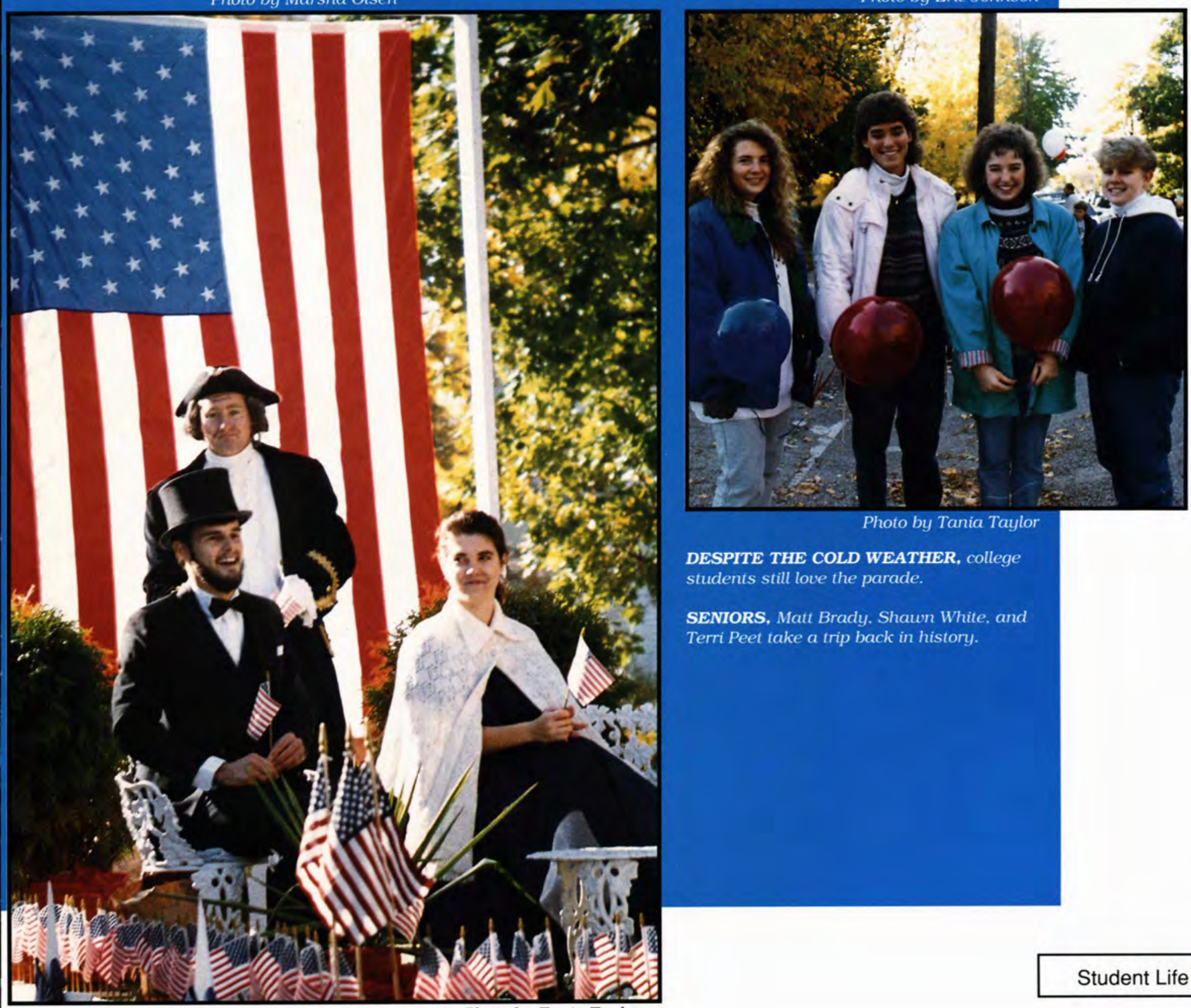

DESPITE THE COLD WEATHER, college

students still love the parade.

SENIORS, Matt Brady. Shawn White, and

Terri Peet take a trip back in history. 


\section{Competition,}

Exercise

\section{and Spirit}

Intramurals provide a break from books

Intramural sports allow Cedarville students to enjoy intense competition and physical activity in an environment that fosters good spirits and sportsmanship. Participants make friends both on their teams and with their competitors. Intramurals promote personal pride, team spirit, and Christian fellowship while allowing all to play to the best of their abilities. Intramurals serve as a vital function to Cedarville's social life.

-Chris Reimers

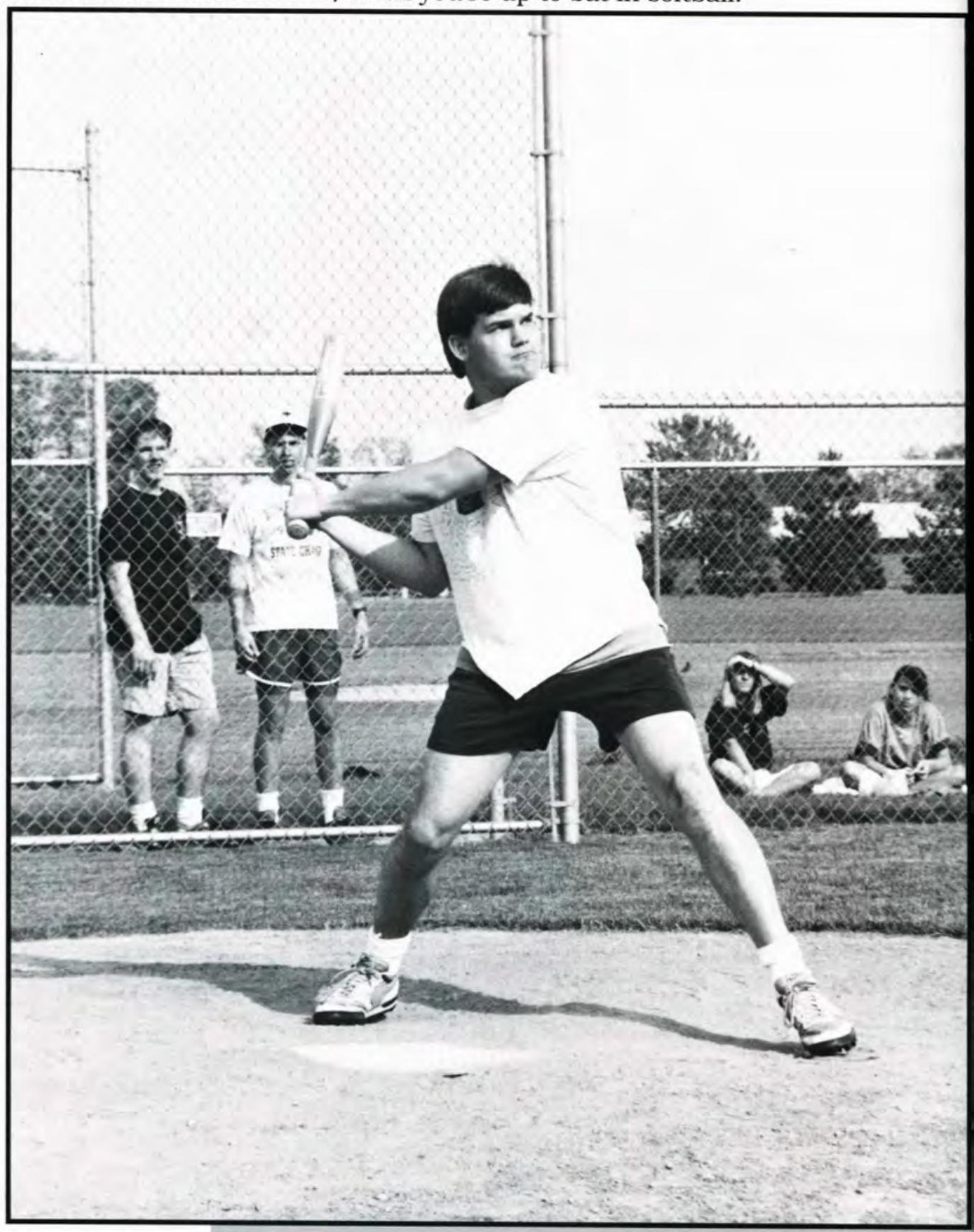

GETTING READY TO SCORE 'TWO MORE!

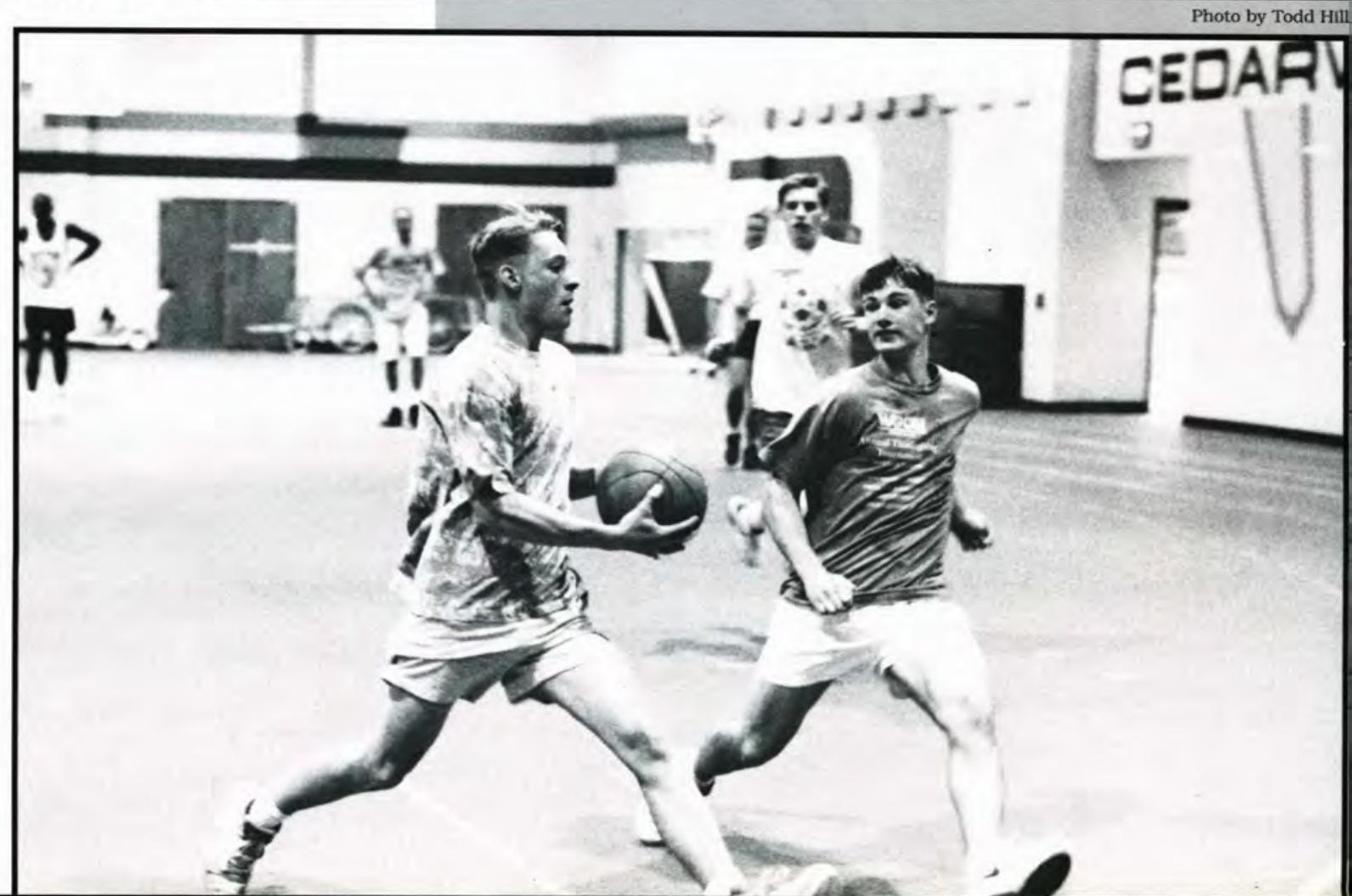




\section{Unity Makes Memorable Experiences}

WITH THE LIFE OF SPRING QUARTER, Terri Durham, David Bates, and Michael Carlisle laugh at the memories of the past four years.
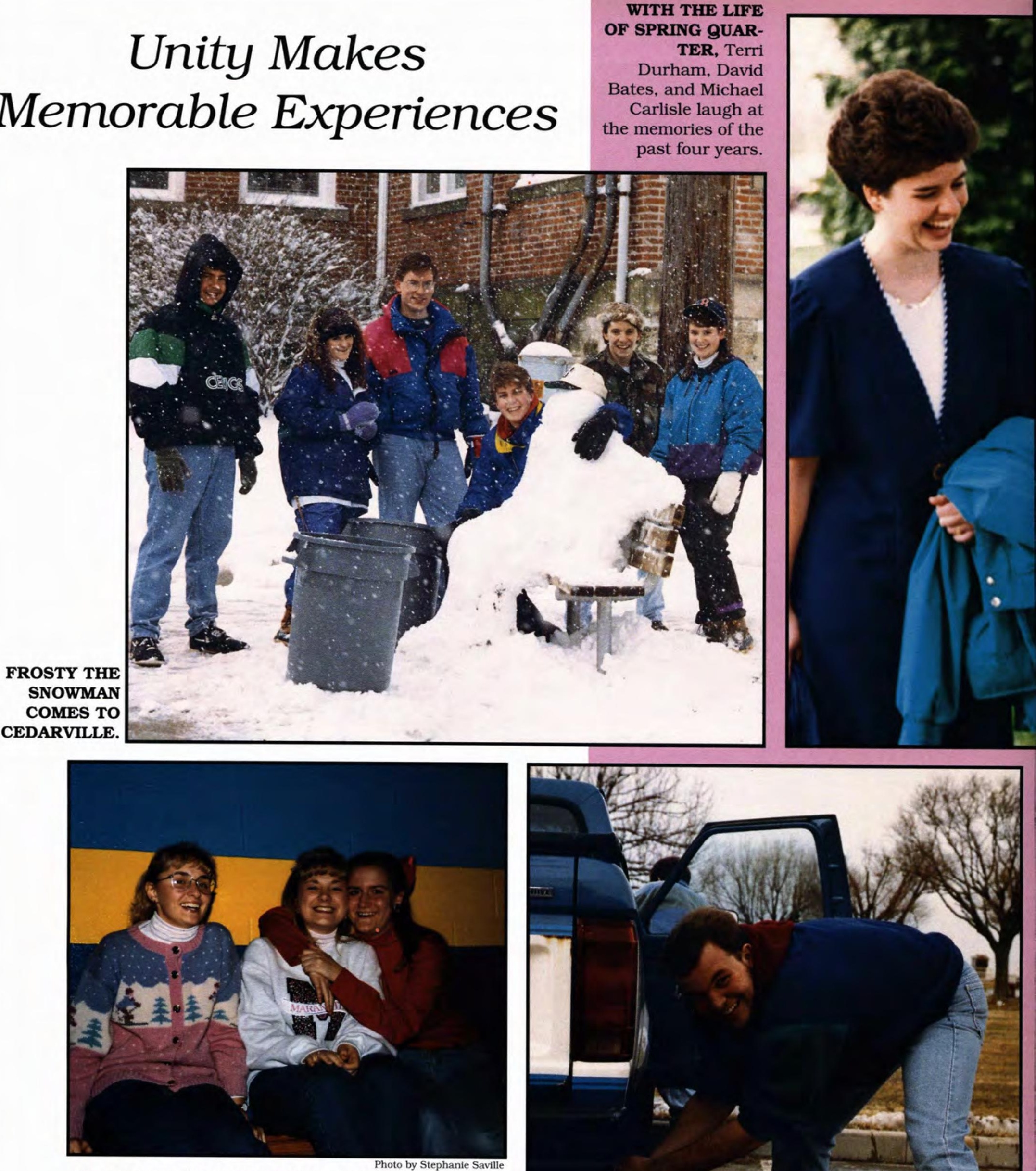

AT A JACKETS BASKETBALL GAME, Jennifer

Bartosiewicz receives a hug from a friend.

SPARE TIME? Joe Lausin spends his spare time washing the tires on his Ford truck.

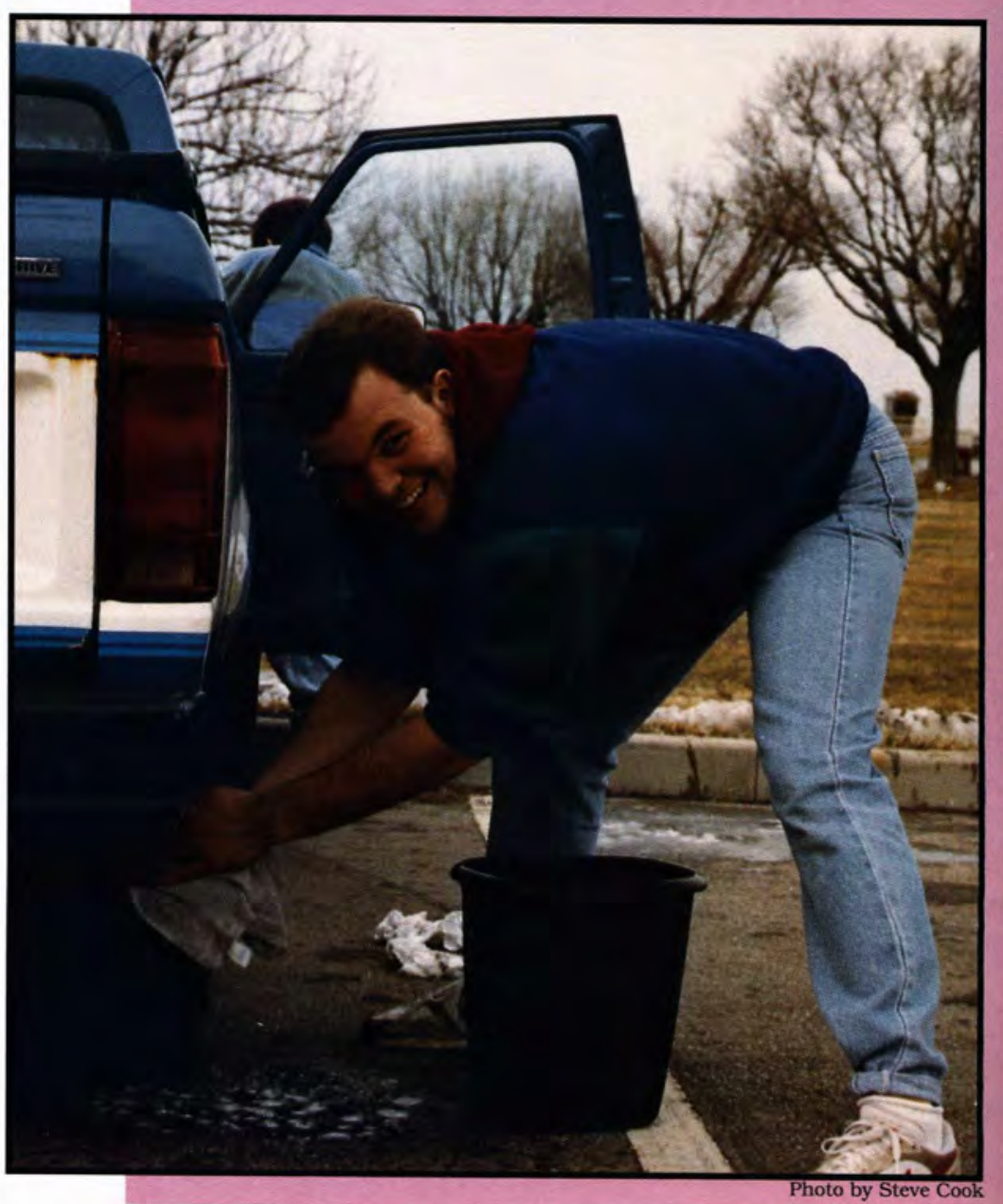




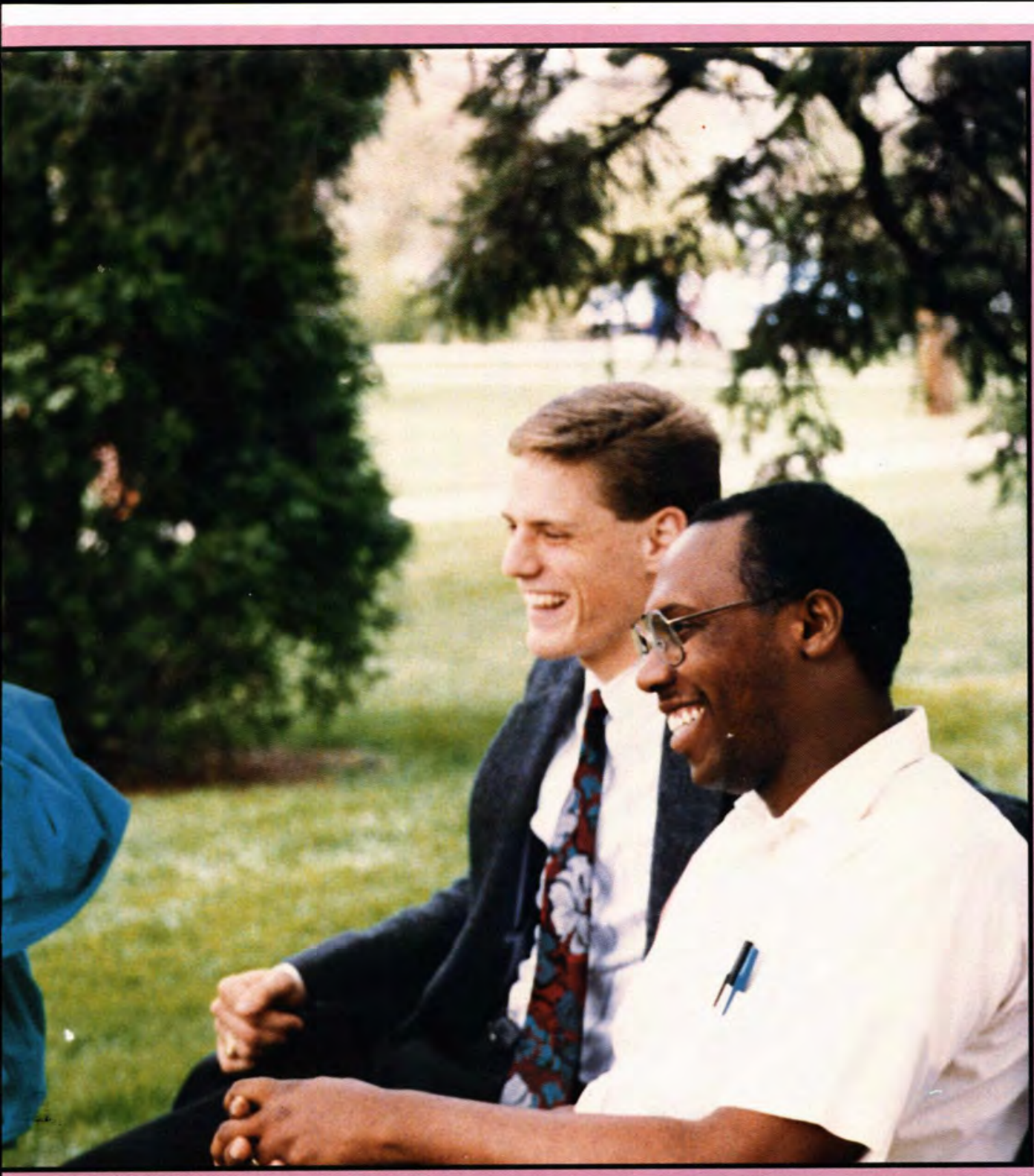

DISCUSSING THE INTRAMURAL

SOFTBALL GAME, Stephanie

Kirchoff and Chris Wilson enjoy a beautiful spring day.
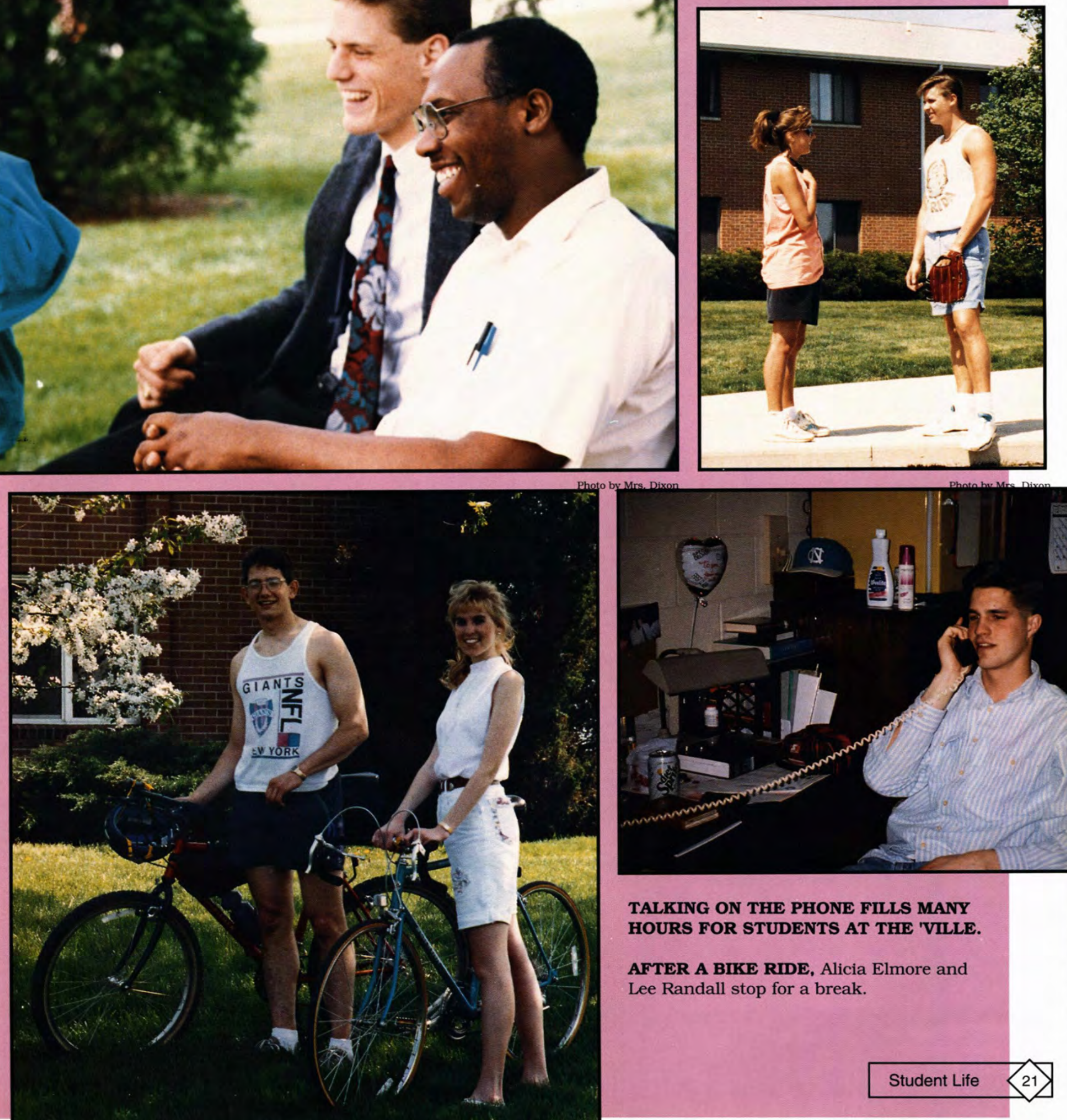

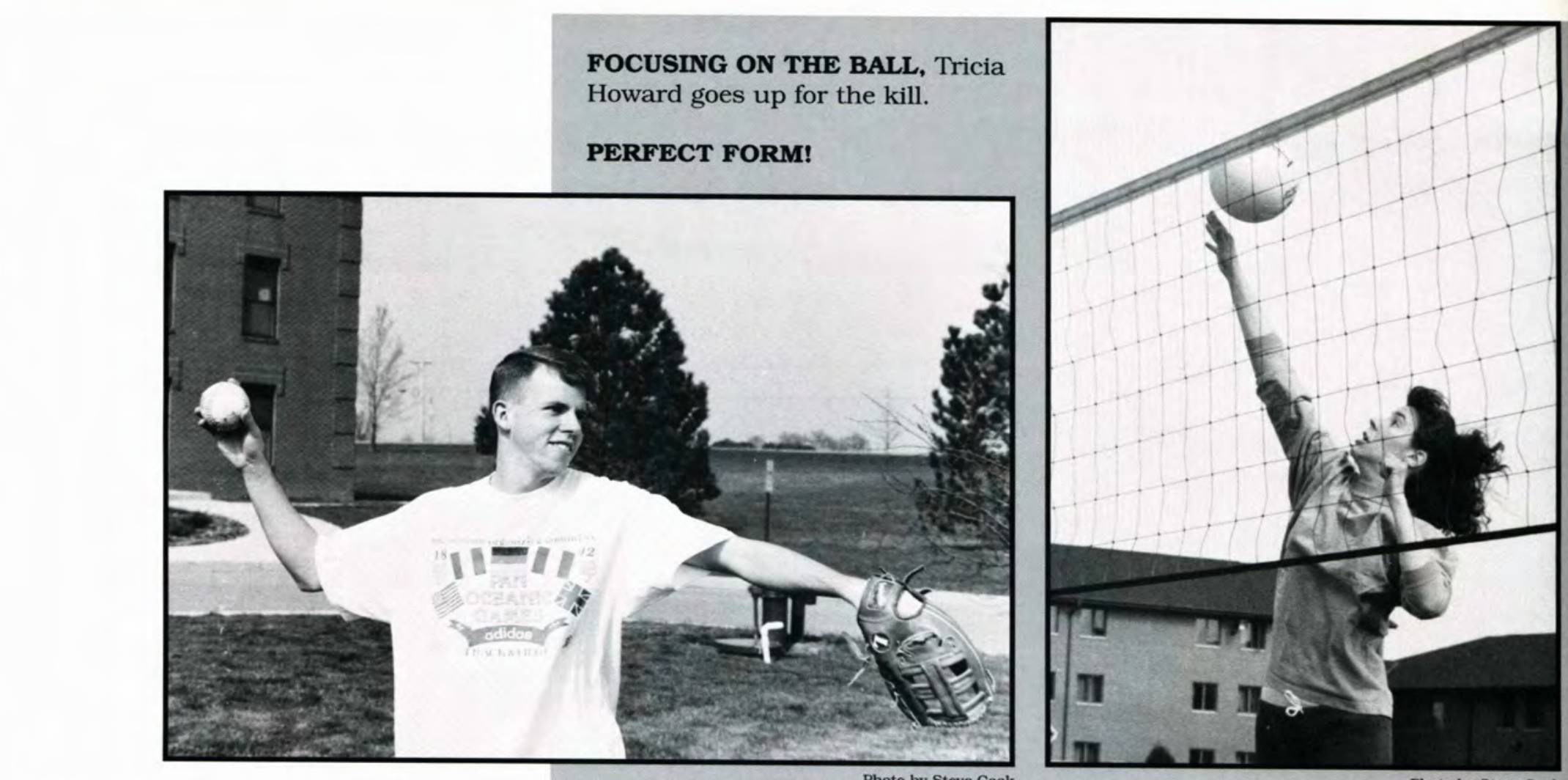

Intramurals Add to the Cedarville Experience

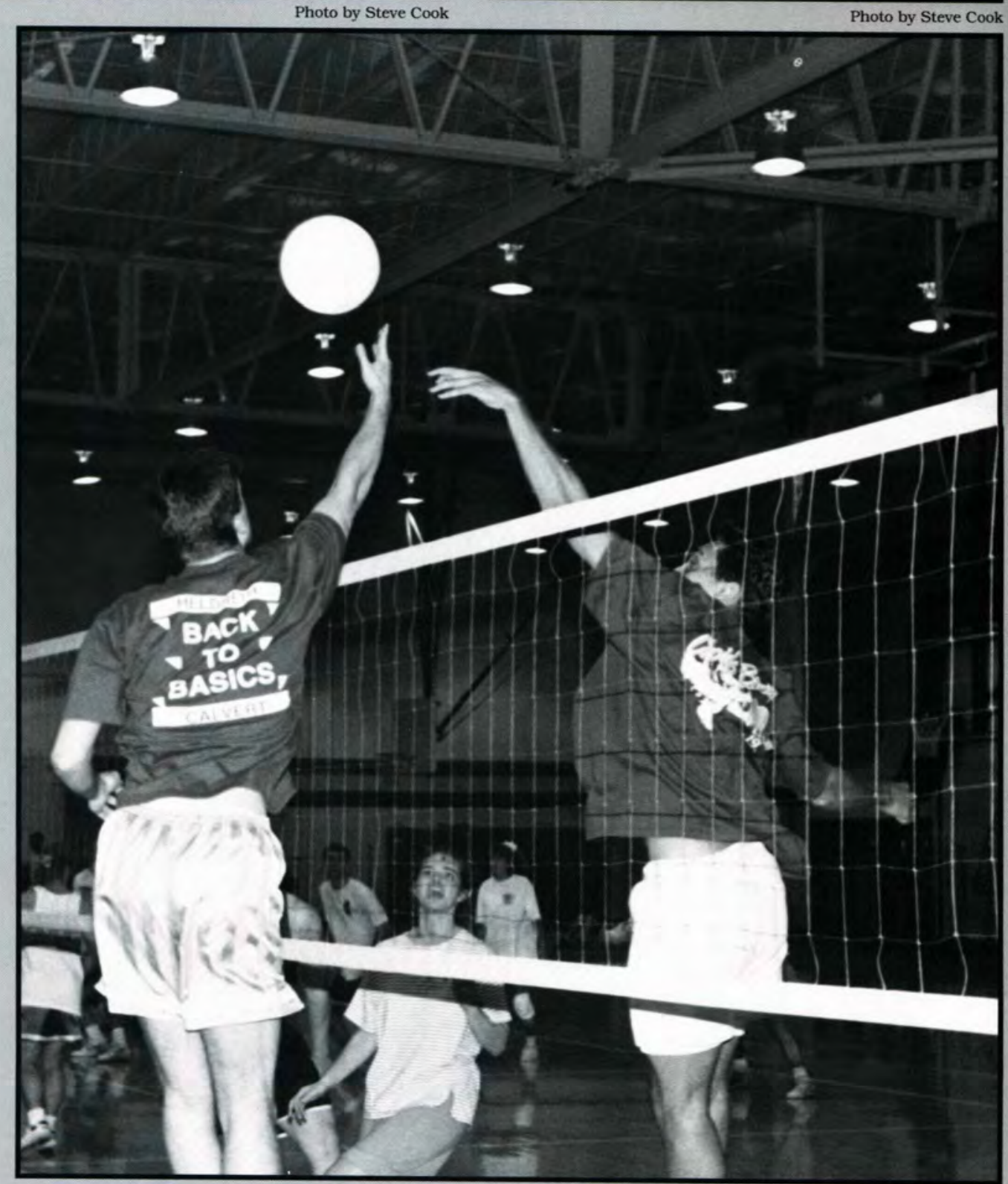

THE BATTLE AT THE NET IS KEY IN THIS VOLLEYBALL GAME. ${ }^{\text {Photo by Todd Hill }}$ 


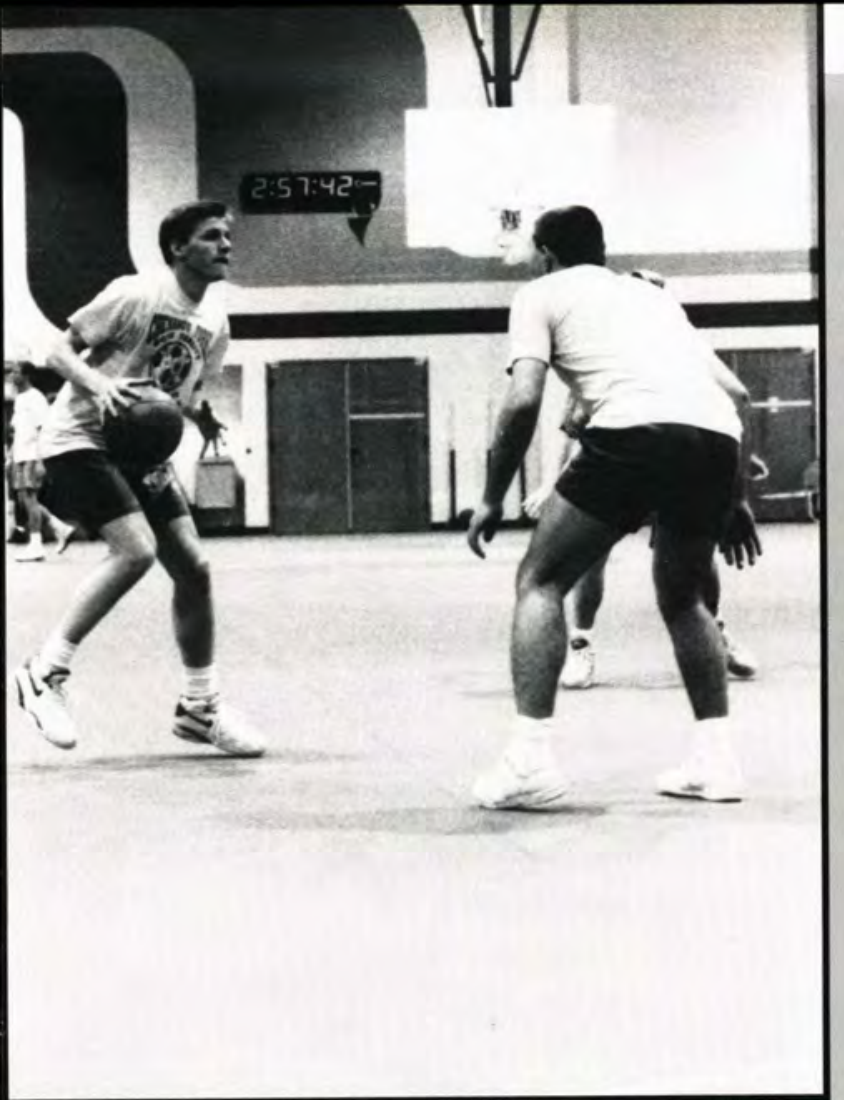

Photo by Steve Cook

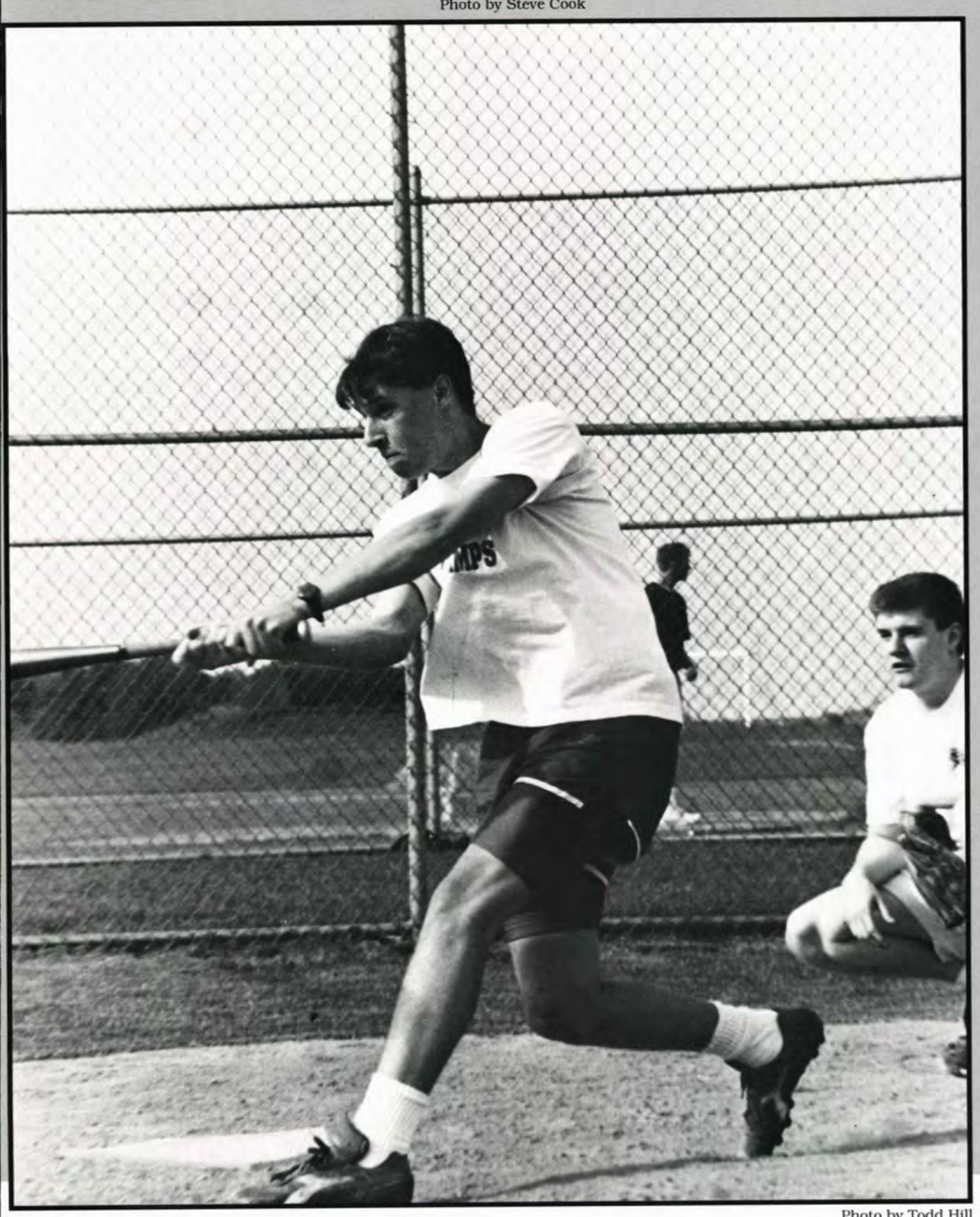

AN INTENSE GAME OF BASKETBALL AT THE

'VILLE.

THE FIELDERS ARE READY, as Bruce Colbert pitches the softball.
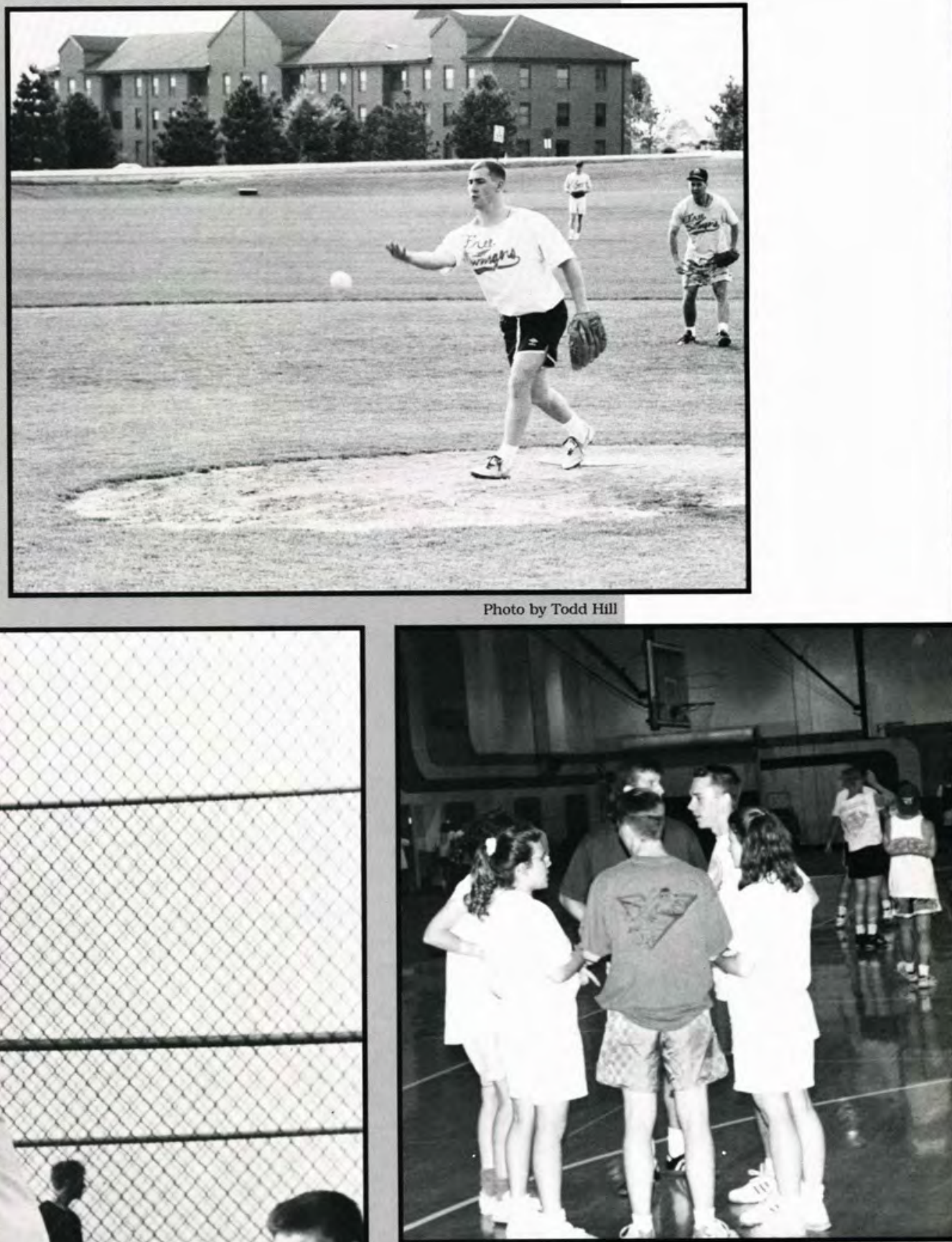

\section{TEAM}

MEETING?

WITH DETER-

MINATION LIKE

THAT, how

could he possi-

bly lose? 


\section{Open House Reunites}

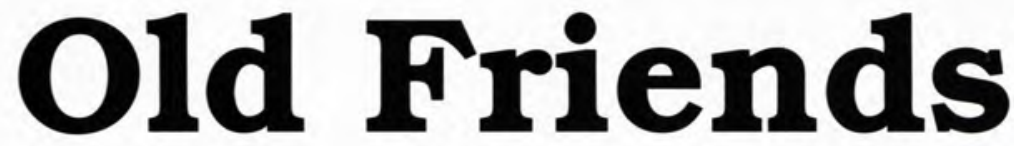

If you love old folks or just enjoy a good laugh, Carr basement was the place to be at Christmas Open House this year. They won first place for the men in the campus competition with their theme "The Basement Boys' Christmas Reunion."Traveling 50years into the future, the fourteen residents of the basement got dressed up in their "Sunday best" and wandered through the hall of their "Retirement Manor" entertaining all the Christmas visitors by proudly showing off pictures of their grandchildren, complaining about health, and reminiscing about the "good ol' days." R.A. of the basement boys, Jeff Burr, said, "I think we had more fun than any of our visitors."

The guys did a great job, and word quickly traveled around campus, "You have to go see Carr Basement!" One of the basement boys, David (Gramps) Shumaker, stated, "We didn't have much time to prepare this year, but it was a clever idea the guys had. It turned out to be a good time, and I'm glad we won. By the way, have I shown you pictures of my beautiful granddaughter?..."

-Kathleen Coy
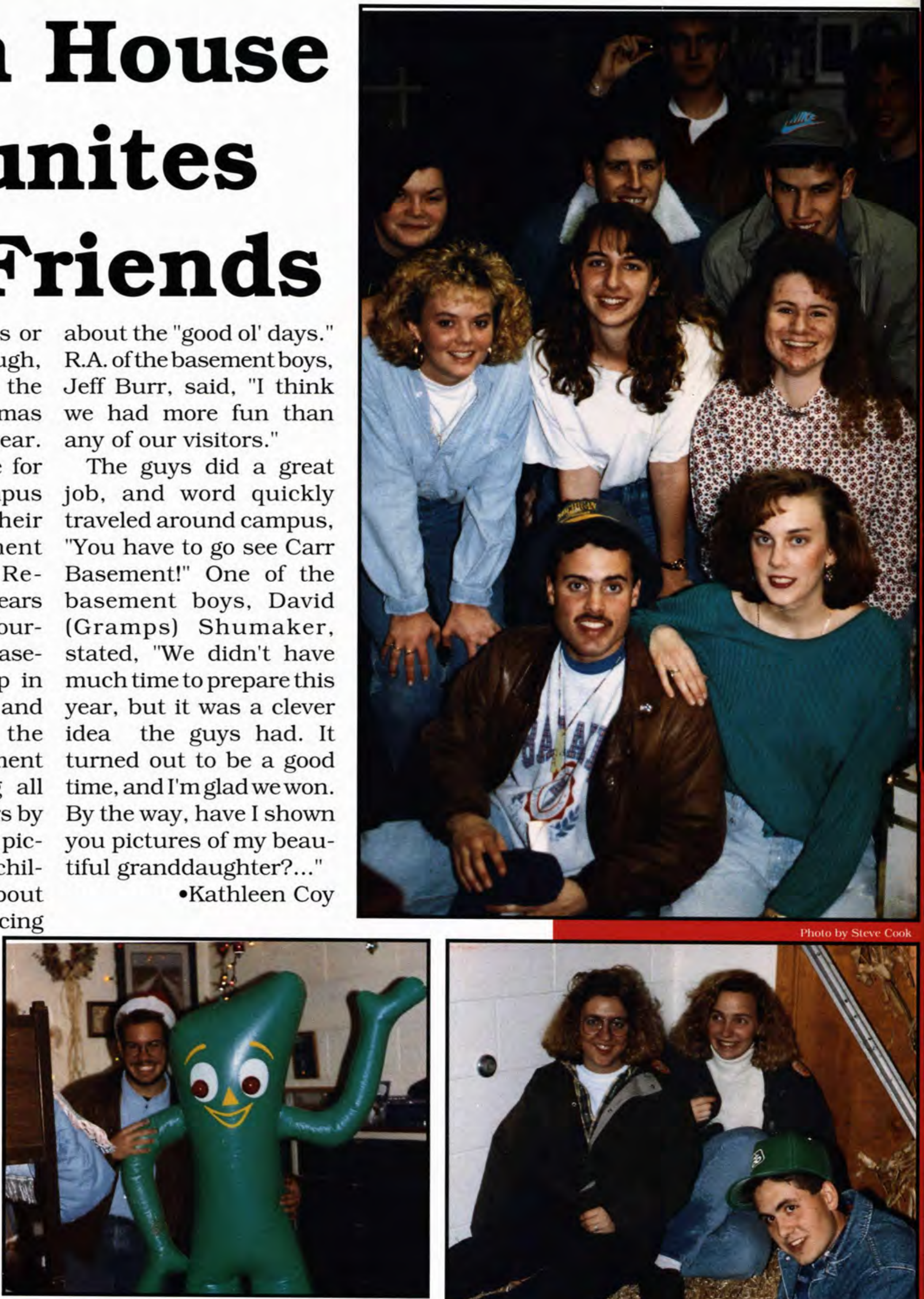

Top: SAY CHEESE FOR SANTA.

hoto by Steve Cook Right: A REINDEER IN THE MANGER? Above: A CHRISTMAS GUMBY? Eric Johnson poses with his friend Gumby.

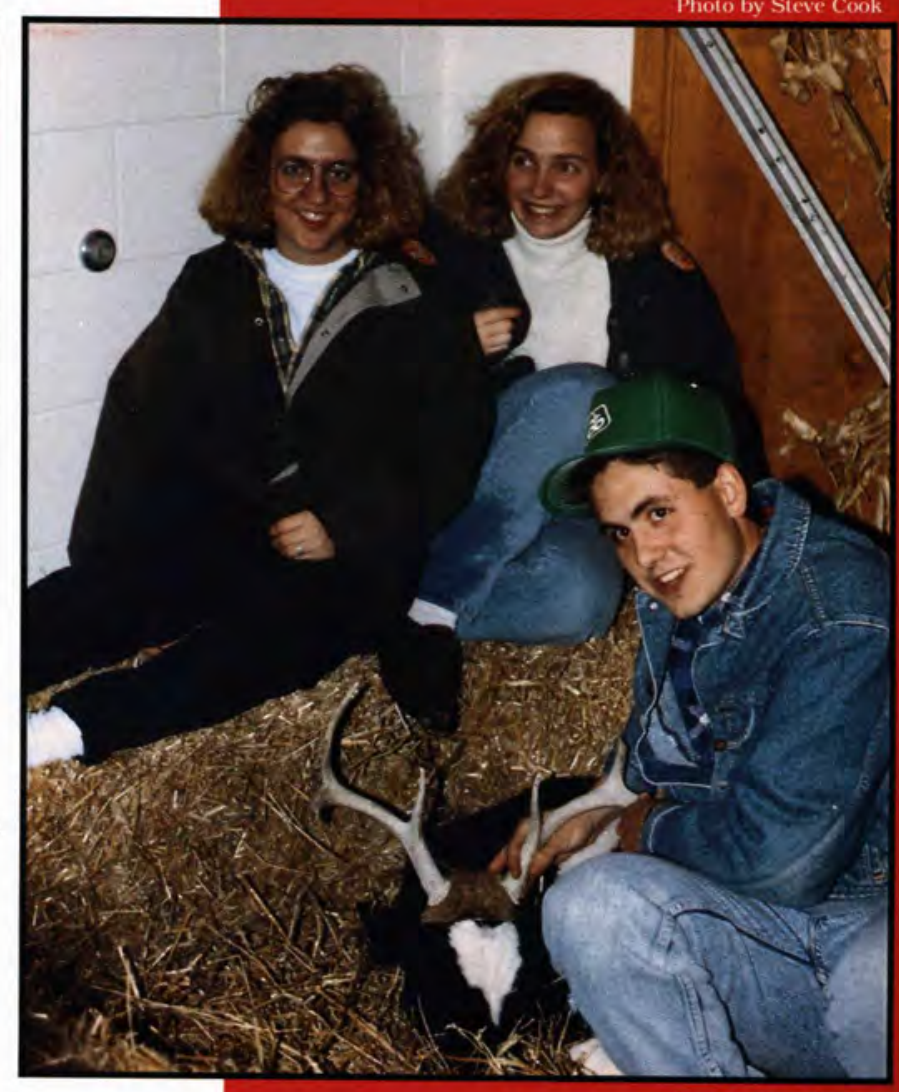


FRIENDS GATHER IN MADDOX.

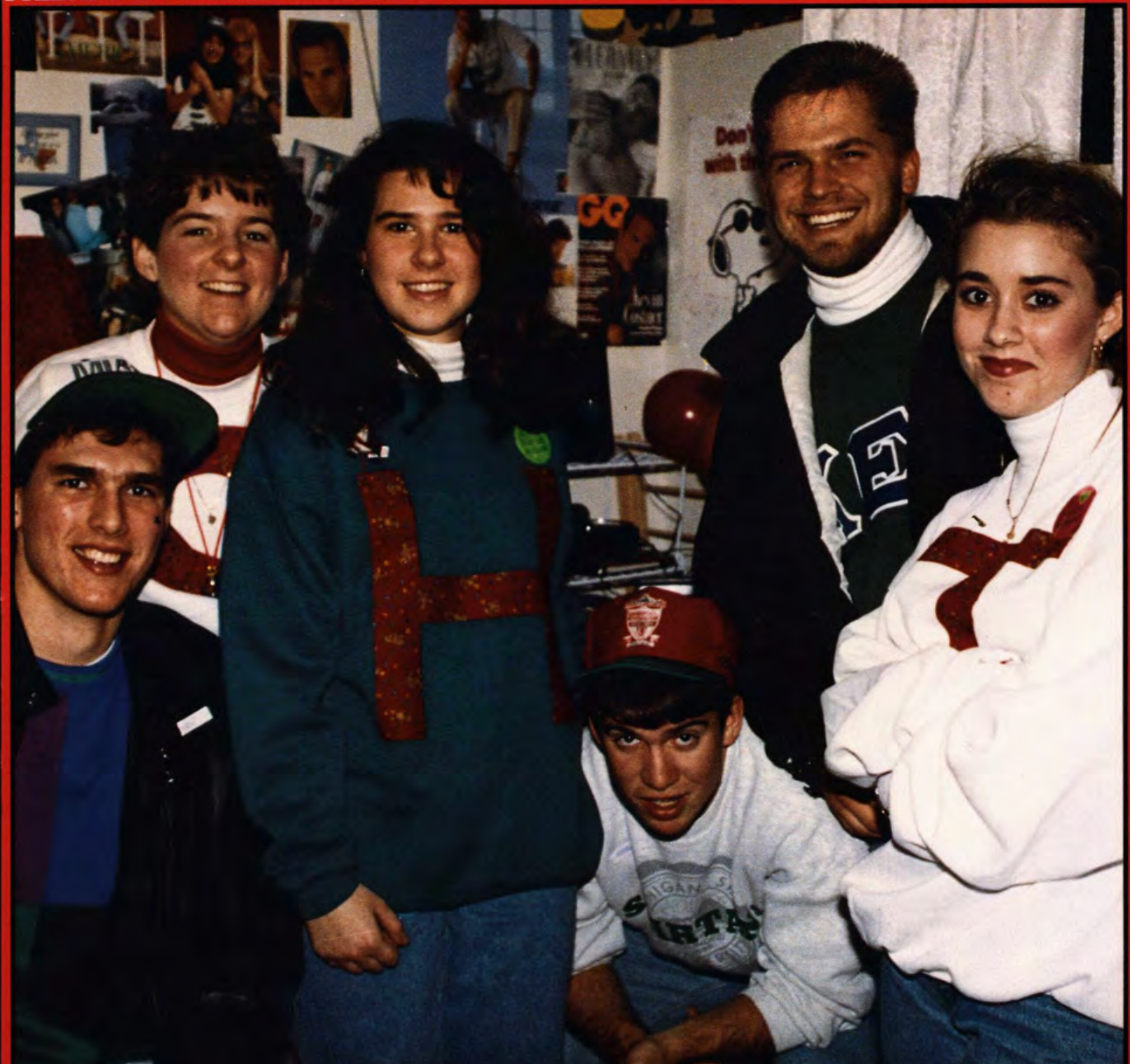

SPREADING A

LITTLE

CHRISTMAS

CHEER.

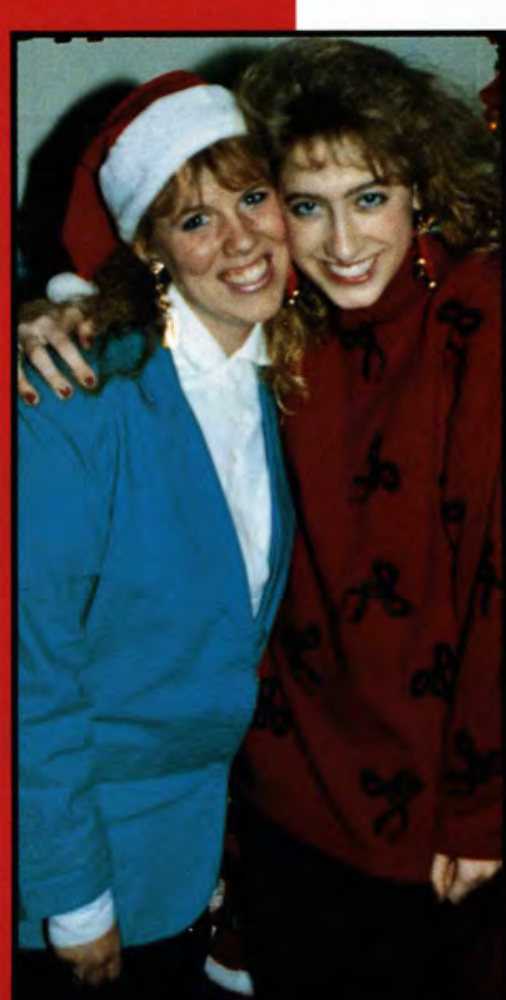

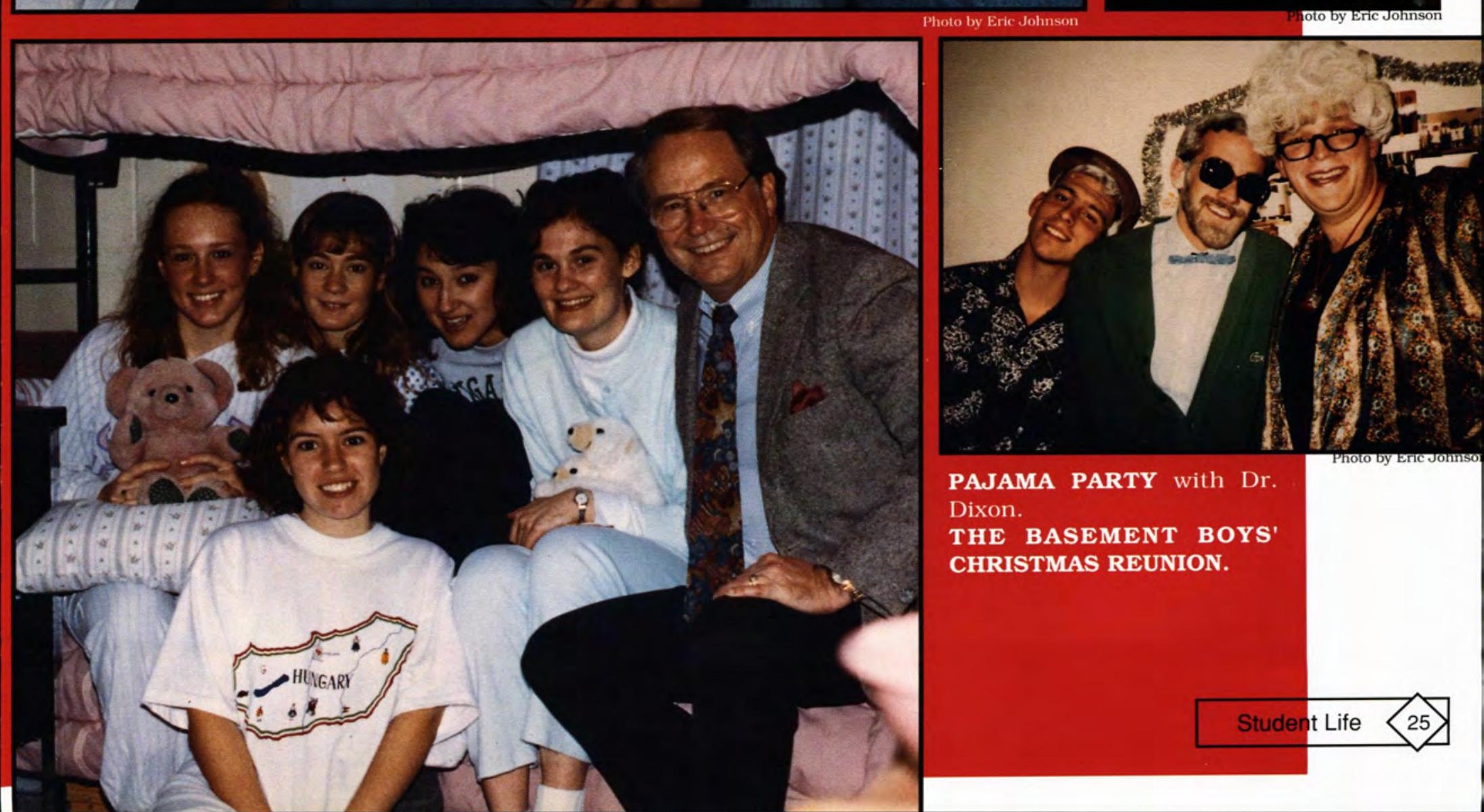




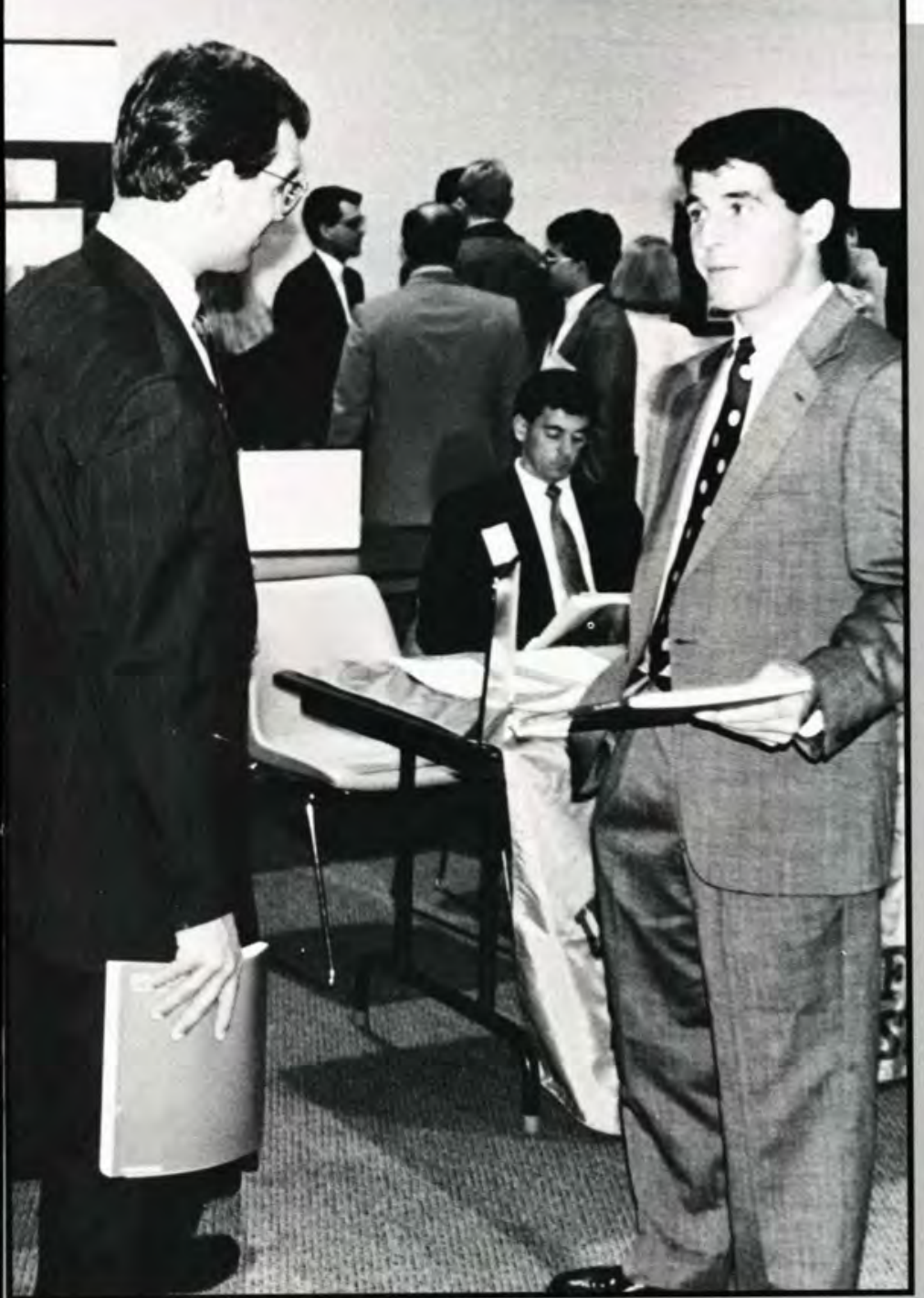

\section{The Nerves of the Job Search}

Is my tie straight? Does it for the day. match my shirt and suit? Should I wear black shoes or brown? Come on, you're my roommate; you're supposed to be able to help me with such life changing decisions!

Everything needs to be just so when you go to a job interview or when you are trying to network and make employer contacts. For seniors especially, Career Day has been a time to dress-toimpress and dress-for-success. Even though the annual event is held in the cafeteria, a normally casual place, the nerves and anxieties of students in their freshly pressed suits and dresses can make eating the last thing on their agenda

Winding through rows of business, seminary, and graduate school representatives, students are able to gather information about particular companies, inquire about specific job openings, leave their resumes with businesses of interest, and collect a wide array of pens, pencils, and candy. Even if none of the businesses represented are of interest to a student, chatting with their representatives may ease some of the strain they would feel at their first important job interview. So when that big interview rolls around, straighten that tie, pull your shoulders back, make sure your socks match, go forth and conquer! $\bullet$ Marsha Olsen
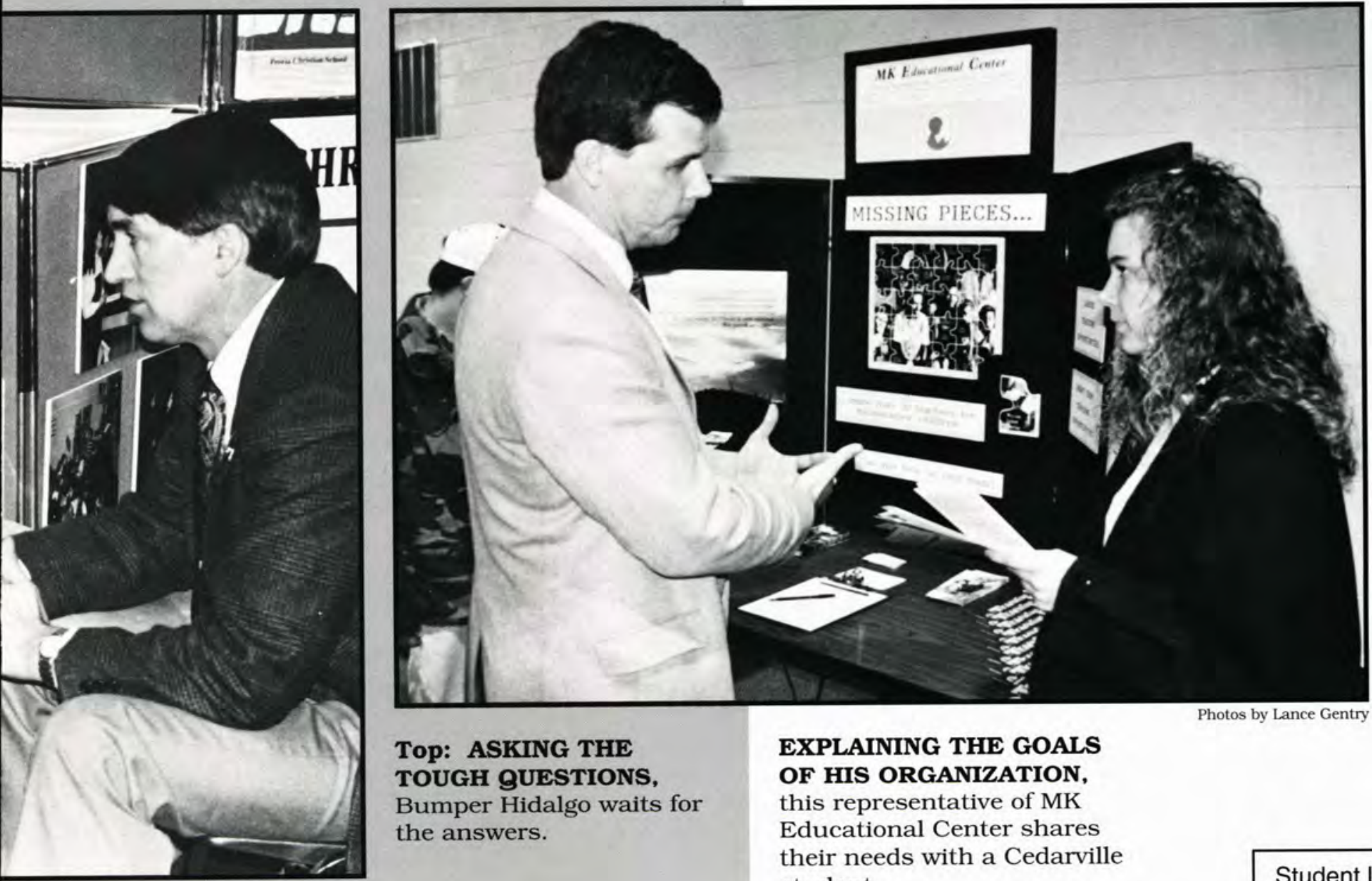

Top: ASKING THE TOUGH QUESTIONS. Bumper Hidalgo waits for the answers.
EXPLAINING THE GOALS OF HIS ORGANIZATION,

this representative of MK Educational Center shares their needs with a Cedarville student.
Photos by Lance Gentry 


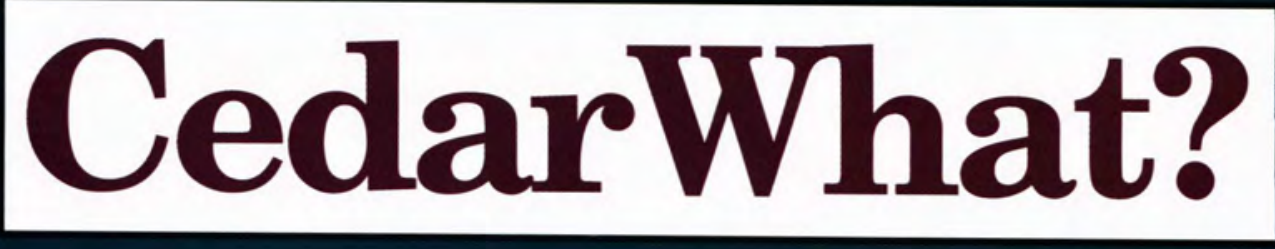

THE CEDARWHAT? CANDIDATES. Jon and Donna Purple vs.

Drs. Clevenger and Colman.
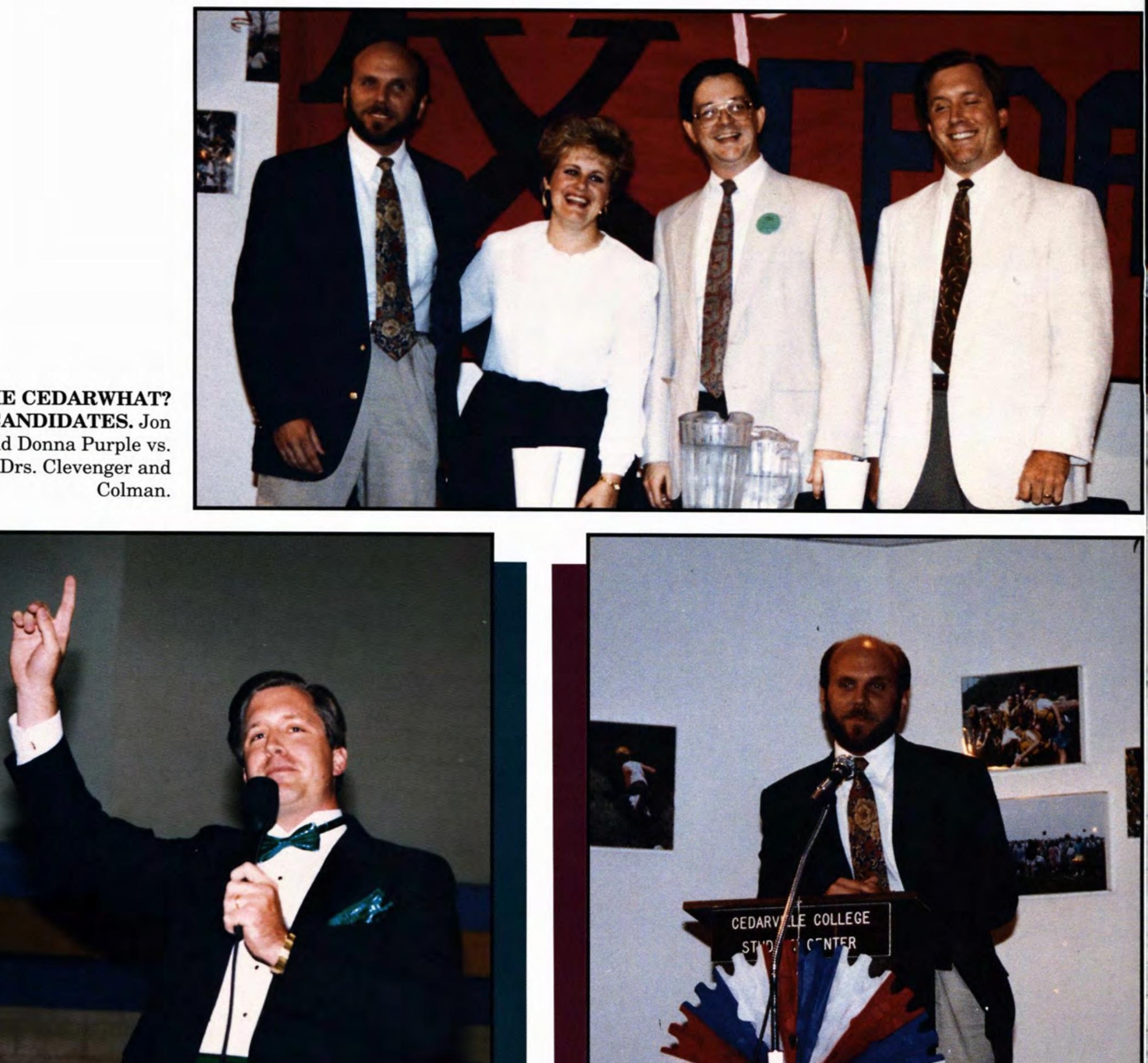

ON THE CAMPAIGN TRAIL, Dr. Colman makes his first point at the Organizational Fair. AT THE DEBATE, Jon Purple pauses before answering the opposition.

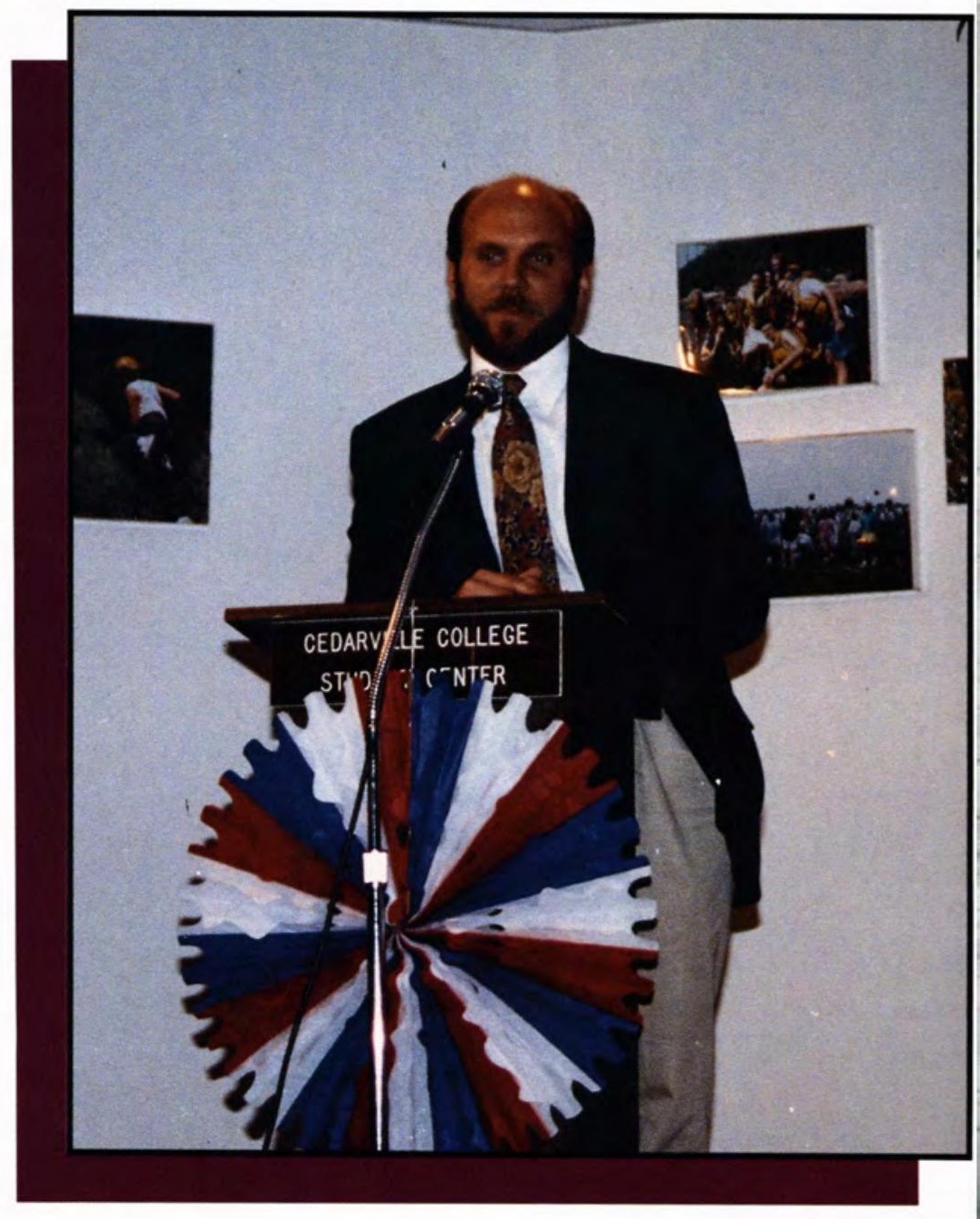


LOYAL CEDARGREEN FANS, Nathan Dobert, Heather Rifenberick, Ryan Huebner, and Doug Moore, display their support at the debate.
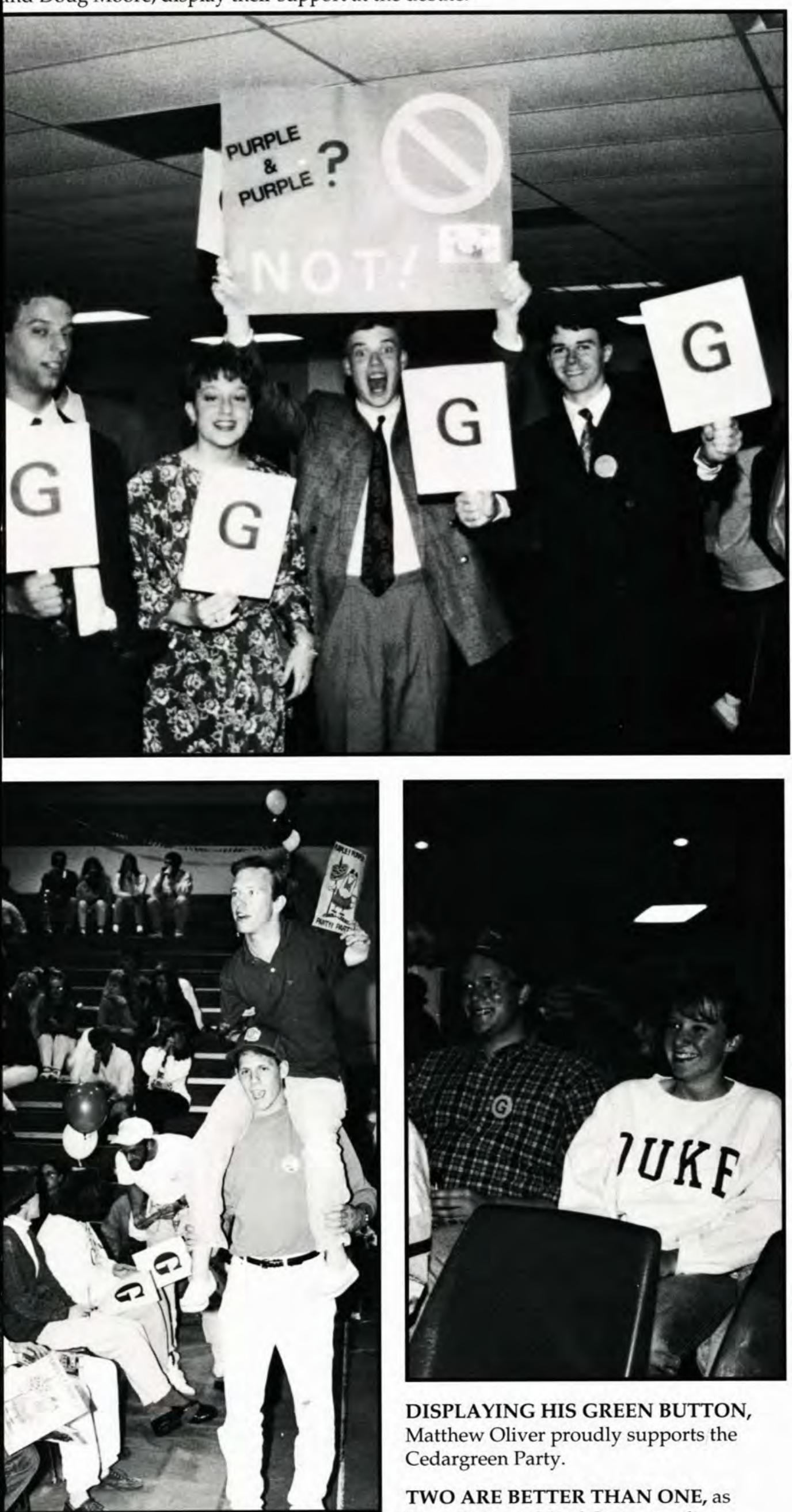

DISPLAYING HIS GREEN BUTTON, Matthew Oliver proudly supports the Cedargreen Party.

TWO ARE BETTER THAN ONE, as Dave Bates and Karl Cooper realize, when it comes to seeing all the action at the CedarWhat? convention.

\section{From the Candidates}

HI! I'M FROM CEDARVILLE... "Cedar what?!" That question, which haunts all Cedarvillians, has become the theme of a mock election held on our campus every four years in honor (or dishonor) of the national elections. Lest I be accused of journalistic onesidedness, I shall turn the rest of this article over to the candidates. (Lest you forget though, the Purple Party destroyed their competition!)

The CedarWhat? campaign was a great example of a microcosm of the national election. It was fun to watch normally thinking, responsible people turn into mindless followers of one party or the other. I'm looking forward to a long vacation, now that the election is over. - Dr. Jim Colman, defeated CedarWhat? candidate

The opportunity to run in the CedarWhat? election as the candidates for the PARTY!PARTY! was a once-in-a-lifetime experience (meaning we'd never do it again)! We had a great time working with the students in our campaign. Their encouragement and support, which included Tyler Thompson painting his truck purple, made it all worthwhile. We have some wonderful memories, great pictures, video footage and friendships that will transcend our political reign! In closing, we want to thank you, the voters of CedarWhat?, for exercising both your right to vote and your right to PARTY!PARTY! President and Vice-President elect, Jon and Donna PURPLE!PURPLE!

- Jim Foster 


\section{CedarWhat? \\ Convention}

Purple!Purple! Defeats CedarGreen Party

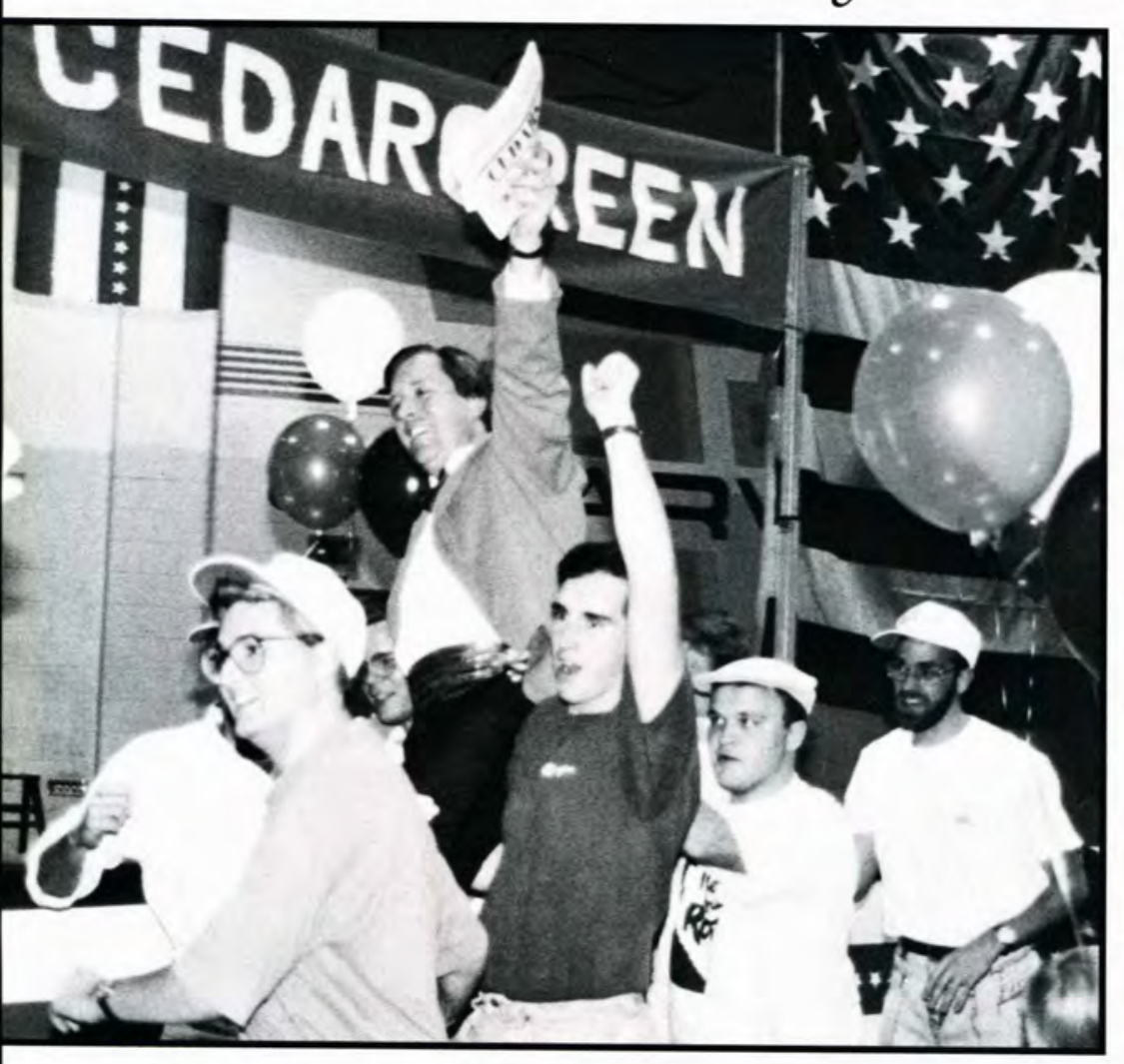

HOLD HIM DOWN! Ben Kalich tries to avoid floating up with his bunch of balloons at the CedarWhat? convention.

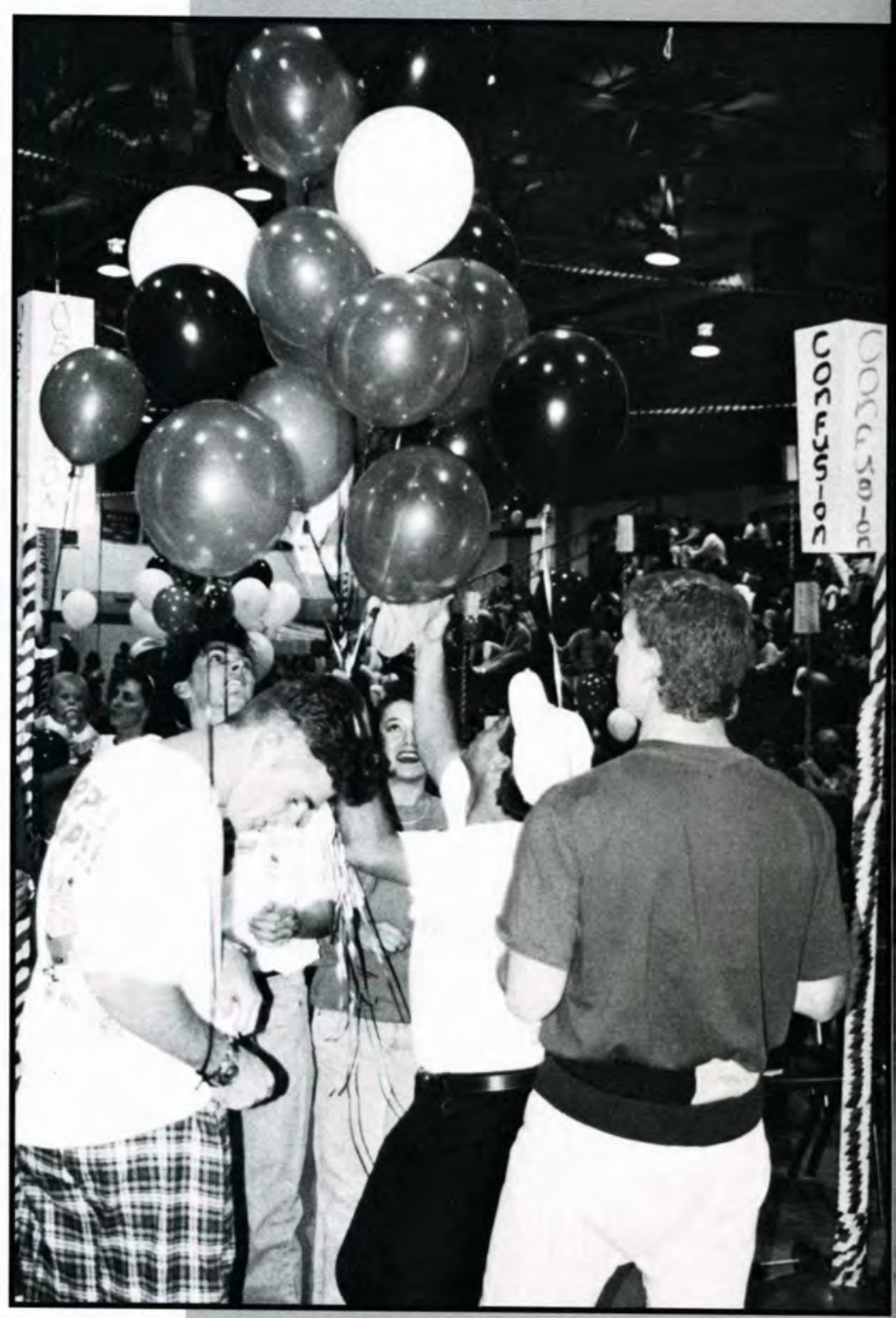

WARMING UP FOR THE CONVENTION, candidate Dr. Colman goes for a ride on the shoulders of his supporters. PURPLE!PURPLE! TRUCK!TRUCK!

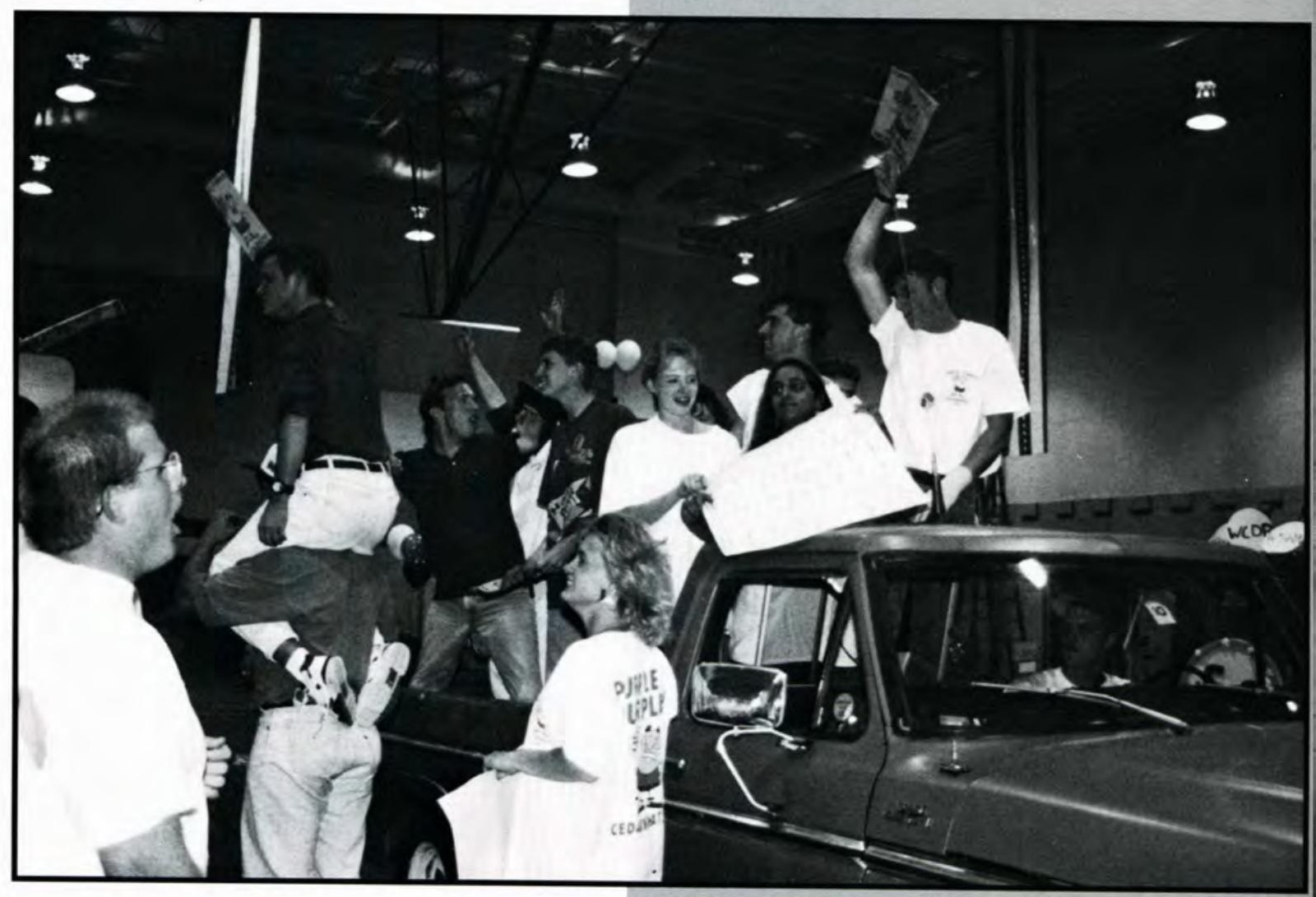




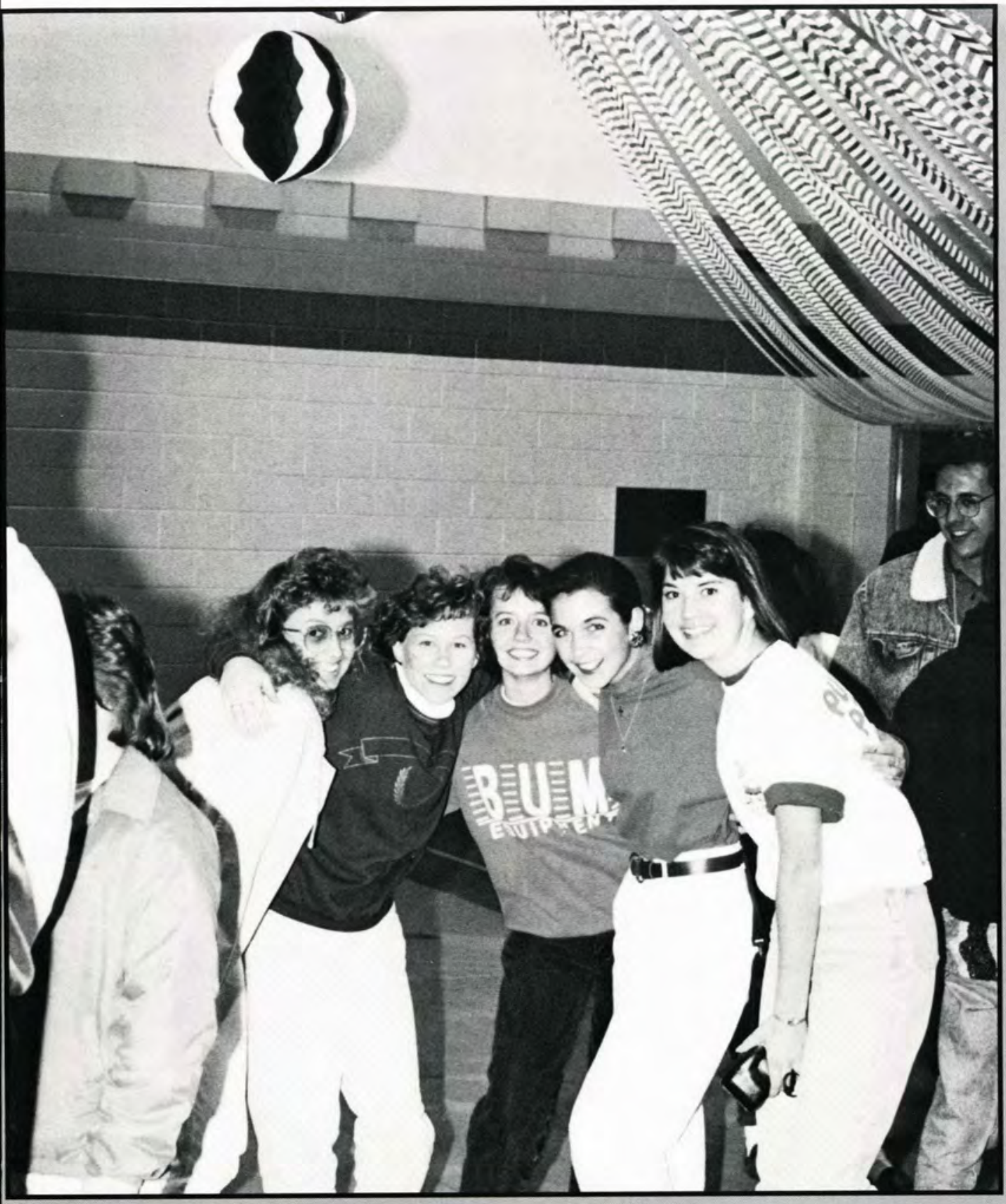

PURPLE!PURPLE! Karyn

Wyman, Jeanette Rome, Brenda Killian, Ann Guest, and Lori

Smith look forward to a Purple Victory!

\section{GREEN FACES!}

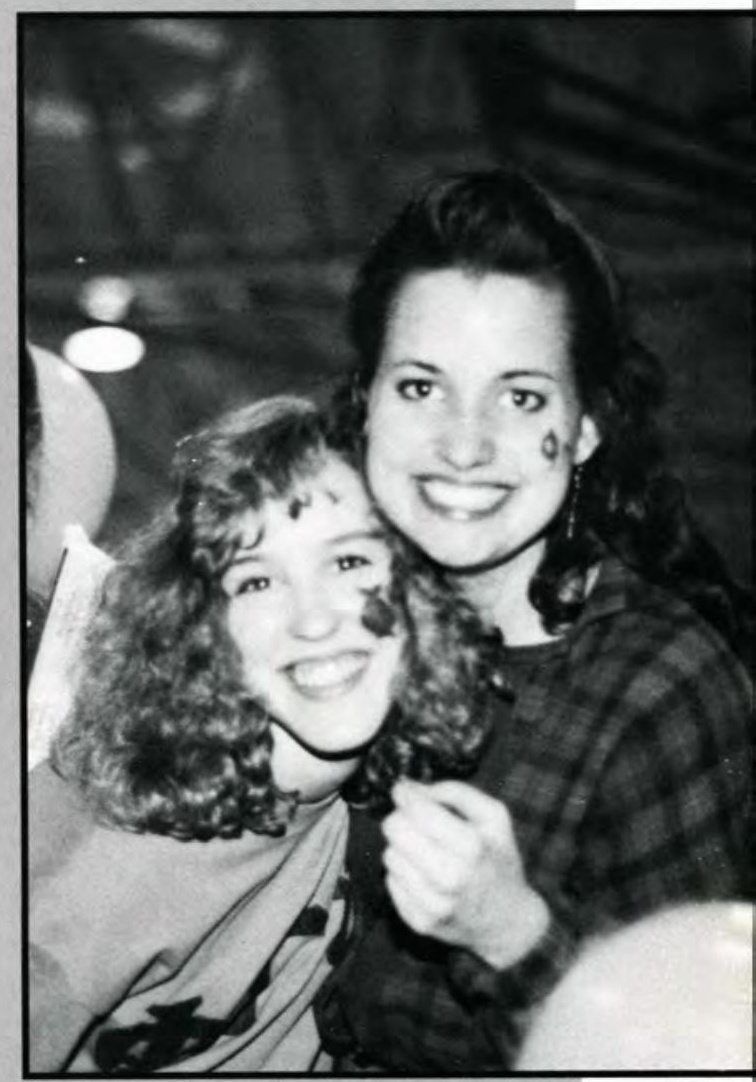

\section{X}

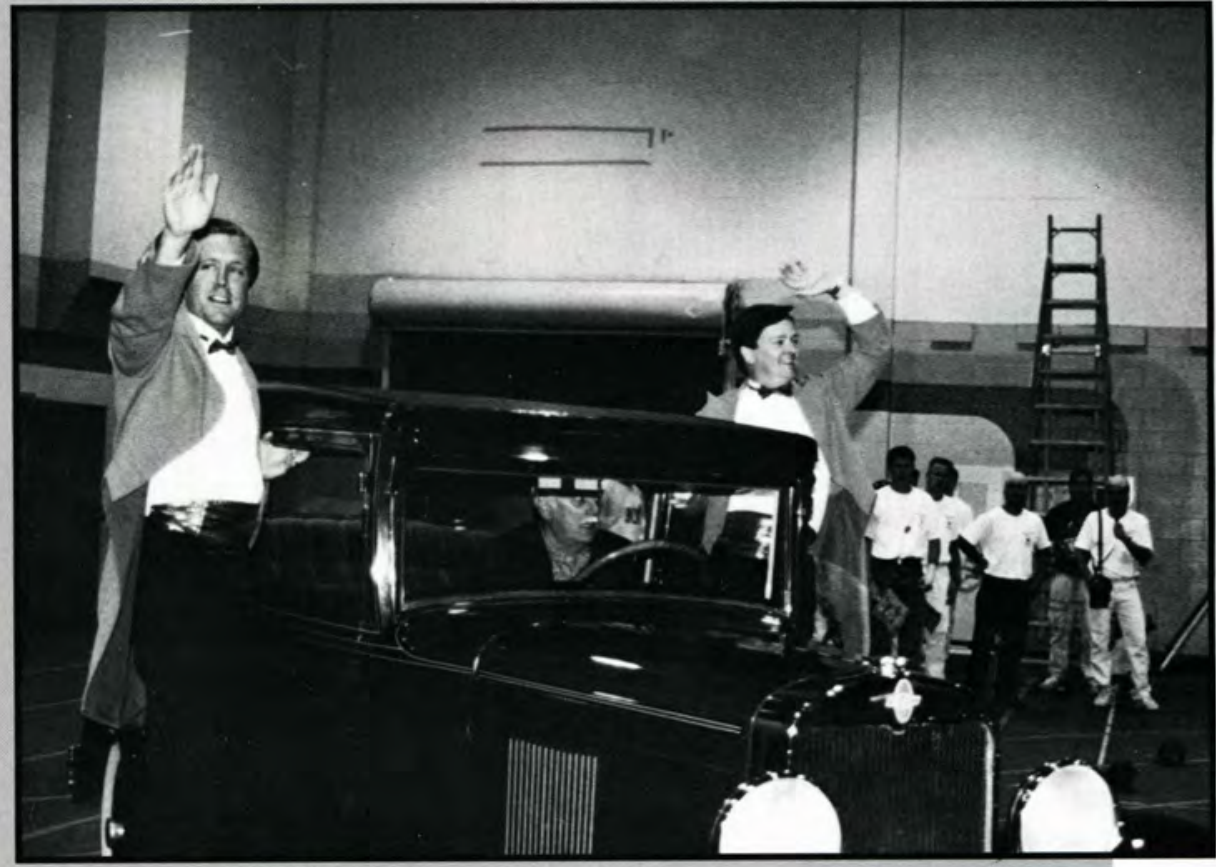

MAKING A GRAND OLE ENTRY, Colman and Clevenger wave to their supporters.

PRESENTING PRESIDENT AND VICE-PRESIDENT OF

CEDARWHAT? JON AND DONNA PURPLE!! 


\section{Faculty}

"And we beseech you, brethren, to know them which labour among you, and are over you in the Lord, and admonish you; and to esteem them very highly in love for their work's sake."

-- I Thessalonians 5:12-13a

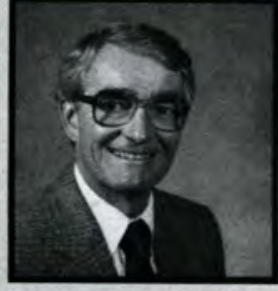

Robert Gromacki, Th.D. Chair

Biblical Education

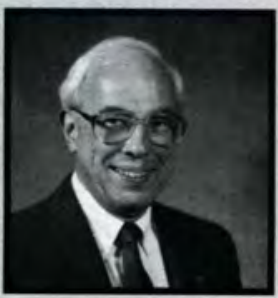

Jack Riggs, Th.D.

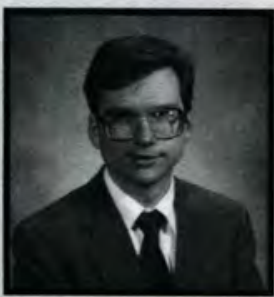

Charles Hartman, M.B.A.

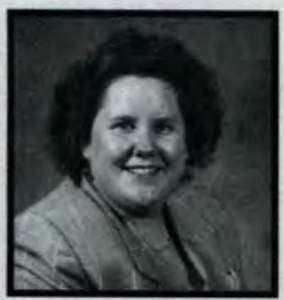

Sandra Terkelsen, M.B.A.

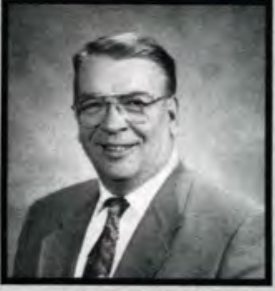

Richard Blumenstock, Th.M.

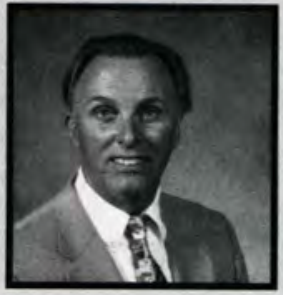

David Warren, Th.M.

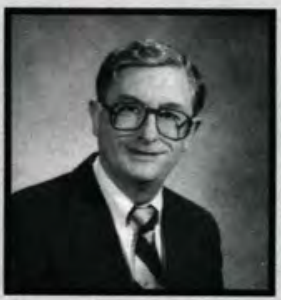

Marinus Hazen, M.B.A.

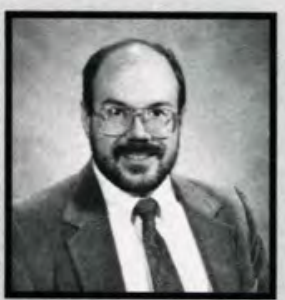

Bert Wheeler, Ph.D.

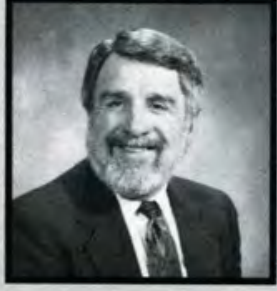

David Drullinger, D.Min

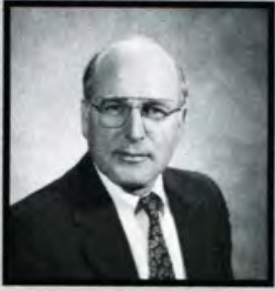

Ronald Walker D.B.A Chair

Business Administration

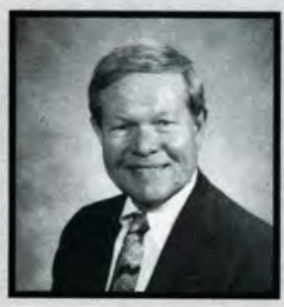

Walter Hoffman, M.B.A.

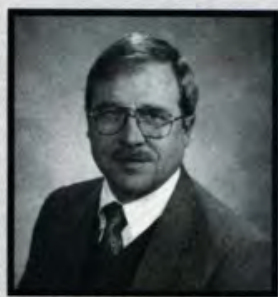

James Phipps, Ph.D Chair,

Communication Arts

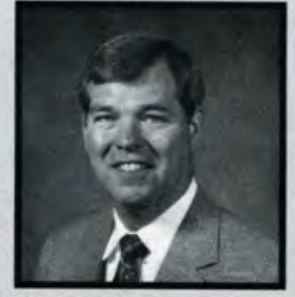

Floyd Elmore, Th.D

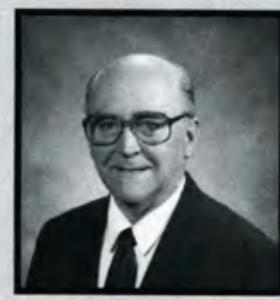

Richard Baldwin, Ph.D.

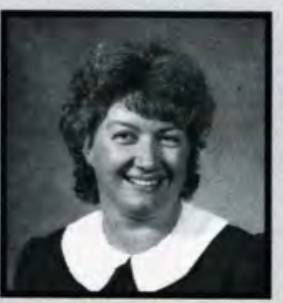

Martha Johnson, M.A.

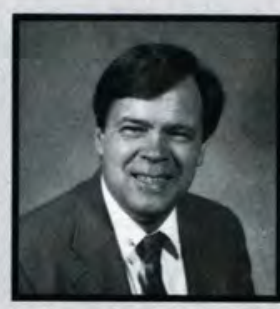

J. Wesley Baker, Ph.D.

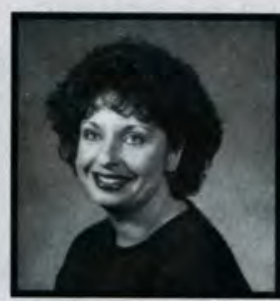

Diane Merchant, M.A

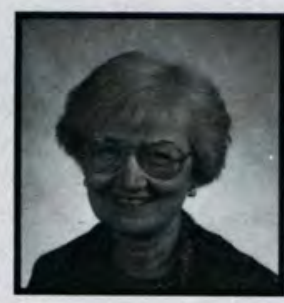

Sue Baker, D.Ed.

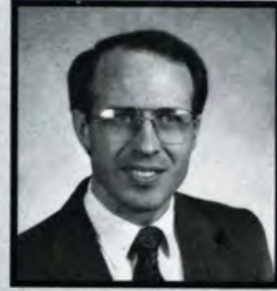

Dan Estes, Ph.D.

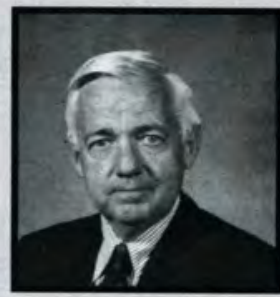

John Cassidy, D.B.A

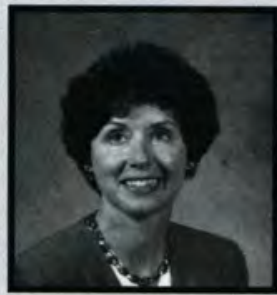

Betty Orme, M.S.

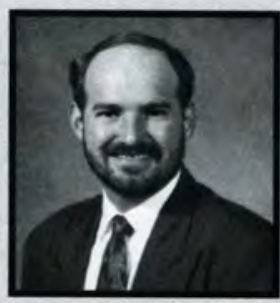

Gary Barker, M.F.A.

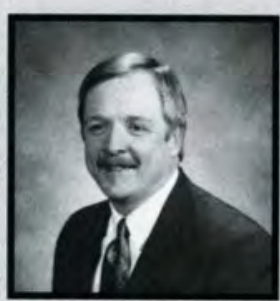

Kurt Moreland, M.A.

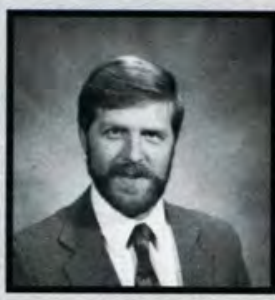

W. Philip Bassett, Ph.D.

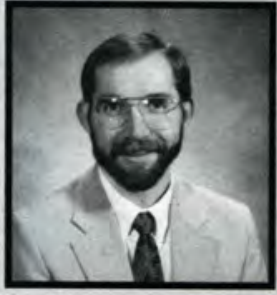

Chris Miller, Th.M.

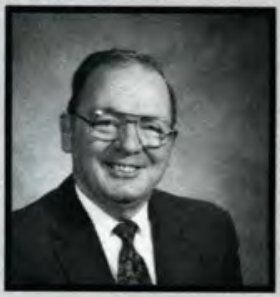

Clifford Fawcett, D.B.A.

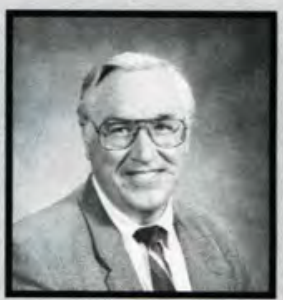

Galen Smith, M.S

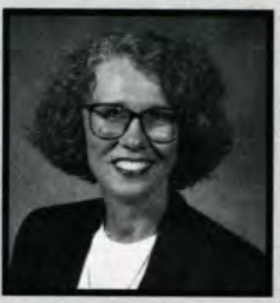

Deborah Haffey, M.M.

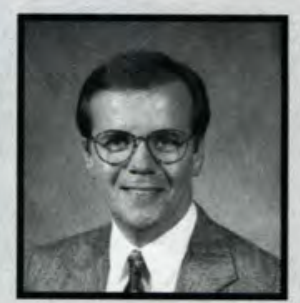

David Robey, Ph.D.

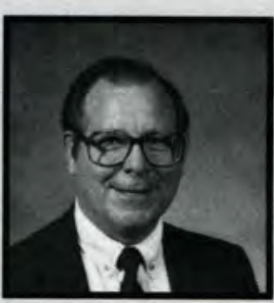

Omer Bonenberger, D.Ed.

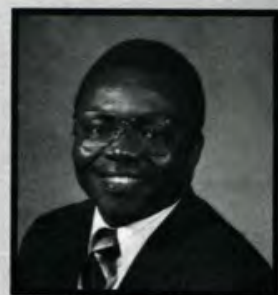

Patrick Nnoromele, Ph.D

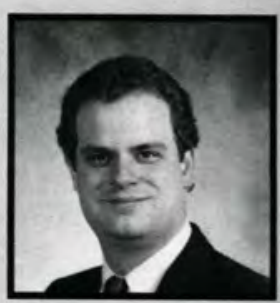

Jeff Fawcett, M.B.A

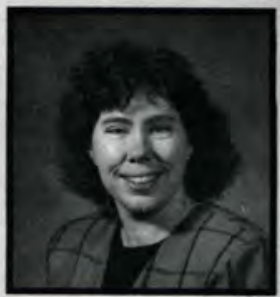

Sarah Smith, Ph.D.

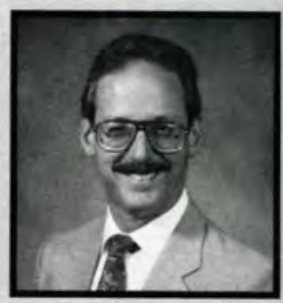

Michael Lopez, Ph.D.

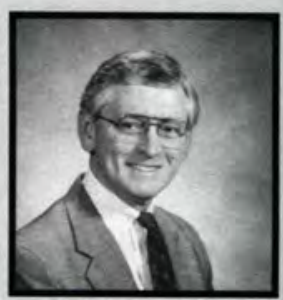

Merlin Ager, Ph.D. Chair,

Education

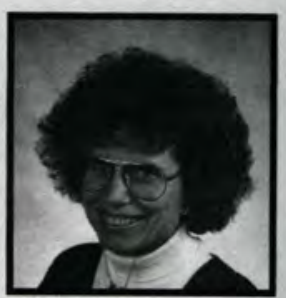

Sharon Eimers, D.Ed. 


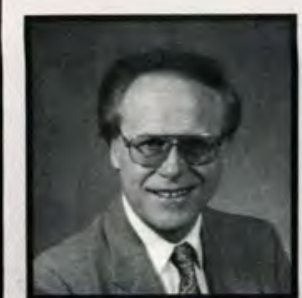

Dwayne Frank, D.Ed.

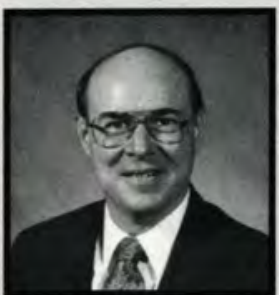

Harwood Hegna, Ph.D.

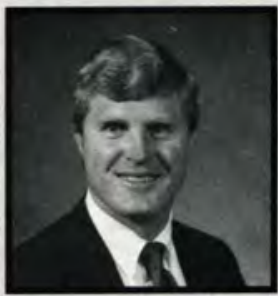

Evan Hellwig, Ph.D.

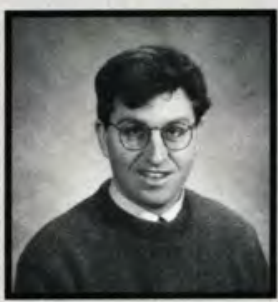

Kevin Heath, M.A

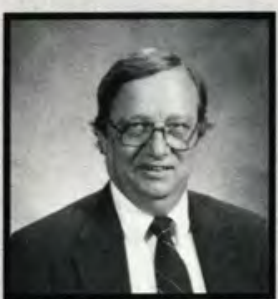

Jack Simons, MFA

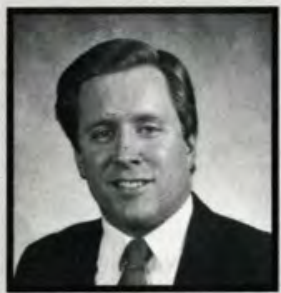

James Colman, Ph.D.

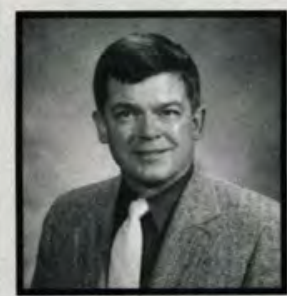

Jerry Rodgers, B.M.

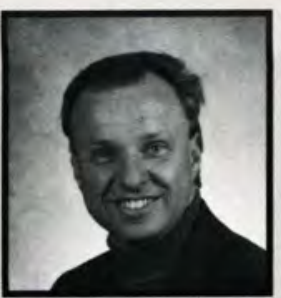

Tim Heaton, M.A.

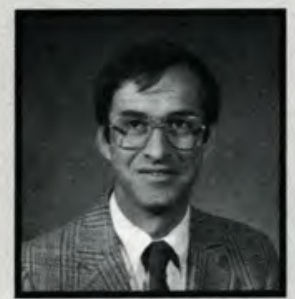

Robert Laramore, M.S.E.

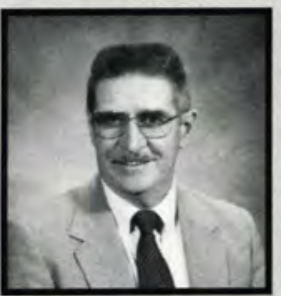

Elvin King, M.Ed.

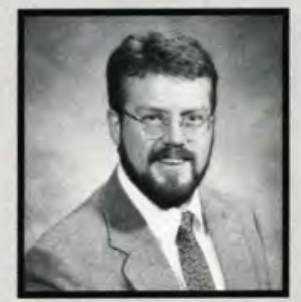

Donald Humphreys, M.S.

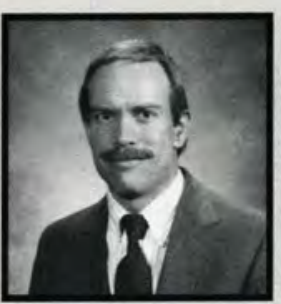

James Snowden, J.D.

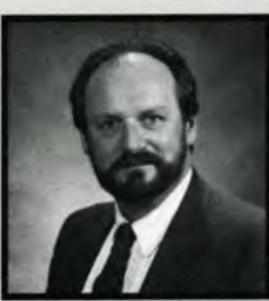

Michael DiCuirci, M.M.

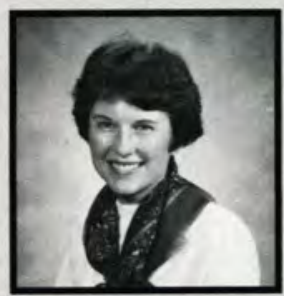

Kathryn Rodgers, M.A

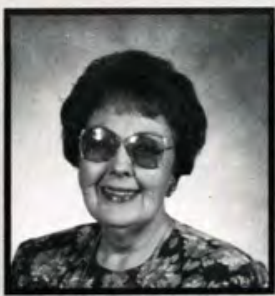

Anna Ruth Hille, M.A.

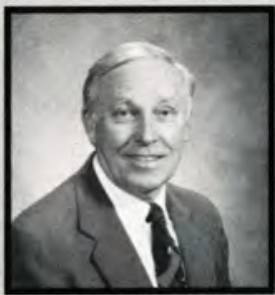

Donald Callan, Ph.D.

Chair.

Health \& Physical Ed.

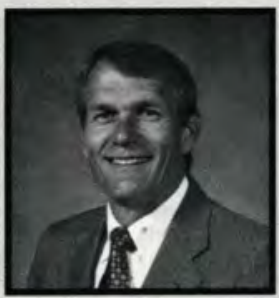

John McGillivray, M.S.

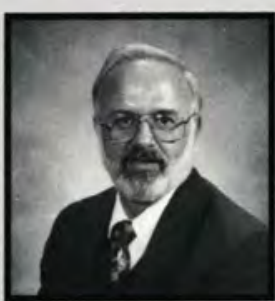

Philip Jones, Ph.D.

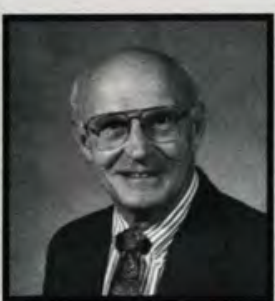

Edward Spencer, M.A.

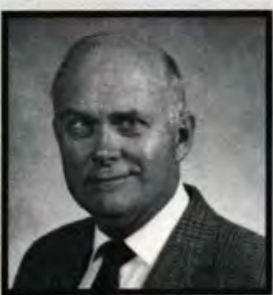

Charles Ellington, Ph.D.

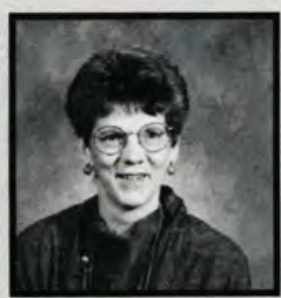

Irene Alyn, Ph.D.

Chair, Nursing

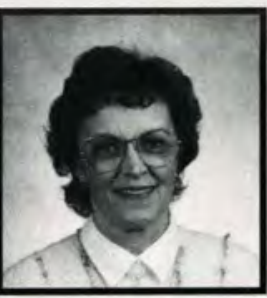

Beverly Monroe, Ph.D.

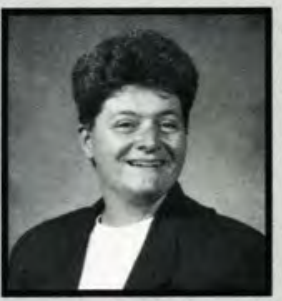

Elaine Brown, M.S. Ed.

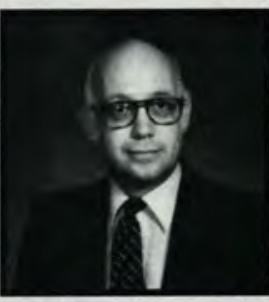

Ray Bartholomew, Ph.D. Chair

Language \& Literature

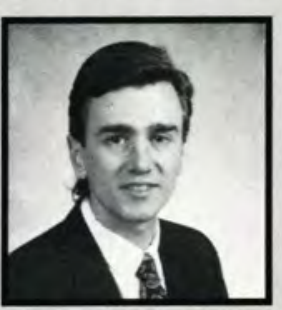

Brian Kennedy, Ph.D.

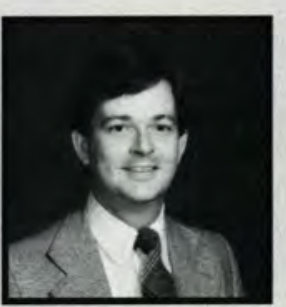

Charles Clevenger, D.M.A. Chair Music

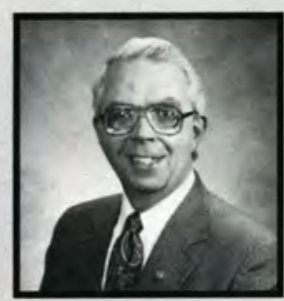

David Matson, Ph.D.

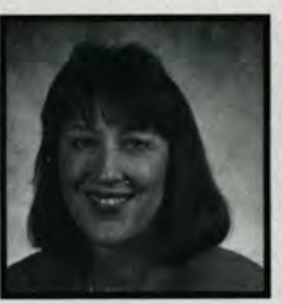

Lois Baker, Ph.D.

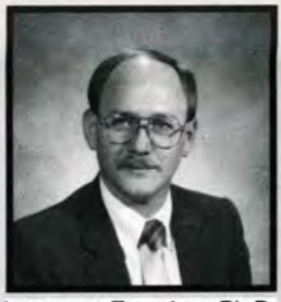

Lawrence Zavodny, Ph.D. Chair.

Engineering

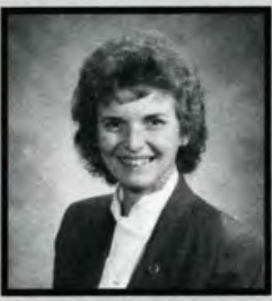

Pamela Diehl, Ph.D.

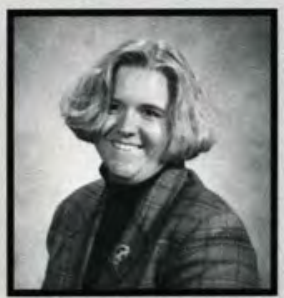

Lisa Davidson, M.A.

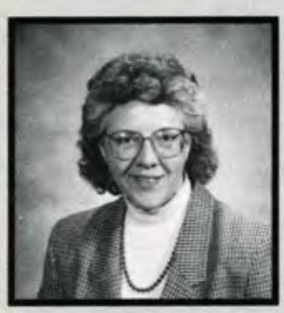

Barbara Loach, Ph.D.

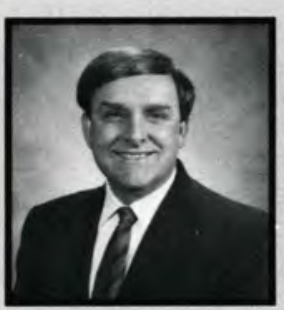

Lyle Anderson, Ph.D.

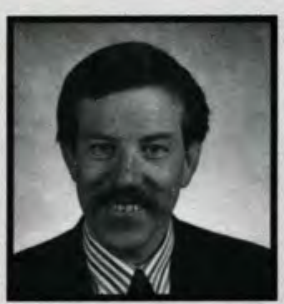

Charles Pagnard, M.M.

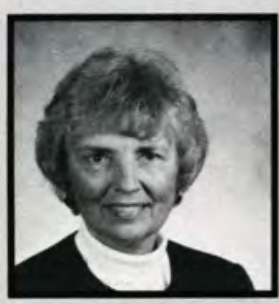

Carolyn Carlson, Ph.D.

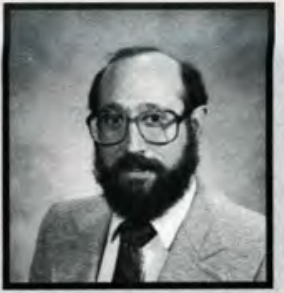

Robert Chasnov, Ph.D.

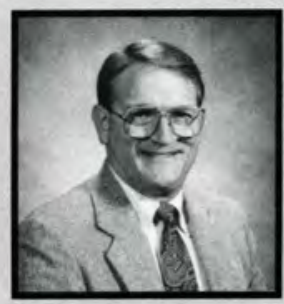

Robert Duchardt, M.S.

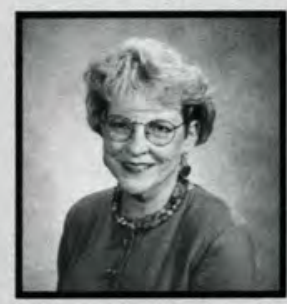

Pat Landers Dixon, M.Ed.

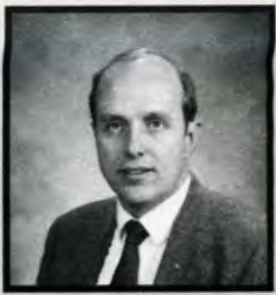

Keith Francis, M.S.E.

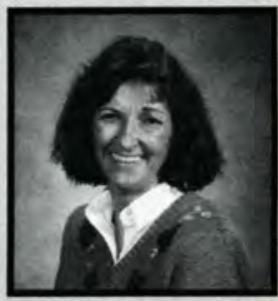

Kathy Freese, M.S.

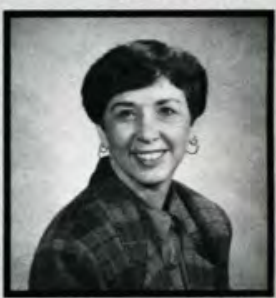

Sandra Harner, M.A.

\section{Ellington Retires}

Dr. Charles Ellington came to Cedarville Col lege in 1975 from Bob Jones University where hu was Chair of the Music $\mathcal{E}$ ducation Department.

$\mathcal{F}$ or the past eighteen years, $\mathcal{D r}$. Ellington ha. served the college as Professor of Vocal Music Coordinator of the vocal programs, Director of the Oratorio Choir, and mentor for students.

$\mathcal{F}$ or a number of years, fie has given fis summe monthis to serve as Choral Manager at the $\mathcal{N}$ (a tional Music Camp at Interlochen, Michigan; and for the past eight years, he has served as Ministe of Music and Choir Director at the Emmanue Baptist Church in Xenia, Ohio.

$\mathcal{H}$ is an exceptional Christian fusband anc father. In every way Charlie Ellington has exem plified those high ideals to which a Christian professor aspires.

- Dr. Charles Clevenge
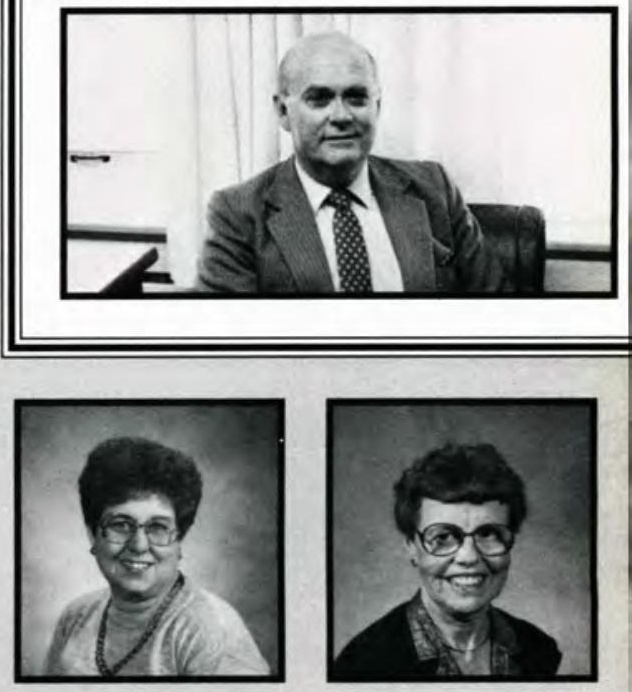

Janet Conway, Ph.D.

Margaret Ingalls, M.S.N. 


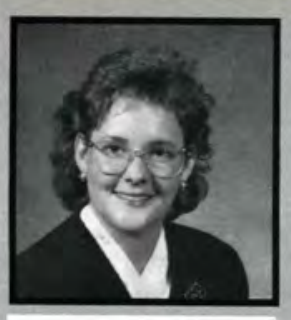

Sandy Pratt, B.S.N

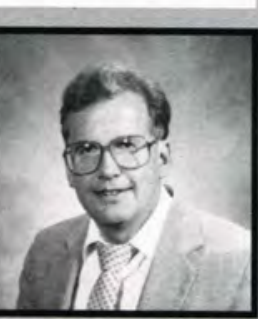

Edwin Braithwaite, Ph.D.

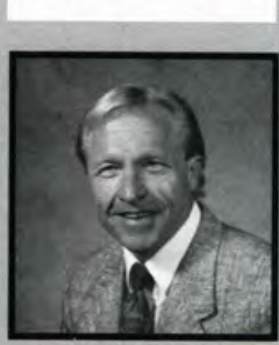

Terry Phipps, Ph.D.

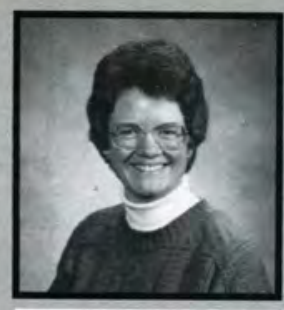

Sharon Rahilly, M.S.N.

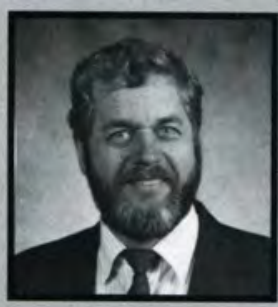

Leroy Eimers, Ph.D.

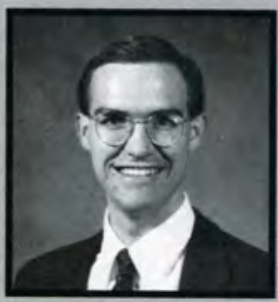

James Sellers, Ph.D.
Douglas Miller, Ph.D.

Dennis Flentge, Ph.D.

\section{Honor Given Where}

\section{It's Due}

Overqualified? pastored for several Compared to the 1992- years in Michigan. In 1993 Faculty Member 1980, he came to of the Year, Dr. Robert Cedarville and has Parr, no one can be been an example of overqualified. Parr dedication to the instiholds a Ph.D. in Soci- tution. A fellow colology, along with three league commented, master's degrees in "The effort which he Religious Education, puts forth for God, his Sociology, and Social family, his church, and Work. Before joining his students could the faculty, Parr never be surpassed."

-Marsha Olsen

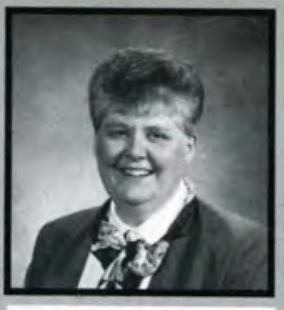

Judith Shrubsole, M.S.
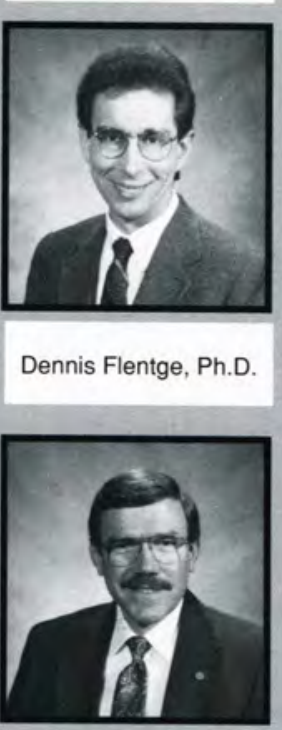

John Silvius, Ph.D.

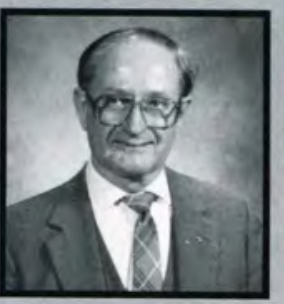

James McGoldrick, Ph.D.

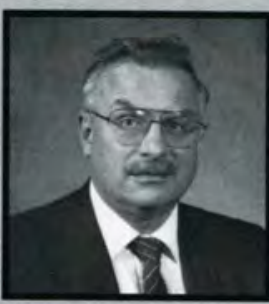

Robert Wiggins, Ph. D.

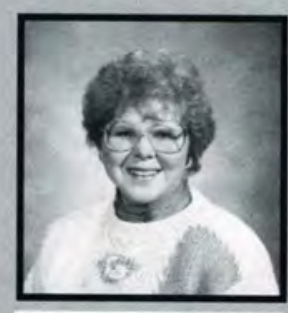

Patricia Ashby, M.L.S

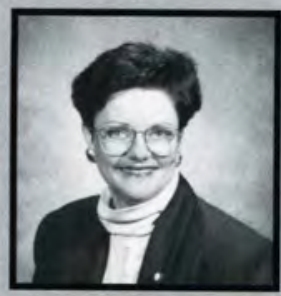

Judy Johnson, M.L.S.

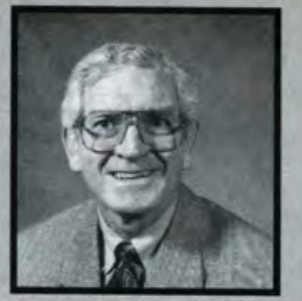

Stanley Ballard, Ph.D. Chair,

Psychology

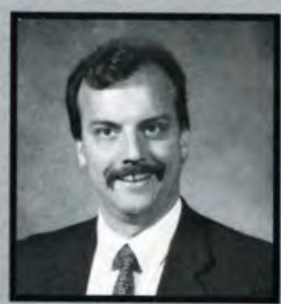

Joseph Francis, Ph.D

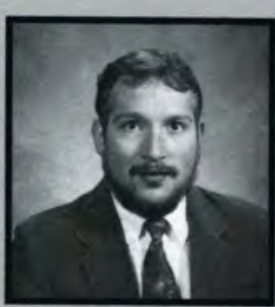

John Whitmore, M.S.

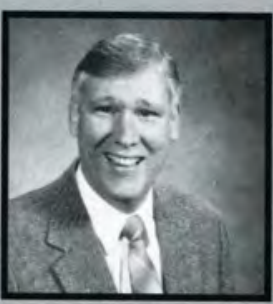

Robert Parr, Ph.D.

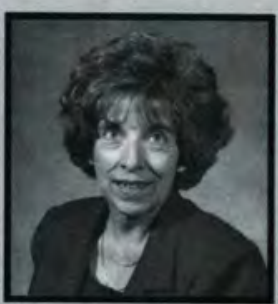

Sandra Entner, MS. Counseling Services

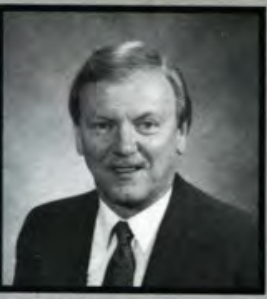

Robert Abbas, Ph.D.

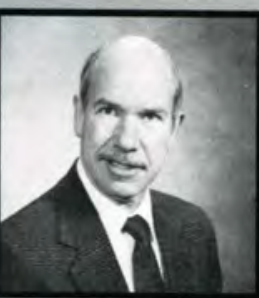

Larry Helmich, Ph.D.

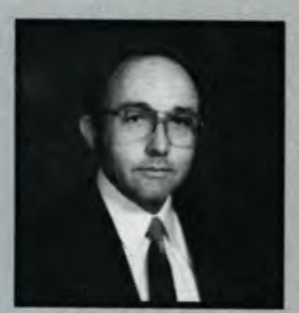

Murray Murdoch, Ph.D. Soc. Sciences/History

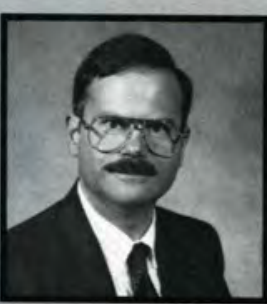

Kevin Sims, Ph.D

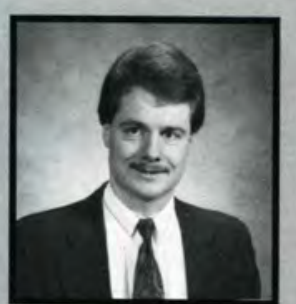

Carl Ruby, M.A.

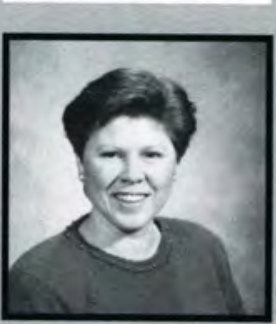

Janice Bosma, M.L.S.

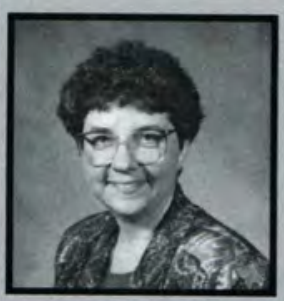

Ruth Martin, M.L.S

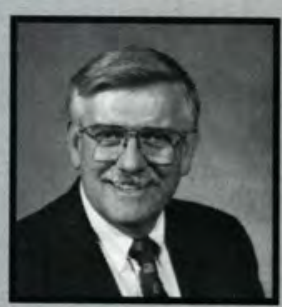

Carl Brandon, M.A

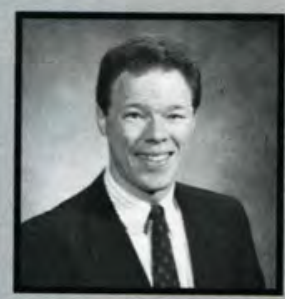

David Ormsbee, B.A. Director of

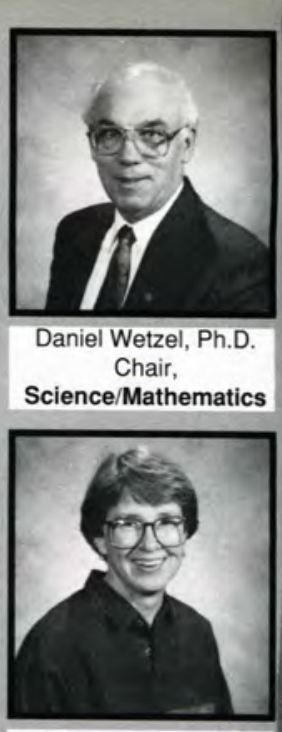

Sue Justis, Ph.D.

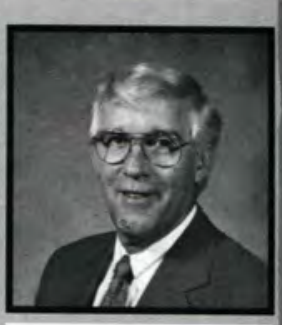

Joseph Halsey, Ph.D.

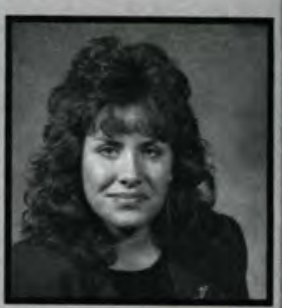

Cynthia Sutter, M.S.W.

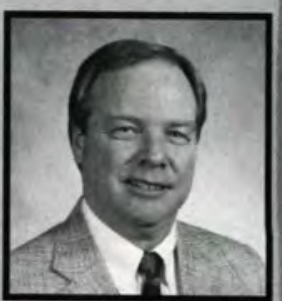

Lynn Brock, M.L.S. Director, Library Admissions

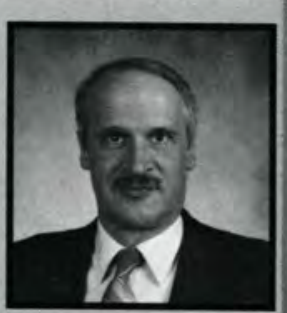

Stephen Brown, M.L.S.

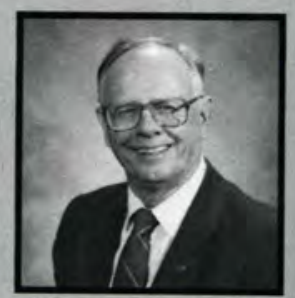




\section{Spencer Completes Thirty Years of Service}

After spending thirty years working in Cedarville's Business Office, Mrs. Dorothy Spencer retired at the end of the 1992-1993 school year. She worked for ten years as a cashier and twenty years as secretary to the Vice-president for Business.

Spencer has enjoyed her time at Cedarville College. She admits that working in a Christian atmosphere has been rewarding, but more than anything else, she has enjoyed the people - especially the students. Always willing to give a smile to anyone passing by her office, Spencer looks forward to beginning a new career -- that of full-time grandmother and hospitality director of her home.

-Marsha Olsen

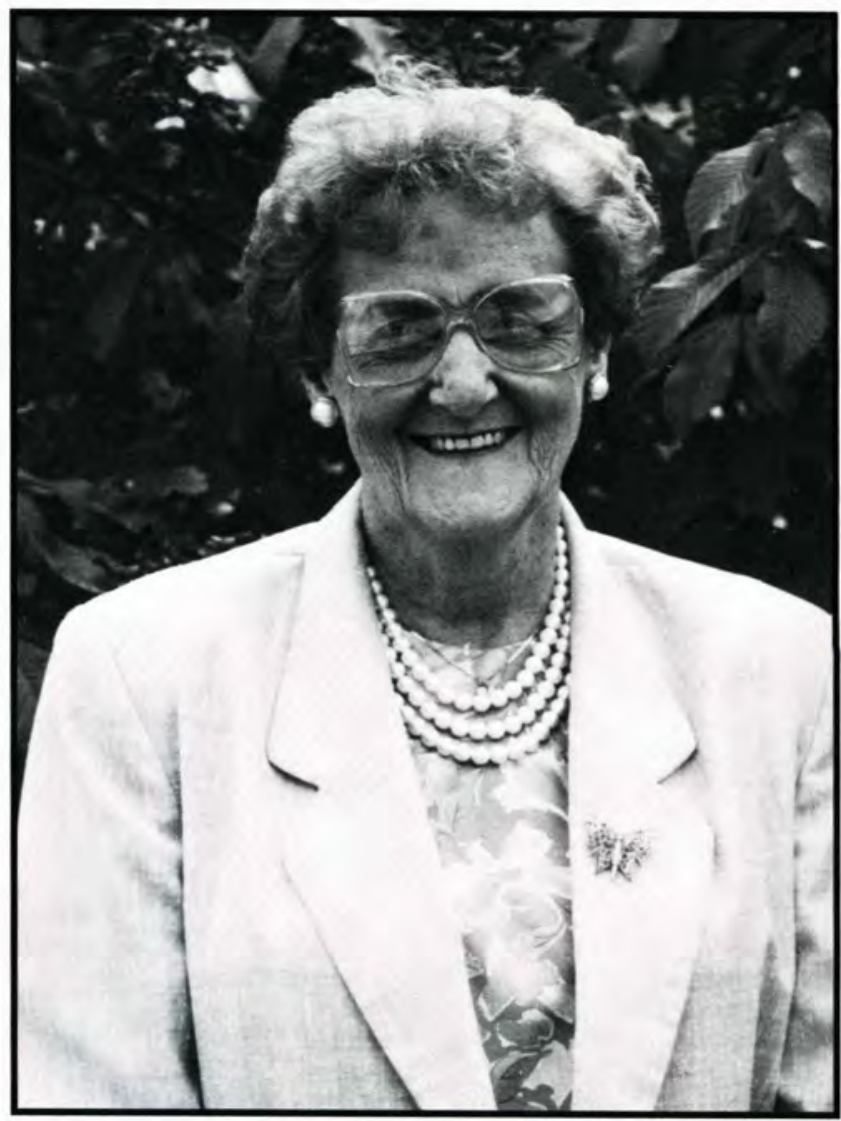

\section{Murtha Kaercher \\ Toinette King \\ Mark Kordic \\ Jill Law \\ Faith Linn \\ Michelle Longo}

Mark Matthews

Alan McCain

Cheryl Miller

Douglas Miller

Rose Marie Payne

Edmond Phillips

Nancy Ranger Joyce Riggs

Beverly Robey Lynn Rohm

Robert Rohm David Rotman

Cheryl Sims Douglas Sjoquist Jon Skillman

Katy Skillman

Benjamin Smith Jane Smith
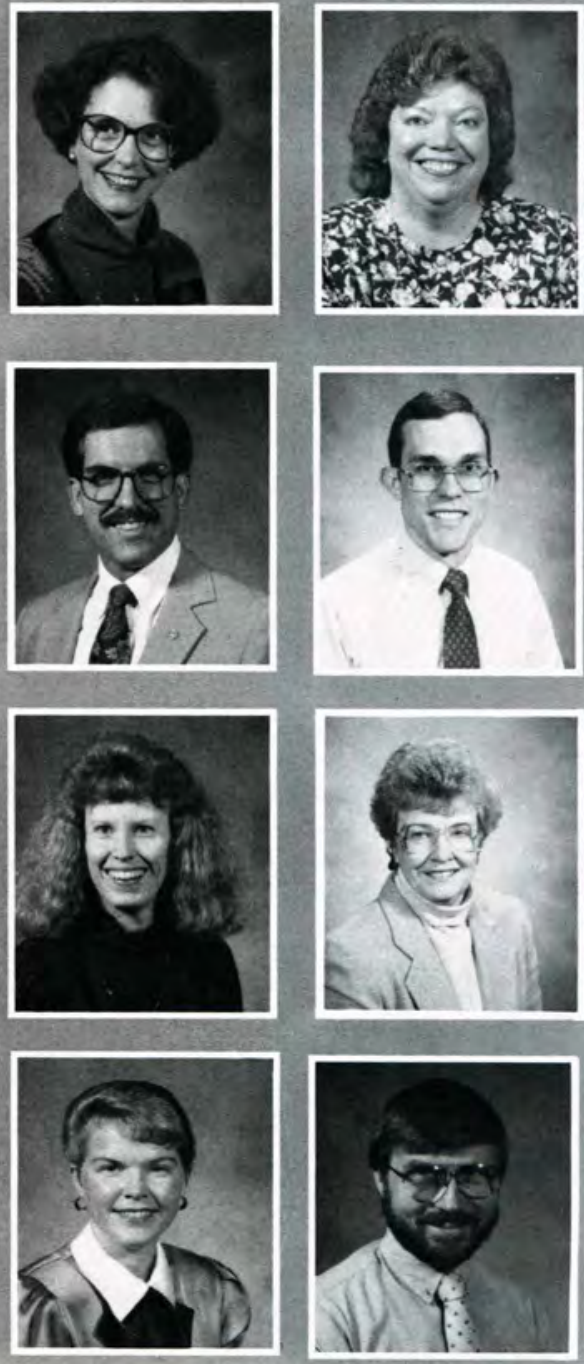
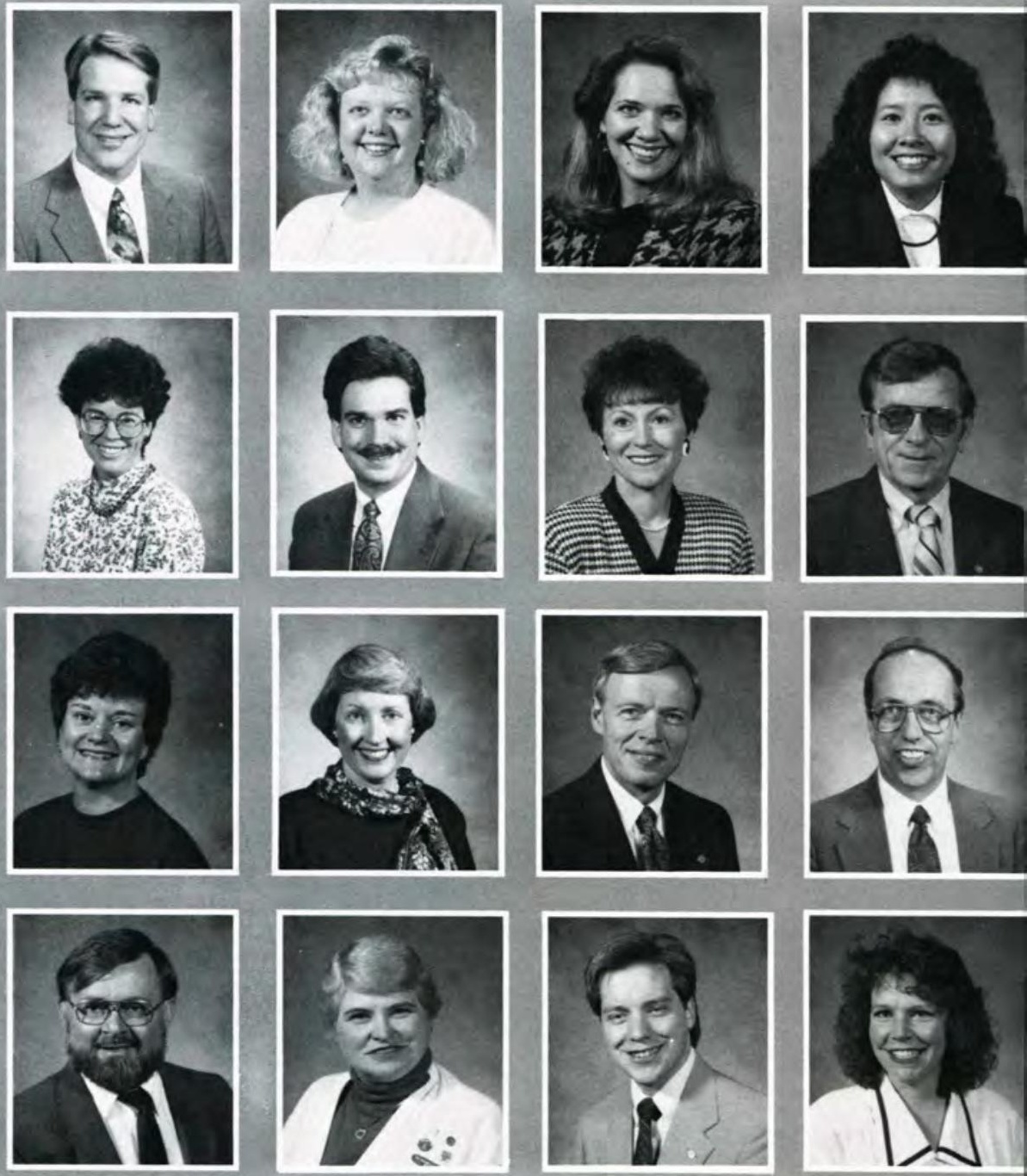

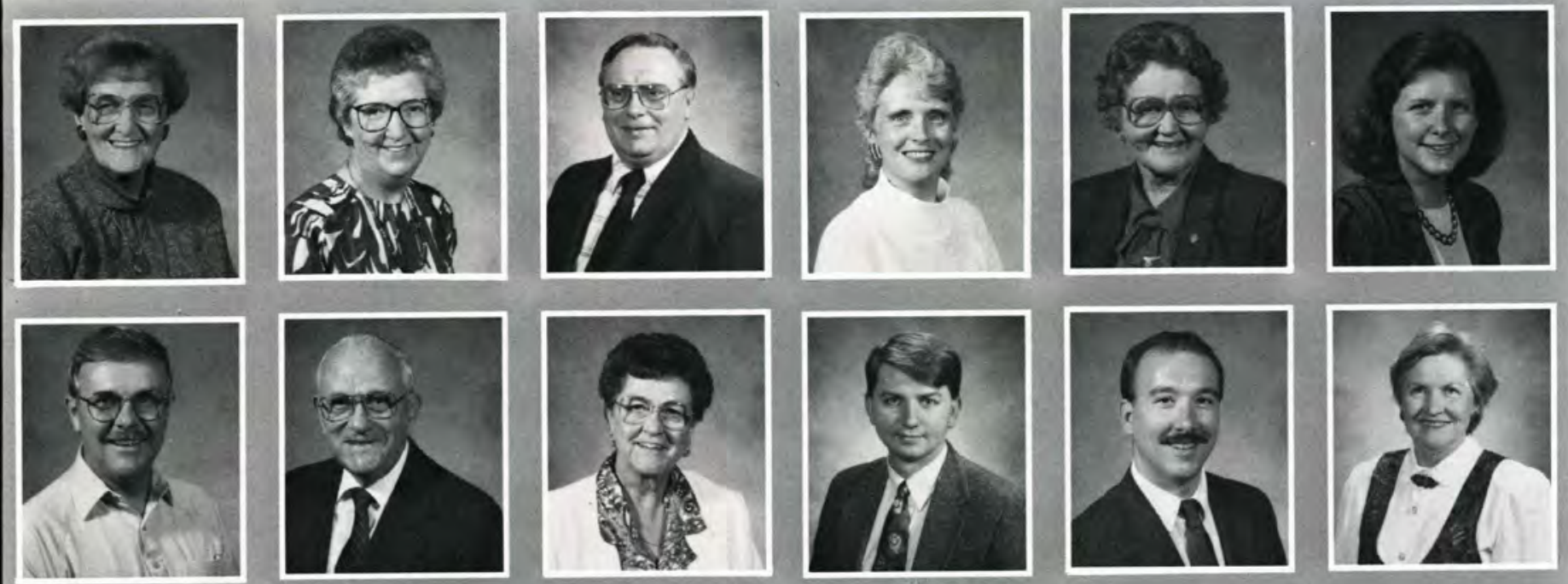

Cooley Turner

Allan Vine

Kitty Vine

Brandon Waltz

Lee Webb

Phyllis Wetzel
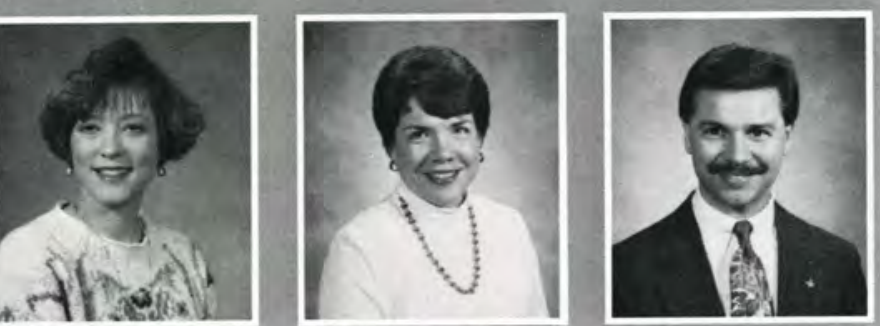

Joy Williams

Glenda Womack

Mark Womack

Gia Wood

Sherrie Wood

Stuart Zaharek

\section{Leaving a Precedent to Follow}

Mr. Englemann was a trustee at Cedarville College for more than 27 years. During that time he was chairman of the board eight times. He served on the Business Committee most of those years and often chaired that committee. In 1976, he received the Honorary Alumnus of the Year Award.

He had a love for God and longed to see people come to the Savior. He wrote his own comments for the printed program of the funeral service, and those comments consisted of sharing the gospel to his loved ones and friends.

He loved his local church and remained faithful to the last hours of his life.

His love for his family was deep and commendable. His wife, Vicki, and sons, Marvin, Jim, and Bob, have a great reservoir of memories to draw upon.

George was a contrast to today's business world in his love for his employer, General Motors. $\mathrm{He}$, indeed, was a loyal employee.

There was little doubt that he loved Cedarville College. Seldom did he miss a board meeting. The Friday before his homegoing on Sunday, I received a handwritten letter from him rejoicing in all of the activities of the Homecoming weekend, the dedication of the ENS Center, and our board meetings.

We love and appreciate his memory. He will be greatly missed.

-Dr. Paul Dixon 


\section{Freshmen}

"Being confident of this very thing, that He who has begun a good work in you will complete it until the day of Jesus Christ."

•Philippians 1:6

Bethany Abbas

Rachel Acton

Jennifer Adams

Arik Akerberg

Kirk Albrecht

Elizabeth Amundson

Christopher Anderson

Eric Anderson

Susan Anderson

Daniel Andresen

Amy Andrews

Sarah Armstrong

April Artman

Douglas Ashley Jill Aumsbaugh

Amy Awabdy

Jeremy Awbrey

Angela Baker

David Baker

James Baker

Malinda Barenscheer

Charlotte Barlock

Carolyn Bartlett

Amy Bates

Michael Bauer

Melissa Baughman Deborah Baumgardner

Rebecca Beasley

Rachel Beecher

Matthew Beiler

Scott Bennett

Kristina Bennick

Kari Beres

Robert Bergen

Anthea Bertelson

Andrew Biddle

Eric Blair

Elizabeth Blevins Patricia Blood

Matthew Boehm

Nathan Bolhuis

Stephanie Bolsem Laura Boothe

Darlene Borgman Scott Borling

Heather Bossley Heidi Bossley Heidi Bowen
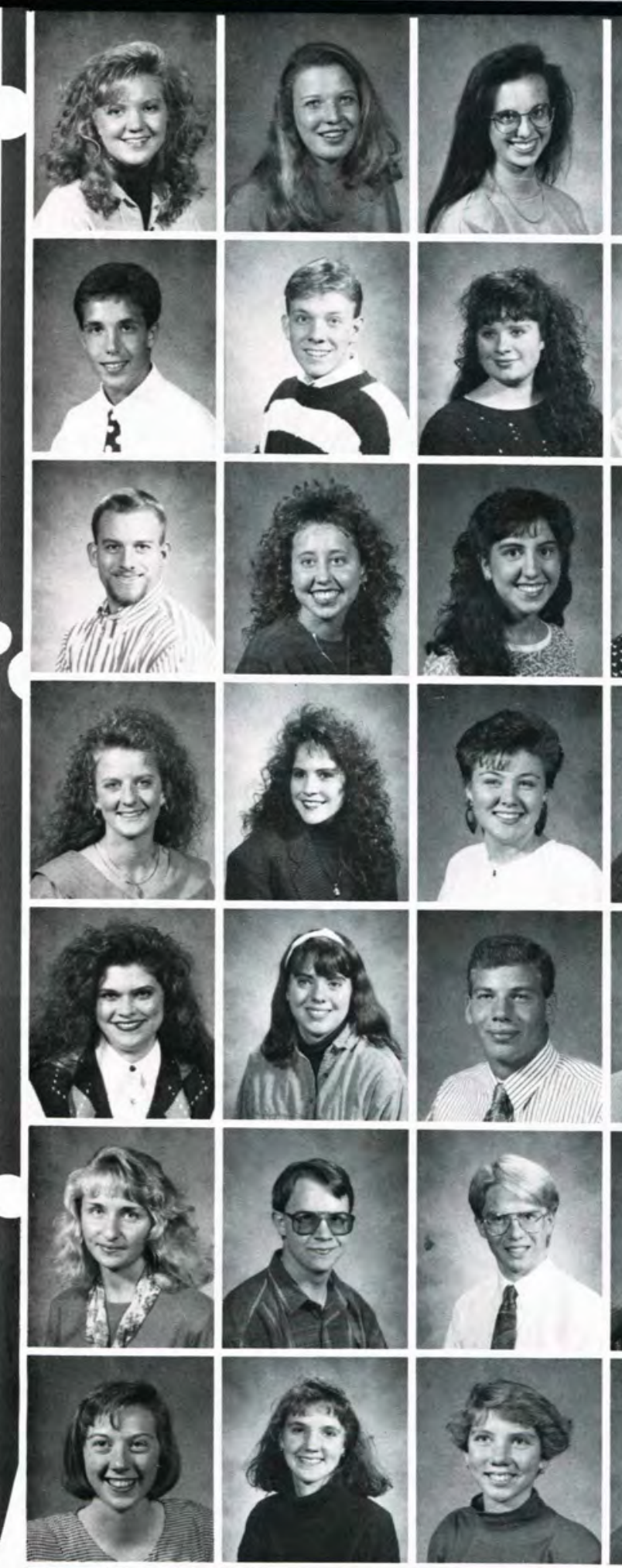
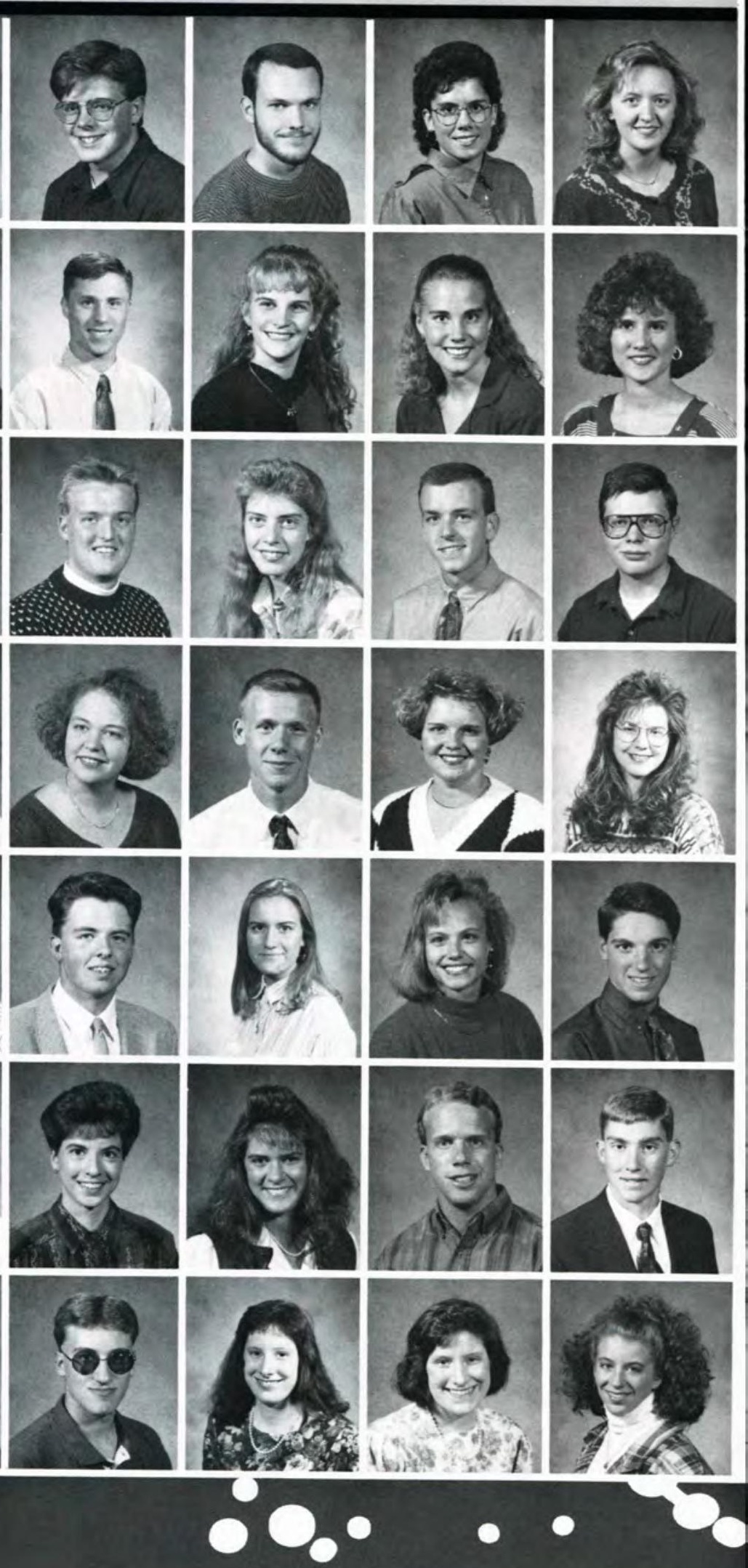


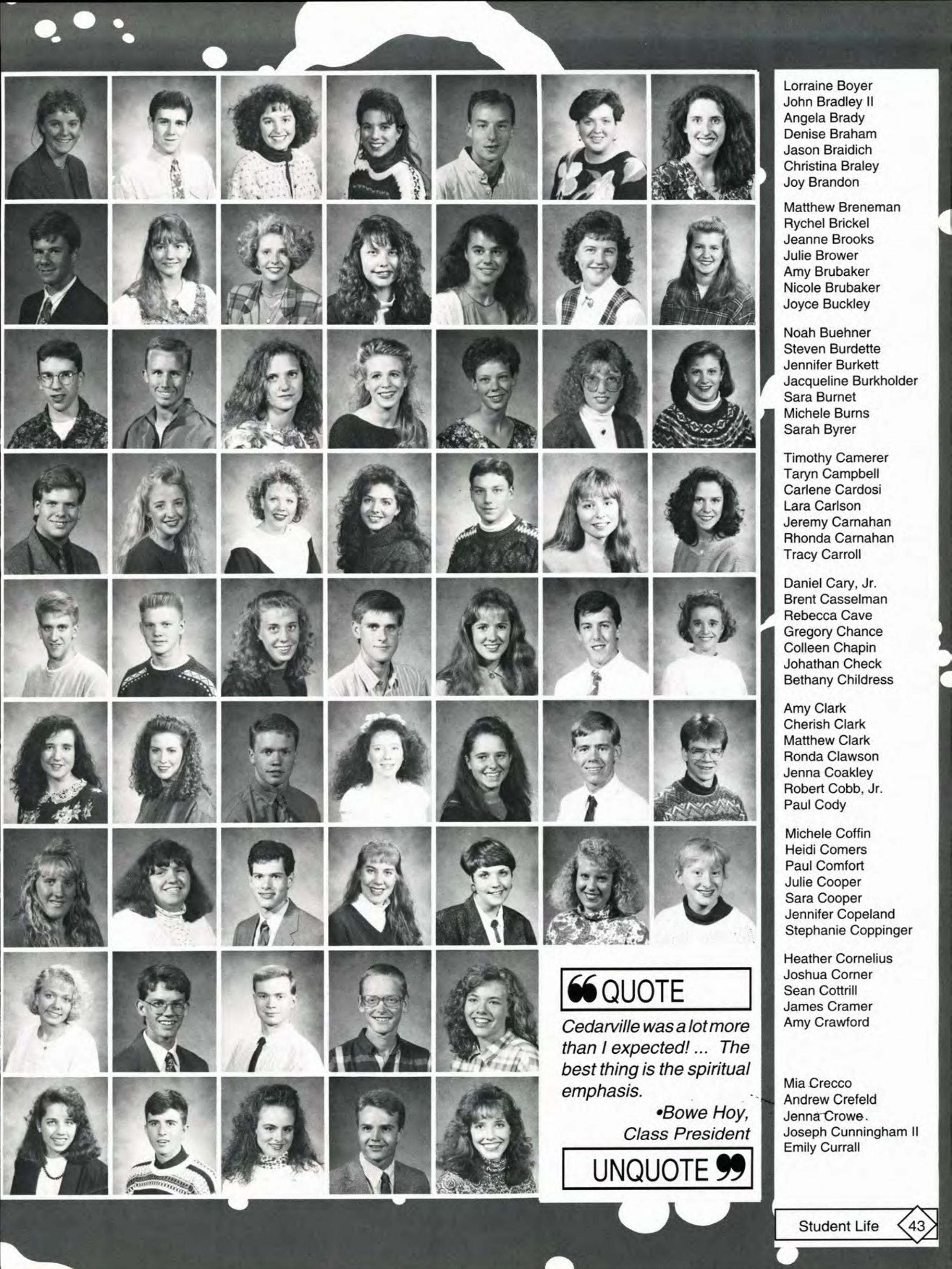


Brent Gibbs

Elliott Gilham

Jason Gilmore

Joy Gilson

Carrie Glidewell

Claire Goetsch

Jack Goodenough

Jennifer Gordey

Nathan Gordon

Jessica Gottwals

Christine Gower Heidi Grant

Jennifer Green

Carly Gregory

Sclie Griffie

Casey Griffiths

Lisa Groeber

Kimberly Gurry

Kimberly Guyn

Kevin Gwin

Sean Gysen

Jennifer Habegger

David Hackney

Melissa Hadley

Michael Hall

Olivia Hammond

Jamie Hand

Brian Hannah

Angela Hanson

Amie Hapeman

Bryan Harju

Melissa Harner

Jennifer Hartenstein

Melissa Hartman

James Harty

Jeremy Haskell

Karen Hatcher

Christopher Hawkins

Kimberly Hazekamp

Elissa Heale

Ruth Heckman

Roger Heffner

David Heim

Nicole Hernandez

Mark Hershner

Misty Hetzler

Heather Hicks Anita Hill

Natasha Hill

Thomas Hill

Christina Hillman

Jessica Hinshaw

Christopher Hitz

Kristine Hoadley

Randall Hoffman

Terri Hoffman

Julie Holaday

Amy Hoop

Leah Hoover

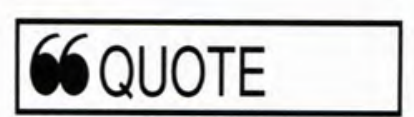

It is better to remain

silent and appear a

fool than to speak and

remove all doubt!

-Lori Olson
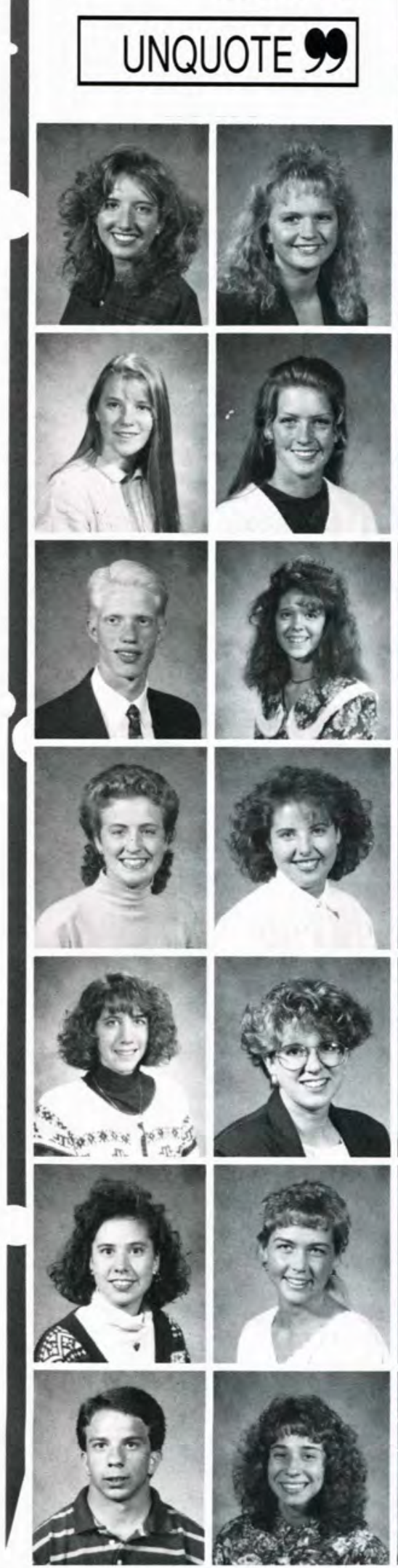
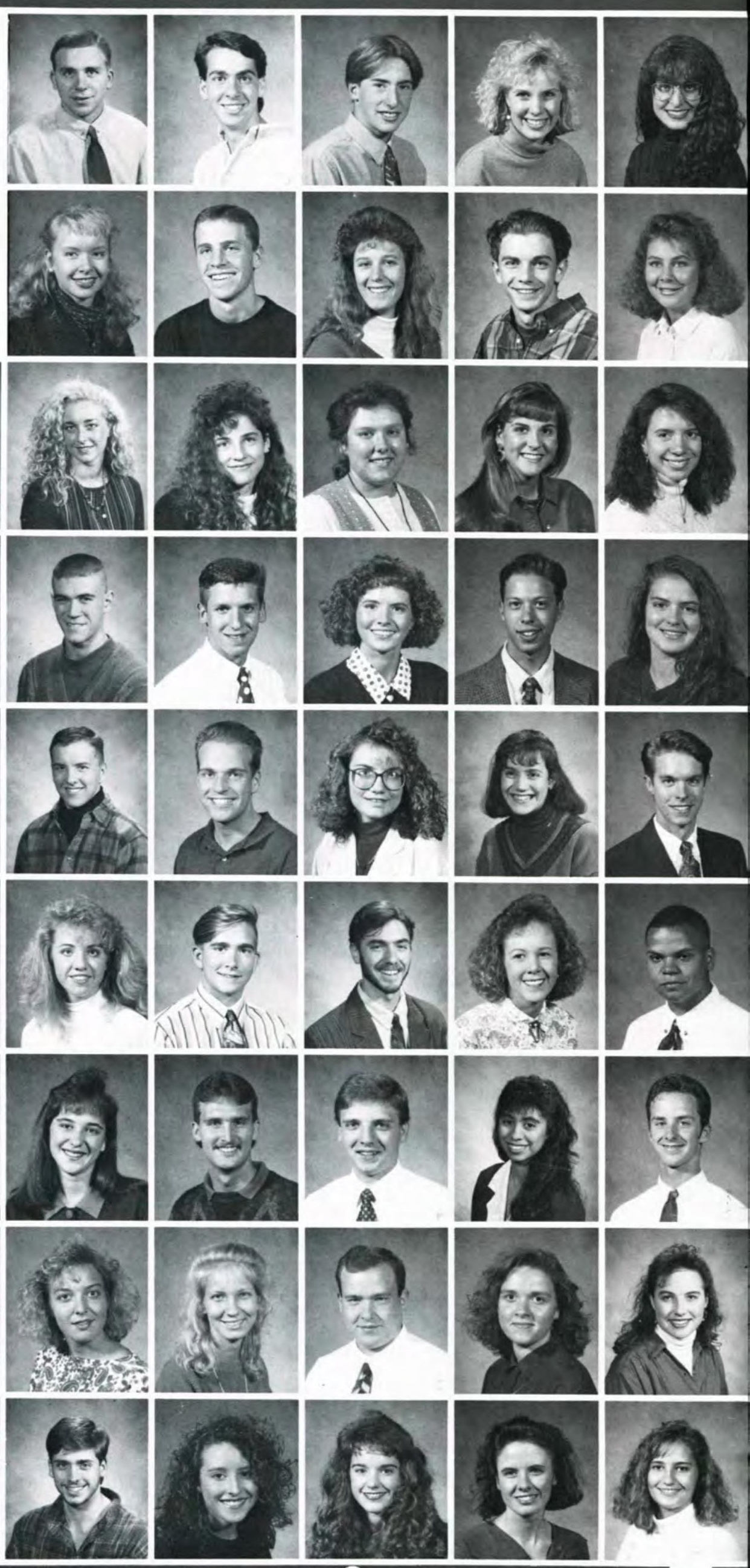

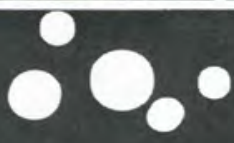




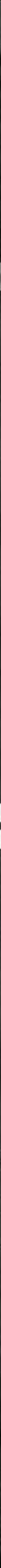




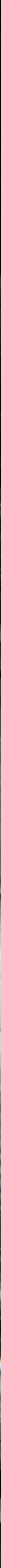




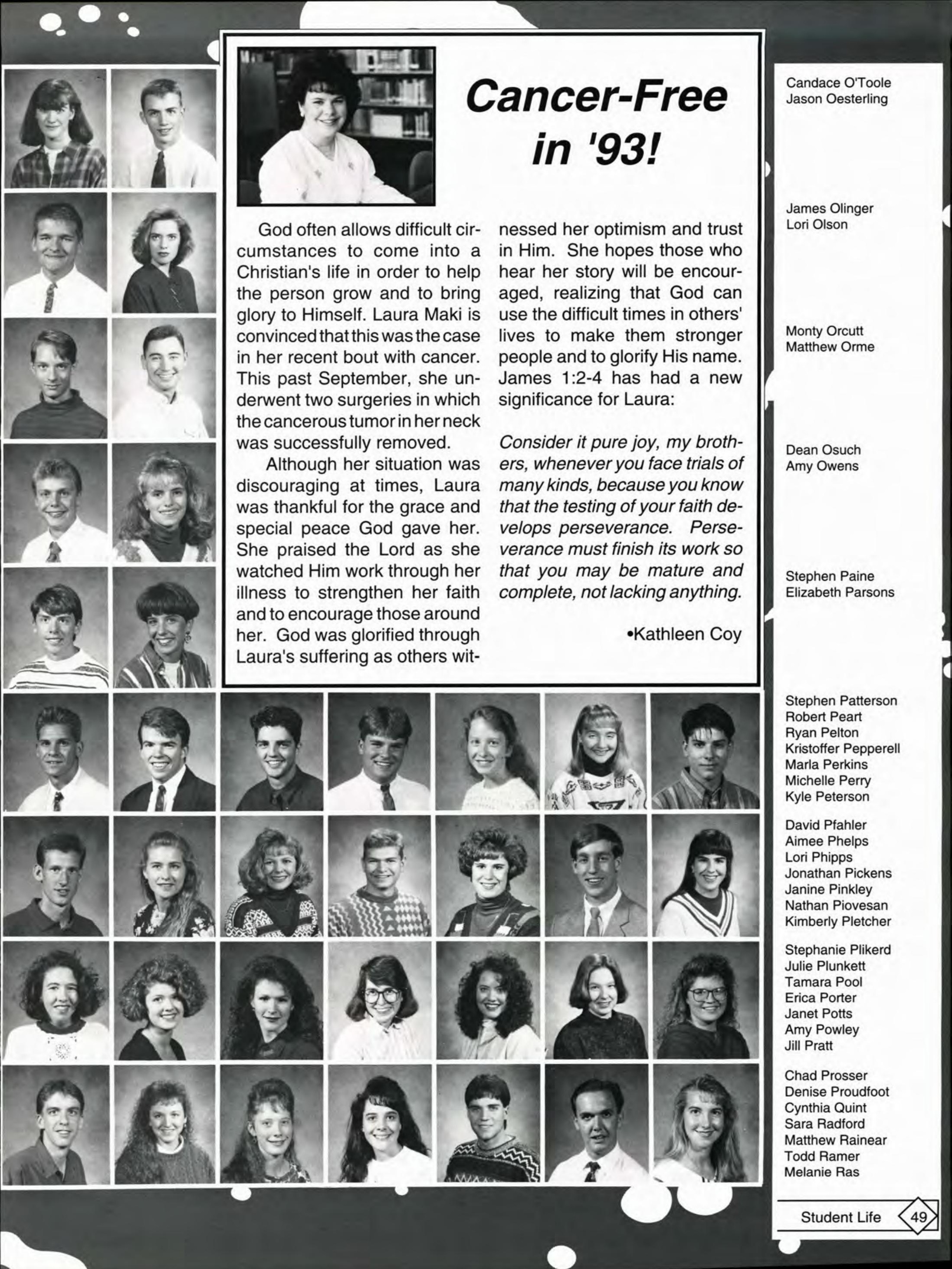


Christopher Rayder Angela Ream Maria Redfern Melissa Reed Jenni Reeve

William Reimers Jeffrey Reiner

Angela Rich Rebecca Rich Hillary Rinehart Kristin Rinehart Scott Robar Aaron Roberts Karen Robertson

Jared Robey

Winona Robinson Nathan Rohrer Amber Rohweder Jennifer Roloff Susan Rooke Douglas Rose Jennifer Ross Rachel Ross Diane Russell Pamela Rutledge Krista Ryan Christy Sarkisian Stephanie Saville

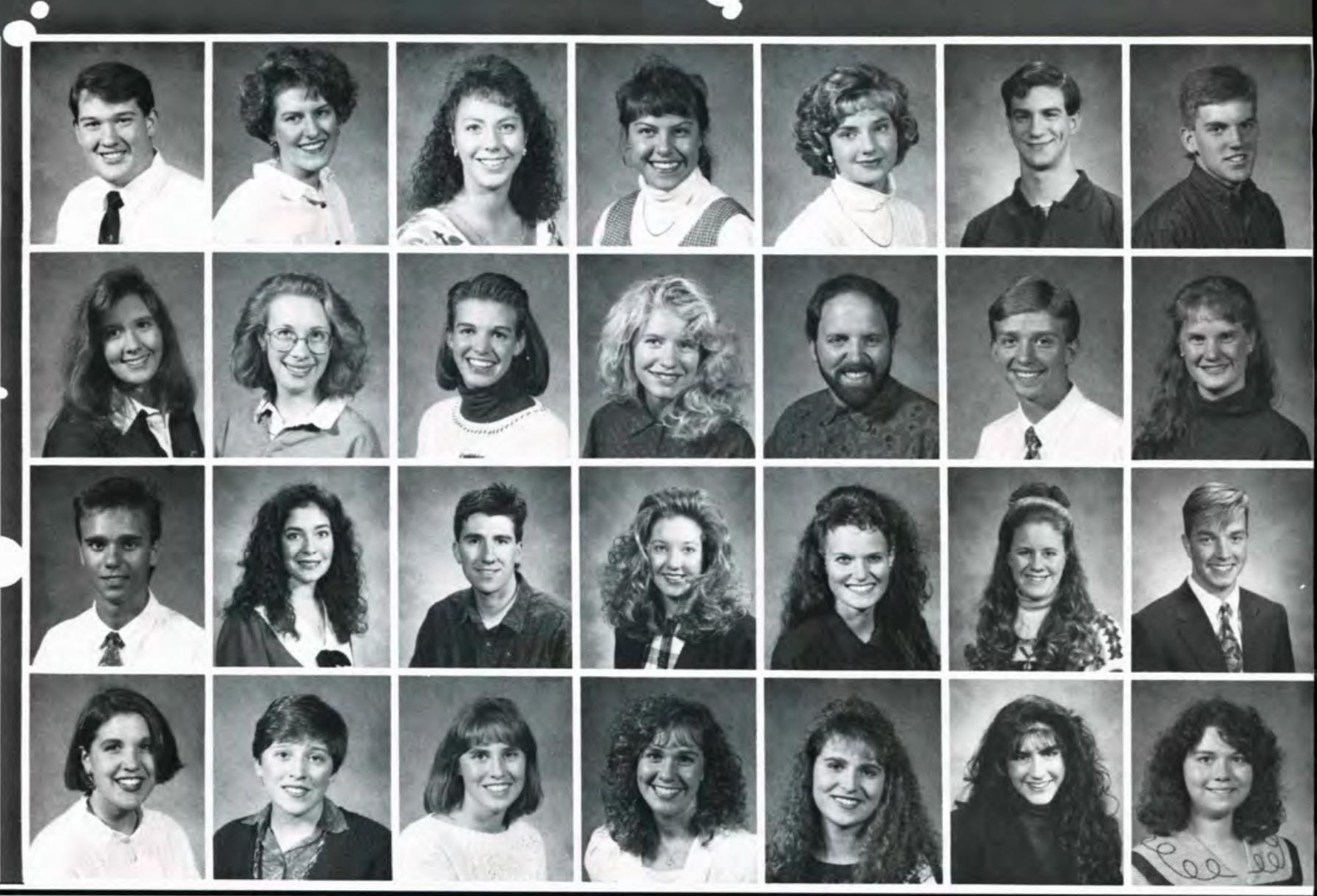

\section{The}

\section{Village}

\section{Lights Up}

Each year in the spirit of Christmas, Cedarville businesses, churches, and the college come together to host the Little Town of Lights. Shop owners consider the event a unique way of saying "thank you" to the people of the community for doing business with them.

The evening gives people a reason to go downtown just to say "Hi" to their neighbors and friends and to enjoy the Christmas festivities. Those passing by enjoy gazing at the shops decorated with lights and trimmings, a live nativity scene, caroling, free Christmas goodies, and

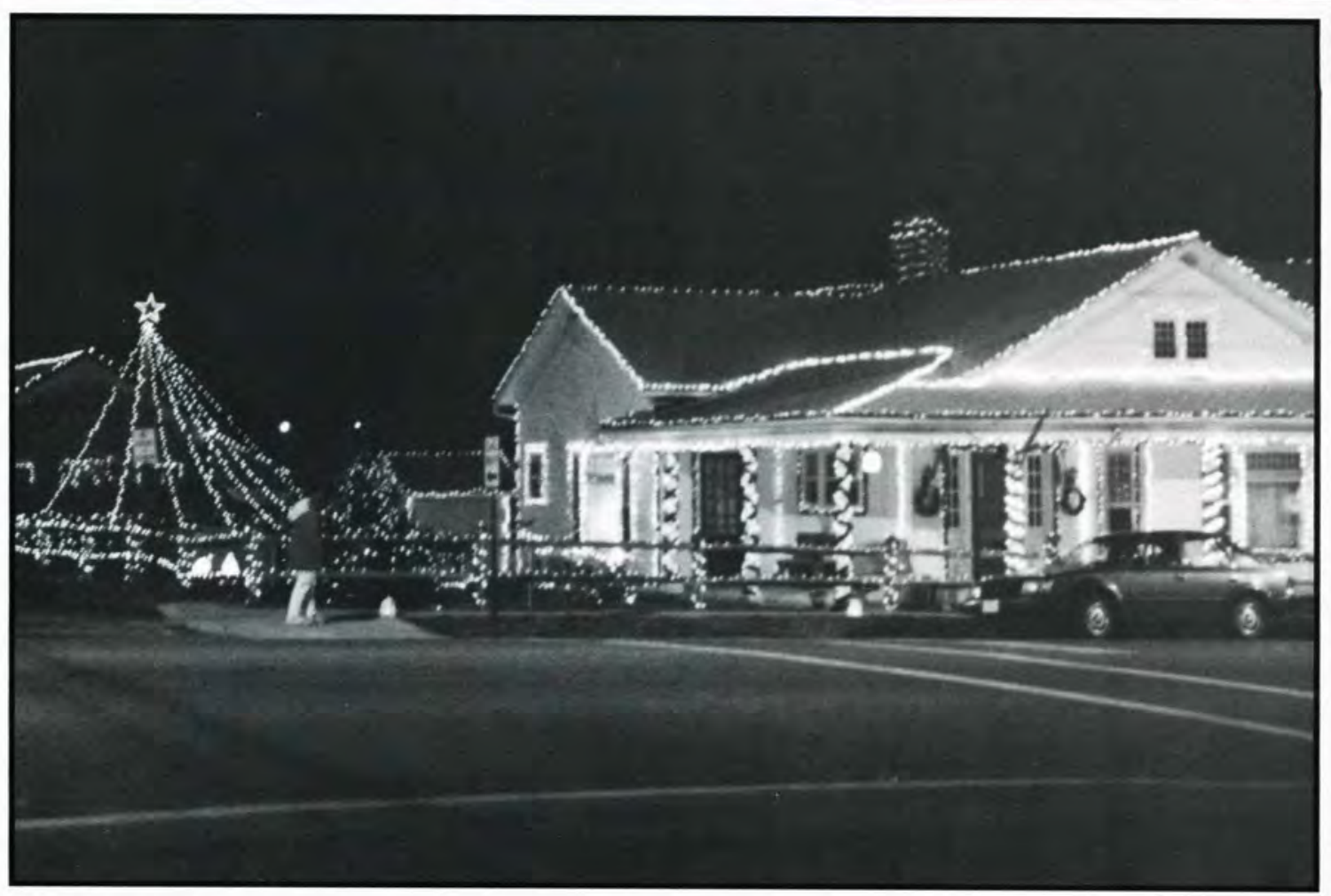

much more!

Some Cedarville students took plastic milk jugs and made lumineers for lining Main Street, WSRN provided sound and music, and SGA helped plan and organize student involvement in the event.

Too often, individuals view the college as separate from the community. Little Town of Lights enabled students and residents alike to bridge that invisible gap. -Marsha Olsen 


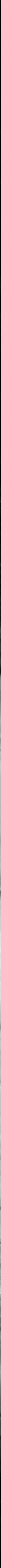


NET ACTION IN THE MUD CAN GET A LITTLE DIRTY.

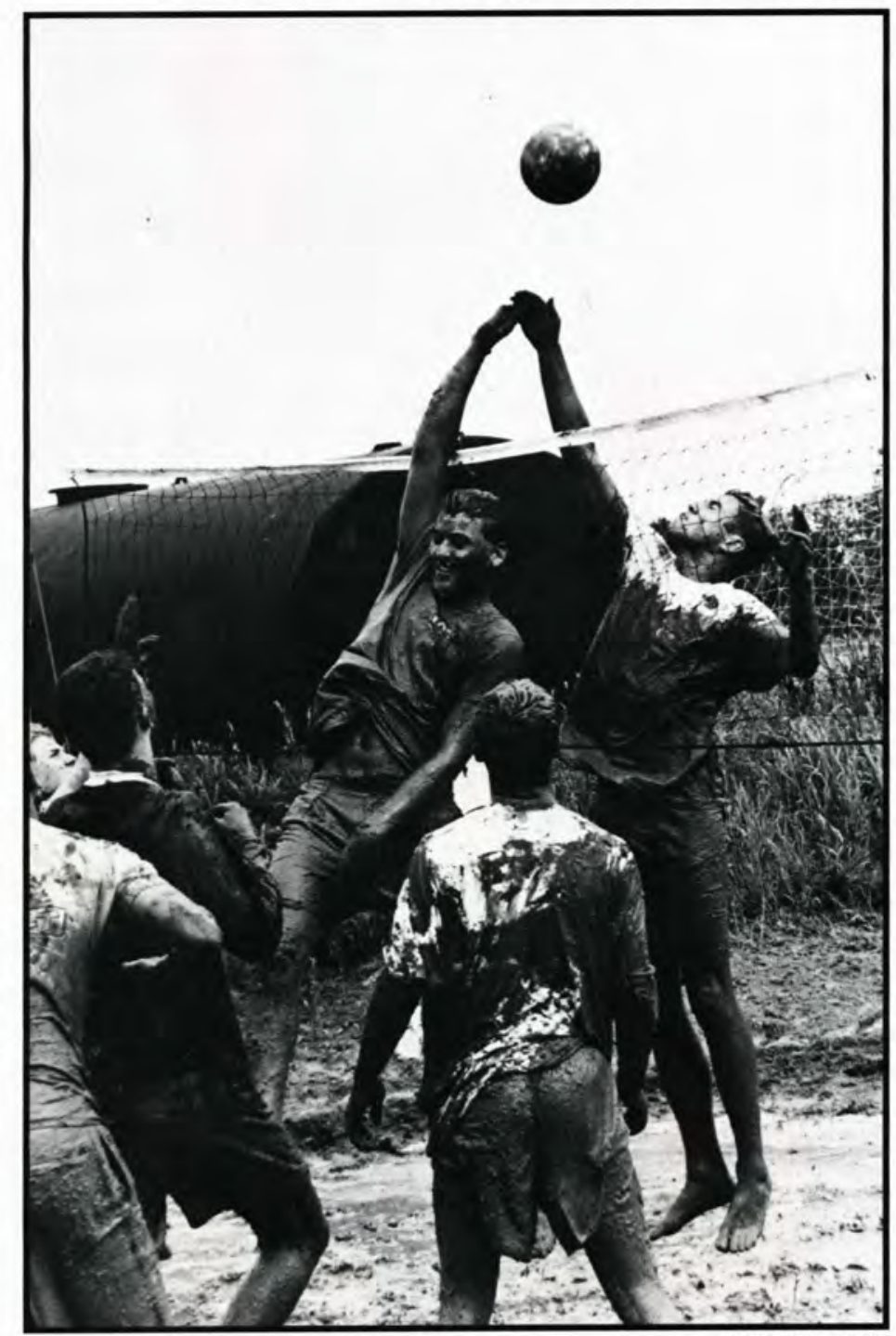

\section{Oozeball}

\section{An Annual Must at Cedarville}

What happens when thousands of gallons of water, dirt, volleyball and Cedarville students are mixed? Oozeball is what happens. An annual ritual of spring quarter, Oozeball takes the rules of volleyball and plays the game on a court of mud. A much looked-forward-to fun filled tension release, this game must be played to be appreciated to its fullest extent.

-Chris Reimers

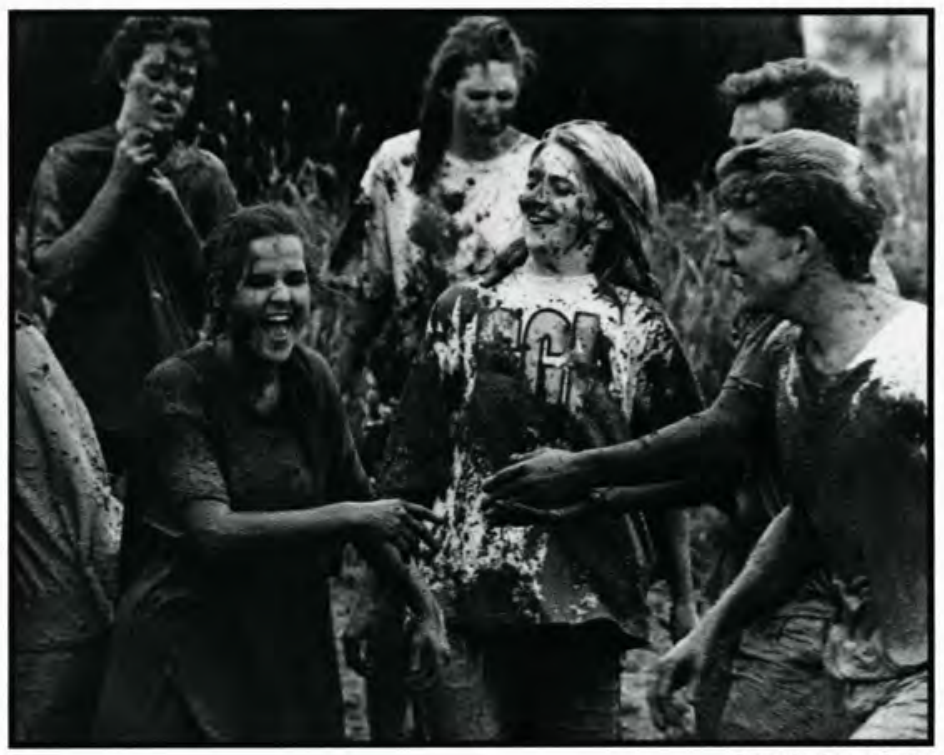

Photo by Steve Cook
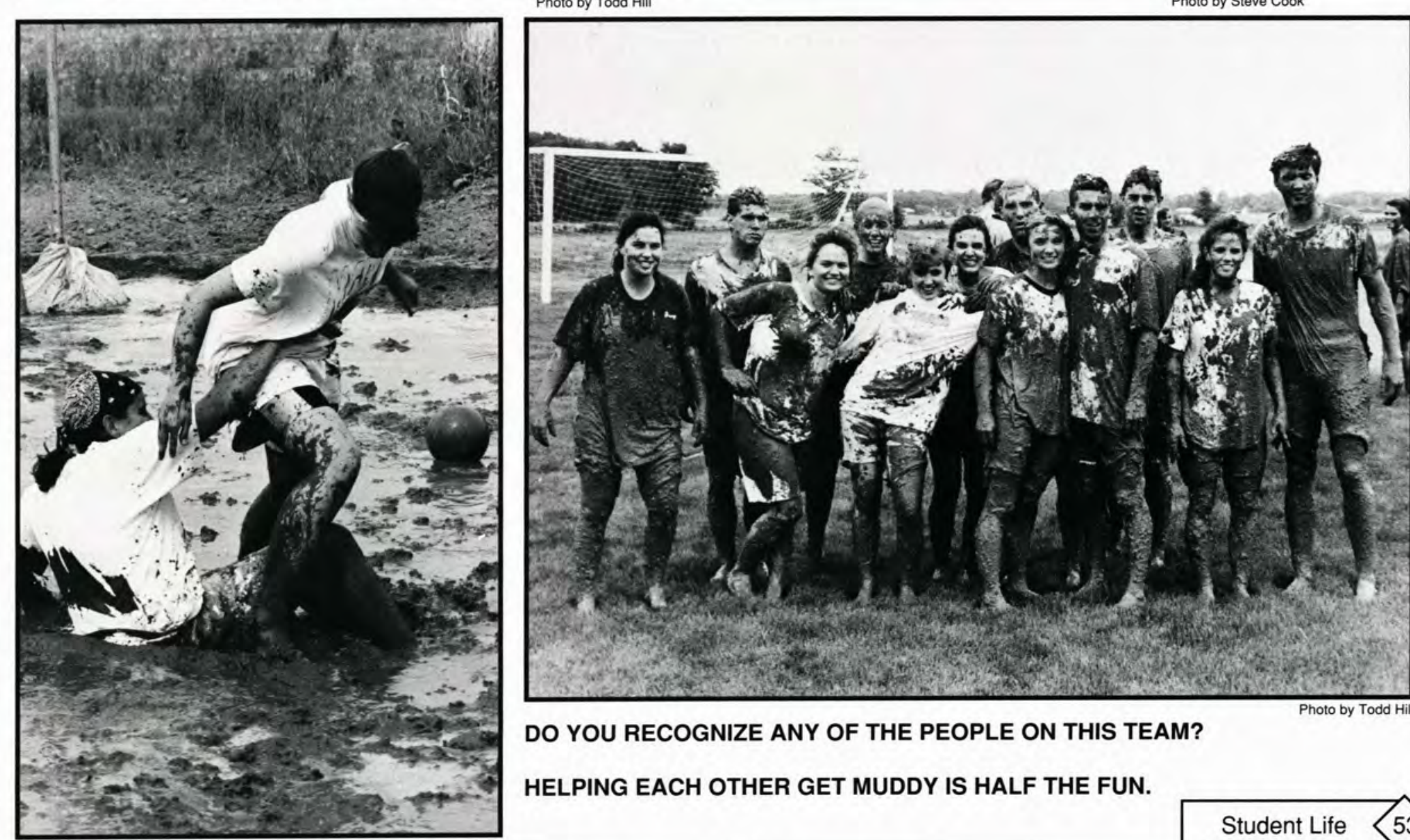

DO YOU RECOGNIZE ANY OF THE PEOPLE ON THIS TEAM?

Photo by Todd Hill

HELPING EACH OTHER GET MUDDY IS HALF THE FUN. 


\section{Sophomores}

"Moreover it is required in stewards, that a man be found faithful."

-I Corinthians 4:2

Jennifer Bartosiewicz

Erik Bauer

Carrie Beaty

Karen Beck

Wesley Beebe

Robert Beecher III

Tiffany Beheler

Nathan Beitler

Laurie Bell

Alicia Bennett

Rebecca Berkheiser

Devon Berry

Cinnamon Bierly

Jeffrey Bigam

Maria Biggs

Jeffrey Bingham

Jeffrey Blackburn

Shane Blansette

Amanda Blew

Mark Buchynski

Kathryn Bond

Jacqueline Bondorff Janet Bonga Jason Borton

Tricia Botdorf Jeffrey Bowen

Tonya Bowling Wendy Boyer

Jennifer Bradley

Melinda Bradley

Molly Brandenburg

John Branstetter

Stephanie Bresnahan

Tina Bridewell

Debora Brunner
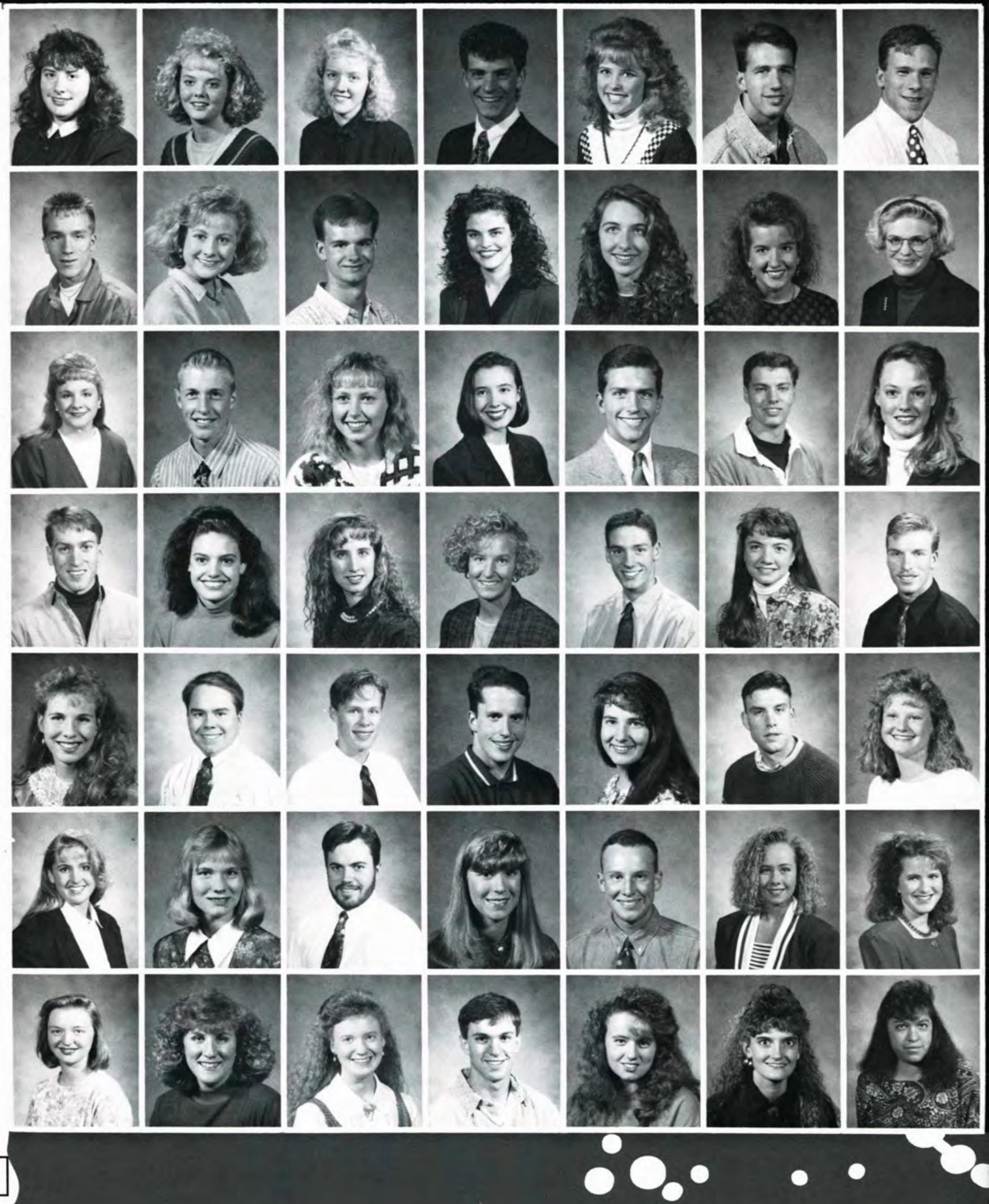

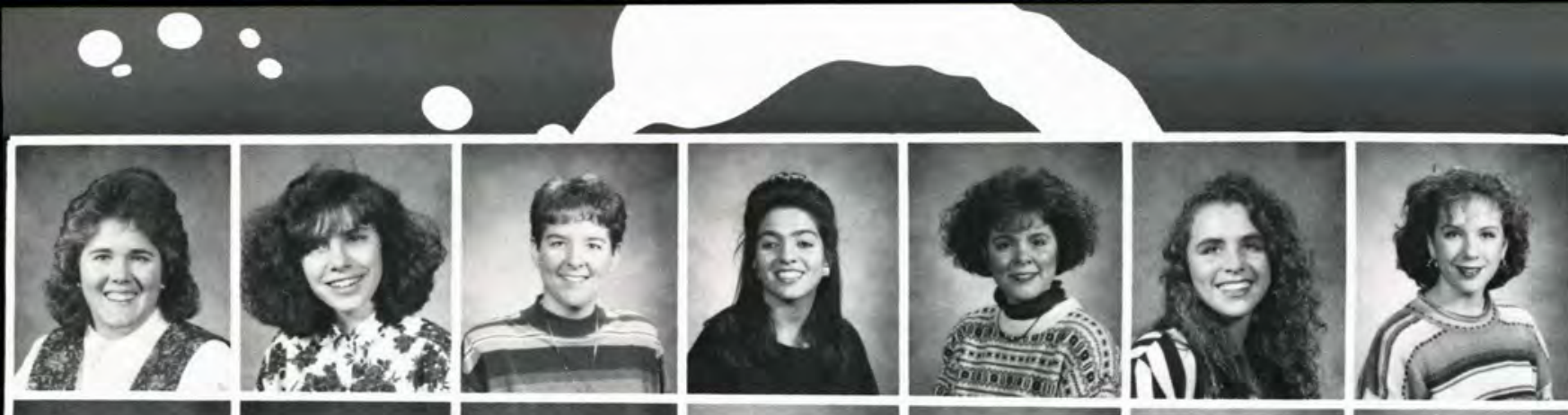

Tammy Bucklew

Amy Buehner

Shandis Buffington

Stephanie Bunn

Sara Burkhard

Deborah Burkley

April Burns

Brian Burns

JulieLynn Burns

Evelyn Bussa

Jennifer Butler

William Butts

Spring Cadwell

Rachel Cain

Clifford Caldwell

Scott Calhoun

Jacqueline Call

Bradley Callahan
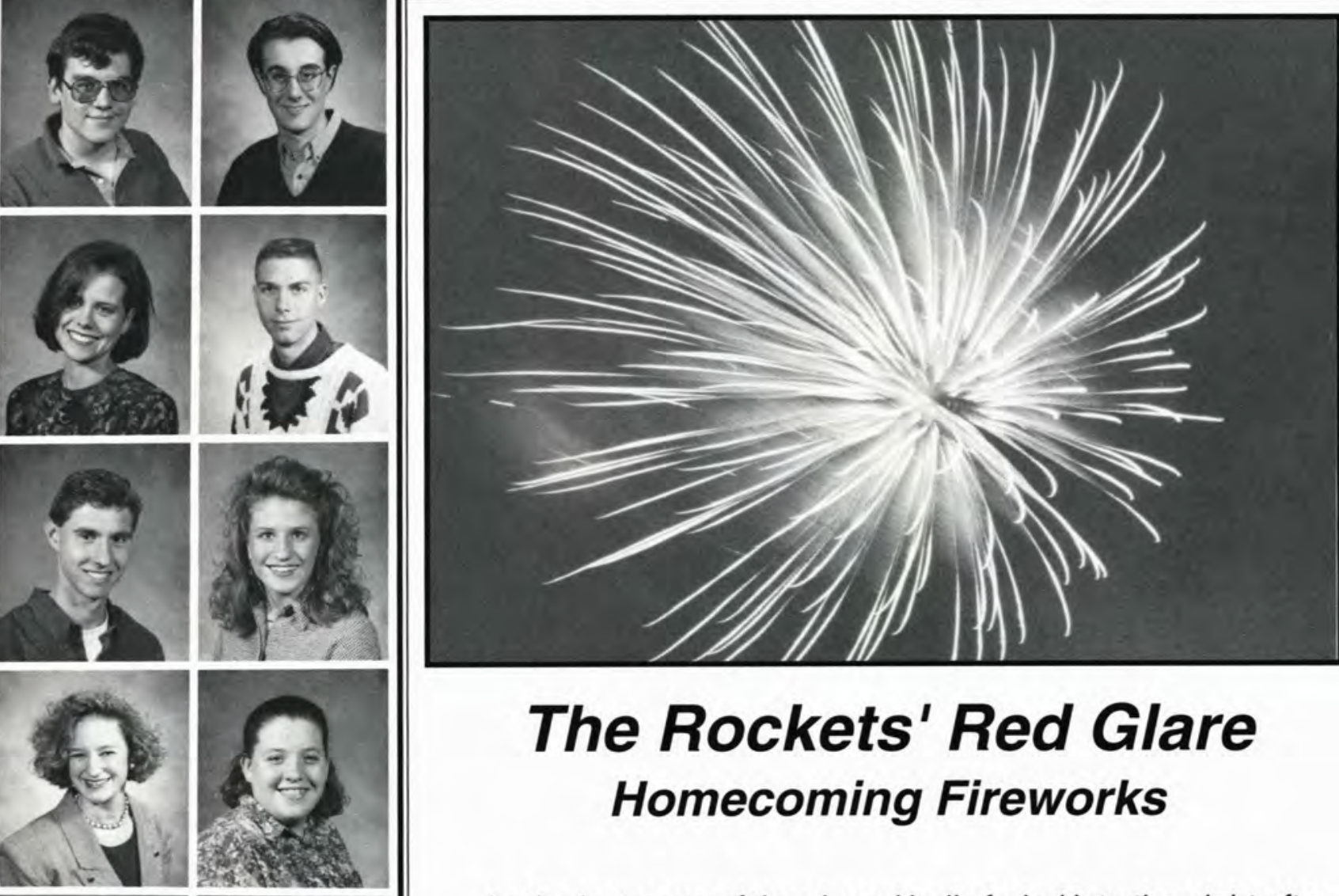

\section{The Rockets' Red Glare}

\section{Homecoming Fireworks}

As the last gong of the chapel bells faded into the night after the annual Prism concert, students, alumni, and Cedarville residents were treated to the Homecoming fireworks over Cedar Lake. Against a pitch black sky, displays of white, green, red, orange, and purple delighted the crowd gathered on the crisp fall night. Crackles, booms, and pops broke the silence and brought enthusiastic cheers from the spectators. A failed launch exploded on the ground close to the launch area, but fortunately, no one was injured, and the show continued. A pyrotechnic Cedarville sign surprised the audience and signalled the beginning of two forty-five second rapid fire flurries of fireworks. The acrid smell of explosives permeated the air but went almost unnoticed by the crowd as they were captivated by an incredible grande finale that lit the sky -- a beautiful end to a spectacular night!

-Chris Reimers

Eric Case

Wendy Cassidy

Steven Caton Johanna Chang

Rebecca Childers Heather Christie 
Keri Christner Clifford Clavin

Steven Clement Vivian Clemons

Kelly Cline Lisa Coe

Melissa Colemar Julie Cone

Bobbi Conley

Kimberly Conner John Cooley Sandra Costello Jason Cowdery

Rebecca Coy Jeanette Crapo Jennifer Crawford

Jonathan Crider Kristen Crum

Deborah Cruver

George Curry IV Gail Damon

Dacia Davis

Melanie Dawson

Paul Dean

Jennifer Dea

Stephen Deaton Bradley Deetscreek

Colleen Delp Jodi Dick Michael Dick

Gail Dieter Jennifer Dinelli William Dodson William Droke Kevin Duti Sarah Dye Brett Dyson

\section{Students Feel ... ... Hunger Pains}

November 16-20 was a typical week at Chuck's except for one thing: students did not waste as much food as usual. Sure, some still complained about the food, pitched their meals, and decided on a dinner of cereal ... again. But many students had a new appreciation for the food and for others around the world who would be thrilled to receive such a meal.

Cedarville's first annual Hunger Awareness Week was a success. Various speakers and activities throughout the week informed students about the sad situations of the homeless and the hungry. Several campus organizations gave the college family a chance to get involved by collecting money through projects such as "Snack Attack" and the campus-wide Young's Run, in which students donated the money they would have spent on food to help the needy in the Xenia/Dayton area. This special week gave students a greater awareness of the problems of the hungry, as well as a greater desire to sacrifice their time and money to help those in need.

$\bullet$ Kathleen Coy
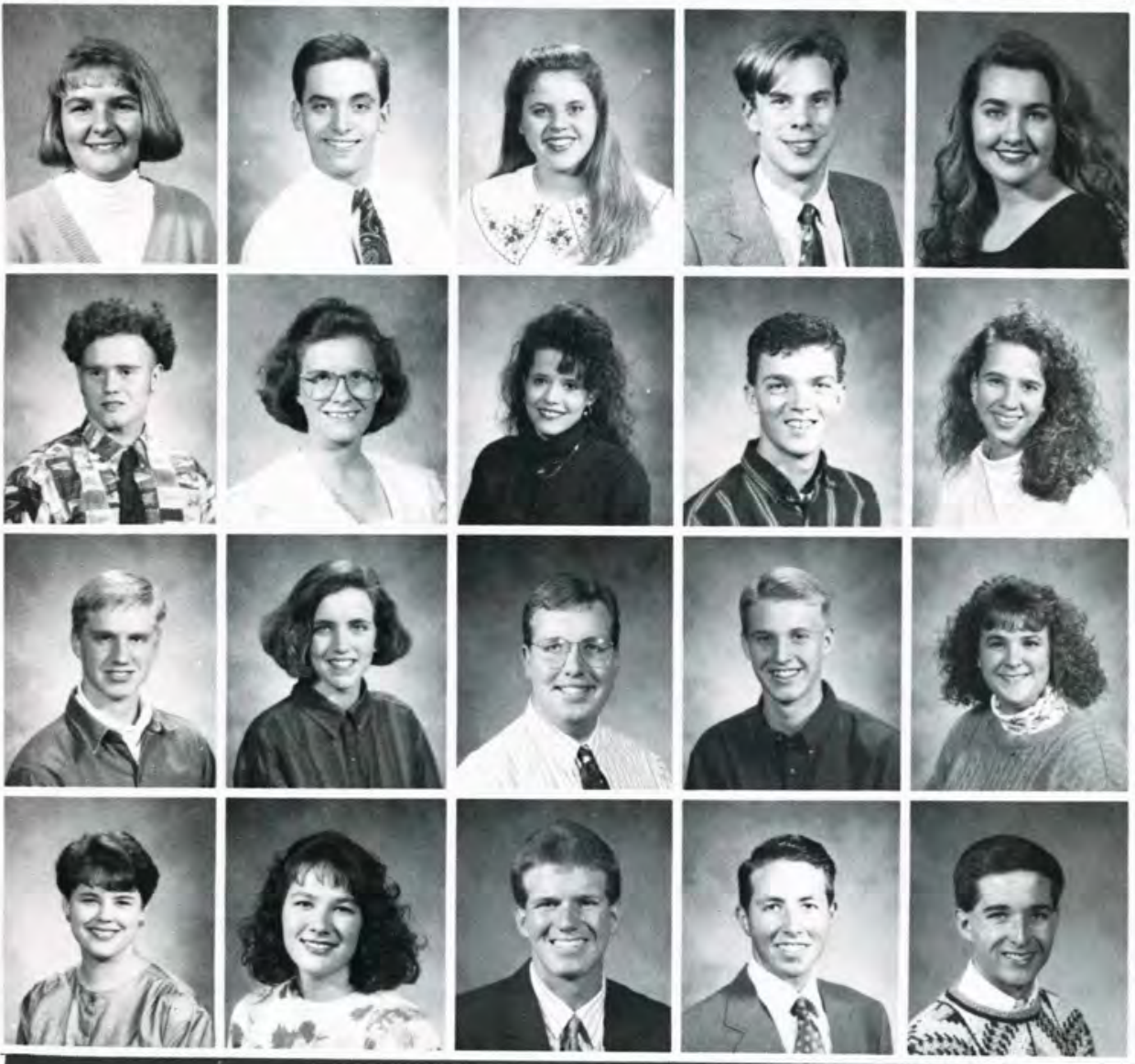
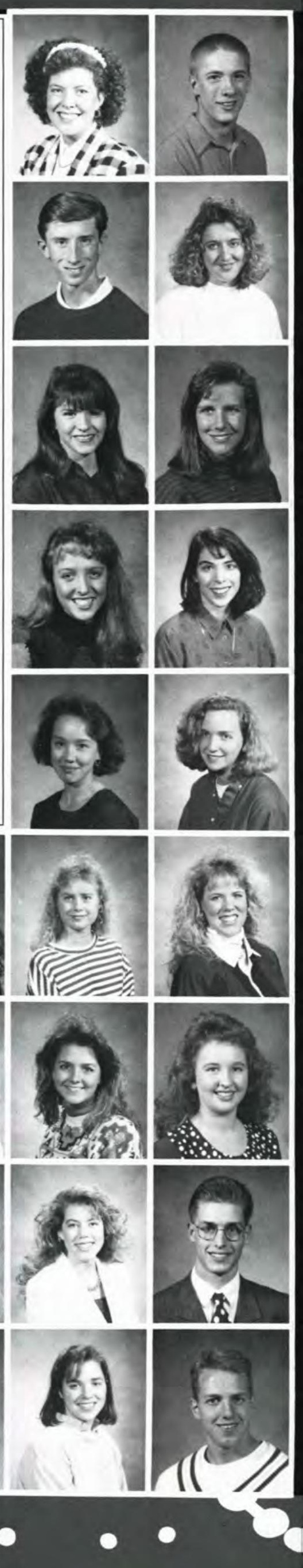


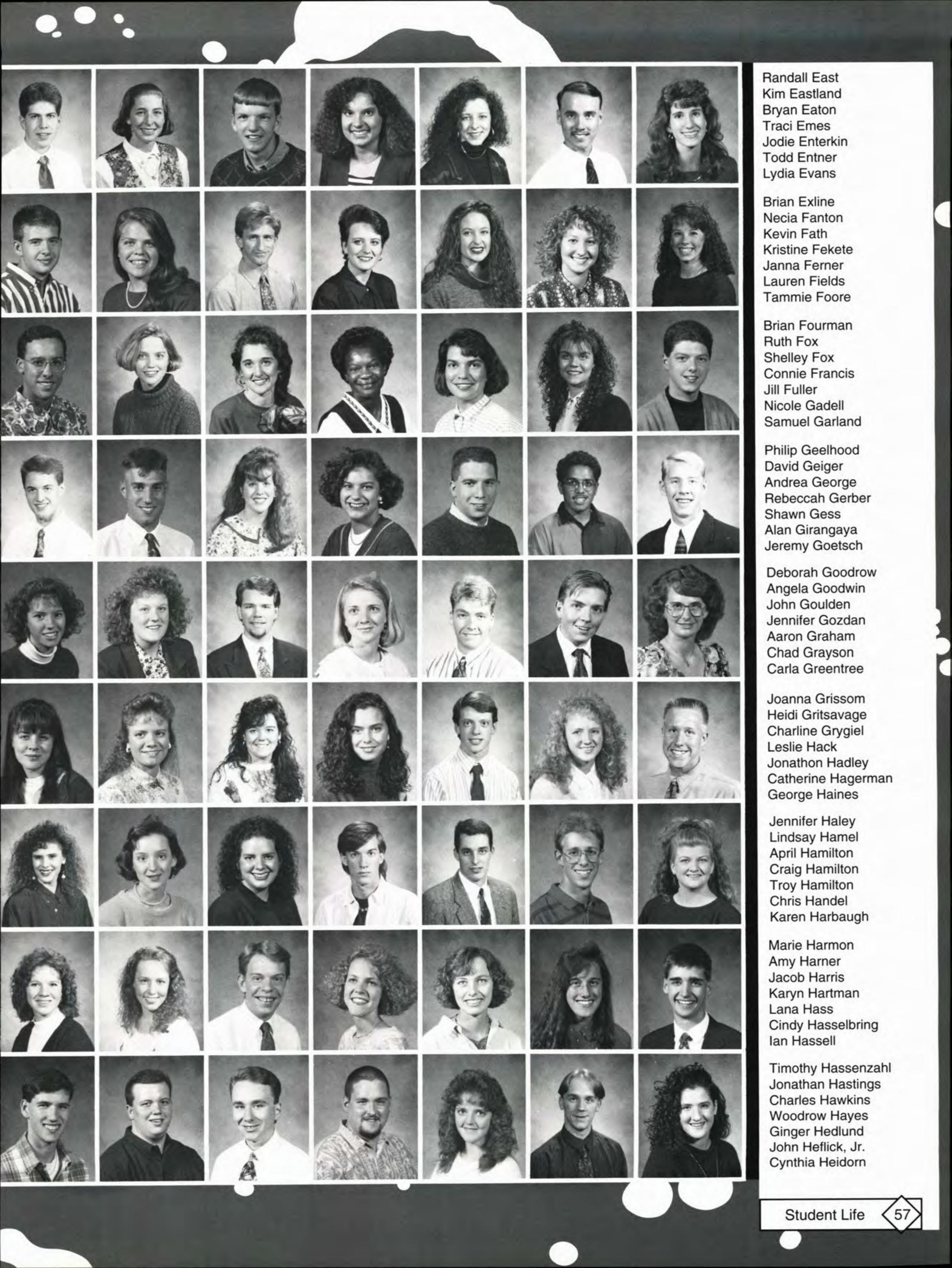


Mistalina Heinold Greta Hendricks

Alithea Henriquez Jennifer Henry

Linford Herschberger

Rebecca Hezlitt Sandra Hickox
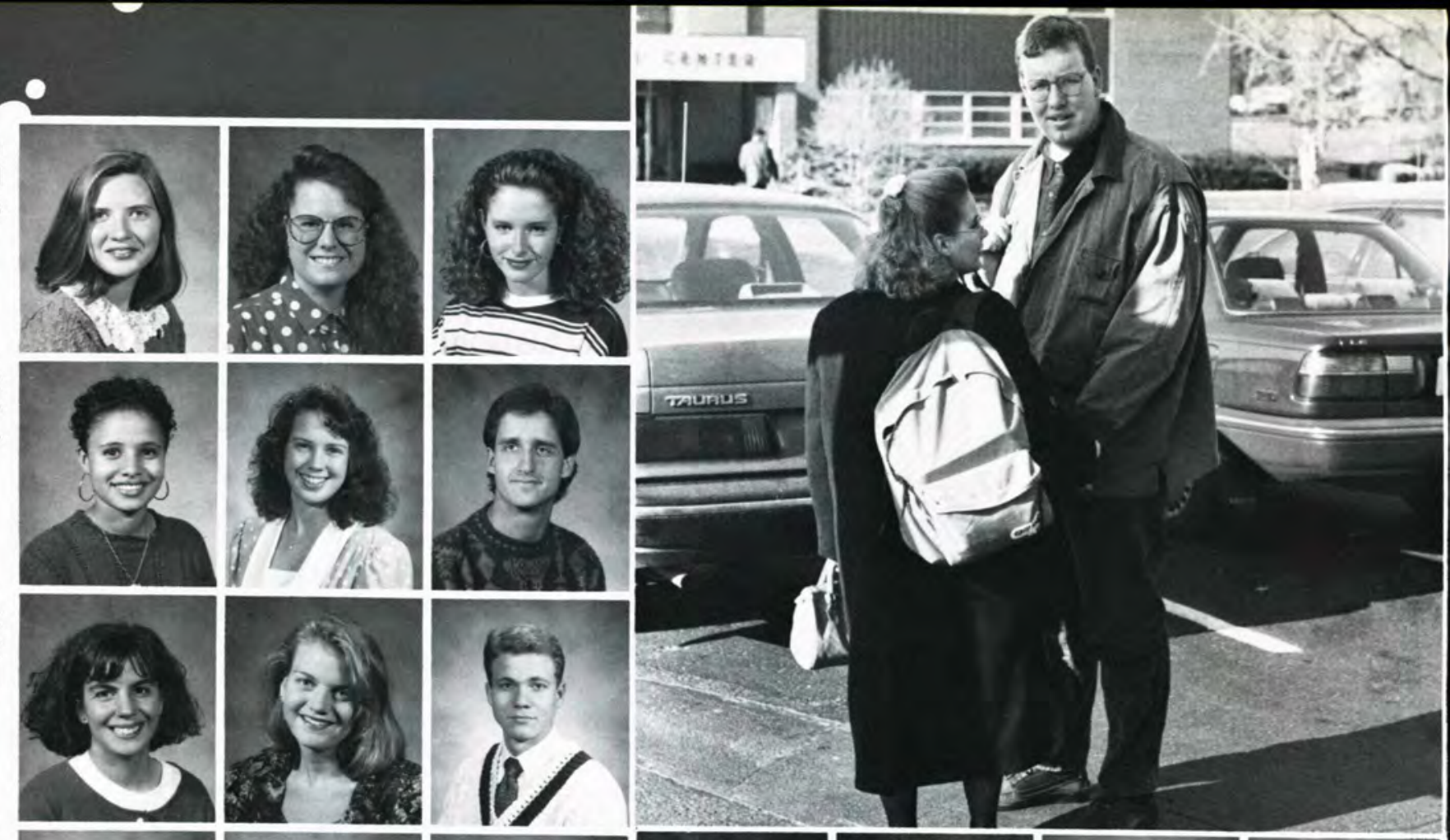

$$
\text { Todd Hill }
$$

\section{Janelle Hiller
Jenny Himes \\ Nathan $\mathrm{Ho}$ \\ Stephen Hodson \\ Rodney Hoewing \\ Margret Hofmann \\ Sherene Hohmann}

Camille Holloway

Thile Holloway

Richard Homan

Melissa Honeywell Adam Hook

Heidi Hoover

Kara Howe

Jeffrey Hoyt

Ryan Huebner Angela Hunsberger

Jill Hunsberger

Jeffrey Hunt

Keith Hurt

Cheryl Hyback

Kristine Illjes

Janelle Jackson

Emily Jagger

Robert James, Jr.

Clark Jeffries

Stephen Jenks

Naomi Jensen

Eric Johnson

Erik Johnson

Mark Jones

Natalie Jones

Jill Jordan

Deidre Kaufman

Michelle Keen

Anne Kelly

Jennifer Kierstead

Brian Kigar

Celia King

Kurt King

Stephanie Kirchoff

Amy Kirkbride
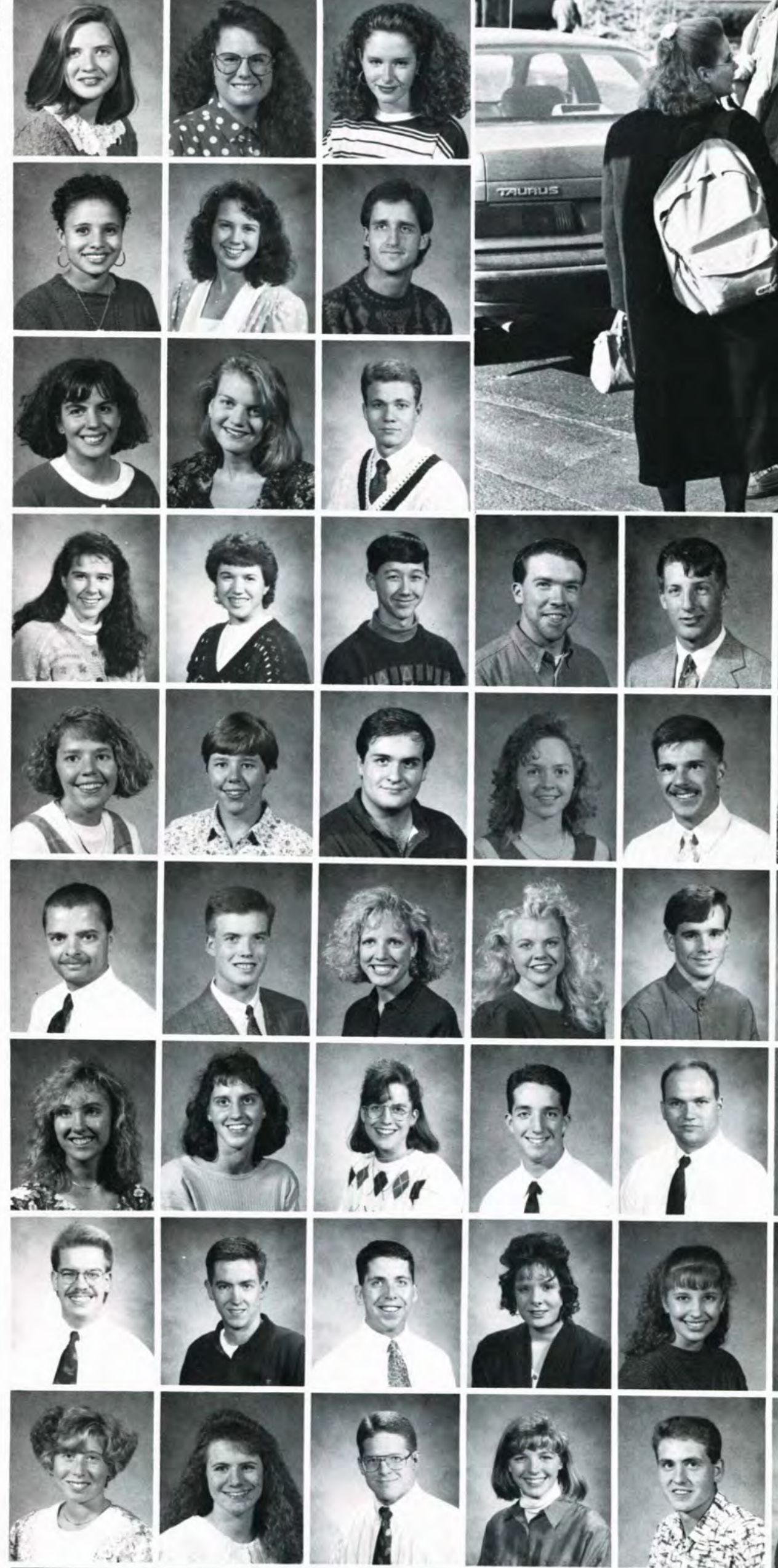

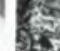
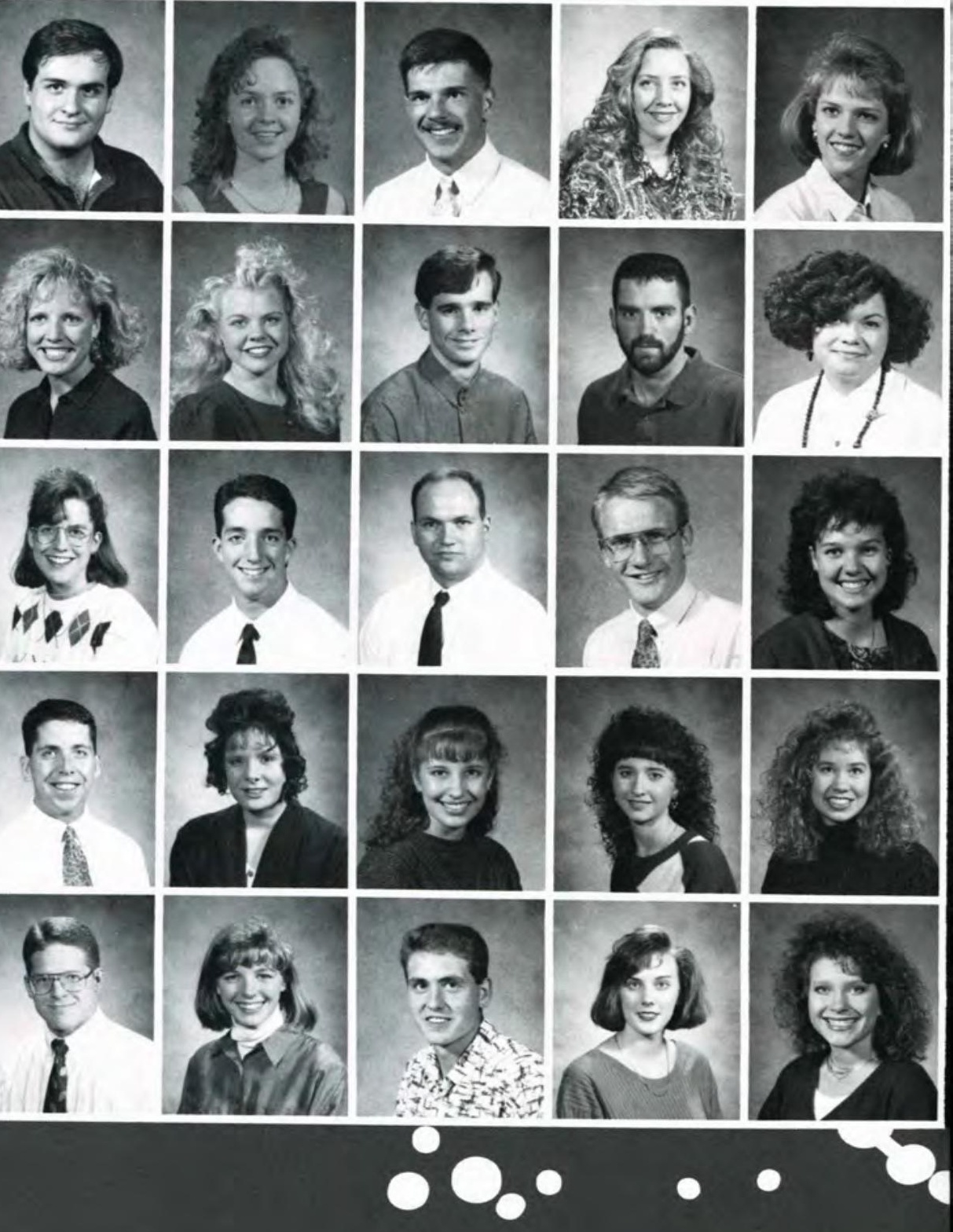


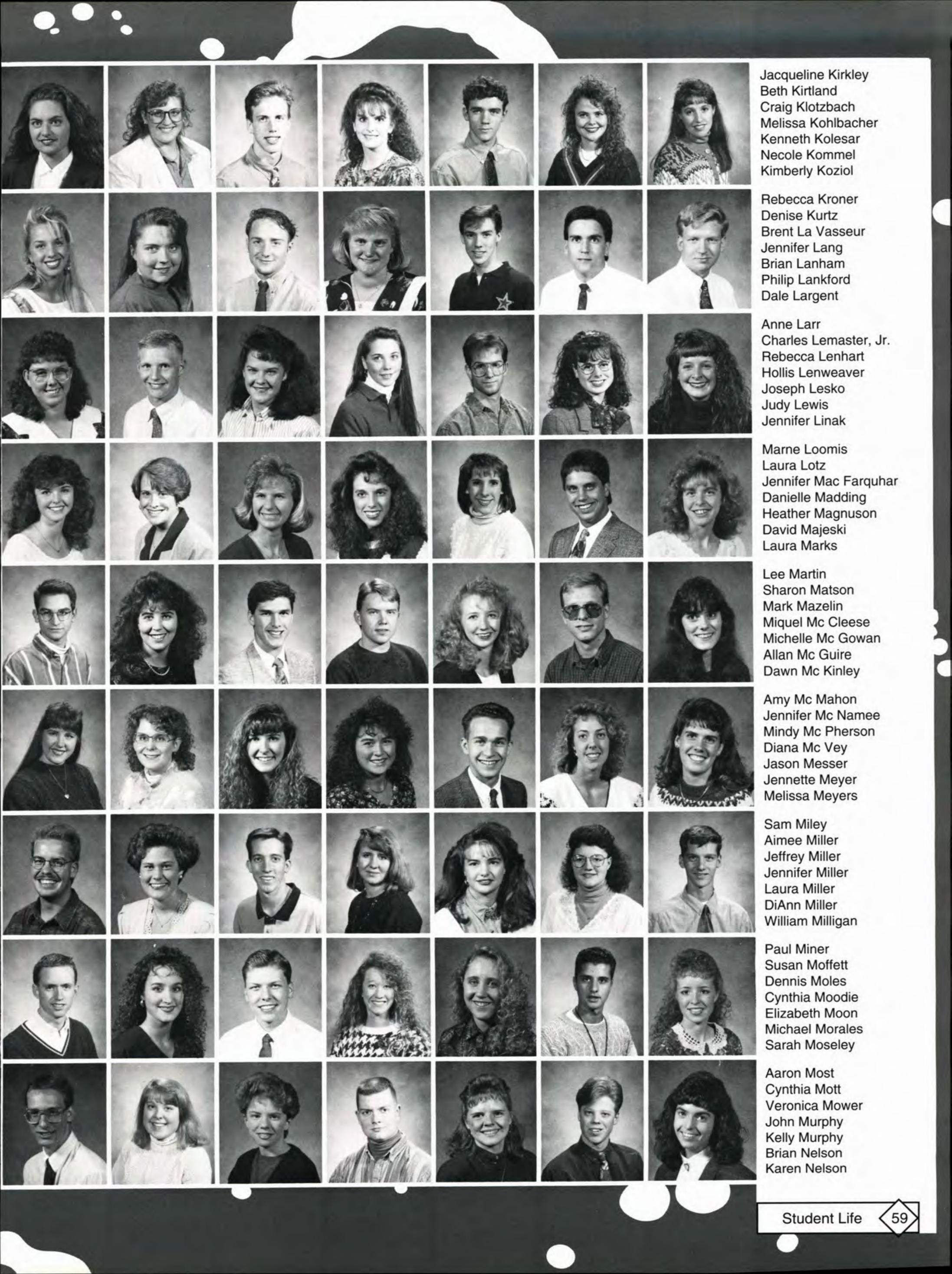




\section{RUSE AND \\ SHUNE!}

It's Tuesday morning and your alarm rings, calling the hour at 6:30. If you are sane, you hit the snooze and put off the day ahead for yet a few more minutes. If you happen to be a sophomore, however, you rise, shower, and leave to have breakfast with Dr. Dixon. Yes, it's the much-talked-about Sophomore Celebration! Every quarter, sophomores gather in the President's Dining Room for breakfast. But the breakfast is more than just eating and running; students enjoy a time of fellowship, meeting with one another and with Dr. Dixon. "Why would anyone want to get up at 6:30 for breakfast?" you may ask yourself. Well, the top three reasons for going are as follows:

1. Get my free mug since I'll never make a 4.0 !

2. I'll never be a sophomore again: why not?!

3. I get up at that time anyway.

-Chad Cornwell

Michael Pasquale Michael Passineau
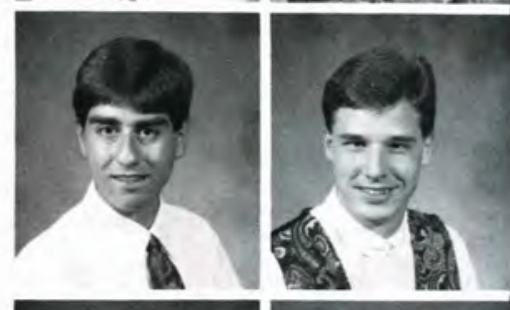

Rory Patterson Heather Perry
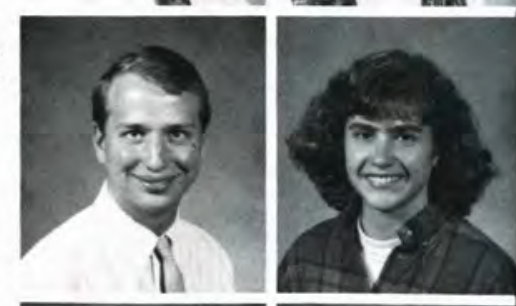

Chadwick Persons Penny Persons
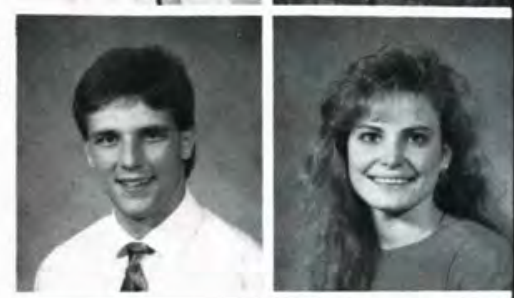

Amy Peterson Sandra Peura
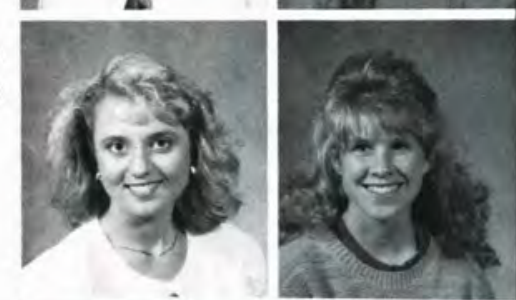

Marianne Phillips Beth Pickell
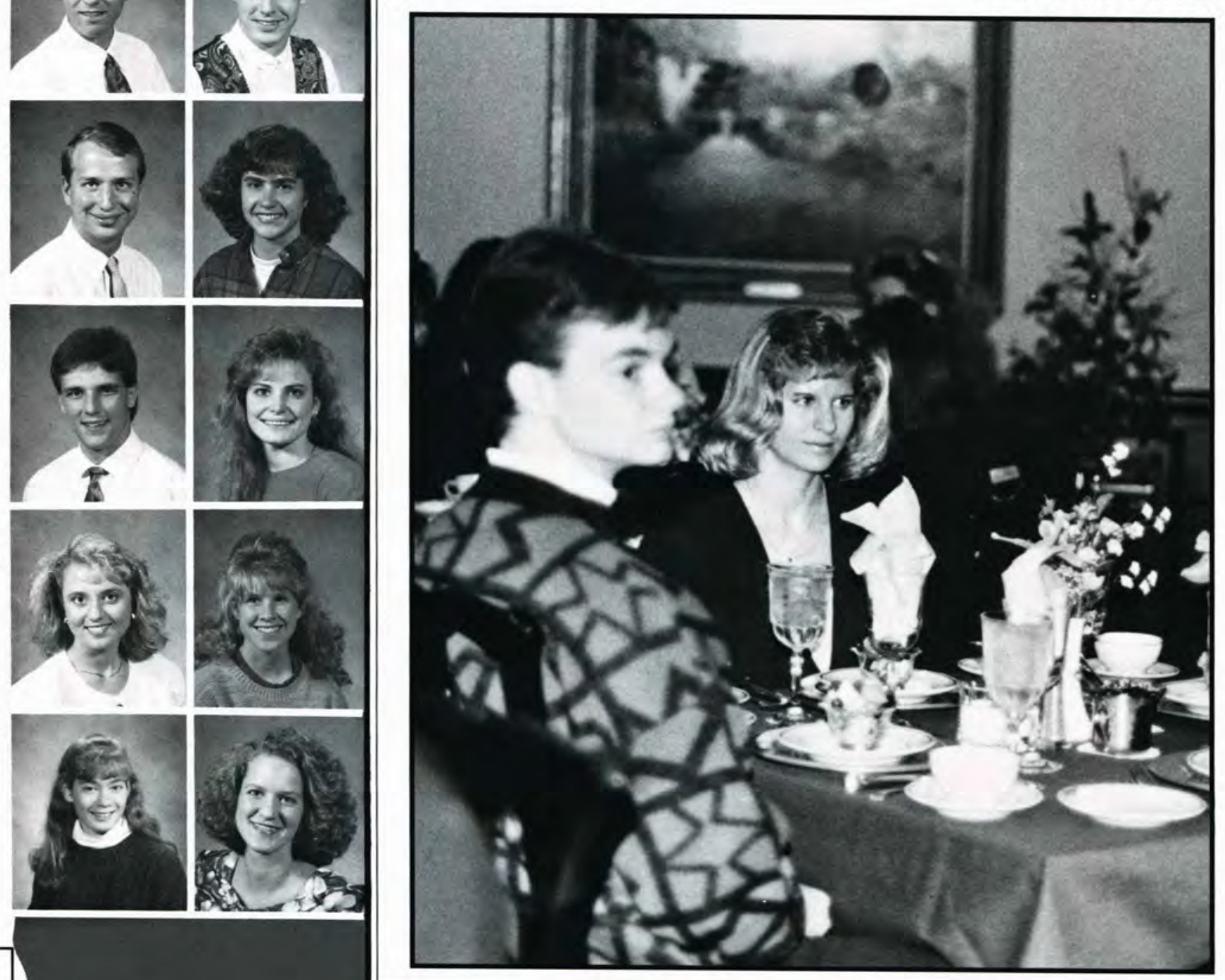

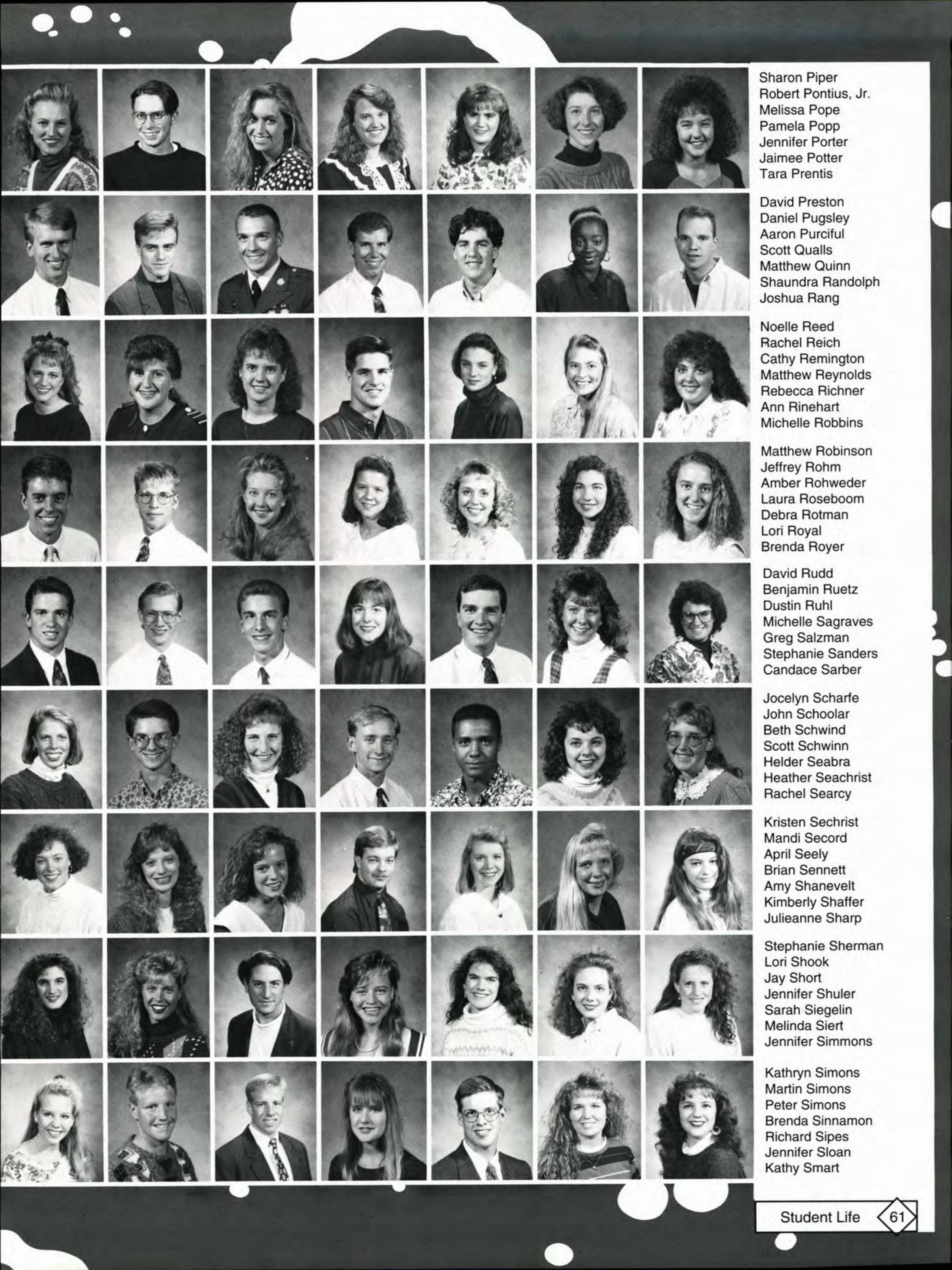
Lynne Smith

Teresa Smith

Virginia Snakenberg

Ryan Snedaker

Randal Snell

Bradley Snyder

Phillip Snyder

Cherith Somerville

Elizabeth Sorg
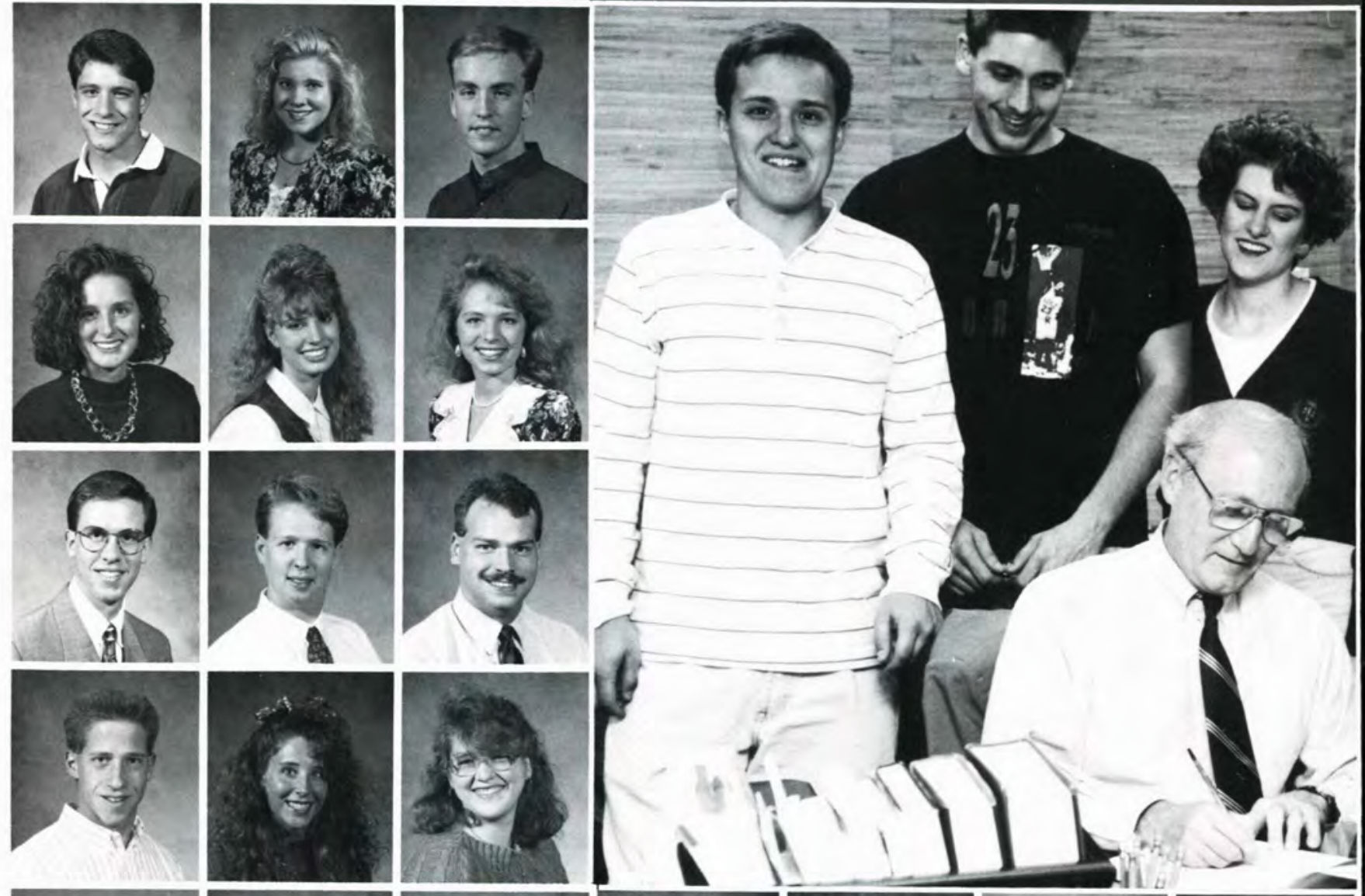

Jennifer Sorg

James Spaulding IV Jeremy Spieth

Bob Stacey

Leah Stanley

Jennifer Staples

Joanna Staples

Aaron Stark

Michelle Steenwyk

Loretta Stephen

Allison Stevens

Andrew Stewart

Kimberly Stitzel

Byron Stover

Kathleen Streicker

Christin Stutes

Yvonne Stutzman

David Sutter

Anissa Sutton James Swigart

Then Tang

Cynthia Tate Janna Taylor

Sheri Terrill

Troy Terrill

Chris Terry

Catherine Tharp

David Thigpen

Jacqueline Thomson

Kristine Thorsen

Tiffany Trimble

Paula Triplett

Darren Truax

Lemuel Usita

Kevin Vaughn
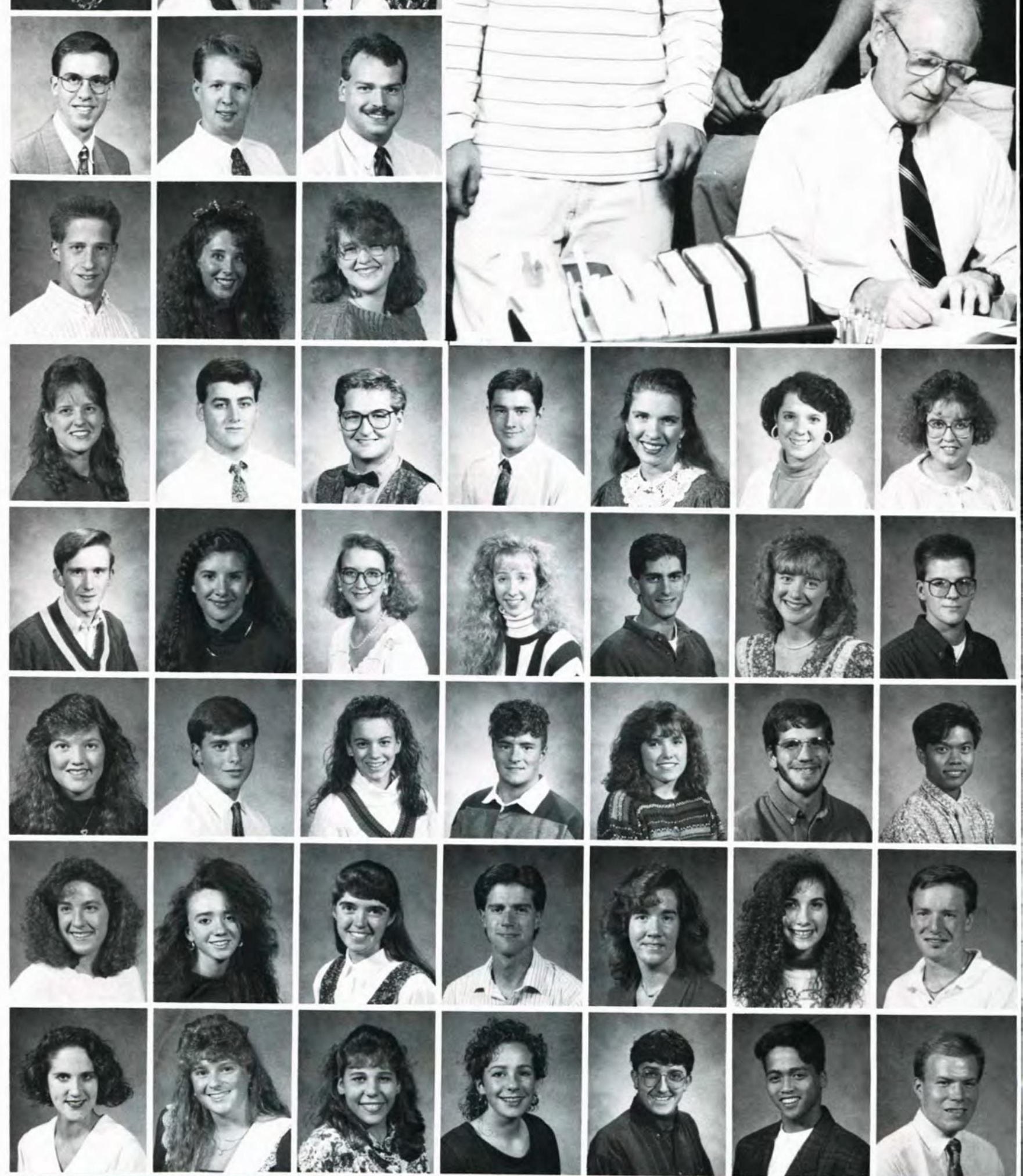


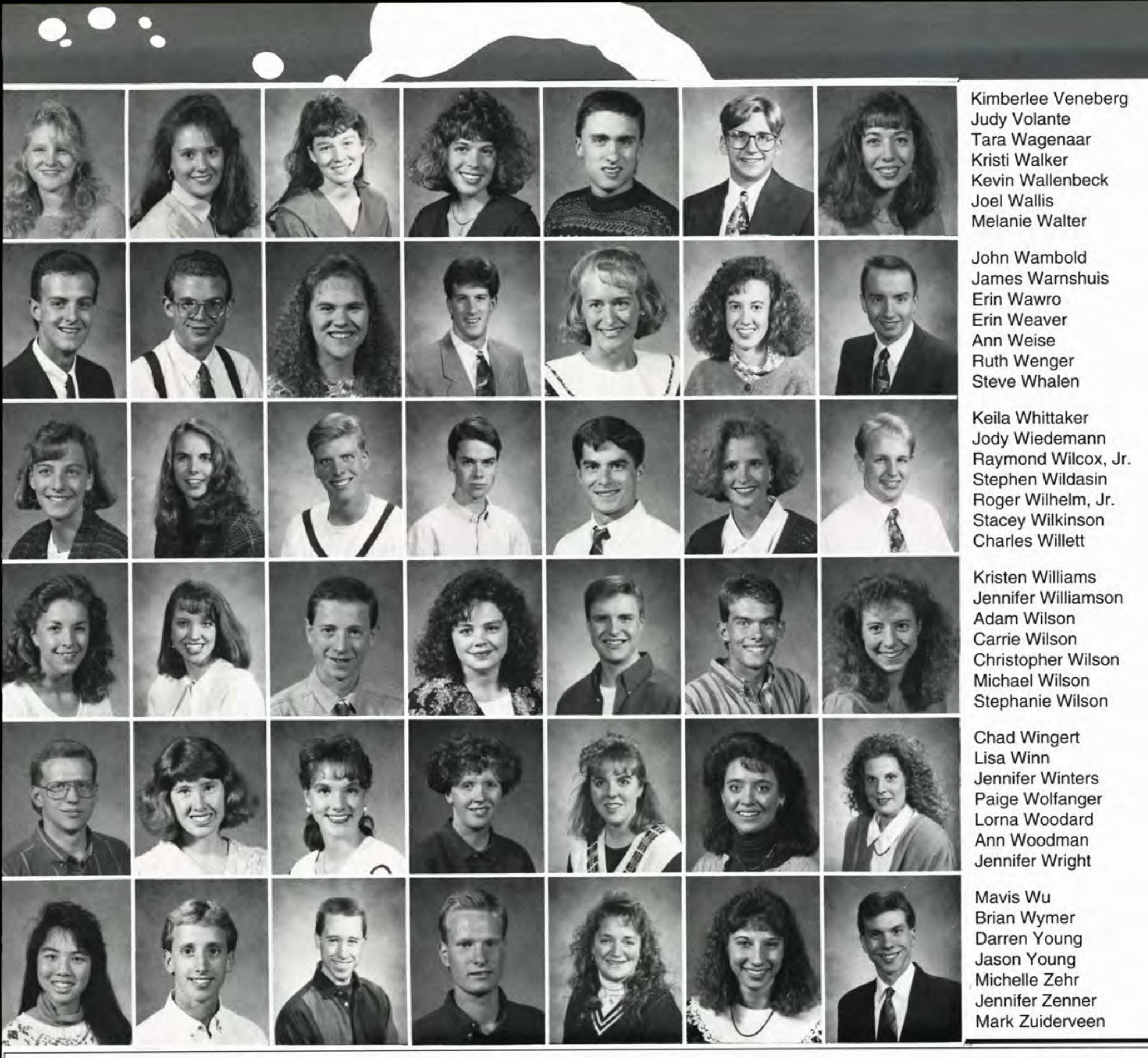

\section{Paying for College with a Promise -- ROTC}

Cedarville College has a number of students involved in the Army and Air Force ROTC programs. These programs allow the students to serve part-time in the reserves while the government finances their college degrees. After they graduate, they then serve in the active-duty forces. The students benefit by receiving a college edu- cation at little or no cost erate with students from fun as well. to themselves, and the Wright State. Juniors armed forces benefit by and seniors in the Army gaining college-edu- program meet with their cated officers.

Because of its com- State three times a week paratively small size, for exercise, and all Cedarville does not ROTC students attend have its own regular leadership labs about ROTC units. Students twice a quarter. These in the Army ROTC pro- labs include training acgram work with Central tivities such as firing $M$ State's "Marauders" 16 rifles; but they are detachment, while the not always times of rigAir Force students op- orous work; some are
ROTC is not for everyone. Students who opt for this program commit themselves to eight years in the armed forces upon receipt of their commissions. In spite of the long hours of training and the promise to at least eight years of service, ROTC gives students "an opportunity to see what they are." •David Holmes 


\section{Juniors}

"For you have need of endurance, so that after you have done the will of God, you may receive the promise: 'For yet a little while, and $\mathrm{He}$ who is coming will come and will not tarry.' Now the just shall live by faith."

-Hebrews 10:36-38

Craig Albrecht Stephanie Alexander

Denise Allen

Kimli Arjani

Paul Armour

Rebecca Armstrong Eric Ashcraft

Nicholas Awabdy

Katherine Baier

Brian Barnes

Robert Barnum, Jr.

Jeremy Barton

Kristen Baughey

Renee Beasley

Kristine Beck

Sharon Beckham

Jeffrey Beiler II

Andrew Bell

Kevin Belmont

Shari Benim

Christina Berry

Harold Beshaw

Mary Besosa

Robert Besosa

Nathan Bickel

Benjamin Biddle

Kristie Biggers

Eric Binning

Melissa Bird

Aaron Bishop

Darcey Blenis

Brian Blind

Thomas Bockmann

Brian Bolger

Jenifer Bork

Misty Borkholder

Jenae Bouchard

Carmen Bower

Todd Breneman

Amy Brien

Molly Broman

Mary Jo Brooks

Raechelle Brooks

Melanie Brown

Stephanie Brown

Jenny Bryant

Jeffrey Buckingham

John Burkholder

Robert Burns
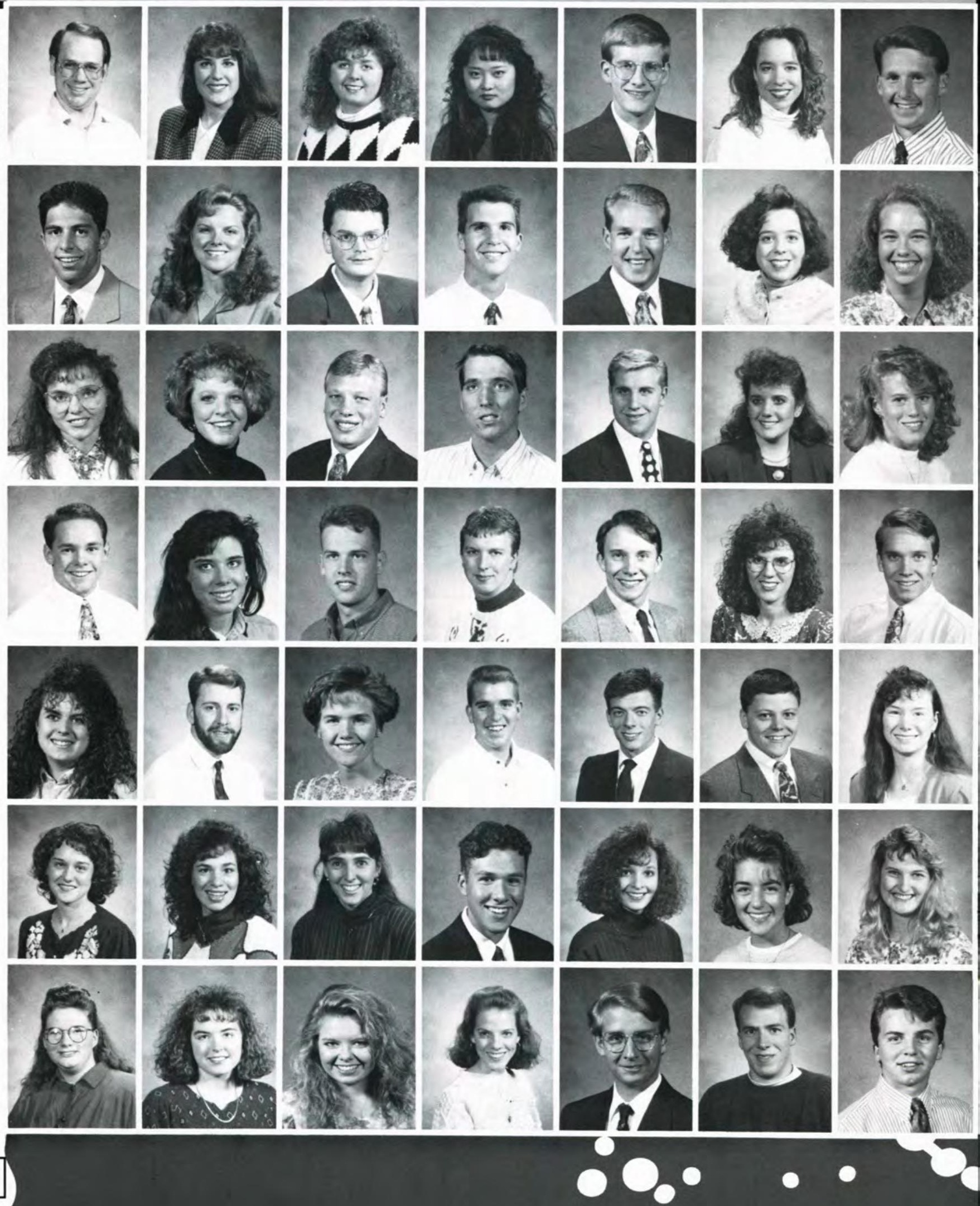
Melissa Freeman Jeff Gabbard

Darin Gall

Cindy Gannon

David Gardner

Sherry Gavitt

Lance Gentry

Rebecca Gerendas Nathan Gill

Rebecca Gillam Sean Godden

Matthew Goding Joyce Goga

Kimberly Goldbourn

Brian Good

Christopher Good

Dana Gosser

Amy Graves

Philip Graves

Carrie Grayson

Claire Grazier

Jack Greenly, Jr.

Annette Greentree

Elizabeth Greist

Jeremy Grinnell

Reid Gritsavage

Eliza Gromko

Cory Grove

Cathleen Hahnenstein

Christine Hahnenstein

Darryl Hammock, Jr. Nathan Han

Heather Hannah

Amy Harbeson

Suzanne Harding

Aaron Harju Scott Hartley

Angela Hartman

Todd Haseltine

Michelle Heldreth

Alyson Heller

Kara Henry

Gwendolyn Herr John Herrick

Ryan Hewson

Ruth Heyd

Georgia Hickman

Aaron Hiebert

Ann Higley

Marcy Hintz

Lynette Hochstedler

Michelle Holcomb

Rachel Holley

David Holmes

Benjamin Horine Jennifer Horton

Rhonda Houston

Rachel Howard

Tiffany Howell

Timothy Hoy

Pearl Huber

Phil Huber

Dana Hull
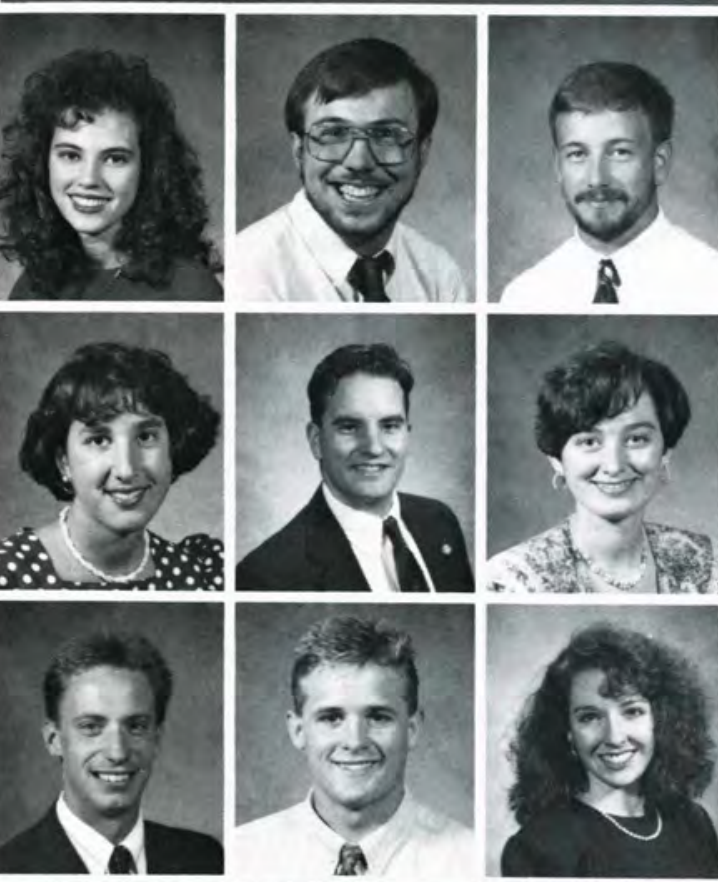

(n)
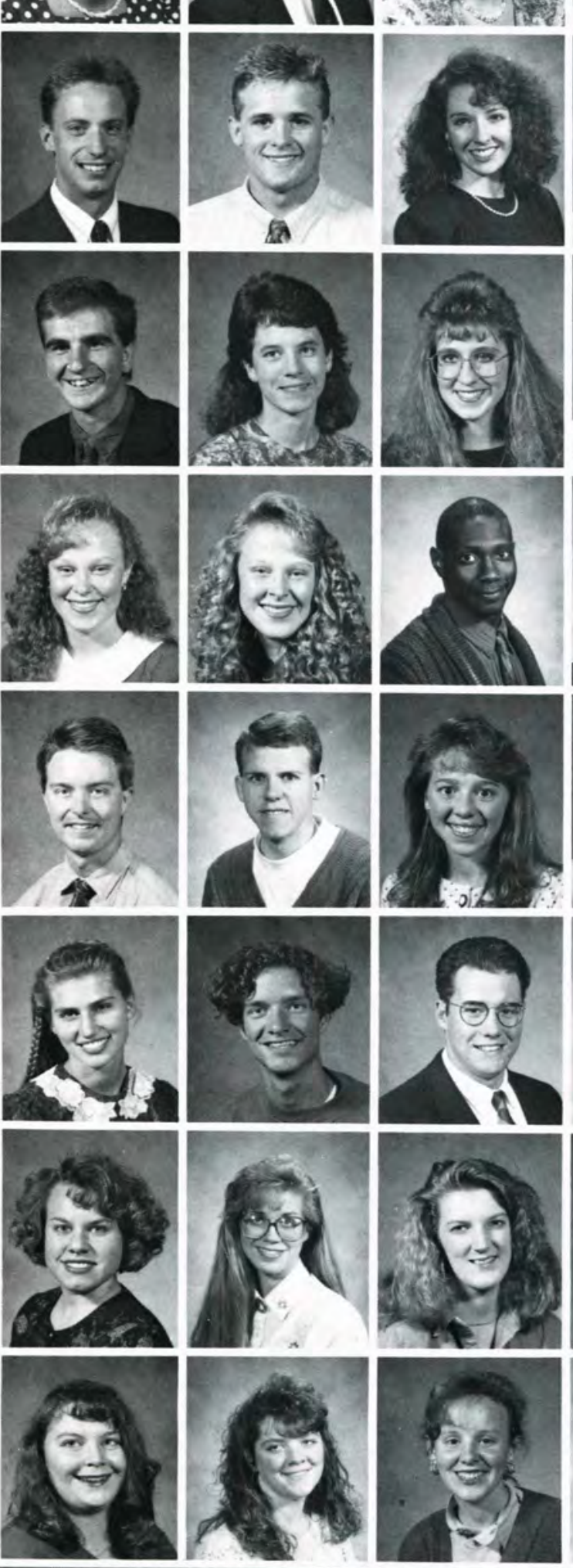
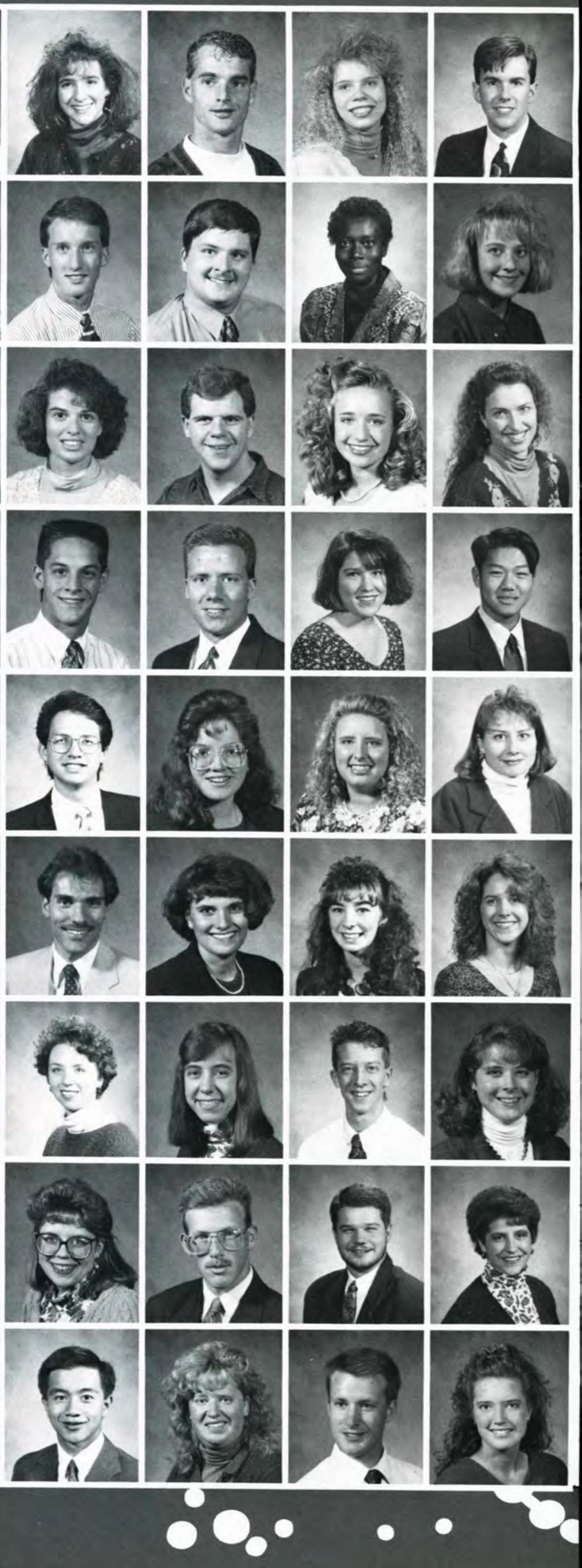


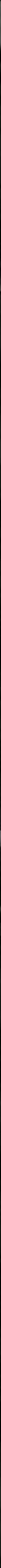




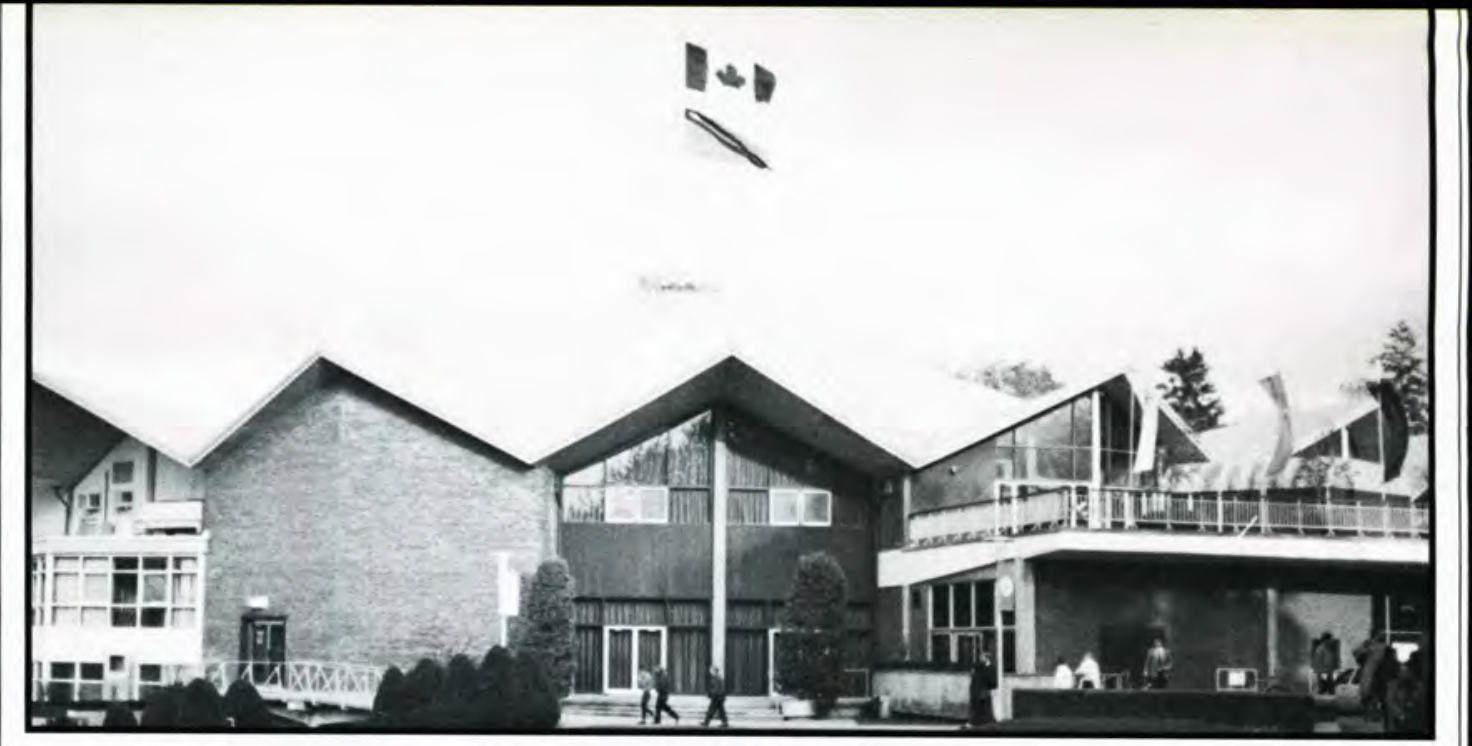

Kristin Milner

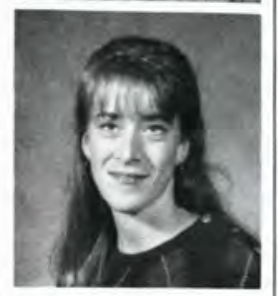

\section{Memories Surface of Shakespeare and Spencer}

\section{Students Escape to the Stratford Festival}

The Friday morning sun rises waking the campus to a final day of classes, but rather than fieading to class, a small group of Cedarville students load their luggage as they embark on a different adventure that will paint an unforgettable masterpiece in their fiall of memories. The adventure involved a weekend full of culture, friends, and Shakespeare at the Stratford Festival.

Though not a well-known annual event, a few students have discovered the splendor of this weekend excursion into Canada. Memories are made for some on the trip from Cedarville to Stratford. Convincing an officer that you left the drugs you never had at fiome so you can pass through customs and persuading your driver that 100 kilometers per fiour is not the same as 100 miles per hour remove all boredom from an eight fiour trip.

Once in Stratford, the romantic town filled with little shops and cafes satisfies the culturally curious mind as well as the impulses of the professional shopper. A casual stroll along the maple tree-lined sidewalks or kicking the leaves beside a swan- dotted pond refreshes even the most serious student.

But for all, memories were made at the theatre which was the highlight of the weekend. Even to the non-English major, the performances of these world-renowned actors and actresses bring a greater appreciation of the wit and creativity of Shakespeare.

Of course, this weekend recipe of memories not only included the ingredients of culture and Elizabethan English, but also spending three days with special friends and the one-and-only Mr. Spencer. The crazy moments of midnight jokes, dressing formally for a walk in the rain, and conversing in a civilized manner over a spot of tea etch a memory that will be recalled with many smiles and laughter! Hopefully each year, more students will take fiold of this once-in-a-lifetime experience and never forget it!

- Brian Broaddus
Hope Morse Donald Mosley, Jr. Tina Mulanax Loren Mullins James Murphy Melinda Myles Daniel Neil

Jennifer Neudeck Aaron Newcomb Lorraine Newton William Orser

Deanna Osborn Matthias Otto Bradley Palmer

Krista Pantana

Zachary Pappas Kevin Pearson Tim Pearson Carlene Perdue Deborah Perkins

Heather Peters Dora Lee Peterson

Cheryl Phillips Alex Pierce Doug Pierce Stewart Pierce Chad Parrow Eric Phillips

\section{-}
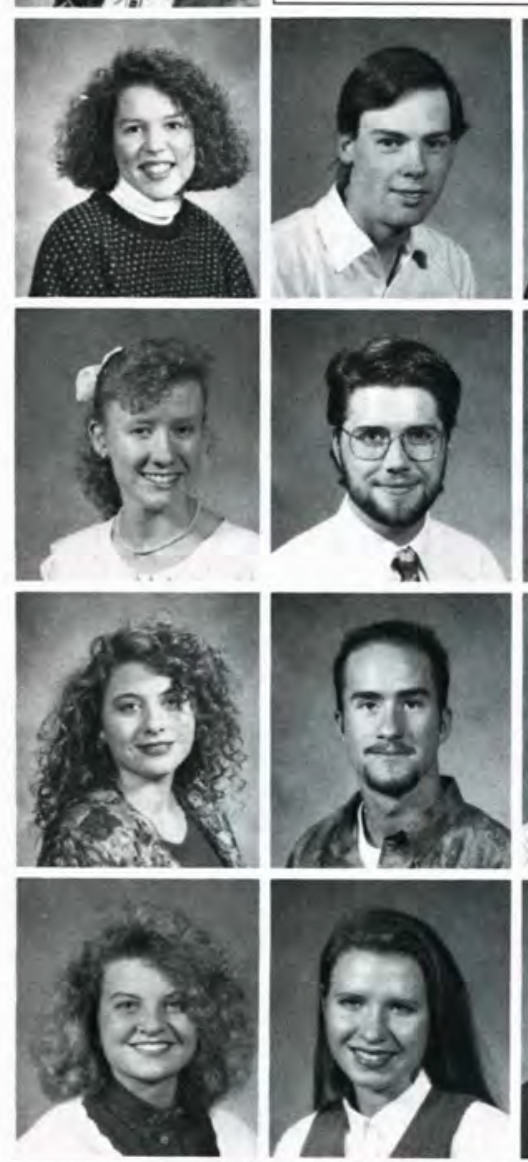
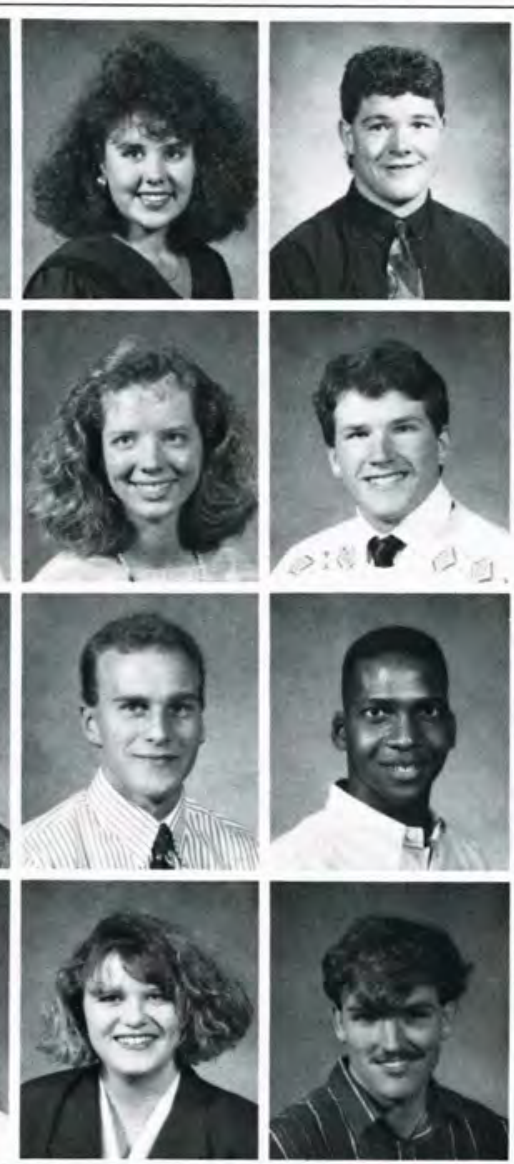
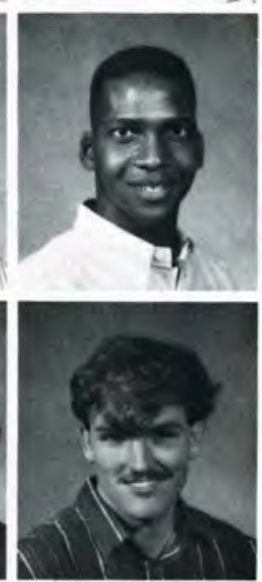
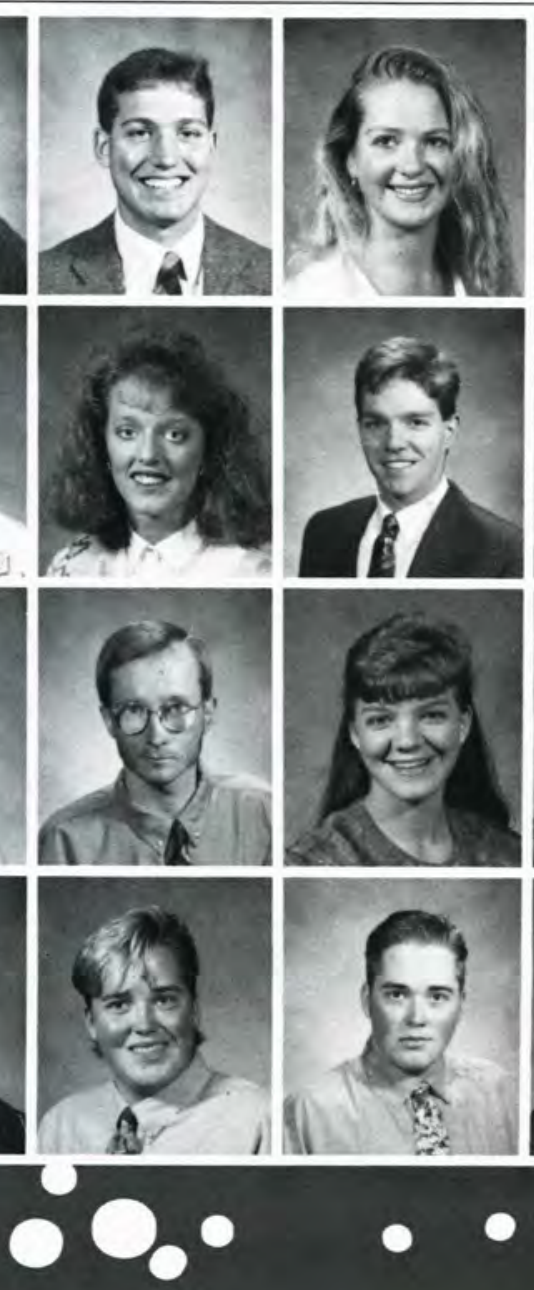
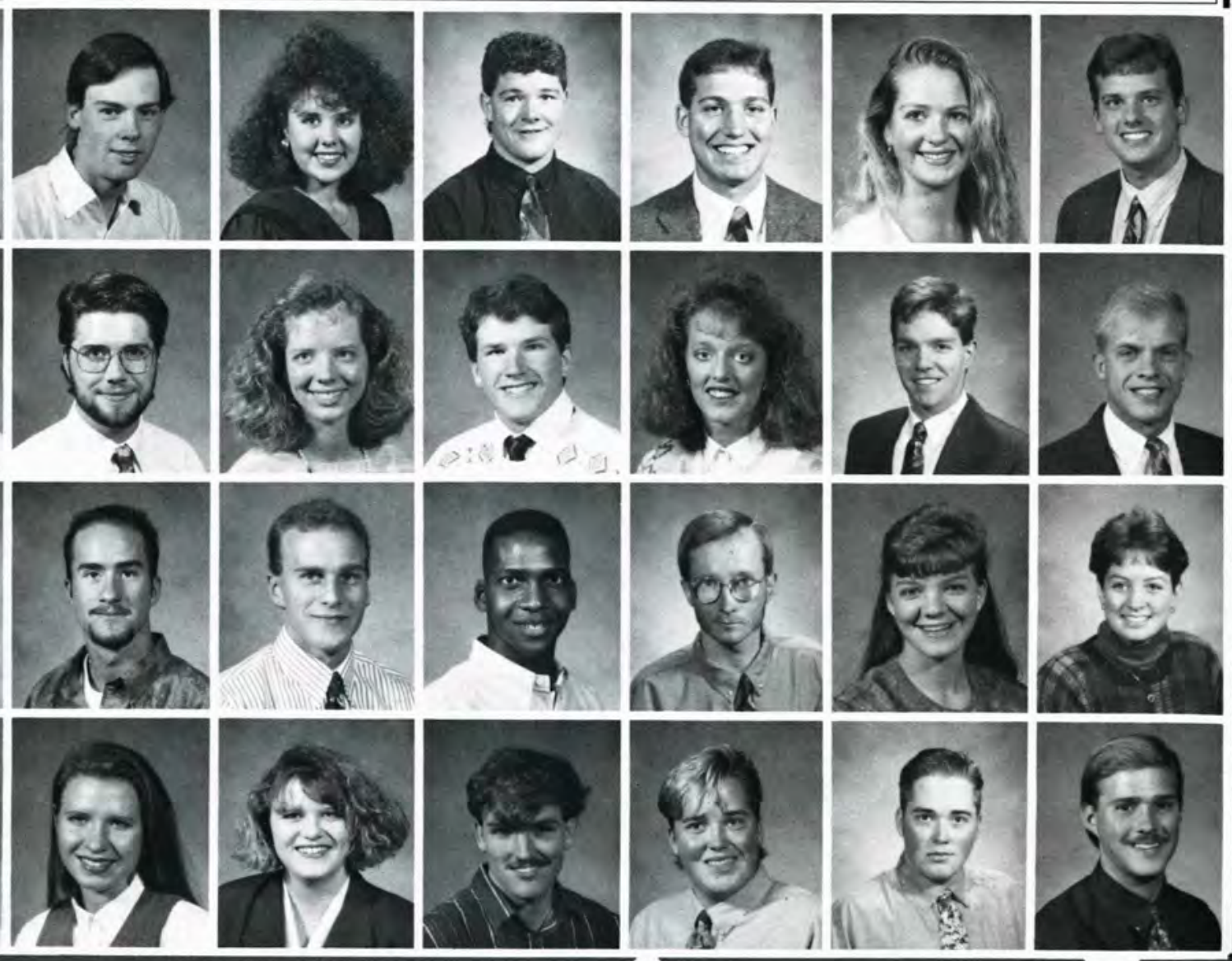


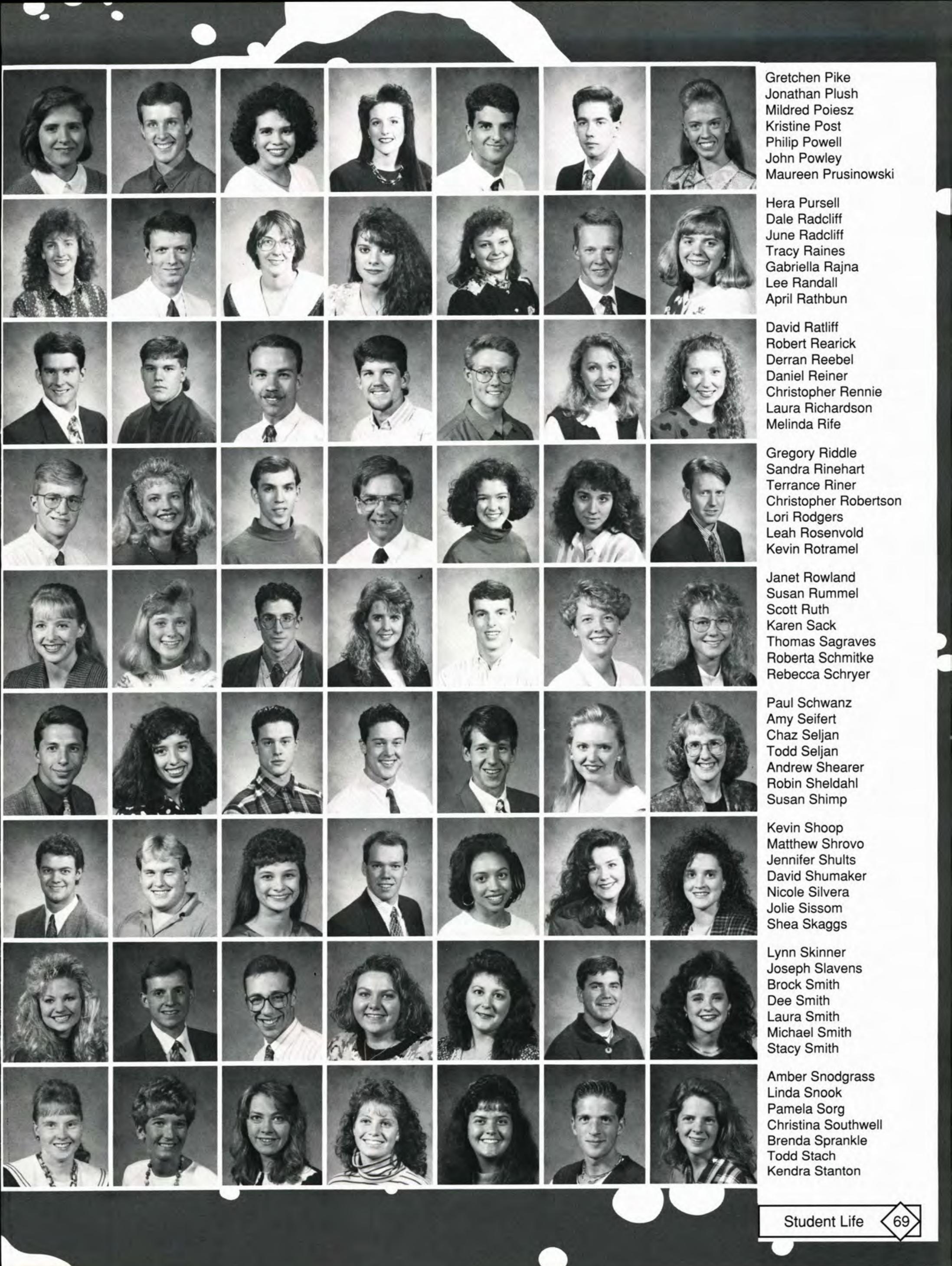


Gretchen Steininger Gary Stickley Sarah Stiles Allison Stolar William Stoll III Stephen Stone Randall Strobl

Katherine Stull Rebbeca Sturrock Robert Sutherland Tracy Swackhamer Sharon Swanson Rita Swartzentruber Amy Tapp

Sara Taylor John Terpstra Christy Thomas Jill Thompson

Tyler Thompson Christine Threlfall Robert Tonelli

Andra Traucht Timothy Trow Joshua Trowsdale Adam Ulery Mark Utz

Ryan Van Deusen Kristi Van Dyke

Sonja Van Wert Jonathan Varner Josette Walborn Julie Walker

Elizabeth Walsh Lynn Walter Wendy Walters

Erin Ward Molly Ward Shannon Wenger Malia Weiss Troy West Heidi Westbeld Wendy Weyand

Jill Weyhe
Laurel White
Scott Whitten
Jennifer Wilfert
Mike Wilkerson
Lisa Wilkes
Julie Williams

Michael Wilson, Jr. David Wilson Kenneth Wilt Tina Wingate Stephen Wintle Tammy Wittkamper Mark Wong

Jodi Woodhams Timothy Woodward Kristen Wylie Michelle Yates Daniel Zerby
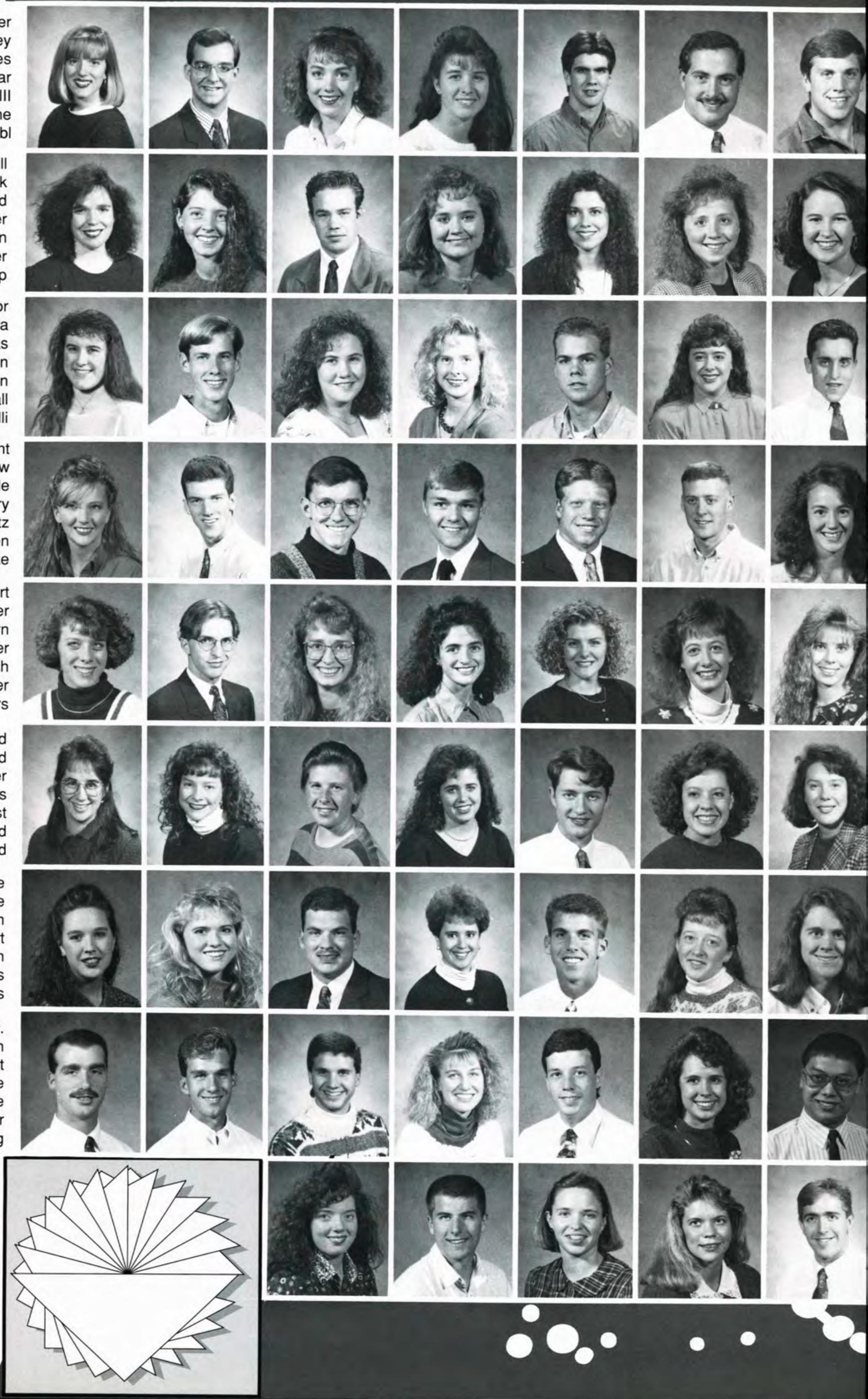


\section{Non-graduating Seniors}

"Be strong and courageous. Do not be terrified; do not be discouraged, for the Lord your God will be with you wherever you go."

-Joshua 1:9
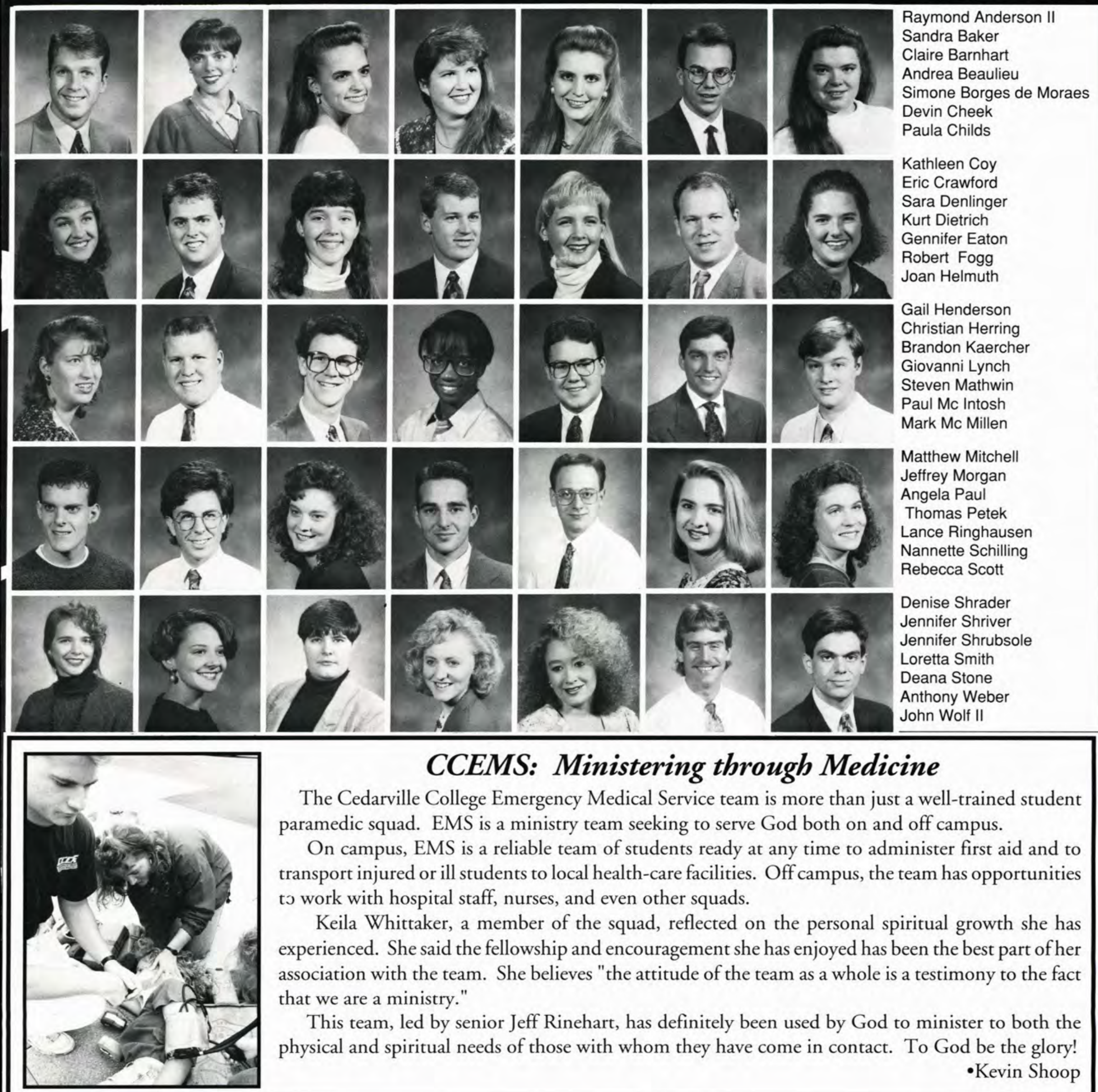

\section{CCEMS: Ministering through Medicine}

The Cedarville College Emergency Medical Service team is more than just a well-trained student paramedic squad. EMS is a ministry team seeking to serve God both on and off campus.

On campus, EMS is a reliable team of students ready at any time to administer first aid and to transport injured or ill students to local health-care facilities. Off campus, the team has opportunities to work with hospital staff, nurses, and even other squads.

Keila Whittaker, a member of the squad, reflected on the personal spiritual growth she has experienced. She said the fellowship and encouragement she has enjoyed has been the best part of her association with the team. She believes "the attitude of the team as a whole is a testimony to the fact that we are a ministry."

This team, led by senior Jeff Rinehart, has definitely been used by God to minister to both the physical and spiritual needs of those with whom they have come in contact. To God be the glory! 
AT THE ELECTION

PARTY, Brian Burns

smiles with his balloon.
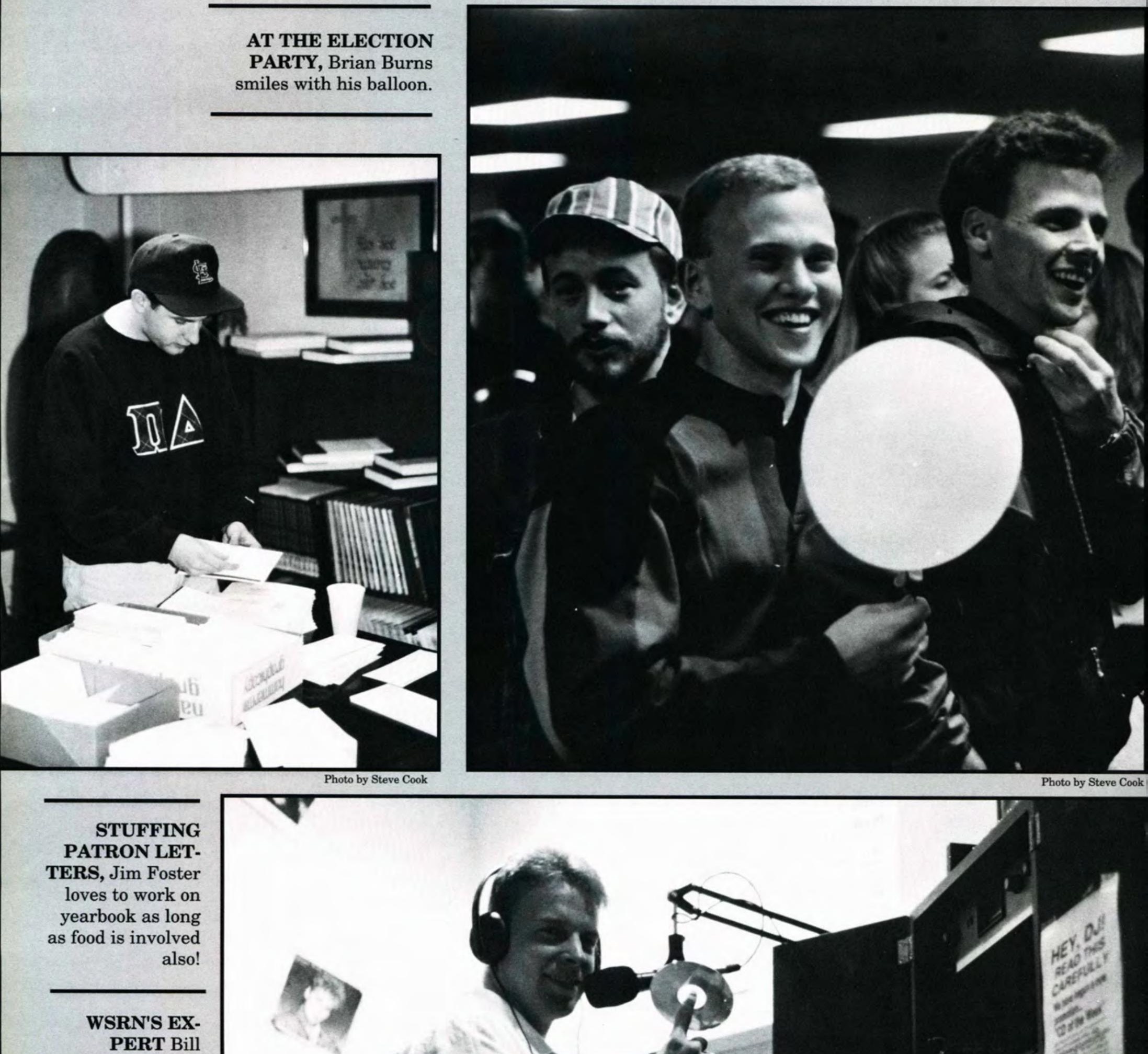

Montgomery spins a $\mathrm{CD}$ on his finger.
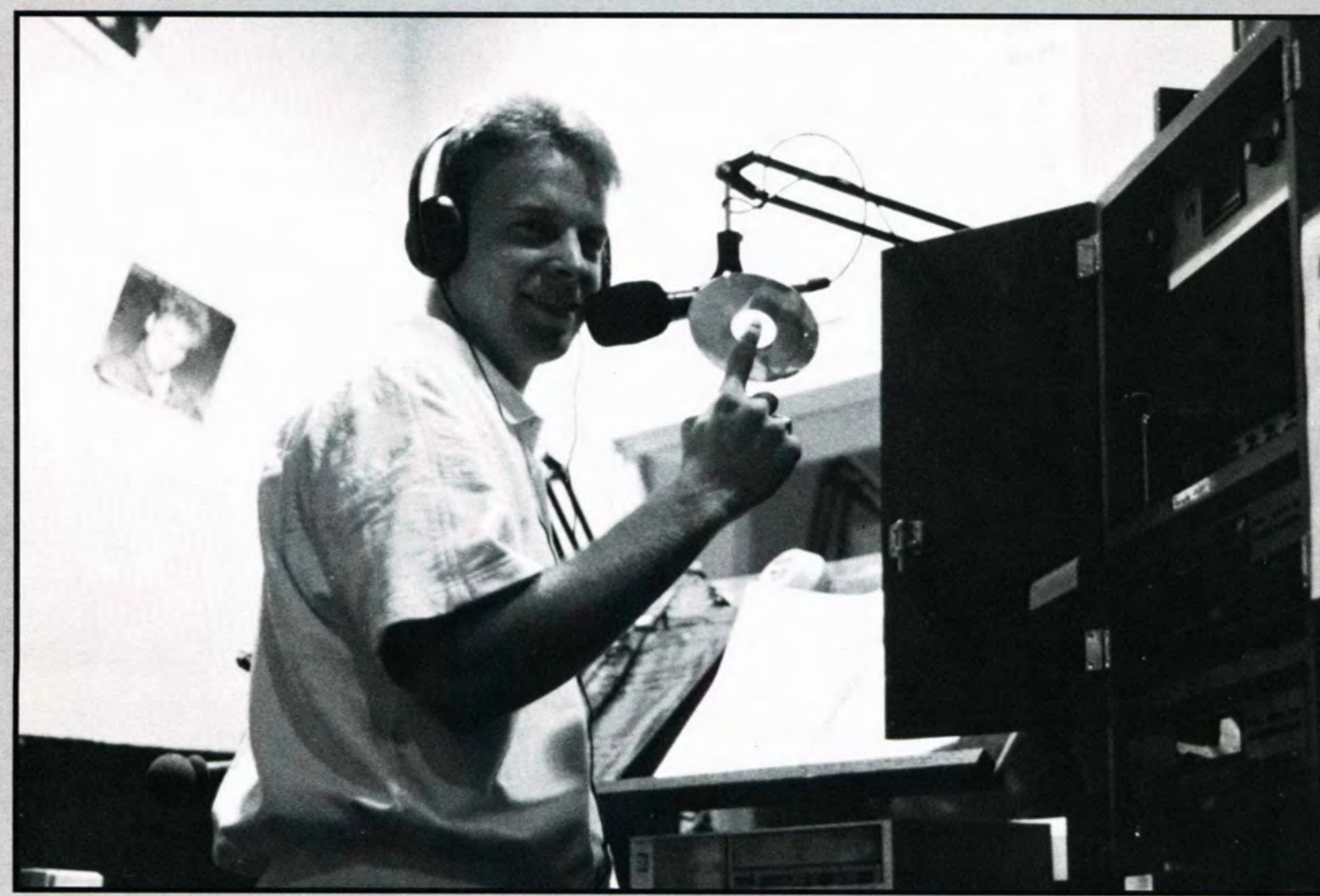


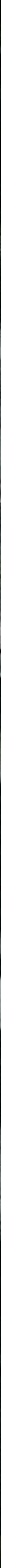



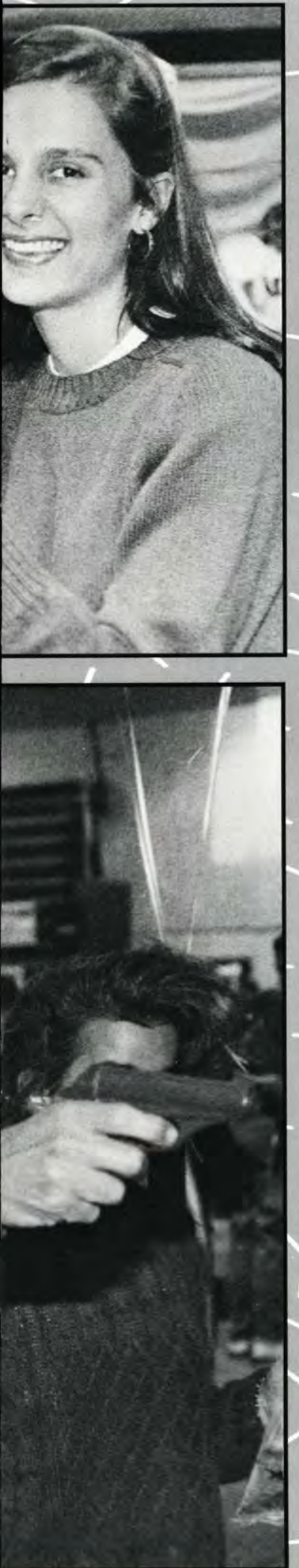

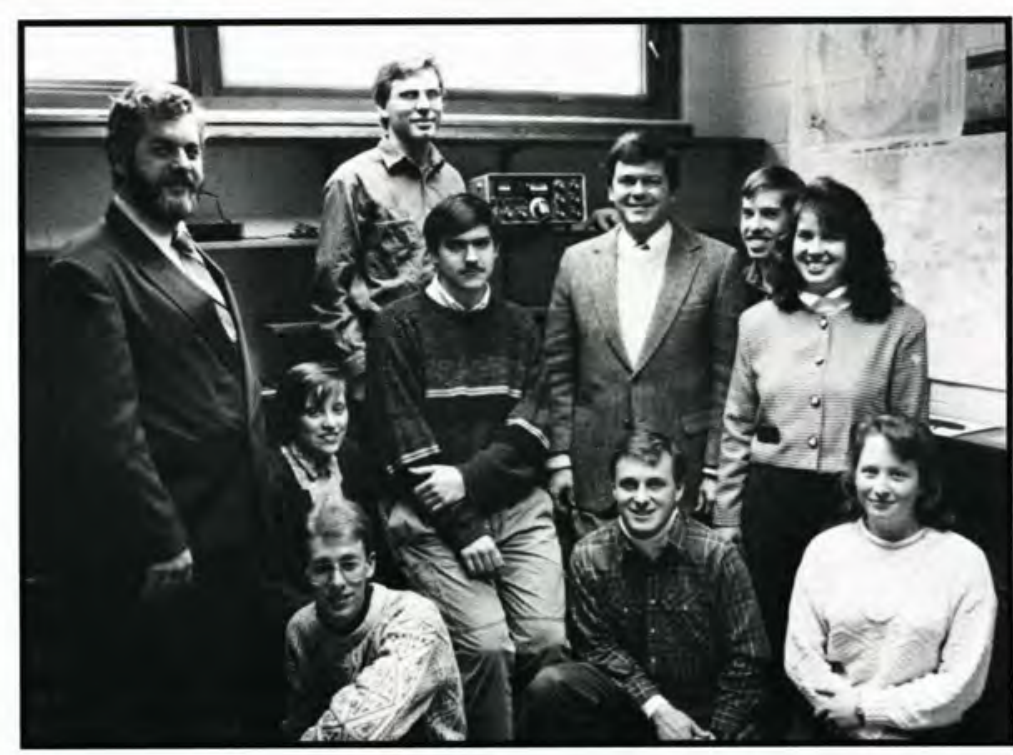

Front row: Dr. Lee Eimers, Chris Handel, Stephen Heath, Marla Perkins. Second row: Rachel Ross, Alex Kulin, Mr. Jerry Rodgers, Robert Jackson, Jennifer Henry, L. Allan McGuire.

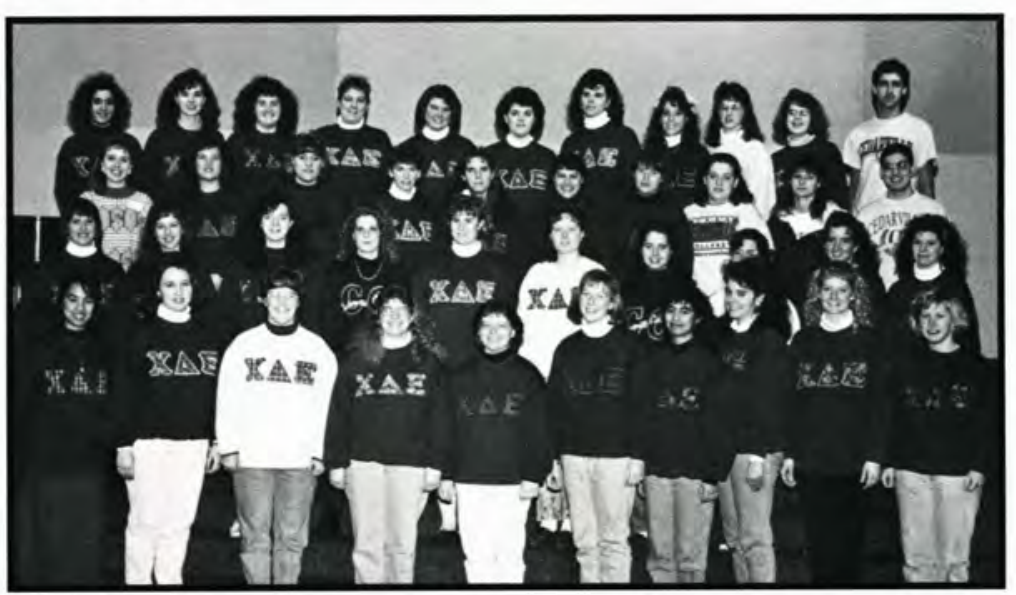

Front row: Mavis Wu, Melanie Dawson, Kathleen M. Irish, Melissa Austin, Julie McFadden, Stephanie Bolsem, Nicole Hernandez, Valerie Kaufman, Tami Haberstich, Shanda Strayer. Second row: Amy McMahon, Spring Cadwell, Jodi Woodhams, Jennifer Wright, Janine Pinkley, Lynann Salzman, Jenna Coakley, Emily Jagger, Janie Barrett, Mindy Clapper. Third row: Debbie Rotman, Kathy Streicker, Kara Wood, Kayley O'Keefe, Sue DeMan, Melissa Reed, Gail Henderson, Olivia Carter, Michelle Southworth, Jim Murphy. Back row: Amy McWhinnie, Jena Winters, Allison Broadhead, Jennifer Doak, Becky Mc Intyre, Gabrielle Gerber, Becky Swinerton, Cherith Somerville, Vonda Horst, Dawn Cunningham, Linford Herschberger.

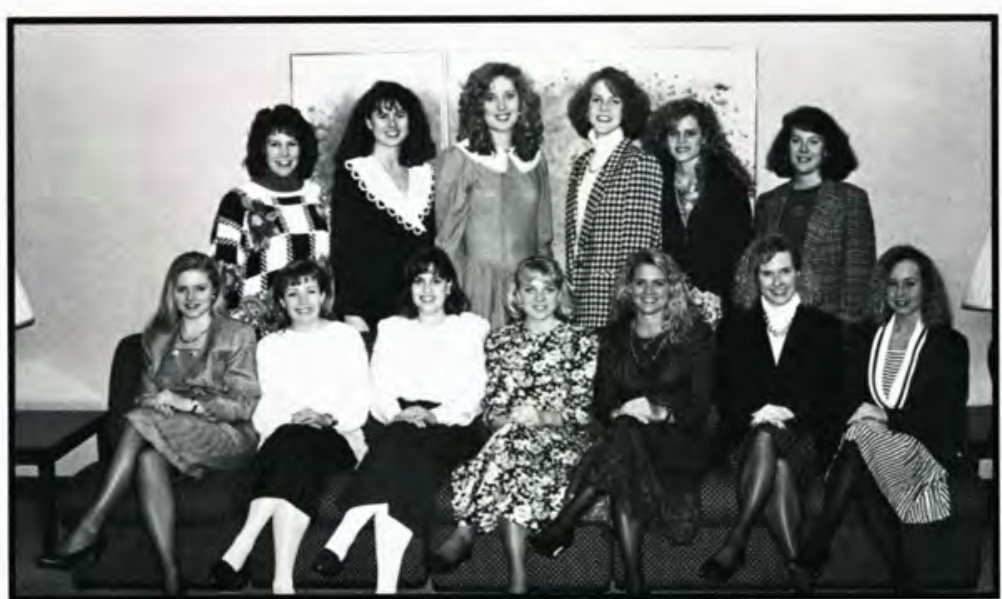

Front row: Robin Sheldahl, Nikki Starr, Lisa Gillett, Beth Fales, Laurel White, Jil Thompson, Tonya Bosling. Back row: Jane Adams Smith, Advisor, Mary Sweetland, Elizabeth Miller, Karyn Hartman, Katrina Parlin, Wendy Weyand.

\section{CCARC}

How would you like to communicate with the entire world without it costing you an arm and a leg? The Cedarville College Amateur Radio Club was started this year with the purpose of maintaining a college amateur radio station. The club uses Morse Code and voice to communicate with the world. The C.C.A.R.C is able to train and license the students, faculty, or staff in Amateur Radio. One of the club's objectives is to provide communication between missionary parents and their children on campus.

\section{Chi Delta}

\section{Epsilon}

Developing character and dedication in education is the desire of Chi Delta Epsilon, Cedarville's elementary education club. Students in this organization strive to increase in professional development and awareness, to participate in community outreach, and to encourage each other as they prepare for a career in education. Among other activities, Chi Delta Epsilon participated in Homeless Awareness Week this year. The group sponsored a coat drive and sent volunteer teams to the Dayton Gospel Mission in order to better understand and meet the need of the homeless.

\section{Delta $\mathrm{Pi}$}

\section{Sigma}

Delta Pi Sigma is a women's service organization which focuses on meeting the physical and spiritual needs of those in the community. The organization strives to prepare women for their roles after graduation and to give them the opportunity to serve God by serving others. Group members participate in various community service activities, such as helping with childcare at the Xenia Domestic Violence Shelter each week. They encourage devotion to Christ and give students the chance to grow closer to the Lord and to each other as they learn how they can serve Christ and others in their community 


\section{Earth \\ Stewardship}

While faced with ecological and social issues, members of the Earth Stewardship Organization attempt to recognize the intrinsic value of creation. Devotionals and social activities such as volunteer work, intercampus forums, and article reviews are all placed under the rubric of stewardship. How can we go beyond managing, and instead live along with what God has created?

\section{Phi}

\section{Epsilon Beta}

The members of Phi EpsiIon Beta focus their ministry on the New Beginnings crisis pregnancy center in Xenia. The women of this organization do everything from helping with remodeling work at the center to working as receptionists or directly interacting with the women who come to the center for help. Besides the time they have to get to know one another in biweekly meetings and on quarterly retreats, they feel the most rewarding aspect of their ministry is the time spent interacting and counseling with the women at the center.

\section{SAE}

Students in engineering have the opportunity to be involved in the student chapter of the Dayton Chapter of SAE, the Society of Automotive Engineers. Every month there are seminars on current engineering advancements that both students and professional engineers attend. This gives the students a chance not only to learn more about their future profession but also to talk to other engineers in the area. Members are encouraged to participate in one of many projects, including the Super Mileage contest, the Aero-Design team, the Mini-Baha competition, and Robotics.

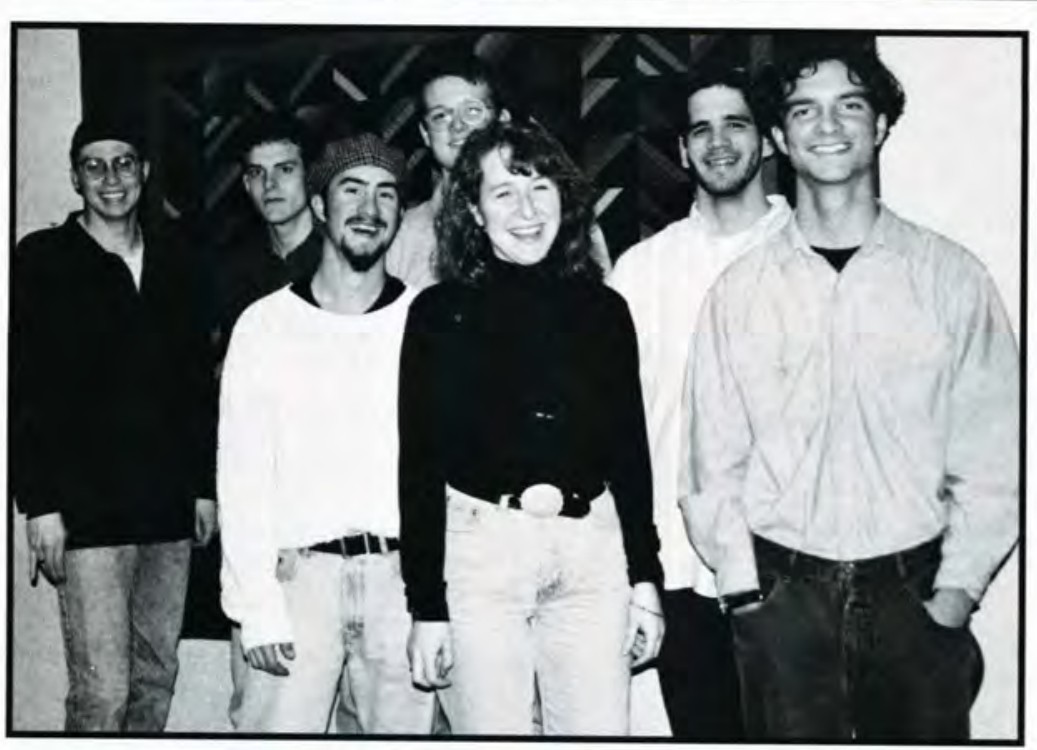

Front row: Zach Pappas, Julie Mulder, John Herrick. Back row: Bob Pontius, Matt Mitchell, Bryan Smith, Jim Swiggart.

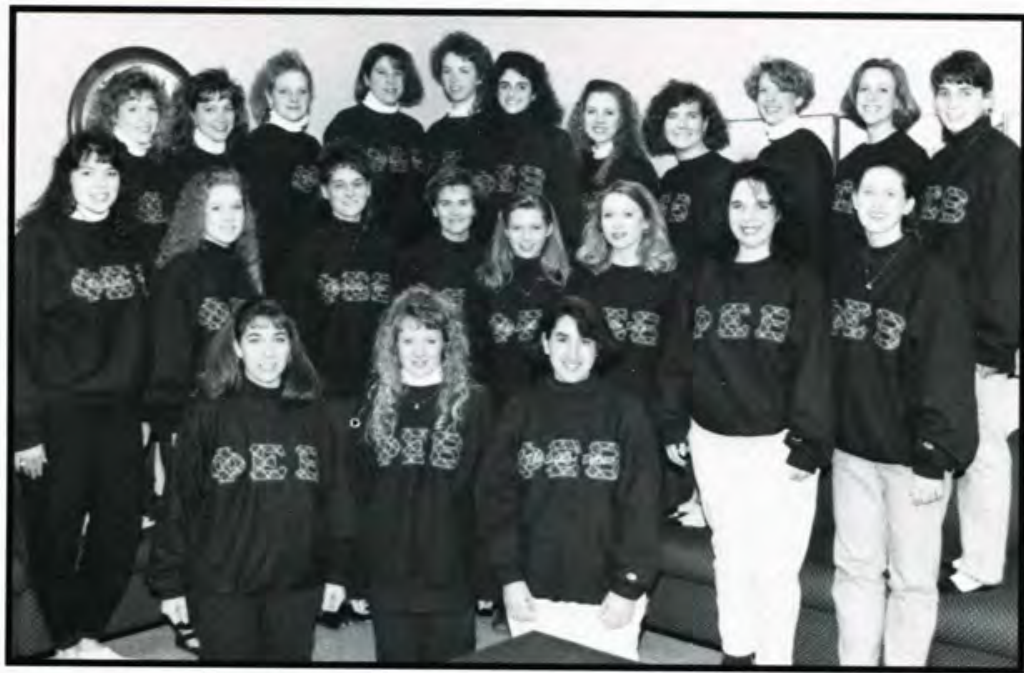

Front row: Melanie Walter, Stephanie Winchip, Rebecca Gerendas. Second row: Annette Fortune, Mindie Rife, Misty Borkholder, Darcey Blenis, Krista Dayton, Laura Richardson, Katie Stull, Joy Brandon. Back row: Kara Ward, Molly Ward, April Johnston, Eliza Gromko, Ruth Heyd, Julie Walker, Karla Richardson, Becky Calvert, Roberta Schmitke, Jennifer Billing, Carmen Bower. Not pictured: Melissa Freeman, Amy Tapp, Abby Boone.

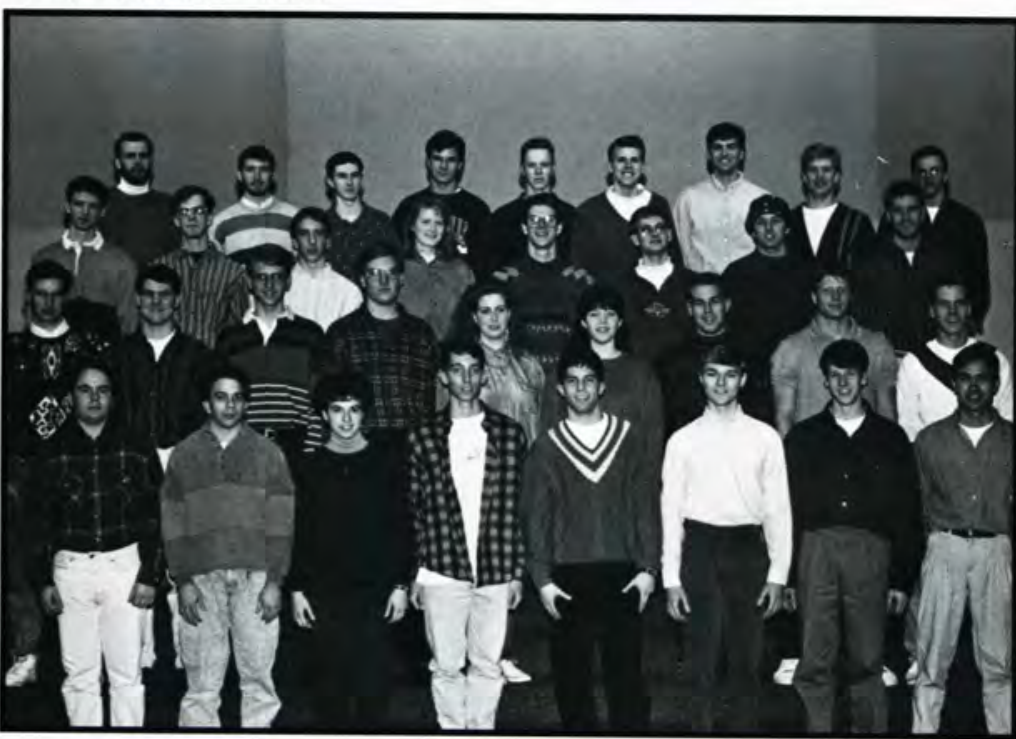

Front Row: Jeff Bingham, Chris Hitz, Beth Blevins, Eric Miller, Nick Awabdy, Adam Ulery, Andrew Shearer, Joe Bowers. Row two: Eric O'Brien, Kenneth Lee, David Preston, Ryan Witters, Cherish Clark, Sara Denlinger, Jeremy Barton, Mark Utz, Jason MacFarlane. Row three: Dale Radcliff, Tim Tuinstra, Kevin Swanson, Chery Miller, Brandon Kaercher, Paul Armour, Matthew Lucas, Kendal Noller. Back row: Brian Cramer, Steve Wurster, Brent McKanna, Matt Benaman, Lee Randall, Scott Hartley, Bill Jariga, Floyd McGriff, Devin Cheek.
FOCUSING ON HIS WORK Marcus Curtis concentrates or precision.

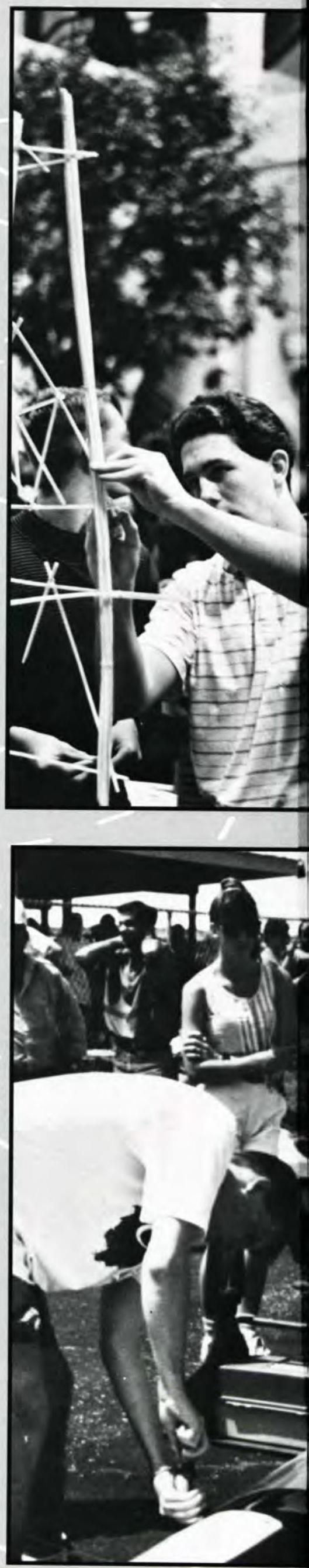



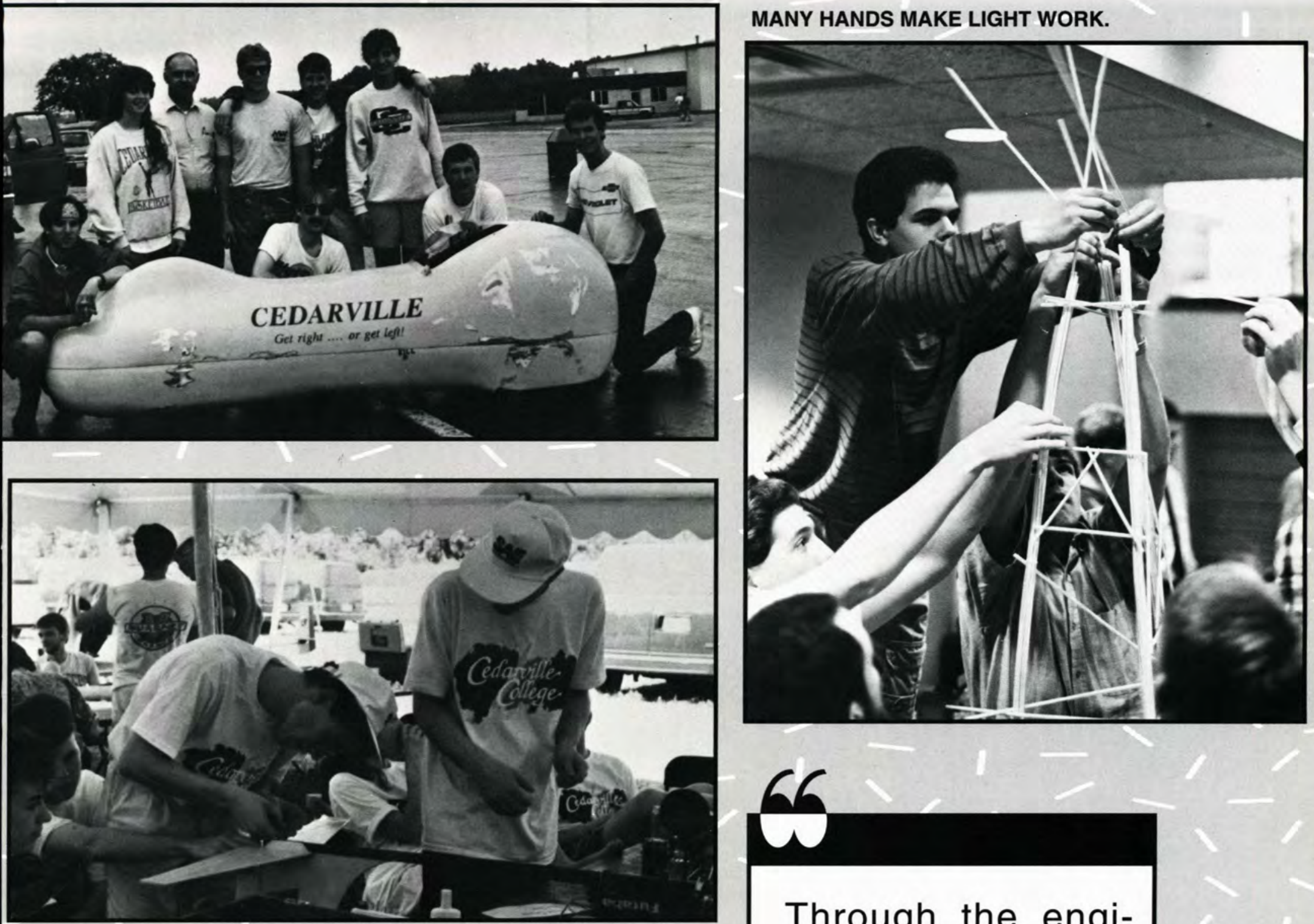

\section{6}

Through the engineers and the challenge of the engineering academics, the SAE conventions bring a positive perspective on the many different fields in engineering. It also shows that there are people out there who actually survived the engineering curriculum. •Nick Awabdy, SAE

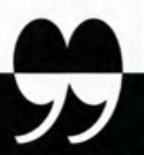


AX TAKES OPPORTUNITY EACH SPRING TO RECOGNIZE A GROUP OF WOMEN WHO EXHIBIT THE QUALITIES THAT AX PROMOTES.

THESE GUYS TAKE A BREAK FROM THE AX SPONSORED LATE SKATE.

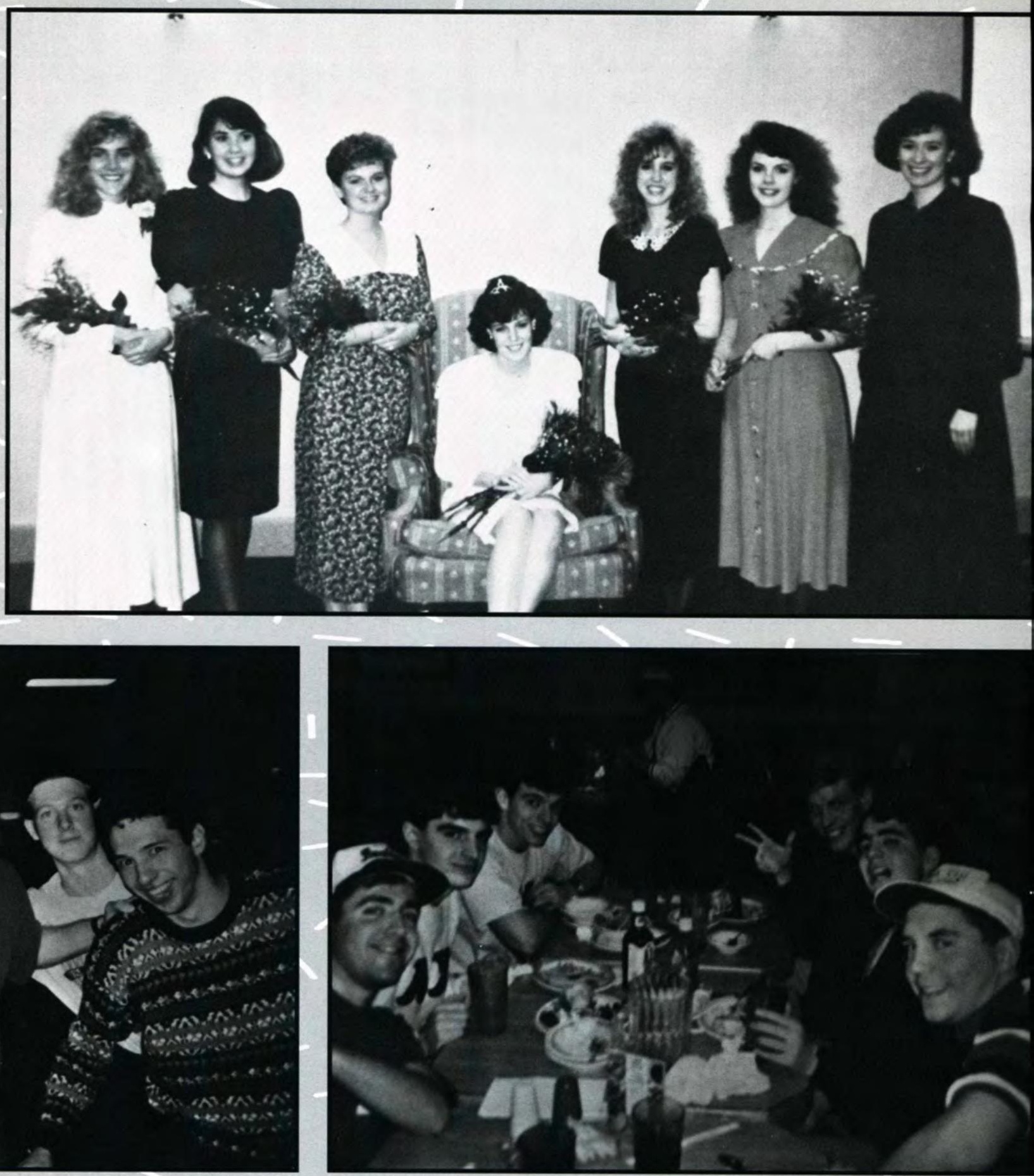

SOME OF THE GUYS ENJOY THEIR NIGHT AT A LOCAL RESTAURANT.

THE AX GUYS WERE ANTICIPATING THE BIG CEDARWHAT? CONVENTION WHERE THE NEW CEDARWHAT? PRESIDENT WOULD BE ANNOUNCED.

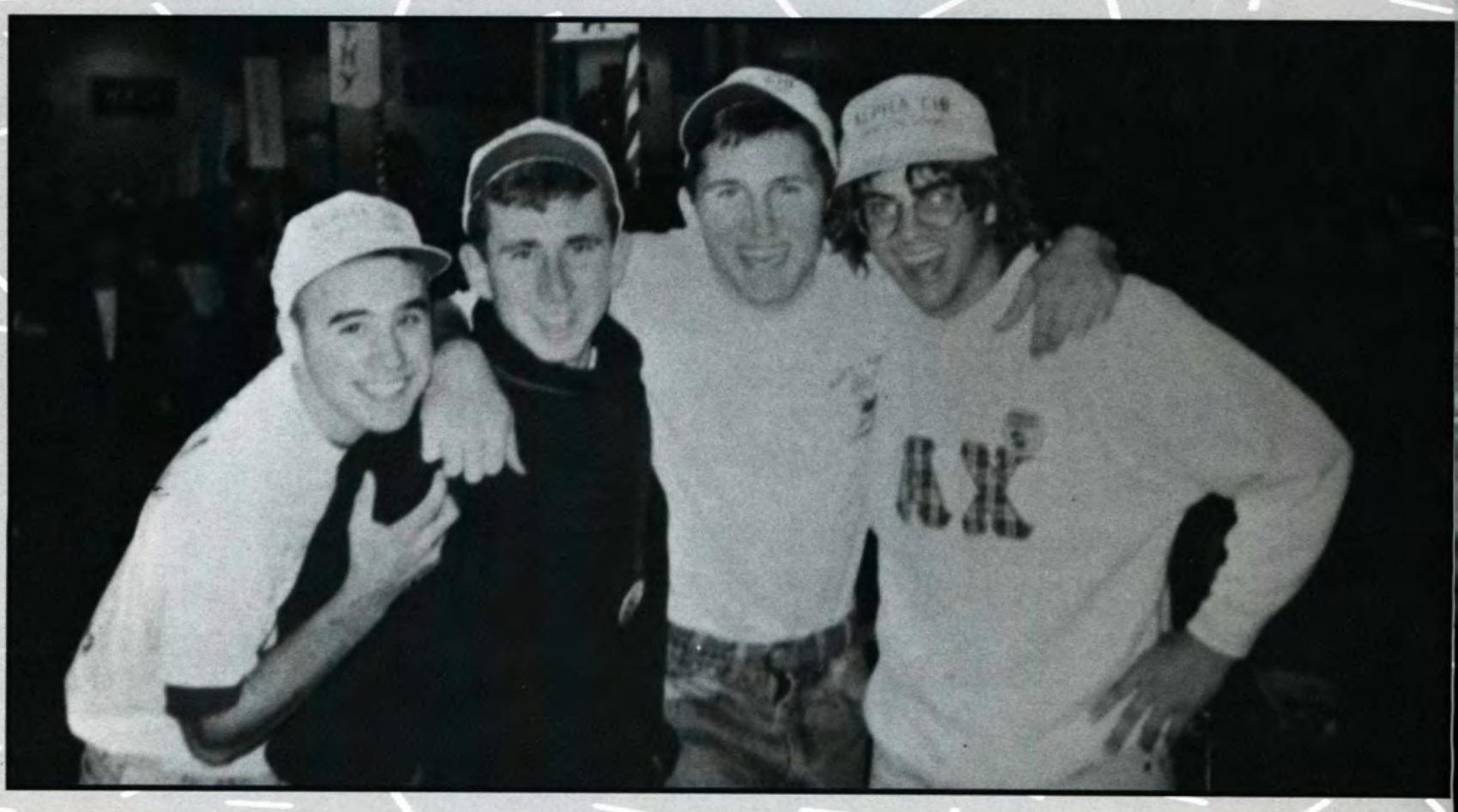




\section{Beta Chi}

Beta Chi is a service organization that provides opportunities for its member who major in broadcasting or are interested in the field. Beta Chi was responsible for the All School Late Night Skate that was held this year. The organization also holds other special activities for its own members such as a fall retreat, a spring camping trip, special speakers for things and occasional trips to TV and radio stations.

\section{CSI}

This year the members of Collegiate Secretaries International have enjoyed numerous activities, including quarterly computer workshop, volunteering at the Crisis Pregnancy Center, and holding a Secretary's Day Banquet for campus secretaries and local church secretaries. The organization is designed to promote interest in the secretarial field and to encourage students in the two-year program to continue their education. CSI provides helpful information and fellowship for students with similar interests in related fields.

\section{MENC}

Professional Music Educators is the collegiate chapter of Music Educators' National Conference. This organization, open to anyone interested in music, strives to keep educators informed of what is currently happening in music education. The members yearly attend a three day conference of music seminars. On the campus they sponsor the PDQ Bach concert and help with the yearly Music Showcase.

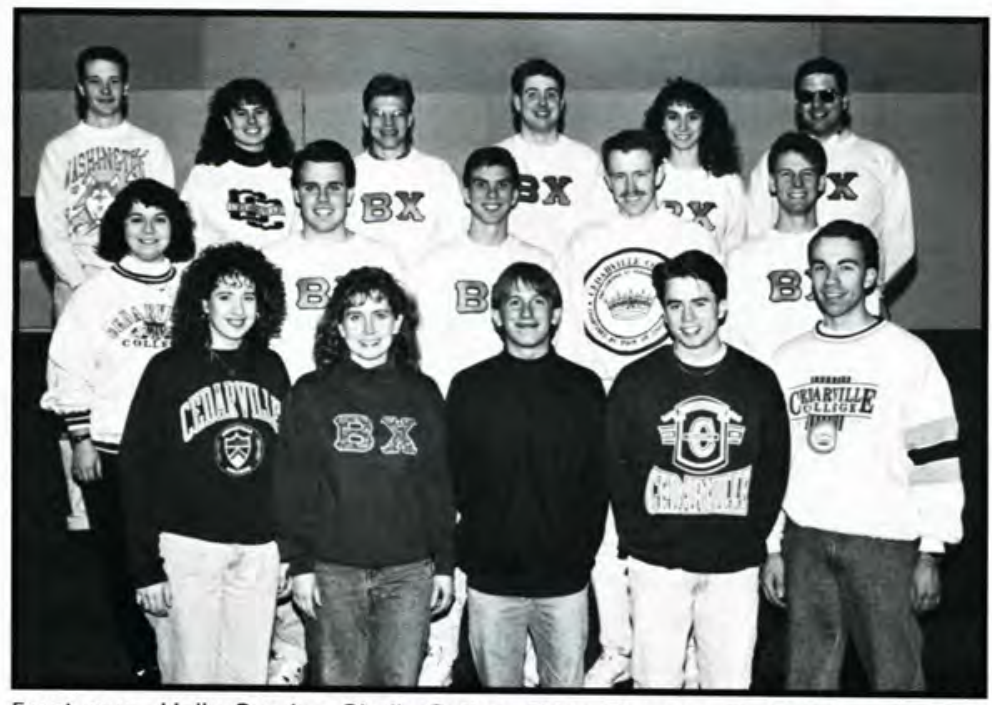

Front row: Holly Snyder, Shelly Sutton, Brian Spencer, Todd Carrer, Derran Reebel. Row two: Stephanie Saville, Stephen Kellogg, Mark Zuiderveen, Rich Doese, Bill Montgomery. Back row: Keith Hamer, Mary Sweetland, Eric Cochran, Tom Mathisen, Leah Rosenvold, Ray Izard.

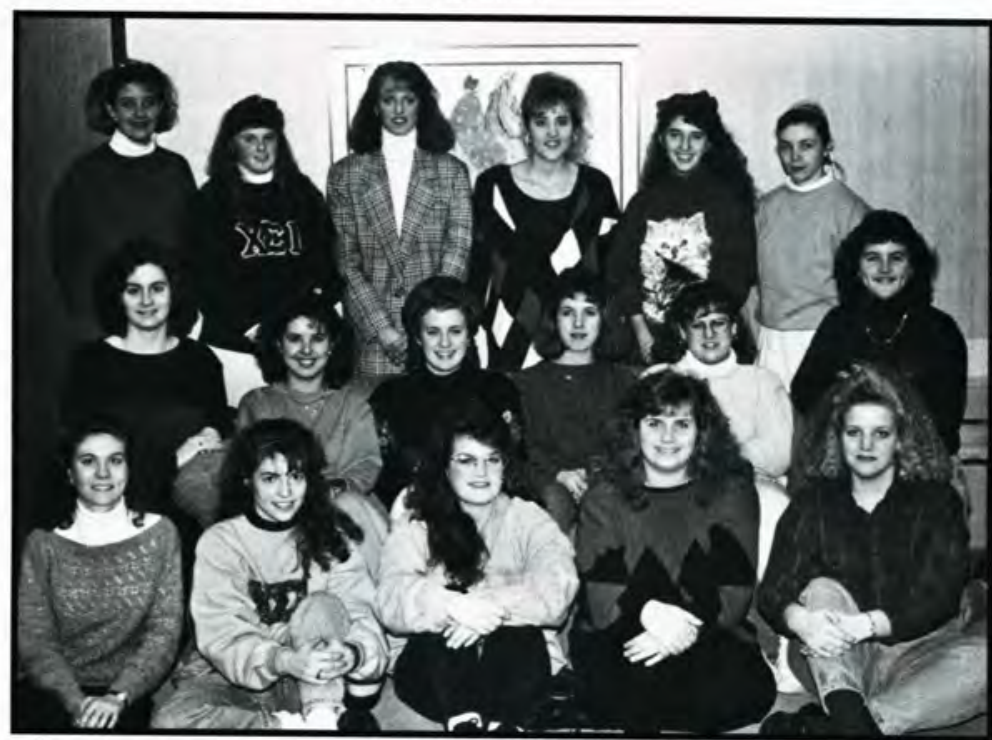

Front row: Rebecca Scott, Leah Halsey, Andrea Mullins, Cheryl Lynn Deinum, April Johnston. Second row: Rachel Creekmur, Jenny Hartenstein, Missy Harner, Abby McQueen, Lisa Lightly, Nicole Brubaker. Back row: Cathy Lubbers, Kris Thorsen, Deanna Osborn, Becky Seguin, Beckie Suko, Dorthy Marner.

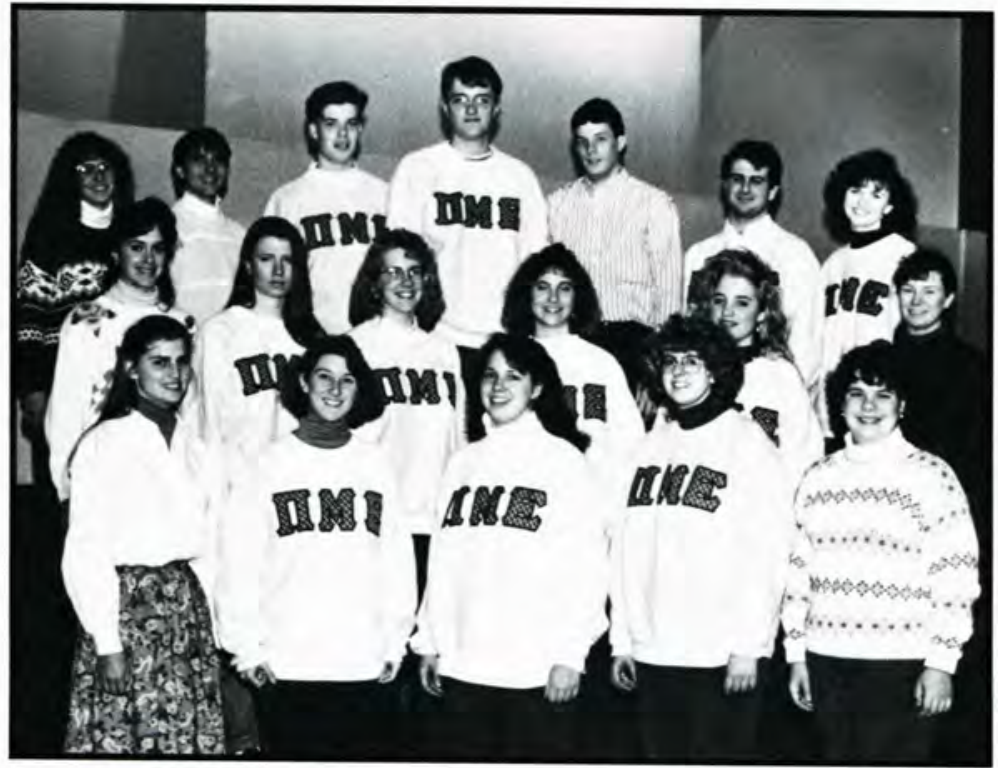

Front row: Wendy Herr, Jaimee Potter, Jennifer Henry, Elissa Heale, Laura Maki. Second row: Tracie Dennison, Doralee Peterson, Susan Shrimp, Lori Kate Lowenhar, Taryn Campbell, Jenifer Bork. Back row: Mindy McPherson, John Misere, Ryan Huebner, Keith Watson, Stephen Wintle, Brian Megilligan, Marne Loomis.

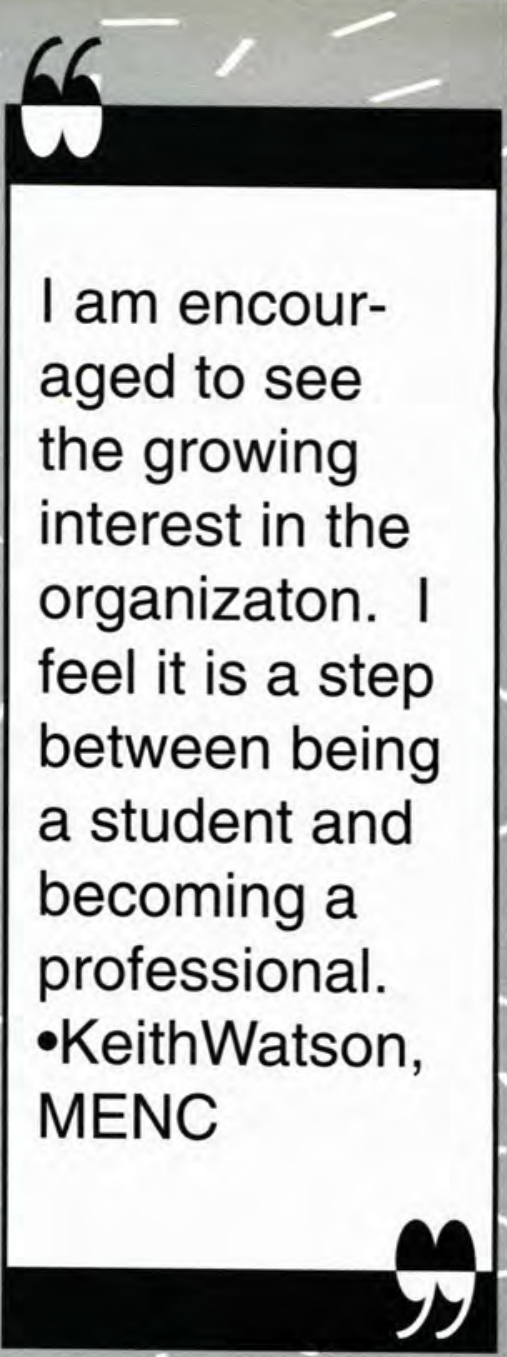

\section{aged to see} the growing interest in the organizaton. I feel it is a step between being a student and becoming a professional. -KeithWatson, MENC 


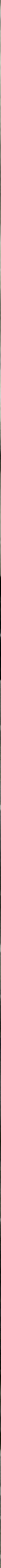




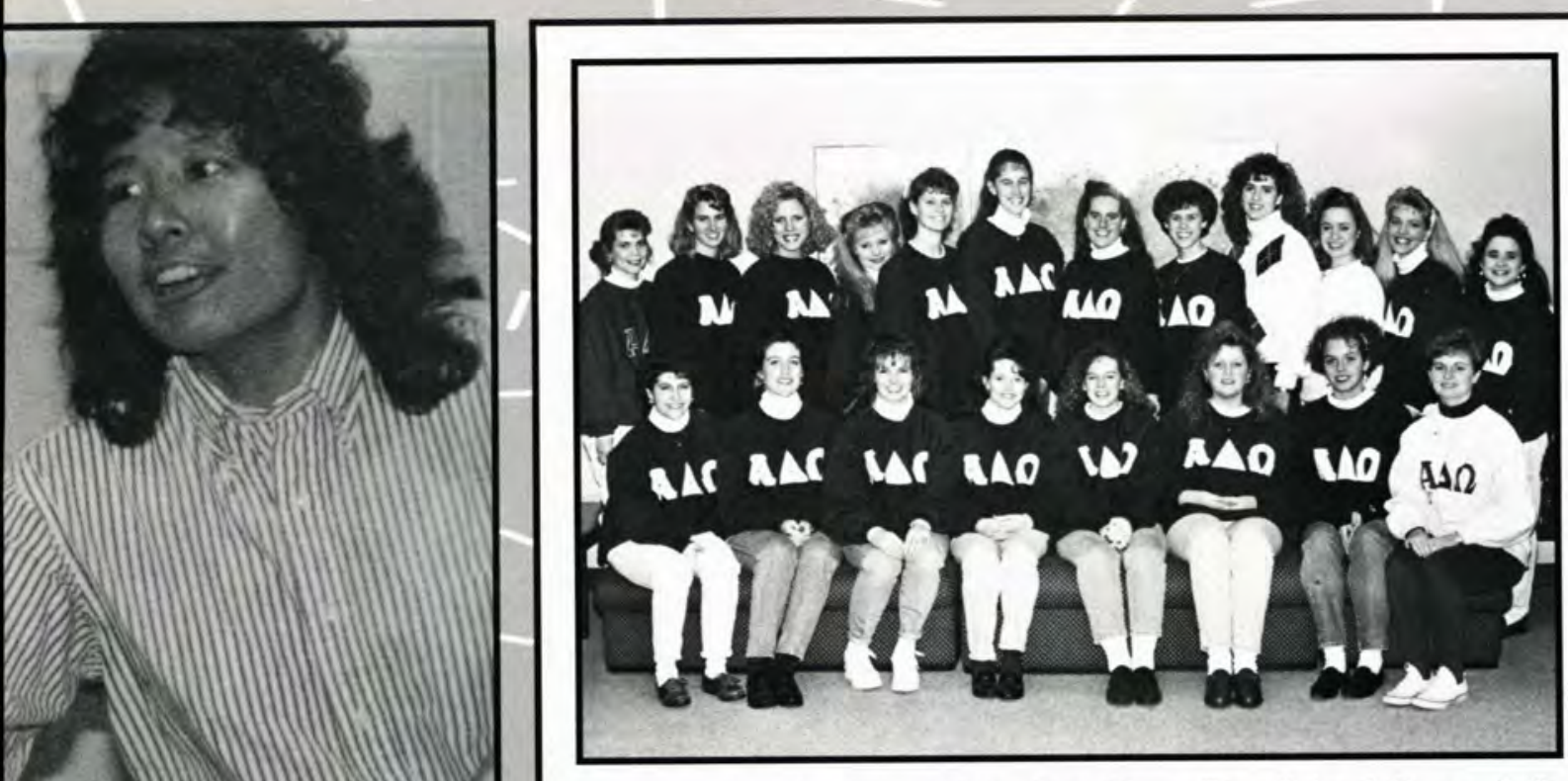

Front row: Jennifer Horton, Kristine Post, Sheryn Titus, Deborah Cruver, April Seely, Holly Kay Murray, Shelly Souza, Susan Beach. Back row: Michelle Yates, Kathleen Gasparro, Angela Hunsberger, Lynn Skinner, Christy Southwell, Cindy Hasselbring, Tammy Clark, Jenine Hyten, Dana Thompson, Carrie Grayson, Sandy Rinehart, Stacy Smith. Not pictured: Rachel Cain, Stephanie Sherman, Keila Whittaker.

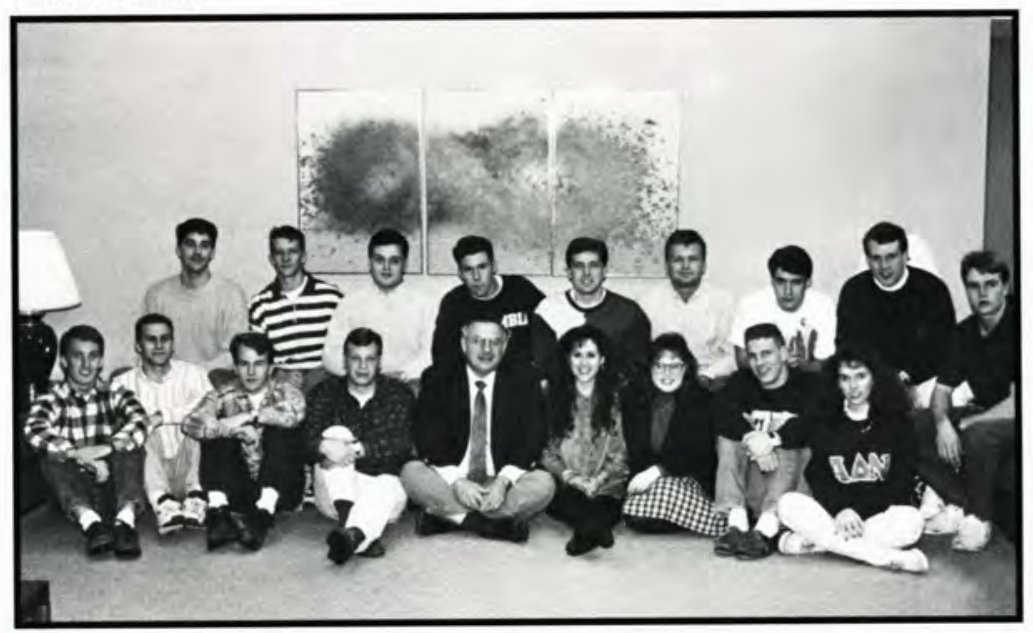

Front row: Sean Godden, Chad Parrow, Lon Erchison, Jeff Beiler, Robert Wiggins, Heidi Keefer, Stephanie McChesney, Stephen Meigs, Dani Madding. Back row: David Ross, Aaron Hiebert, Tim Roop, Todd Breneman, Thomas Halsted, Tom Karrels, Clint Smith, Jeff Cone, Joe Cunningham.

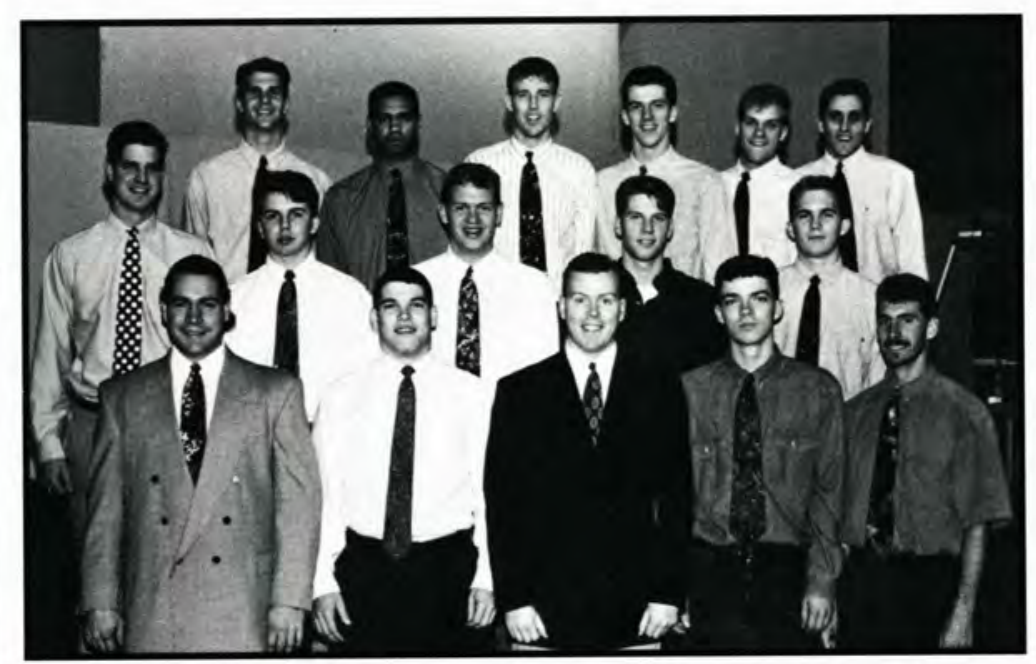

Front row: Rob Christman, Casey Wood, Jonathan Edgerton, Bill Curry, Kevin Conkel. Second row: Matthew Reynolds, Bob Burns, Randy Joiner, Jeff Rohm, Warren B. Sayre. Back row; Robb Barnum, Helder Seabra, Nathan Elmore, Tim Trow, Bradley Palmer, Rob Tonelli.

\section{Alpha Delta Omega}

Alpha Delta Omega is a Christian service organization for women. The goal of this organization is for members to strive for excellence in developing their person wholistically. The "Alpha" and "Omega" reflect the group's desire to make Christ the beginning and end of every area of their lives. ADO focuses on service outreach to the student body and the community through projects such as Barney's Week, Project Angel Tree, and "Cupid's Bash," which they sponsor each year with DOE.

\section{Alpha Delta Nu}

Alpha Delta Nu is a new organization that began in the spring of 1992. The emphasis of this organization is on criminal justice and is open to anyone who is interested in the field of law enforcement or public administration. This year ADN has given members opportunities for exposure to law officers from federal, state, and local districts. Alpha Delta Nu focuses on the problems of today by spending time with law officers and learning more about solutions to some of the problems.

\section{DOE}

The letters in the name of the men's organization DOE stand for discipline, obedience, and excellence. DOE provides fellowship for members in addition to the social and service benefits they provide for the college through various projects and activities. DOE serves the college by hosting such activities as the "Cupid's Bash," participating in the Homecoming Parade and the Organizational Fair. Also, DOE sponsored the all night softball marathon in which teams from both the college and the community participated.

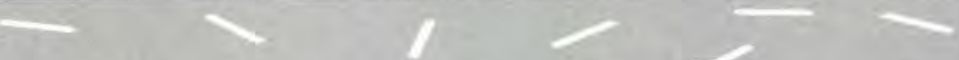




\section{Epsilon Alpha Pi}

As the name Epsilon Alpha $\mathrm{Pi}$ indicates, the emphasis of this social work organization is "working good to all." The group seeks to promote professional development, social awareness, and community outreach. Epsilon Alpha Pi has met peoples' needs by being involved in numerous service activities. Students had the opportunity to participate in National Volunteer Day, donate items to the homeless, sponsor children from Compassion International, and many other ministries.

\section{Pi Delta}

On a regular basis, groups of prospective students, youth leaders, and parents can be seen moving around campus from chapel to the cafeteria to the bookstore. Leading these groups is a fearless member of Pi Delta, who takes time out of his or her busy schedule to show off Cedarville College. This volunteer organization serves as the official host to campus guests. Only students with enthusiasm for the college, excellent communication skills, and professionalism are chosen as members of PiDelta.

\section{Society for Human Resource Management}

The Society for Human Resource Management provides its members with many opportunities to meet professionals and make business contacts in Human Resource Management. At their bimonthly meetings, the members of the $\mathrm{Ce}$ darville chapter of this national organization interview with people who have already had internships, and they discuss current business topics and activities such as their recent tour of the Honda plant. As a step into the professional world, members can sometimes arrange "shadow days" when they accompany a professional through his/her day's experiences.

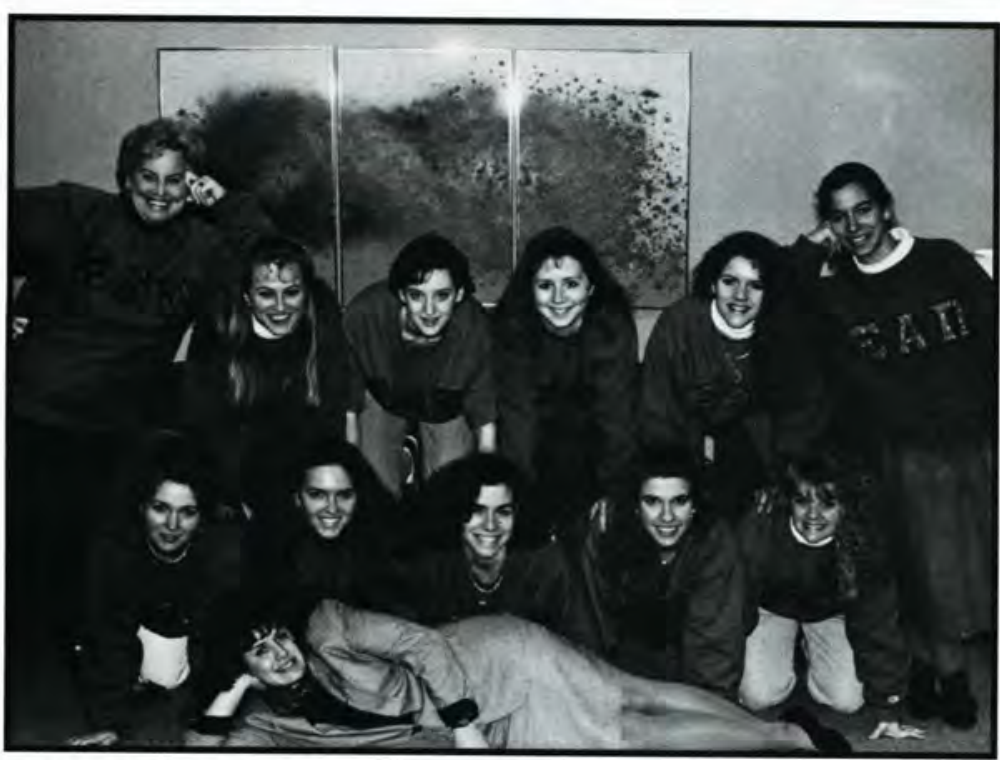

Front row: Jennifer Sloan, Gwendolyn Beebe, Nichole Bouchard, Leah Stanley Kim Geremia, Cindy Sutter, advisor. Second row: Beverly McComb Davies, Sharon Piper, Lindsay Hamel, Rita Swartzetruber, Lori Shaw, Charlene Yoder.

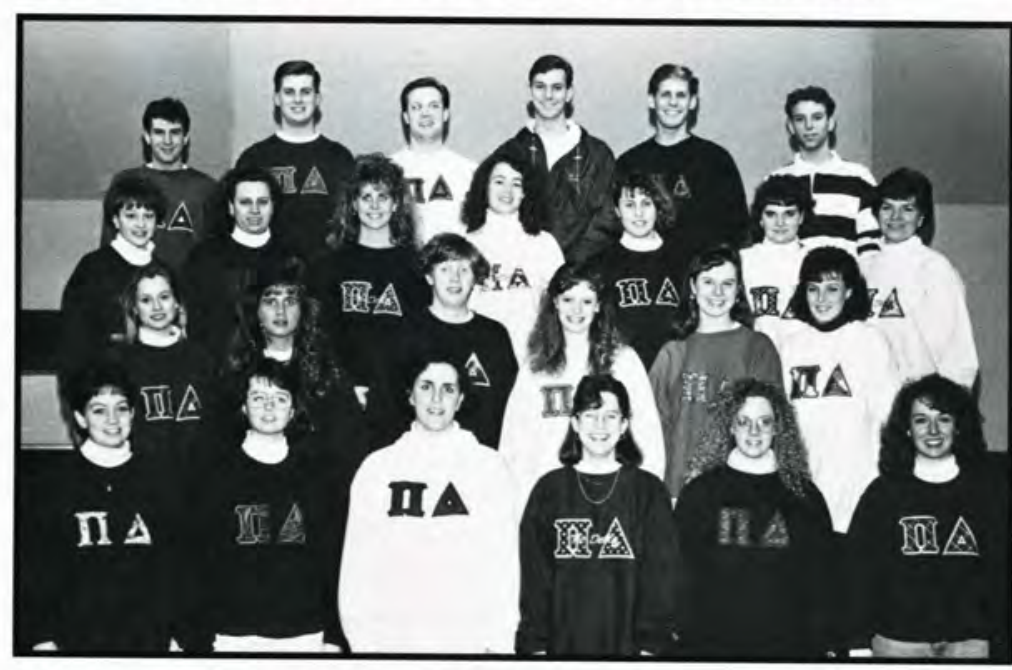

Front row: Debbie Perkins, Brenda Killian, Kirsten Gibbs, Emily Jagger, Tamara Wymer, Dana Gosser. Row two: Amy Riniker, Debbie Henry, Paige Wolfanger, Mandi Secord, Jean Kurtz, Sheri Leeds. Row three: Heather Rifenberick, Dawn Pangburn, Dana Daniels, Kristi VanDyke, Beverly Check, Shelly Heldreth, Denise Uhl. Back row: Jim Foster, Matt Brown, Mark Holsinger, Mark Vroegop, Dave Bates, Nathan Dobert.

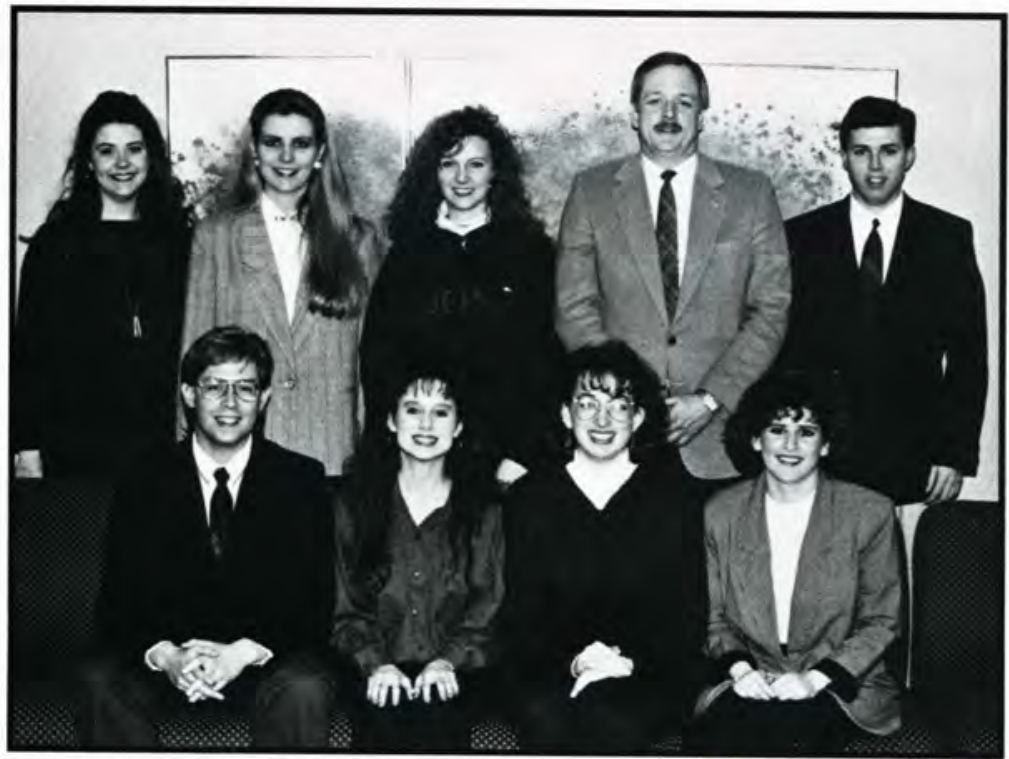

Front row: Mitch Hall, Apryl Hoover, Lisa Barnitz, Julie Buentello. Back row: Jolie Sissom, Vivian Borges de Moraes, Andra Traucht, Kurt Moreland, Advisor, Jim Edgerton.
EPSILON ALPHA PI HELPED GREENE COUNTY DOMESTIC VIOLENCE PROJECT IN NATIONAL "MAKE A DIFFERENCE DAY."

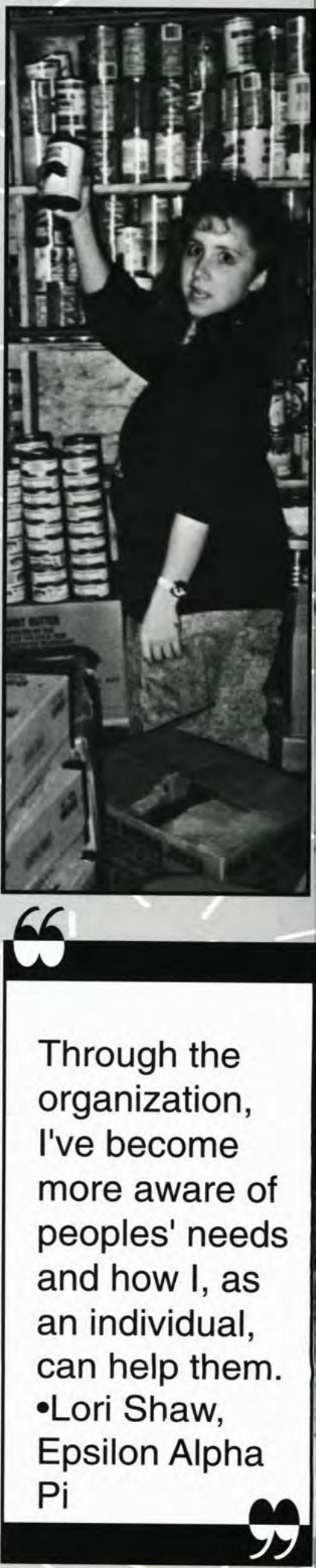


$\begin{array}{ll} & \text { UNAFRAID TO WEAR HER } \\ \text { JOINING IN THE CHANT!! } & \begin{array}{l}\text { SUPPORT, Shelly Souza loves } \\ \text { Bush-Quayle. }\end{array}\end{array}$
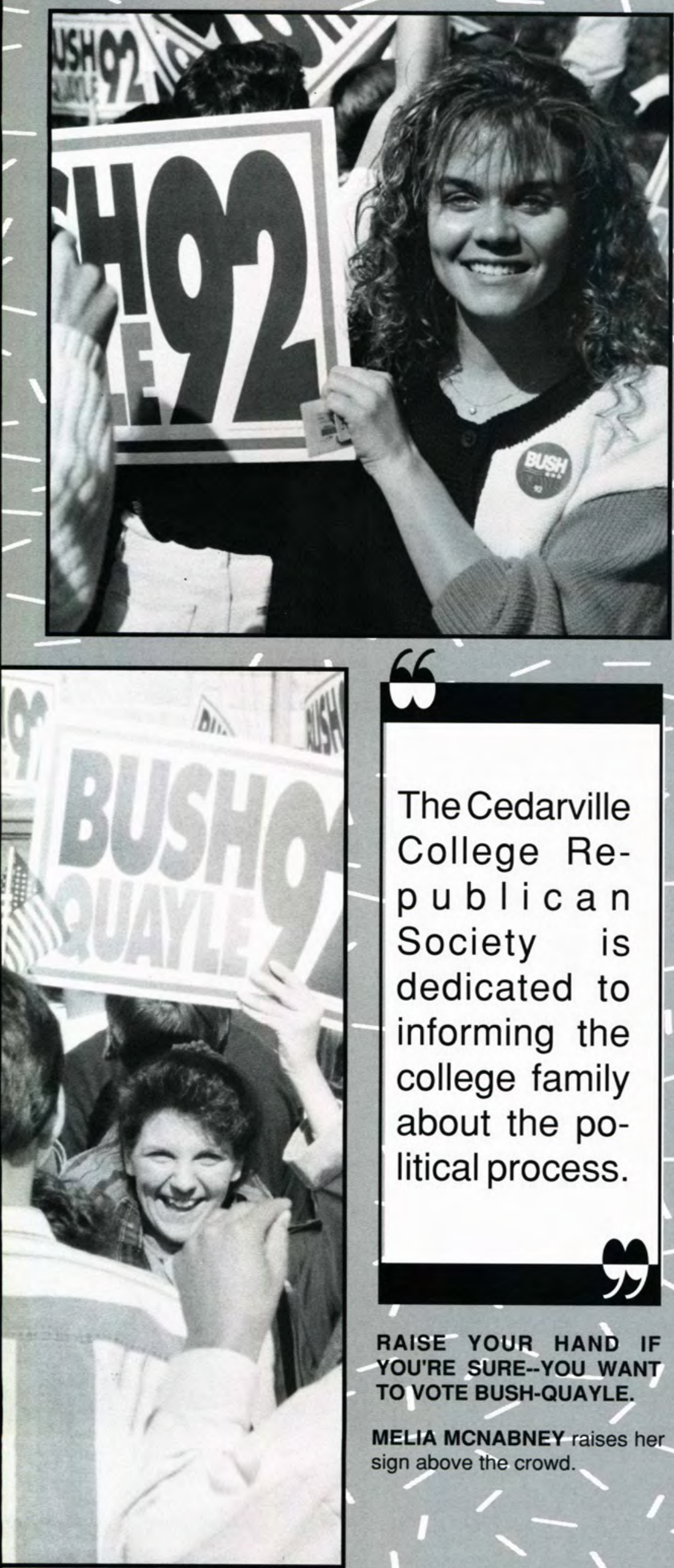

88) Organizations

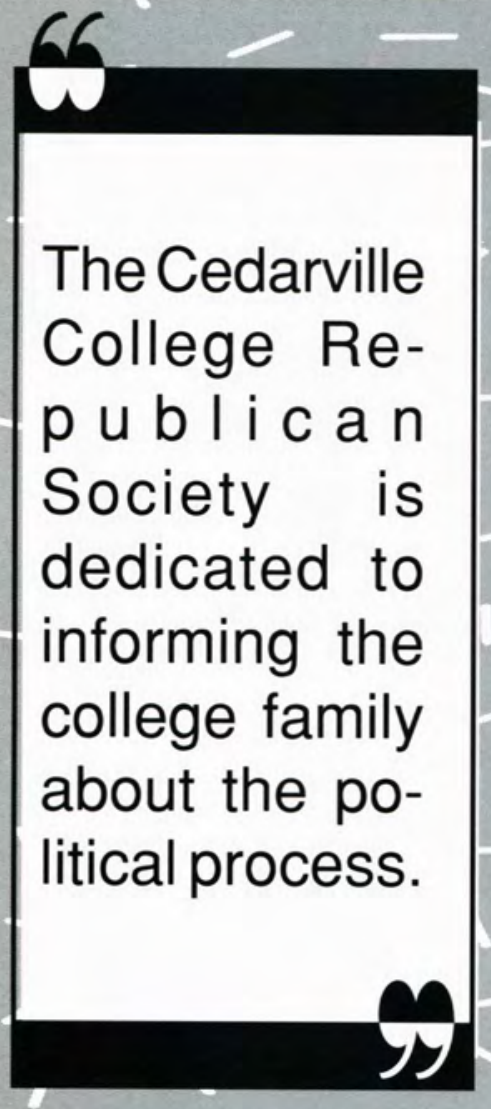

RAISE YOUR HAND IF YOU'RE SURE--YOU WANT TO VOTE BUSH-QUAYLE.

MELIA MCNABNEY raises her sign above the crowd.

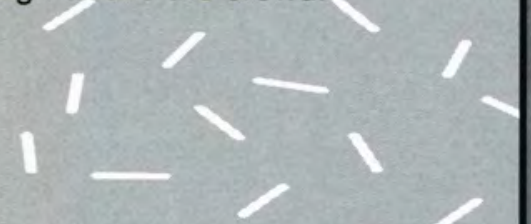

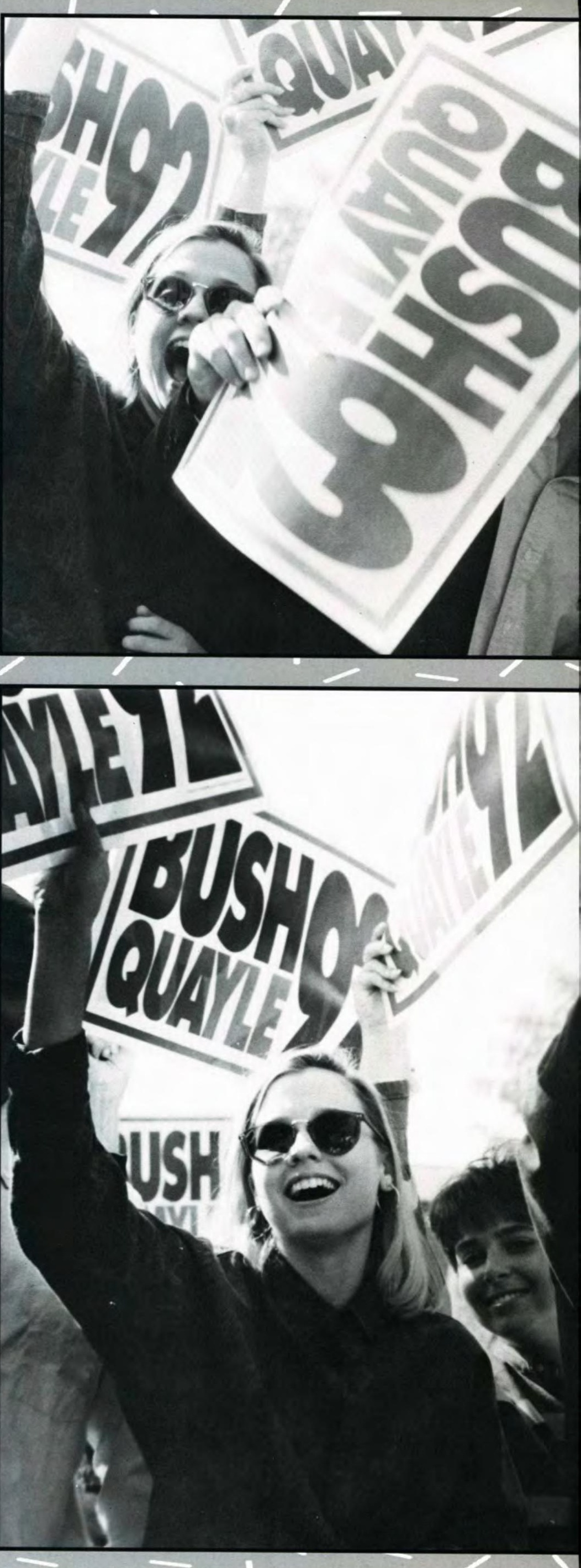




\section{Phi Gamma Psi}

Phi Gamma Psi was formed to promote social interaction for women on Cedarville Campus. The members of this organization desire to minister to one another by getting to know each other during their alternating prayer meetings and business meetings held each week. These women sponsor the biannual Masquerade Party and participate in Barney's Week, Hunger Awareness Week, community services and the Organizational Fair.

\section{Pi Sigma Nu}

$\mathrm{Pi} \mathrm{Sig}$ is a social fraternity which seeks to develop a devoted camaraderie among its members, who commonly refer to each other as brothers. PiSigaccomplishes this brotherhood by holding weekly meetings, Bible studies, social outings each quarter, camping and white water rafting trips, and, of course, pledging.

\section{Delta Chi}

A new organization this year, Delta Chi is a welcome addition to the lives of many secondary education majors. This organization brings together those secondary majors from several disciplines. Members of this organization seek to prepare themselves to be professional and to be community servants. Prayer support for the Education Department, student teachers and area eductors is a priority for Delta Chi.

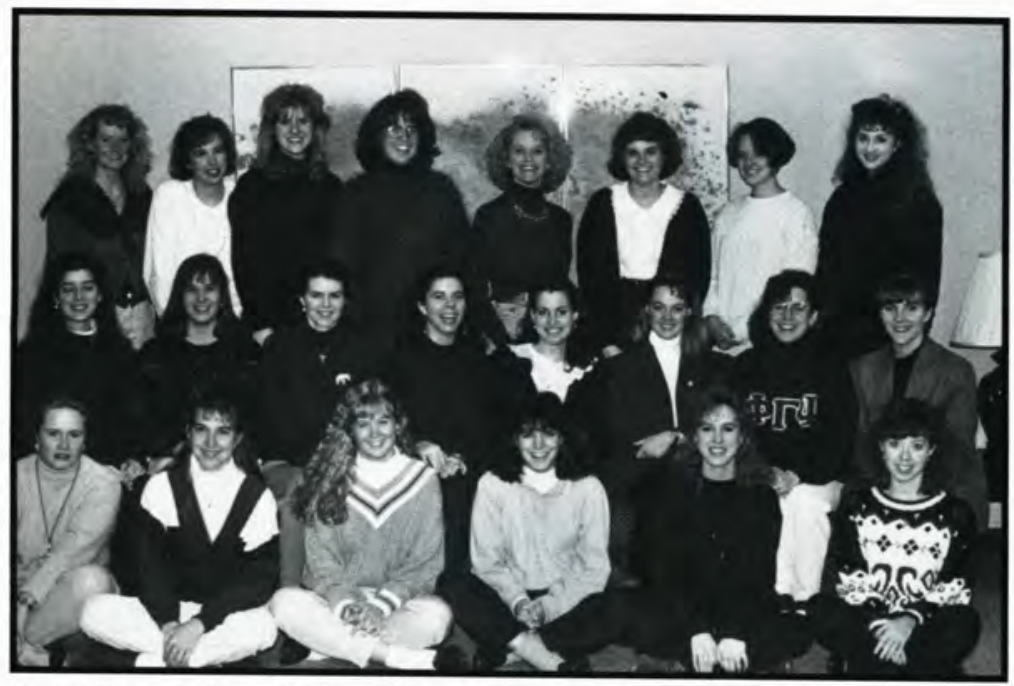

Front row: Debbie Koch, Melanie Ras, Carrie Scott, Debbie Richard, Allison Knowles, Sandra Waddell. Second row: Michelle Ferrigno, Carmen Hunt, Jenny Rotroff, Angela Nettleingham, Abbe Beach, Tiffany Beheler, Emily Jagger, Tracy Quinn. Back row: Tami Haberstich, Mag Hoffmann, Dawn Ambrose, Melinda McDugle, Susanne Justice, Shelly Heldreth, Jennifer Shriver, Julie Burns.

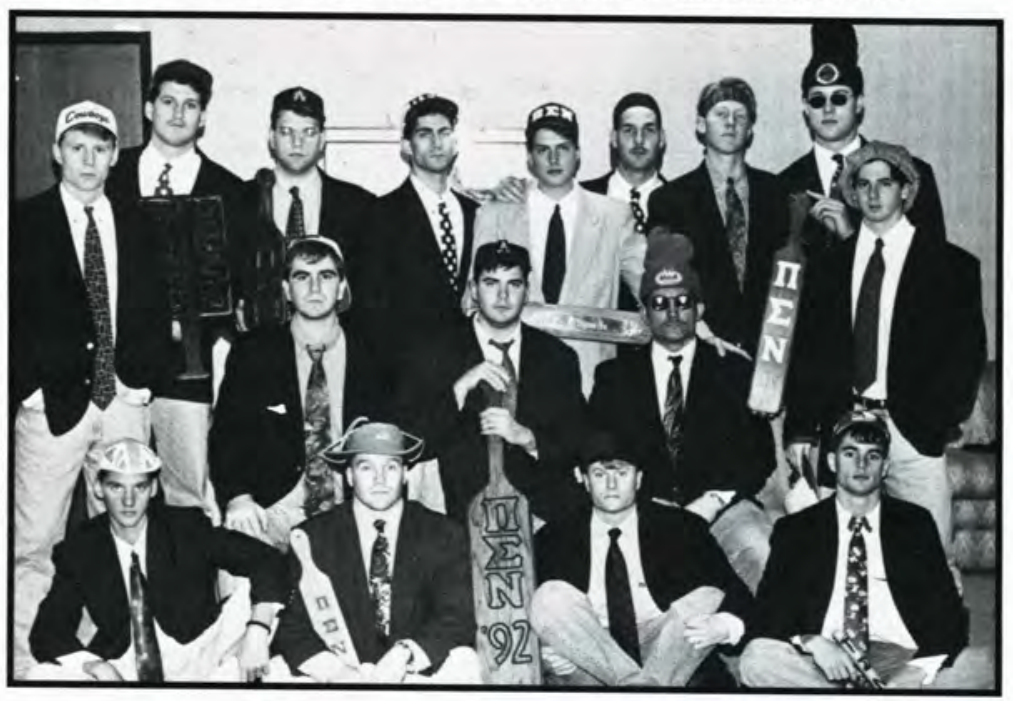

Front row: Skippy Gardner, Paul Melvin, Link "Will the Thrill" Milligan. Second row: Tom tutone Kadamus, Jack Greenly, Helmet, Chico Dego Marzano. Back row: John Snake Keenan, Tim "Ping" Lee, Stewy, Jim Hanssen, Pad6, Kevin "Roach" Rotramel, Todd "Arnold" Seljan.

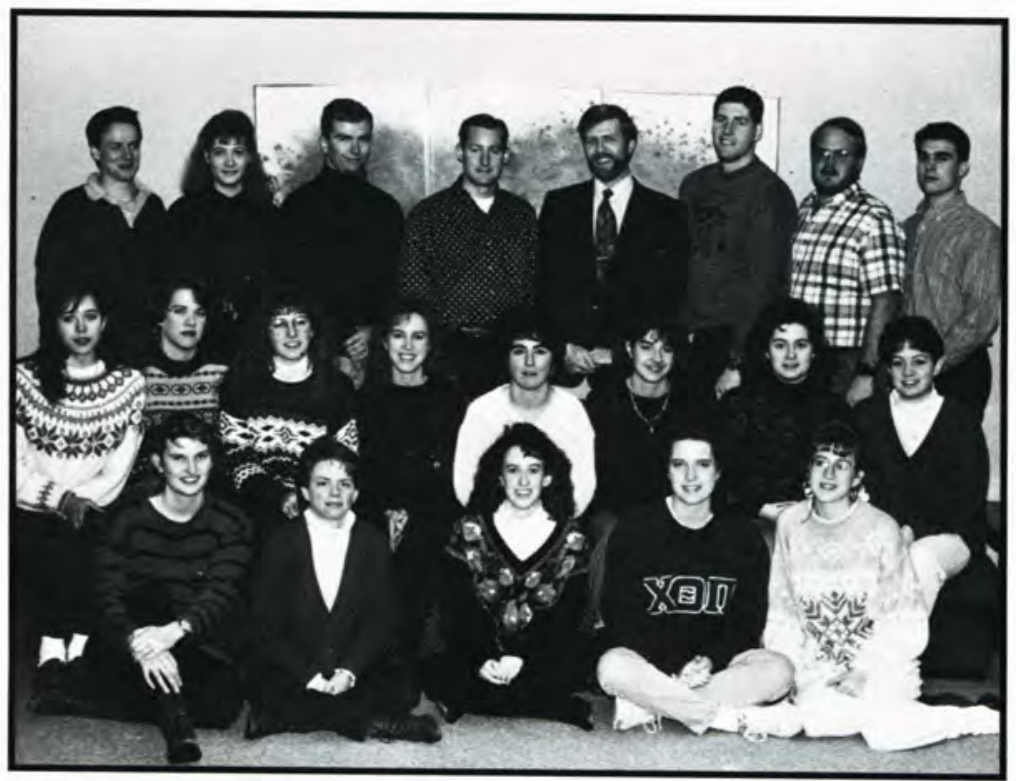

Front row: Mary Jo Brooks, Veronica Mower, Ruth Wenger, Dana Hull, Beth Greist. Second row: Jennifer Call, Rachel McDonald, Mindy McPherson, Allison Knowles, Shelly M. Fiorito, Cathy Noble, Rachel Creekmur, Debbie Perkins. Back row: David Thigpen, Lynn Walter, Tim Edsell, Matt Brady, Phil Bassett, Jeff Hunter, Donald Shade, Kevin Snow.
THE MEMBERS OF PHI EPSILON BETA PARTICIPATE IN THE EVENING'S MYSTERIOUS WHO-DUN-IT. 
We seek to prepare ourselves to be more effective Christian educators through social interaction, professional stimulation and community service. -Matt Brady Delta Chi
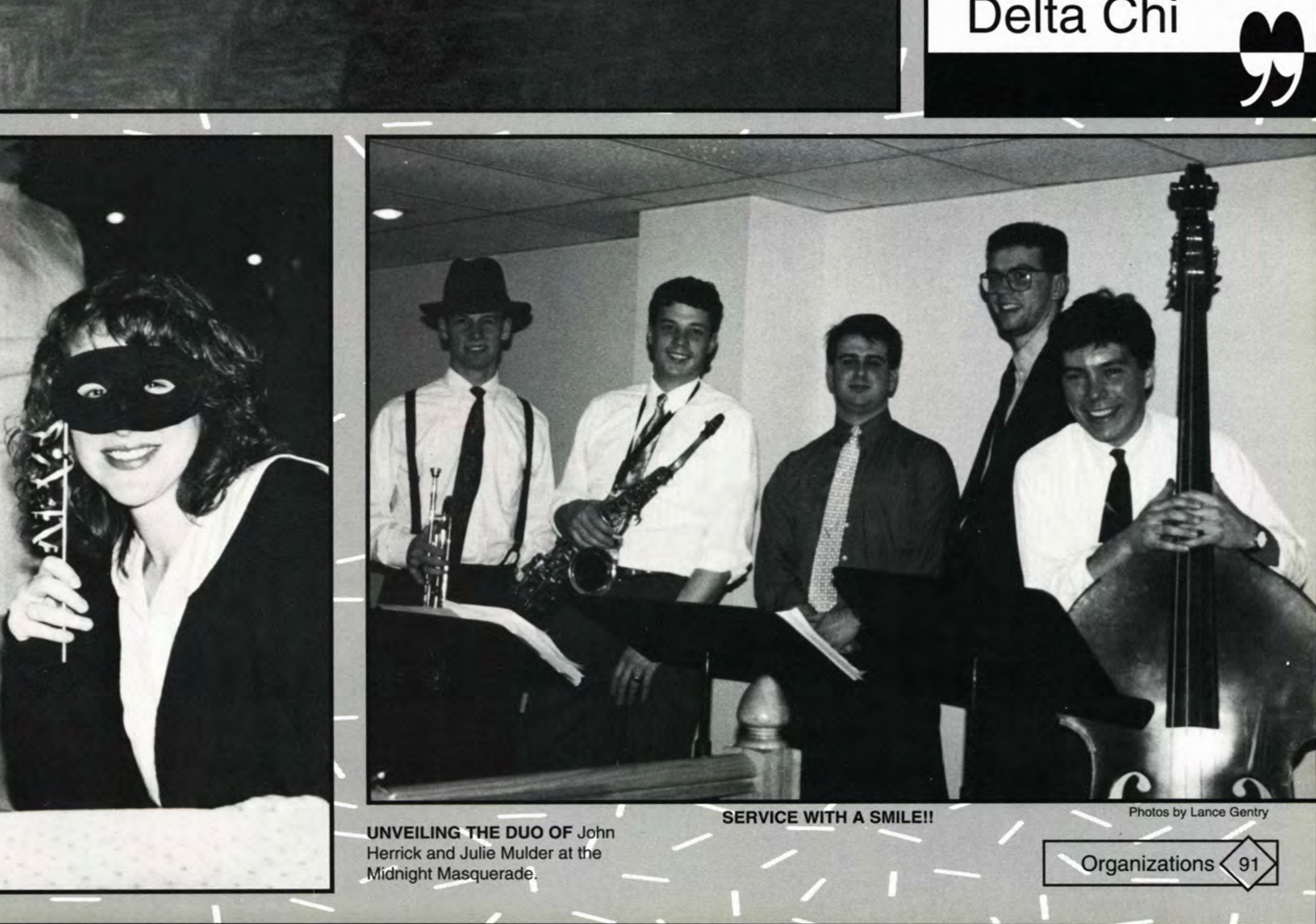


\section{CEDARS}

\section{Combining Commitment and Creativity}

Cedars, the newspaper of Cedarville College, requires the input of many individuals with varied talents. Since Cedars is a bi-weekly publication, the members of the staff spend approximately every other week generating the material they need for an issue. The alternating weeks are then spent editing, designing layouts, and publishing.

Putting an extra strand of creativity into each issue of the paper becomes a difficult challenge for all. One new aspect of the paper this year has been the addition of Glowmer to the staff. His column has brought a creative twist to the happenings in Cedarville. In fact, polls show that most students read Glowmer right after the ever-popular SideWalk Talk.

Before creativity or humor, however, the staff has committed themselves to producing a quality publication. Each issue of Cedars includes a statement of their primary goal: "Committed to the pursuit of excellence, Cedars will continually strive to honor and glorify our Lord Jesus Christ." -Marsha Olsen
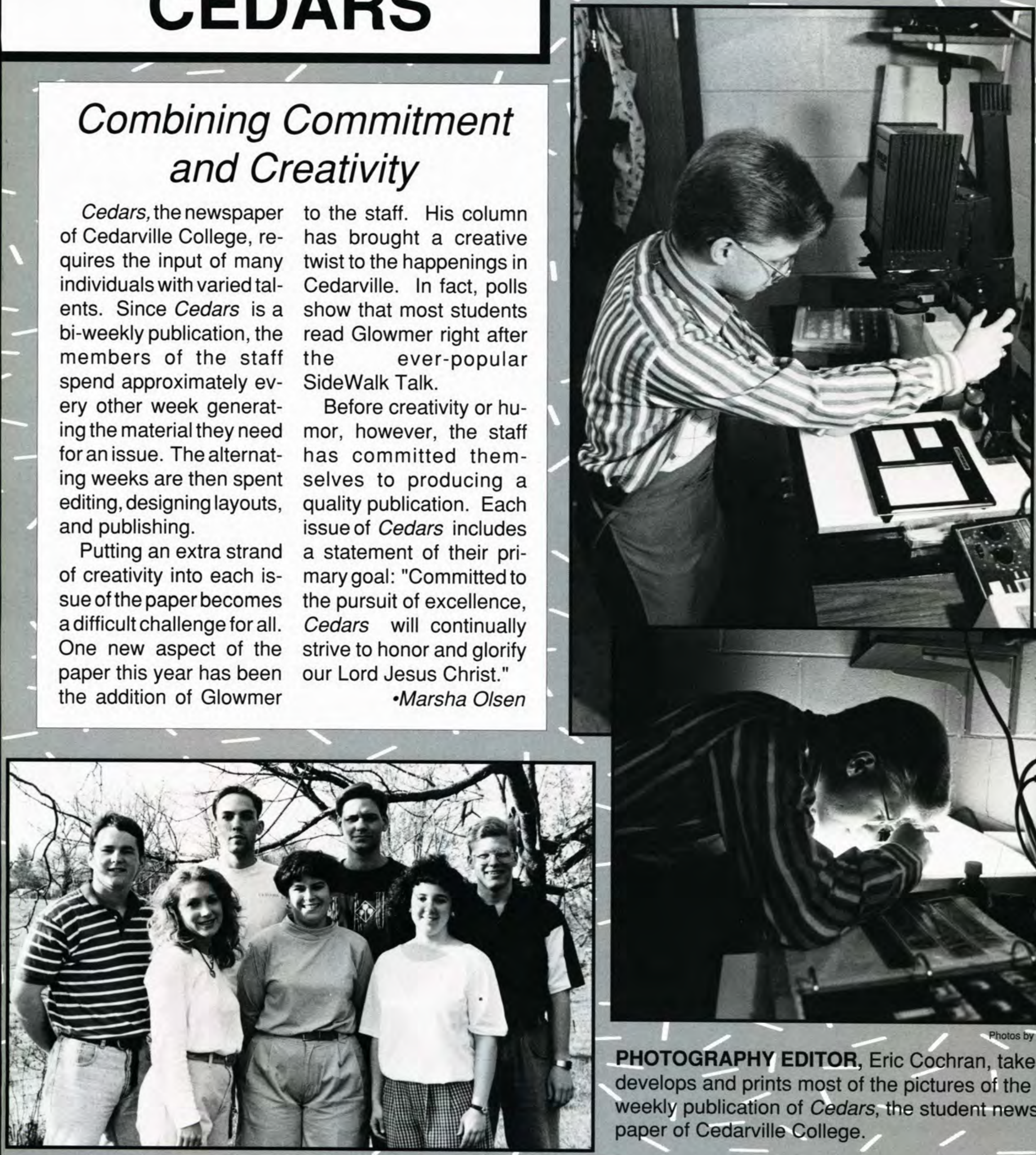

PHOTOGRAPHY EDITOR, Eric Cochran, takes develops and prints most of the pictures of the biweekly publication of Cedars, the student news- $f$ paper of Cedarville College.

Front row: Laura Richardson, Jennifer Ross, Cheryl Davis. Back row: Brian Bales, Pat Riner, Jay Ross, Eric Cochran. 


\section{WSRN}

"Good Morning; It's the campus into bed at straight up 6 o'clock. I'm night. Mornings feature MarkButton. You're listen- the campus' favorite trivia ing to AM 530, WSRN! show, "Dialing for DoHere's a 'Current Cut' by MichaelEnglish, "'Take the Time."'WSRN, the student radio network of Cedarville College, begins another broadcast day from their studios high atop Collins Hall. The radio station is run by students under the supervision of advisor Mr. Jim Leightenheimer. Broadcasting majors, as well as those in Com Arts and various other majors, do not just get practical lab experience, but they actually run a real radio station. Their responsibilities include station management, production, promotions, sales, and announcing.

Early mornings and late nights are the curse of the radio announcer: getting up in time to remind the rooster to crow and staying up long enough to tuck

nuts," where the winner receives donuts from Young's Dairy. WSRNhas many evening feature shows including "The Monday Night Kickoff," "Christian Music Weekly," "Now That's Music," and the longest running show on WSRN, "The Latebreak Request Show."

The staff at WSRN is dedicated to quality radio broadcasting that will glorify God and encourage the student body. They prove this through many hours of dedicated service. Serving the student body with radio programming and station remotes across campus allows WSRN to stay on the cutting edge of the broadcasting industry, preparing the graduates for entrance into the job market. -Bill Montgomery

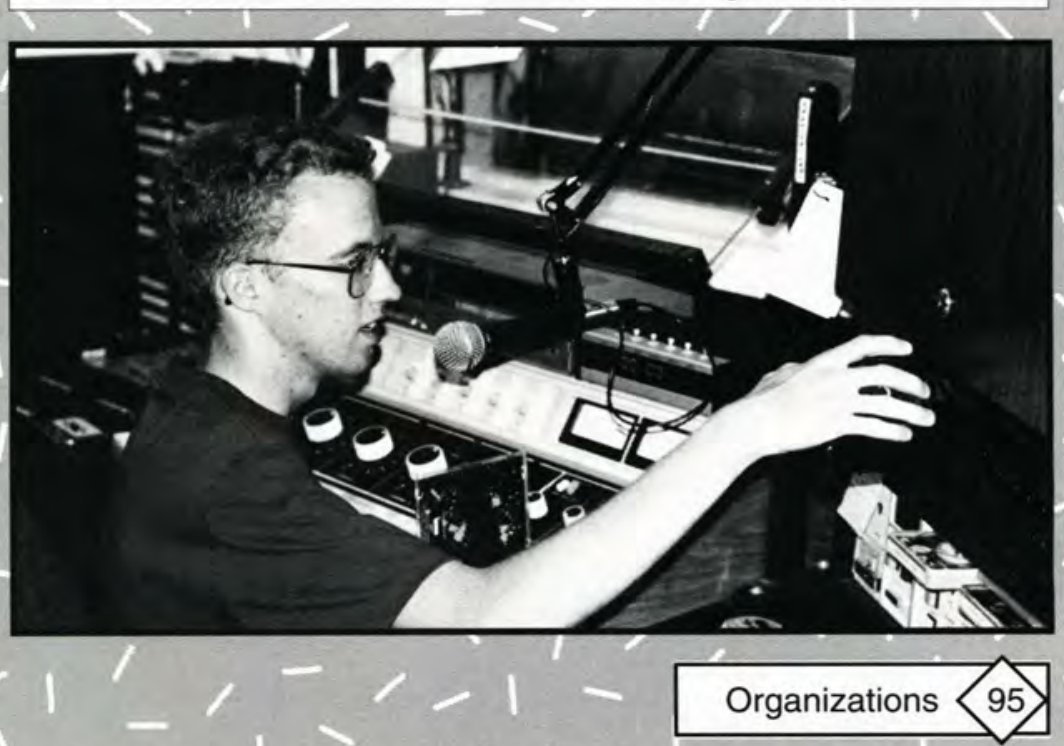


IN FRESHMAN CLASS CHAPEL, Mark Totten shares his heart with the freshman calss.

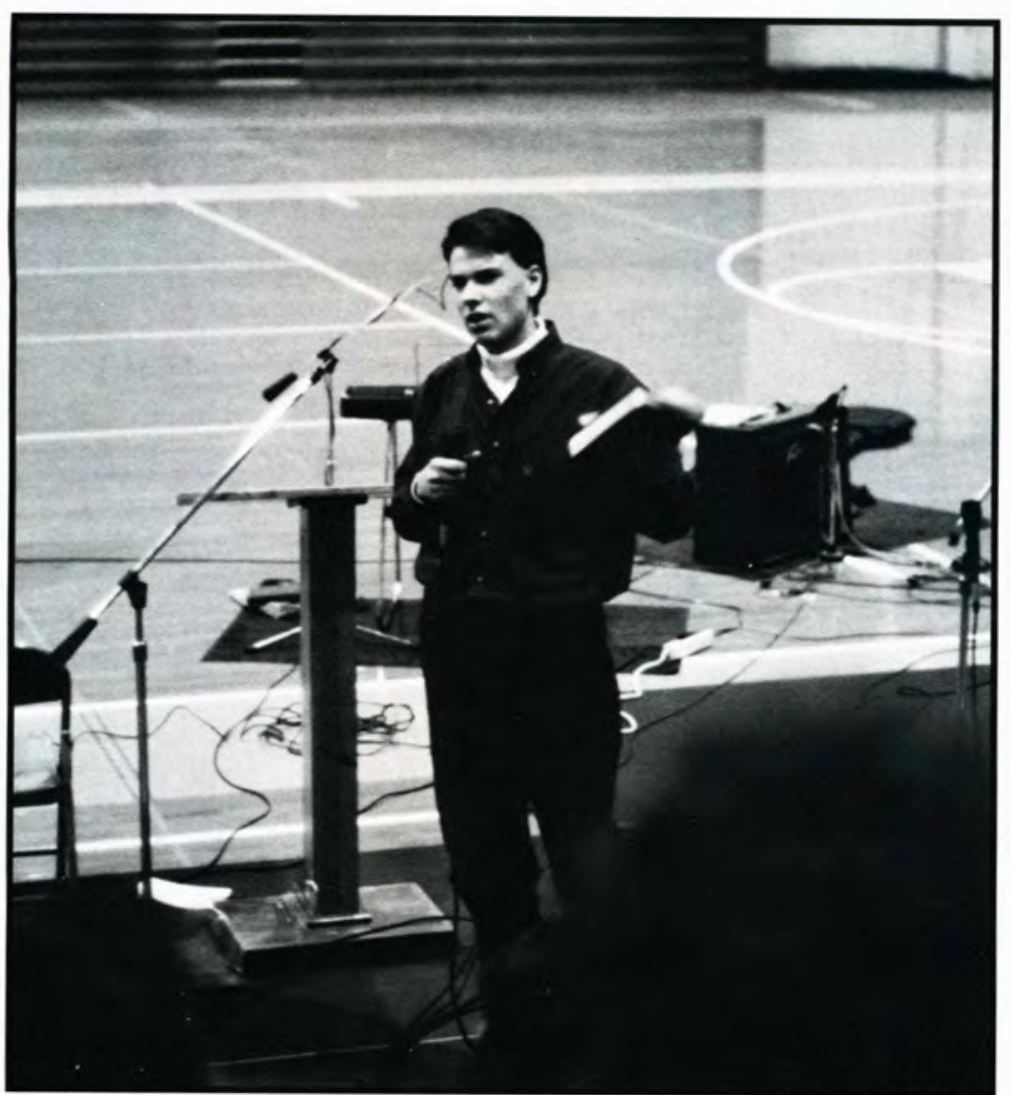

Photo by Andy Biddle

\section{Class Officers}

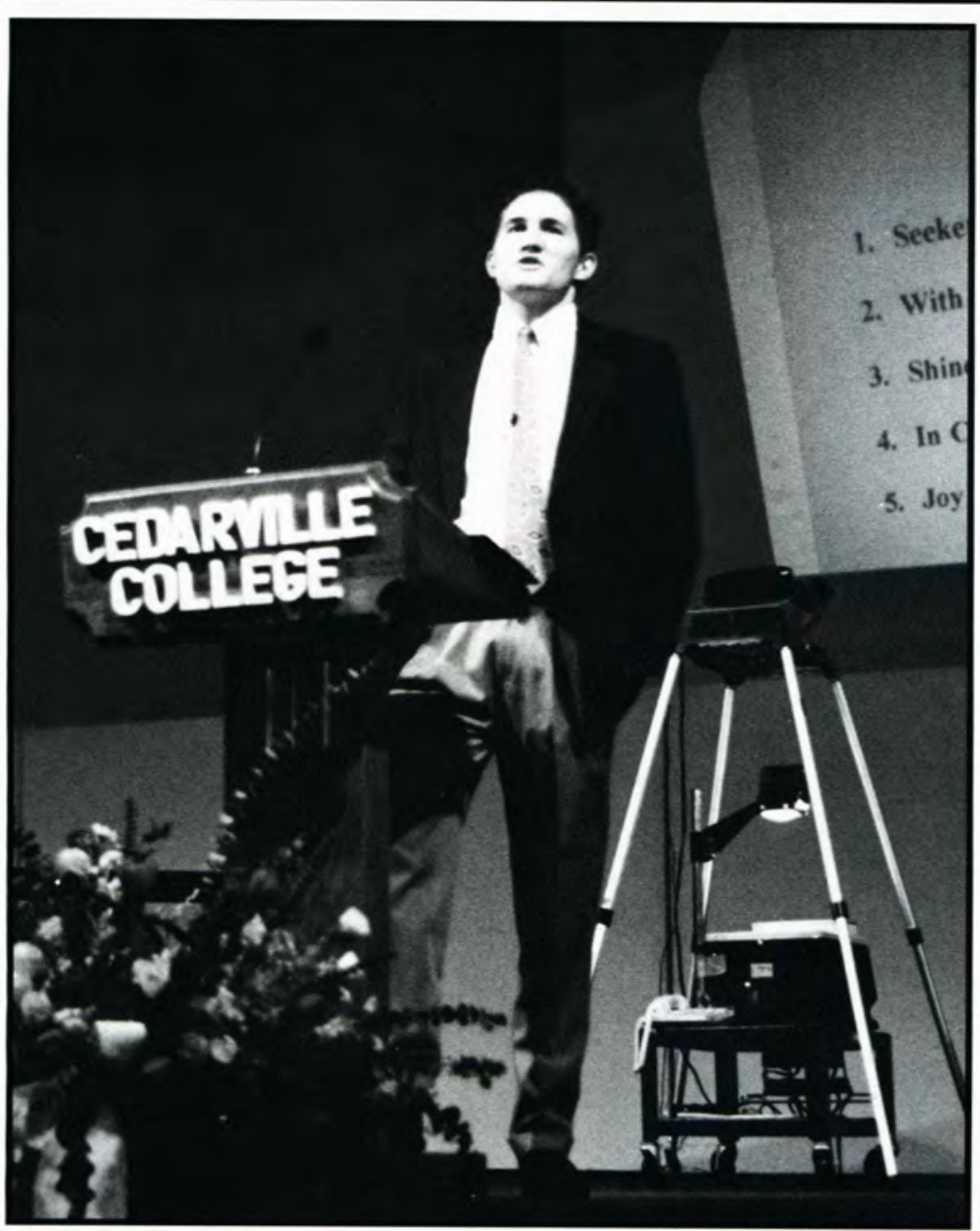

Photo by Steve Cook

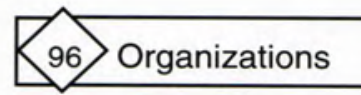

SENIOR CLASS CHAPLAIN, Jeff Burr announces the Senior Class song in chapel.
SGA PRESIDENT, PAUL ANDERSON, addresses the student body.

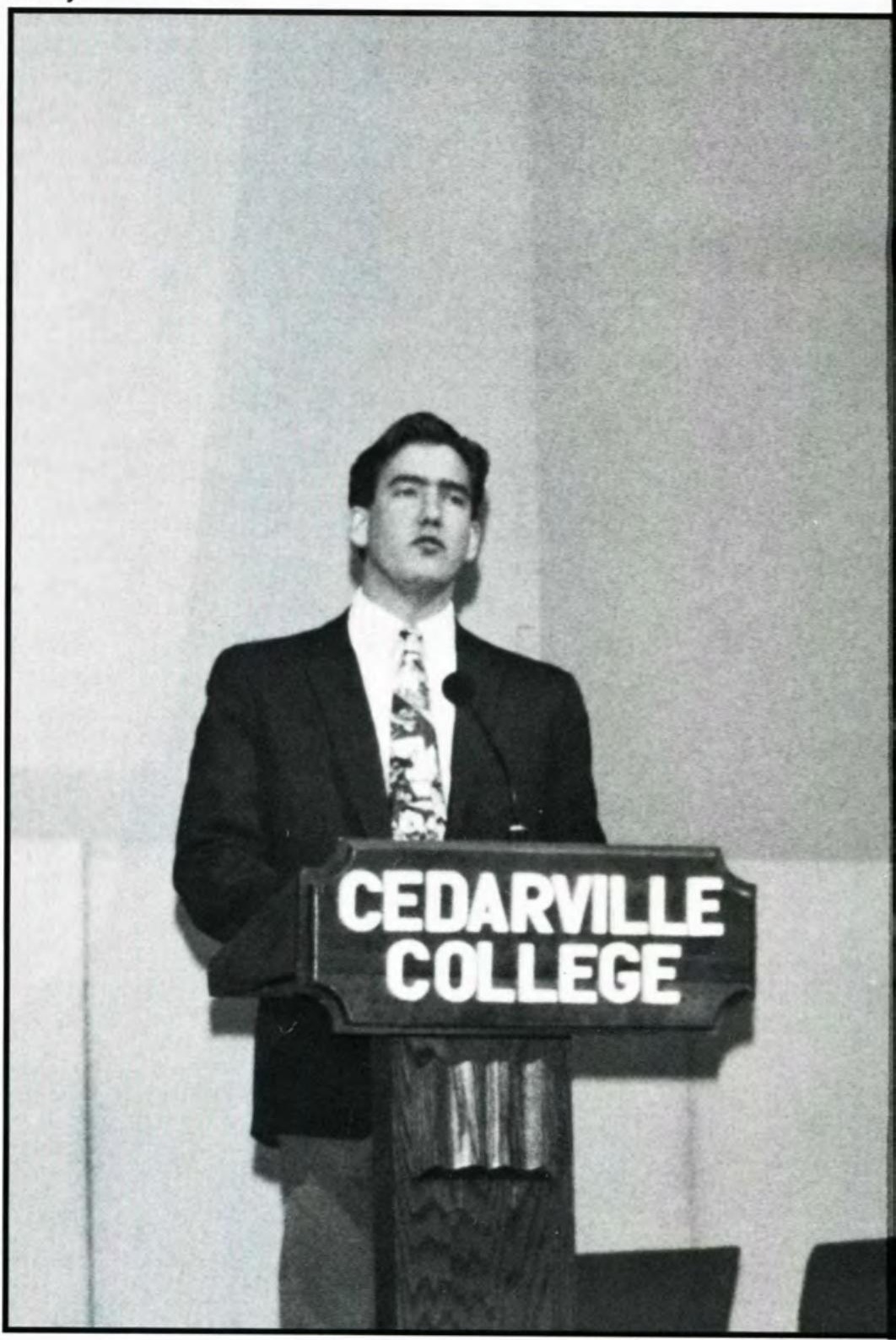

Photo by Jeff Buckingham

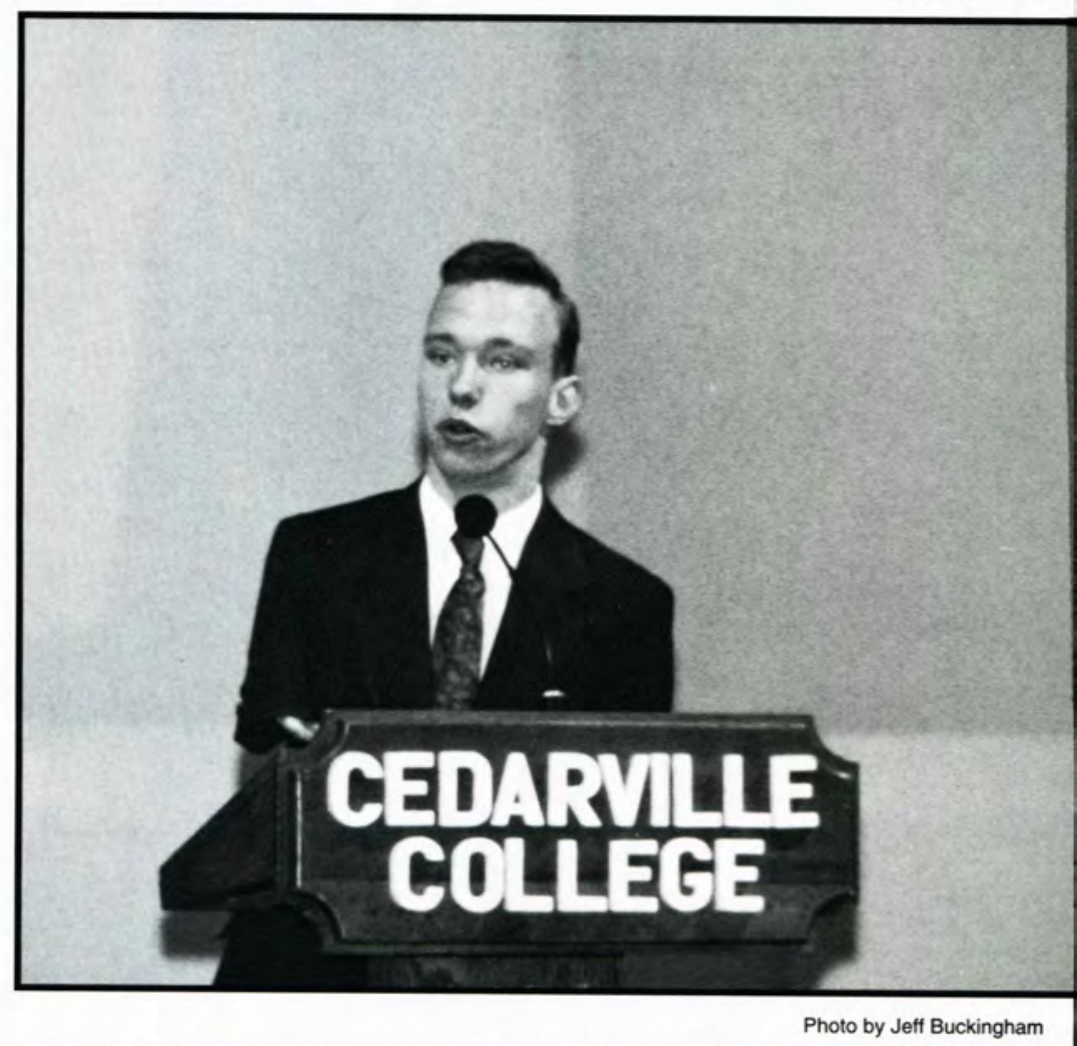

MAKING ANNOUNCEMENTS REGARDING UP COMING ELECTIONS, Karl Cooper addresses the student body. 


\section{CLASS OFFICERS}

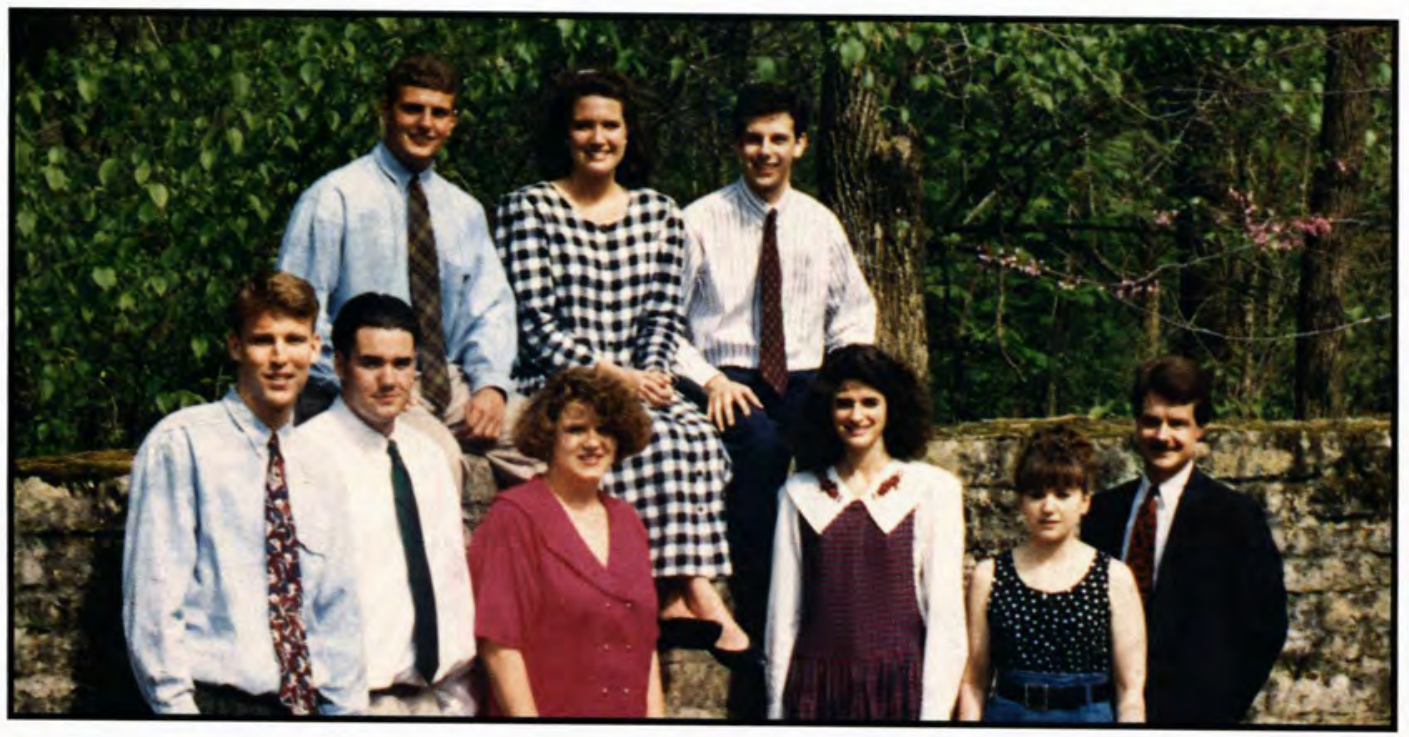

Junior Class

Ryan Linnehan, SGA

Representative; Dana Hull, SGA Representative; David Moore,

President; Nathan

Elmore, Chaplain;

Ryan Hewson, Treasurer; Cheryl Phillips, Vice President; Julie Walker, Secretary; Abbey Boone, SGA

Representative;

Mr. Carl Ruby.

\section{Freshman Class}

Tim Williams,SGA

Representative;

Bowe Hoy, Presi-

dent; Ruth

Heckman, Secretary; Mark Totten,

Chaplain; Lisa

Lough, Vice President; Jennifer

Gordey, SGA Representative; Chad Prosser, Treasurer.

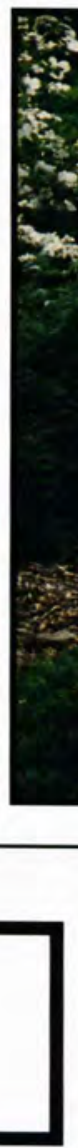

Executive Committee

Bruce Moore, Karl Cooper, Brian Netteingham, Joe Slavens, Kristi VanDyke. Not Pictured: Shelly Heldreth.

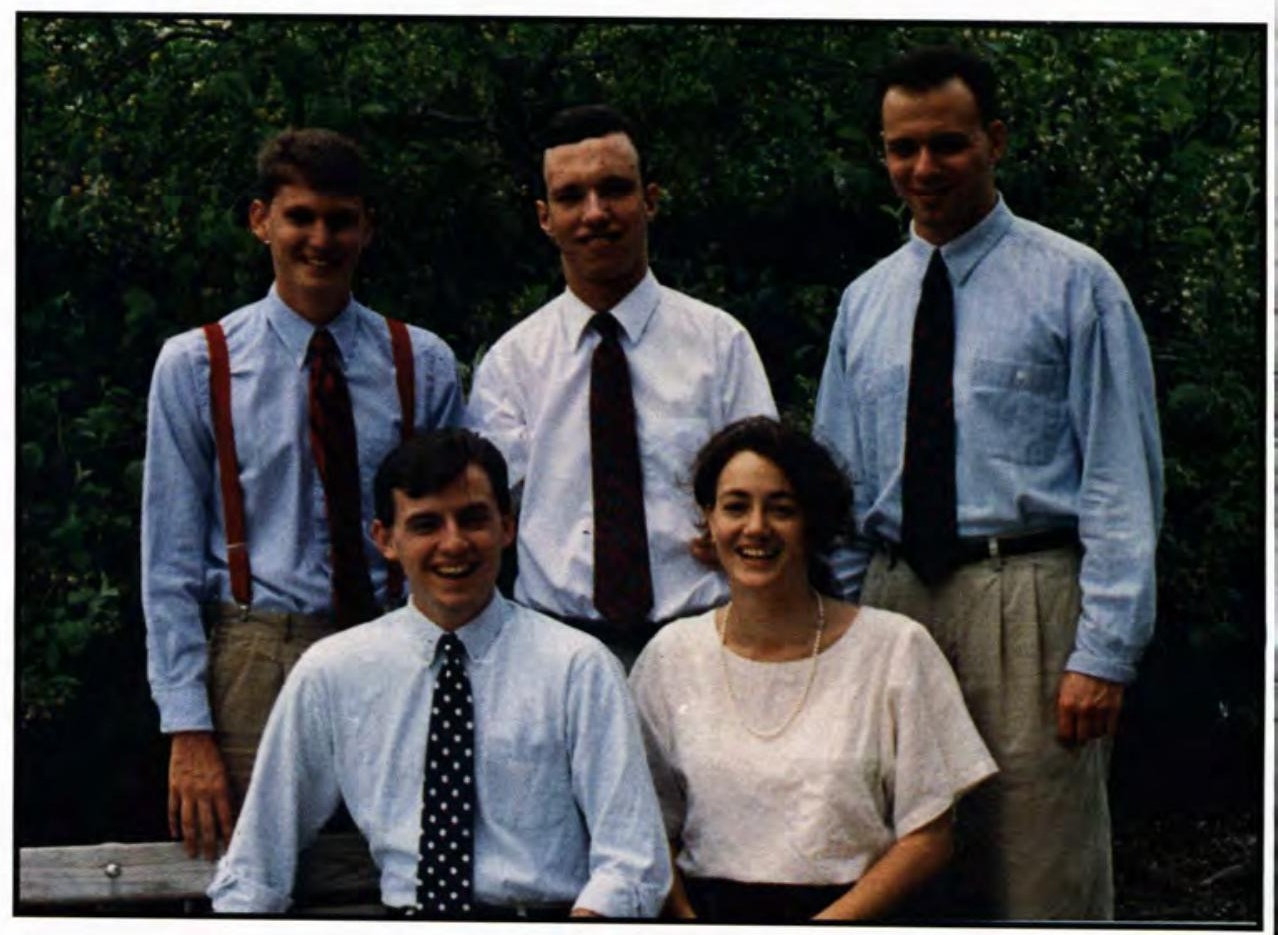




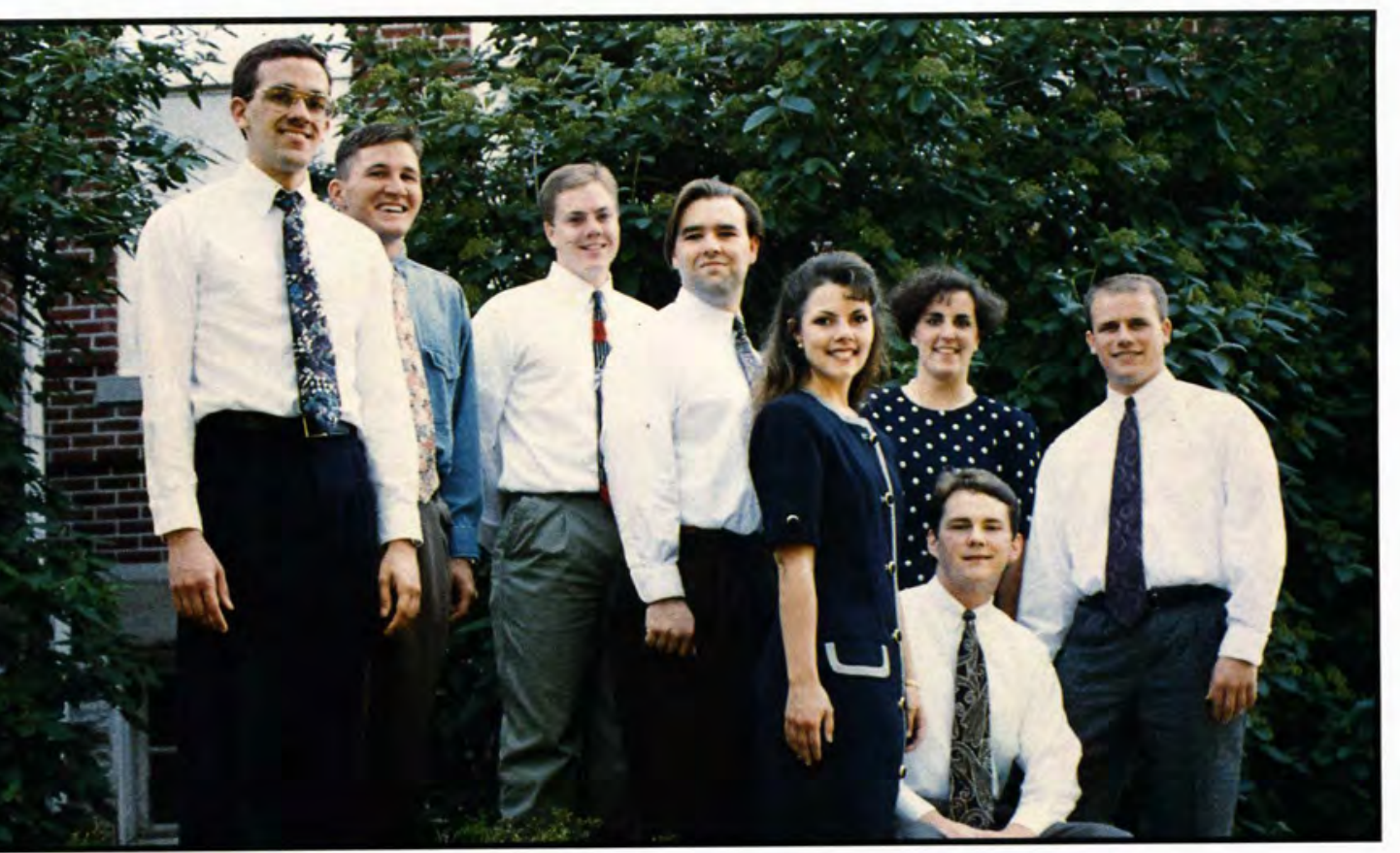

Senior Class

Ken Vanderwest, Jeff Burr, Chaplain; Steve Holden, Vice President; Paul McGrady, Kim Higginbotham, SGA Representative; Kirsten Gibbs, Secretary; Chad Coe, SGA Representative; Brian Bales, President.

\section{Sophomore Class} Jennifer Butler, SGA Representative; Mike

Pasquale, Treasurer; Ken Nichols, Vice President; Jonathan Misirian, President; Chad Vitarelli, Chaplain; Tonya Bowling, Secretary.
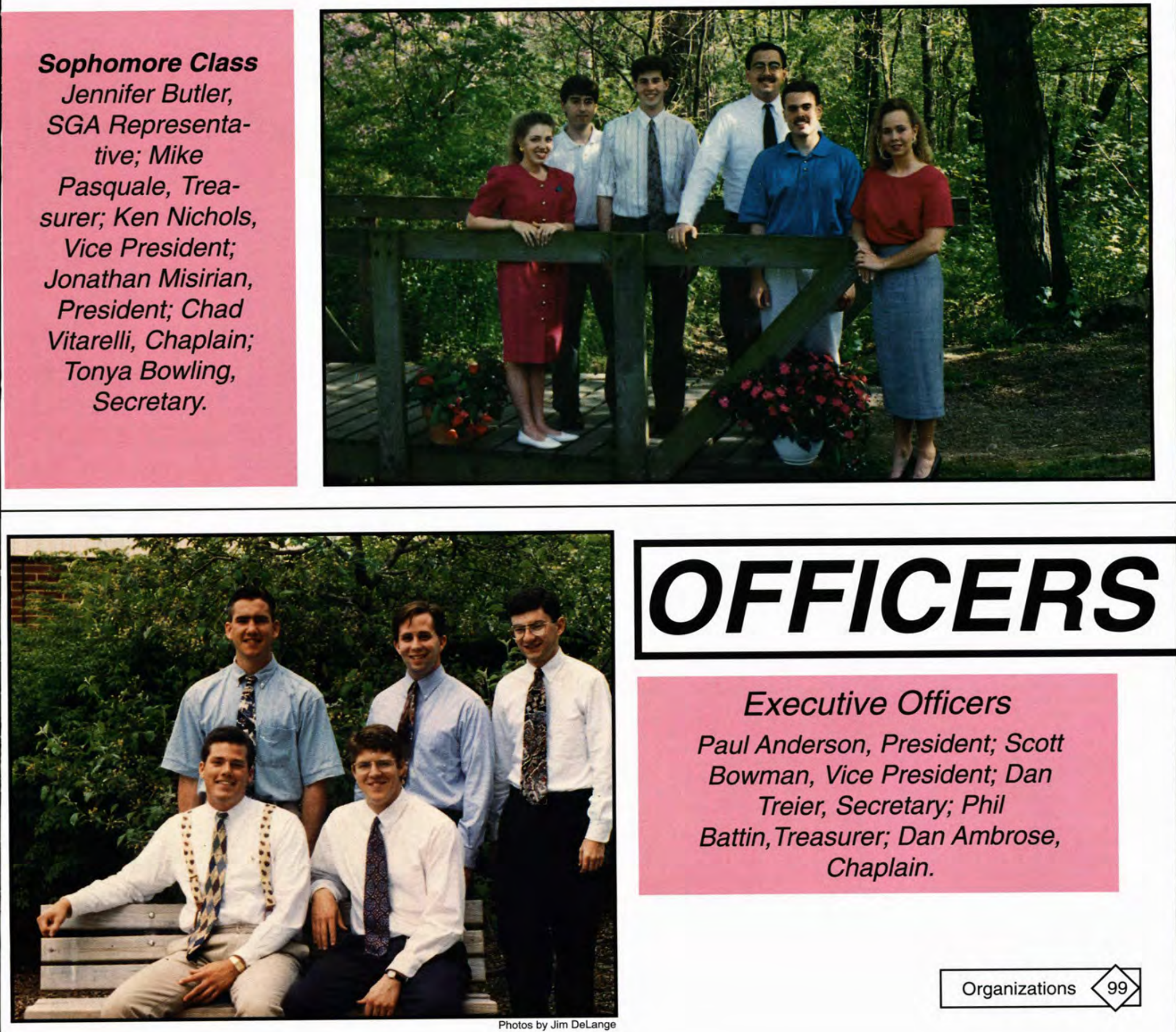

\section{Executive Officers}

Paul Anderson, President; Scott Bowman, Vice President; Dan Treier, Secretary; Phil Battin, Treasurer; Dan Ambrose, Chaplain. 


\section{Collaborative Learning Produces Another Miracle}

"It's a miracle this book ever comes together." Uncle Al may argue that our yearbook should not be called the Miracle, and others may prefer its former title, the Cedrus, but to each staff member, holding a completed bound book in one's hands seems like a miracle.

Like Gideon's army, a remnant of the children of Israel, the small staff working on the yearbook accomplishes an amazing feat each year - documenting events, capturing memories on film and in writing, and organizing those happenings into a semblance of order known as the yearbook.

This process, though it may be time-consuming, offers the staff a great creative outlet allowing them to contribute their ideas and thoughts to a lasting publication.
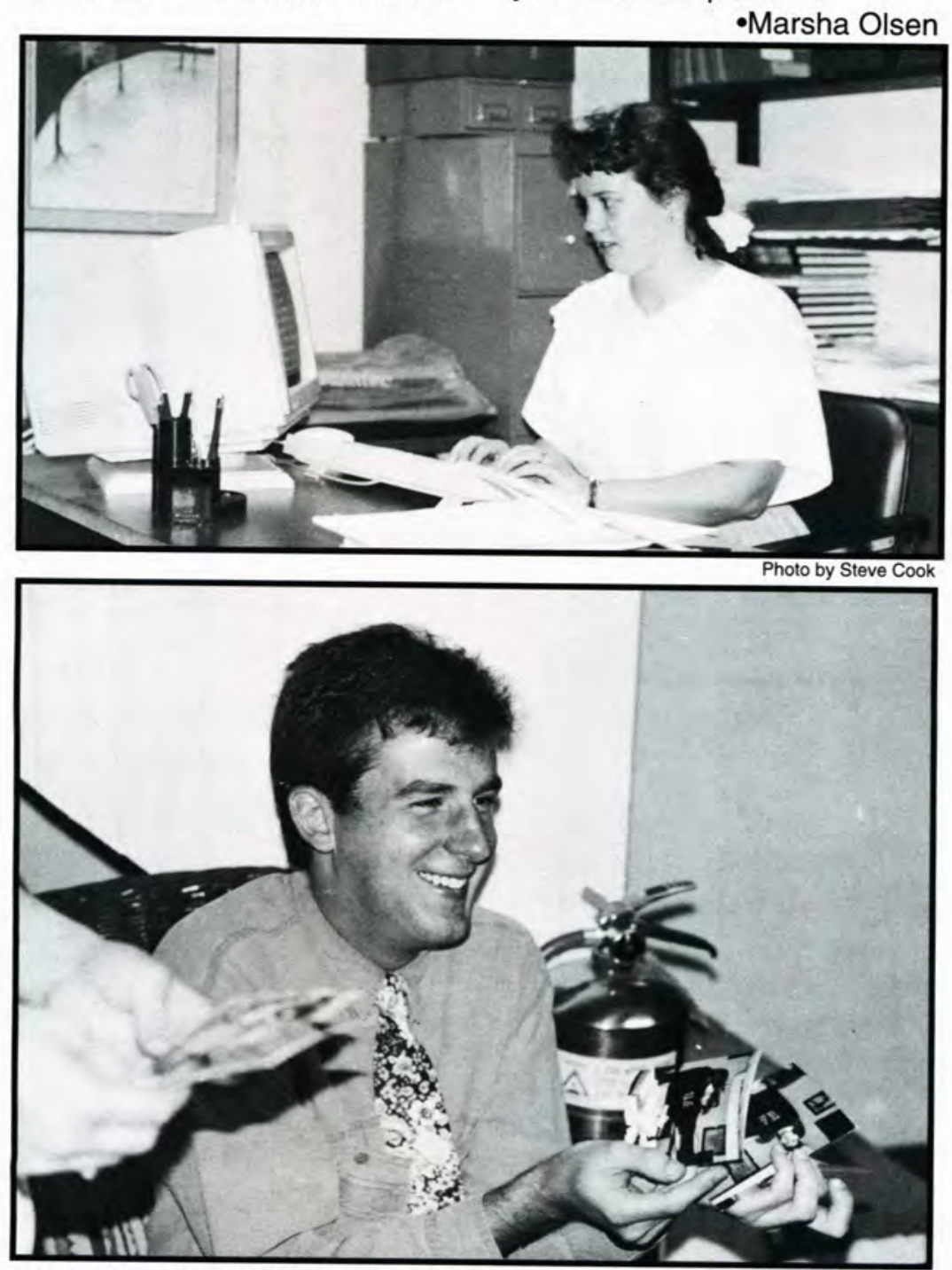

INTENT ON MAKING THIS ARTICLE CREATIVE, Jennifer Henry adds the finishing touches.

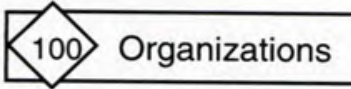

From the day the books are distributed, the Miracle functions as an advertising and recruiting tool for the college, a potential TWIRP date or homecoming date directory, and the primary reference for alumni reminiscing about their college years.

Of all the challenges of working on staff, the greatest one is dedication. Deadlines seem to fall when it's least convenient and only the faithful meet them. For those faithful students who have made this year's book a success, contributing in small or big ways, the editorial staff wants to say, "Thankyou." Producing a Miracle would have been impossible without the collaborative efforts of all. May you be pleased with the results of this book, finally seeing your efforts in print.

-Marsha Olsen
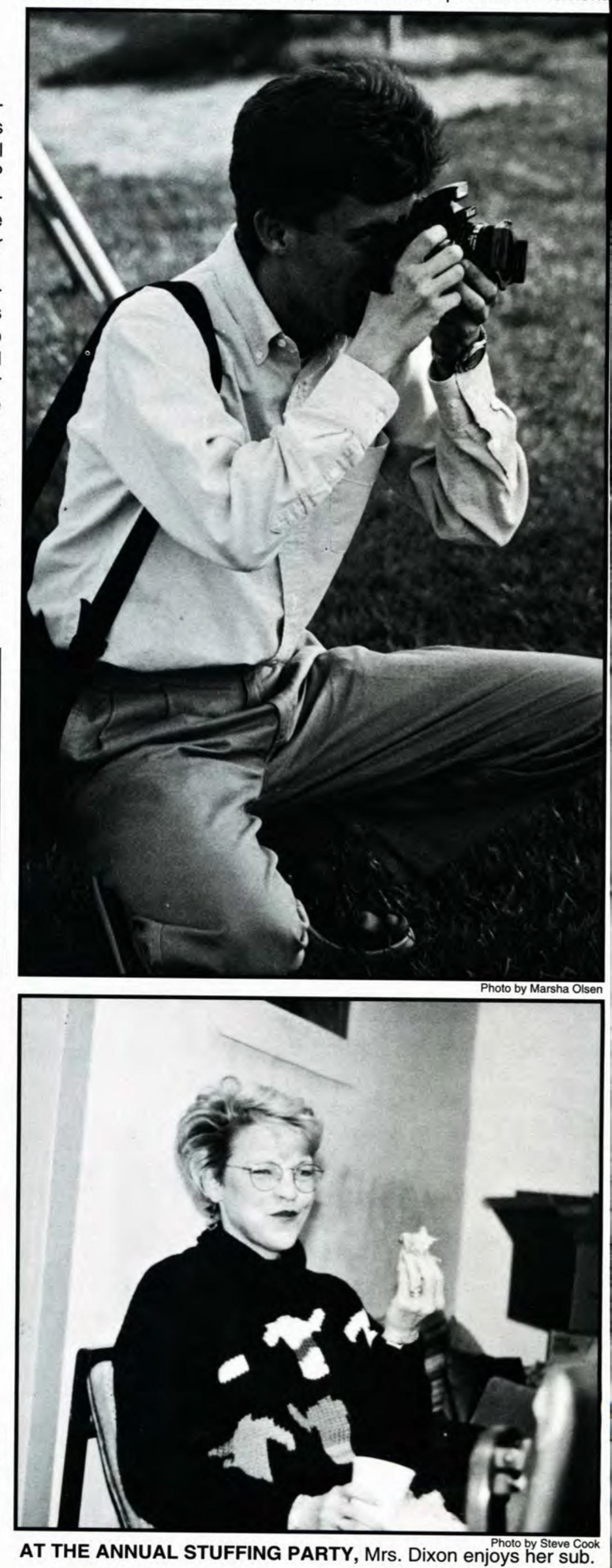


\section{MIRACLE STAFF}

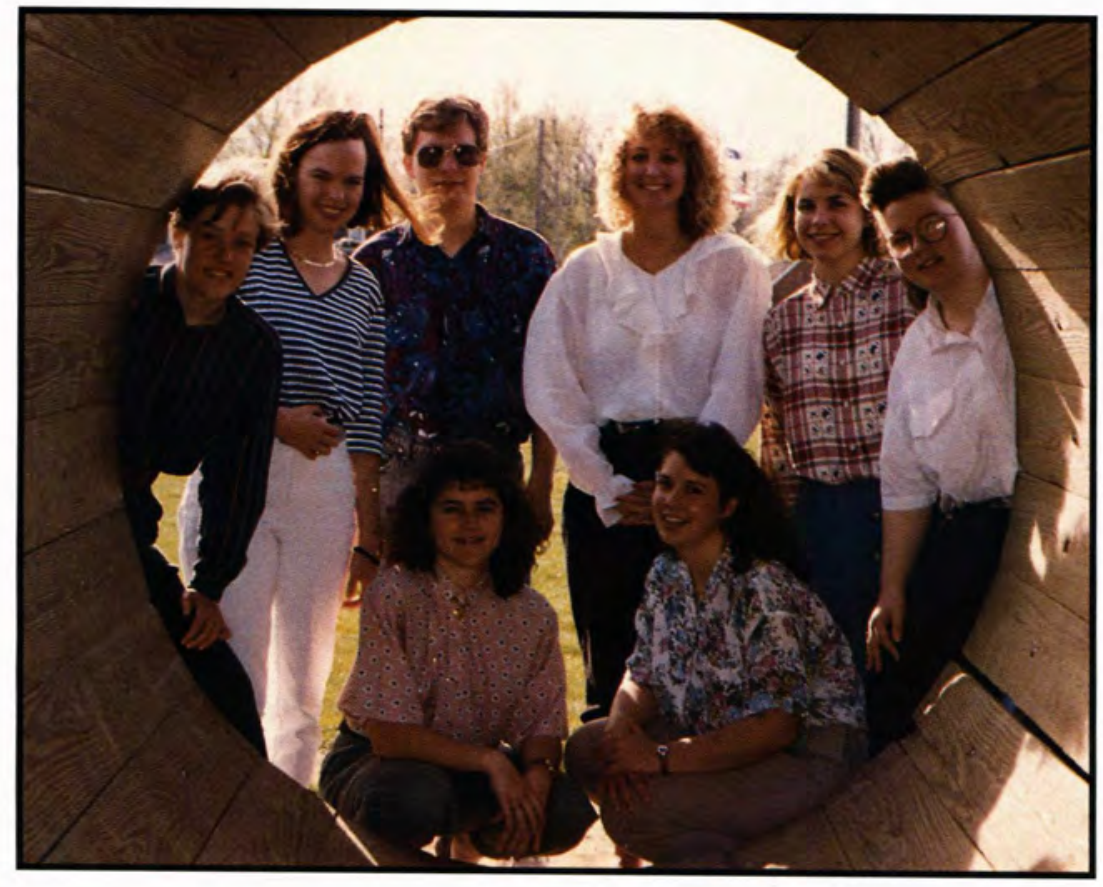

Layout Staff: Melissa VanDeWege, Elizabeth Fulton, Allen McQuire, Lauren Fields, Becky Edwards, Rachelle Brooks,

Nicole Brubaker, Jennifer Henry.

Photography Staff: Stephanie Saville, Todd Hill, Ray Izard, Lance Gentry, Tania Taylor, Jeff Buckingham, Andy Biddle. Not pictured:

Robb Barnum.
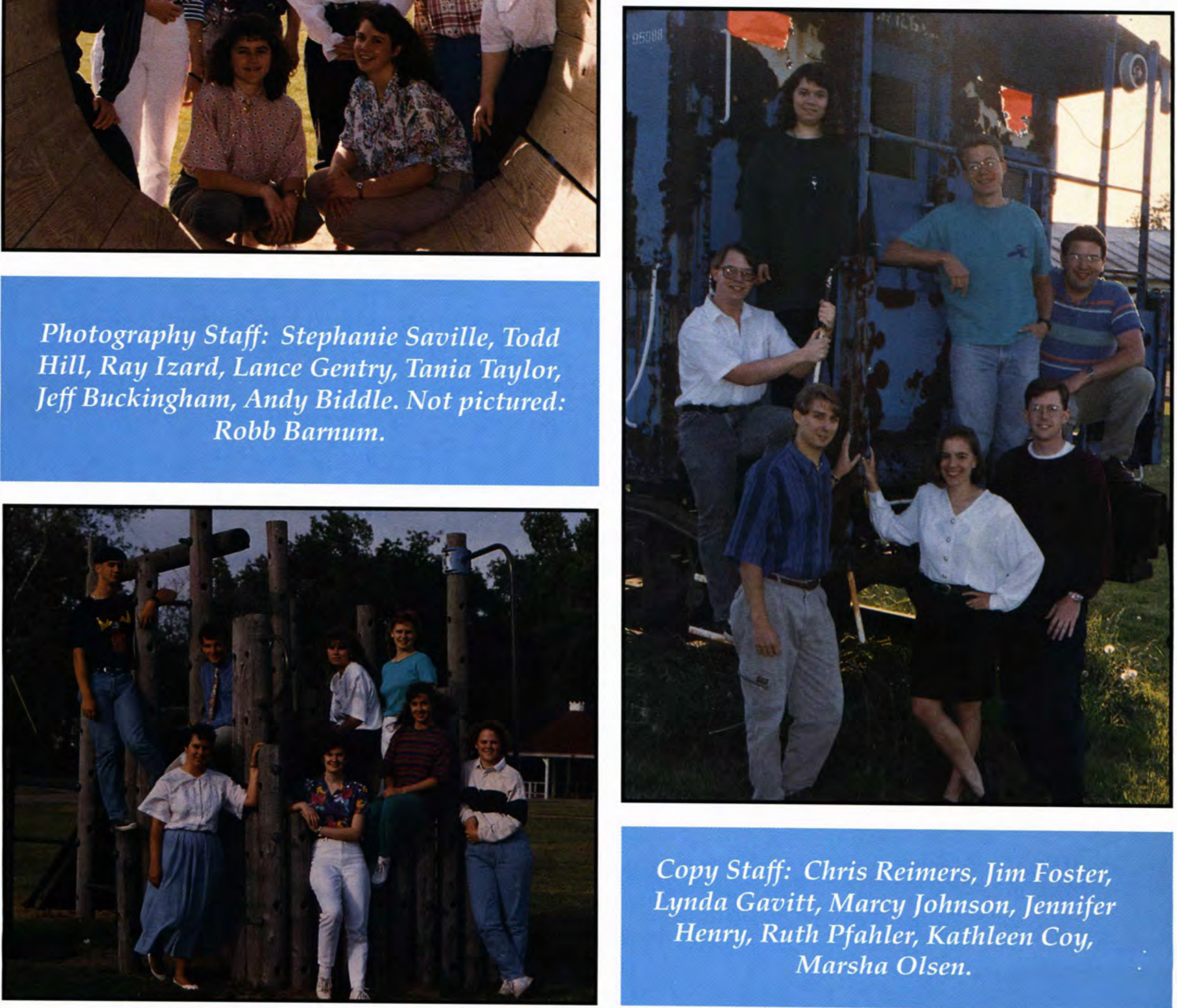

Copy Staff: Chris Reimers, Jim Foster, Lynda Gavitt, Marcy Johnson, Jennifer Henry, Ruth Pfahler, Kathleen Coy, Marsha Olsen. 

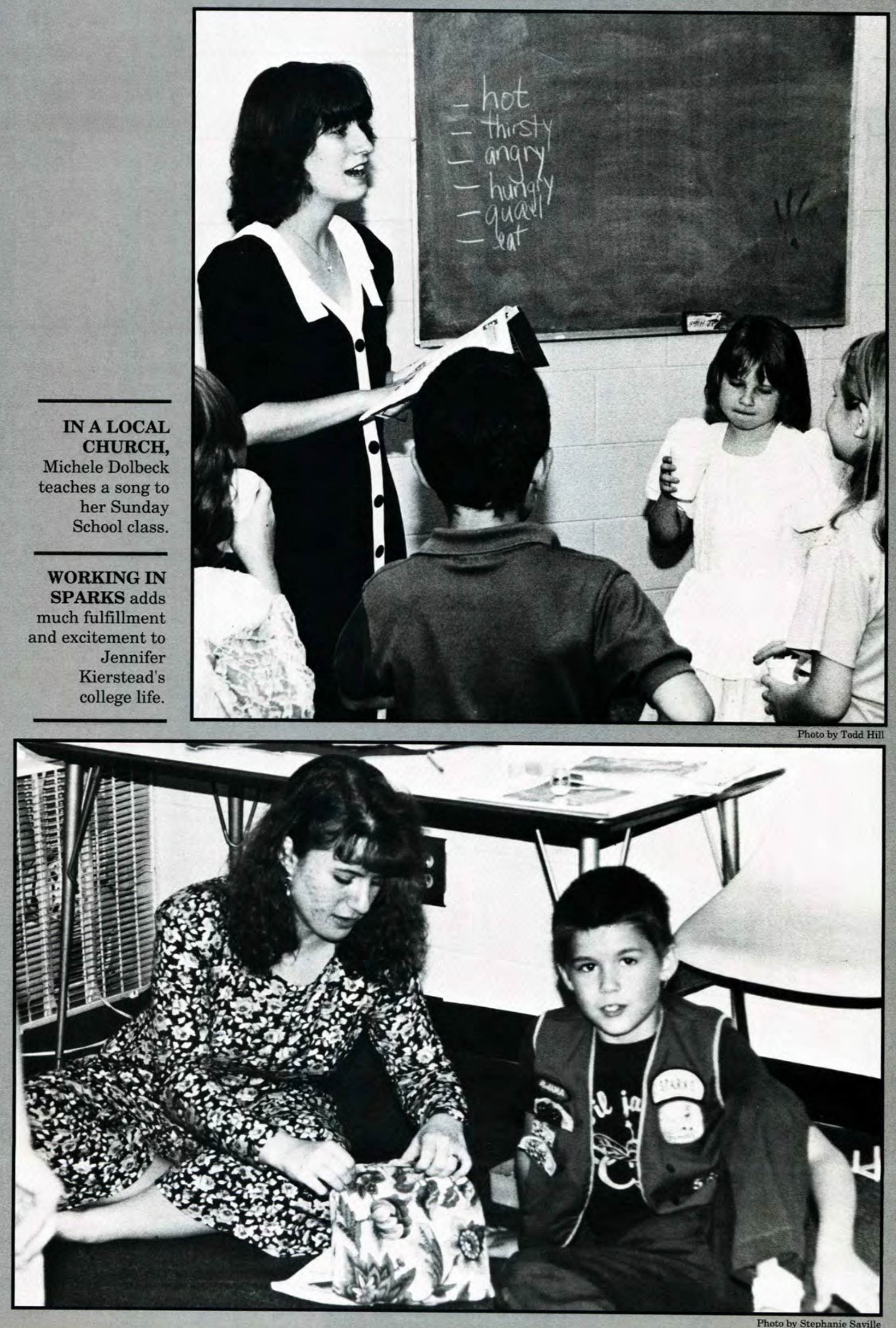

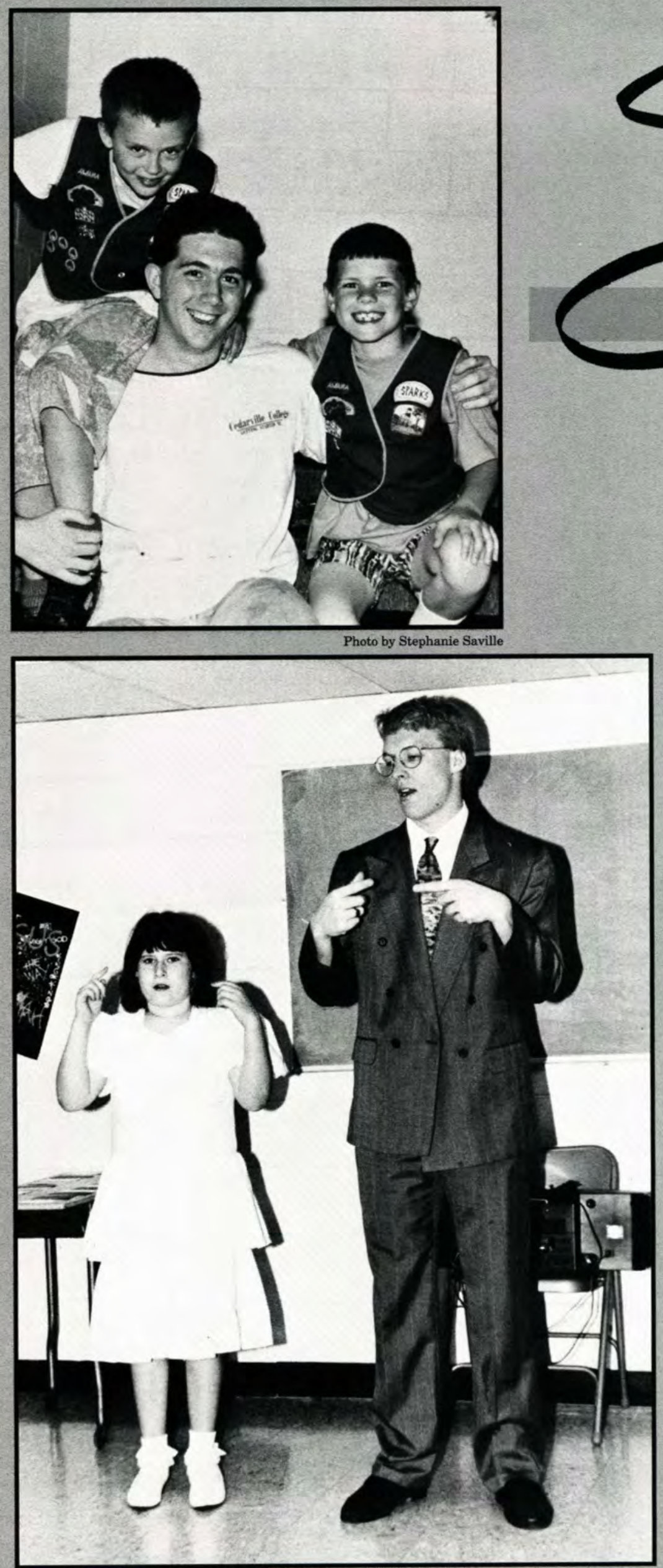

Photo by Todd $\mathrm{H}$ MUSIC IS A BIG PART OF EVERY SUNDAY SCHOOL CLASS.

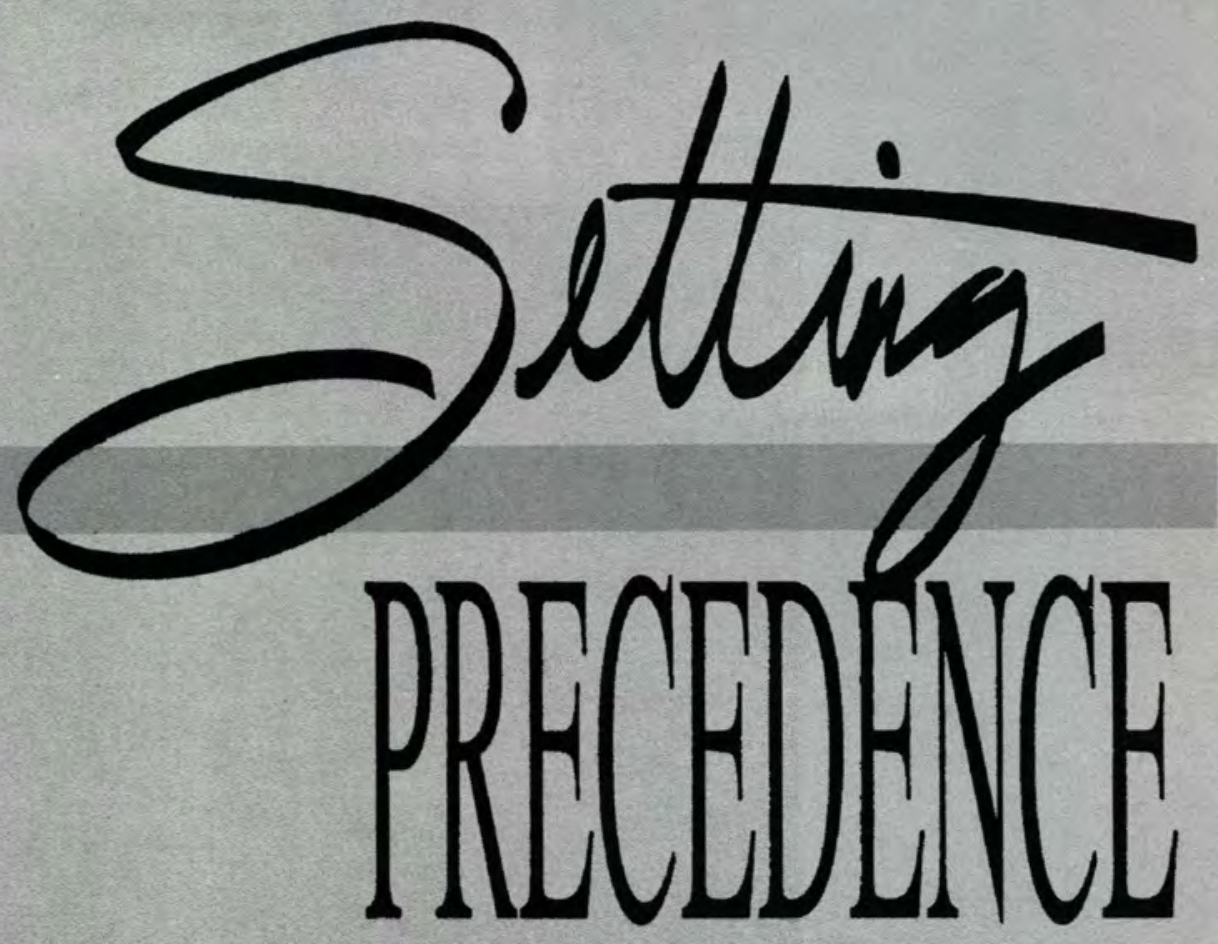

in Christian Ministries

Fellowship 106-107

Chapel 108-109

Day of Prayer 110-111

Traveling Teams $112-115$

Ministry Teams 116-131

Swordbearers 132-133 
LEADING THE CAMPUS IN WORSHIP, Charlie Thorsen directs the music.

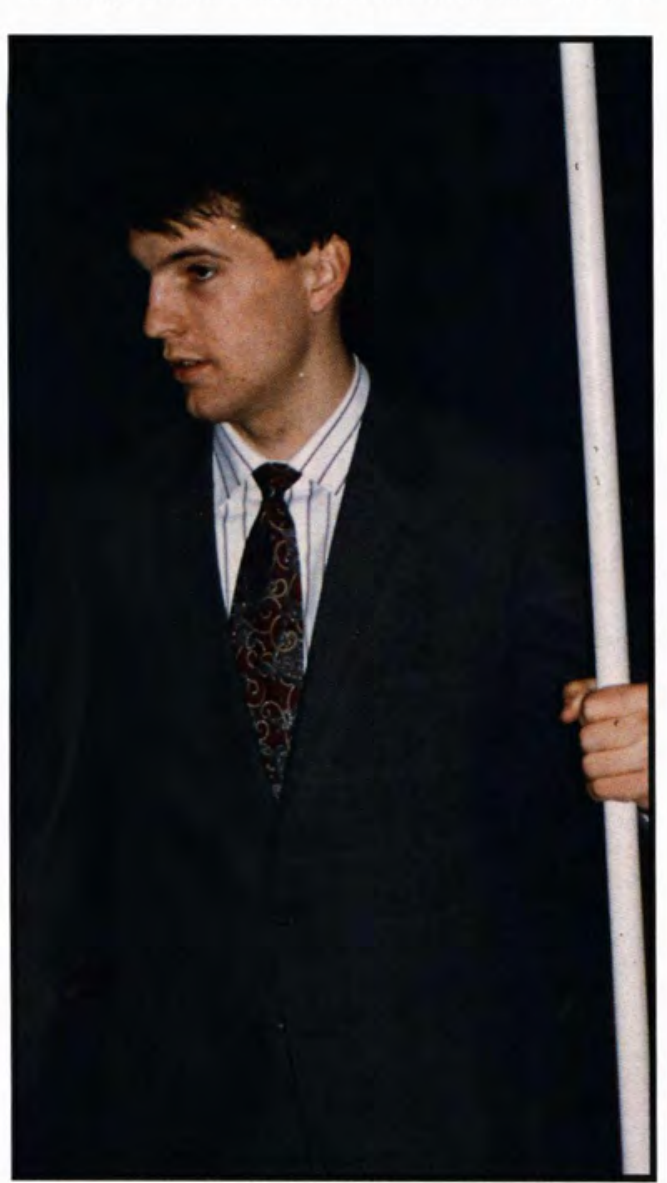

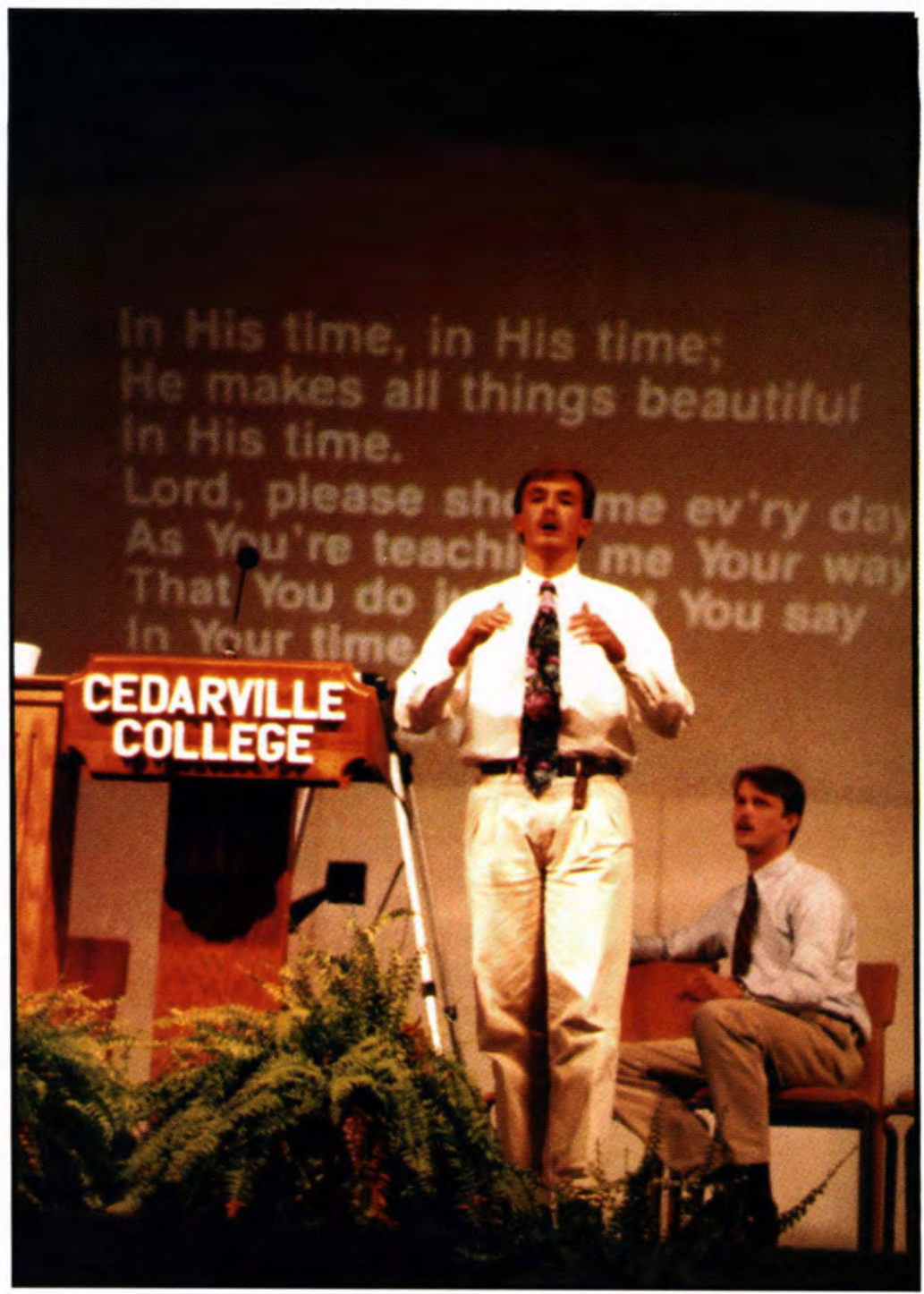

SERVING HIS FELLOW STUDENTS, Andy Baker helps by arranging the banners for fellowship.

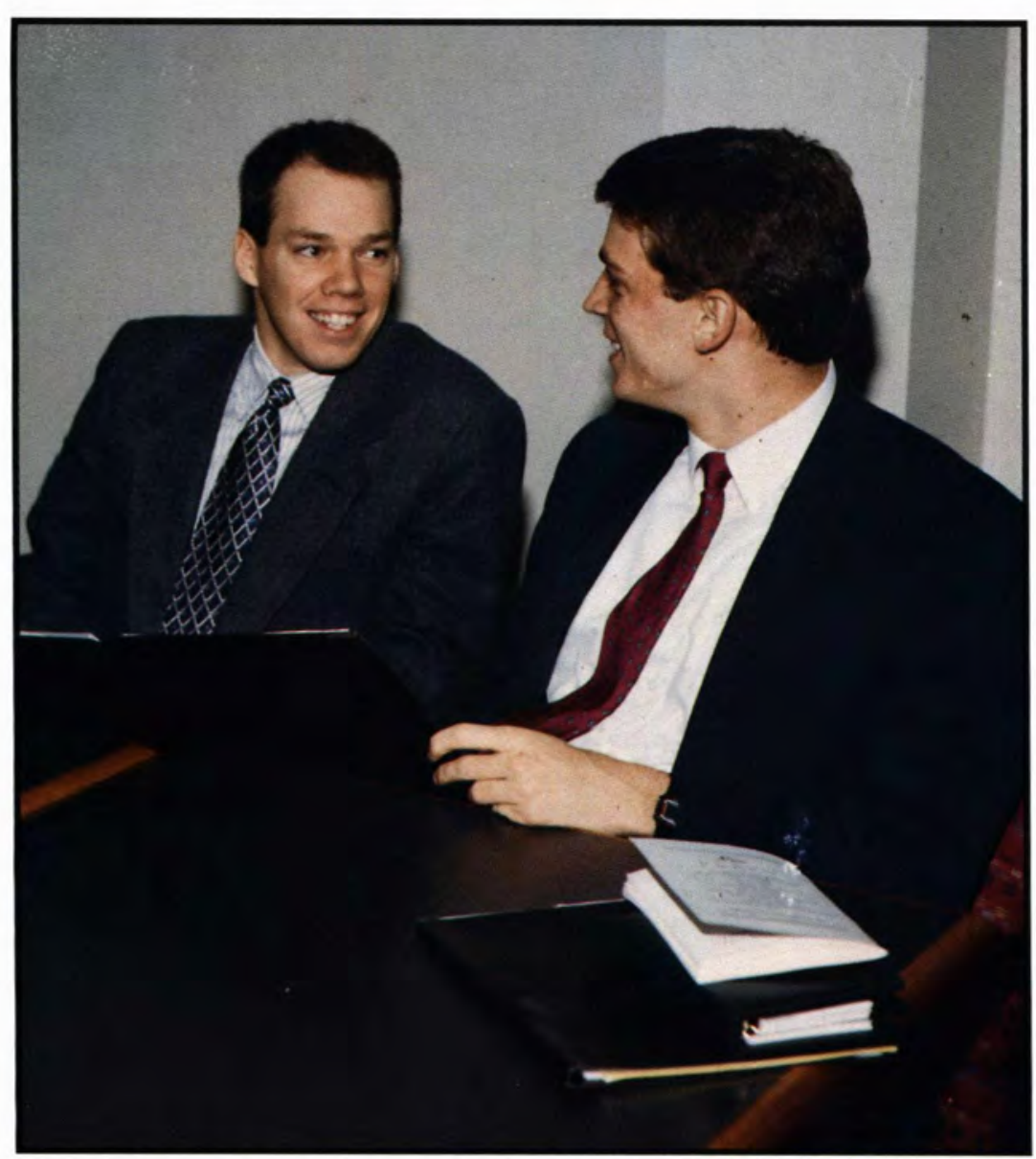

RELIEVING THE STRESS OF THE DAY, Dave Shumaker and John Warnshuis laugh to keep from falling asleep.

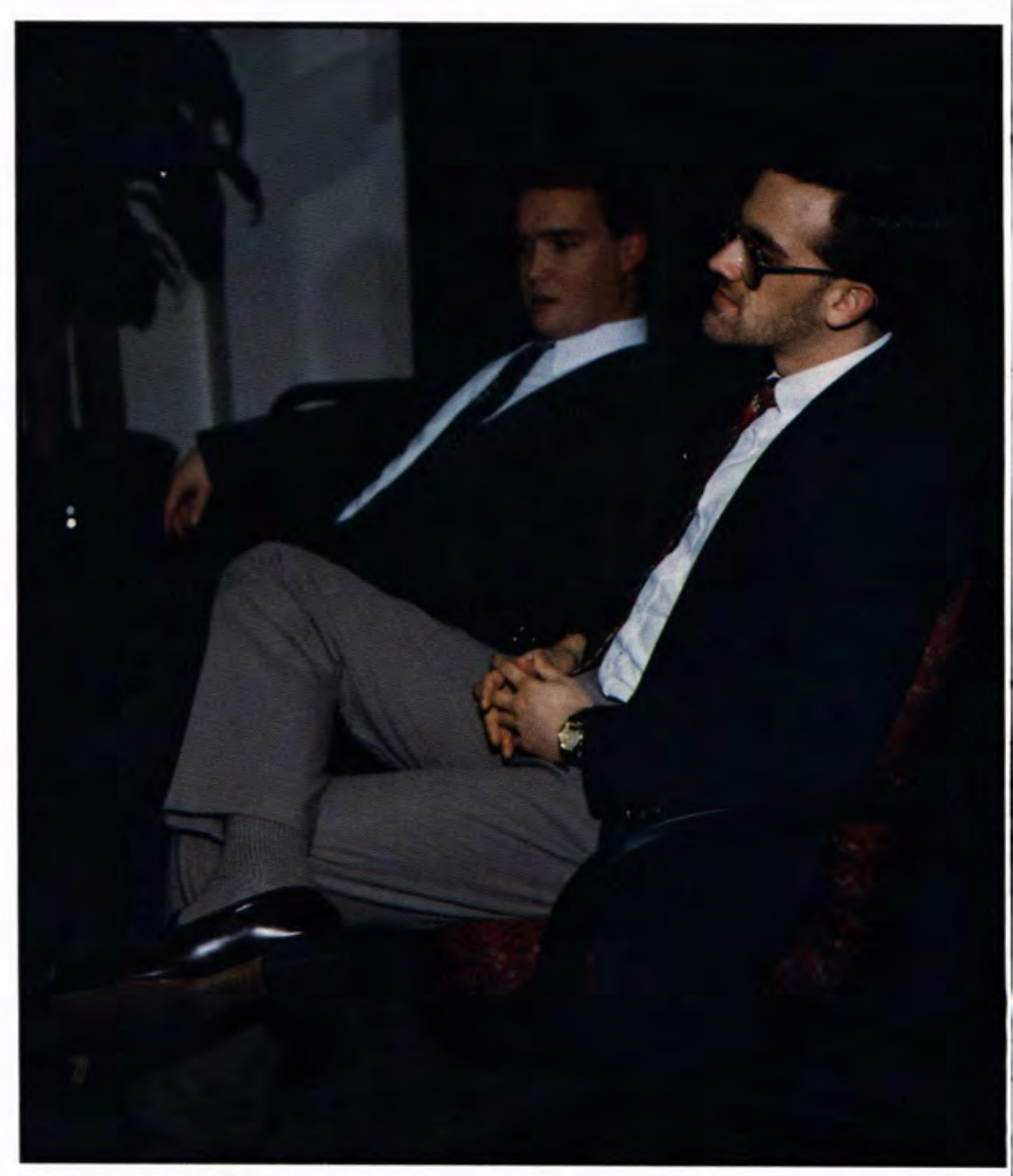

DEEP IN THOUGHT, Ken Vanderwest and Steve Brock ponder what to do next week in fellowship. 


\section{ADVISORY 7}

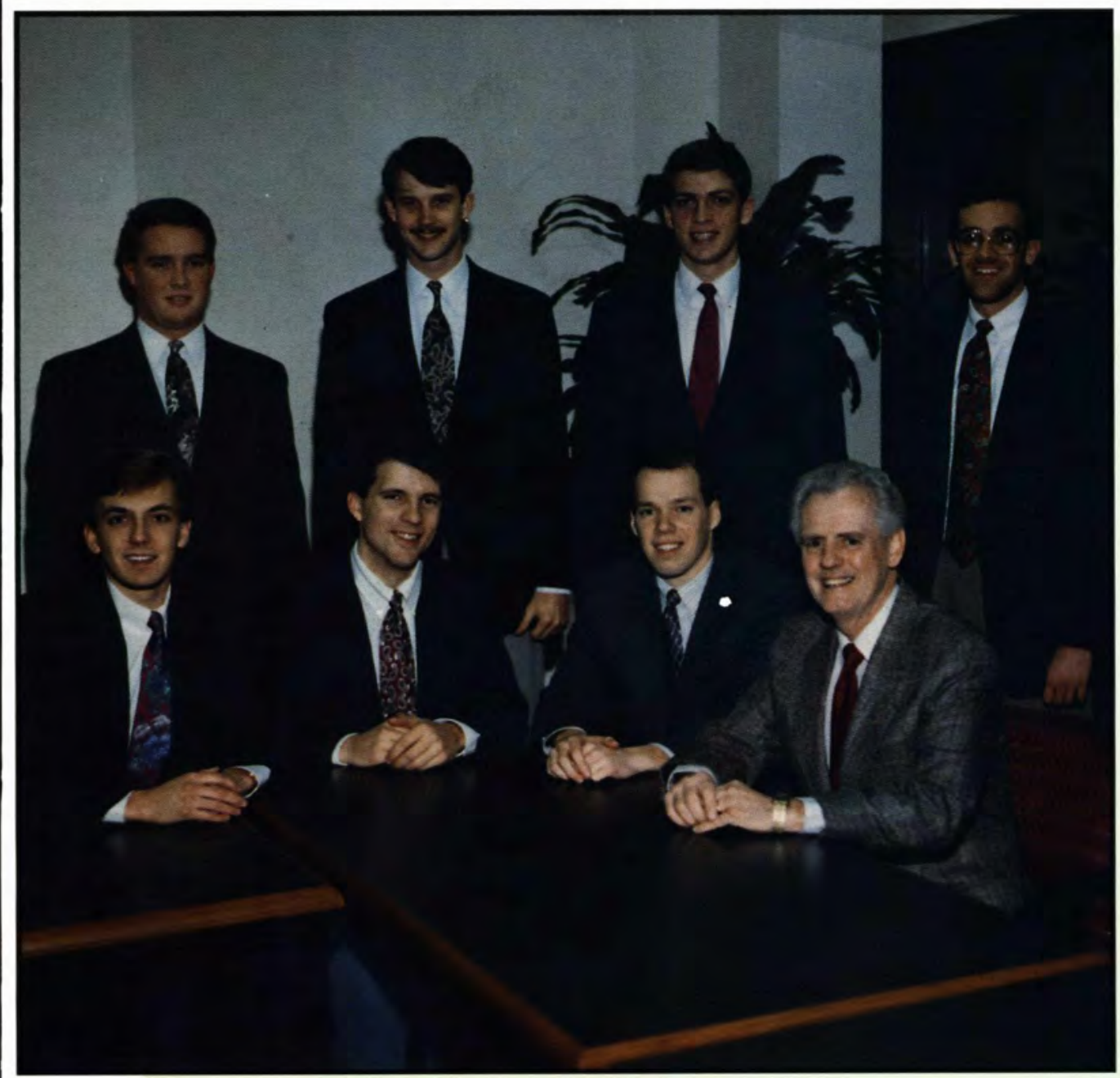

Front row: Charlie Thorsen, Andy Baker, David Shumaker, Pastor Green. Back row: Steve Brock, Brian Broadus, John Warnshuis, Ken Vanderwest.

The goal of the Advisory 7 group is to "provide Spirit-filled worship services for the students, to foster spiritual growth, to encourage involvement in students' home churches, and to equip students to minister in their own sphere of influence."

This ministry is an independent, student organized fellowship that allows students to become involved in God's worship in a way not possible in area churches.

USING HIS ABILITIES IN PUBLIC SPEAKING, David Shumaker reads Scripture. 


\section{September 28, $1992 \quad$ - $\quad$ May 31, 1993}

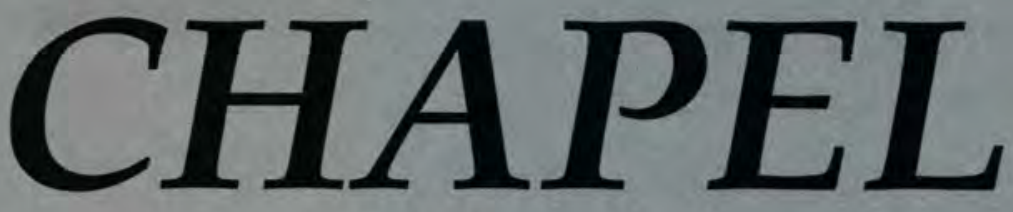

\section{Vessels for His Glory}

"The longer water sits inside the pot, the more stagnant it becomes. It's best to pour that water out as soon as the pot fills; and the sooner it's filled up again, the less it has to be cleaned." John Mourglia of "The Potter's House" ministry spoke these words to the student body in April as he molded clay from the chapel platform. While working, he spoke of God's process in preparing his children for $\mathrm{His}$ work.

Each chapel speaker of the 1992-93 school year contributed to the formation of God's vessels at Cedarville College, pouring their spiritual growth and insight out into more than 2,100 students. The wellknown speakers of the three annual conferences worked to make students "pliable" again at the beginning of each quarter: Dr. Erwin Lutzer, pastor at Moody Church, urged students to "Come to Grips" and "Keep the Dream Alive"; Dr. Joseph Stowell III, President of Moody BibleInstitute, spoke on controlling self-significance; and Dr. Ronald Blue, President of C.A.M. International, guided Cedarvillians toward evangelism and discipleship in the spring missions conference.

Many other chapels filled our "pots" with renewed vigor. Cedarville's own Dr. Drullinger put an eye-witness twist on the Christmas story, while his colleagues Dr. Gromacki, Dr. Estes, Dr. Riggs, and Mr. Warren also spoke. Dr. Elmore spoke of Christ's return after many Americans looking forward to an October 28 rapture were disappointed. The Southgate Children's Choir, the Dayton Choir Boys, Mr. Kirby Lancaster from Australia as well as Back to Genesis speakers, Ken Ham and Duane Gish, all gave us new enthusiasm to share the news of our Savior.

As the chapel bells chime ten times each weekday morning, a tremendous power for God is gathered in one place. The heartfelt prayer of the administration, faculty, staff, students, and speakers is that Cedarville's "pot" will not contain stagnant water, but will continually overflow into the hearts and lives of people around the globe. We are vessels for the Master's use and "from those to whom much is given, much is expected."

-Victoria Johnson
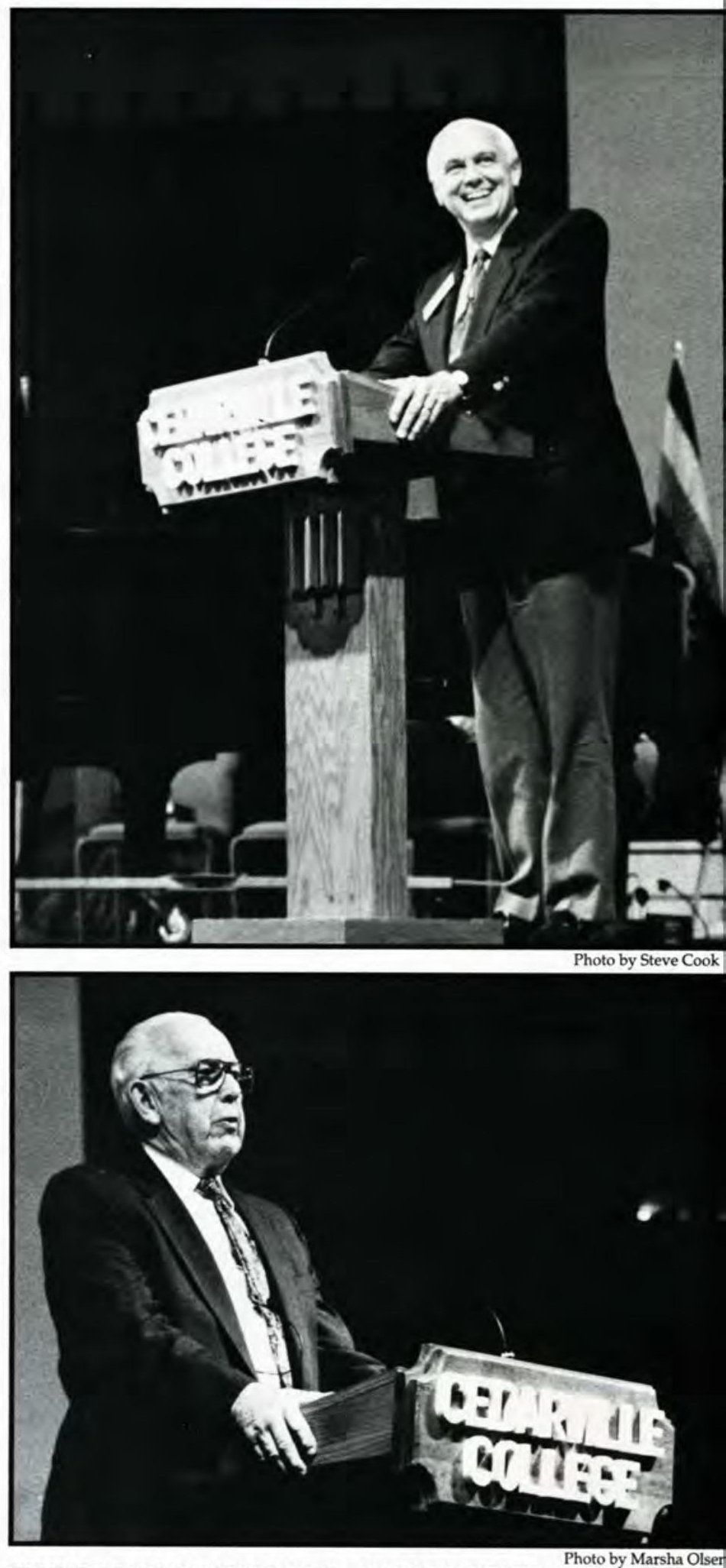

SPRING MISSIONARY CONFER- SHARING MUCH WISDOM WITH ENCE SPEAKER, Dr. Ronald Blue, THE COLLEGE FAMILY, Dr.

challenged students to become an Jeremiah speaks to a school that deeply AAA Club Member. appreciates his efforts in its success. 


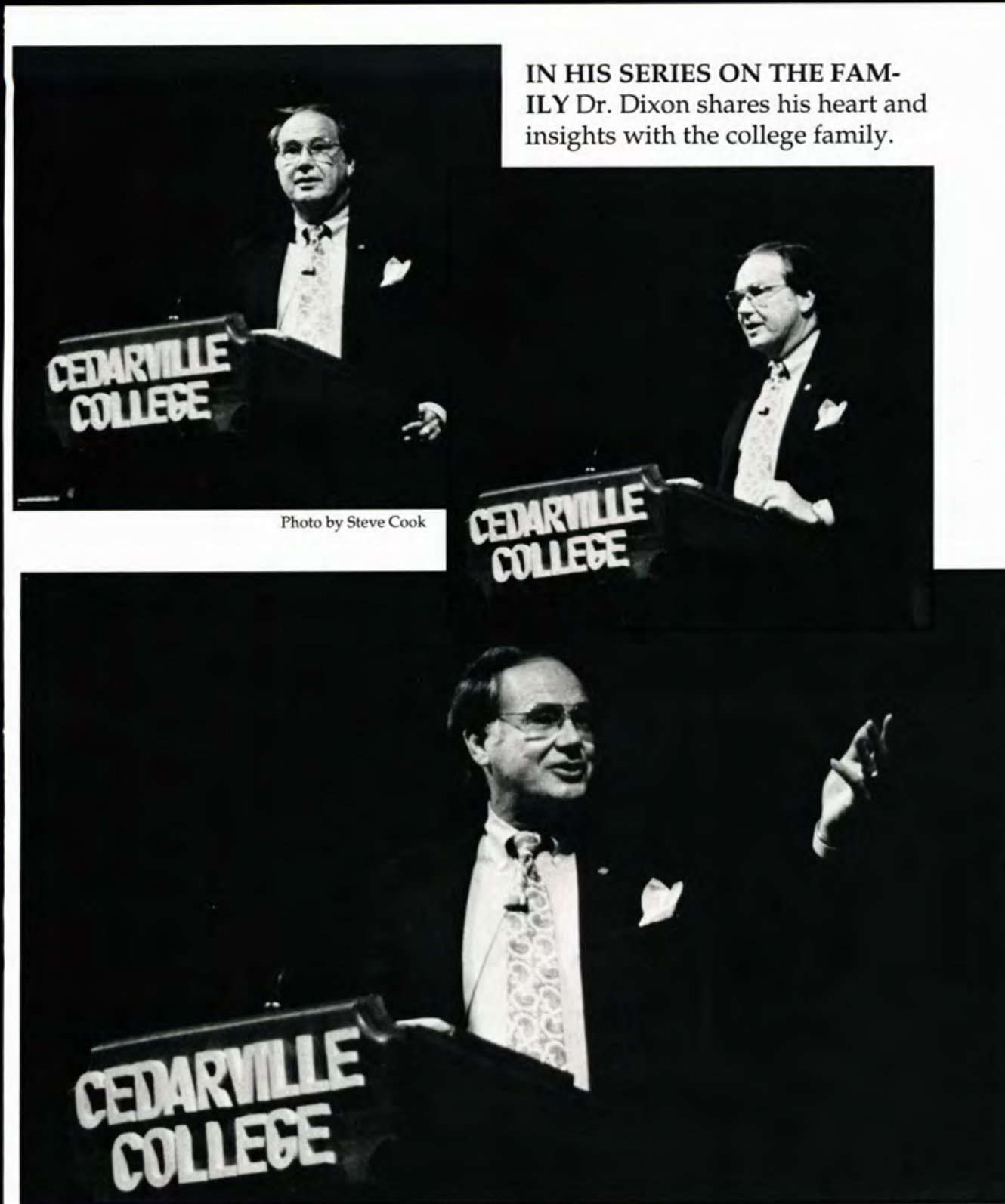

FALL BIBLE CONFERENCE SPEAKER, Dr.

Erwin Lutzer, challenges students to keep the dream alive.

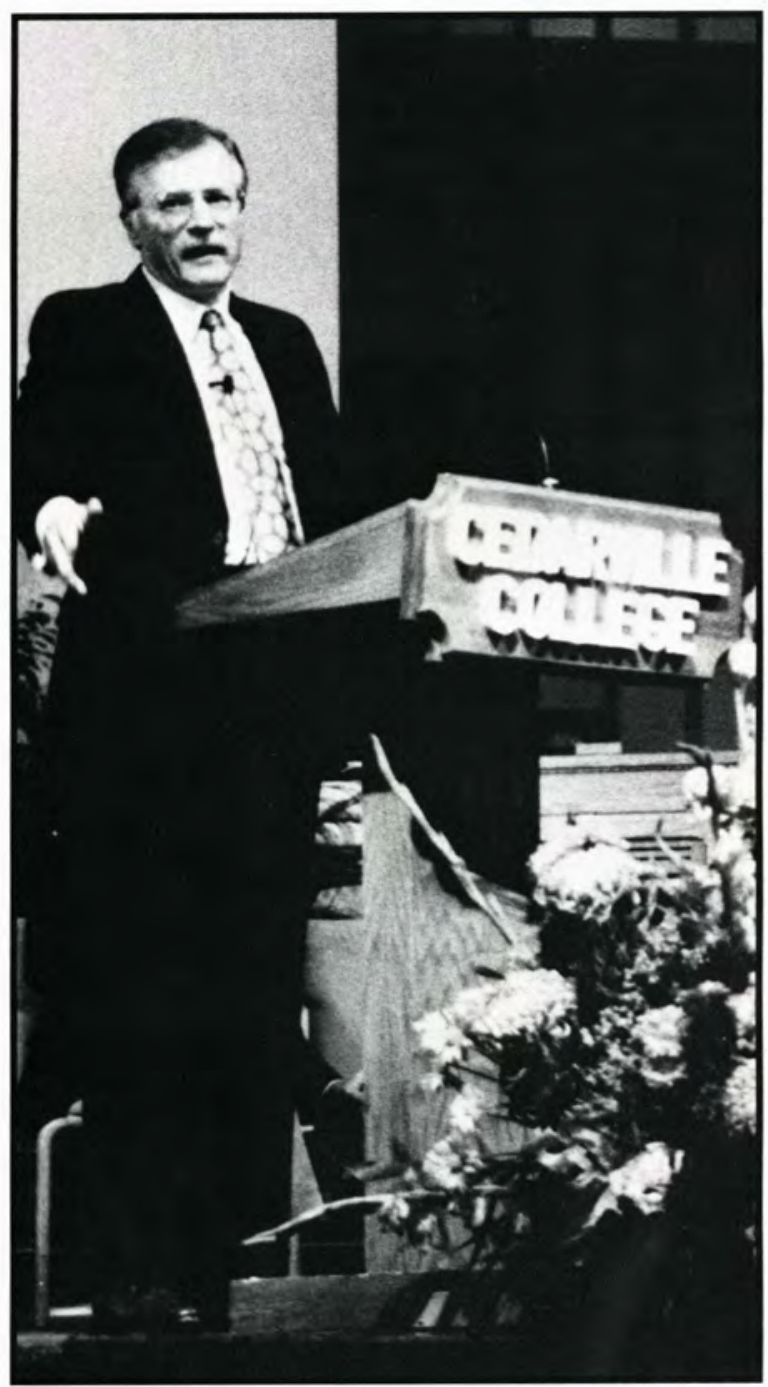

Photo by Steve Cook
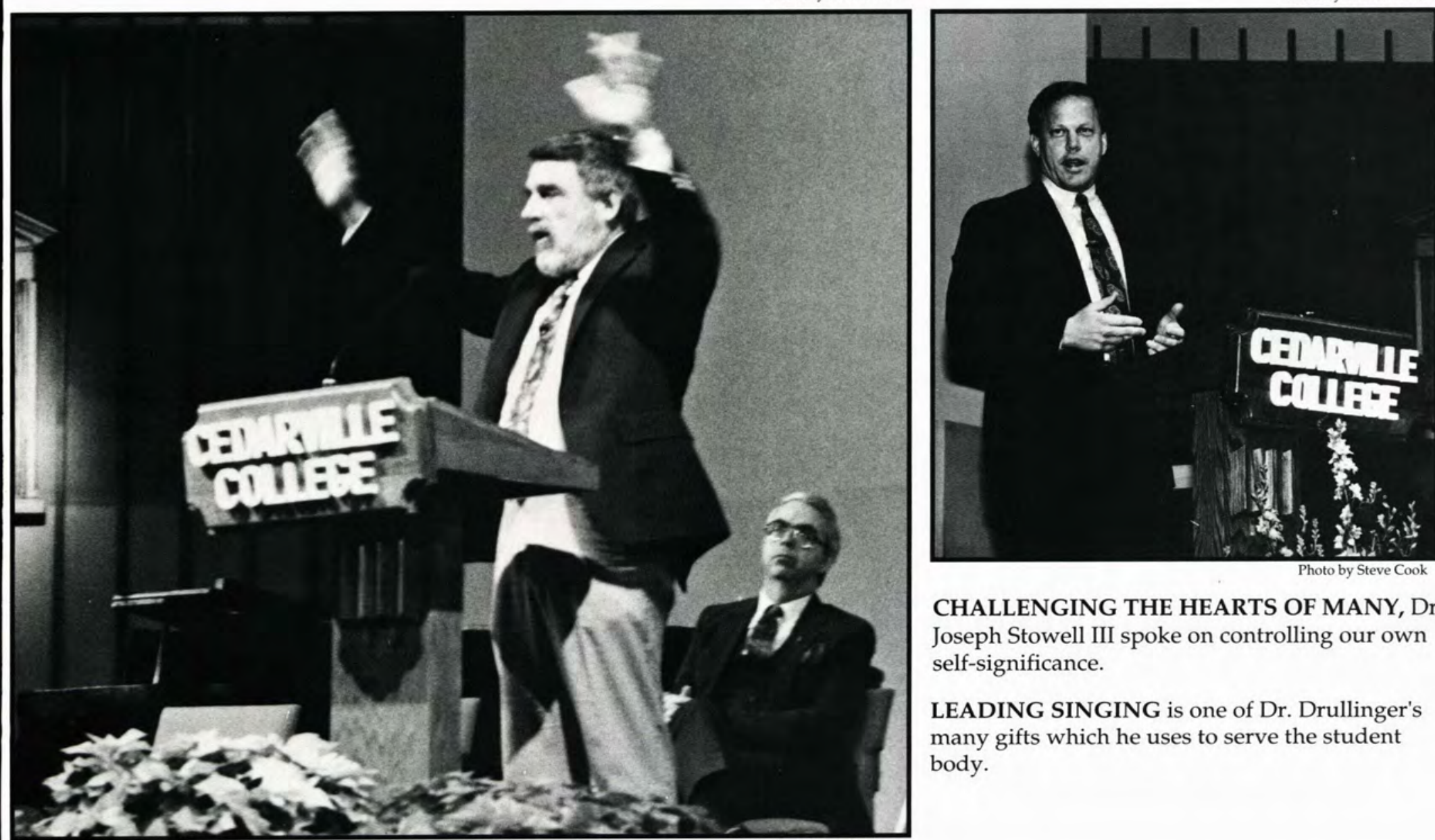

CHALLENGING THE HEARTS OF MANY, Dr.

Joseph Stowell III spoke on controlling our own self-significance.

LEADING SINGING is one of Dr. Drullinger's many gifts which he uses to serve the student body. 


\section{Time Out -- Back to the} Huddle

The biannual Day of Prayer redirects students, faculty and staff from the pursuit of knowledge to praise and petitioning of God. This day is an important one to many in the school because of the effects it has in the lives of the people for whom they pray. Many burdens are made lighter by sharing them and praying about them in a group setting. The closeness of the Day of Prayer both comforts and encourages those with concerns weighing on their minds. It also adds to the sense that Cedarville is not just a place to learn, but it is a community of brothers and sisters in Christ who are here to help each other grow. $\bullet$ Chris Reimers
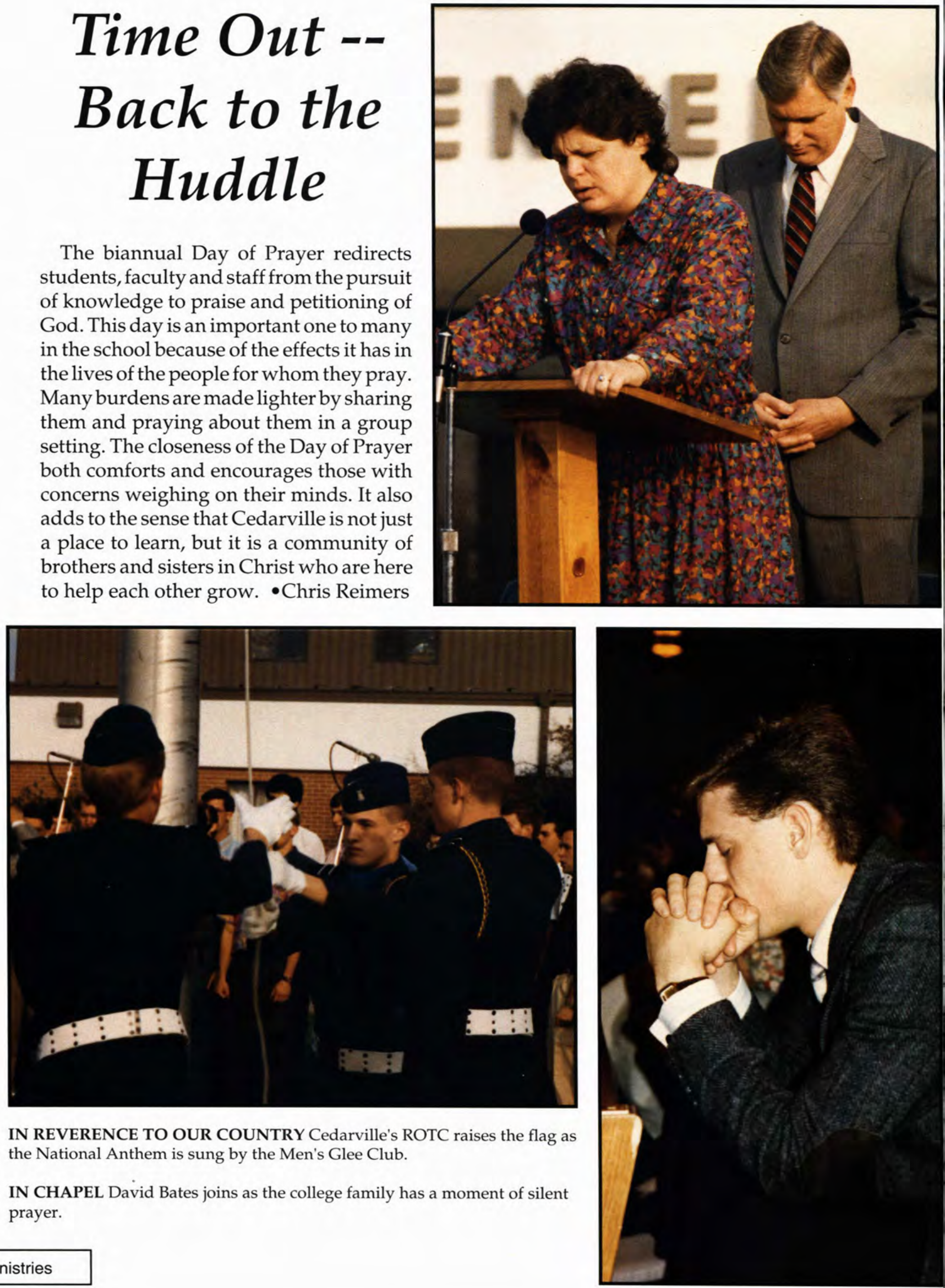

IN REVERENCE TO OUR COUNTRY Cedarville's ROTC raises the flag as the National Anthem is sung by the Men's Glee Club.

IN CHAPEL David Bates joins as the college family has a moment of silent prayer. 


\section{Traveling}

\section{Teams}

Carmen Bower,

Steve Caton, Melanie Dawson, Tracie Dennison, Jennifer Dilling, Christopher Handel, Bruce McKanna, Heather Rifenberick, Rob Reed, Doug Schmitt.

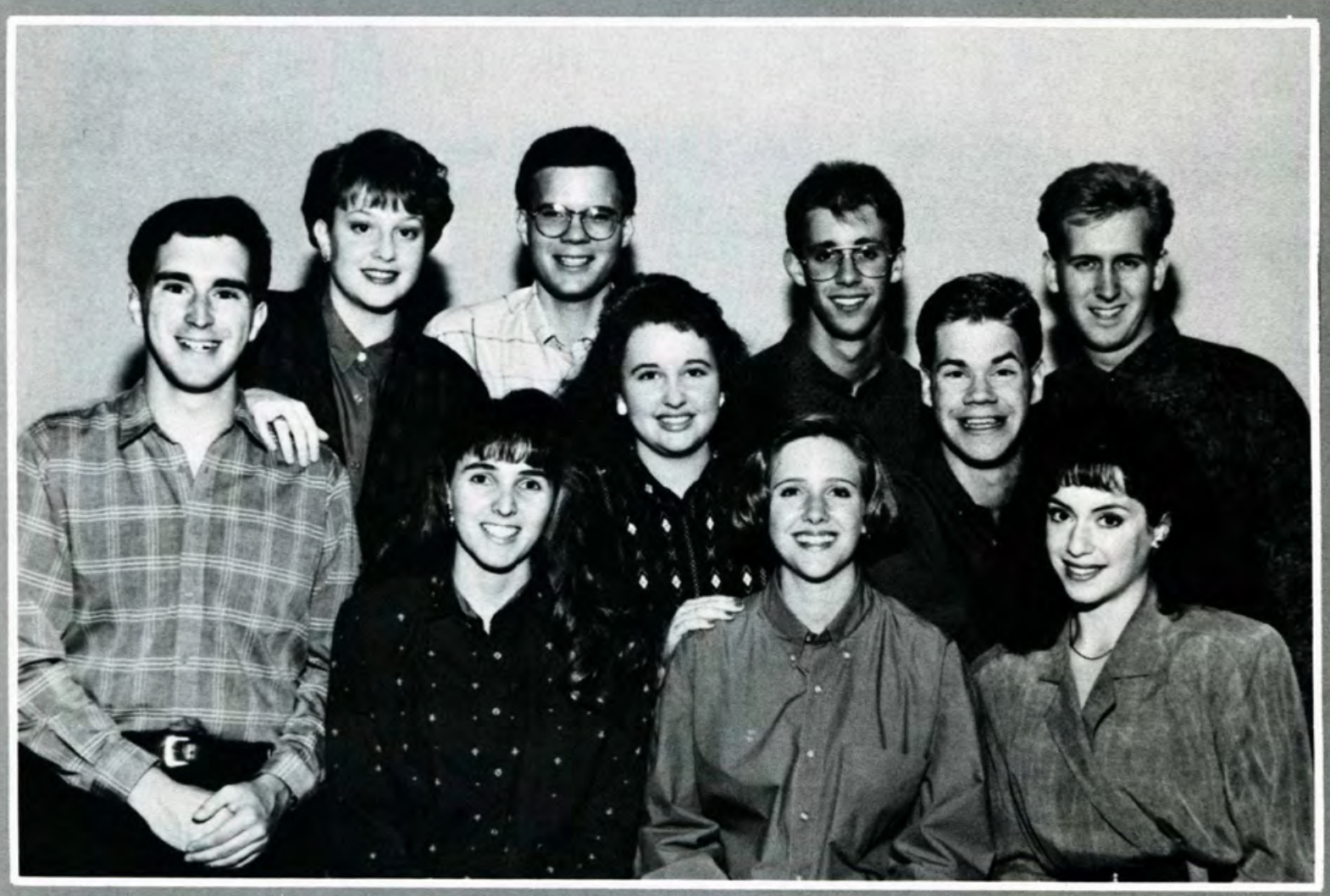

\section{Abundant Life Singers}




\section{Kingsmen Quartet}

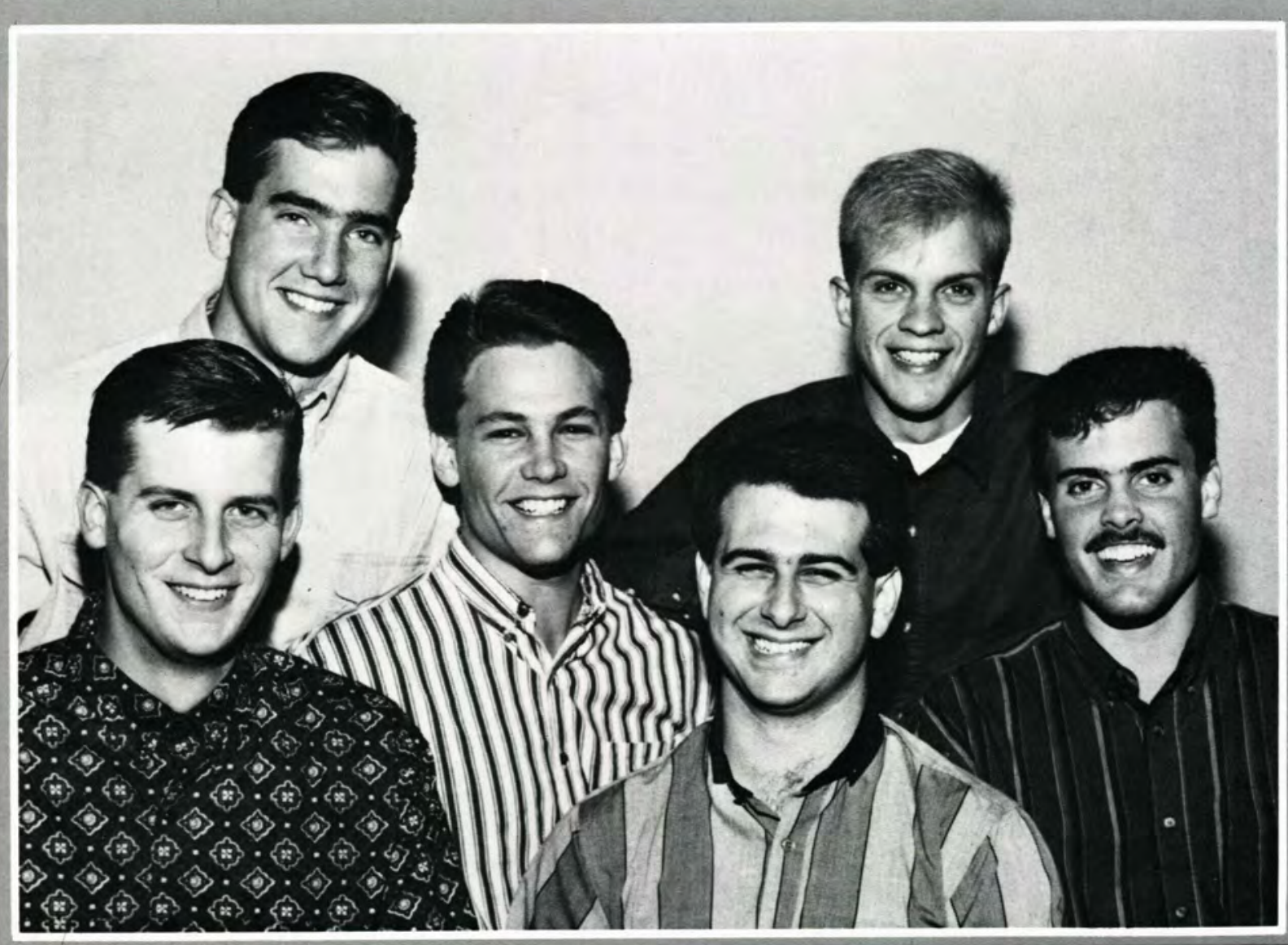

Paul Anderson, Matt Brown, Jay LeBlanc, Brian Megilligan, Brad Palmer, Chad Vitarelli.

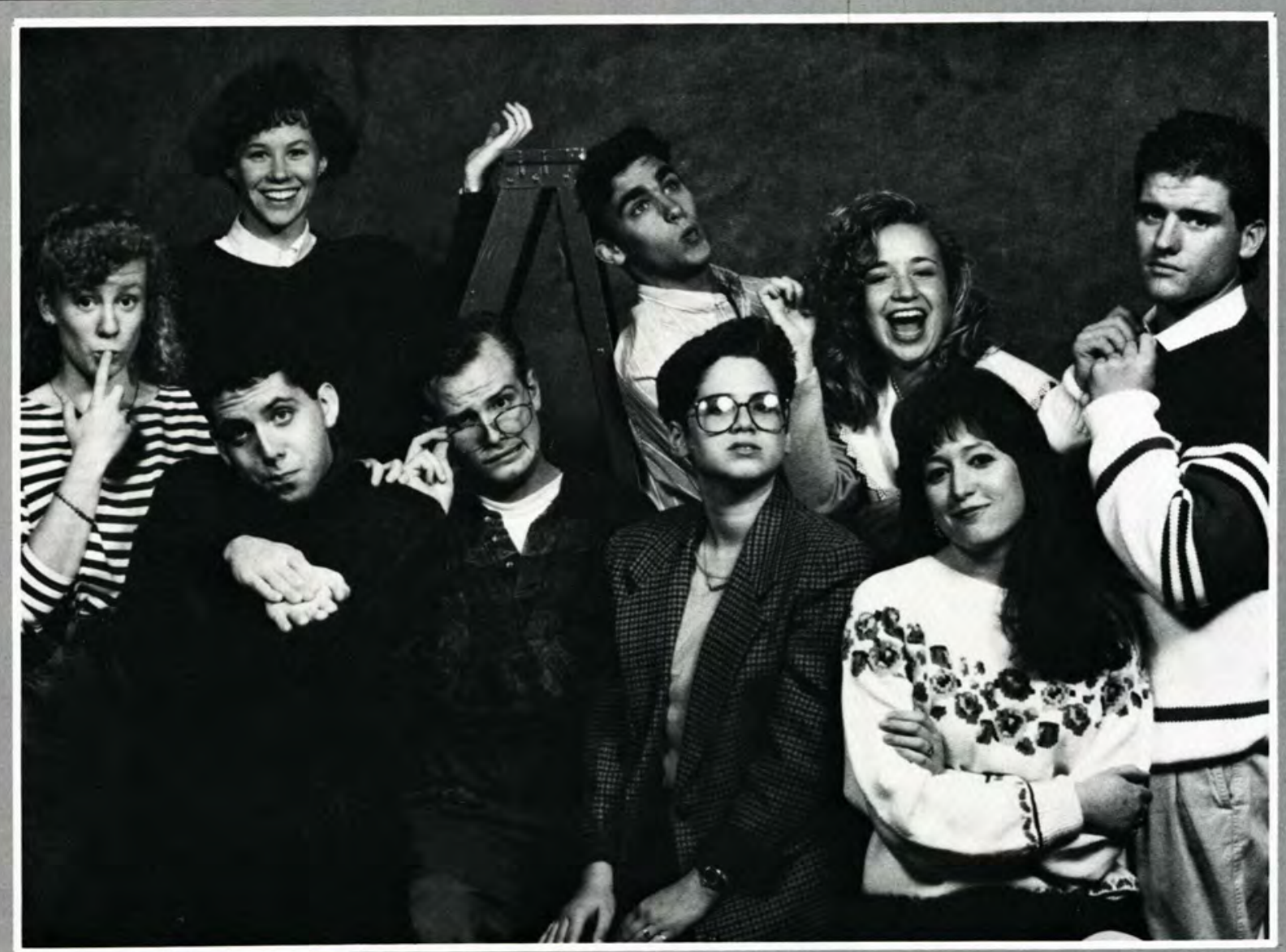

Mike Collins, Charles Dean, Carrie Grayson, Mark Jones, Lynda Michael, Jennifer Neudeck, Kevin Parliament, Ali Parsell, Jeanette Rome. 
Joseph Bowers, Angel Dugan, Todd Jenista, Lisa Keever,

Dan Neil, Lianne Wright.

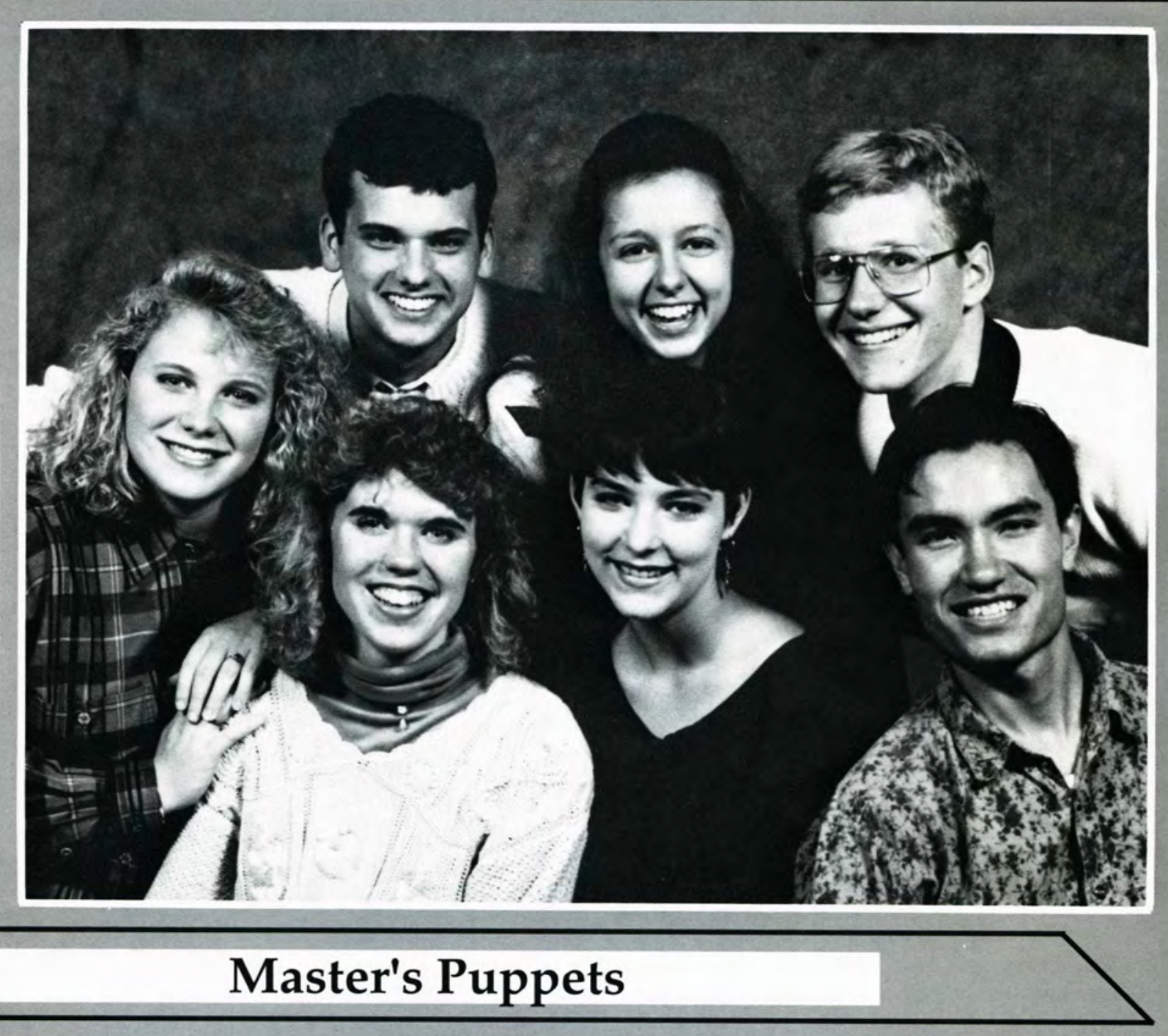

Colleen Chapin, Brett Dyson, Mark Irving, Debbie Rotman, John Terpstra.

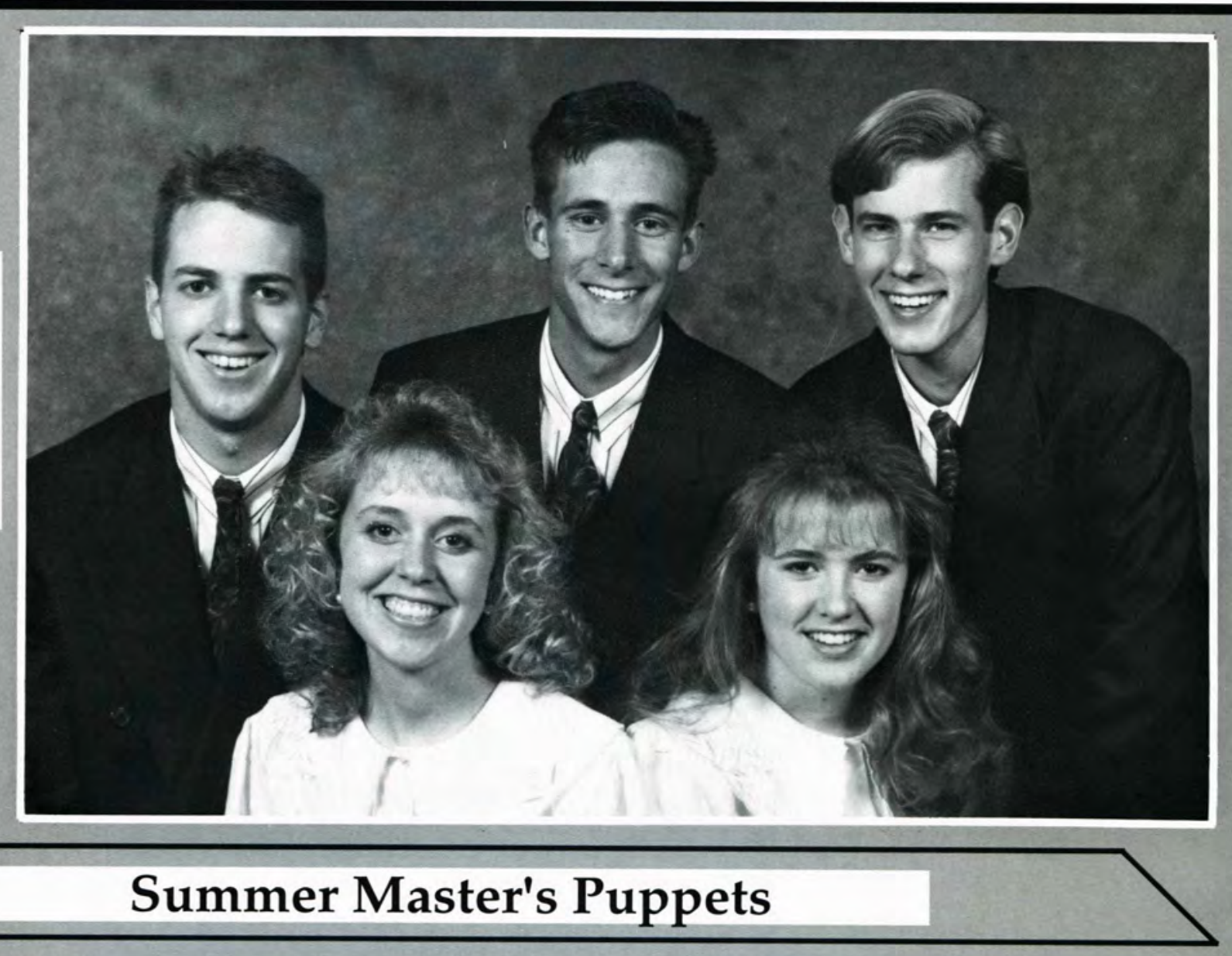




\section{Spring Swordbearers}
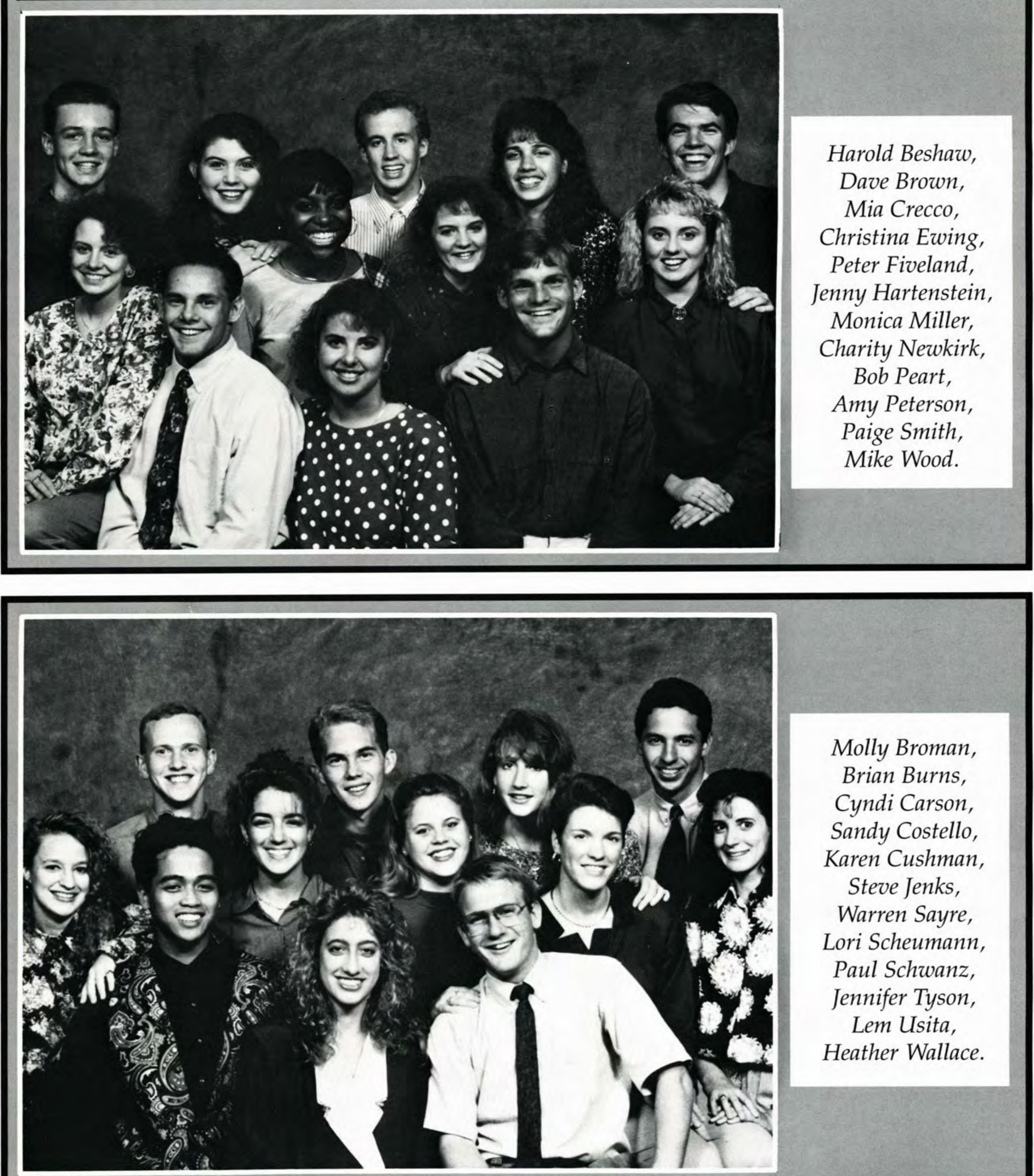

Molly Broman, Brian Burns, Cyndi Carson, Sandy Costello, Karen Cushman, Steve Jenks, Warren Sayre, Lori Scheumann, Paul Schwanz, Jennifer Tyson, Lem Usita, Heather Wallace. 


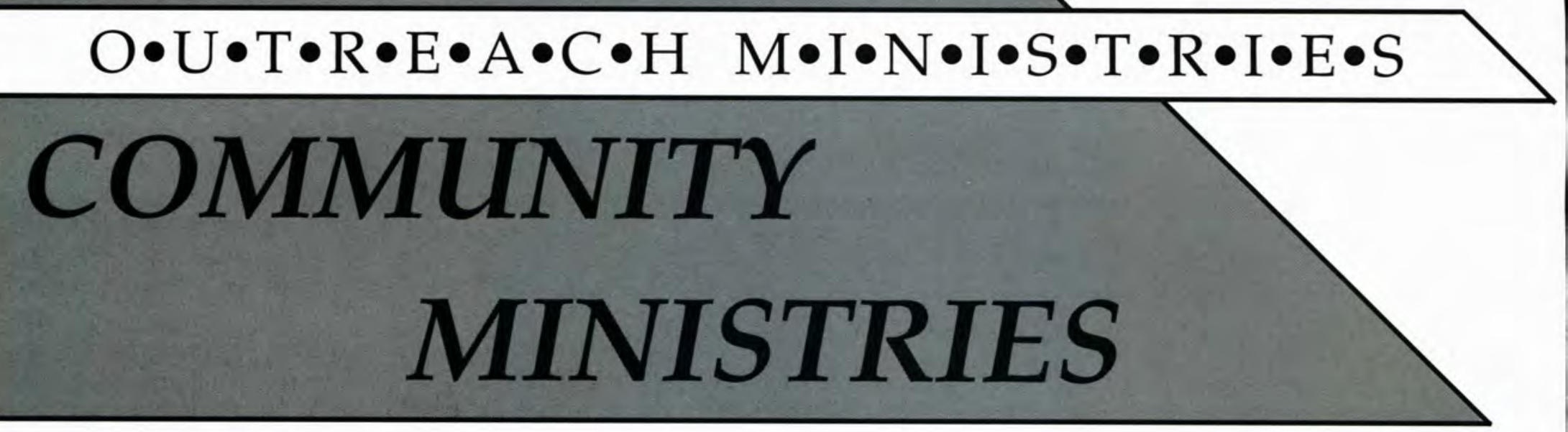

Adult Literacy provides an opportunity for Cedarville students to help adults at the Greene County Career and Opportunity Center whoare pursuing their GED degrees. In the process, students build friendships which often lead to excellent witnessing opportunities.

\section{Adult Literacy}

Front row: Cheryl Hyback, Shelly Eastlund, Lori Kate Lowenhar, Sandra Waddell, Elizabeth Moon. Second row: David Preston, Ben Rice, Julie Cone, Dawn McGlothin, Ruth Pfahler, Missy Harner. Back row:MattCutler,Scott Hartley, Becky Lunn, Jennifer Gozdan, Michele Dolbeck, Beth Greist.
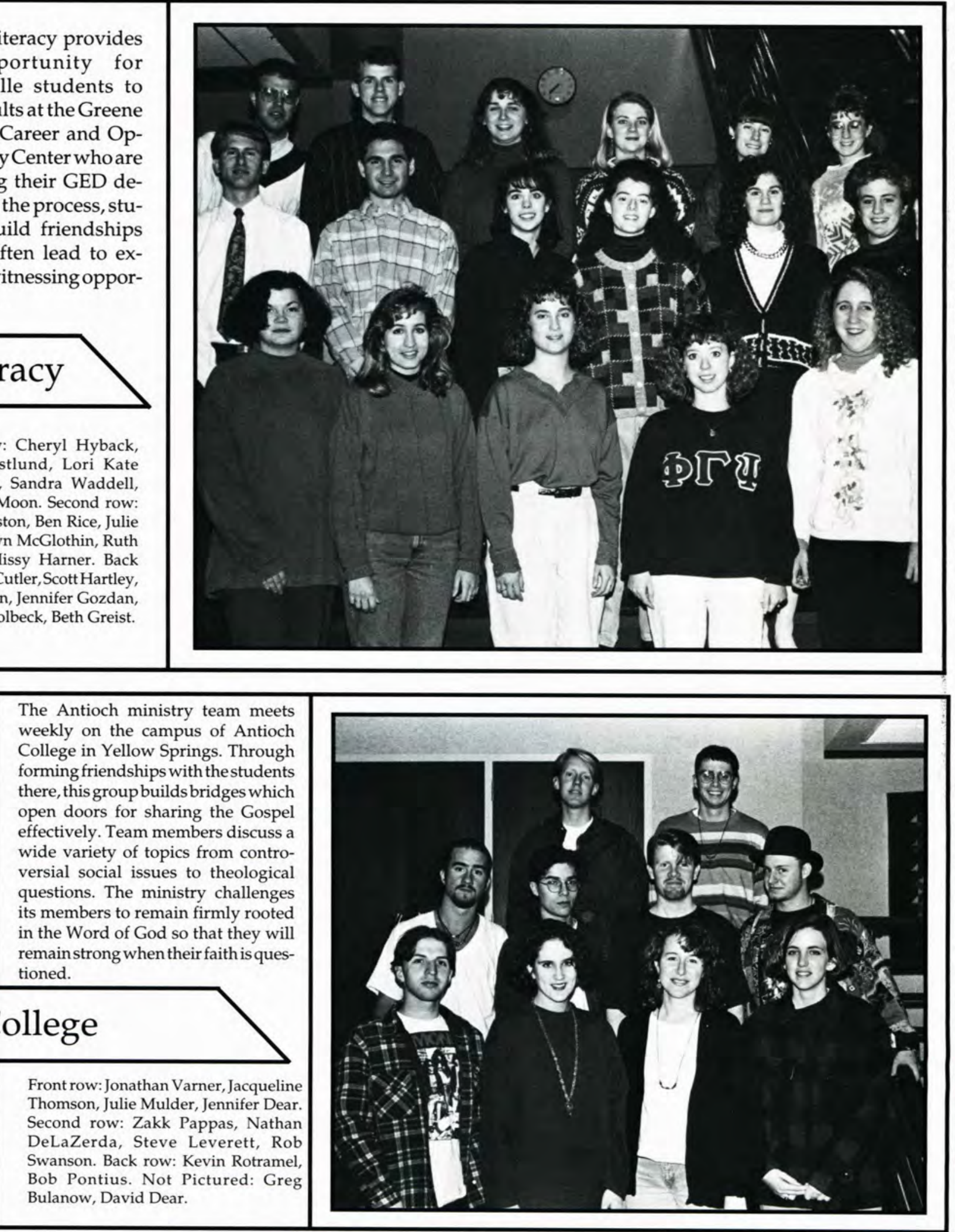
"Inasmuch as you did it to one of the least of these My brethren, you did it to me" (Matthew 25:40b). The Dayton Gospel Mission ministry team seeks to fulfill the physical needs of people while at the same time feeding their spiritual hunger with the Lord. The team goes to Dayton three times a week and meets once a week for prayer. The team serves food to the hungry, works with a group of children, and distributes clothing. Students strive to implement Christ's love in all they do at the missionwhether it be saying "hello" to an older member of the congregation or giving a hug to an inner-city child.

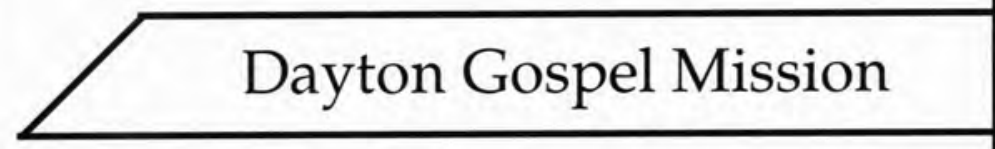

Front row: Michelle Yates, Sandy Hickox, Becky Sturrock, Mona Ludwig, Tiffany Howell, Amy Harbeson. Back row: David Moore, Clint Smith, Chris Wilson, Jeff Miller, Melissa Wall, Allison Broadhead. Not pictured: Abby Boone, Ron Miller, Tim Gardner, Carre Armstrong.

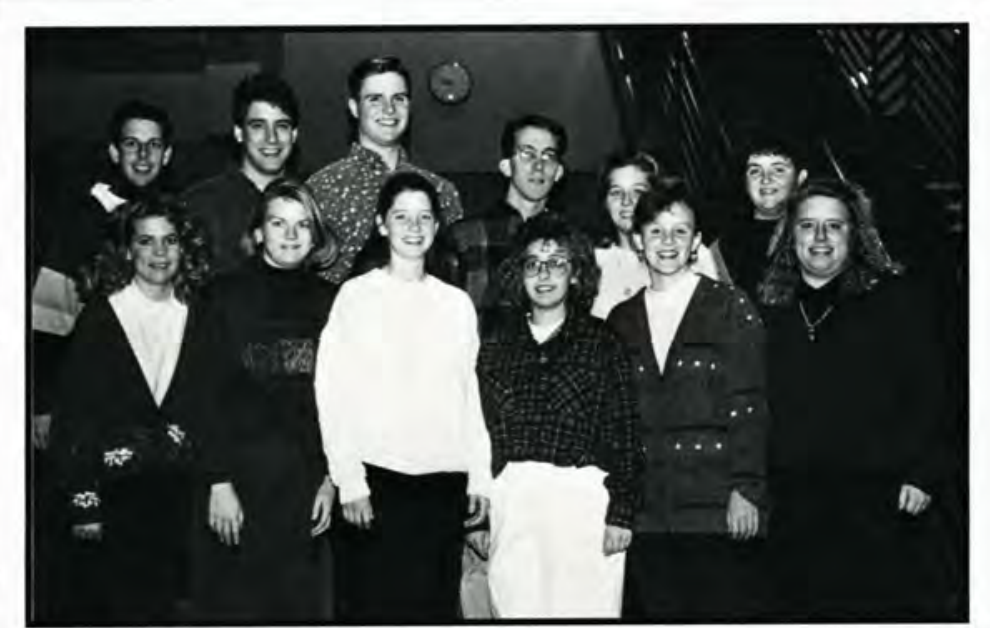

Twice a month, a group of Cedarville students goes to the Rescue Mission in downtown Cincinnati. They talk with the people there and hold a service of singing, drama, and preaching. During the service, some of the team members help prepare a meal. After the service, they help serve it to the needy of downtown Cincinnati. Serving the people while they eat during the meal gives the team a chance to talk about the service.

\section{Cincinnati Rescue Mission}

On floor (left to right): CyndiHeidorn, Joy McVey, Tracy Justice, Melissa Matthews, Mike Vrbanac, Tim Nicklas, Rebecca Berkheiser, Andi Schimmenti. On stairs (from top to bottom): Kevin Shoop, Kevin Vaughn, Kevin Kuczynski, Anthea Bertelson, Rhonda Carnahan, Janelle Jackson, Mary Jo Brooks, Susie Jones.

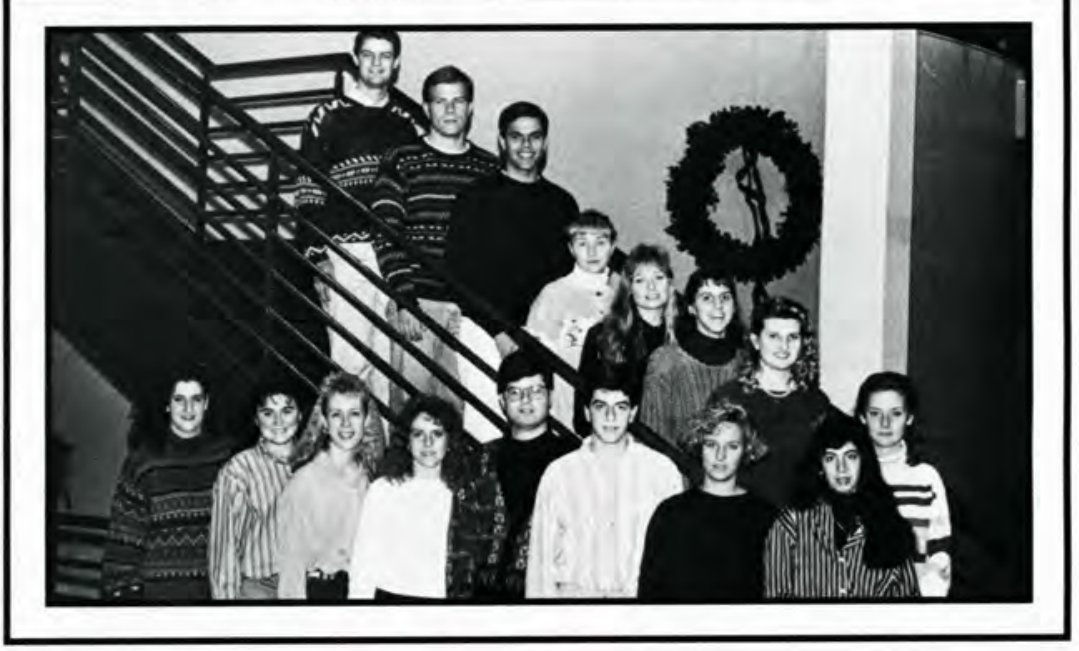

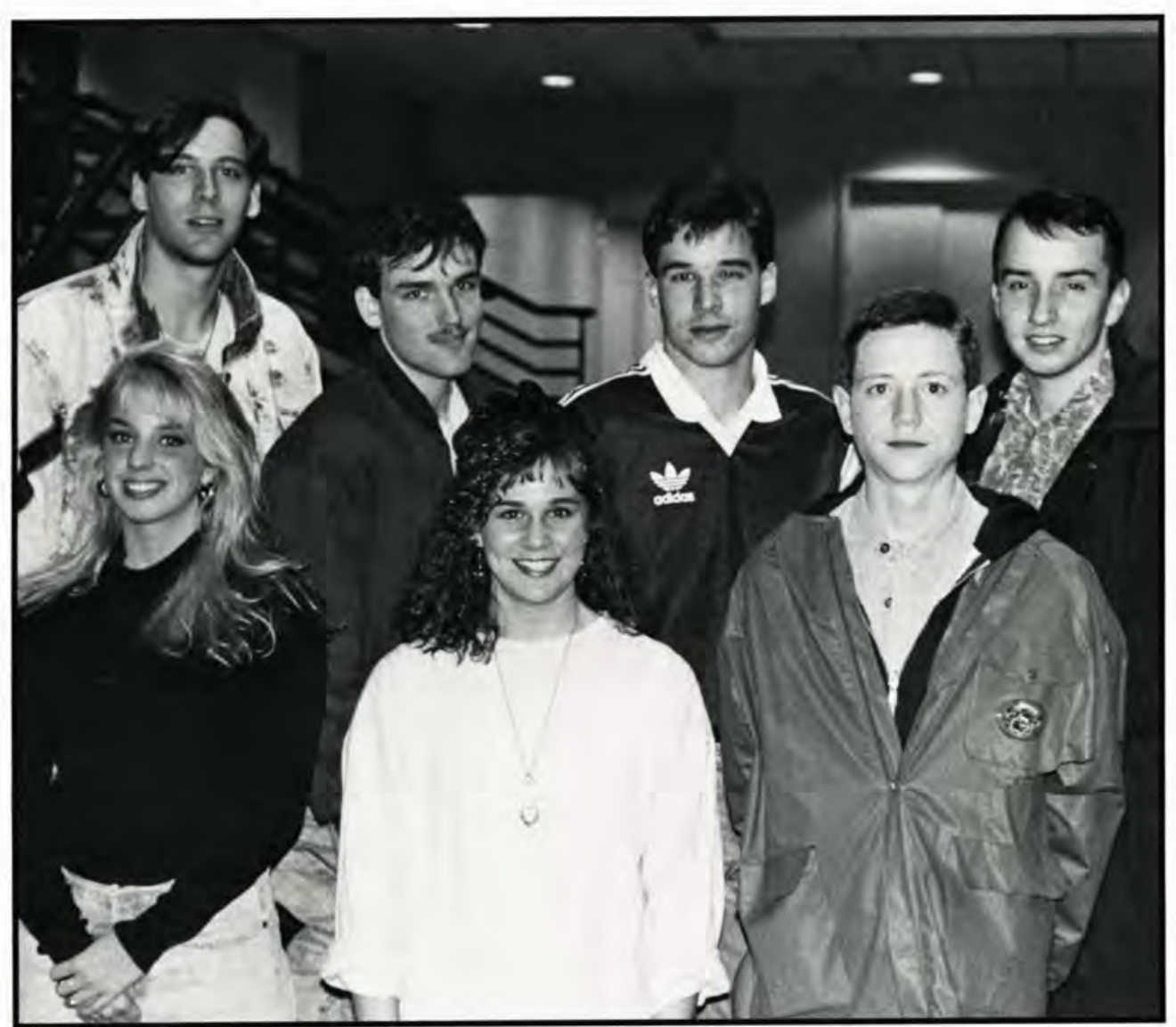

A new ministry this year, this team sought to use "any means possible" to witness for Christ on the campus of Wittenberg University in hopes that they would see other collegestudents come to Christ. They used water polo, open forums, room-toroom contact, and whatever else they could think of to share the gospel on a rather reserved and wealthy campus. Through both success and frustration, they saw God working out His purposes in ways they did not expect. James 5:1-11 encouraged them as they tried to be patient in watching His will fulfilled.

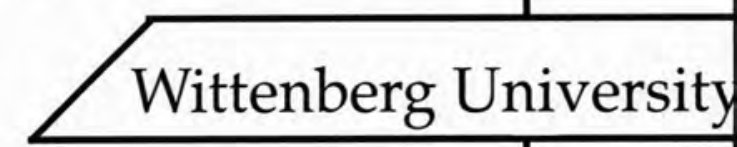

Front row: Rebecca Kroner, Pam Rutledge, Adam Wilson. Backrow: Christopher Eckart, Eric Phillips, Michael Passineau, Steve Whalen. 
Front row: Melanie Walter, Michelle Green, Laura Roseboom. Back row: Paige L. Wolfanger, Christina Braley, Kathy Streicker, Sara Taylor.

\section{Miami Valley CPC}

The ministry at Miami Valley Crisis Pregnancy Center does not focus on stopping women from having abortions, but rather on sharing Christ with those who come into the center. Working at the Crisis Pregnancy Center requires much compassion for these women, as well as faith and courage to speak to them. Although contact with the women is usually limited to one visit, God can use that visit to plant the seeds of His Word.

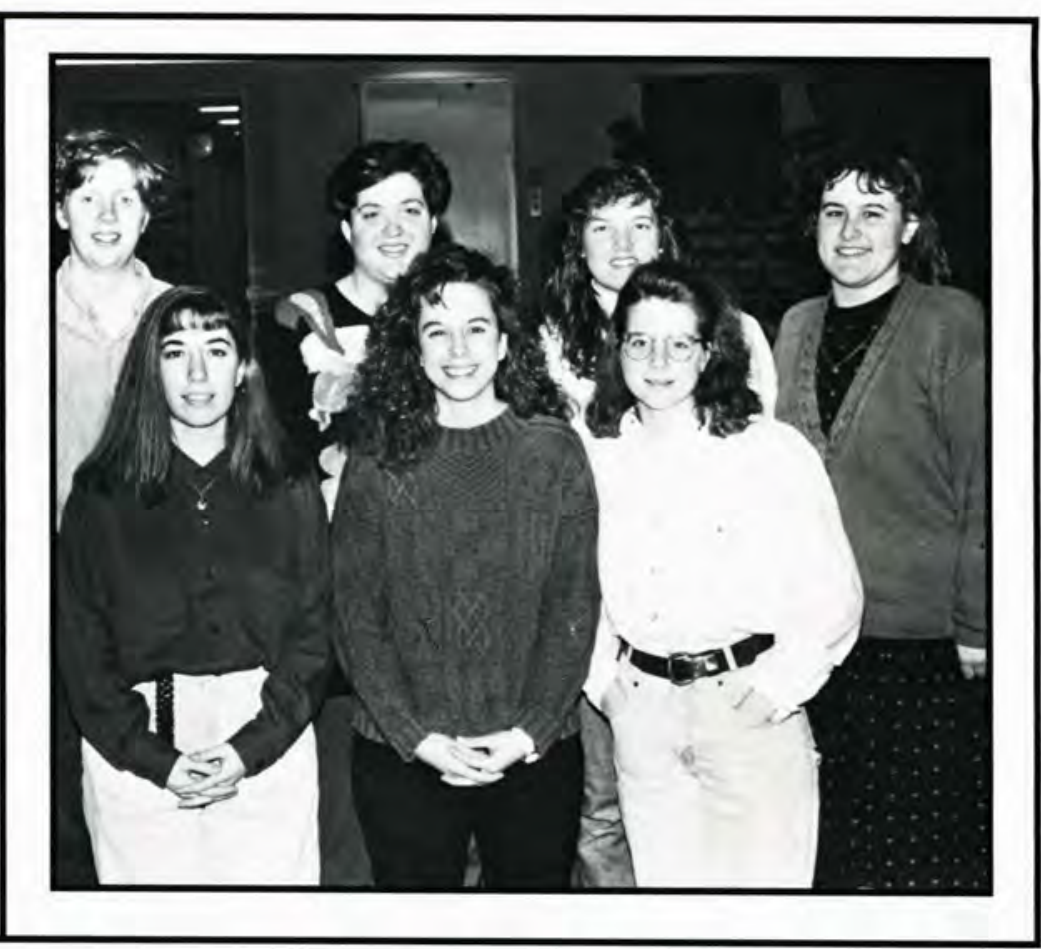

The ministry team that serves at the Springfield Crisis Pregnancy Center is made up of Office Technology, Business Communications Technology, and Business Education majors. They serve at the CPC by helping out in the office. Handling patient files and doing other paperwork for the center frees up the counselors so that they can spend more of their time with their clients.

\section{Springfield CPC}

Floor (left to right): Abby Mc Queen, April Seely, Traci Emes, Julie Fiorito, Ondrea Mullins, Missy Harner, Rebecca Scott. Stairs (top to bottom): Lisa Lightly, April Case, Kris Thorsen, Deanna Osborn, Deidre Moore, Dorothy Marner. Not pictured: Rachel Creekmur, Jenny Rotroff.
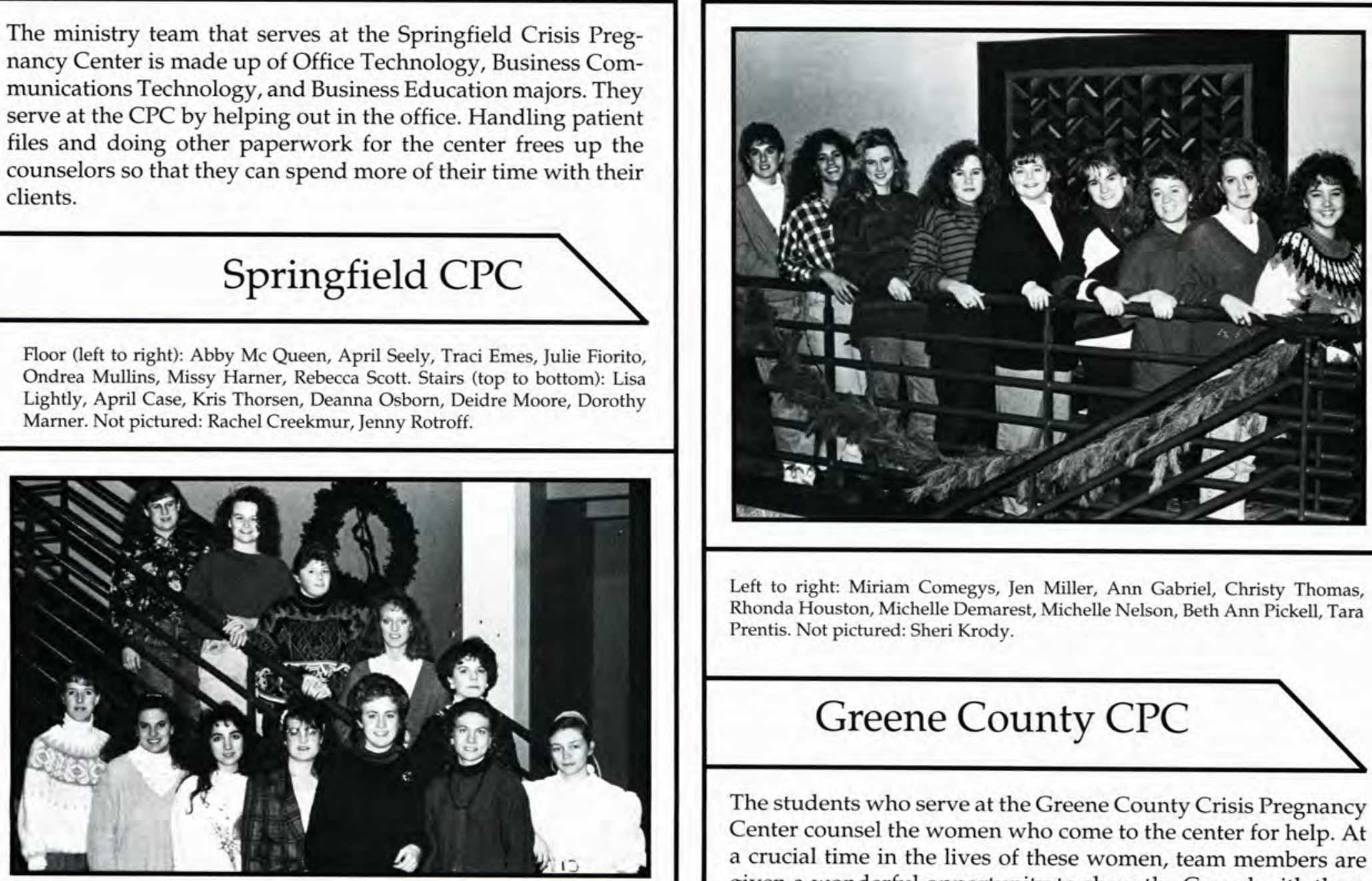

Left to right: Miriam Comegys, Jen Miller, Ann Gabriel, Christy Thomas, Rhonda Houston, Michelle Demarest, Michelle Nelson, Beth Ann Pickell, Tara Prentis. Not pictured: Sheri Krody.

\section{Greene County CPC}

The students who serve at the Greene County Crisis Pregnancy Center counsel the women who come to the center for help. At a crucial time in the lives of these women, team members are given a wonderful opportunity to share the Gospel with them and counsel them whether their test results are positive or negative. Along with counseling, the center provides clothing, furniture, housing, and other services to women in need. 


\section{$\mathrm{Y} \bullet \mathrm{O} \bullet \mathrm{U} \bullet \mathrm{T} \bullet \mathrm{H} \quad \mathrm{M} \bullet \mathrm{I} \bullet \mathrm{N} \bullet \mathrm{I} \bullet \mathrm{S} \bullet \mathrm{T} \bullet \mathrm{R} \bullet \mathrm{I} \bullet \mathrm{E} \bullet \mathrm{S}$}

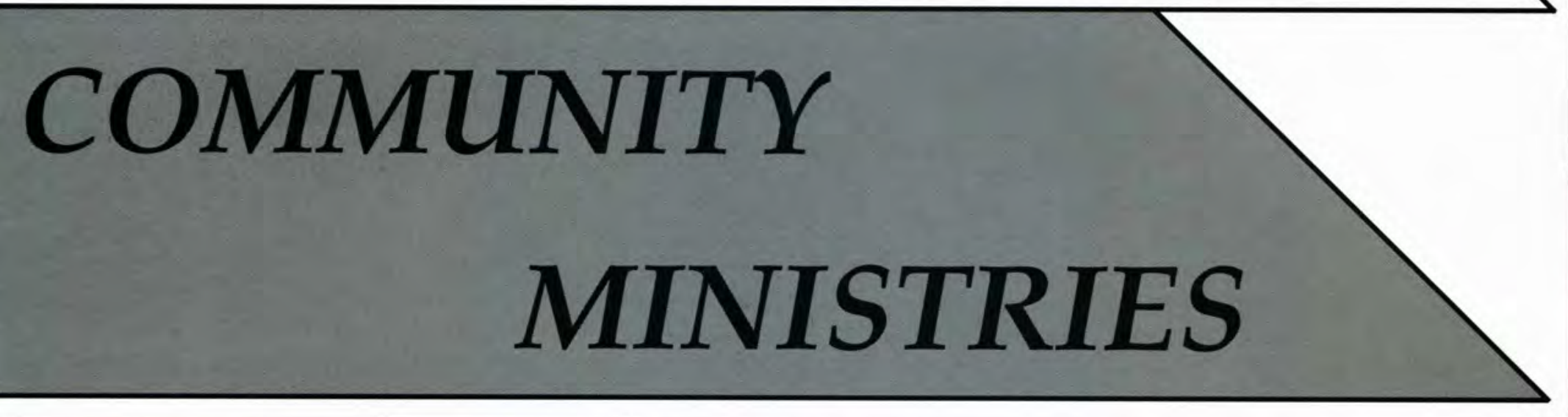

1st Airborne, also known as Dayton Children's Ministry, travels to Parkside (Dayton's Projects) every Saturday and spends several hours with the children living there. The activities include everything from songs and stories to coloring and ping pong. The children look forward to seeing the team members and will often ask where someone is if he or she is not there. The team rejoices that a ten-year-old girl made a decision for salvation only a few weeks after they began going to Parkside. The name "1st Airborne" comes from I Thessalonians 4:17 which says we "will be caught up together with them in the clouds to meet the Lord in the air." The team prays that as a result of this ministry, many more children will join those who will be airborne when Christ returns.

\section{1st Airborne}

Front row: Pearl Huber, Janet Bonga, Jennifer Butler. Second row: Kathy Wainwright, Jeffrey Gabbard, Christy Lyn Sarkisian. Third row: Dennis Moles, Timothy Courtright, Christopher Ehlers. Back row: Jon Pickens.

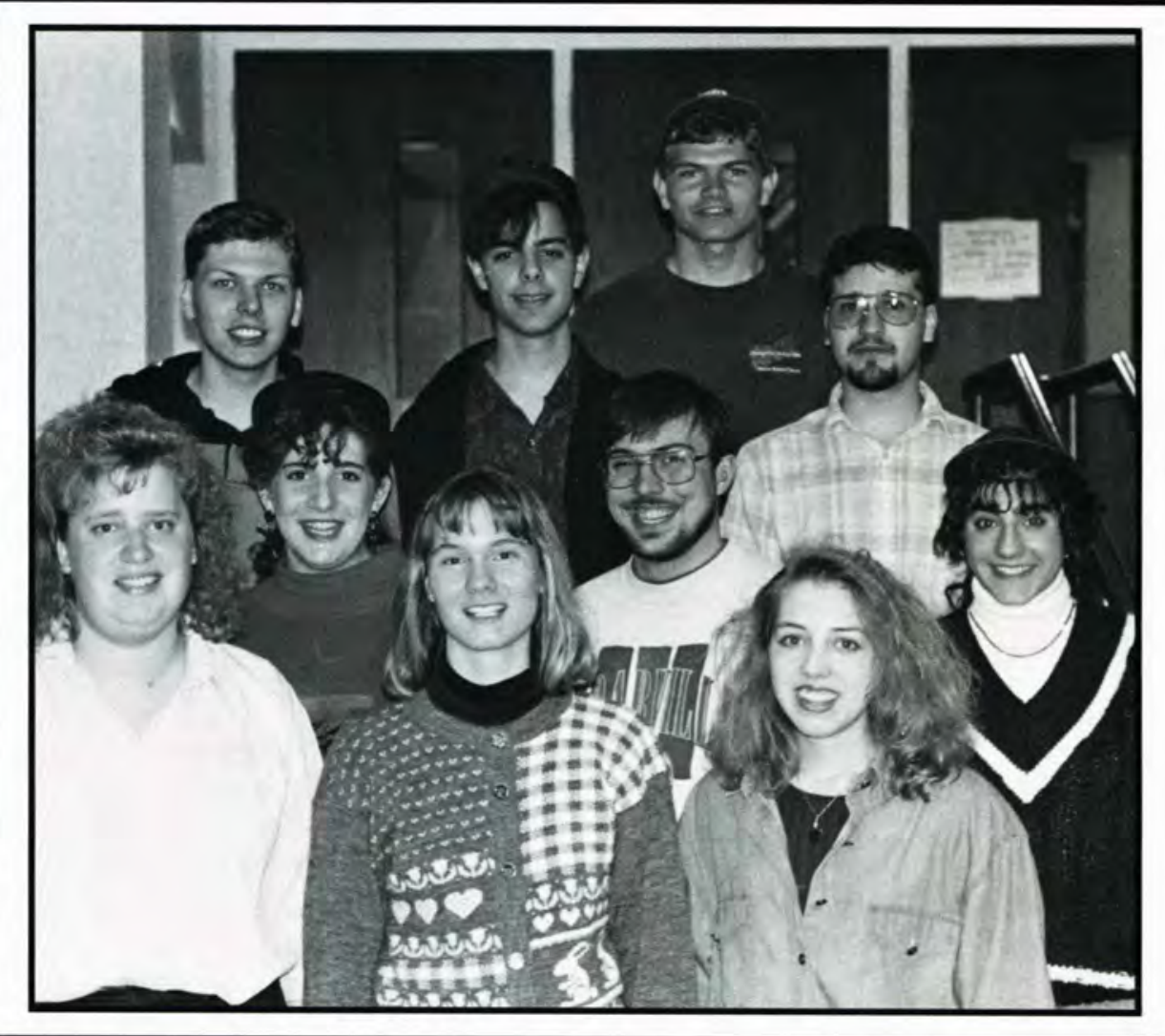

Individuals involved in the Bible Clubs ministry seek to reach out with the Gospel to youngsters in the area. They meet with area children after school one day a week for Bible stories, songs, games, and snacks. Besides their weekly meeting, each member tries to spend some time one on one with a child during the week.

\section{Bible Clubs}

Front row: Rebecca Wine, Anne Rinehart, Spring Cadwell, Amy Brubaker, Elta Hamblen. Second Row: Jennifer Habegger, Rebecca Wright, Melissa Honeywell, Jennifer MacFarquhar, Heidi Ann Wolters. Back row: Jen Warriner, Agnes Biddle (Director), Janeen Whitney, Chris Terry, Cherith Somerville, Stephanie Wilson.

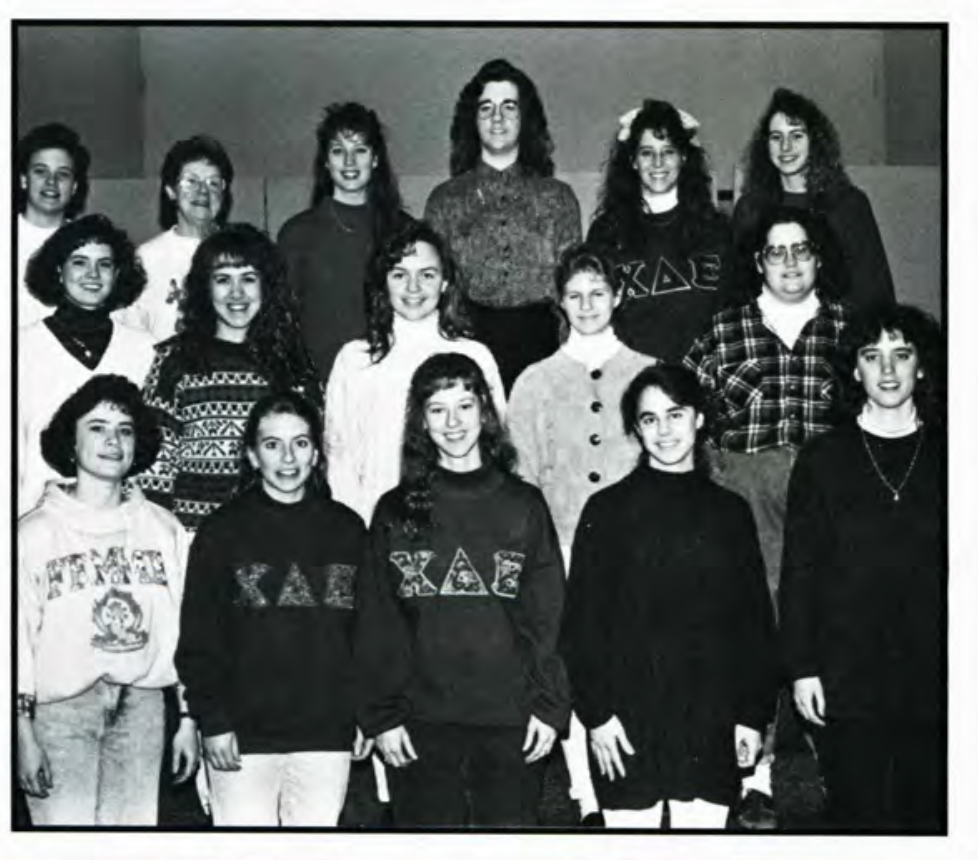


College partners are college students who team up with elementary students from the area. The college student meets with his or her individual partner at least once a week to provide friendship and to participate in activities that will bean encouragement to the child. Some of the children come from unstable homes, and college partners become a positive influence for the children. Each college student strives to be a friend and mentor for his or her partner.

\section{College Partners}

Front row: Keila Whittaker, Molly Ward, Karie Kuster, Janet Chezik. Second Row: Melissa Meyers,Stephanie Kirchoff, Sena Lund,HeidiGritsavage,Heather C. Fulton. Back row: Ken Kolesar, Juan Herrick, Jim Swigart, Andy Jamieson.

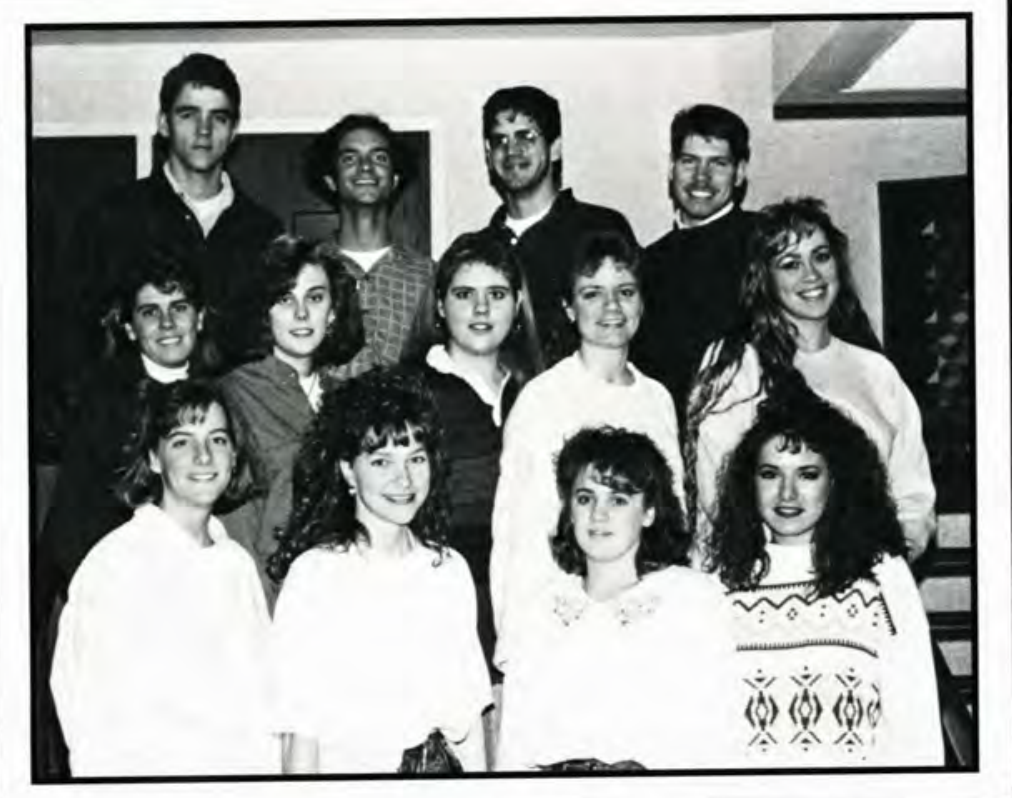

Honors Tutoring involves helping students of CedarCliff schools in their academic pursuits. Through tutoring, team members get to know students and are given opportunities to witness to them. They also place a priority on praying for the needs of those they tutor.

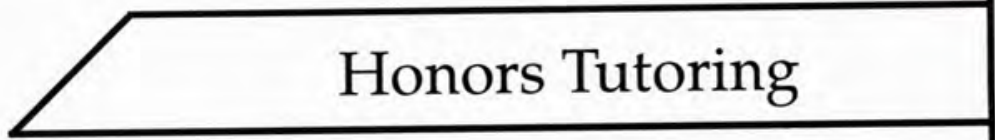

Front row: Michelle Lynn Perry, Amy Andrews, Joyce Colangelo. Second row: Amy Davis, Kim Veneberg, Kim Gurry, RachelSearcy. Back row: Matthew Boehm, Laurel Barnhart, Martha Shrubsole, David Heim.

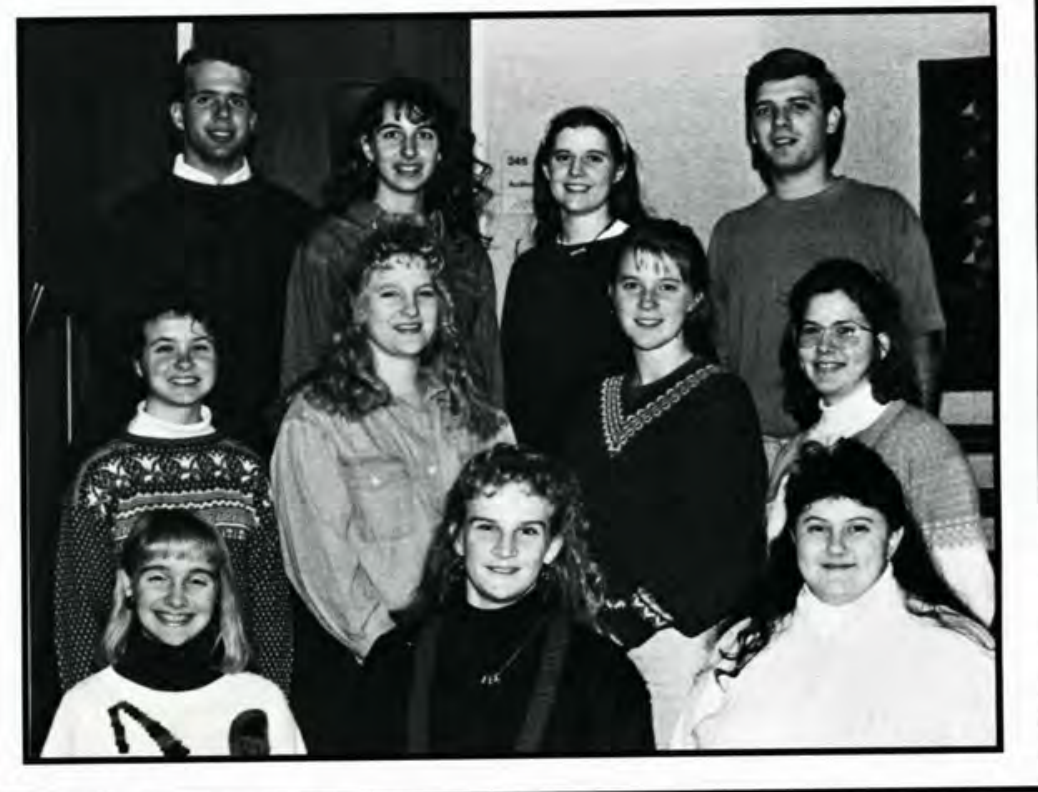

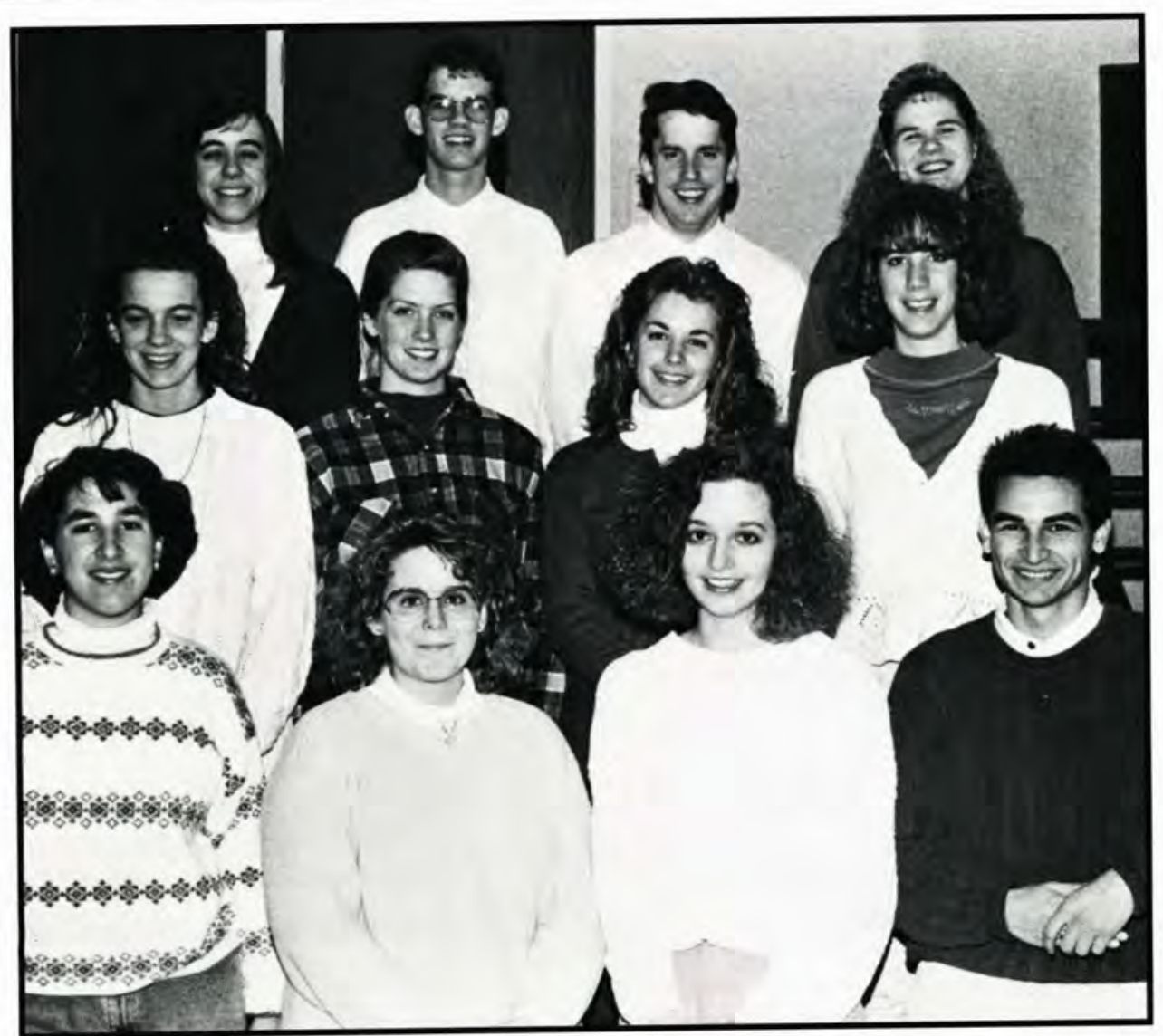

Front row: Rebecca Gerendas, Jenn Mc Namee, Amy Brien, Lee Martin. Second row: Yvonne Stutzman, Kimberly Guyn, Kristen Williams, Kimberly Hazekamp. Back row: Georgia Hickman, Joshua Corner, Shane Blansette, Erin Wawro.

\section{CedarKids}

CedarKidsseeks to reach children in the village of Cedarville. CedarKids meets each Monday in the Maddox co-ed lounge for a time of Bible verses, Bible stories, songs and games. The CedarKids team desires to see these kids come to know Christ or grow in their walk with Him. By taking timeeach week to get to know these kids in a personal way, the team has been able to encourage the kids and to be encouraged by them. 
Located near the village park, the Cedarville Youth Center gives high school students in the community a place to go after school. This group of college students goes to the center for at least an hour a week to supervise planned activities. Through this ministry, team members build friendships with Cedarville teens and develop opportunities to share their Savior with them.

\section{Youth Center}

Right to Left: Jenna Coakley, Nathan $\mathrm{Hu}$, Brent Underwood, Brian Naess, Brian Harriman, Derek Johnson.
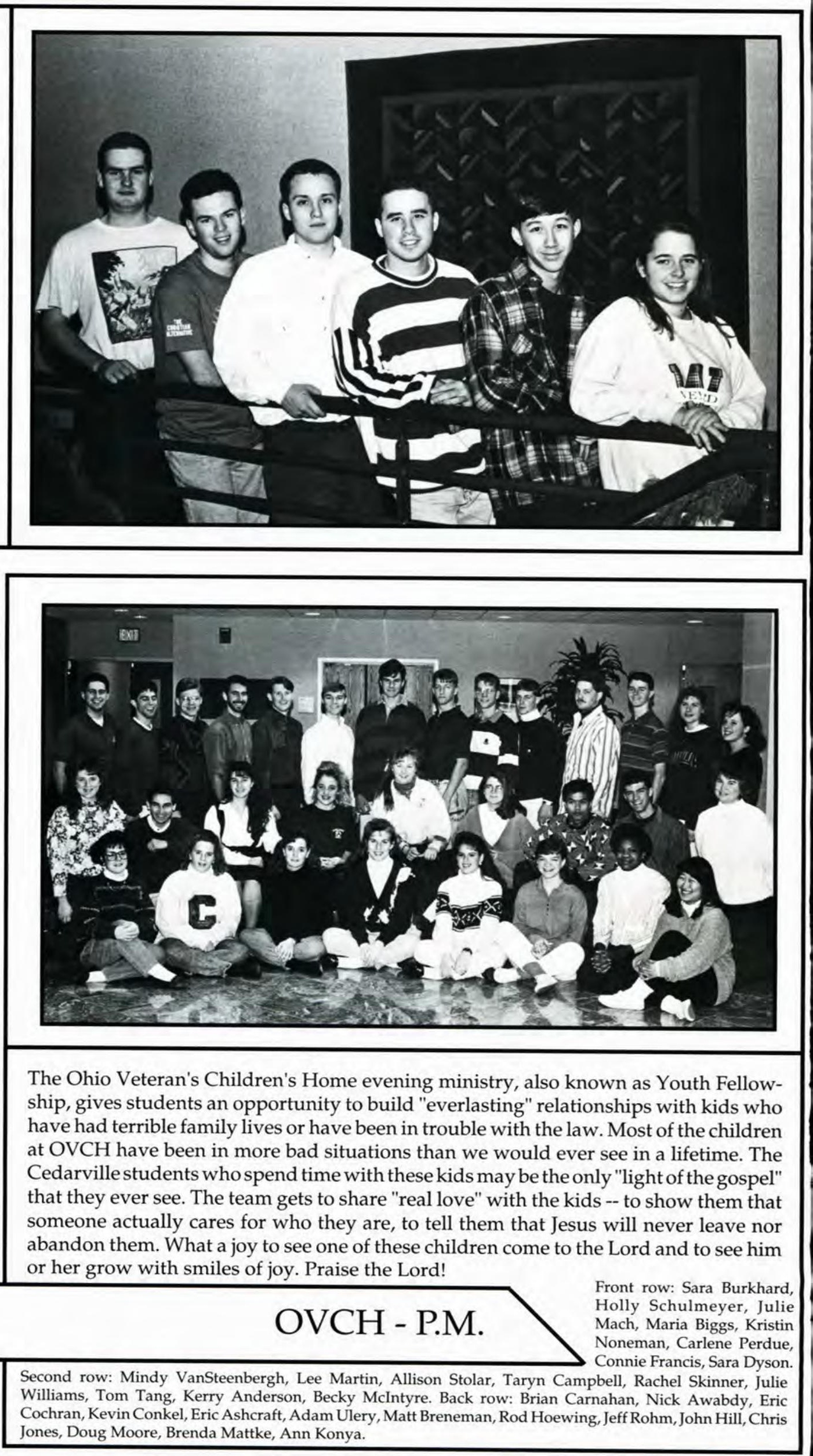

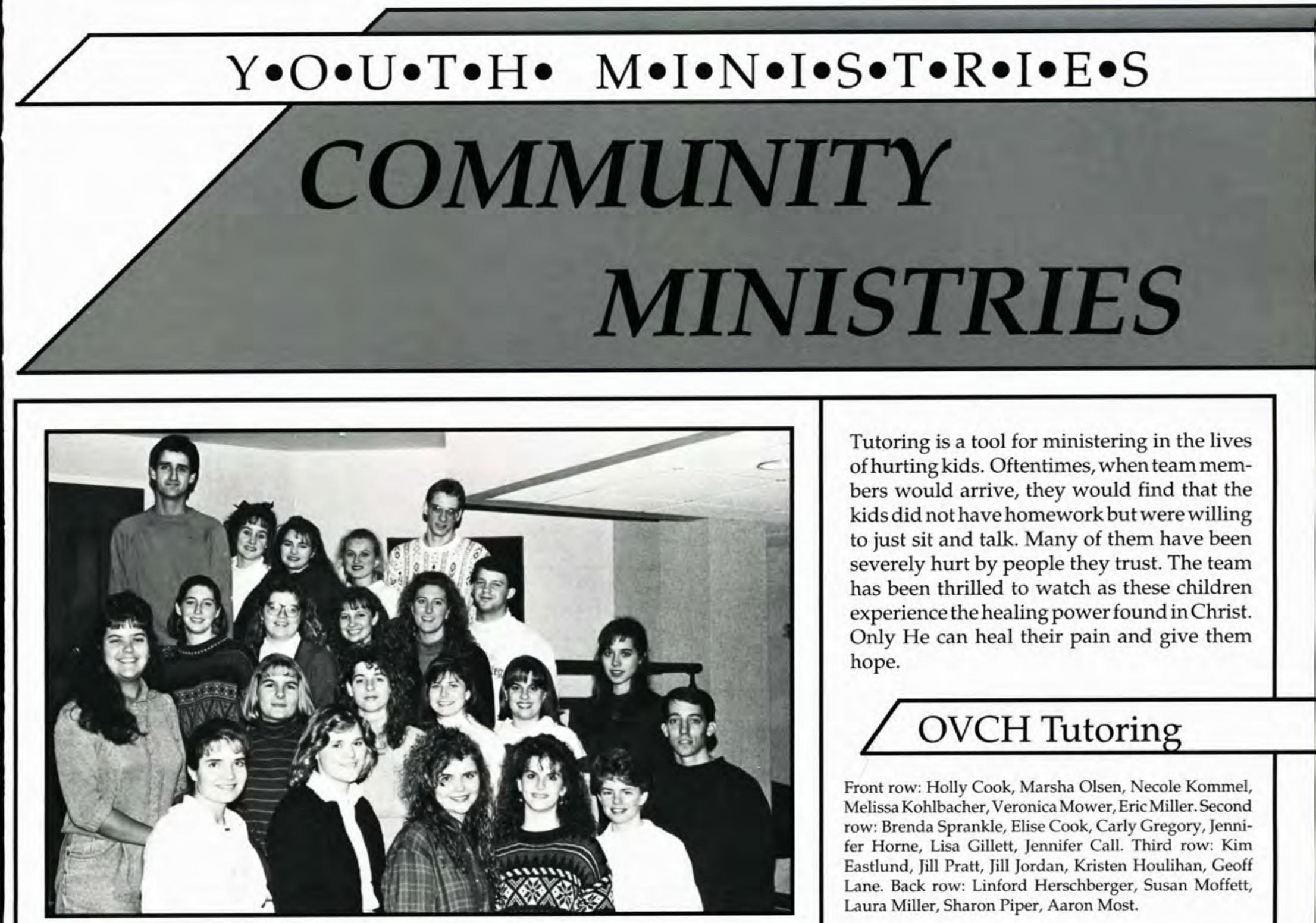

Tutoring is a tool for ministering in the lives of hurting kids. Oftentimes, when team members would arrive, they would find that the kids did not have homework but were willing to just sit and talk. Many of them have been severely hurt by people they trust. The team has been thrilled to watch as these children experience the healing power found in Christ. Only $\mathrm{He}$ can heal their pain and give them hope.

\section{OVCH Tutoring}

Front row: Holly Cook, Marsha Olsen, Necole Kommel, Melissa Kohlbacher, Veronica Mower, Eric Miller.Second row: Brenda Sprankle, Elise Cook, Carly Gregory, Jennifer Horne, Lisa Gillett, Jennifer Call. Third row: Kim Eastlund, Jill Pratt, Jill Jordan, Kristen Houlihan, Geoff Lane. Back row: Linford Herschberger, Susan Moffett, Laura Miller, Sharon Piper, Aaron Most.

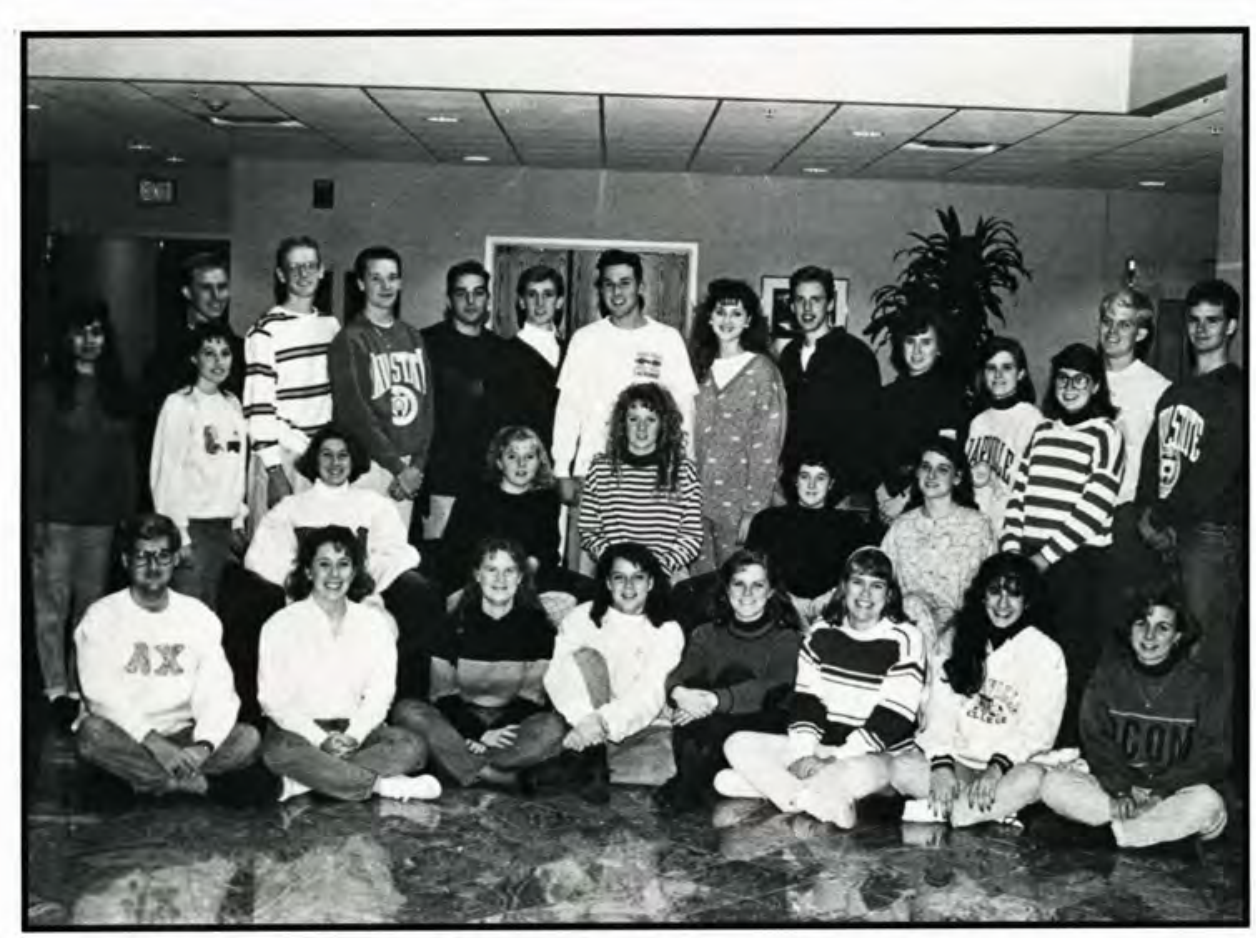

Praise the Lord!
At the Ohio Veteran's Children's Home (O.V.C.H.), Cedarville students face an exciting yet very challenging ministry on Sunday mornings. Team responsibilities and opportunities vary. Some plan and present Sunday School and children's church lessons for the younger children, while others search the campus for even a few high school students who may be interested in attending Sunday School. The major goal of the team is to build friendships and relationships with the students in hopes that they will receive Jesus Christ as personal Lord and Savior. The OVCH ministry gives students a wonderful opportunity to reach out to children who truly need love, friendship, and a personal relationship with Jesus.

Front row: Jeremy Spieth, Krista Keesling,

Karen Robertson,

Debbie Logan, Katie

Baier, Leslie Wenzel,

Christy Lyn Sarkisian,

Suzanne Stern. Second Row: Kim Koziol, Jaimee Potter, Laura Powers, Stephanie Winchip, Cheryl Davis, Misty Borkholder, Erica Porter, Larry Bandy. Back row: Nicole Hernandez, Steven Burdette, Jim Cramer, Keith Hamer, Greg Petek, Brian Wymer, Todd Breneman, JulieLynn Burns, Craig Klotzbach, Karla Warnken, Gretchen Pike, Brent Luman. 


\section{$\mathrm{V} \bullet \mathrm{I} \bullet \mathrm{S} \bullet \mathrm{I} \bullet \mathrm{T} \bullet \mathrm{A} \bullet \mathrm{T} \bullet \mathrm{I} \bullet \mathrm{O} \bullet \mathrm{N} \quad \mathrm{M} \bullet \mathrm{I} \bullet \mathrm{N} \bullet \mathrm{I} \bullet \mathrm{S} \bullet \mathrm{T} \bullet \mathrm{R} \bullet \mathrm{I} \bullet \mathrm{E} \bullet \mathrm{S}$}

COMMUNITY

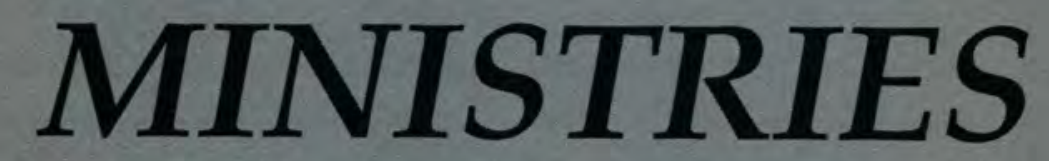

Building into the lives of others is a special privilege that makes this ministry at Heathergreene Nursing Home unique. On a weekly basis, we are able to talk, laugh, and share with our friends in the home. We are grateful for the opportunity to minister through friendships and caring. Often, we have found that we are the ones to leave with a blessing! - -Jen Dinelli

\section{Heathergreene I}

Floor (left to right): Mindy McPherson, Sarah McCarty, Karen Nelson, Rosanne McColm. Stairs (top to bottom): Jennifer Dinelli, Angela Carson, Christine M. Jones, Heidi Hoover, Jennifer Simmons, Jennifer Allen, John Wambold.

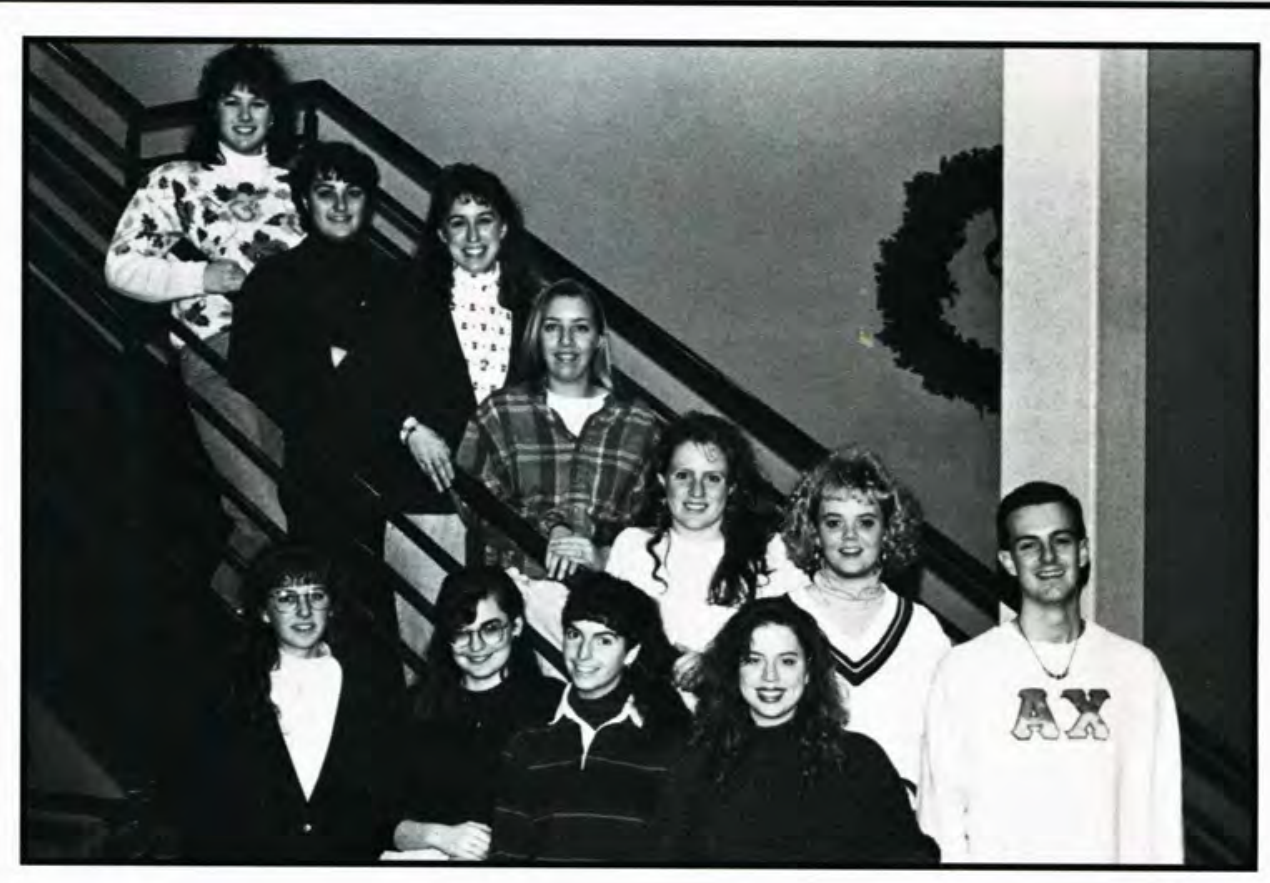

The ministry of Heathergreene II involves ministering to the elderly by establishing a foundation of trust and respect with an elderly person. The members of the team try to form friendships with the residents, especially with those who do not normally receive visits. Through spending time with the residents, students get to know them and are able to better minister and pray for them. Through personal testimony, singing, special music, and special activities throughout the year, these students strive to present the Gospel to the elderly.

\section{Heathergreene II}

Top to bottom: Chad Wingert, Kari Schoonover, Jackie Cordier, Sara Dyson, Jenny Mosby, Kimberly Koziol, Cindy Tweedy, Brenda Royer, Christopher Handel. Not pictured: Jennifer Henry.

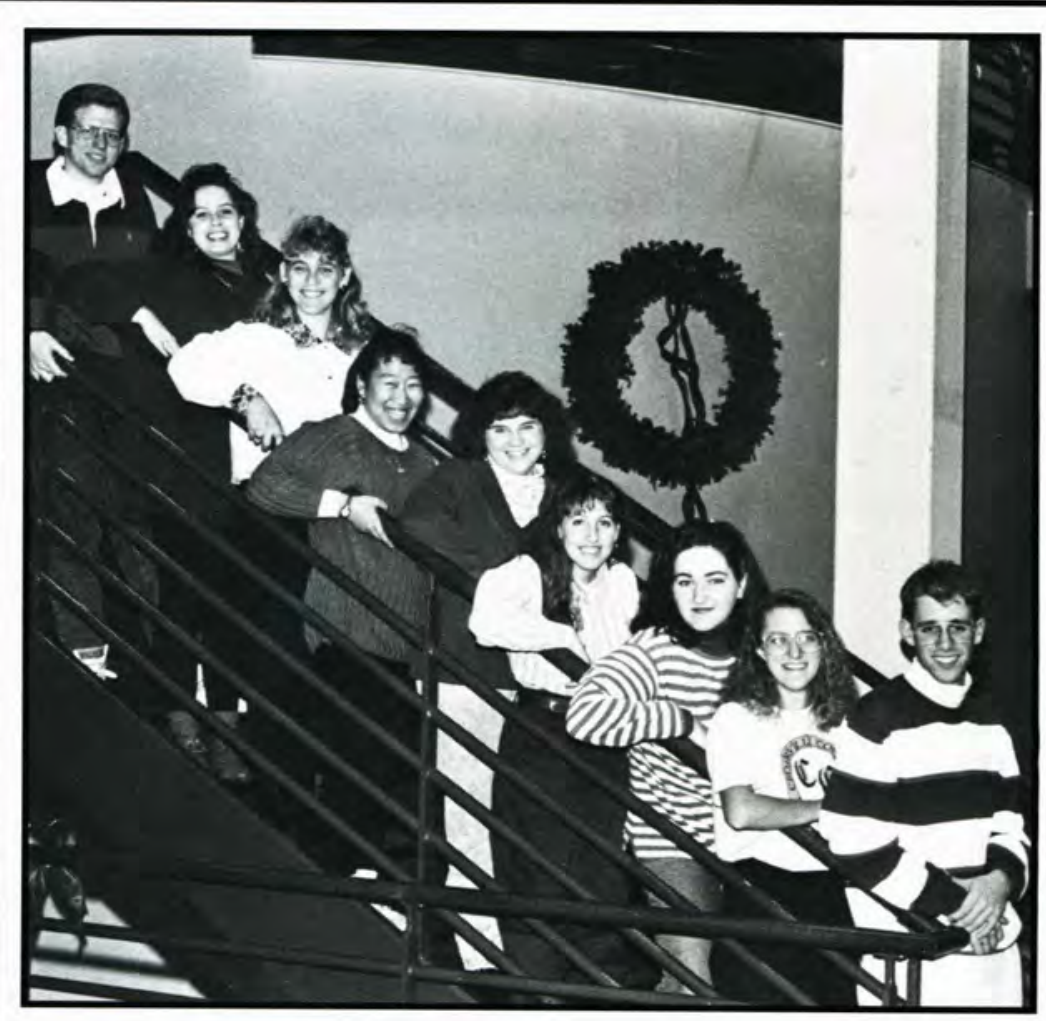


The Ronald McDonald House Christian ministry team serves families whose children are in the Dayton Children's Hospital. The team chose I Peter 4:10 as its key verse for the year, "As each one has received a gift, minister it to one another, as good stewards of the manifold grace of God." The team desires to have a servant's heart and to portray their Christian testimony of "the manifold grace of God." This ministry requires both faithfulness and commitment.

\section{Ronald McDonald House}

Front row: Denise Allen, Candie O'Toole, April M. Johnston, Amy Hoop. Back row: Don E.Smith, Jr., Leah Hoover, JulieStafford, Andy Biddle, Amy McMahonleader.

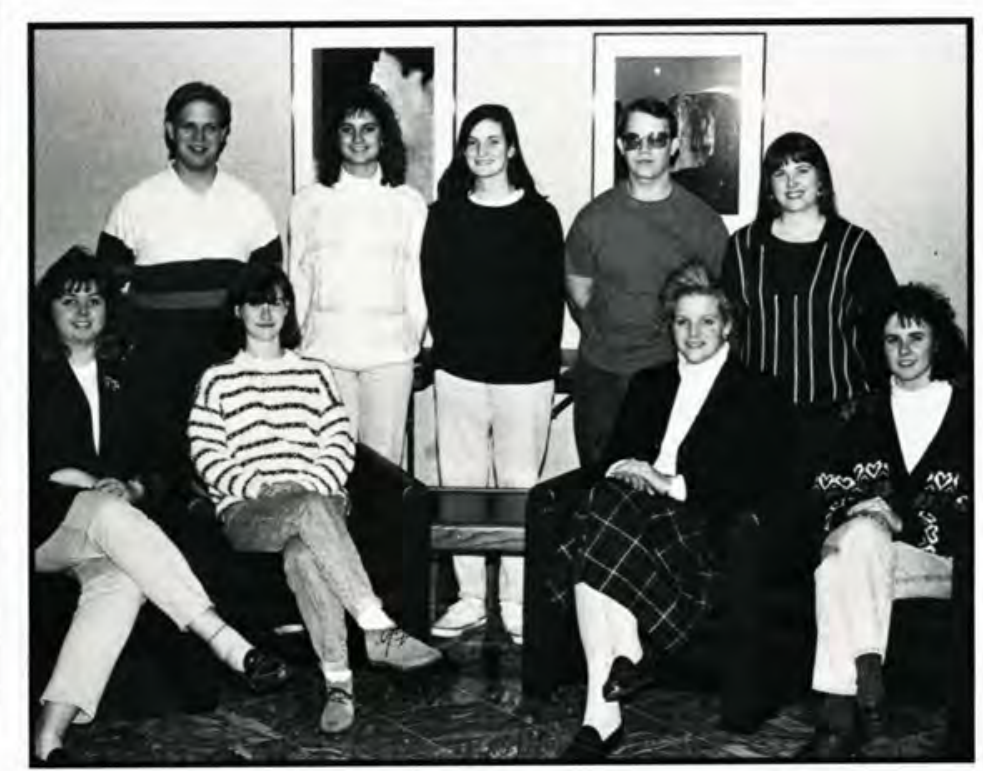

The members of the Greene Memorial Hospital team have the privilege of serving both staff and patients in the Emergency Center. Some of their activities include making beds, taking patients to radiology, delivering lab specimens, and visiting with those who need encouragement. This ministry enables students to share Christ through their actions and attitudes by living out their testimonies.

\section{Greene Memorial Hospital}

Front row: Lisa Groeber, Dawn Merritt, Angela Rich, Laurel Barnhart, Jennifer Bradley, Rebecca MaGee. Second Row: Anita Hill, Rebecca Lodge, Nathan Piovesan, Cathy Remington, Jennifer Kitzrow, Amy Crawford, Amy Estle. Back row: Carrie Eargle, Carrie Eldeen, Michele West, Sarah Sizemore, Becky Edwards, Jennifer Burkett, Laura Huggler.

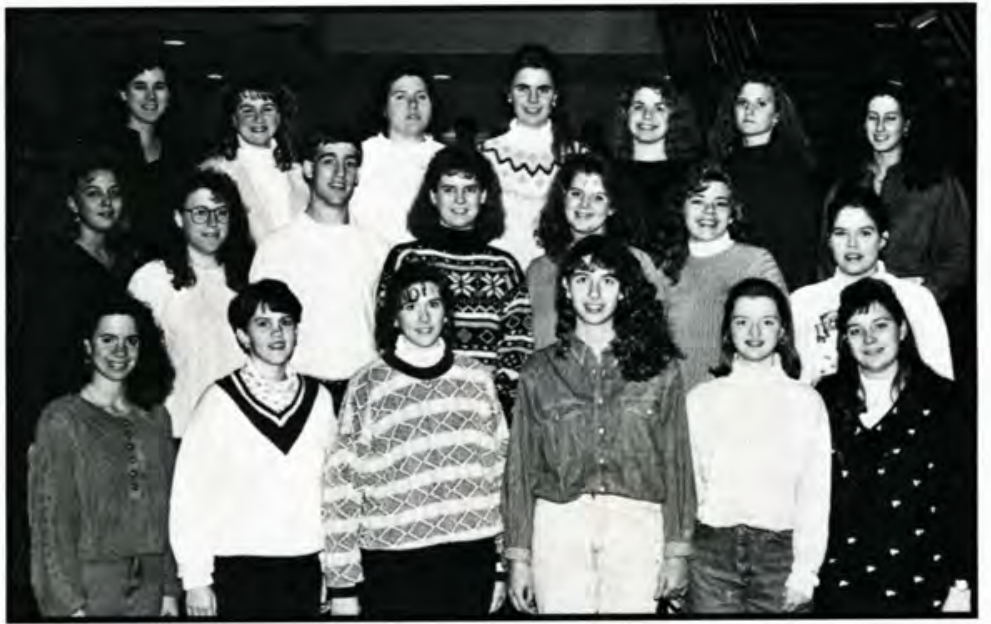

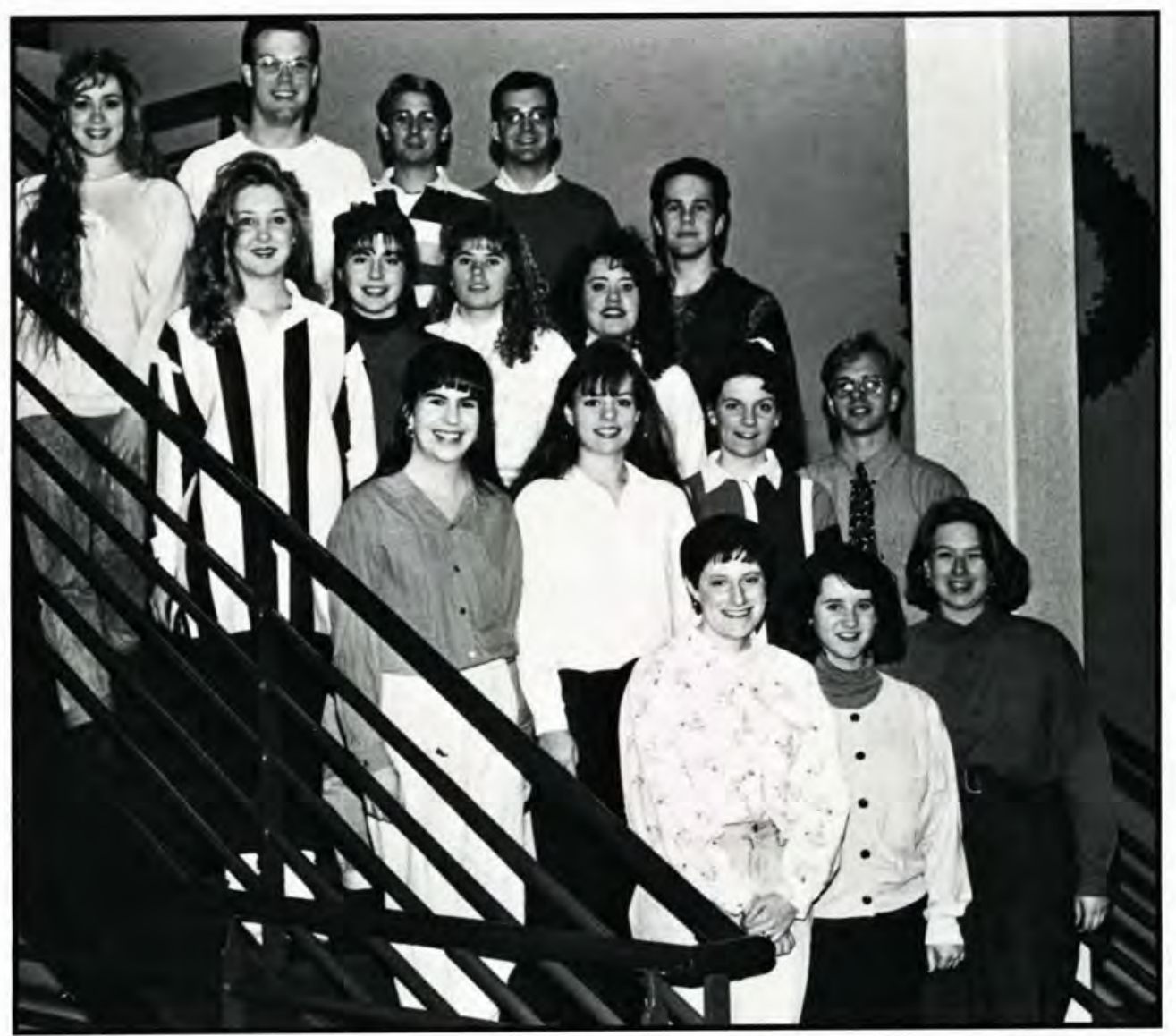

At Mercy Hospital in Springfield, Ohio, Cedarville students offically serve as "volunteers." They perform duties ranging from delivering flowers to refilling water pitchers and escorting discharged patients to waiting family members. The team has portrayed their testimony through actions and through their conversations. They also had many opportunities to talk to high school students who worked with them as volunteers.

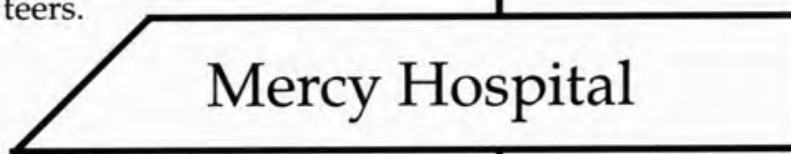

Front row: Heidi Bossley, Dawn Kauffman, Amy Powley. Second row: Kim Pletcher, Melissa Yorgey, Melia McNabney, Brian Longfellow. Third row: Mike Collins, Janet Potts, Lynda Gavitt, Rebecca Smith, Amber Rohweder. Back row: Heather L. Fulton, Mark Holsinger, Jef Buckingham, Gary Stickley. Not pictured: Will Orser. 
Left to right: Kelly Seboe, Julie Walker, Tim Keib, Aimee Miller, John Neill, Andrew Crefeld, Matt Gilson, Penni Ruhl.

\section{Greene County Jail}

This jail team allows students to interact with inmates at the Greene County Jail in Xenia, $\mathrm{OH}$. A key part of their ministry is not talking, but just listening to hurting people--something difficult for most. Searching theScriptures for the answers to their tough questions, we try to show them our love and God's love for them. Tim Keib, leader of this ministry, said that he's amazed by how much one can grow simply looking for answers in the Bible. The team is knit together with a common goal--"planting the seed" of God's Word in the hearts of these inmates.

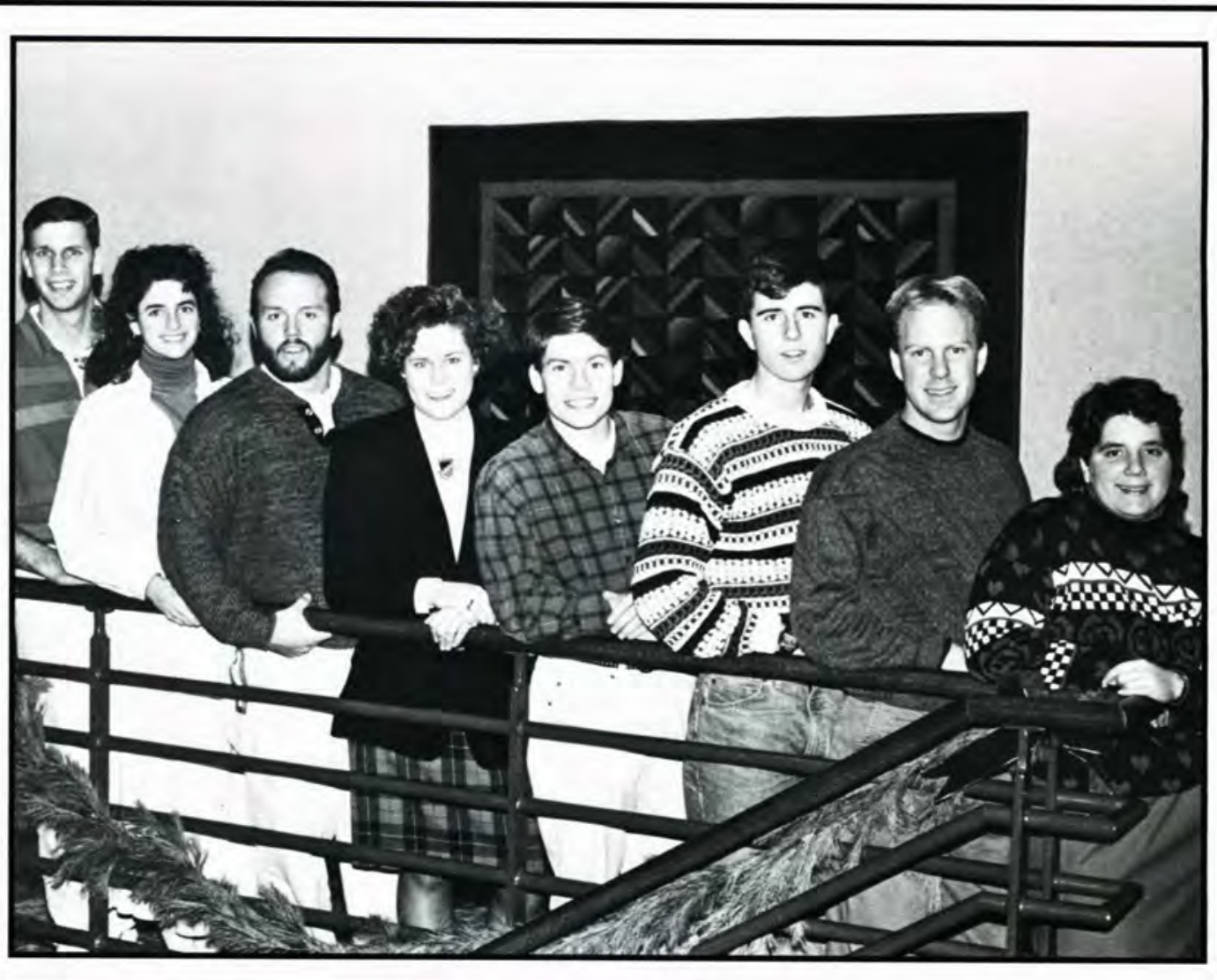

Operation Rebirth, a boys' home for a group of eight teenagers, offers an environment where they can turn their troubled lives around. The teenagers live on an 8-acre farm. The team goes to the home to lead the boys in a time of singing, a short devotional, and a game. The team enjoys the time of fellowship with the boys, and many great relationships are established. The Operation Rebirth team focuses on developing friendships and using them to challenge the boys spiritually.

\section{Operation Rebirth}

Front row: Sue DeMan, William L. Droke, Ray W. Izard, Philip M. Huber. Back row: Kevin Fath, Stephen J. Wildasin, Michelle Holcomb. Not pictured: Tammy Strong.

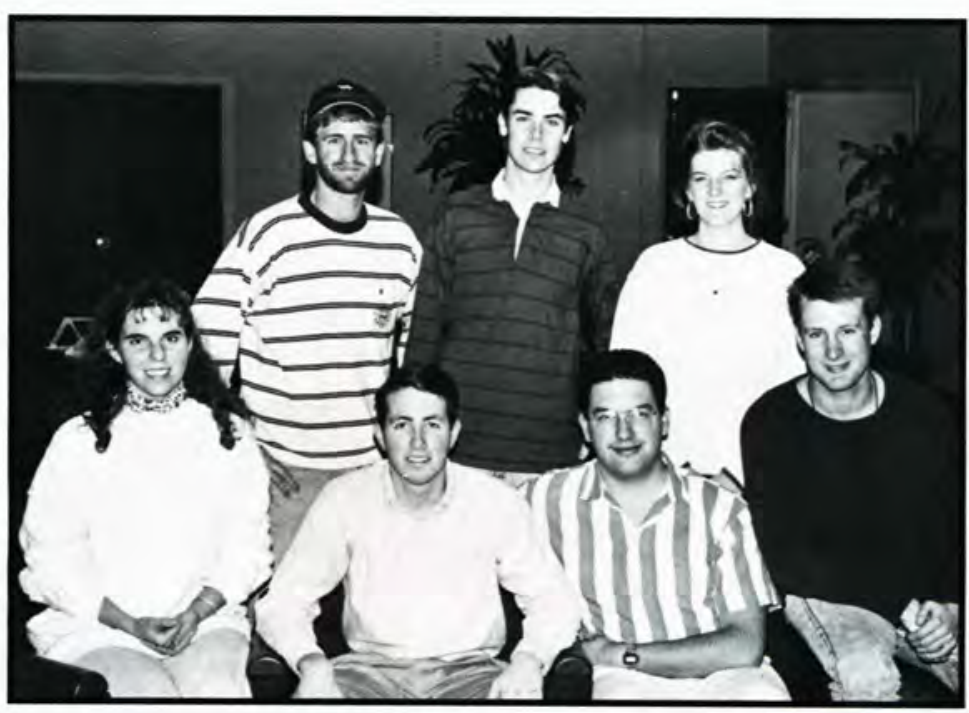



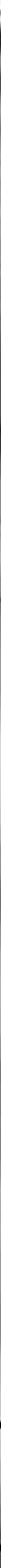

The primary purpose of the Dayton Detention Home ministry is to share the message of salvation through Christ with the kids at the home. Team members believe that salvation will lead the kids to a fulfilling life once they leave the detention home. The team holds a church service each Sunday morning. Following the service, they split up and go to various units establishing relationships with the kids and sharing the gospel. The home has over 100, 1218 year old kids who are hungry for attention and love. Each dedicated team member desires to have the kids see Jesus in them. The Lord has done miraculous things at the home this year, bringing over 20 kids to a saving knowledge of Himself! Praise the Lord!

Front row: Becky Bradley, Jennifer Myers, Nicole Gadell, Jennifer Dear, Debbie Burkley, Krista Pantana, Tracy Raines. Second row: Dana Hull, Luman Strong, Lara Carlson, Tiffany Beheler, Alithea Henriquez, Matthew Reynolds, William Butts, Charline Grygiel. Back row: Carrie Glidewell, Carlene Cardosi, Holly Snyder, Rebecca Coy, Erik Benson, Kyle Schwendemann, Mark Combs, Jay Murphy, Harold Edington, Jim Geise, Mark Utz, Matt Comrie. Not pictured: Aimee Phelps.

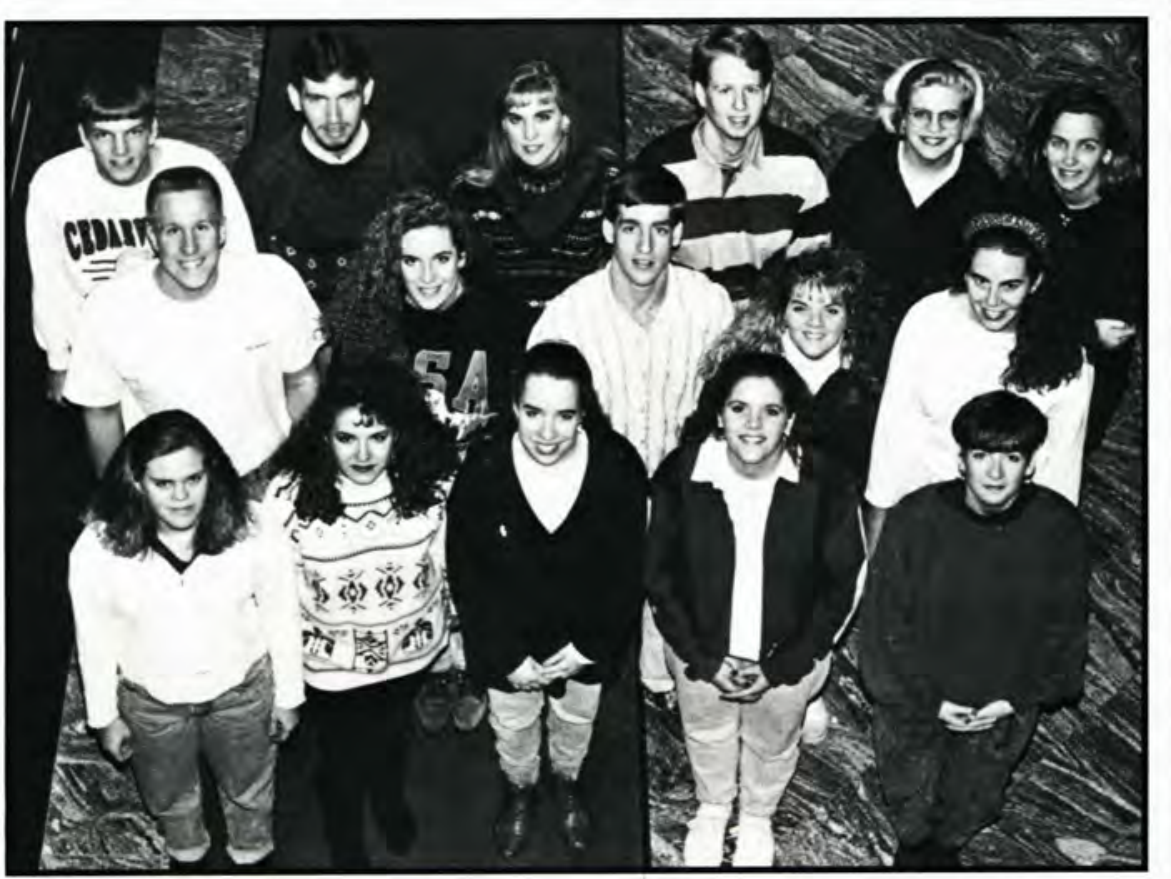

The Greene County Juvenile Detention Center and the Greene County Treatment Center are big brother/big sister type ministries. Spending timeindividually with these teens allows the team members to show the teens that they care, and it also gives them an opportunity to share Christ's love with them. This year the teams saw one teenager come to know the Lord. They thank God that He is still in the business of mending broken hearts.

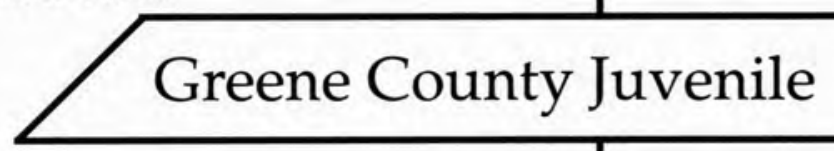

Front row: Tamara Sitorius, Janet Chezik, Rebecca Armstrong, LoriShaw, Leah Denson. Second row: George Haines, Lisa Lough, Nathan Piovesan, Kim Geremia, Amy Dirr. Back row: Bryan Eaton, Steve Wurster, Alicia Elmore, Randy Snell, Slone Bartley, Kim Conner. 


\section{$\mathrm{V} \bullet \mathrm{I} \bullet \mathrm{S} \bullet \mathrm{I} \bullet \mathrm{T} \bullet \mathrm{A} \bullet \mathrm{T} \bullet \mathrm{I} \bullet \mathrm{O} \bullet \mathrm{N} \quad \mathrm{M} \bullet \mathrm{I} \bullet \mathrm{N} \bullet \mathrm{I} \bullet \mathrm{S} \bullet \mathrm{T} \bullet \mathrm{R} \bullet \mathrm{I} \bullet \mathrm{E} \bullet \mathrm{S}$}
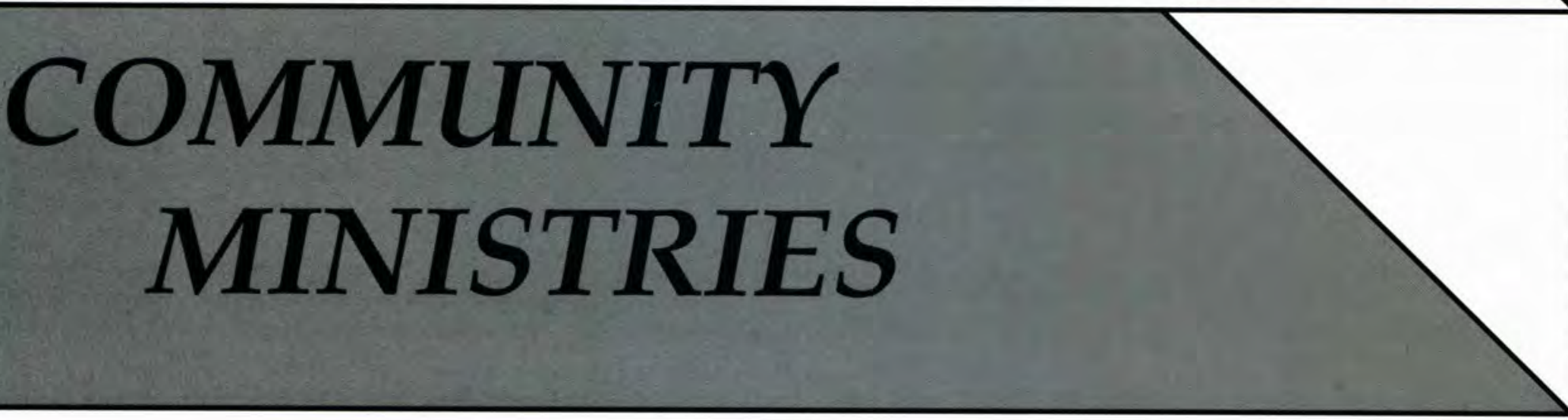

Traveling to the Mueller Home in Springfield, Ohio, this ministry team works with the mentally handicapped people who live there. The members of the team consider it a blessing to see the people grow in the Lord as they have opportunities to minister to them. God has blessed their ministry. Just before Christmas break this year, $\mathrm{He}$ answered their prayer for a good attendance and they had over 22 residents present. They didn't even have enough crafts to pass around, yet they were greatly encouraged.

\section{Mueller Residential Services}

Front row: Kelly Cline, Jenn Vanderbilt, Mavis Wu, Nicki Silvera. Second row: Andrea George, Ann Woodman, Debbie Brunner, Amy Buehner. Back row: Christopher Rayder, Chuck Willett, Rachel Reich. Not pictured: Amy Bates, Georgia Hickman, Marci Garwick, Kristi Nordaas.

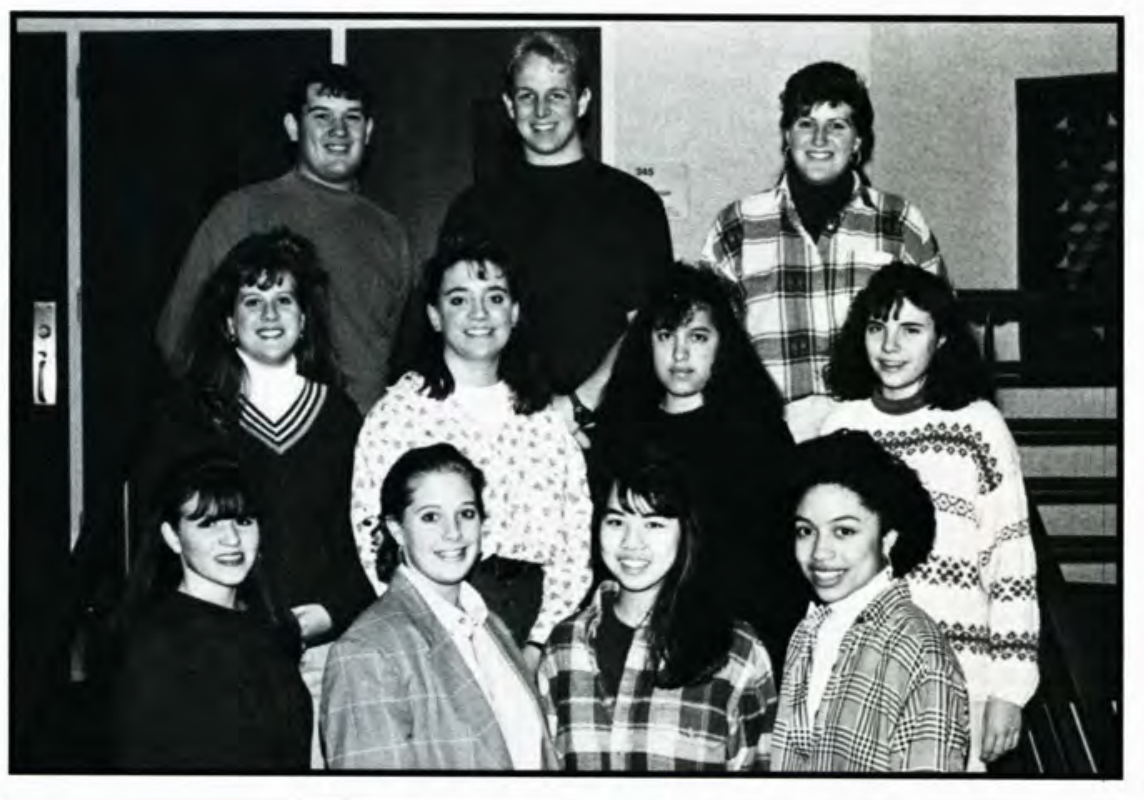

Listening, sharing, and just being a friend -- can a ministry be simpler than this? The Bristol House, located in Springfield, houses many elderly people who are looking for a friend, someone they can talk to. Through the friendships which have resulted from visiting the home weekly, Cedarville students have had the opportunity to be a testimony to their elderly friends through both life and speech.

\section{Bristol House}

Front row: Carla Heim, Denise Kurtz, Bethann Mohn, Joyce Colangelo. Second row: Julie Holaday, Candace Sarber, J. Brian Schoolar, Maria Redfern, Matt Clark. Back row: Christian Herring, Darryl Hammock, Aaron Jex, Andrea L. Eimers, Stephen Valentine. Not pictured: DiAnn Miller.

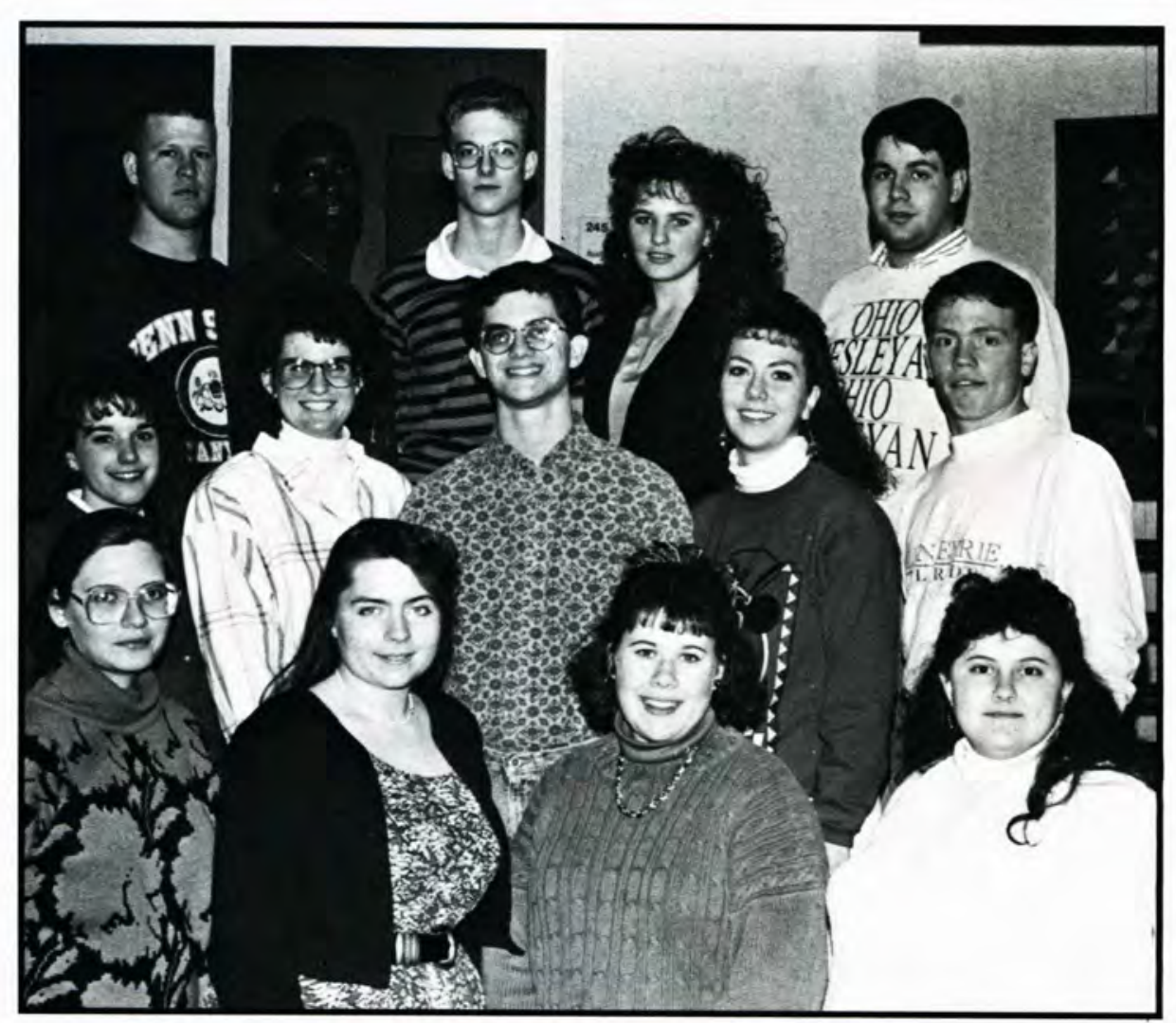


The Greenewood Manor team is committed to go to the nursing home every Wednesday evening. The members talk with the residents and are encouraged to establish a close friendship with at least one person. They invite the residents to attend a 20 minute service of singing and sharing. In this service, team members have prayer, lead songs, and give a short devotional.

\section{Greenewood Manor}

Front row: Dana Gosser, Debbie Perkins, Sue Rummel, Laura Campbell. Second row: Andrea Katz, Heidi Westbeld, Jodi Woodhams, Milie Poiesz. Back row: Joe Lausin, Holly Moor, Stacey Wires, Tabi Leininger. Not pictured: Dan Treier.

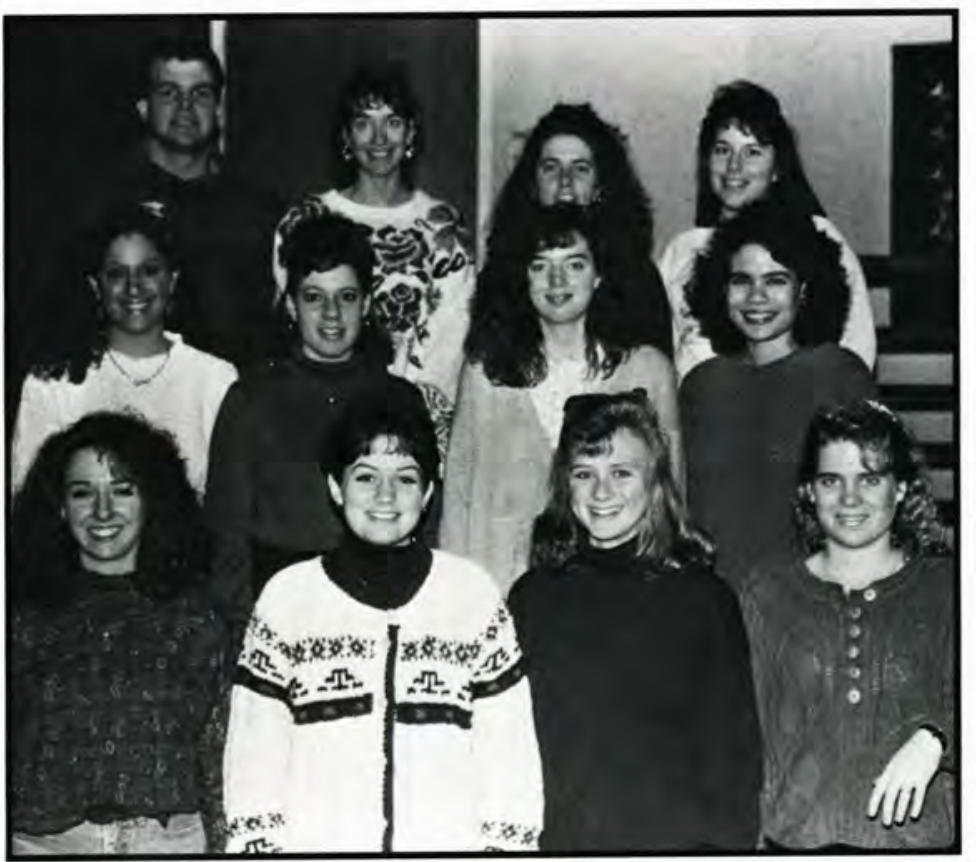

Once a week, this team visits the apartments across the street from the college and holds a Bible study in their community room. The people on the team agree that they always seem to receive more blessings than the elderly. Each team member also visits a specific individual from the apartments on a one-to-one basis each week. Team leader, Stephanie Hunsaker says, "CedarCliff is a very fulfilling ministry easing the loneliness of the elderly there." Team members have enjoyed watching the elderly grow spiritually, but they've also experienced the joy of developing closer friendships with the elderly.

\section{CedarCliff Elderly}

Front row: Tara Wagenaar, Amy Tapp, Stephanie Hunsaker, Tracy Swackhamer, Darcey Blenis. Back row: Kathleen Coy, Connie Winch, Ben Bird, Lori L. Landwehr, Heather Hicks, Heather Magnuson. Not pictured: Gabe Gerger, Lisa Haaksma.

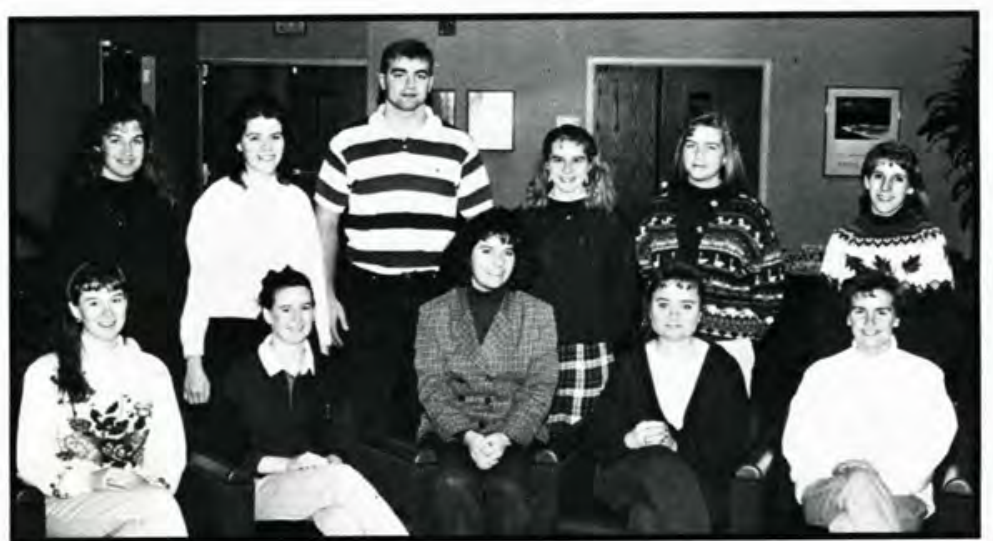

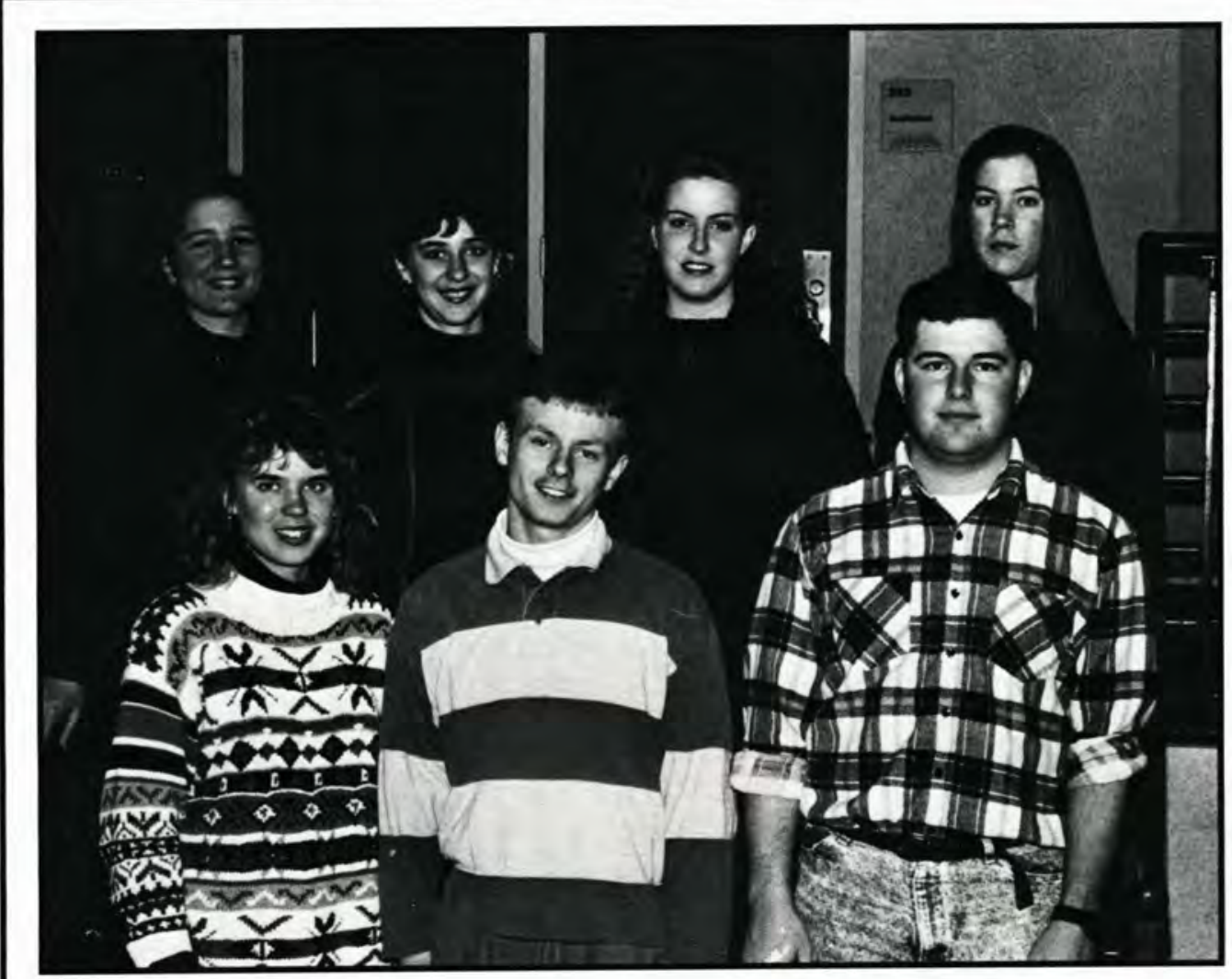

Front row: Lianne Wright, Dave Mullins, Sam Failor. Back row: Tara Luther,

Ruth Heckman, Cherish Clark, and Sarah

Laramore.

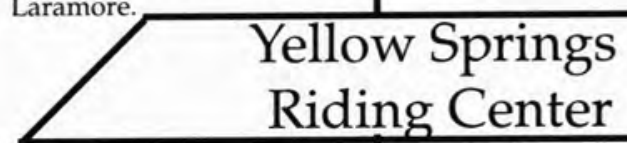

At the Yellow Springs Riding Center, students experience a unique opportunity for service. They may not present the gospel directly, but they are able to share their faith in an indirect manner. As they work with the mentally handicapped, the team members seek to show their love and care for the patients through their service and godly attitudes. 
Front row: Julianne Edgerton, Carly Farmer, Lora Myers. Back row: Kevin King, Randy Joiner, Sam Failor.

\section{Hillside Independent Living}

Students are given an opportunity to serve others at Hillside Independent Living but, as they minister, they find themselves profiting from the experience. Theelderly at Hillside have wisdom that can come only with age, and the students who visit them are able to form valuable friendships. The students and their elderly friends equally anticipate spending time together. For all involved, the visits can "brighten up" life.

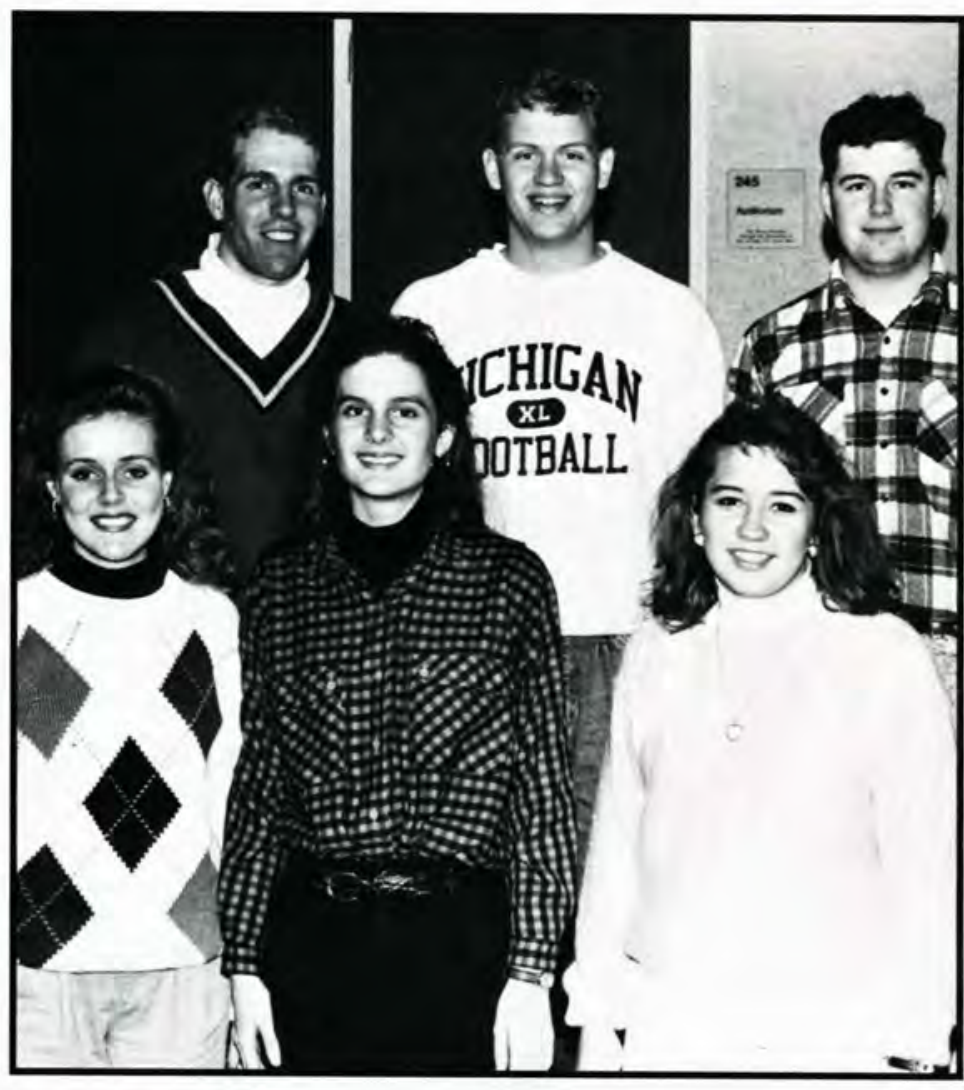

Visiting the Hospitality Home once a week, team members seek to minister to the needs of the elderly. Rather than viewing their weekly visits as an obligation, members look forward to their visits. Members consider their visits a privilege. Each has a personal desire to reach out to the elderly, those most often forgotten in our society. As relationships are built, members enjoy the reward of hearing the words "I love you" from the lips of an elderly friend.

\section{Hospitality Home}




\section{$\mathrm{V} \bullet \mathrm{I} \bullet \mathrm{S} \bullet \mathrm{I} \bullet \mathrm{T} \bullet \mathrm{A} \bullet \mathrm{T} \bullet \mathrm{I} \bullet \mathrm{O} \bullet \mathrm{N} \quad \mathrm{M} \bullet \mathrm{I} \bullet \mathrm{N} \bullet \mathrm{I} \bullet \mathrm{S} \bullet \mathrm{T} \bullet \mathrm{R} \bullet \mathrm{I} \bullet \mathrm{E} \bullet \mathrm{S}$}
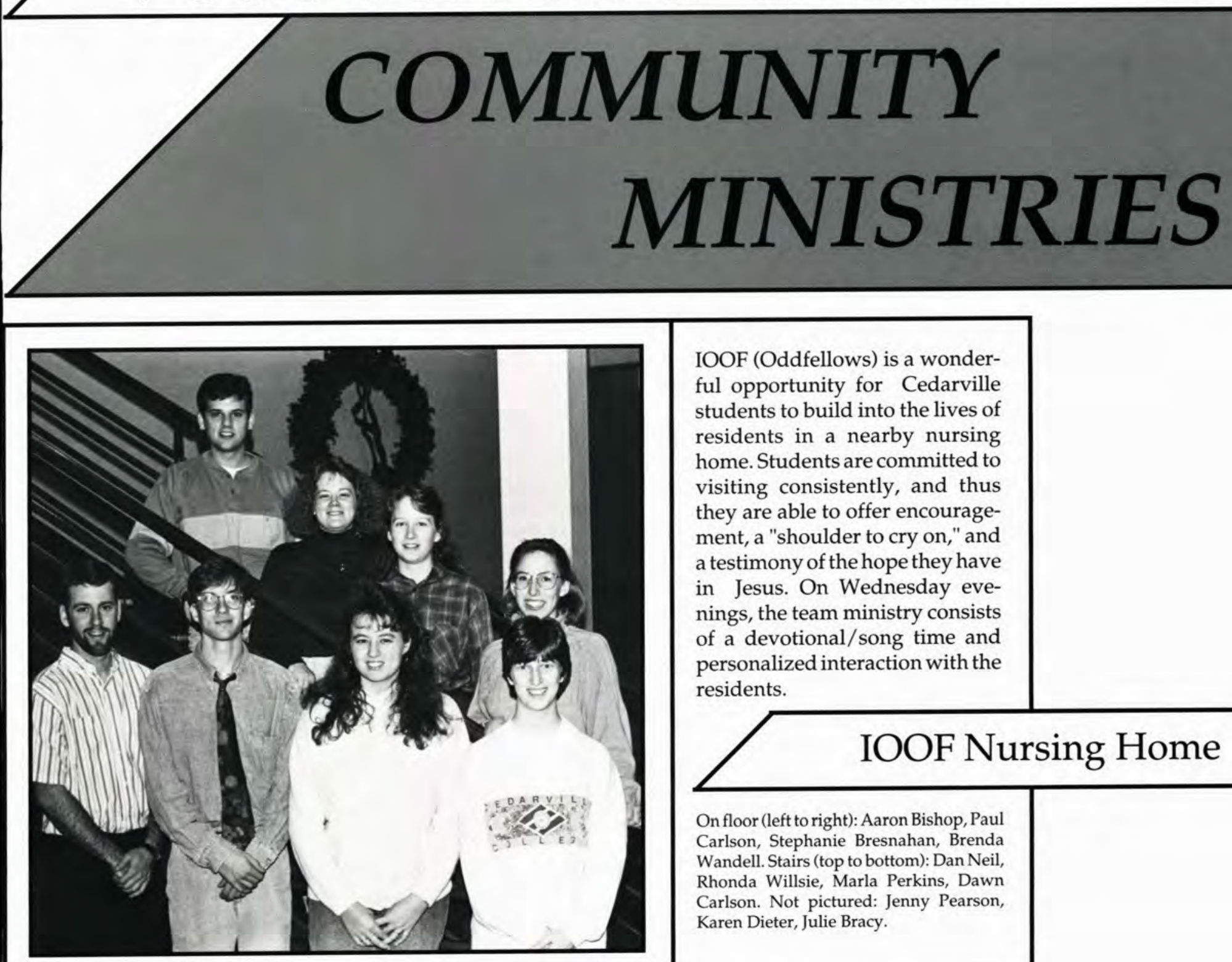

IOOF (Oddfellows) is a wonderful opportunity for Cedarville students to build into the lives of residents in a nearby nursing home. Students are committed to visiting consistently, and thus they are able to offer encouragement, a "shoulder to cry on," and a testimony of the hope they have in Jesus. On Wednesday evenings, the team ministry consists of a devotional/song time and personalized interaction with the residents.

\section{IOOF Nursing Home}

On floor (left to right): Aaron Bishop, Paul Carlson, Stephanie Bresnahan, Brenda Wandell. Stairs (top to bottom): Dan Neil, Rhonda Willsie, Marla Perkins, Dawn Carlson. Not pictured: Jenny Pearson, Karen Dieter, Julie Bracy.

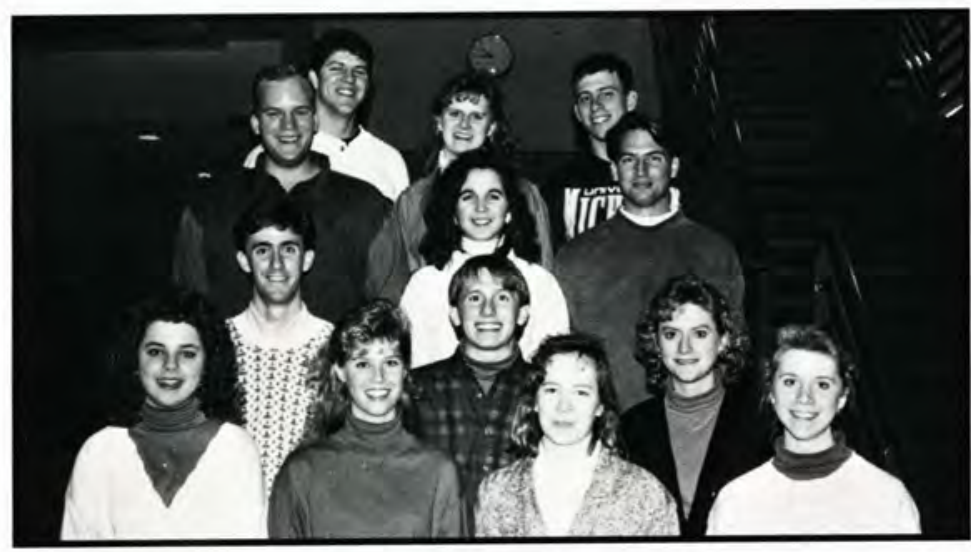

Front row: Heather Seachrist, Lori Shook, Sharon Bush, Amy Shaneyfelt. Second row: Steve Cook, Brian Spencer, Rosemary Pletcher. Third row: Matthew Oliver, Ann Guest, Bleu Tennant. Back row: Dan Ambrose, Marcy Johnson, Randy Southwell.
Every Sunday morning and Wednesday night, the members of this Christian ministry go to the Knights of Pythias Nursing Home in Springfield. During their visit they hold a church service, talk with the staff, and mingle with the residents. Following the service, the college students take the residents back to their rooms and have an opportunity to talk one-on-one with them. Often, lasting friendships are made. The people look forward to the "Cedarville young people" returning and bringing with them a light of hope and the love of God.

\section{Knights of Pythias}




\section{Swordbearers Extension Teams}

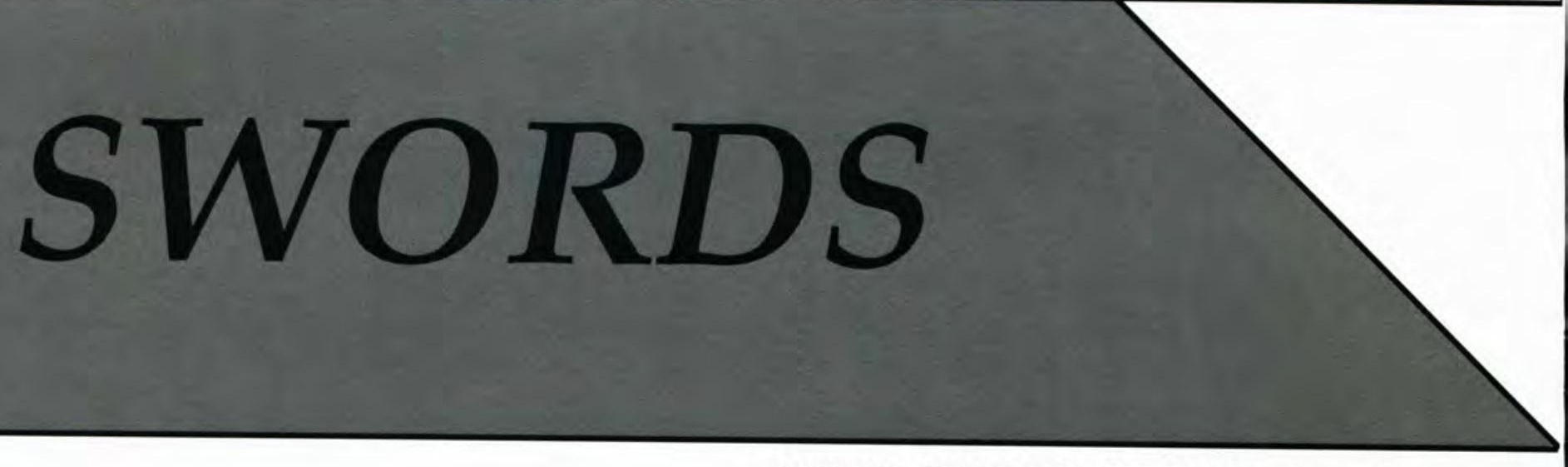

WITH AN ENCOURAGING SMILE, this student helps children become students of God's Word.

\section{SWORDS' Executive Committee}

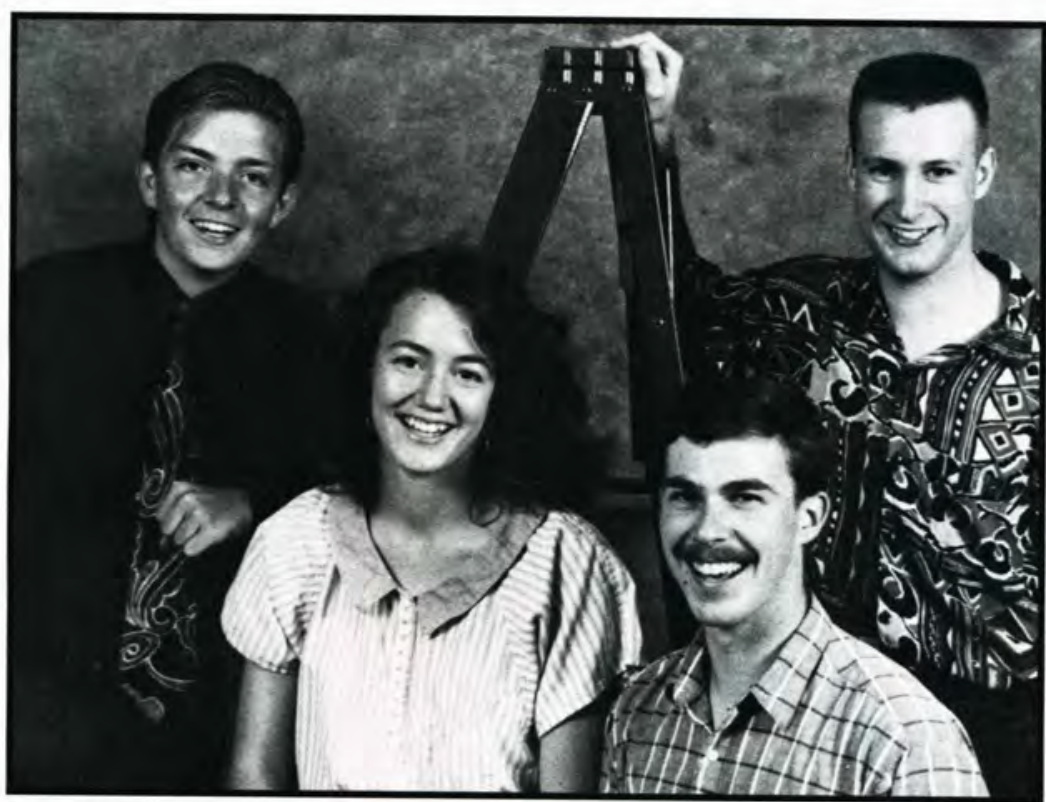

Chad Grayson, Kristi Van Dyke, Tim Alley, Phil Huber

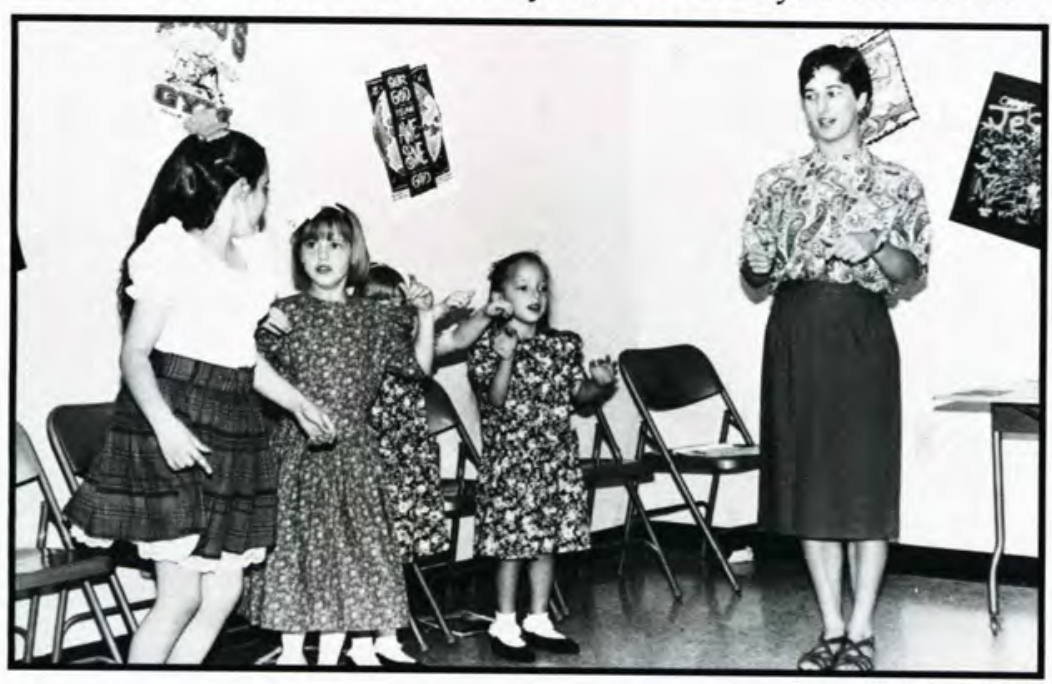

Photo by Todd Hill

THE EXTENSION TEAMS TEACH MANY SONGS IN SUN132) Ministries
DAY SCHOOL CLASSES.

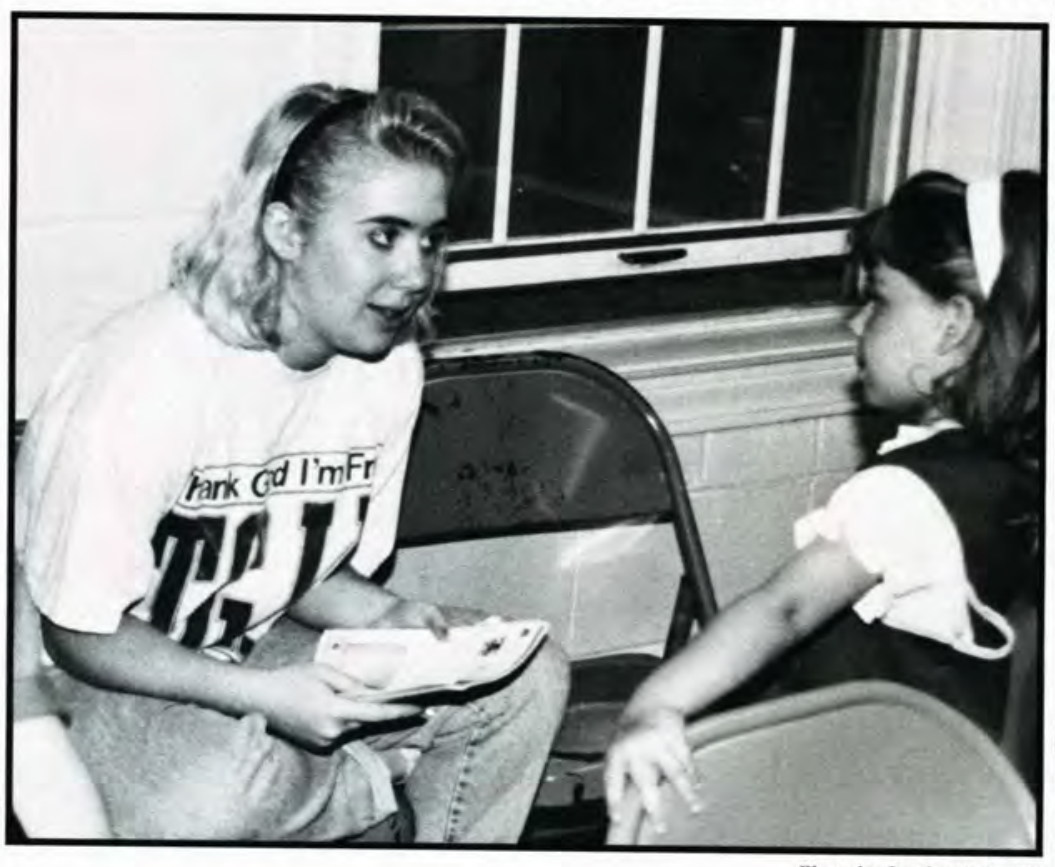

Photo by Stephanie Saville

Airway Baptist Church: Calvary Baptist Church: Jen Adams

Kendra Byler Keri Christner Andy Farcus

Kim Hazecamp

Valarie Kaughman

Pam McClain

Sandy Rhinehart

Shea Skaggs

Berea Bible Church:

Andy Bell

Christie Davids

Mark Hershener

Kristine Hoadly

David Hoskins

Dave McChesney

Cindy Sheets

Wendy Shriver

Jill Winship

Bethel Baptist Church

Gerry Burkett

Yolanda Everson

Tracy Mahan

Beth Messiah

Congregation:

Jen Lang

Becky Searcy Jason Southwell

Matt Stockhom

Sarah Warnken

Shawn White

Jennifer Yaggi

Calvary Grace Brethren: Jeff Morgan

Sarah Mosely

John Robertson

Laura Tourinsky

Connie Winch

Central Baptist:

Chad Grayson

Mark Kakkuri

Amy Owens

Jon Pickens

Chapel in Ohmer Park:

Mark Solomon

Jennifer Staple

Brenda Woods

Tricia Botdorf

Wendy Weyand

Cornerstone Baptist Church: Brian Kigar

Tim Alley

Kim Gurry
Noah Buehner

Matt Goding

Nathan Ho

risti Van Dyke

Dayton Avenue Baptist: Tabi Leininger

hris Nickel

(

Tamara Wymer

Emmanuel Baptist:

Amy Awabdy

Steph Bolsem

Tamara Doden

Peter Fulton

Chris Reimer

e Russell

r Schultz

Phil Snyder 


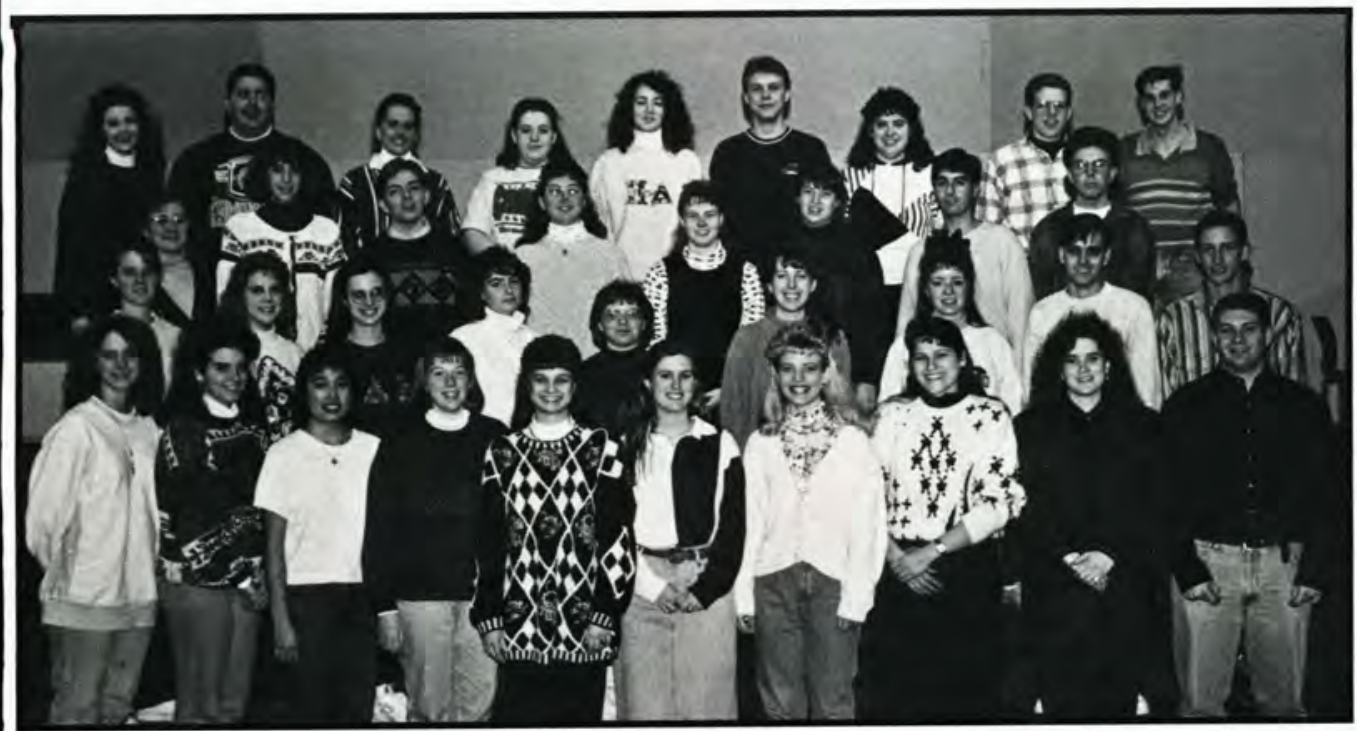

Front row: Kara Henry, Valerie Kaufman, Debi Wong, Stephanie Bolsem, Jenny Shults, Catie Giles, Sandy Rinehart, Kendra Byler, Shea Skaggs, Andy Farkus. Second row: Kim Gurry, Pamela McClain, Jennifer Adams, Stephanie C. Brown, Julie McFadden, Susan Brunton, Sarah Moseley, John Robertson, Connie Winch. Third row: Evelyn Bussa, Kim Hazekamp, Chad Grayson, Anne Larr, Amber Snodgrass, Gail Henderson, Mike Pasquale, Jeffrey Morgan. Back row: Jolie Sissom, Shawn Joers, Tammy Clark, Olivia Carter Kristi Van Dyke, Dean Osuch, Mindy Abrams, Chad Wingert, Ken Nichols.
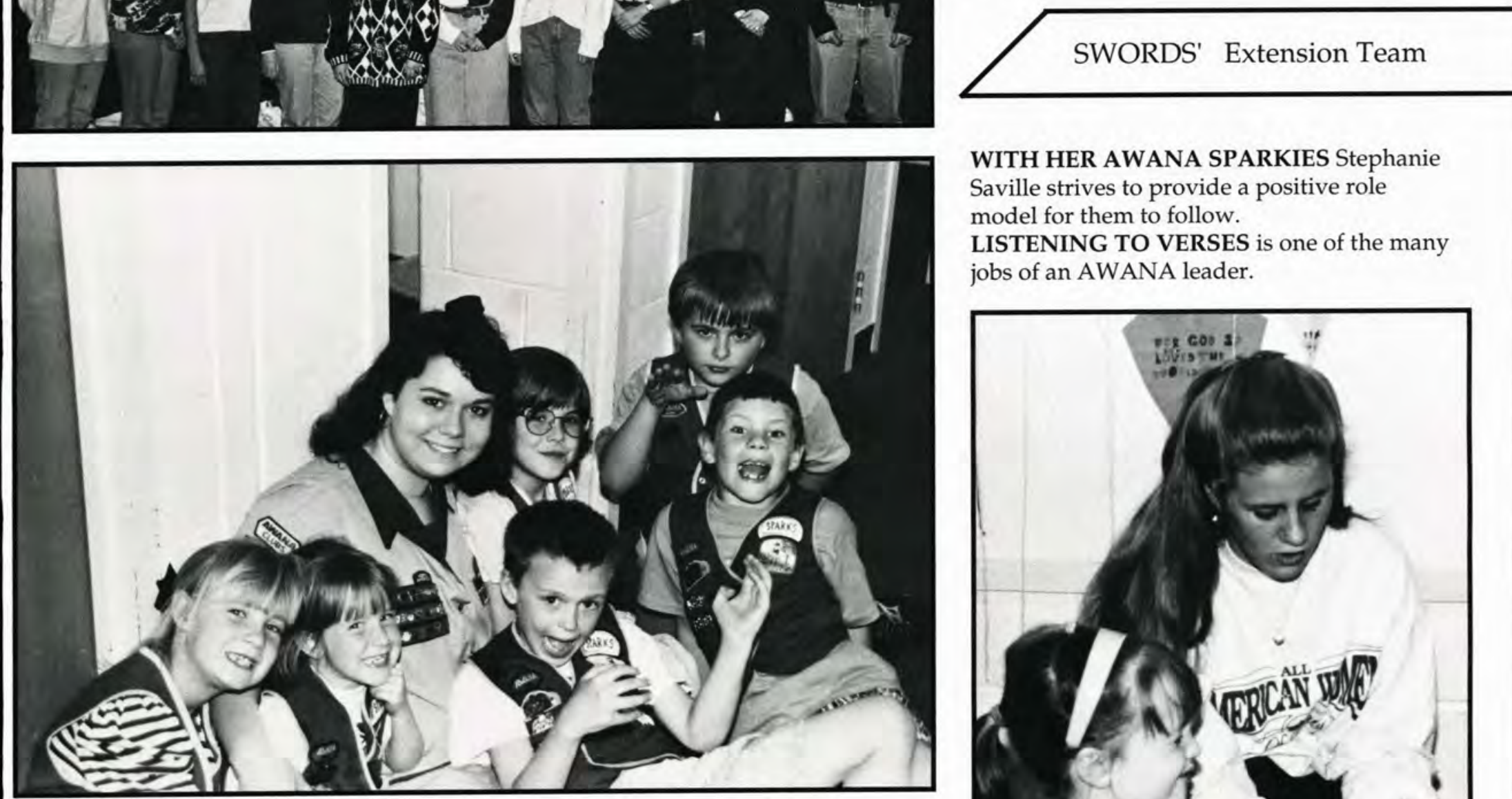

WITH HER AWANA SPARKIES Stephanie Saville strives to provide a positive role model for them to follow.

LISTENING TO VERSES is one of the many jobs of an AWANA leader.

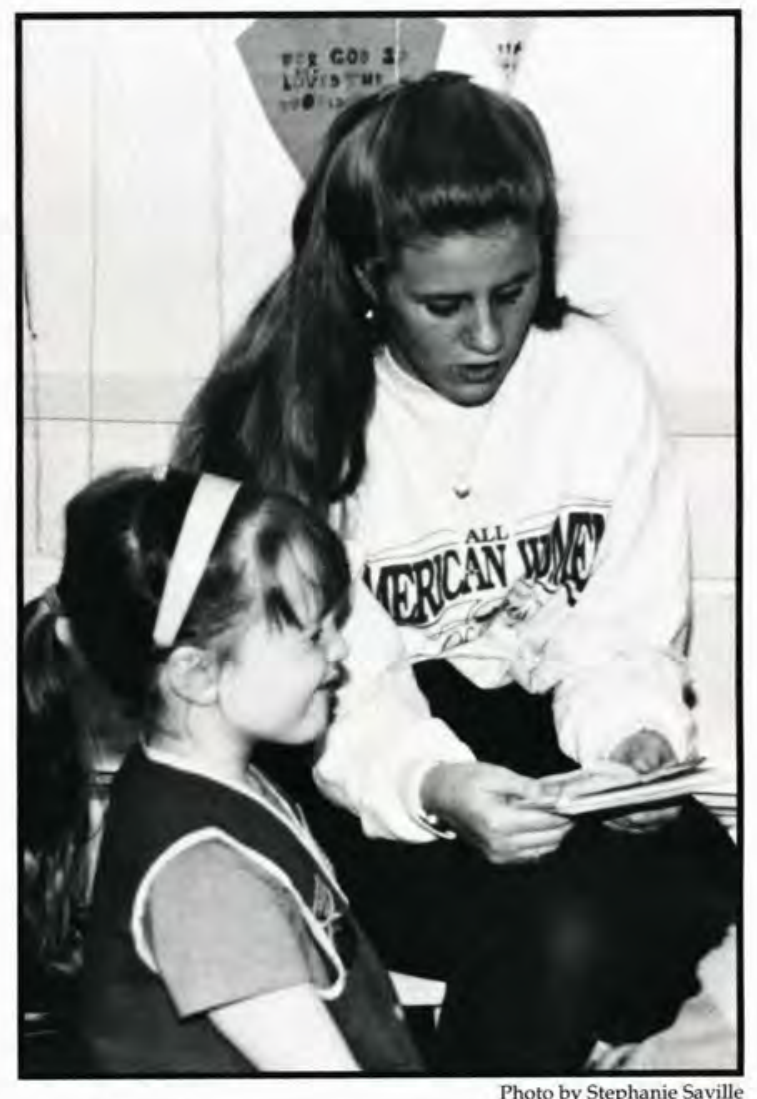

Faith Baptist Church: Kathy Bond Scott Borling Amanda Jeremiah Julie McFadden Steve Smith Denise Uhl

\section{First Baptist:}

Mindy Abrams

Gail Henderson

Dean Osuch

First Baptist Bellbrook:

Doug Gentry

Dave Hackney

Michelle Stennwyk

Kimberly Veneberg

Good Shepherd's Baptist Northwest Bible Church:

\section{Church:}

Kristina Milentis

Ken Nichols

Lori Olsen

Maureen Prusinowski

Allison Heller

Grace Brethren Vandalia: Tom Johnson

Nathan Beitler

Eric Bloxham

Shelly Clemens

Christy Hillman

William Kigar

LaRae Martin

Kristi Nordaas
Grand Heights Baptist:

Robert Bergen

Paul Comfort

Jennifer Henry

Tara Luther

Trish Manning

Kelly Murphy

Kelly Navarre

Maranatha Baptist Church: Cindy Hasselbring

Donna Ademeit

Joy Brandon

Melissa Davis

Sarah Good

Melissa Henry

Mike Pasquale

Jennifer Roloff

Randy Southwell

Duane Curtis

Michelle Dolbeck

Petre Road Baptist:

Jennifer Bork

Carl Smith - TL

Prince of Peace United Brethren:

Olivia Carter
Carla Greentree

Tracy Justice

Stephanie Plikerd

Rachel Searcy

Shawnee Hills:

Rachel Beecher

Rob Beecher

John Bradley

Beth Irving

David Kimmel

Julie Mummey

Cynthia Quint

Dale Radcliff

Ryan Snedaker

Wendy Soules

Melissa Van de Wege

Jennifer Zenner

South Fairborn Baptist Church:

Sue De Man

Phil Huber

Brenda Sprankle

Southgate Baptist:

Shannon Barnard

Molly Brandenburg

Nicki Brubaker

Michelle Carrol

Tammy Clark

Brian Bramer
Eve Edsell

David Holmes

Anne Larr

Laura Marshall

Amber Snodgrass

Heather Terry

Chad Wingert

Debi Wong

Mark Wong

Trinity Alliance Church: Jenni Bond

Becky Calvert

Jennifer Doak

Travis Edgell

Jim Olinger

Union Baptist Church: Wright Patterson AFB:

Mark Bochynski Rachel Acton

Stephanie Brown Jennifer Crawford

Susan Brunton

Victory Baptist:

Angela Carson

Mia Crecco

Sarah McCarty

Kim Pletcher

Melissa Yorgey

Sara Cooper

Jodi Dick

Carri Gray

Shawn Joers

Jason Kinniburg

Amy McNieve

Jeff Miller

Sara Siegelin

Becca Shopp

Nikki Starr

Steven Wikstrom
Places of Ministry 
ANTICIPATING THE BOUNCE OF THE

BALL requires great concentration in softball.
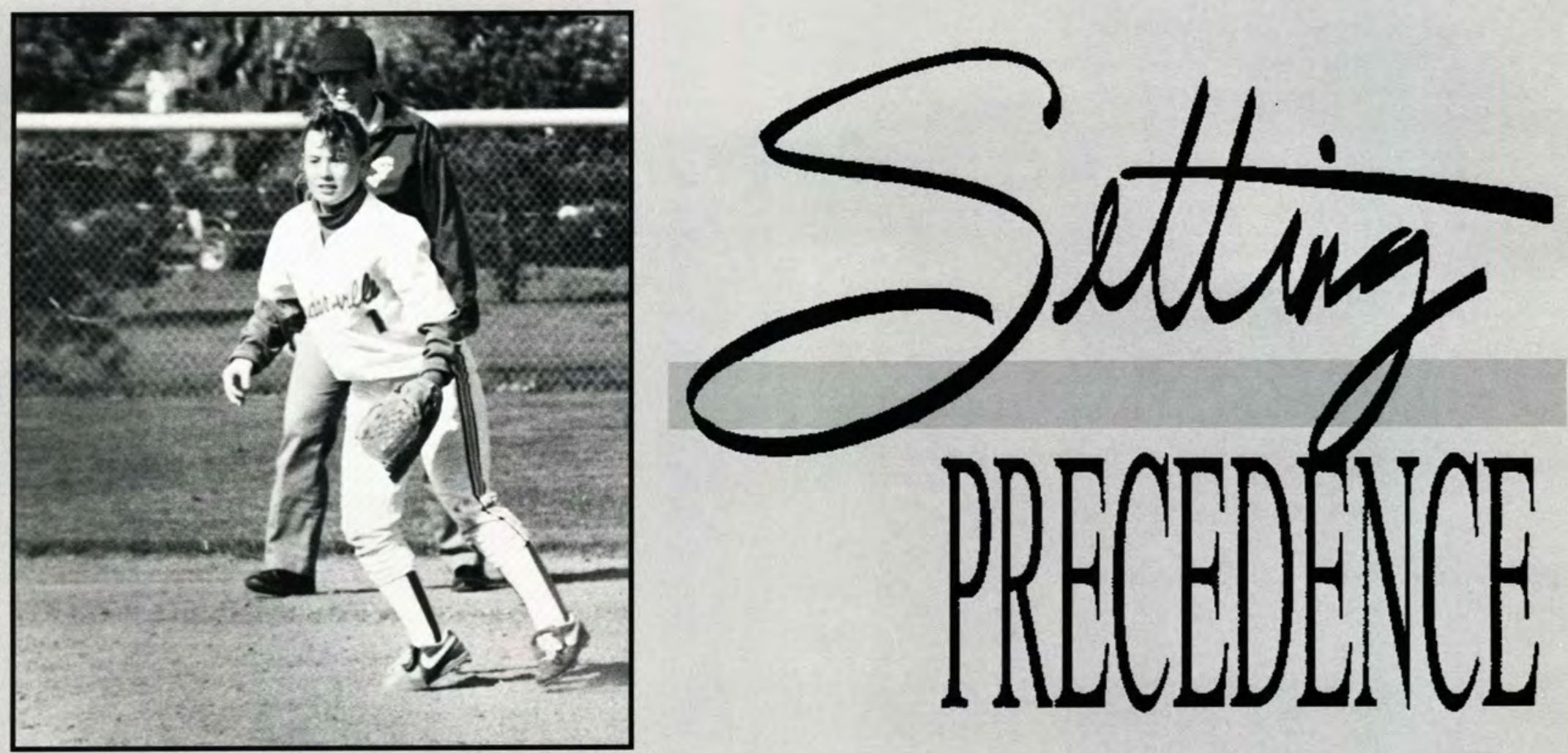

Photo by Tania Taylo

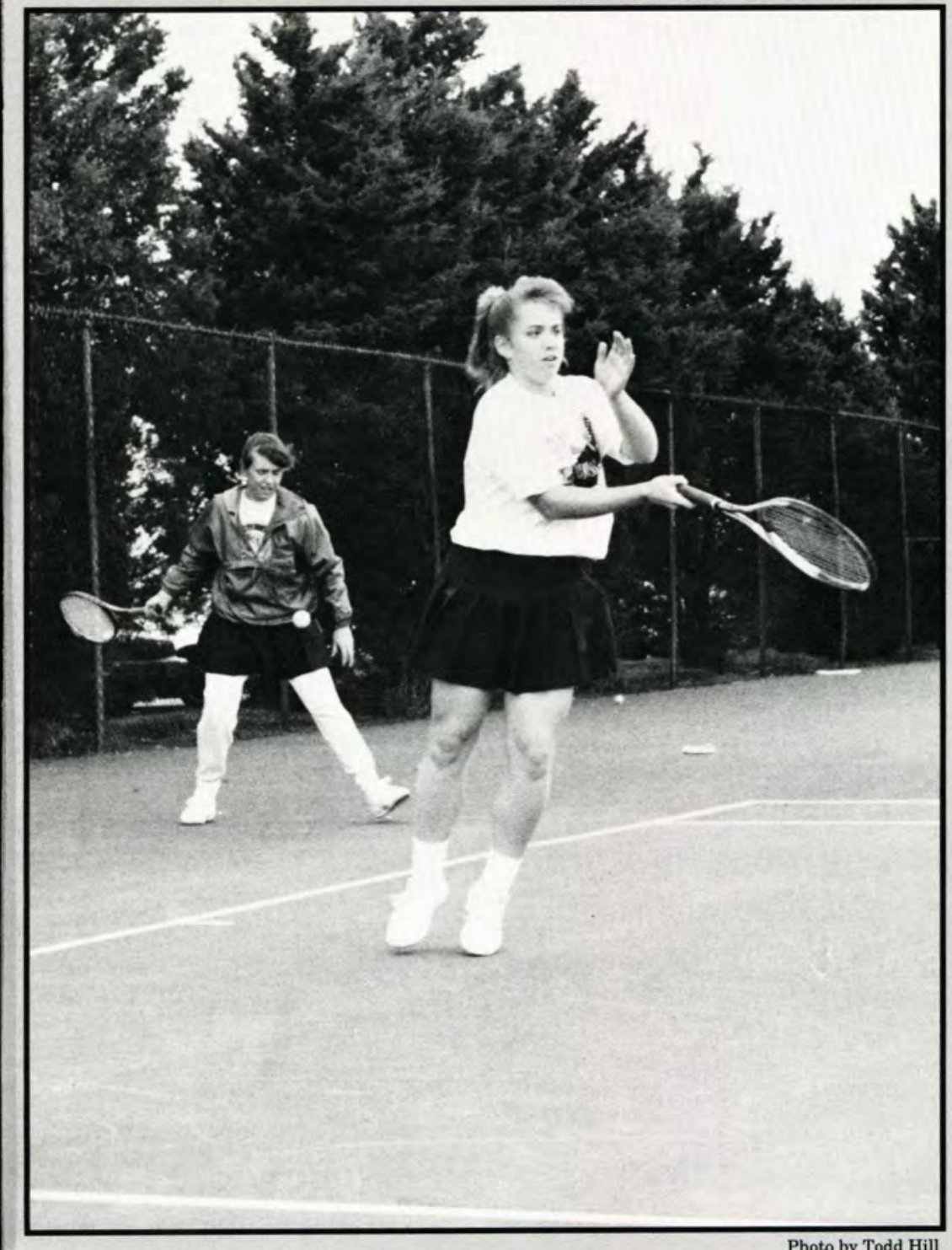

\section{in Sports}

Soccer

136-137

Volleyball

138-139

Cross Country

$140-141$

Club Volleyball/Pep Band 142-143

Spirit

144-145

Basketball

$146-149$

Baseball

$150-151$

Softball

152-153

Track

154-155

Tennis

$156-159$

Golf

$160-161$ 


\section{True Winners Revealed}

How important is winning? According to the soccer team, winning a game involves more than simply getting the higher score or receiving a trophy. Winning is knowing that each member played his best and glorified God through his performance. Team members and coach alike strive to please the Lord each time they compete.

In working with the soccer team, Coach McGillivray's greatest challenge has been to prepare them to work as hard as they can; to play with the mind-set that they will win; and yet train them to accept defeat graciously when they lose. McGillivray has been encouraged by the spiritual growth and maturity he has seen in his team this year. He feels a sense of accomplishment and excitement as he has been able to watch God work in the lives of his players.

The attitudes and character of the team members reflect the goals their coach has set for them. Jason Crary, one of the team captains, shares a valuable lesson he learned while playing soccer at Cedarville: "Our coach is incredibly strict with us on the field. Through his emphasis on discipline, I have learned to become more aware of what I am doing and how I affect others. Someone will always be watching me." Though very competitive on the field, Crary's highest goal is that the team play their best and maintain a good attitude, even in difficult situations.

Randy Southwell, another team captain, also believes that winning is more than the score at the end of a game. He says, "I feel good about a game well played--even if we did not win. My goal is to do my best."
The score at the end of the game is important to the soccer team, but having the most goals is not their first priority. To them, the most important goals are not the ones they kick into a net at the end of the field. Rather, they endeavor to work together, play their best, and glorify the Lord, both in victory and defeat.

-Kathleen Coy

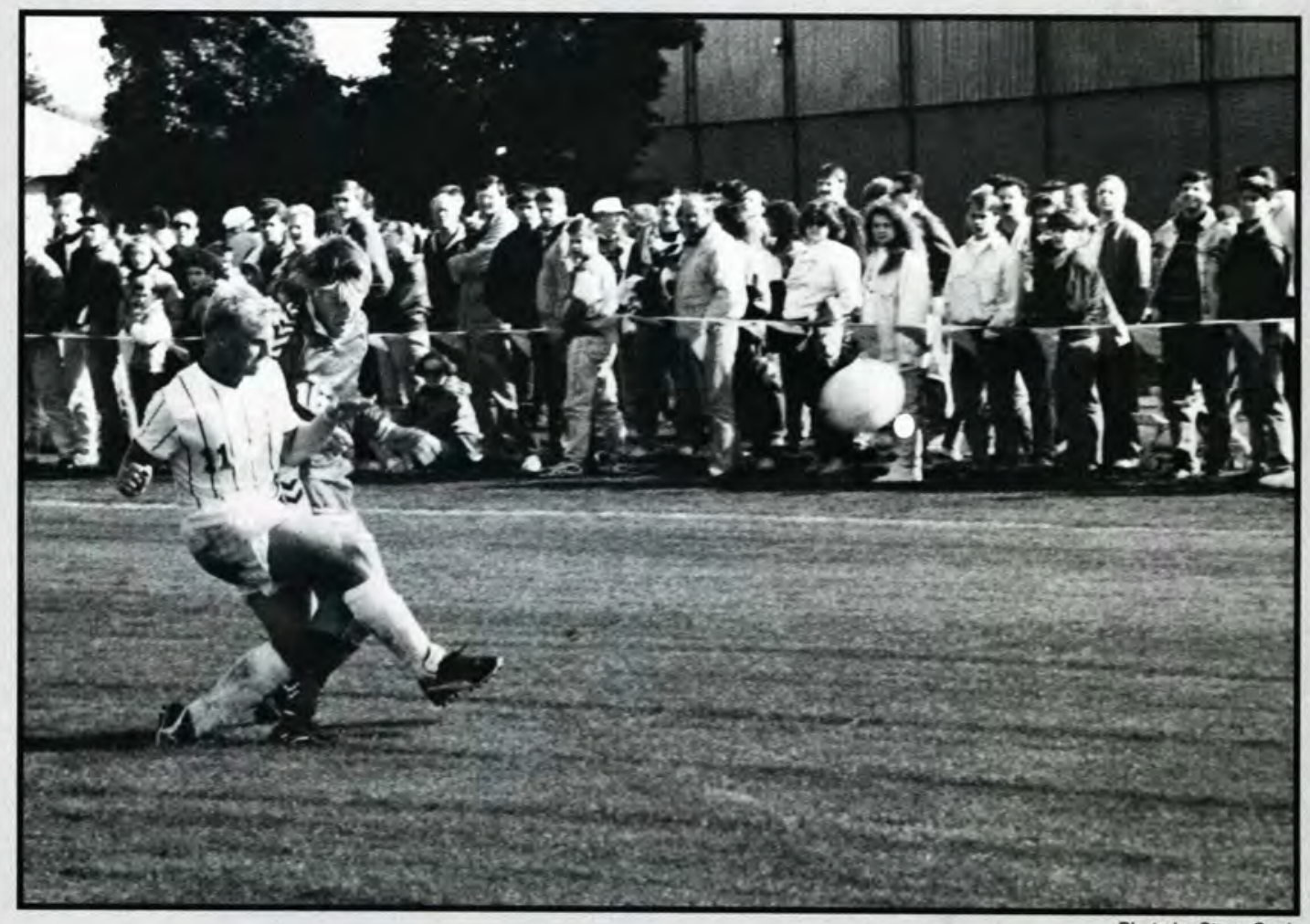

Photo by Steve Cook

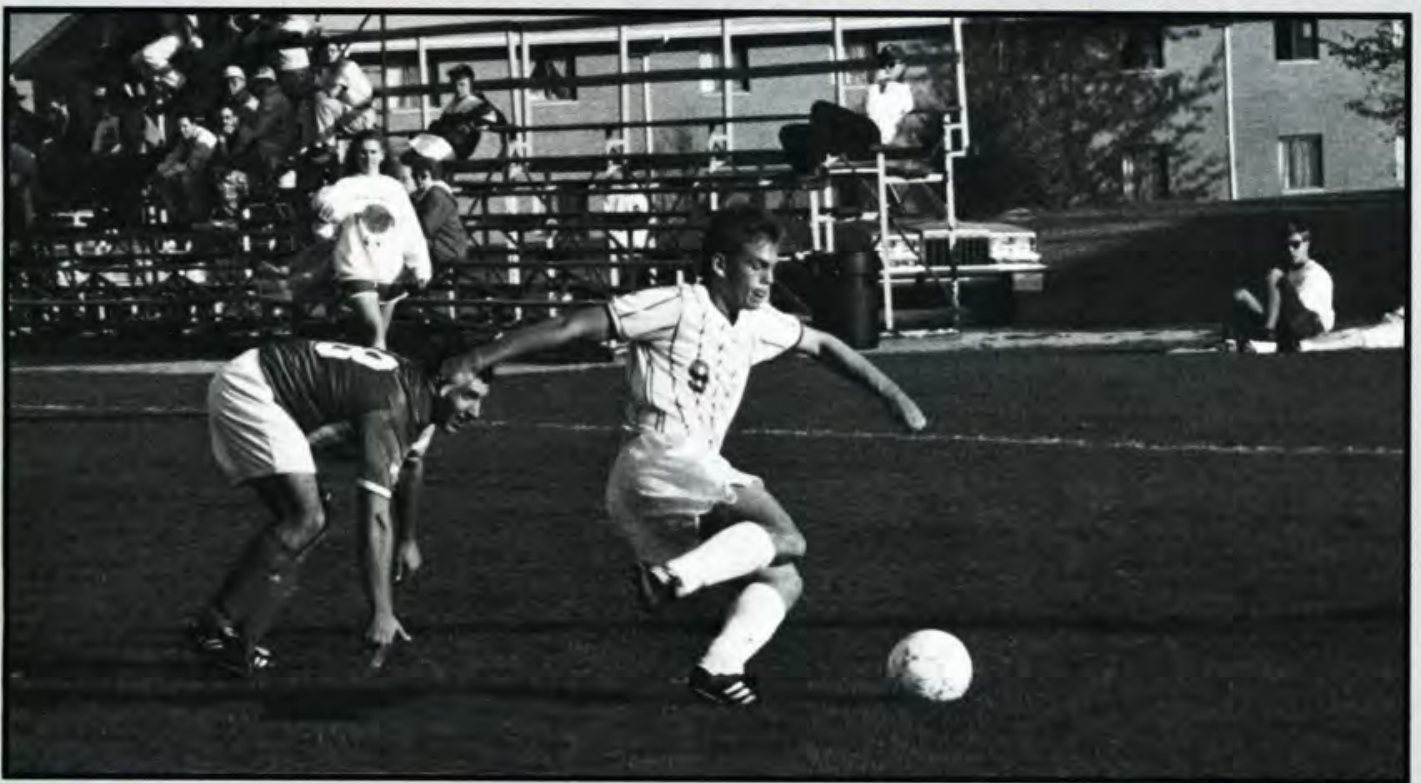

Bottom left: WITH A SWIFT, HARD KICK, Eric Reini passes the ball to his teammate.

Top: FIGHTING TO REMAIN WITHIN THE BOUNDARIES, Kevin Belmont attempts to regain control of the ball.

Bottom right: CONCENTRATION allows Ken Kolesar to retain possession.

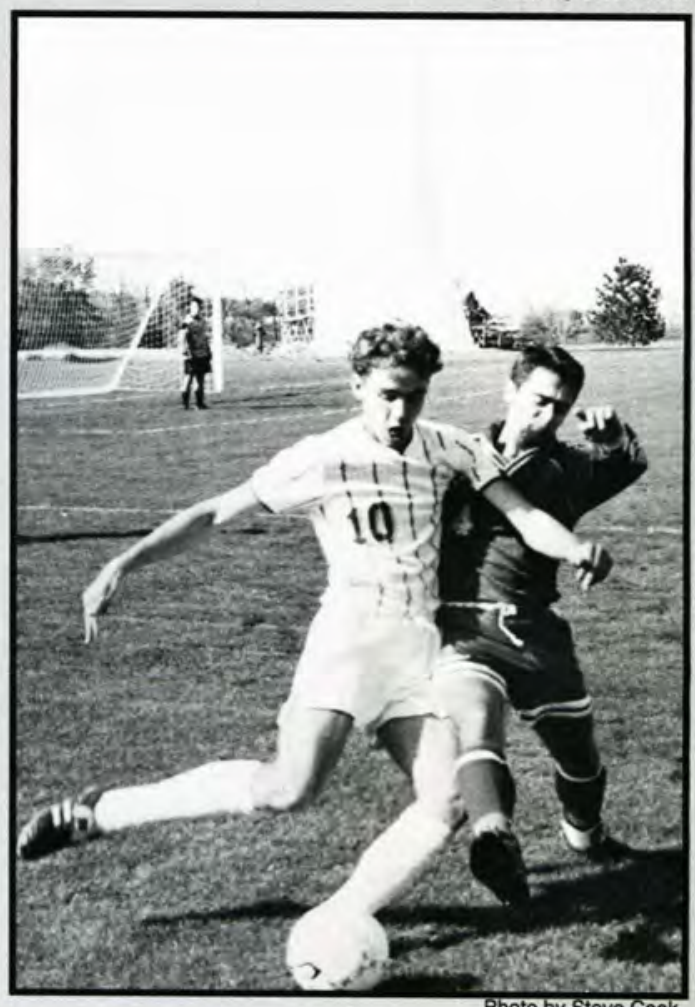




\section{Scoreboard}

\begin{tabular}{llll} 
Tiffin & L & Wooster & W \\
Hanover & L & Muskingum & W \\
Indianapolis & W & Tiffin & W \\
Central State & W & Rio Grande & L \\
Anderson & W & Otterbein & W \\
Taylor & L & Muskingum & W \\
Otterbein & W & Mount St. Joseph & W \\
Indianapolis & W & Wittenberg & W \\
Spring Arbor & L & Walsh & W \\
Rio Grande & L & Ohio Dominican & W \\
Walsh & L & Sue Bennett & W \\
Malone & W & Spring Arbor & L \\
Lake Erie & W & Indiana Wesleyan & W \\
Ohio Dominican & W & Oakland City & L \\
Urbana & W & Concordia & W \\
Shawnee State & W & Urbana & W \\
Bethany & W & Shawnee State & W \\
Ohio Wesleyan & W & Central State & W \\
Wilmington & W & Mt. Vernon Nazarene & L \\
Ohio Wesleyan & L & Findlay & L \\
Mt. Vernon Nazarene & W & Tiffin & W \\
Defiance & W & Rio Grande & W \\
Denison & W & Mount St. Joseph & L \\
& & & \\
\hline
\end{tabular}

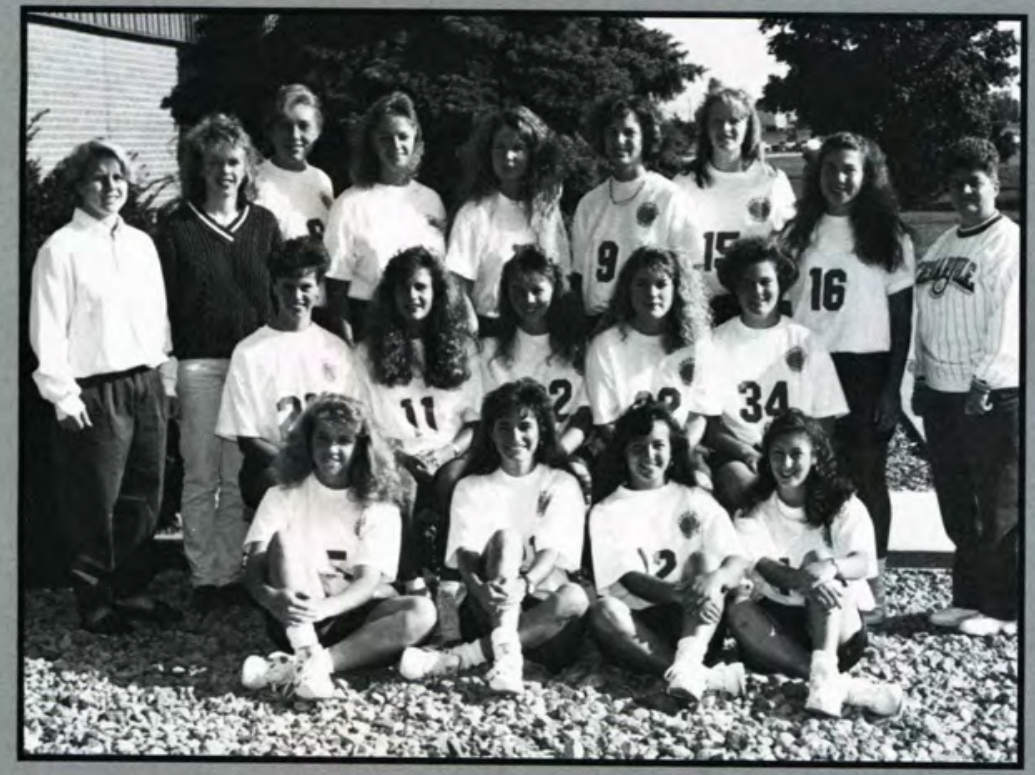

Front row: Melissa Hartman, Dee Hauser, Lynette Cruz, Laura Huggler. Second row: Stephanie Yankovich, Deb Henry, Angie Hartman, Carrie Jacobs, Aimee Miller. Back row: Robin Lynch, Lori Driskal, Elizabeth Miller, Amy Zehr, Jennifer Slaon, Lana Haus, Cheryl Miller, Lori Royal, Coach Elaine Brown. 


\section{$\Delta n$ Era Ends \\ Cross Country teams are a success}

\section{Scoreboard}

Midwest Collegiate

Friendship Invitational

All-Ohio Championship

Wittenberg Invitational

15th of 26

1st of 4

13th of 32

1st of 6
Gettysburg Invitational

NAIA District 22

NCCAA Nationals

NAIA Nationals 7th of 17

4th of 5

2nd of 15

no team

Four seniors, all of whom have run for Cedarville since they were freshmen, graduate in June. Krista Pritchard is the most successful women's cross-country runner in Cedarville's history. She capped her senior season by placing 36th at the NAIA National championship meet--the highest finish by a woman in Cedarville's history. The other three seniors who also helped provide leadership were Sharie Bolender (three time NCCAA all-American), as well as Claire Barnhart and Renee Lawson, both three-time varsity letter winners. Fortunately for Cedarville, the underclassmen contributed significantly to an excellent season and will provide strength for the team in the future. This year, the women were champions at the Friendship Invitational at John Bryan Park, as well as the Wittenberg Invitational. They finished their season by placing second in the NCCAA National championship meet. They were led by individual champion Krista Pritchard, Sharie Bolender, who fought mononucleosis all season, and freshman Laura "Mama" Boothe.

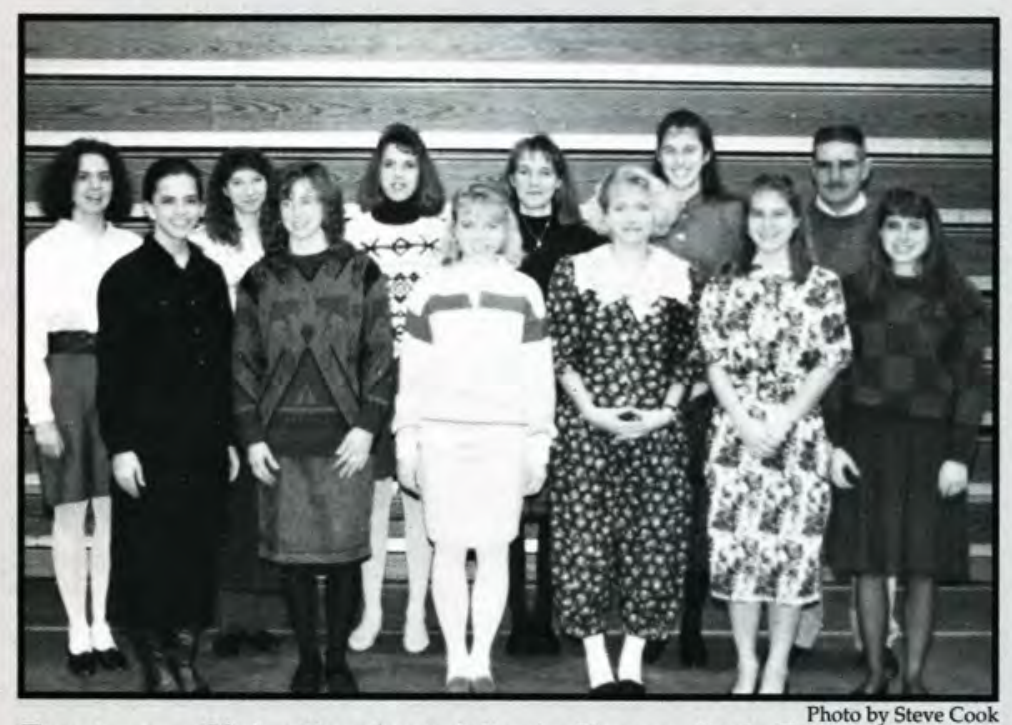

Front row: Claire Barnhart, Marcia Knaus, Beth Fales, Heather Cornelius, Lori Landwehr, Wendy Cassidy. Back row: Sharie Bolender, Jennifer Zenner, Abby McQueen, Laura Boothe, Cindy Hasselbring, Coach King. Not Pictured: Renee Lawson and Krista Pritchard.
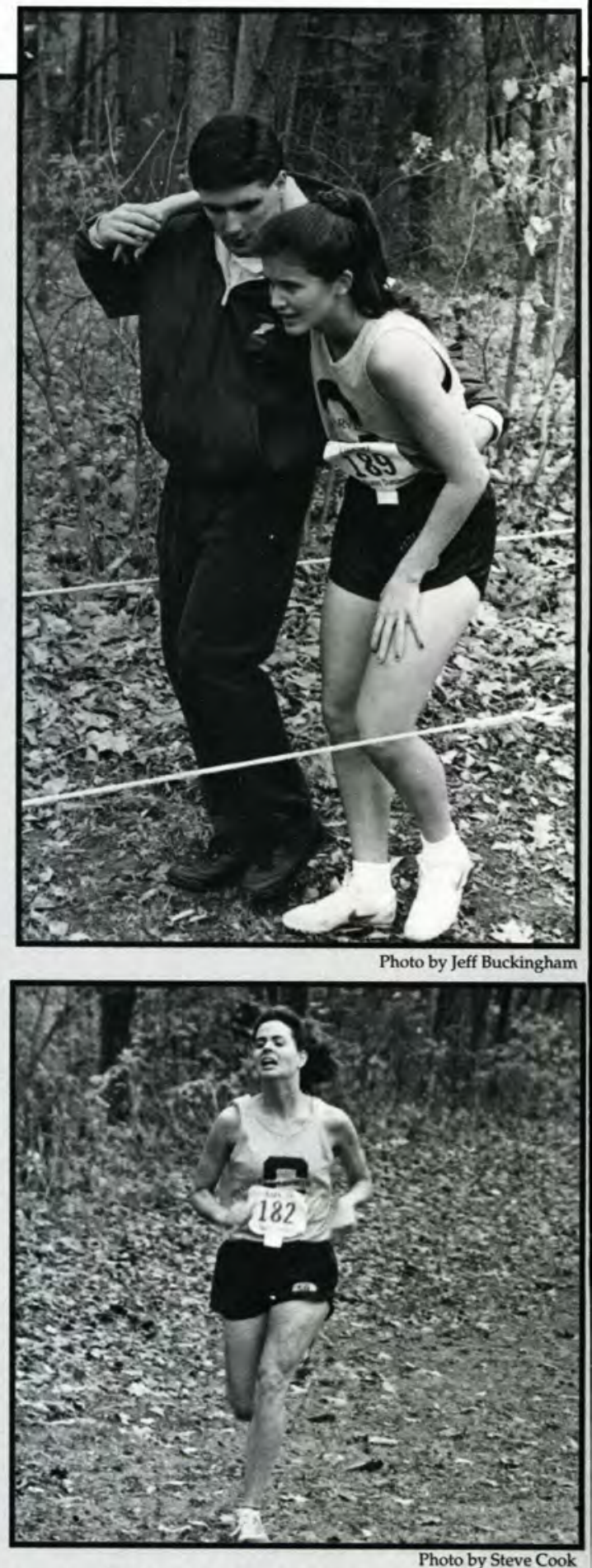

Top: THE HELPING HANDS of Chad Persons assist Renee Lawson.

Bottom: TAKING ONE STEP at a time, Sharie Bolender fights off the pain and continues running. 
PETER CASALETTO WORKS on keeping pace as he rounds the corner.
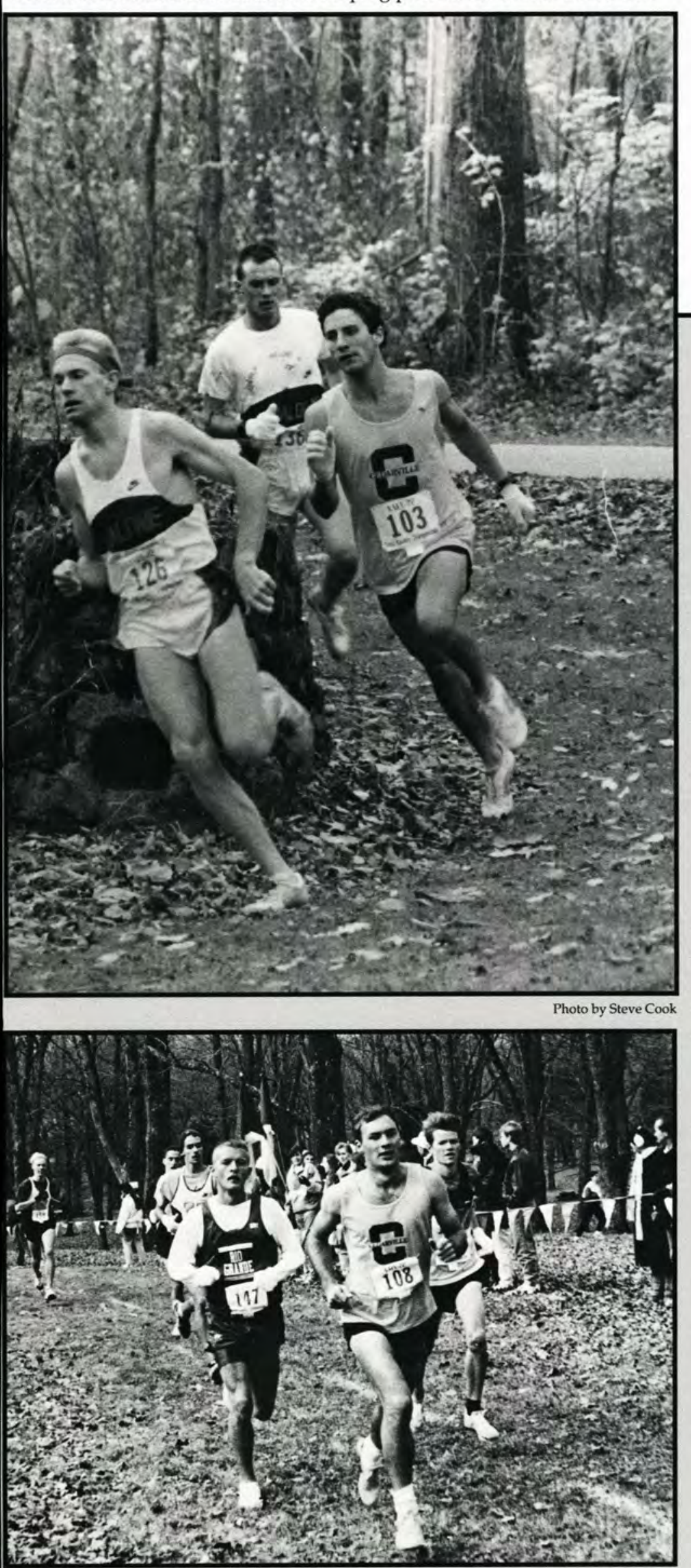

Photo by Jeff Buckingham OUT IN FRONT of the pack, Micah Mitchell presses on to the finish line

\section{Scoreboard}

Midwest Collegiate

Friendship Invitational

All-Ohio Championship

Wittenberg Invitational

Gettysburg Invitational

NAIA District 22

NCCAA Nationals

NAIA Nationals

12th of 23

2nd of 3

16th of 37

2nd of 56

5 th of 17

2nd of 5

3rd of 19

11th of 40

Fact: The team included five Fact: Peter Casaletto won new faces, none of whom two races and finished 3rd in madethevarsity seven. [Note: the NCCAA championship They all made good progress meet in his best season ever. during the season and should INote: Pete has been a leader be strong contributors next on the team for 5 years (one season.]

Fact: Most of the team was greatly missed next season.] sick or injured at some point Fact: Cedarville College's in the season. [Note: The team Men's Cross-Country Team patiently waited on the Lord finished 11that theNAIANa(Isaiah 40:11) and by Nation- tional meet in Kenosha, Wisals, they were ready.] consin. [Note: Coach King

Fact: Kevin Conkel was was NAIA District 22 coach ready to pack it in and red of the year, and the team shirt halfway through the sea- raced through 5 miles of son. [Note: He didn't. Instead, three-inch deep mud to place Kevin led the team at NAIA higher at the National meet Nationals. He will be co-cap- than any others in Cedarville tain again next year.] history!] $\bullet$ Foz, the Manager

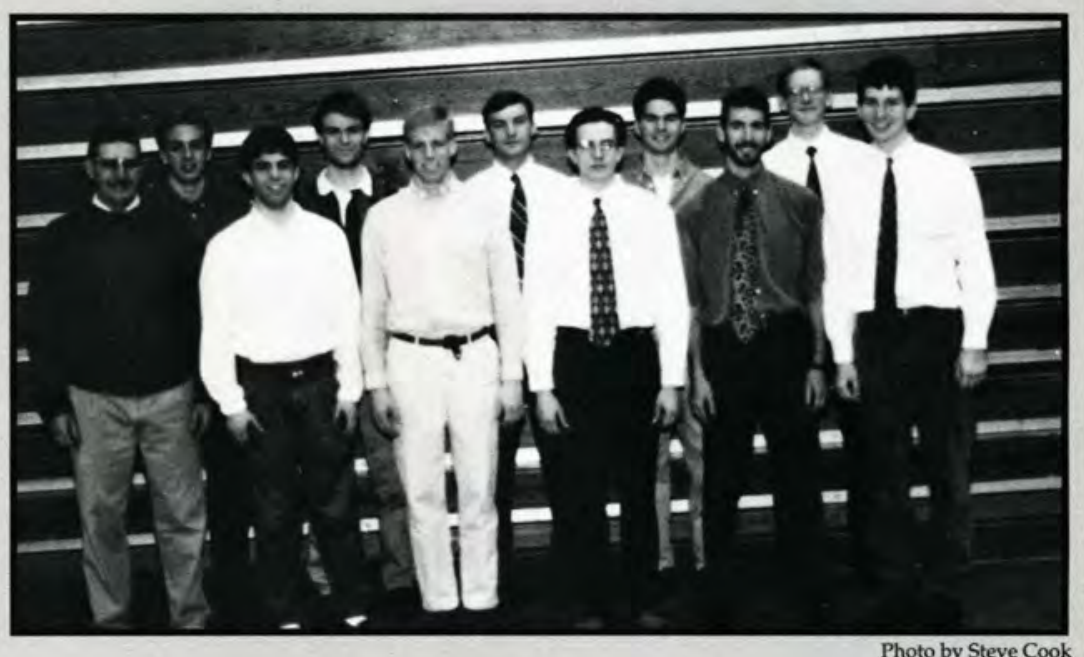

Front row: Coach King, Nick Awabdy, Peter Simons, John Porter, Kevin Conkel, Brian Miller. Back row: Jason Taylor, Chris Nickel, Micah Mitchell, Chad Eder, and Jim Cramer. 
IAKING THE BEAT, Seth Johnson uses his rums to cheer the Jackets on to victory.

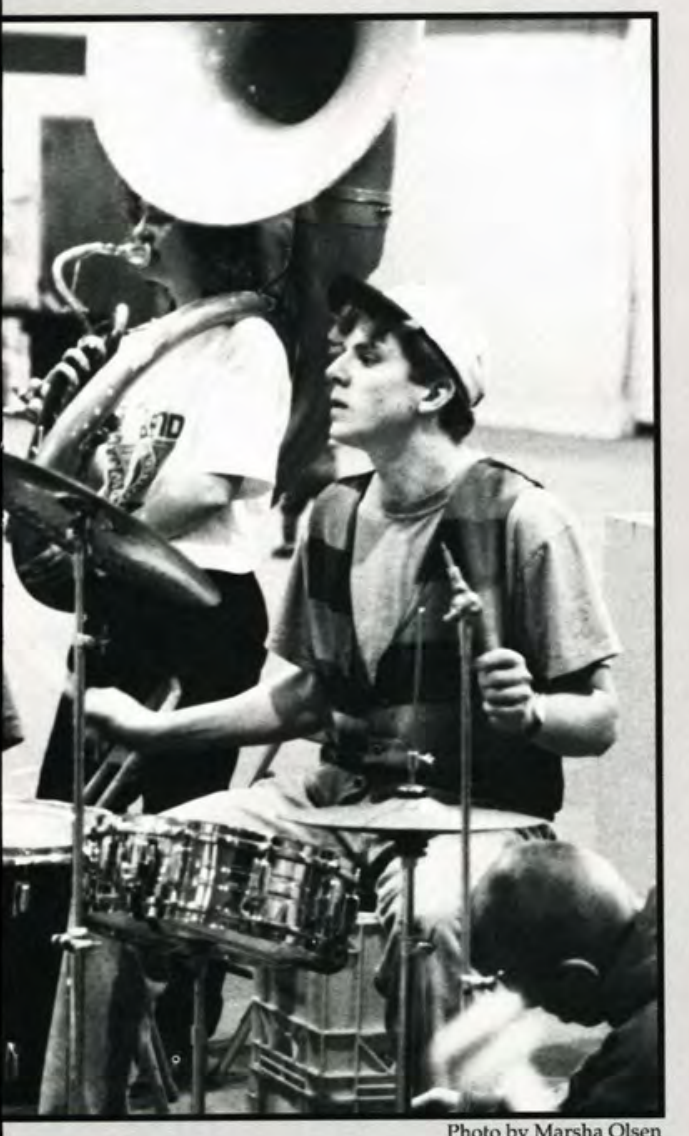

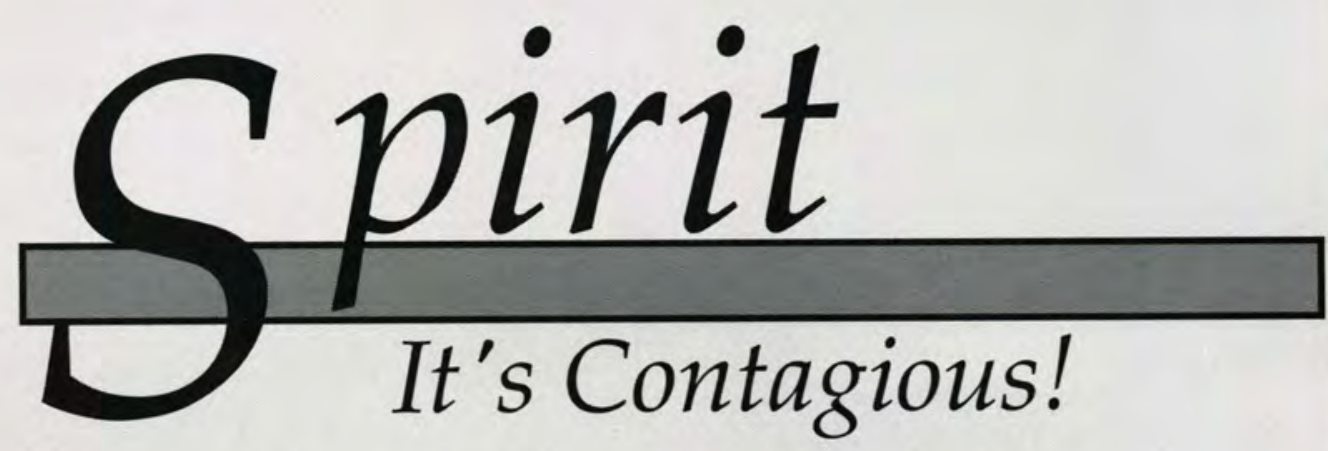

Pep Band Raises Spirits

All you have to do is set foot in the CedarvilleCollege Athletic Center when the Yellow Jackets are playing basketball, and you will know the students of Cedarville have no problem with lack of school spirit. By the time the basketball players take the court, the pep band stretches five rows deep for the entire width of the court behind the home basket, and every remaining inch of bleachers and floor space is filled with rockin', wavin', cheerin' fans. When the tuba bel- lows the first two notes of "Hang on Sloopy," that's the sign for every Cedarville student to rise to his or her feet and cheer. Of course, the cheerleaders for the Yellow Jackets are happy with their jobs. It is a rare occasion when they have to resort to the "Let's get fired up" cheer. Cedarville fans are rarin' to go for every game of the season.

The Cedarville College spirit is everywhere and it is contagious!

- Ruth Pfahler

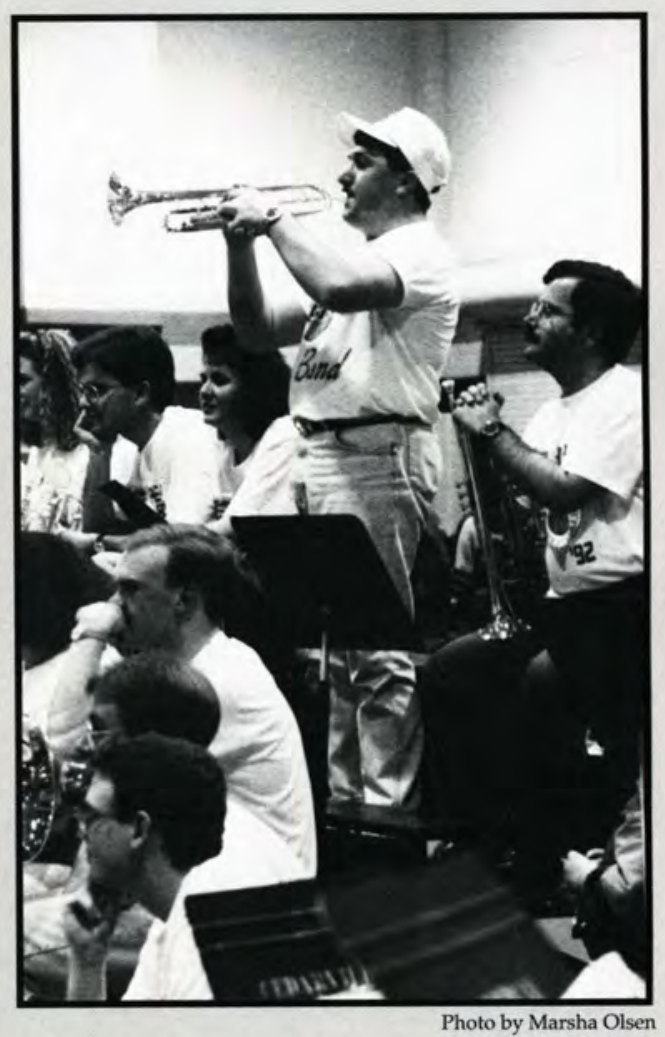

WITH INTENT FACES, the Pep Band takes a break to enjoy the game. 
Yellow

\section{Jacket}

\section{Spirit}

CEDARVILLE'S OWN YELLOW JACKET!

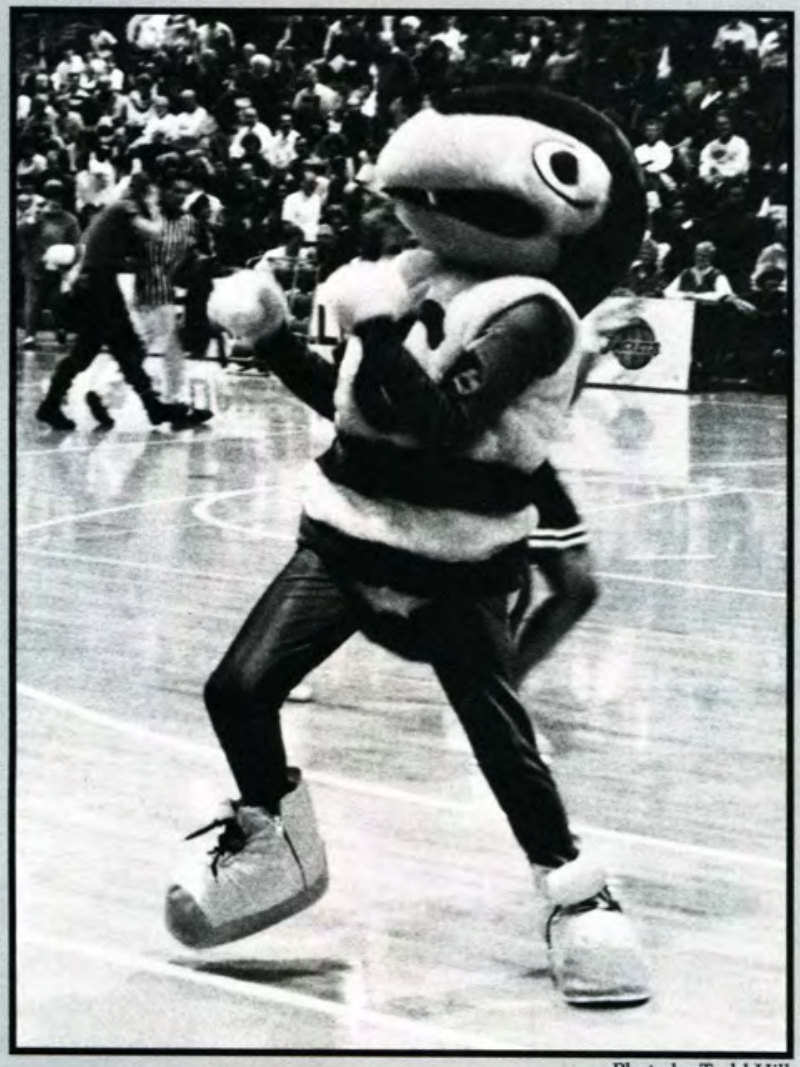

hoto by Todd Hill

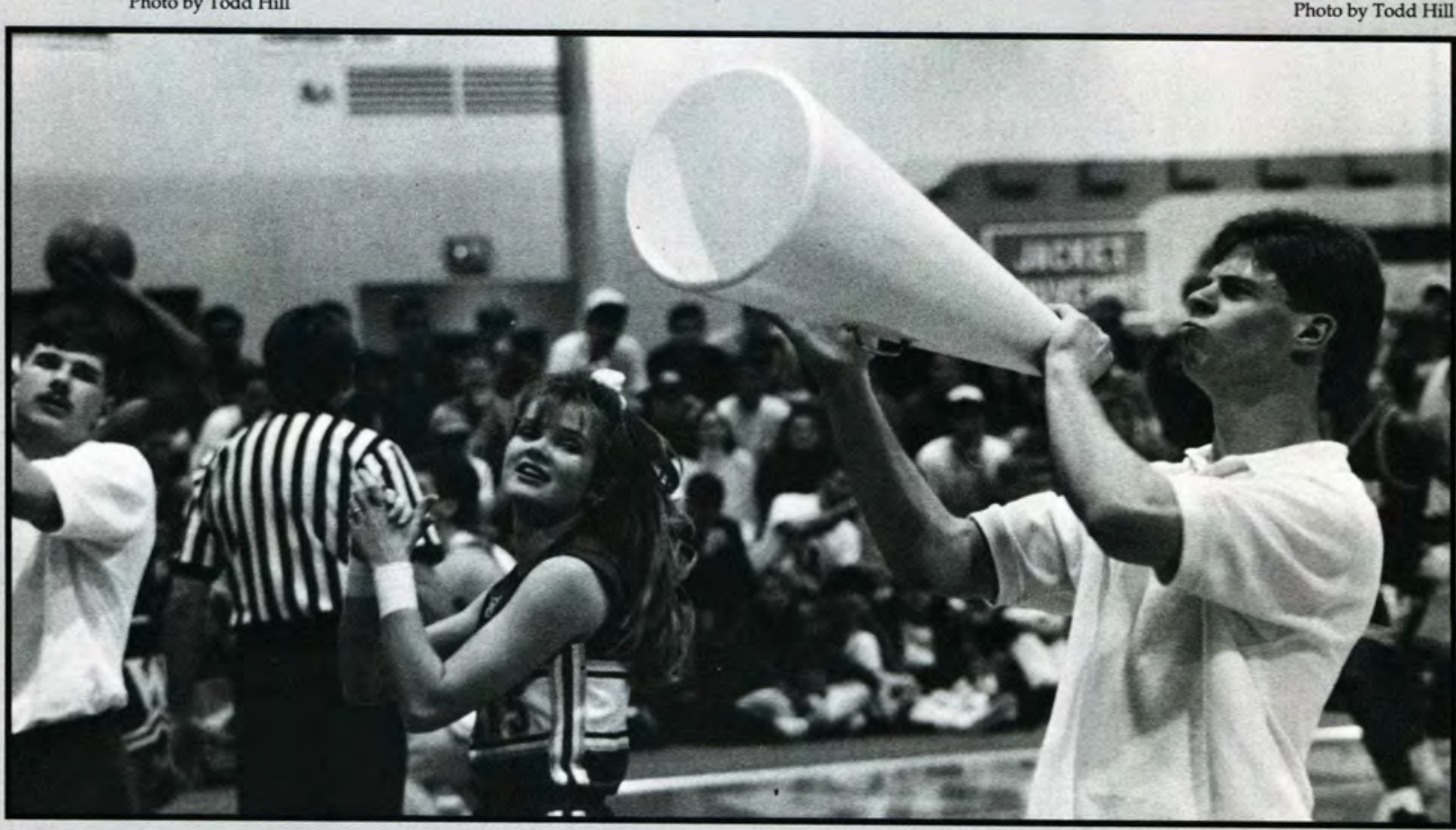

CEDARVILLE, CEDARVILLE, WHAT DO YA SAY? We back the Jackets all the way!

WITH GREAT SPIRIT Adam Hook yells for the Jackets.

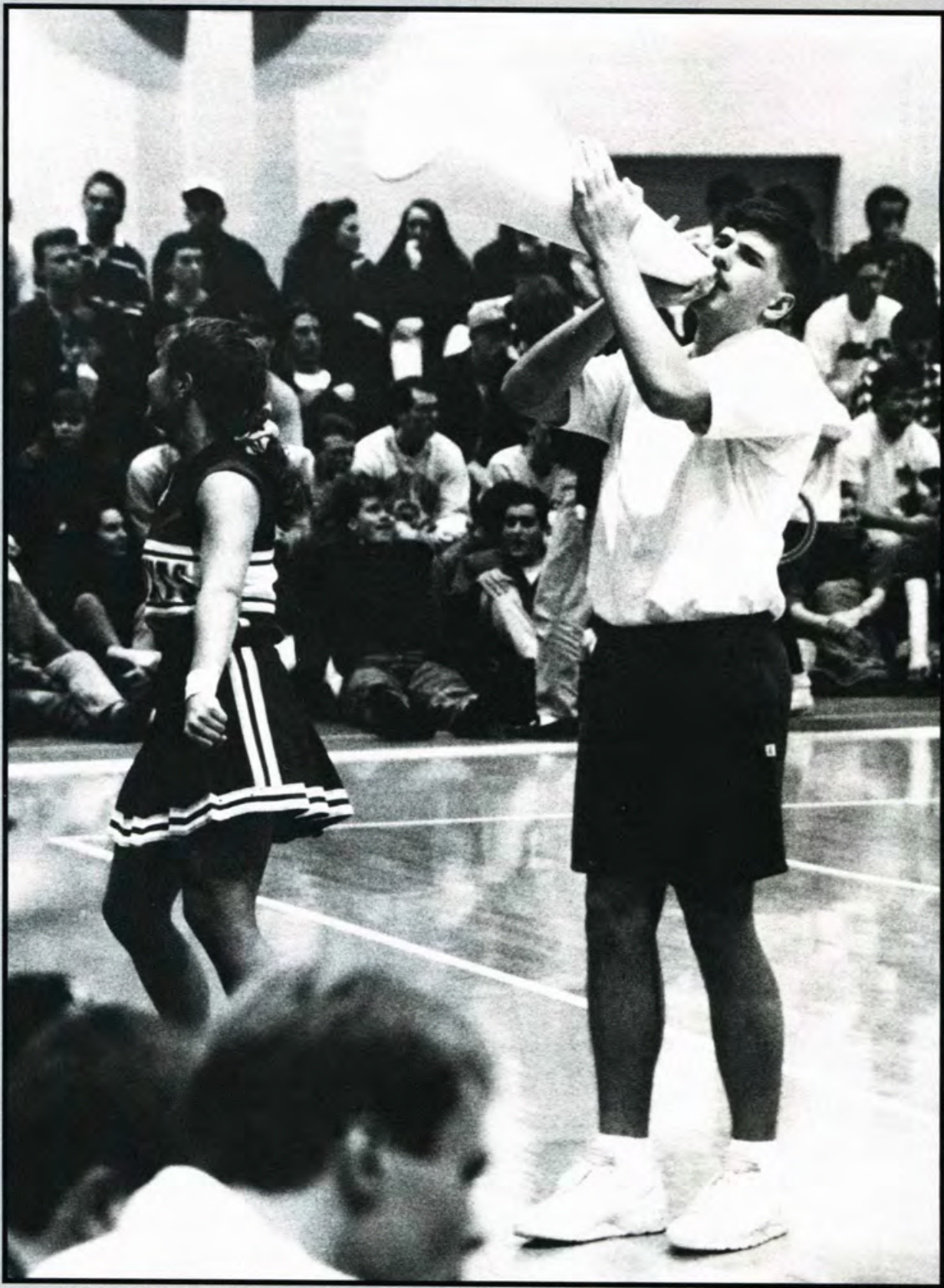

Photo by Todd Hil 


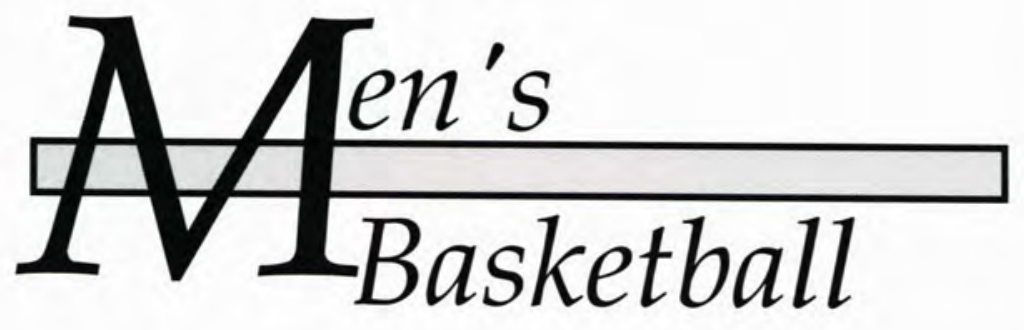

\begin{tabular}{llcl}
\multicolumn{3}{c}{ Scoreboard } \\
Score & Opponent & $104-93$ & Urbana \\
$100-61$ & Concordia & $90-83$ & Shawnee State \\
$81-75$ & Indiana Wesleyan & $89-76$ & Walsh \\
$76-63$ & Western Ontario & $76-79$ & Tiffin \\
$96-71$ & Michigan-Dearborn & $91-110$ & Rio Grande \\
$58-75$ & Taylor & $100-76$ & Ohio Dominican \\
$106-97$ & Spring Arbor & $91-73$ & Mt. Vernon Nazarene \\
$84-61$ & West Chester & $92-79$ & Urbana \\
$86-84$ & Lock Haven & $98-83$ & Shawnee State \\
$95-57$ & Asbury & $82-96$ & Walsh \\
$107-90$ & Wilberforce & $98-99$ & Tiffin \\
$91-86$ & Wilmington & $97-101$ & Rio Grande \\
$112-92$ & Graceland & $83-75$ & Ohio Dominican \\
$67-62$ & Penn State-Behrend & $72-109$ & Mercyhurst \\
$55-67$ & St. Vincent & $97-92$ & Central \\
$108-76$ & Lake Erie & $66-88$ & Findlay \\
$97-73$ & Mt. Vernon Nazarente & & \\
& & &
\end{tabular}

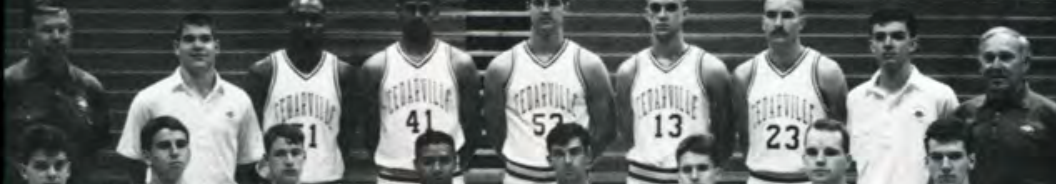

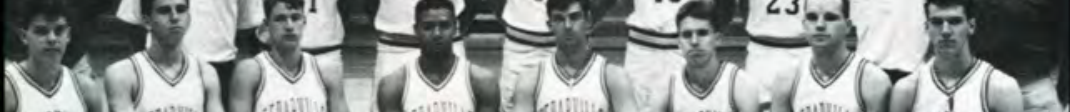

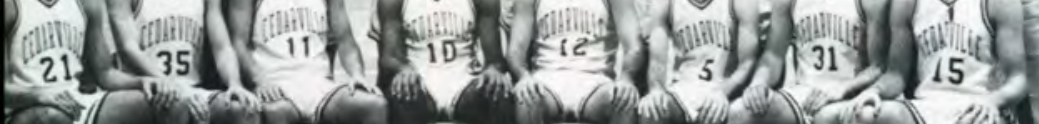
thatringing

$$
\text { हो }
$$

Front row: Nathan Huffman, Todd Lane, Darren Hooley, El Seabra, Mark Combs, Matt Wireman, Josh Rang, Tim Trow. Back row: Coach Pete Reese, Casey Wood, Ken Rucker, David Barnes, Matthew Reynolds, David Whisman, Jaden Callahan, Bill Curry, Dr. Don Callan.

GOING FOR TWO, Kenny Rucker, the Jackets All-American, shoots for yet another basket.

WITH THE REBOUND IN REACH, El Seabra jumps to get the ball for Cedarville.
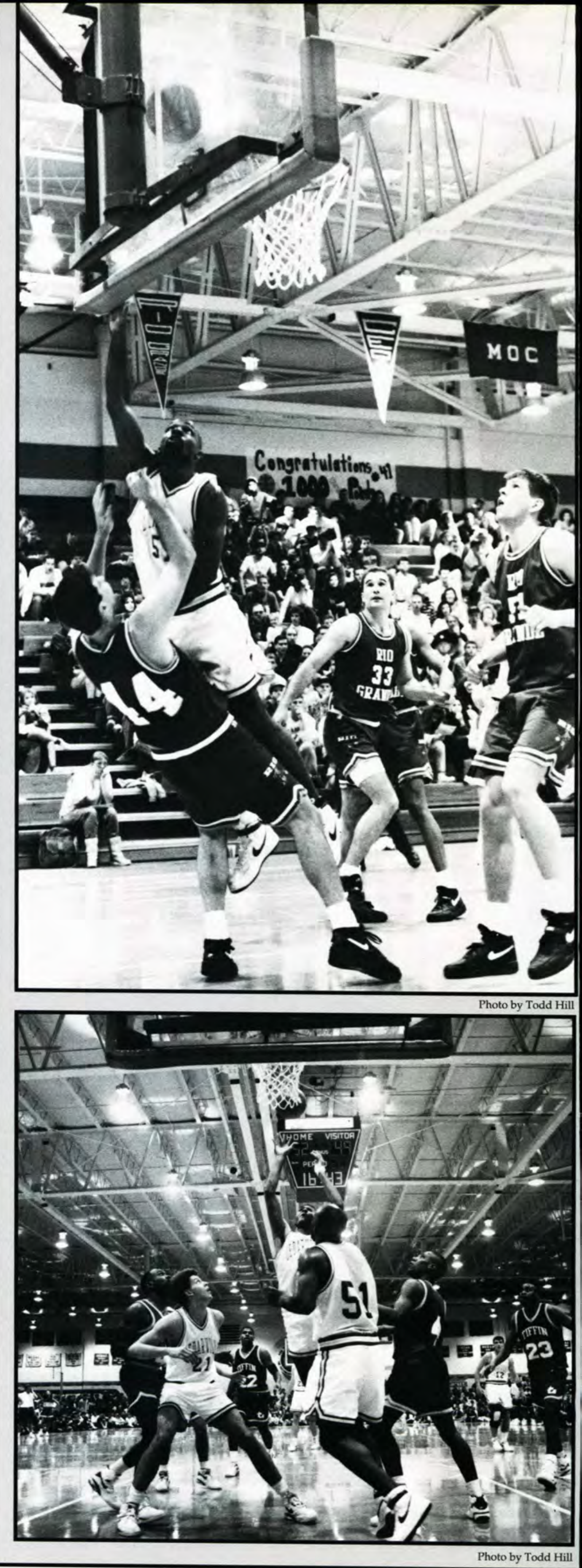


\section{Jackets tie for Third in MOC}

CedarvilleCollege rolled to its sixth straight 20-win season with a 23-9 record. The Yellow Jackets tied for third in the MOC at 9-5, plus head coach Don Callan completed his 33rd season with a 537-397 record. The highlight of the season came midway through January when the Jackets were 17-2 and ranked \#11 nationally in NAIA Division 1.

Ken Rucker, a 6'3" senior forward from Philadelphia, PA., was named to the NAIA Division 1 All-American third team and to the NCCAA first team. He paced the Jackets by averaging 24.5 points and 12.2 rebounds per game, plus was tabbed the NAIA District 22 Division 1 and Mid-Ohio Conference Player of the Year.

Rucker finished his career as the first player in Yellow Jacket basketball history to surpass 2,000 points and 1,000 rebounds. His 2,281 points ranks second to Eric Mounts $(2,648)$ on Cedarville's all-time scoring list while his 1,200 rebounds rates fourth. He and Mounts are Cedarville's only NAIA All-Americans.

Senior forward Jaden Callahan averaged
18.3 points and finished his career sixth among Cedarville's all-time scorers with 1,798 points. He is the Jacket's career leader in three-pointers made (186) and attempted (448).

Two other seniors left their mark on the program. David Barnes finished his career with 1,051 points, while Mark Combs scored 1,009 points and became Cedarville's all-time leader in assists with 498.

Cedarvilleswept NAIA nationally-ranked Urbana University twice by scores of 104-93 and 92-79. The Yellow Jackets were 12-2 at home which included an 89-76 win over MOC champion Walsh University.

Yellow Jacket basketball was a big draw in the Athletic Center once again with 26,112 fans attending Saturday nights. A record crowd of 3,376 showed up for the Li'l Sibs Weekend game on February 13 against Tiffin.

The only starter not graduating from this year's team is 6'2" El Seabra. He was the third leading scorer with 12.3 points per game and shot 51 percent from the field.

-Mark Womack

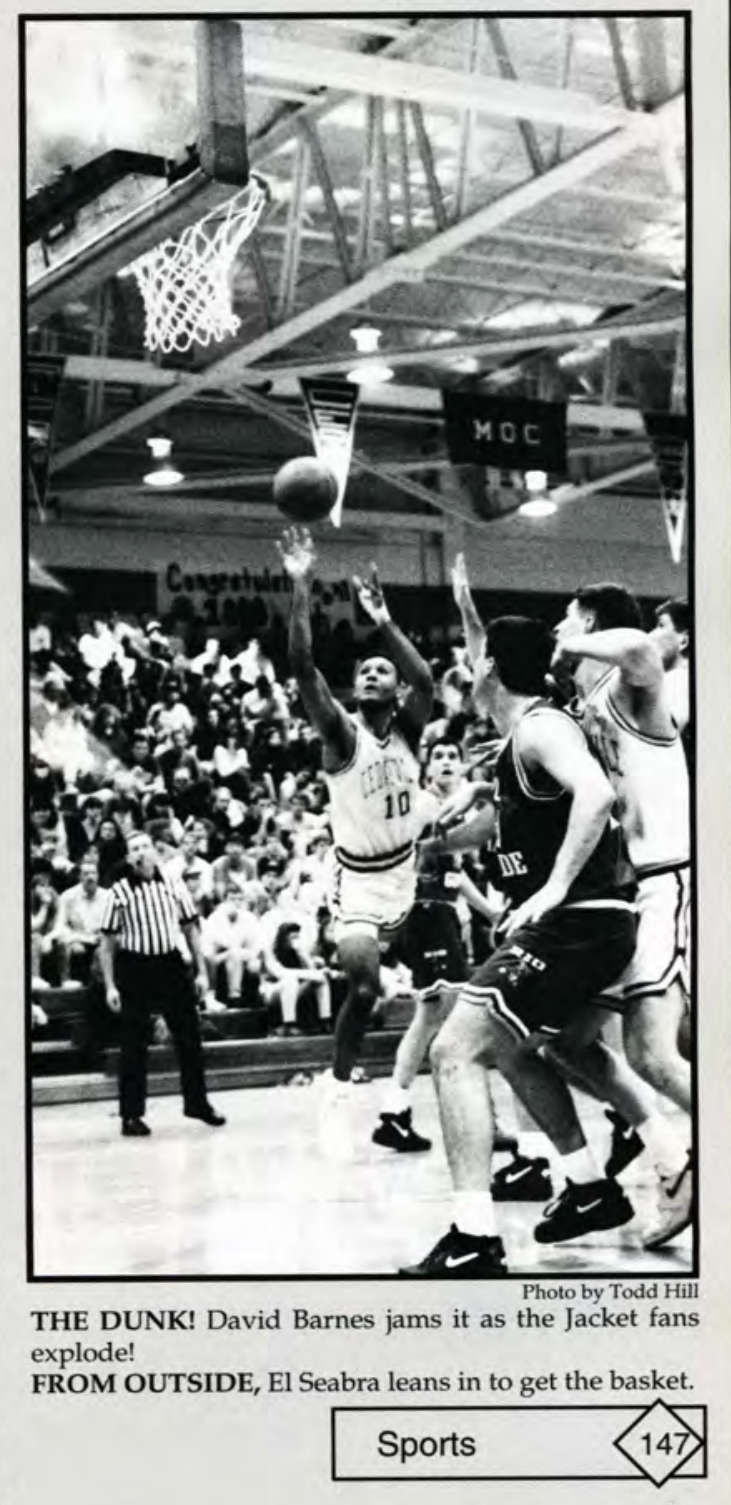

Sports

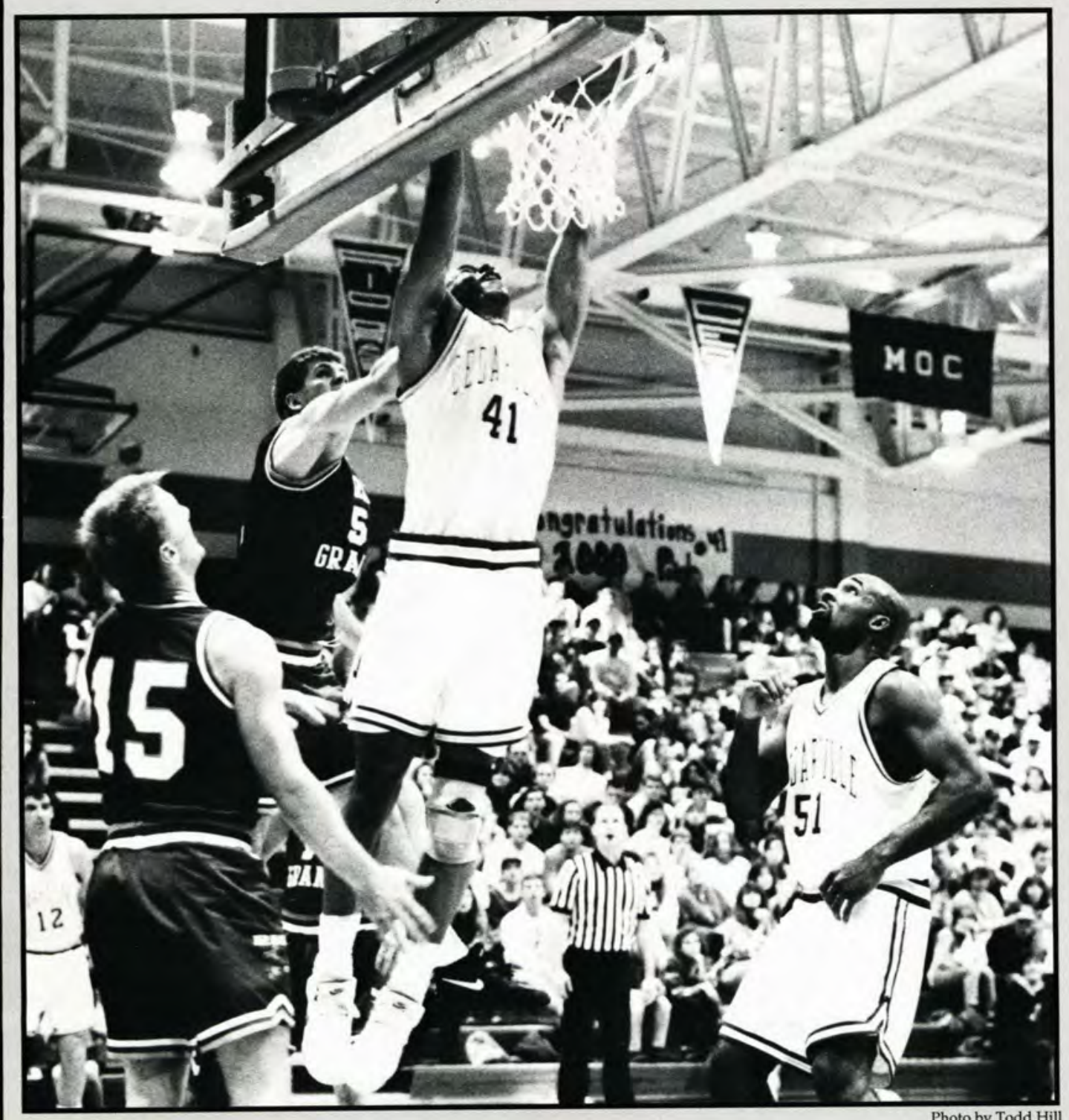


SHOOTING FOR TWO, Melissa

Hartman gives it all she's got.

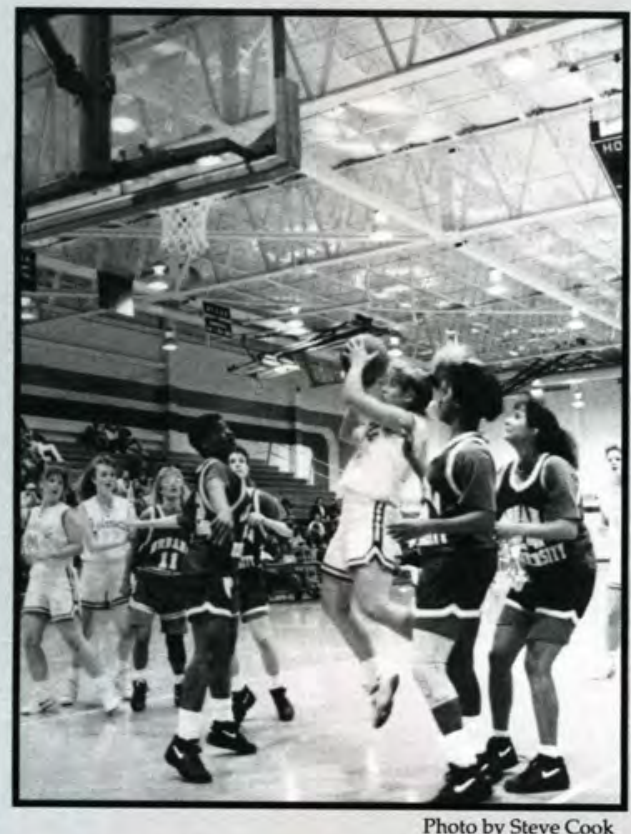

The 1992-93 Lady Jacket basketball season was full of streaks. Cedarville's 18-10 campaign opened with two losses before the club ran off a school record 13-straight victories. Six consecutive losses were followed by five straight wins. But the women finished their season with back-to-back setbacks in NCCAA and NAIA tournament play.

Coach Kathy Freese's team was ranked as high as 23rd nationally in NAIA Division II when they were 13-2 following the memorable winning streak. The Jackets were also rated as high as third in the NCCAA and finished fourth of eight schools in the Mid-Ohio Conference with an 8-6 mark.

Amy Zehr, a 5'9" senior forward from Fort Wayne, IN, was selected to the NAIA Division II and NCCAA All-American first teams. She became the Lady Jackets first NAIA All-American in basketball.

Zehr averaged 24.7 points and 14.0 rebounds per game. She was also named the NAIA District 22 Division II and Mid-Ohio Conference Player of the Year.

Zehr finished her career as the Lady Jackets' all-time leading rebounder with 1,049 rebounds and as the third leading scorer with 1,646 points. She also holds school records for most rebounds in one season (377), plus single-game records for most points (41), rebounds (26), and steals (8).

Another key to the success of the team was the play of freshman point guard Melissa Hartman. She averaged 14.4 points per game which was the most by a Lady Jacket rookie in 16 years. Hartman also averaged 4.0 assists per game and shot .739 from the free throw line, both team highs.

Senior guard Mindy Humble completed her career with 8.5 points per game. She ranked second in assists with 91.

Cedarville won its own invitational as well as the Wilmington Tournament. The Lady Jackets were also 12-2 at home which included a 78-68 win over defending MOC champion Shawnee State.

The women were seeded \#2 in the NCCAA District III playoffs, but were knocked off at home 77-63 by Oakland City in the semifinals. The Jackets were then seeded \#5 in the eight-team NAIA District 22 Division II field, but their season ended with a loss at Tiffin, 79-65.

Besides all the honors that Zehr received this year, Hartman as well as classmate Becky Cave, were both named to the All-MOC Freshmen team. Cinnamon Brown was selected to the NCCAA, MOC, and NAIA District 22 Division II Scholar-Athlete squads. $\quad$ Mark Womback

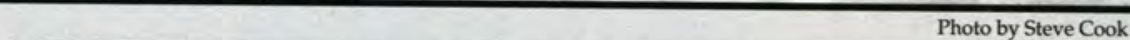

Photo by Steve Cook

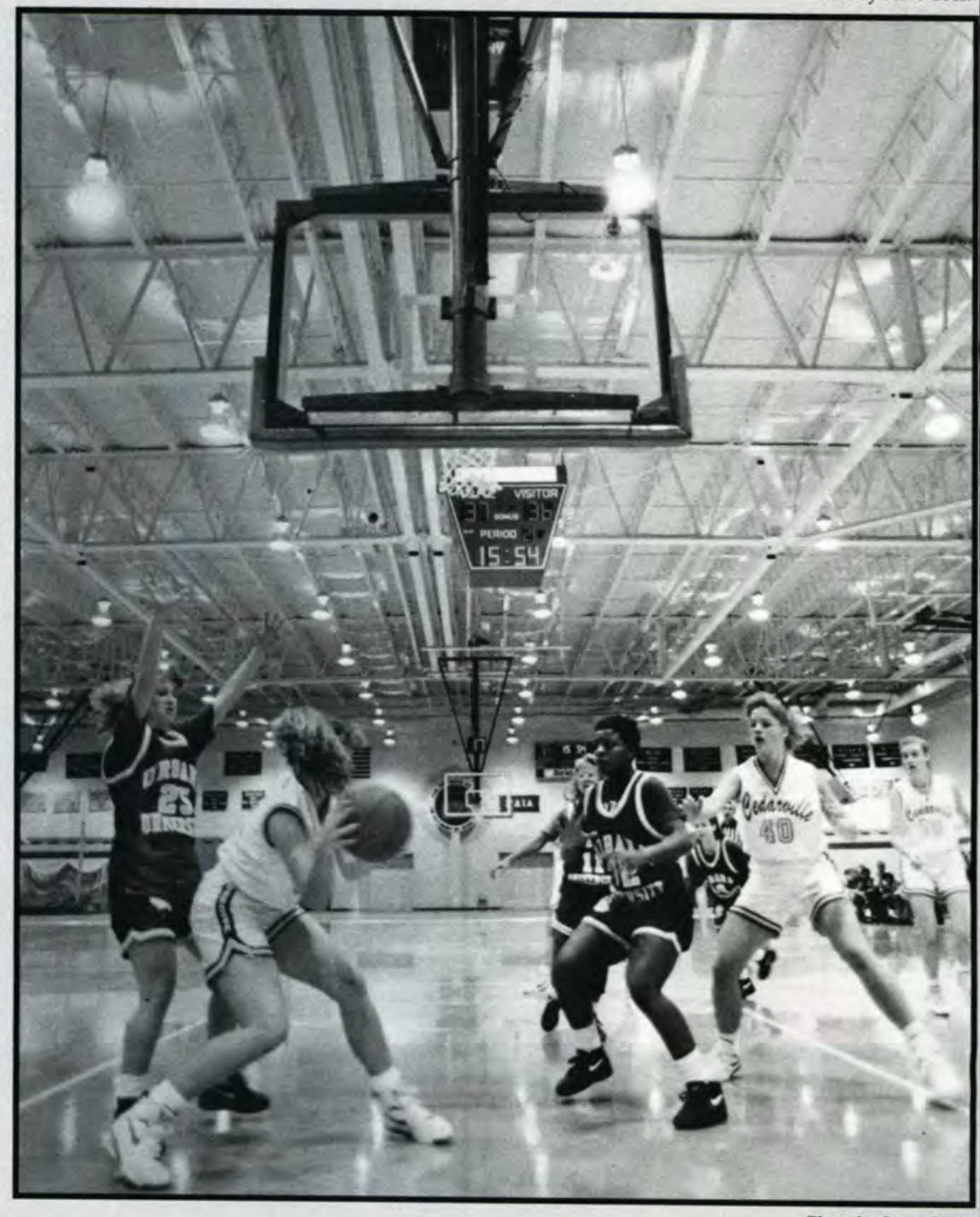

Photo by Steve Cook

LOOKING FOR THE OPEN MAN, Sarah Stiles tries to pass the ball. 

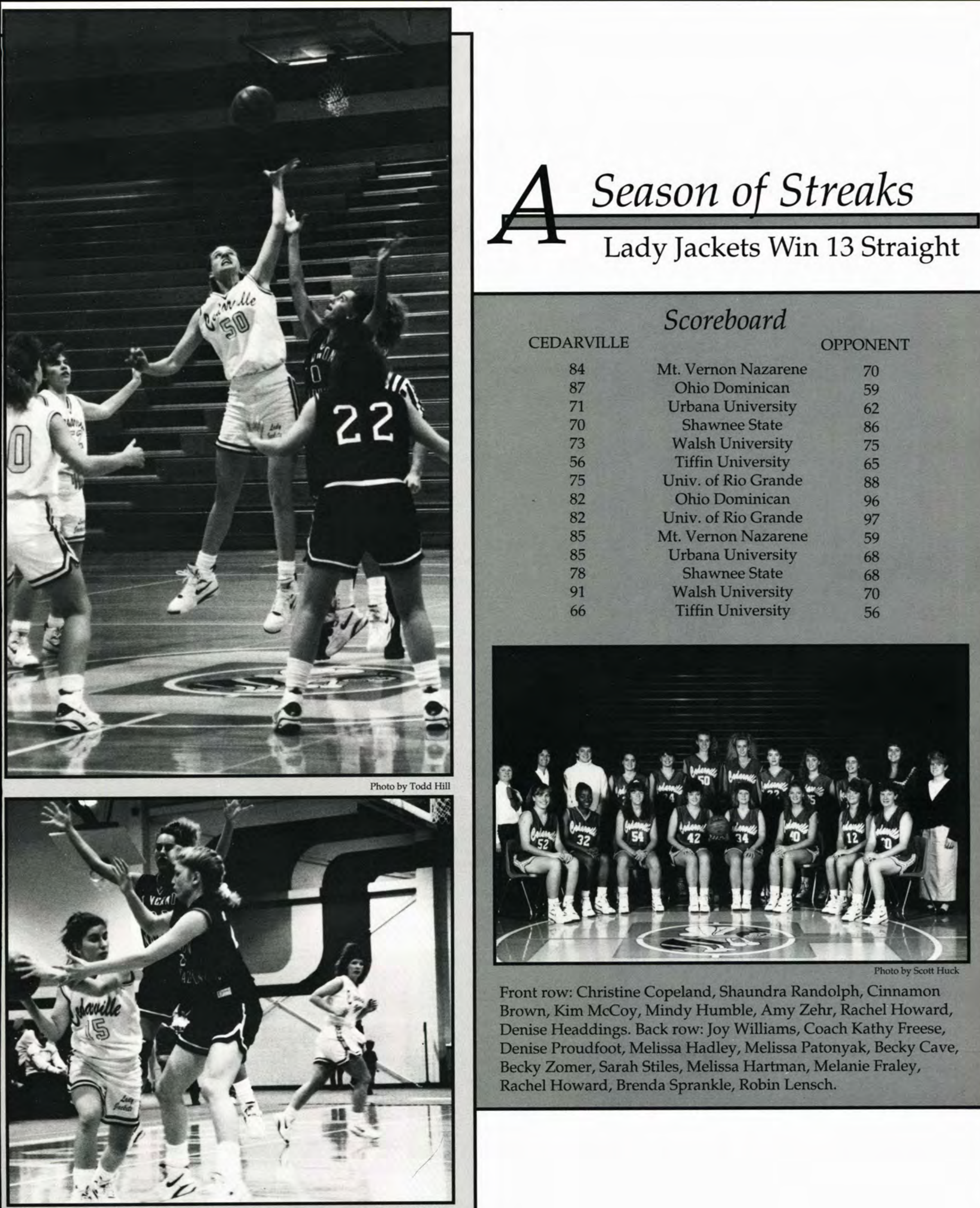

Photo by Todd Hill

BEING OUTNUMBERED does not stop Melanie Fraley from doing her part.

Top: DURING THE TIP OFF, Becky Cave goes up for the 'Ville.

\section{Scoreboard \\ Scoreboard}

CEDARVILLE

84

87

71

70

73

56

75

82

82

85

85

78

91

66
OPPONENT

$\begin{array}{cc}\text { Mt. Vernon Nazarene } & 70 \\ \text { Ohio Dominican } & 59 \\ \text { Urbana University } & 62 \\ \text { Shawnee State } & 86 \\ \text { Walsh University } & 75 \\ \text { Tiffin University } & 65 \\ \text { Univ. of Rio Grande } & 88 \\ \text { Ohio Dominican } & 96 \\ \text { Univ. of Rio Grande } & 97 \\ \text { Mt. Vernon Nazarene } & 59 \\ \text { Urbana University } & 68 \\ \text { Shawnee State } & 68 \\ \text { Walsh University } & 70 \\ \text { Tiffin University } & 56\end{array}$

90

Front row: Christine Copeland, Shaundra Randolph, Cinnamon Brown, Kim McCoy, Mindy Humble, Amy Zehr, Rachel Howard, Denise Headdings. Back row: Joy Williams, Coach Kathy Freese, Denise Proudfoot, Melissa Hadley, Melissa Patonyak, Becky Cave, Becky Zomer, Sarah Stiles, Melissa Hartman, Melanie Fraley, Rachel Howard, Brenda Sprankle, Robin Lensch. 


\section{Ctrong finish}

Jackets win 7 of last 10 games

\section{Scoreboard}

0
3
1
4
4
3
0
2
0
2
2
3
4
3

$\begin{array}{cr}\text { Rio Grande } & 1 \\ \text { Rio Grande } & 5 \\ \text { Tiffin } & 5 \\ \text { Tiffin } & 6 \\ \text { Shawnee State } & 6 \\ \text { Shawnee State } & 8 \\ \text { Urbana } & 2 \\ \text { Urbana } & 8 \\ \text { Ohio Dominican } & 10 \\ \text { Ohio Dominican } & 11 \\ \text { Mt. Vernon Nazarene } & 1 \\ \text { Mt. Vernon Nazarene } & 6 \\ \text { Walsh } & 3 \\ \text { Walsh } & 4\end{array}$

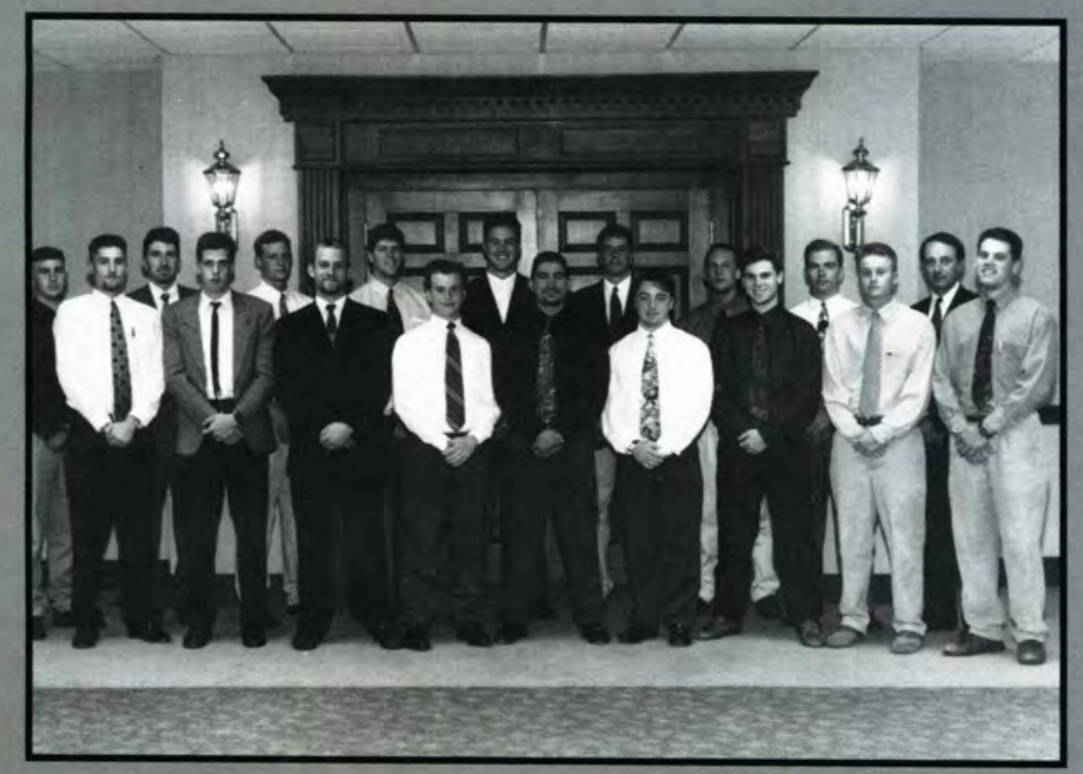

Front row: David Geiger, Brett Popp, Doug Ashley, John Iamaio, Dan Brown, Brian Miller, Stephen Mays, Paul Melbin, James Rinaldi. Back row: Clint Miller, Nathan Rohrer, Ryan VanDeusen, Dan Ambrose, Todd Seljan, Matt Robinson, Jeff Bowen, Tim Edsell, Coach Norris Smith. Not Pictured: Darren Hooley.
FIELDING THE GROUNDER, Darren Hooley thinks of about the play he needs to make next.

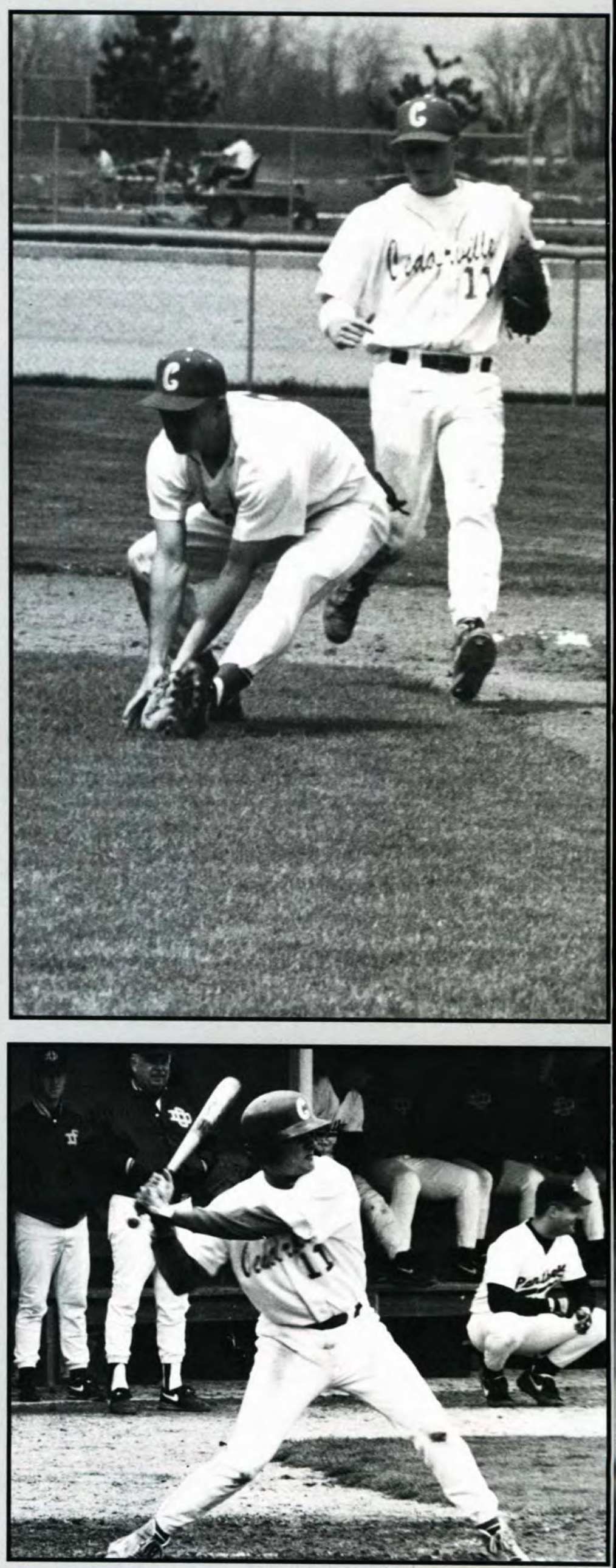

WITH THE COACHES LOOKING ON Paul Melvin concentrates on hitting the ball. 
The Lady Jacket softball team continued its process of rebuilding and finished with a 13-18 record. It was a young team on the field for the second-year coach Kathy Freese with nine of the 14 players being either freshmen or sophomores.

Even with the youth movement, it was the play of seniors Mindy Humble and Julie Rutt that carried the club. Humble lead the team with a .348 batting average and was named to the All-NAIA District 22 unit as an outfielder. She paced the club in at bats (115), hits (40), and runs scored (20), plus was one of only two players to appear in all 35 games. Humble was an honorable mention pick in the Mid-Ohio Conference.

Rutt, also an All-MOC honorable mention performer, was third on the team in hitting with a .341 mark. Her three triples and 20 runs batted in topped the club to go along with a sterling .971 fielding average at first base.

Sophomore righthander DiAnn Miller wrapped up her second full season on the mound by logging $1291 / 3$ innings. She completed all 19 games she started and posted a 7-12 record with one save and 2.33 earned run average. Miller demonstrated good control by allowing only 17 walks the entire season and she pitched one shutout, a 1-0 victory over Wilmington.

Joining Miller on the mound was fellow classmate Julie Sroufe, who experienced her first year in the program. Sroufe was 6-8 with a 2.51 ERA in 95 innings pitched. One of her more impressive outings came in a $1-0$ win over Mount St. Joseph, the number two team in NAIA District 22.

Sroufe also handled the bat well with a .342 average at the plate and 18 runs scored. Freshman utility player Ashli Linkhorn batted an even .300 and tied for the team lead in doubles with six.

Rutt and junior outfielder Shannon Wenger were two of five players named to the All-NAIA District 22 ScholarAthlete softball team. Only juniors and seniors are eligible for the honor and they must carry at least a 3.50 cumulative grade point average. Rutt and Wenger were also the only players for the Mid-Ohio Conference to make the elite group.

-Mark Womack
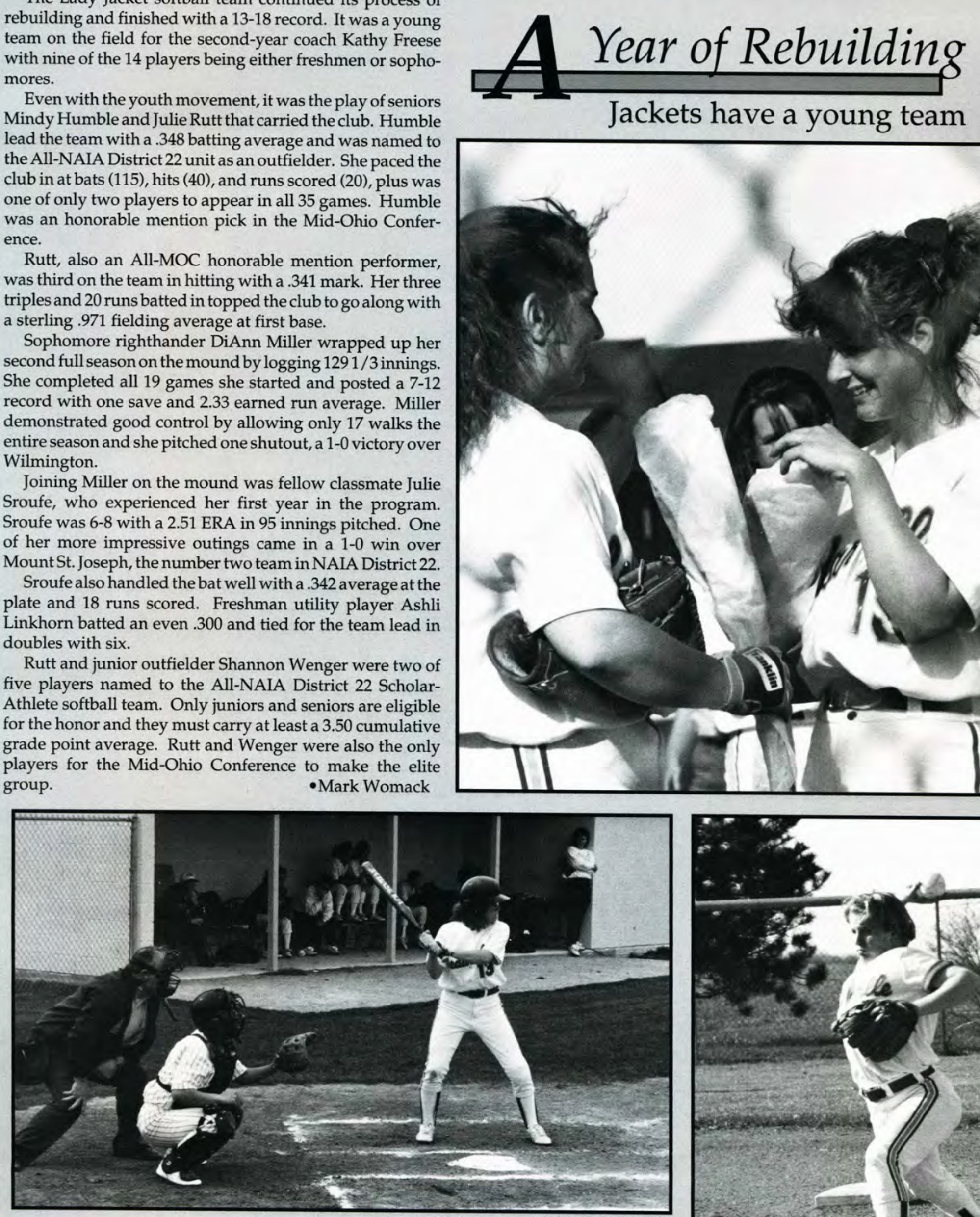

Top Right: AFTER RECEIVING FLOWERS, Julie Rutt and Mindy Humble cherish their memories of softball for a moment.

WAITING FOR THE PITCH, Ashli Linkham anticipates the course the ball will take.

Right: GIVING IT ALL SHE HAS, Robin Lensch throws the ball home. 

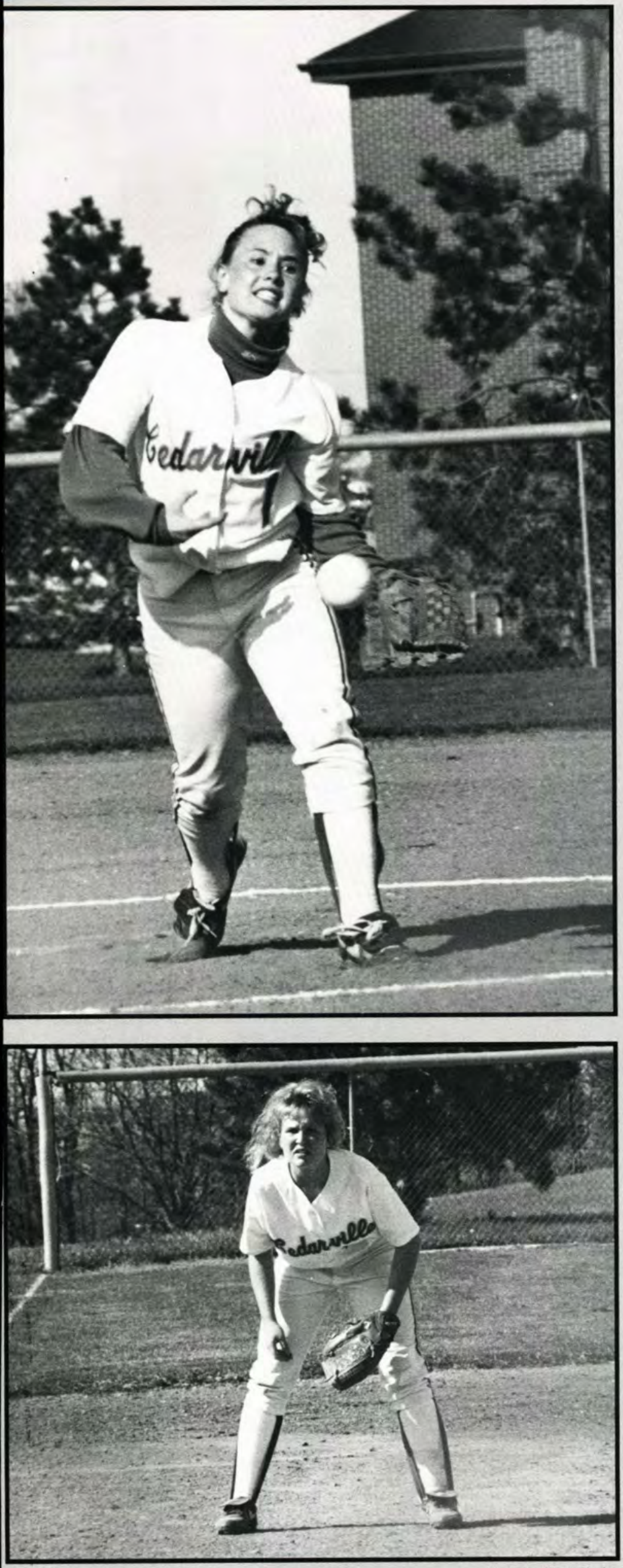

Photos by Tania Taylor ALWAYS IN A READY POSITION Jennifer Sloan pays close attention to the pitch.

Top: WITH MUCH DETERMINATION Julie Sroufe goes for the ball.

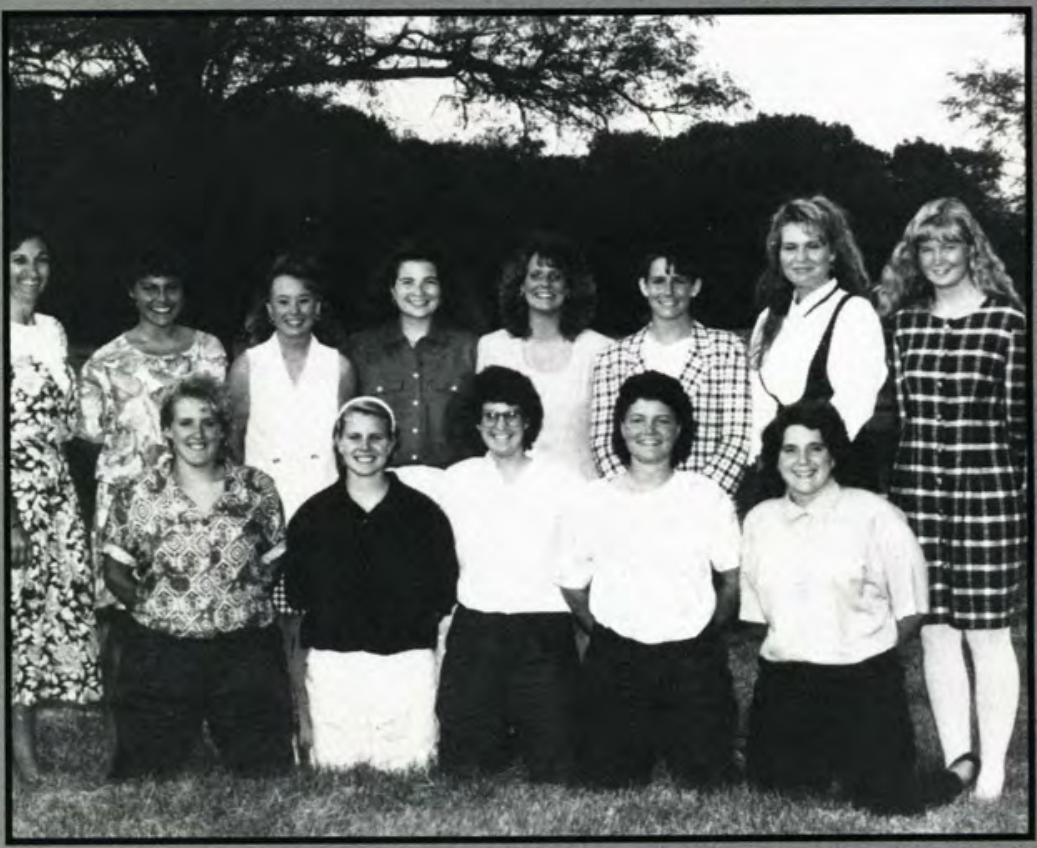

Front row: Shelly Coffin, Manager, Robin Lensch, Candace Sarber, DiAnn Miller, Penni Ruhl. Back row: Coach Kathy Freese, Melissa Reed, Julie Sroufe, Julie Rutt, Mindy Humble, Lisa Coe, Jennifer Sloan, Carrie Scott. Not Pictured: Jenae Bouchard, Ashli Linkhorn, Shannon Wenger. 

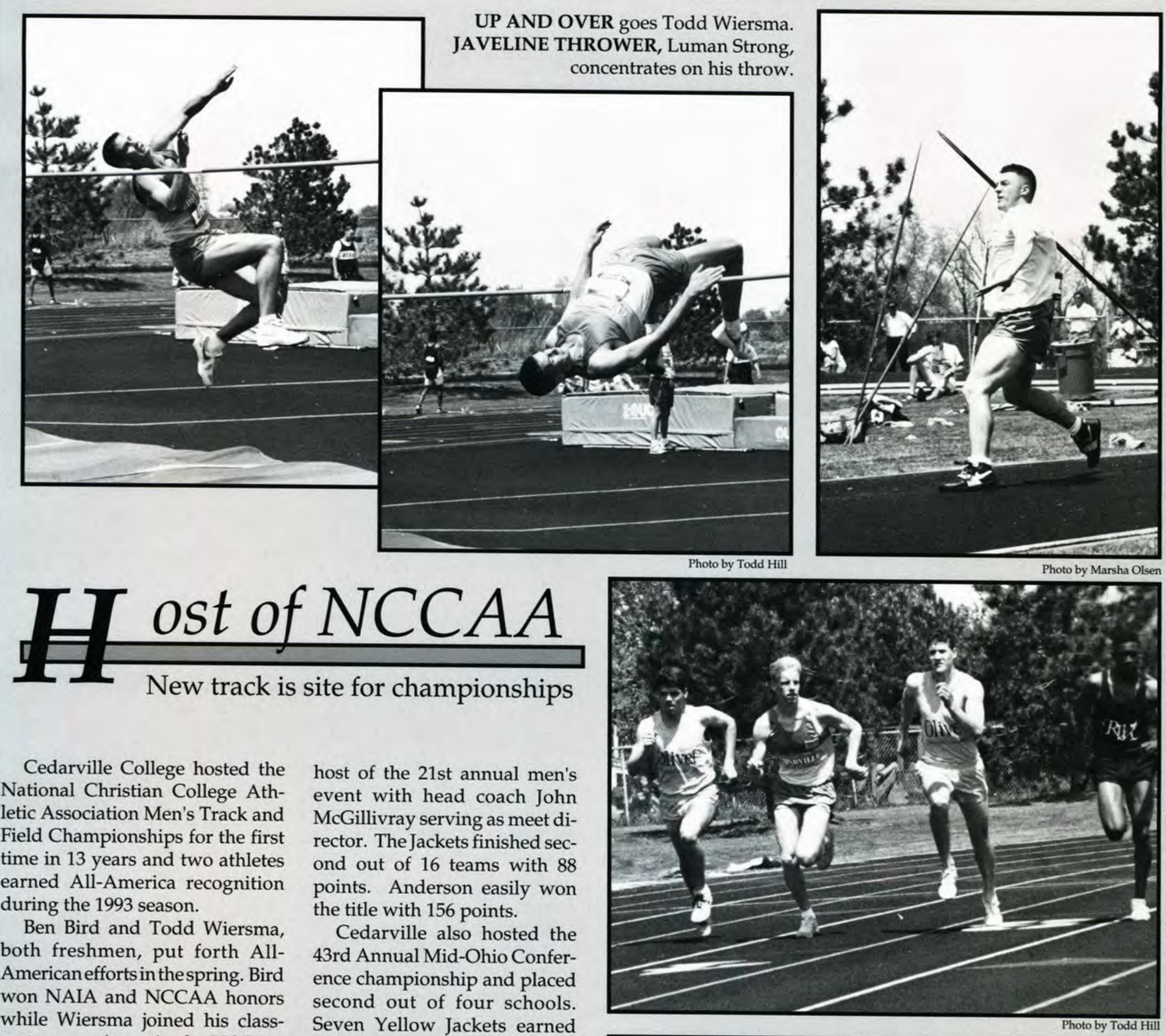

Cedarville College hosted the National Christian College Athletic Association Men's Track and Field Championships for the first time in 13 years and two athletes earned All-America recognition during the 1993 season.

Ben Bird and Todd Wiersma, both freshmen, put forth AllAmerican effortsin the spring. Bird won NAIA and NCCAA honors while Wiersma joined his classmate as a winner in the NCCAA event.

Bird was the Jackets lone NAIA All-American when he placed second in the discus competition at the national meet in Abbotsford, British Columbia. His runner-up heave measured 164 -feet 9 -inches.

Bird won both the discus and shot put events at the NCCAA National. He had a throw of 155feet even in the discus while his winning mark in the shot put was 51-feet $71 / 2$-inches. Wiersma won the javelin competition with a throw of 179-feet 7-inches.

Cedarville College hosted the first eight NCCAA national meets everstaged from 1973 through 1980 and the Yellow Jackets returned as

host of the 21st annual men's event with head coach John McGillivray serving as meet director. The Jackets finished second out of 16 teams with 88 points. Anderson easily won the title with 156 points.

Cedarville also hosted the 43rd Annual Mid-Ohio Conference championship and placed second out of four schools. Seven Yellow Jackets earned spots on theall-conference team led by Todd Wiersma, who won the 110 meter hurdles, high jump, long jump, and was on the winning 400 meter relay team. Other relay members were James Goins, Darryl Hammock, and Steve Barr, who also won the 400 meter dash. Ben Bird swept the discus and shot put event while Jon Plush was victorious in the pole vault.

At the NAIA District 22 meet, Cedarville finished fourth out of six schools. Bird again swept both discus and shot put while Luman Strong was a winner in the javelin. • Mark Womack

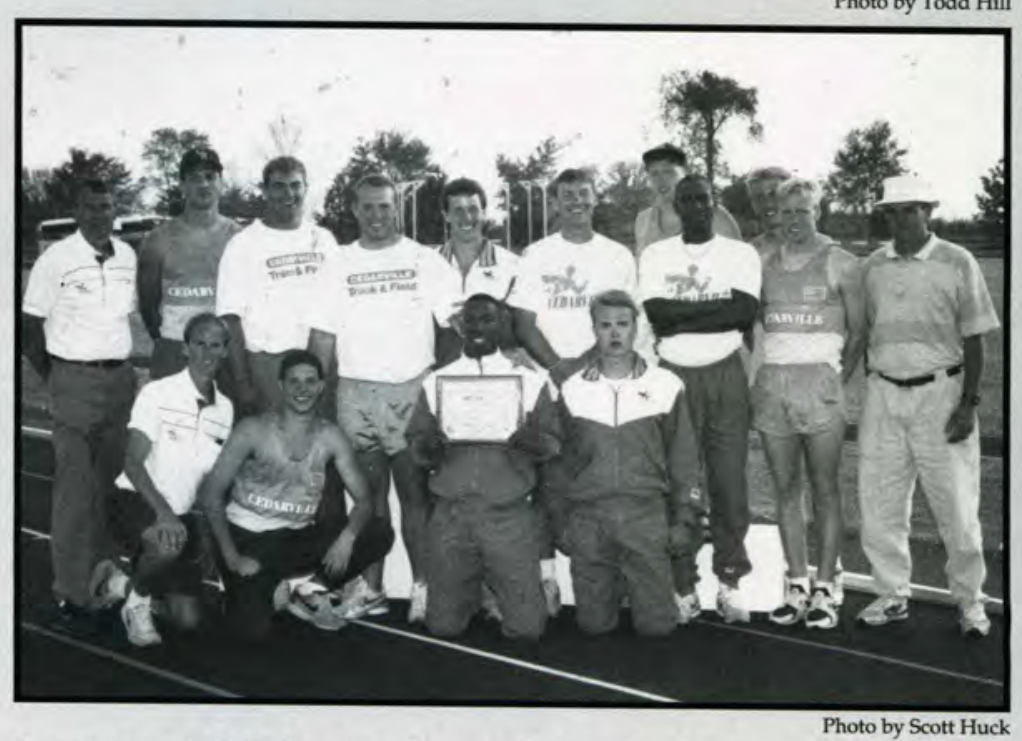

Front row: Jeff Bolender, James Goins. Back row: Coach McGillvray, Steve Barr, Ben Bird, Tim Kieb, Micah Mitchel, Darryl Hammock, Pete Simons, Coach King. 
It was another championship season for the Cedarville College men's tennis team. The Yellow Jackets claimed their fifth straight NAIA District 22 title and 23rd overall in Murray Murdoch's 28 years as head coach. The netters went on to tie for 20th place out of 47 schools at the NAIA Nationals in Kansas City.

Cedarville has a 21-1 record with the lone setback a 6-3 loss at Wittenberg. It was the Jackets' first defeat at the hands of the Tigers in seven years. Murdoch pushed his career record to $551-67$, a .892 winning percentage.

Newcomer and number one player Sino Rasberger, a native of Croatia, won 19 of 20 singles matches during the season to pace the team. His lone loss came in the third round of the national tournament. Rasberger breezed to the District 22 singles title and was ranked as high as 35th nationally in NAIA singles. His name topped the All-NAIA District 22 team.

Matt Kibble closed out his career after advancing to the second round to the national tournament. He was the District 22 singles runner-up after defeating the defending champion in the semifinals. Kibble and Rasberger were rated 20th in NAIA doubles and they advanced to the third round at Kansas City before finishing the spring with a 10-3 record.

Seniors Mike Anthony and Mike Baker finished their senior years with identical 14-3 marks, plus the twosome joined Rasberger and Kibble on the all-district unit. Anthony had a career record of 59-14 while Baker was 56-13. They also had a 9-4 doubles record during the year.

Freshman Jamie Hand had a good experience in his first trip to K.C. with a singles win plus a doubles victory with partner Jeff Blackburn. Hand was 51-3 in singles and made the all-district team, while he and Blackburn won four of five doubles matches.

Junior Cory Grove was the other singles player to take part in the district and national tournaments. He had a 6-2 record to up his career mark to 16-3.

The Yellow Jackets continued their domination of regular season opponents by posting 13 shutouts in dual match competition. That list included wins over Malone, Wright State, and Northern Kentucky. As a team, Cedarville had a 103-17 record in singles and was 44-13 in doubles.

-Mark Womack

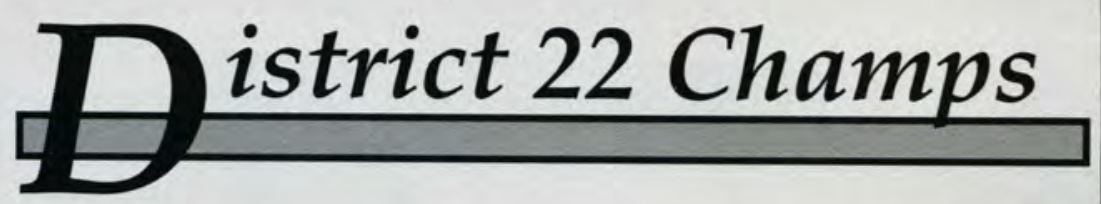

\section{Men's Tennis team goes to Nationals}

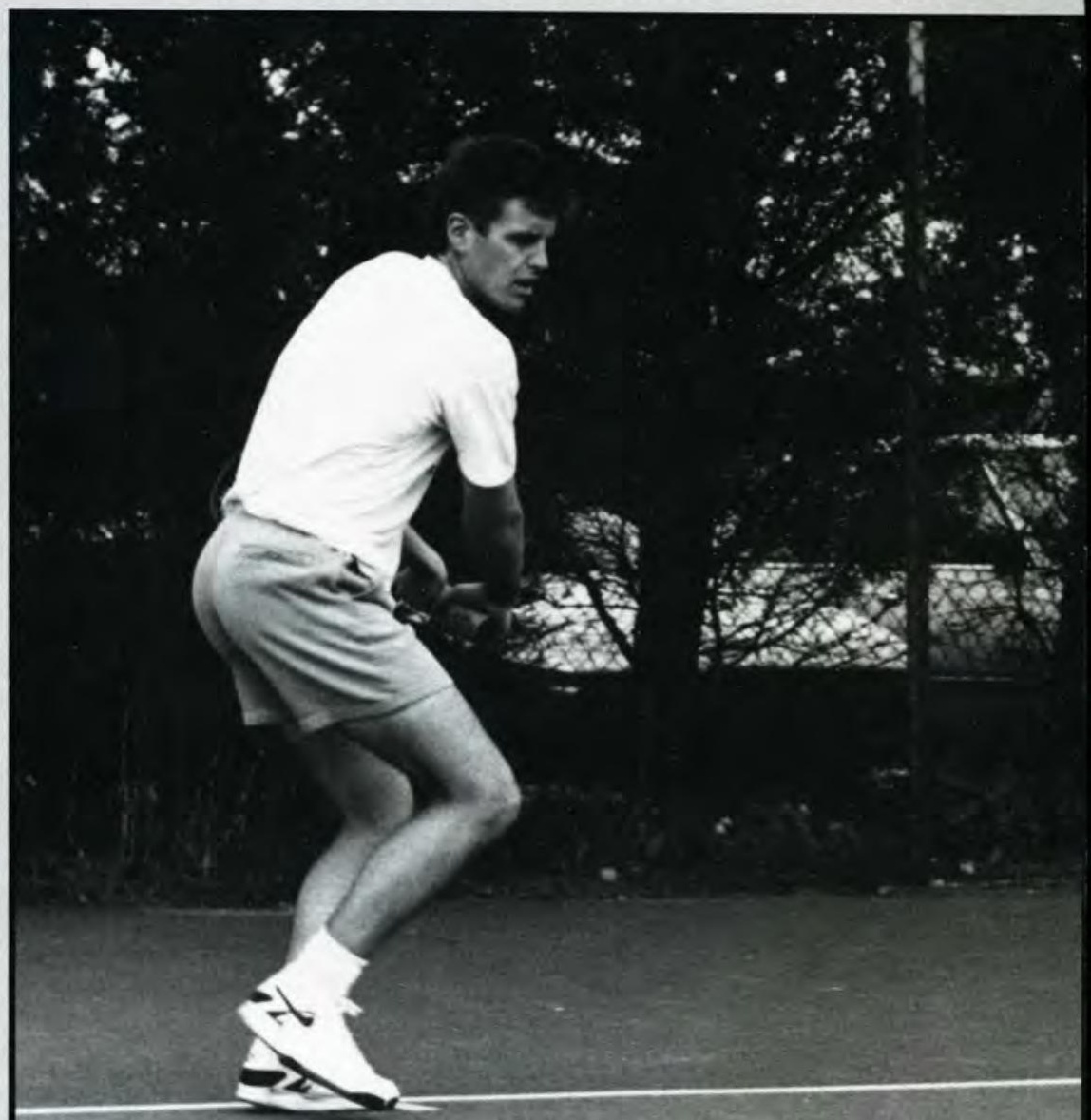

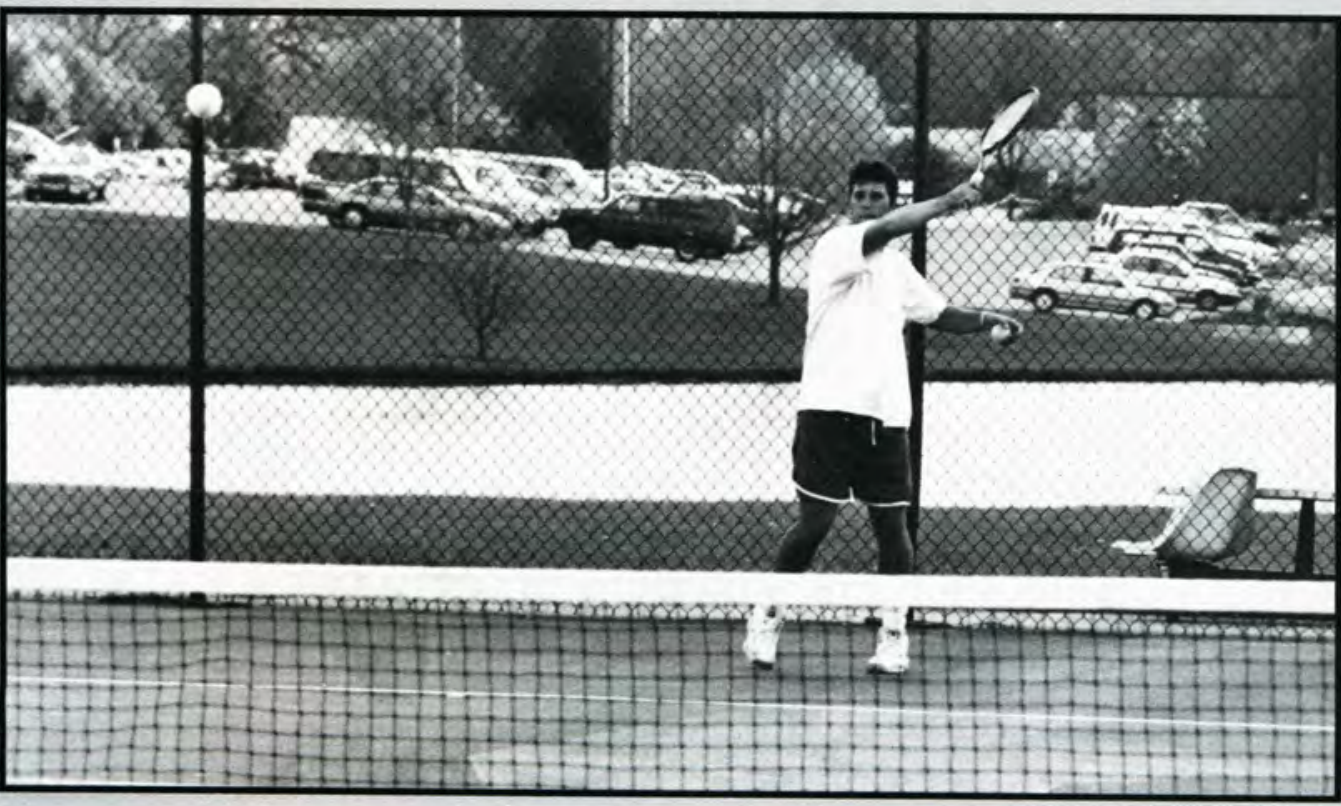

Above: WITH MUCH PRECISION Matt Kibble places the ball in a tough spot for his

Top: ANTICIPATING THE BALL, Michael Baker gets his racquet back. Right: EXTENDING HIMSELF, Michael Baker knows tennis requires all the energy he has.

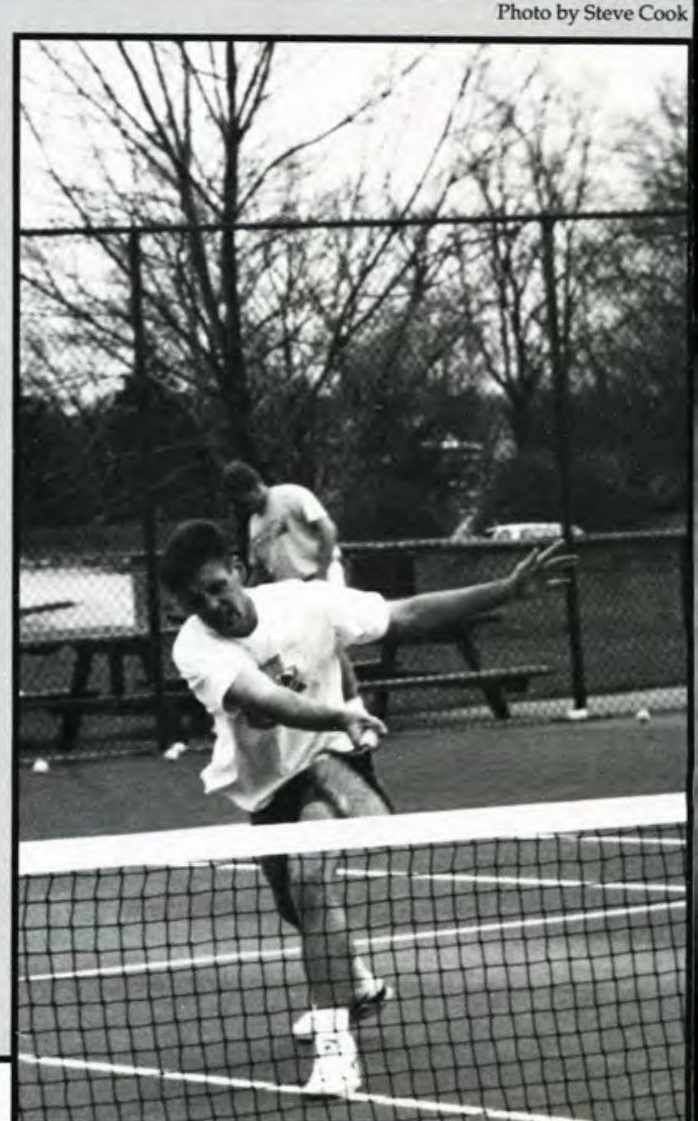




\section{Scoreboard}

CEDARVILLE

OPPONENT

$\begin{array}{lcl}5 & \text { Ohio Wesleyan } & 3 \\ 9 & \text { Mount St. Joseph } & 0 \\ 9 & \text { Findlay } & 0 \\ 9 & \text { Earlham } & 0 \\ 9 & \text { Wilmington } & 0 \\ 9 & \text { Mount St. Joseph } & 0 \\ 9 & \text { Charleston } & 0 \\ 9 & \text { Brescia } & 0 \\ 3 & \text { Wittenberg } & 6 \\ 7 & \text { Walsh } & 2 \\ 9 & \text { Northern Kentucky } & 0 \\ 9 & \text { Malone } & 0 \\ 9 & \text { Tiffin } & 0 \\ 9 & \text { Denison } & 0 \\ 9 & \text { Capital } & 0 \\ 5 & \text { Wright State } & 0\end{array}$

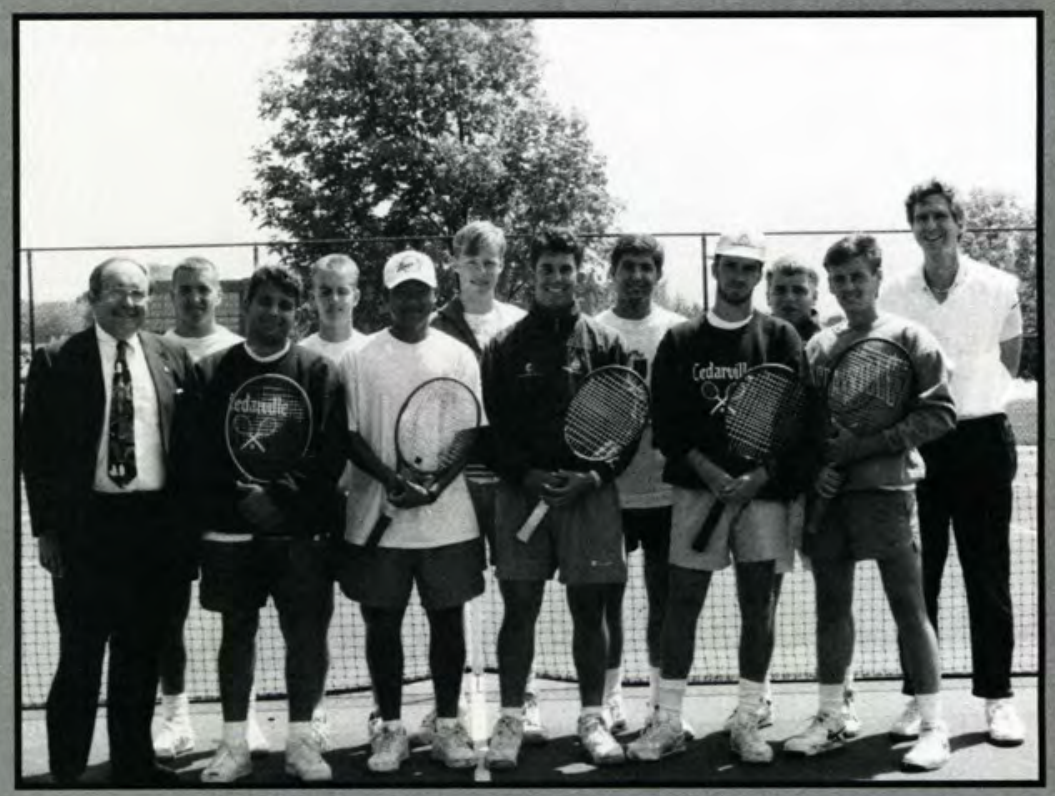

Front row: Dr. Murray Murdoch, Head Coach, Mike Anthony, Cory Groves, Matt Kibble, Sino Rasberger, Mike Baker. Back row: Jamie Hand, Sean Fox, Jeff Blackburn, Marcus Varotti, Jon Lough, Manager. 


\section{Atrip to Nationals

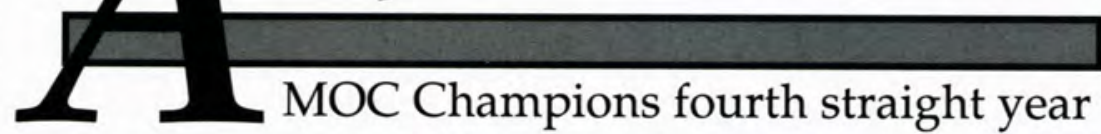

\section{Scoreboard}

CEDARVILLE

OPPONENT

$\begin{array}{lcl}9 & \text { Wilmington } & 0 \\ 6 & \text { Ohio Northern } & 0 \\ 8 & \text { Bluffton } & 1 \\ 9 & \text { Wilmington } & 0 \\ 9 & \text { Tiffin } & 0 \\ 7 & \text { Findlay } & 2 \\ 6 & \text { Malone } & 3 \\ 8 & \text { Walsh } & 1 \\ 6 & \text { Ohio Wesleyan } & 3 \\ 2 & \text { Wittenberg } & 7 \\ 9 & \text { Thomas More } & 0 \\ 9 & \text { Shawnee State } & 0\end{array}$

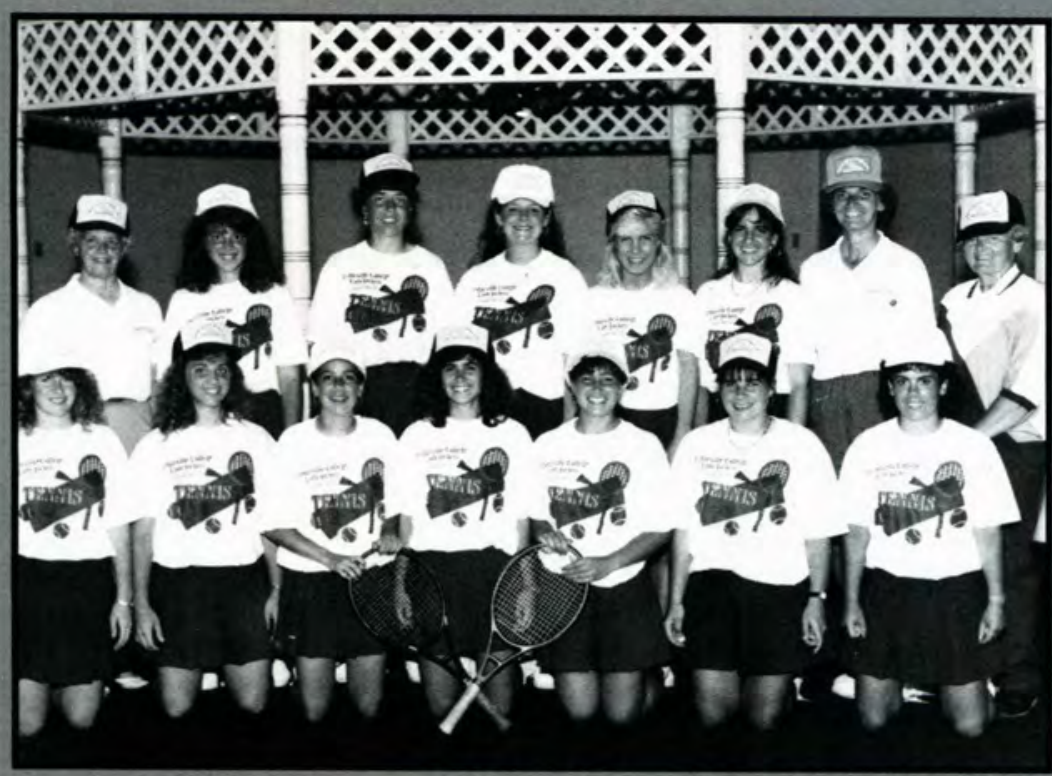

Front row: Julie Seaman, Melissa Hartman, Paula Triplett, Heather Perry, Lynette Cruz, Lynne Kakkuri, Dawn Allen. Back row: Eleanor Taylor, Assistant Coach, Angela Hartman, Cinnamon Brown, Jen Linak, Joy Gilson, Cindy Gannon, Dr. Pam Diehl, Head Coach, Dr. Dee Morris, Assistant Coach
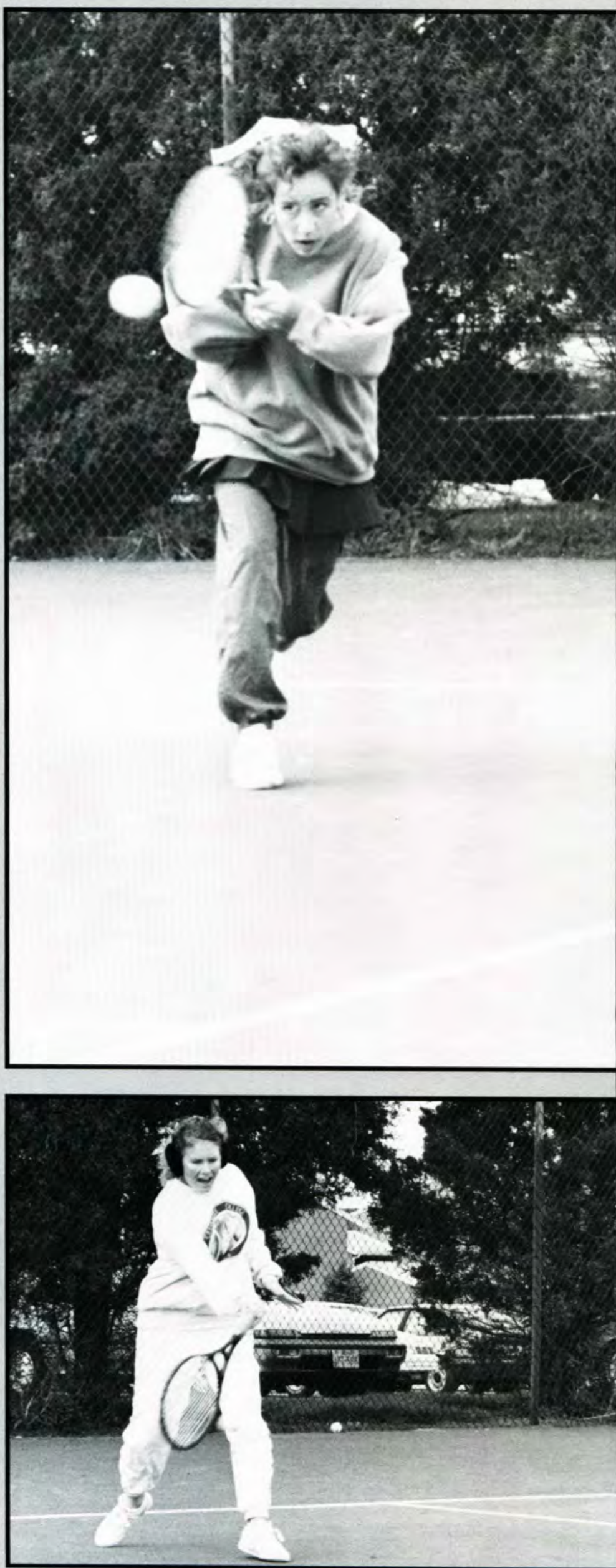

WITH EAR MUFFS TO KEEP HER WARM Julie Seaman talks while she swings.

Top: WITH INTENSITY IN HER EYES Paula Triplett knows exactly where she wants her ball to go. 


\section{Jackets take third in Cedarville Invitational}

The 1993 Cedarville College golf season was marked by the senior leadership of Greg Lawrence and Henry Roy. Lawrence averaged 79.3 strokes per 18 holes while Roy was next on the team at 82.5 and both players participated in all 12 rounds.

Lawrence broke 80 in six of his rounds including a pair of 73's, the lowest scores turned in during the season. His 73 was the lowest in the second round at the Ohio State-Lima Invitational, and he carded the same score in the final round of the NAIA District 22 tournament. Lawrence also had the team's third lowest round when he finished second at the Mt. Vernon Nazarene Invitational with a 77 .

Roy was perhaps the team's most consistent player with nine of his rounds between 79 and 83 . His 79 came in the second round of the OSU-Lime Invitational.

Freshman Jeff Gaglio was third on the team in scoring average at 83.2. His low round of the year was a 79 in the opening round at OSU-Lima.

Junior and three-year letterwinner Ted Kruse averaged 83.7 which included a pair of 78 's. His first 78 occurred when he paced the Jackets at the Walsh Invitational while the other came in the first round of the National Christian College Athletic Association (NCCAA) National Invitational.

Toby Jacobson, the other senior on the team, held down the number five spot and averaged 86.2. His low round was an 82 in the first round of the NAIA District 22 tournament.

The Yellow Jackets placed third out of 13 schools in the 12th Annual Cedarville CollegeInvitational. Theseason-opening event was played on the Reid Park North Course in Springfield for the first time ever.

The tournament was played in temperatures in the low 30's with Walsh nipping Findlay in a tiebreaker after the two schools tied at 318 . The Jackets were 15 shots back at 333 with Roy leading the host school with an 81 .

Cedarville had three other top three finishes. The linksters were third out of 14 schools at OSU-Lima, third of seven at Mt. Vernon Nazarene, and third of six at the NCCAA National Invitational. The Yellow Jackets also finished third out of six schools in the Mid-Ohio Conference race which took place during the season over the course of five separate tournaments.

- Mark Womack

WATCHING HIS BALL, Jeff Gaglio hopes that it lands on the green.
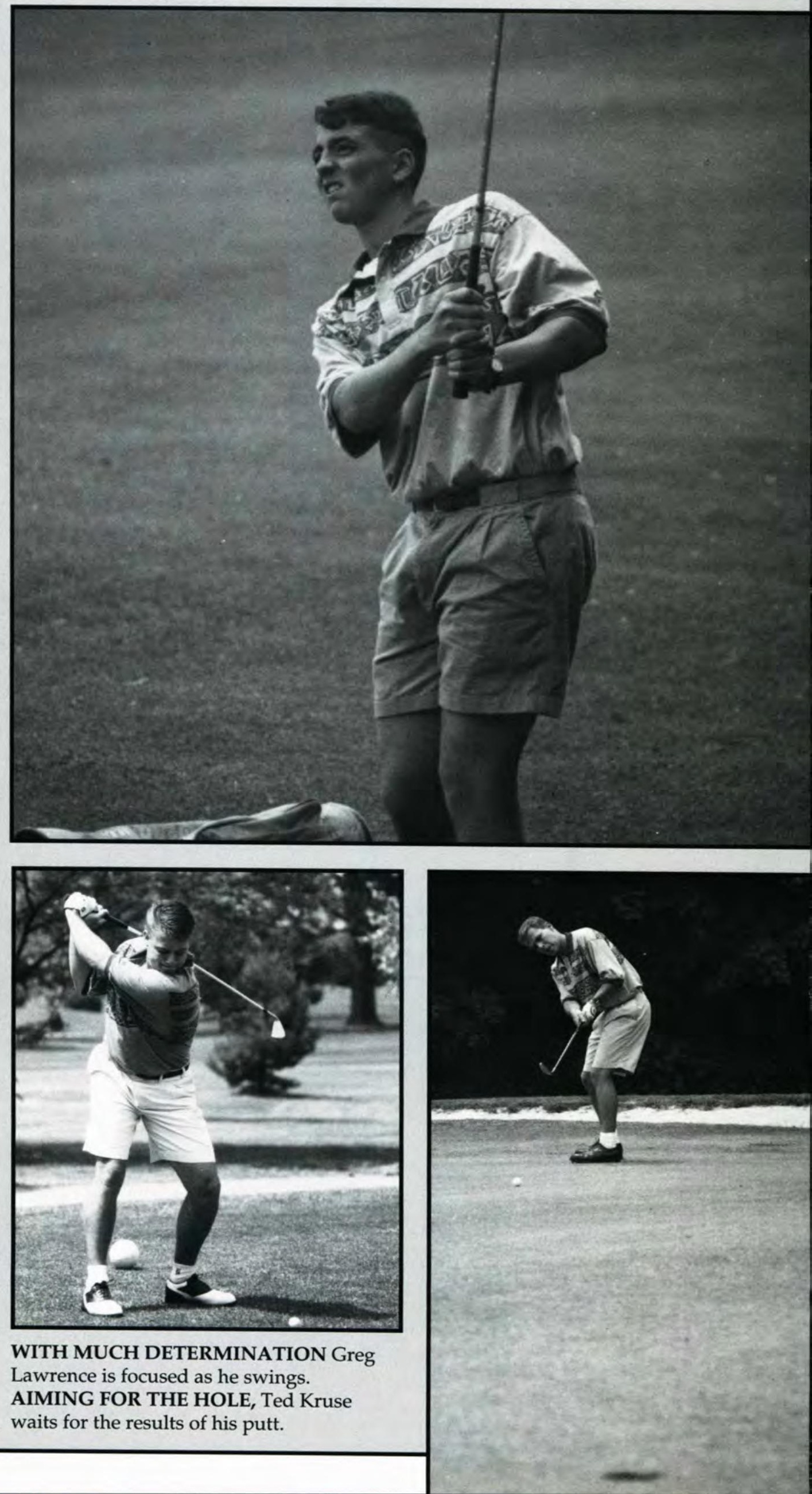

WITH MUCH DETERMINATION Greg

Lawrence is focused as he swings.

AIMING FOR THE HOLE, Ted Kruse

waits for the results of his putt. 


\section{Scoreboard}

Cedarville Invitational

Tiffin Invitational

OSU-Invitational

Urbana Invitational

Mt. Vernon Nazarene Invitational

Walsh Invitational

NCCAA District III

NAIA District 22 3rd of 13

8 th of 18

3rd of 14

5 th of 7

3rd of 7

4 th of 8

3rd of 6

6 th of 8

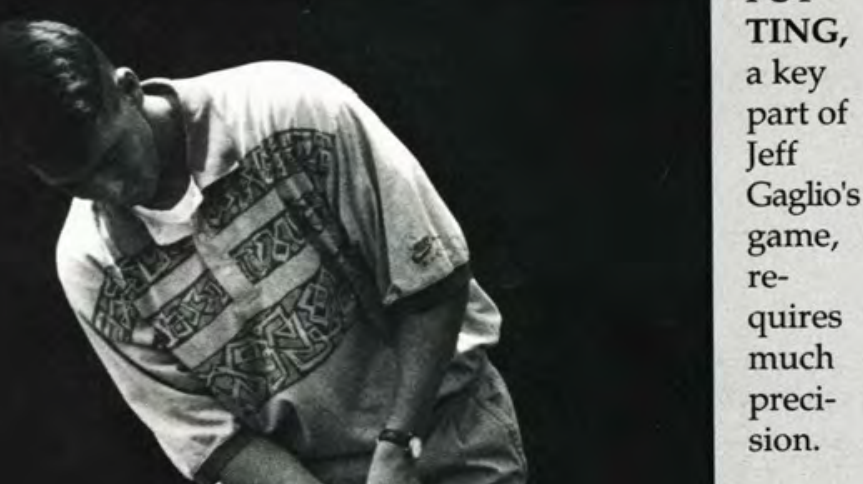

PUT-

TING,

a key

part of

Jeff

Gaglio's

re-

quires

much

sion.

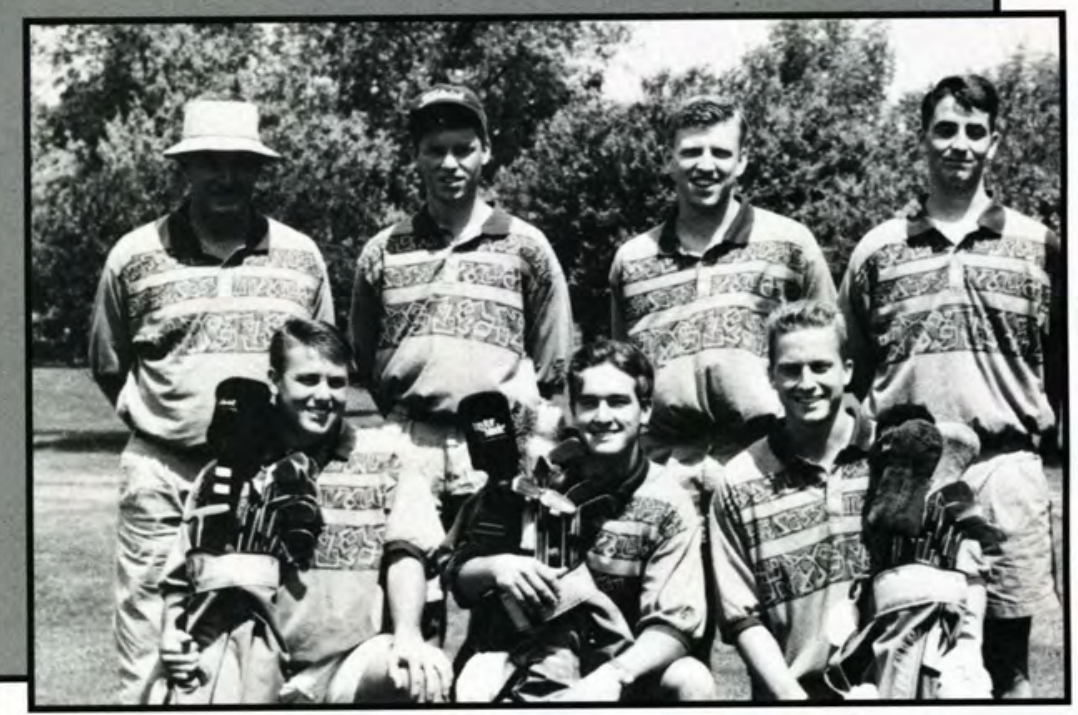

Front row: Greg Lawrence, Henry Roy, Ted Kruse. Back row: Coach Elvin King, Toby Jacobson, Noel Schaak, Jeff Gaglio. Not Pictured: Jeremy Barton. 


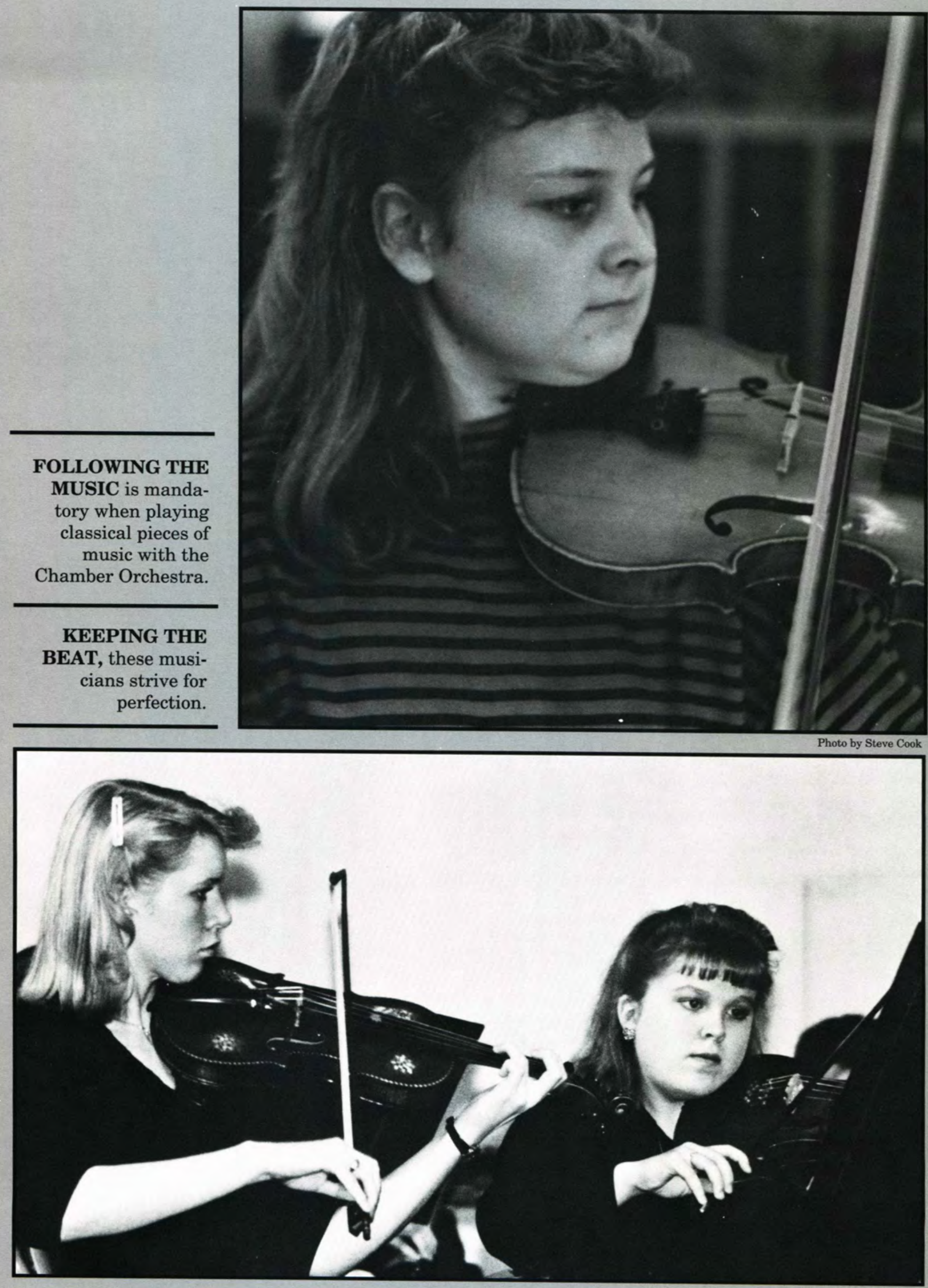



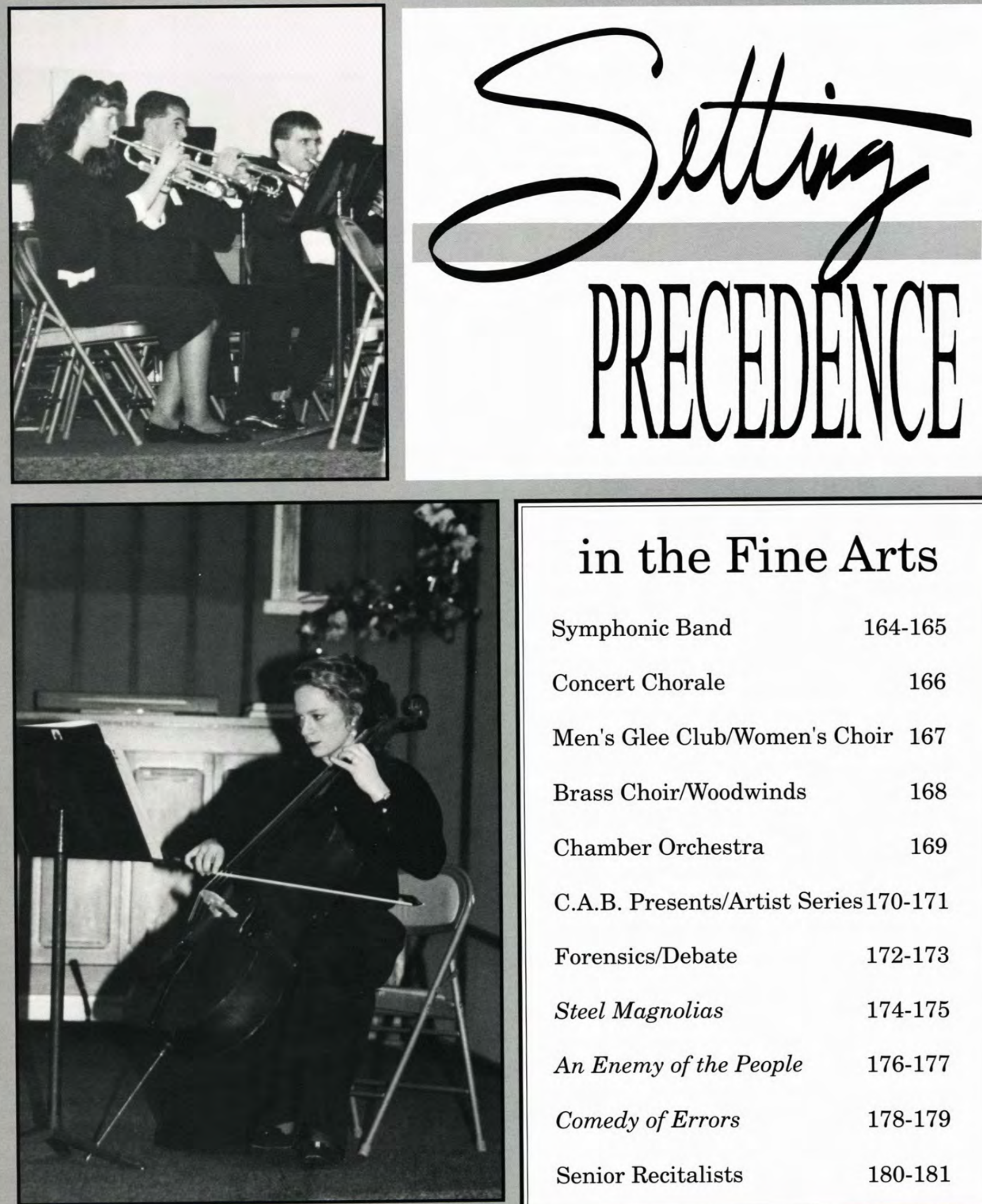

\begin{tabular}{|lr|}
\hline in the Fine Arts \\
Symphonic Band & $164-165$ \\
Concert Chorale & 166 \\
Men's Glee Club/Women's Choir & 167 \\
Brass Choir/Woodwinds & 168 \\
Chamber Orchestra & 169 \\
C.A.B. Presents/Artist Series 170-171 \\
Forensics/Debate & $172-173$ \\
Steel Magnolias & $174-175$ \\
An Enemy of the People & $176-177$ \\
Comedy of Errors & $178-179$ \\
Senior Recitalists & $180-181$ \\
\hline
\end{tabular}




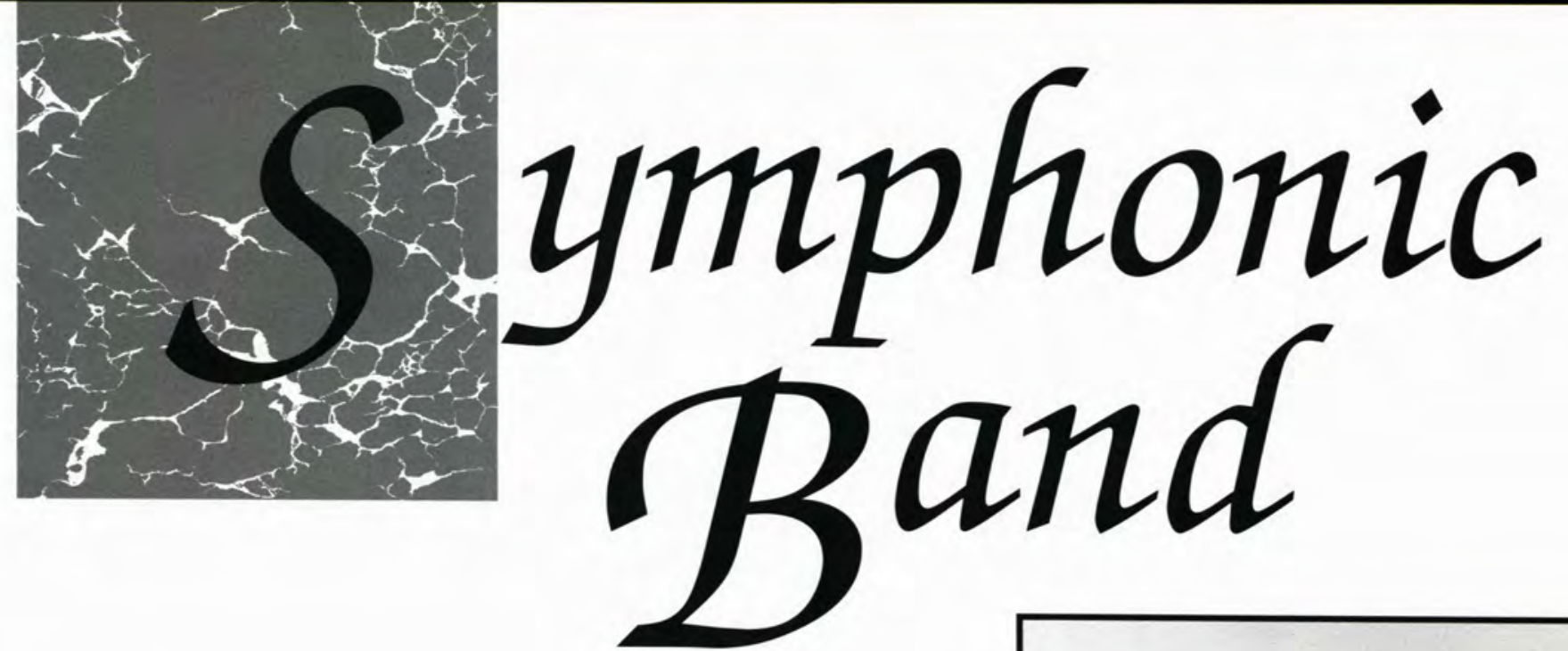

Symphonic Band, under the direction of Michael DiCuirci, is comprised of woodwinds, brass and percussion instruments. The band holds several concerts on campus and in the area, as well as a tour scheduled during spring quarter each year. The Symphonic Band performs a wide range of musical literature, which includes classics, contemporary, pops, and sacred pieces. -Jennifer Henry

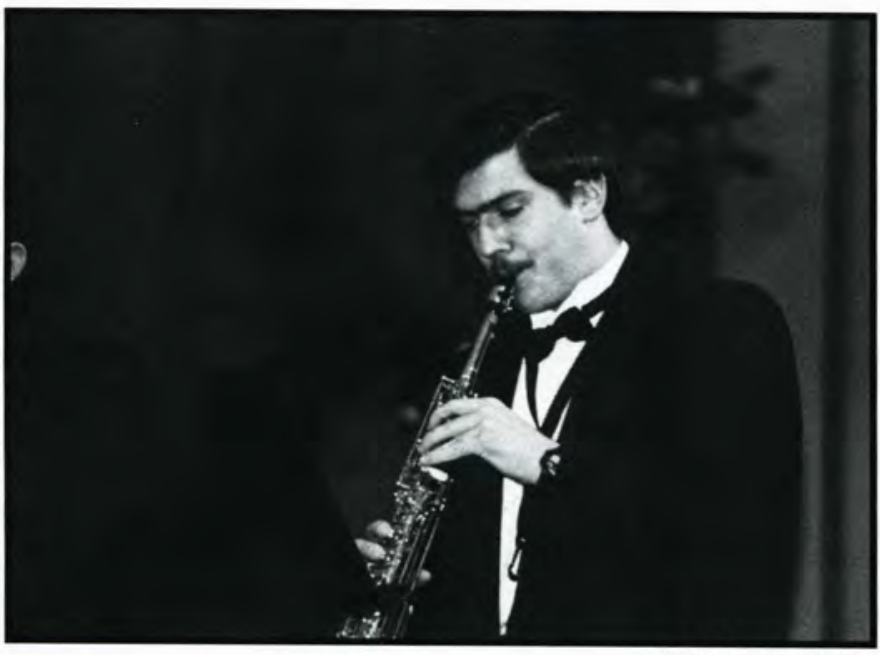

Photo by Lance Gentry
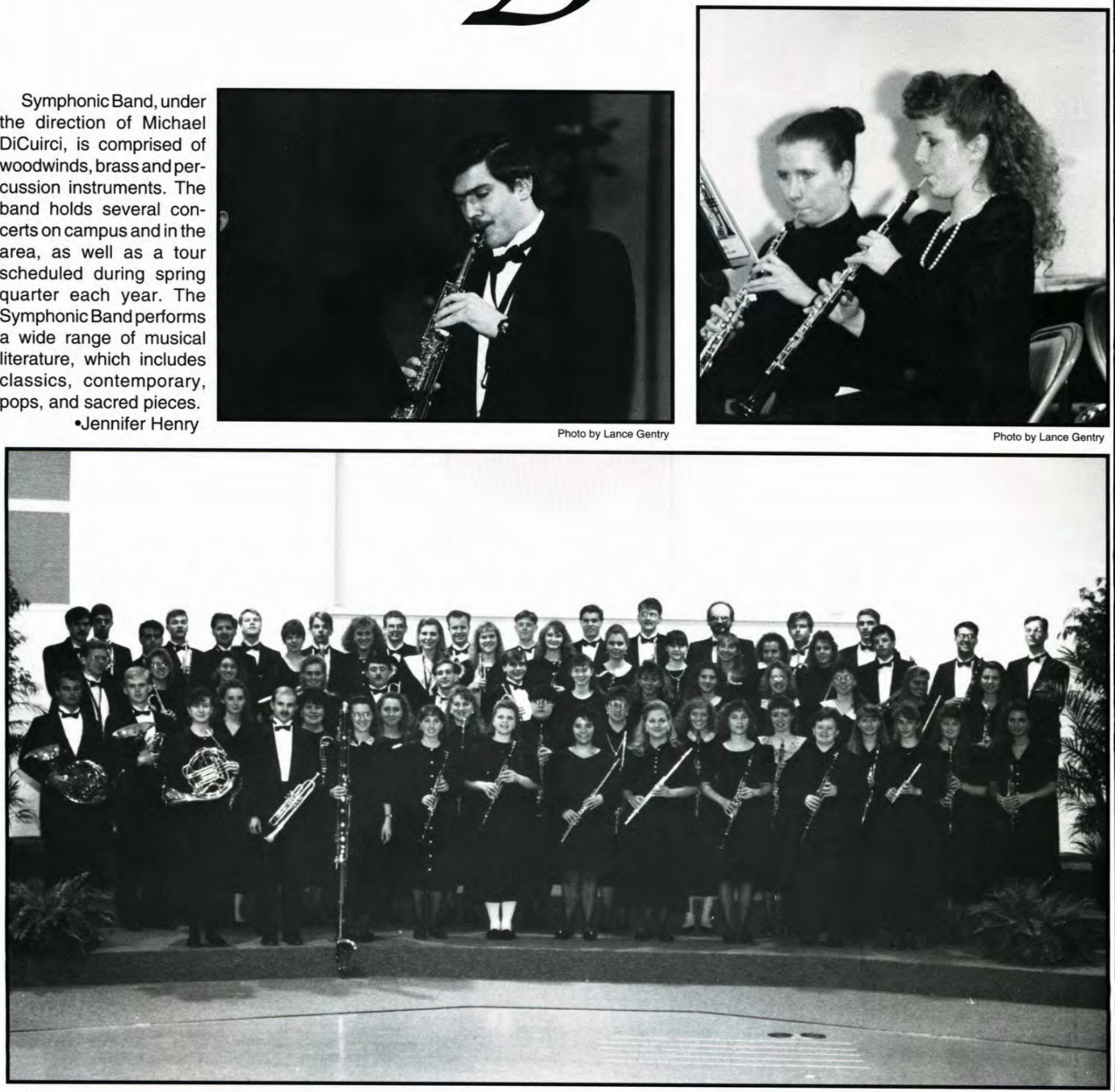

164) Fine Arts 


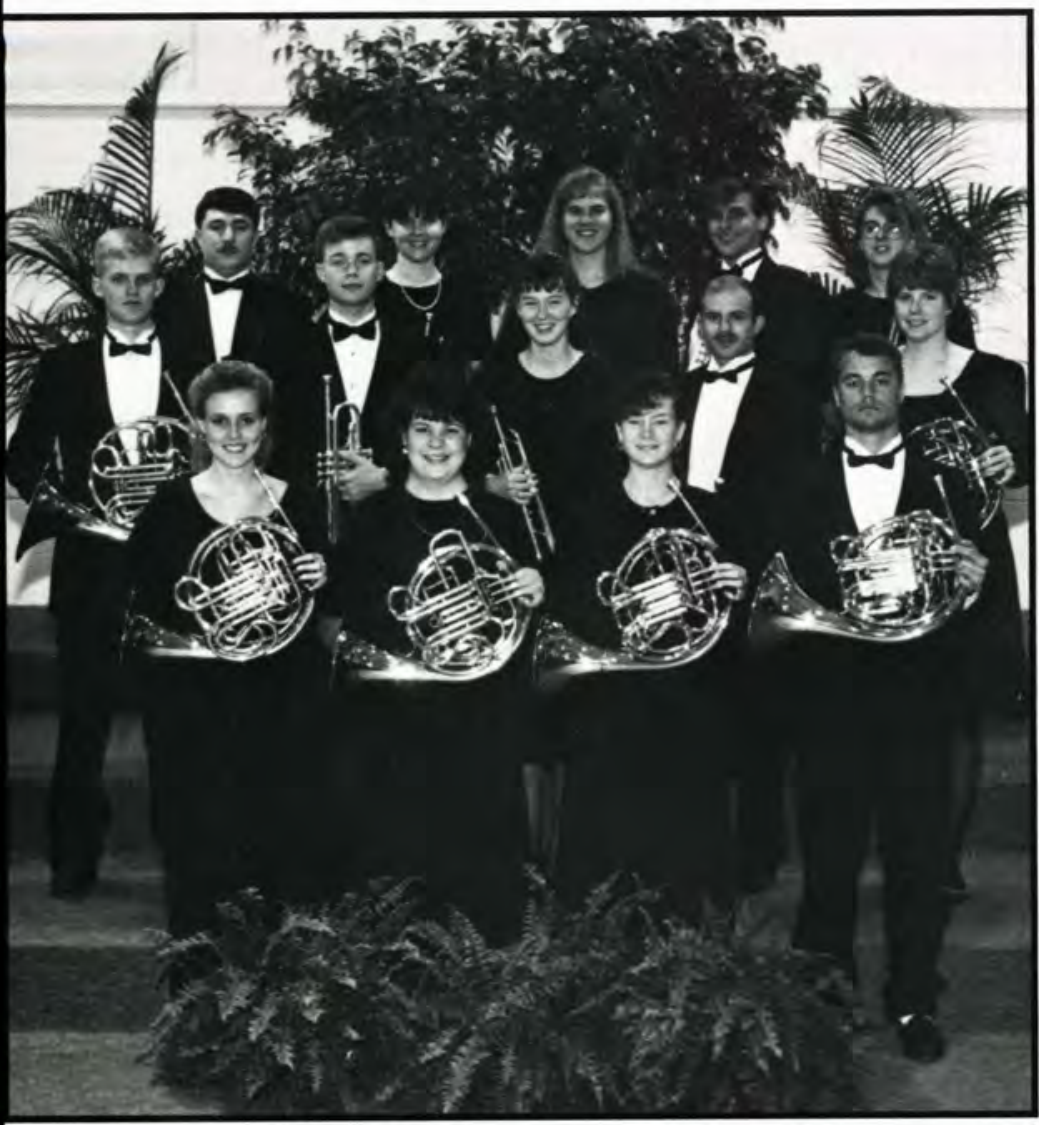

Middle and High Brass

First row: Julianne Edgerton, Laura Maki, Jenifer Bork, Paul

Gardner. Second row: Brent Luman, Sean Cottrill, Tara Wagenaar, Kevin Murachanian, Karen Dieter. Third row; John Filson, Martha Shrubsole, Erin Wawro, Jon Misere, Elissa Heale.

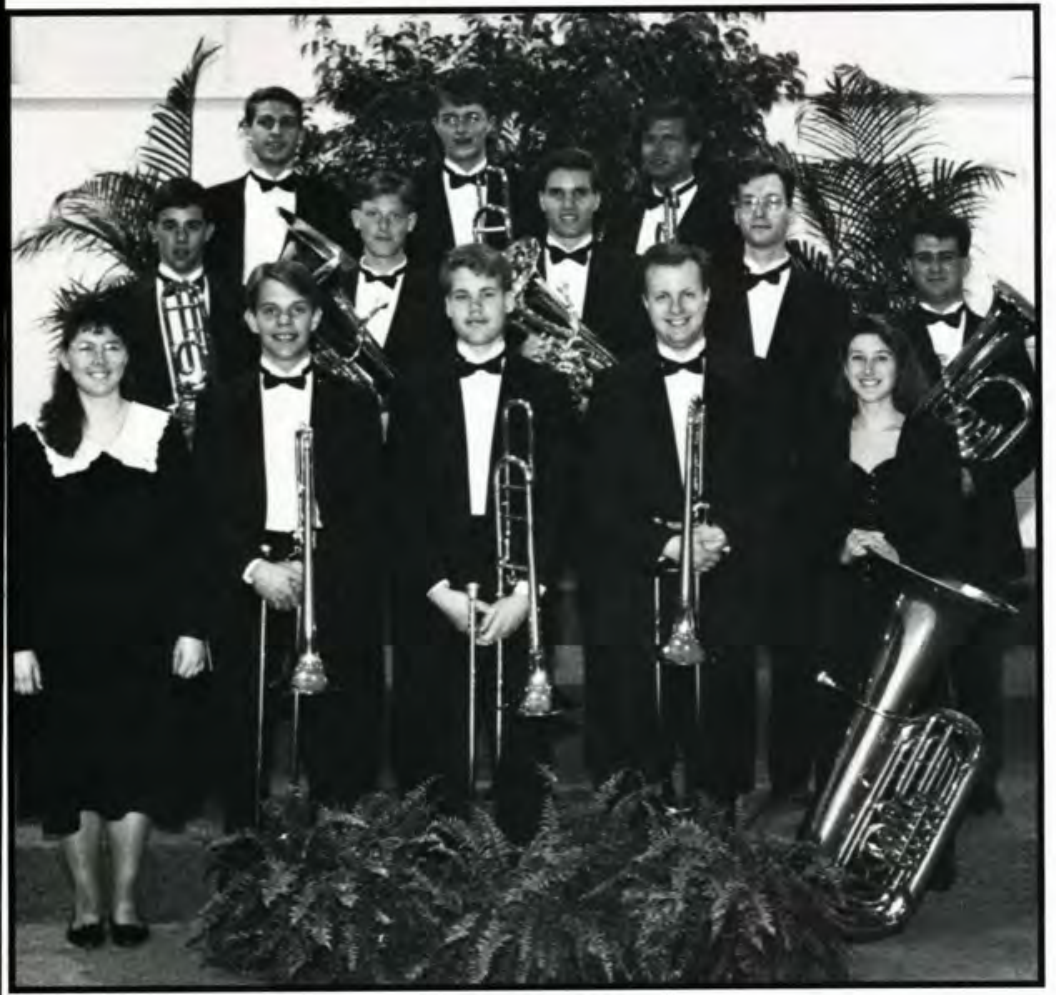

Low Brass and Percussion

First row: Anne Larr, Jacob Harris, Michael Leshan, Paul Currie, Jaimee Potter. Second row: David McMurtry, Nathan Ewels, David Warren, Eric Johnson, Brian Megilligan. Third row: John Warnshuis, Keith Watson, John Ferguson.

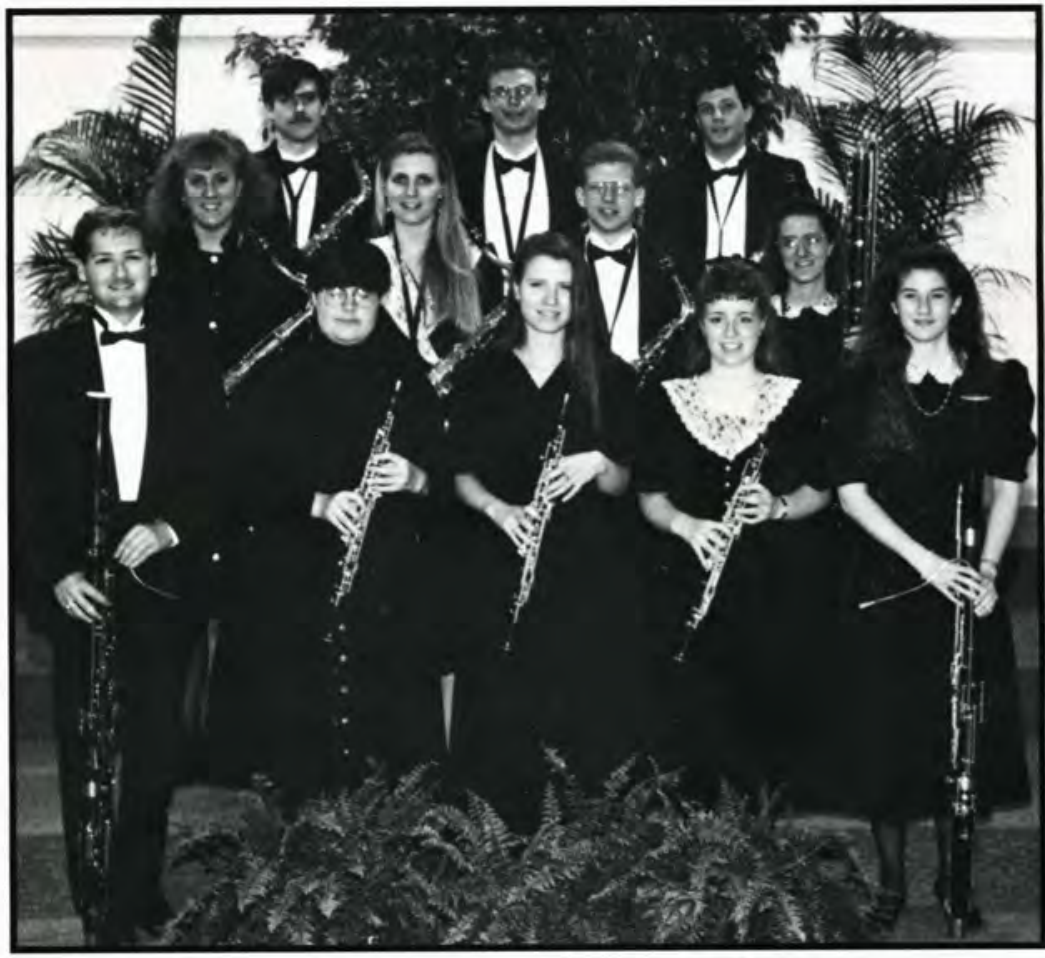

\section{Oboes, Saxaphones and Bassoons}

First row: Jeremy Spieth, Jennifer Shrubsole, Dora Lee Peterson, Sarah Moseley, Michelle Steenwyk. Second row: Melinda Bradley, Vivian Borges de Moraes, Chad Wingert, Brenda Royer. Third row: Alex Kulin, James Warnshuis, Stephen Wintle.

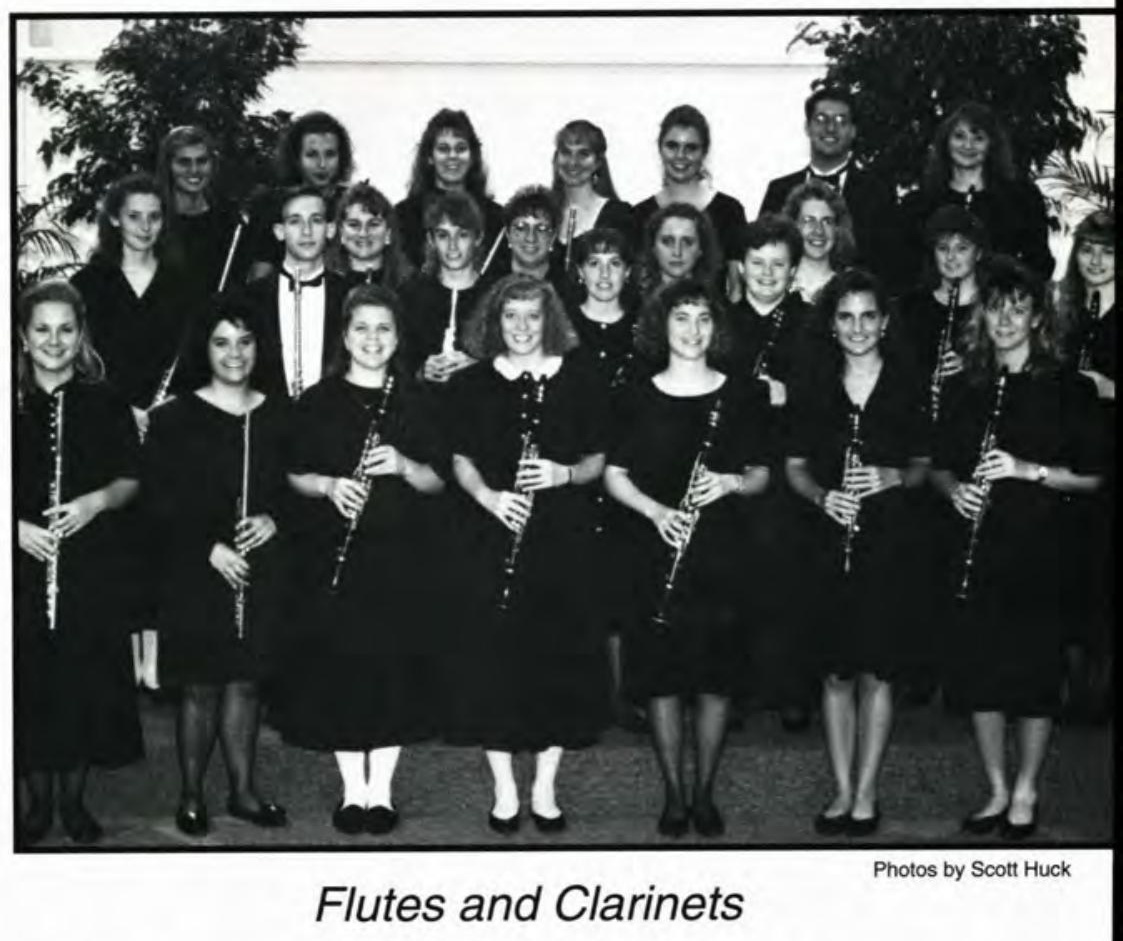

First row: Jennifer Bartosiewicz, Stephanie Hunsaker, Necia Fanton, Gina Kendig, Lori Kate Lowenhar, Amy Whitehead, Stephanie Sanders. Second row: David Bishop, Trish Manning, Kim Koziol, Sally Hutchins. Third row: Susie Jones, Carrie Eldeen, Molly Whitmer, Elizabeth Moon, Susan Shimp, Kristine Thorsen, Rychel Brickel. Fourth row; Wendy Herr, Maggie Hofmann, Jennifer Gordey, Melanie Ras, Sarah Sizemore, Mark Roeder, Gail Currall. 


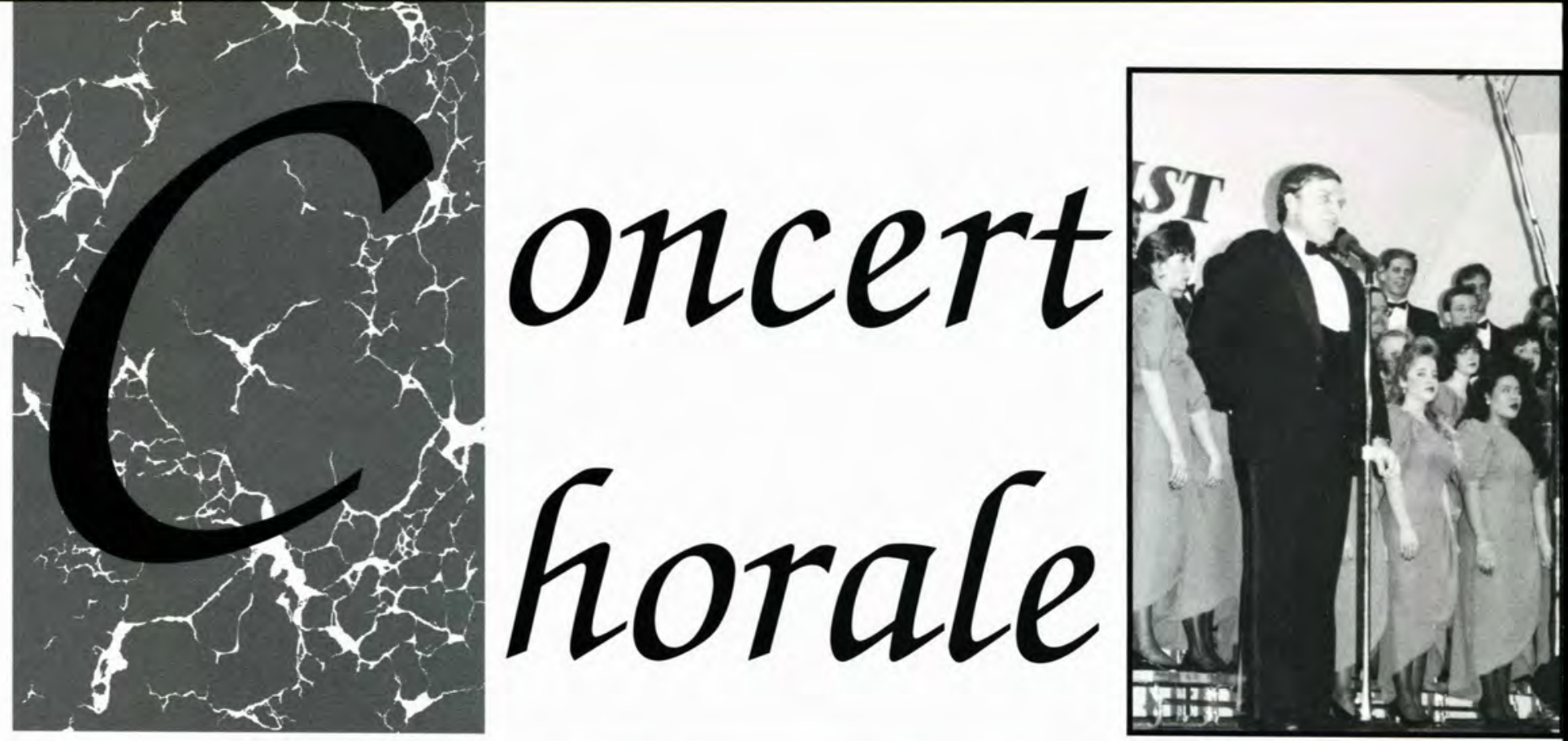

Concert Chorale, headed by $\mathrm{Dr}$. Lyle Anderson, is one of Cedarville's most popular ensembles. It is composed of 50 mixed voices. The repertoire is chosen from a wide range of musical masterpeices, sacred classics, spirituals, anthems and several contemporary works. The Concert Chorale presents several performances each year on campus as well as in churches and schools.

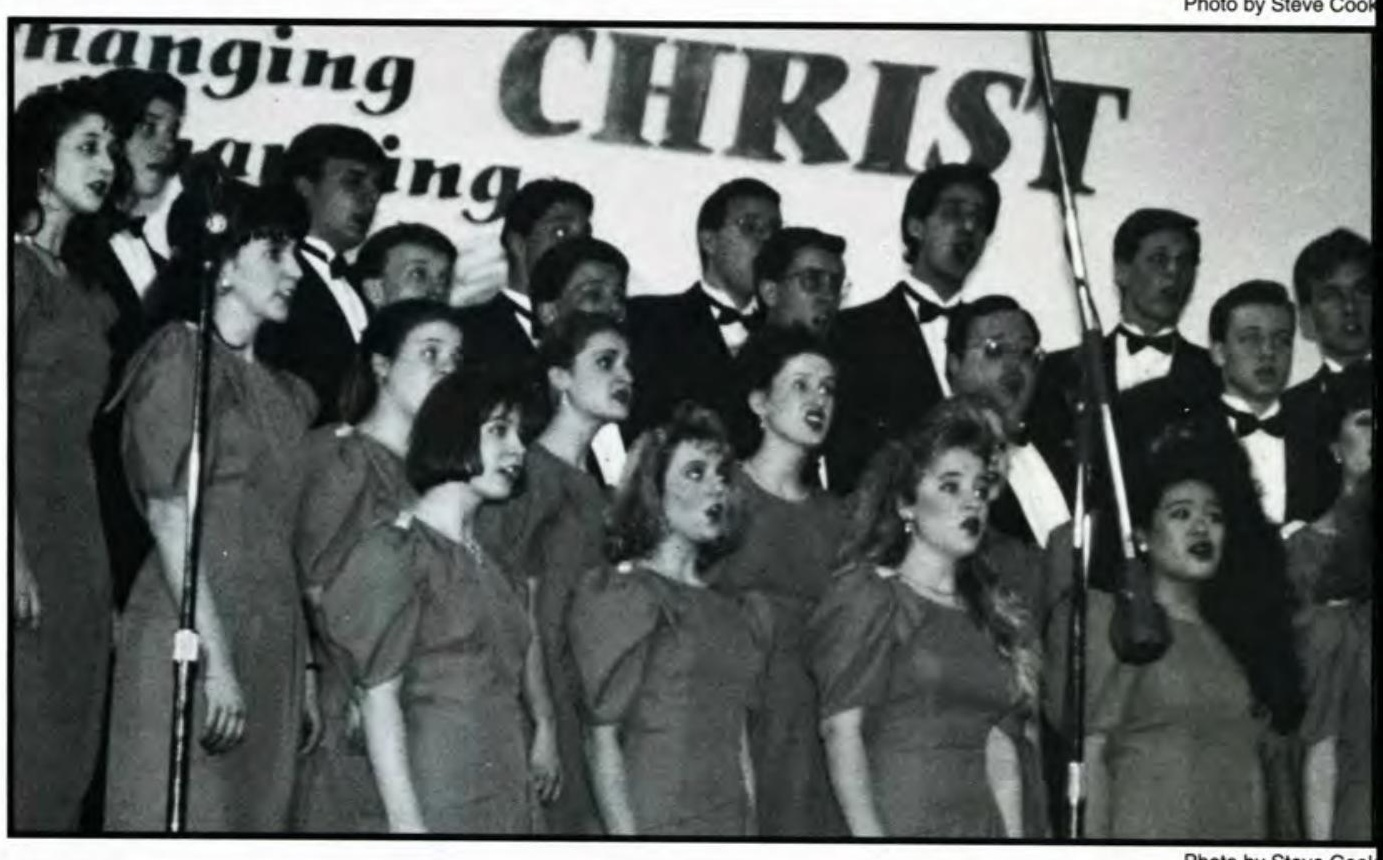

Photo by Steve Cook

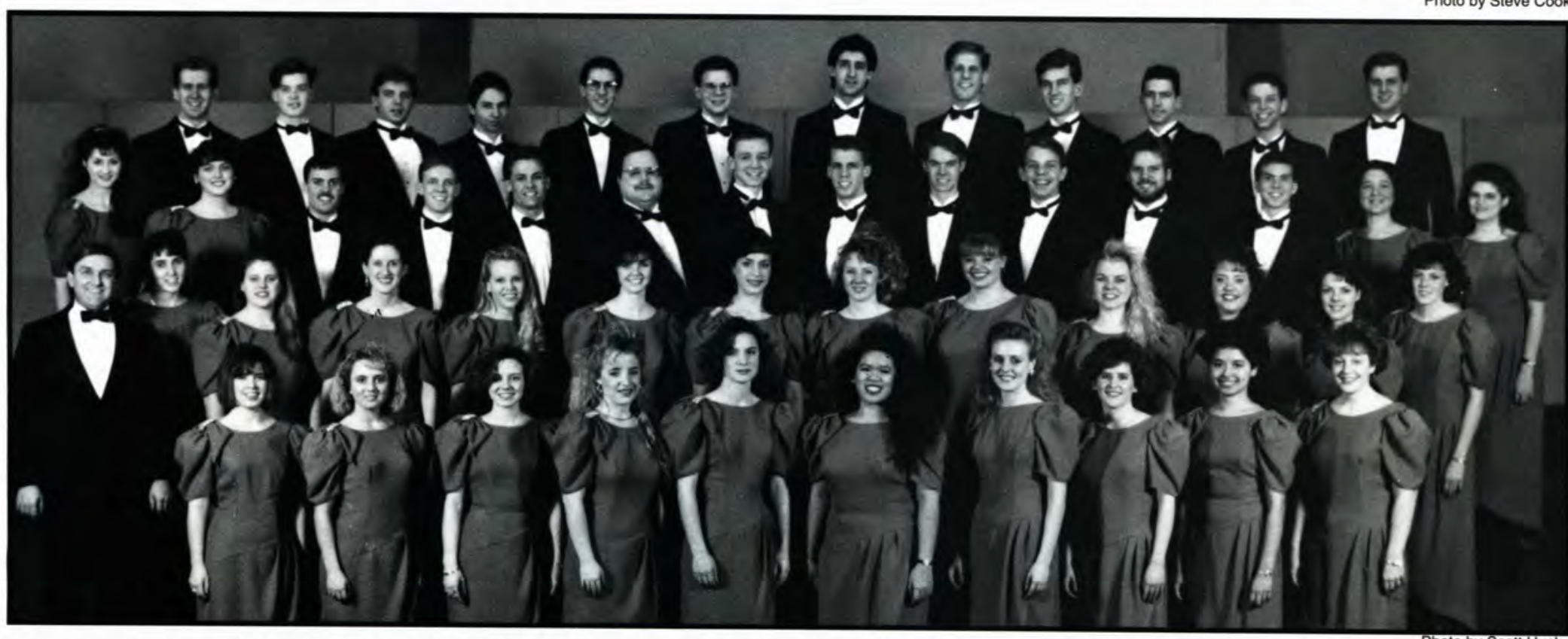

Front row: Stephanie Sherman, Amy Peterson, Charity Newkirk, Taryn Campbell, Becky Richner, Johanna Chang, Julianne Edgerton, Julie Buentello, Gina Jamora, heather Rifenberick. Second row: Dr. Anderson, Sandy Costello, Joy Brandon, Katherine Simons, Marne Loomis, Tracie Dennison, Stephanie Winchip, Jamie Weiss, Jill Hunsberger, Janet Potts, Kim Higginbotham, Sheri Leeds. Third row: Julie Burns, Lori Jones, Chad Vitarelli, Eric Anderson, Jay LeBlanc, Dale Hughes, Mike Wood, David Hoskins, Brian Harju, Jacob Harris, Tim Camerer, Mark Zuiderveen, Tara Luther, Becky Beasley. Fourth row: Steve Caton, Ryan Huebner, David Heim, Paul Schwanz, Ryan Snedaker, Rob Reed, Linford Herschberger, David Bates, Dave Wilson, Wes Beebe, Nathan Dobert, Matt Brown. Not Pictured: Dana Gosser. 

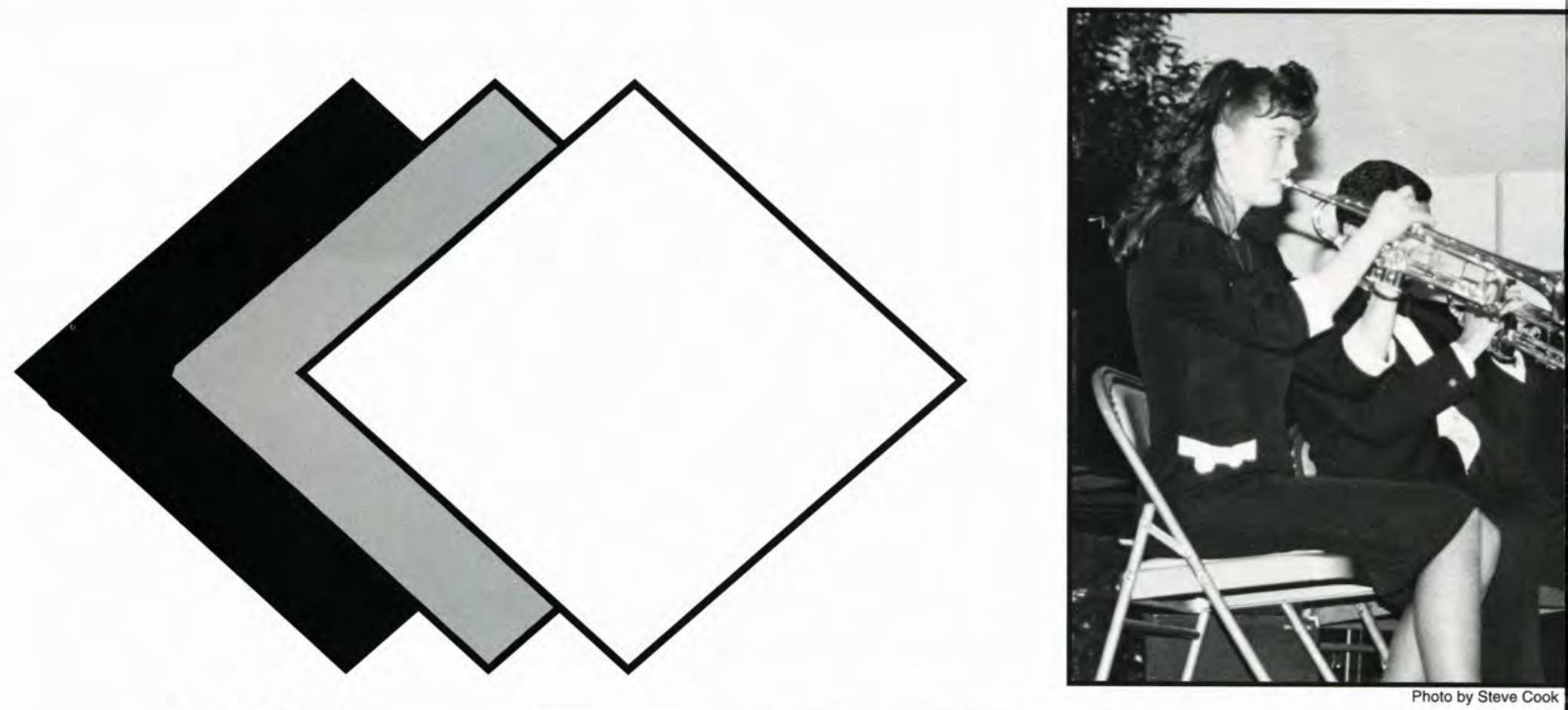

\section{Practice Makes Perfect}

The tension mounts as the performance gets closer. The musician thinks about all the technical work in the music which needs to be perfected a little more. Now, the race is on to get into place for the concert. A hush falls over the audience as they anticipate an evening of wonderful music. Applause follows each piece giving the performers a sense of accomplishment and a shot of adrenaline for the pieces ahead. All of the parts seem to come together better than they had in practice. When the concert ends, each instrumentalist leaves with the feeling of having performed well and pleasing the audience.

-Jennifer Henry
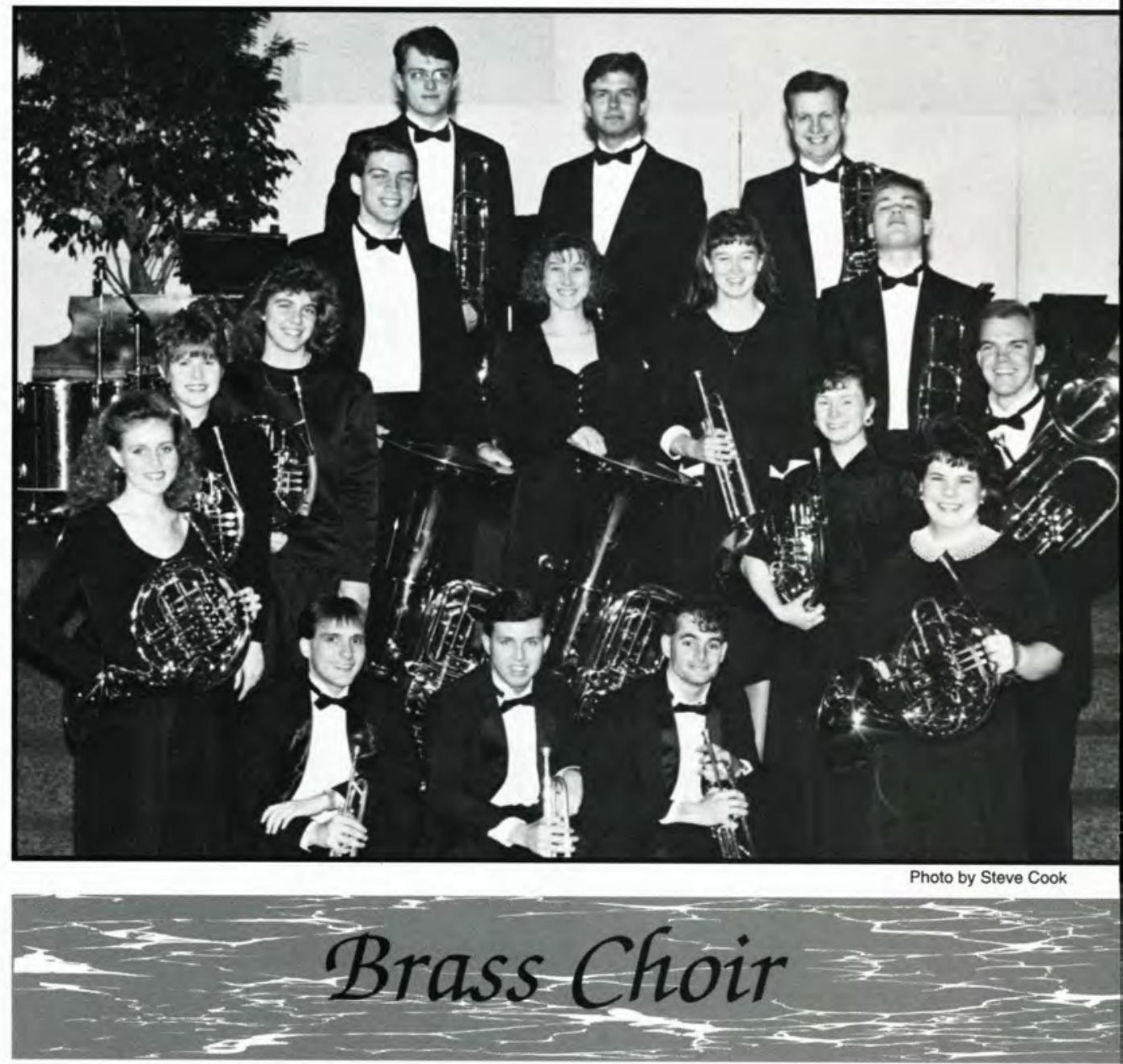

Photo by Steve Cook
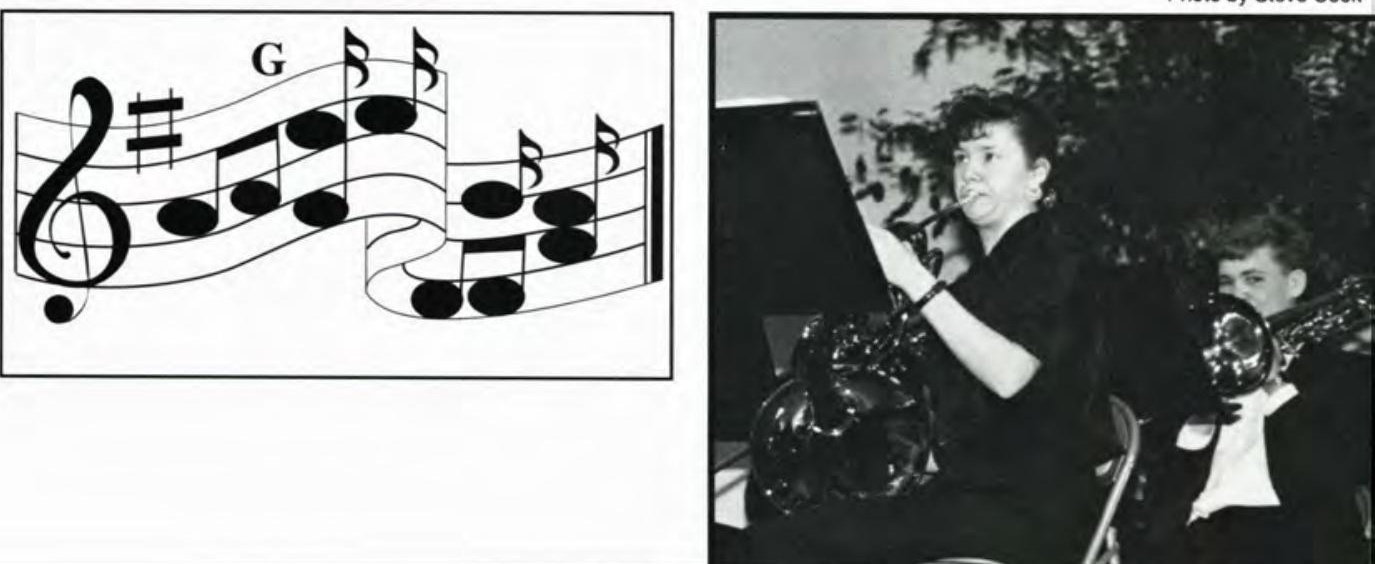

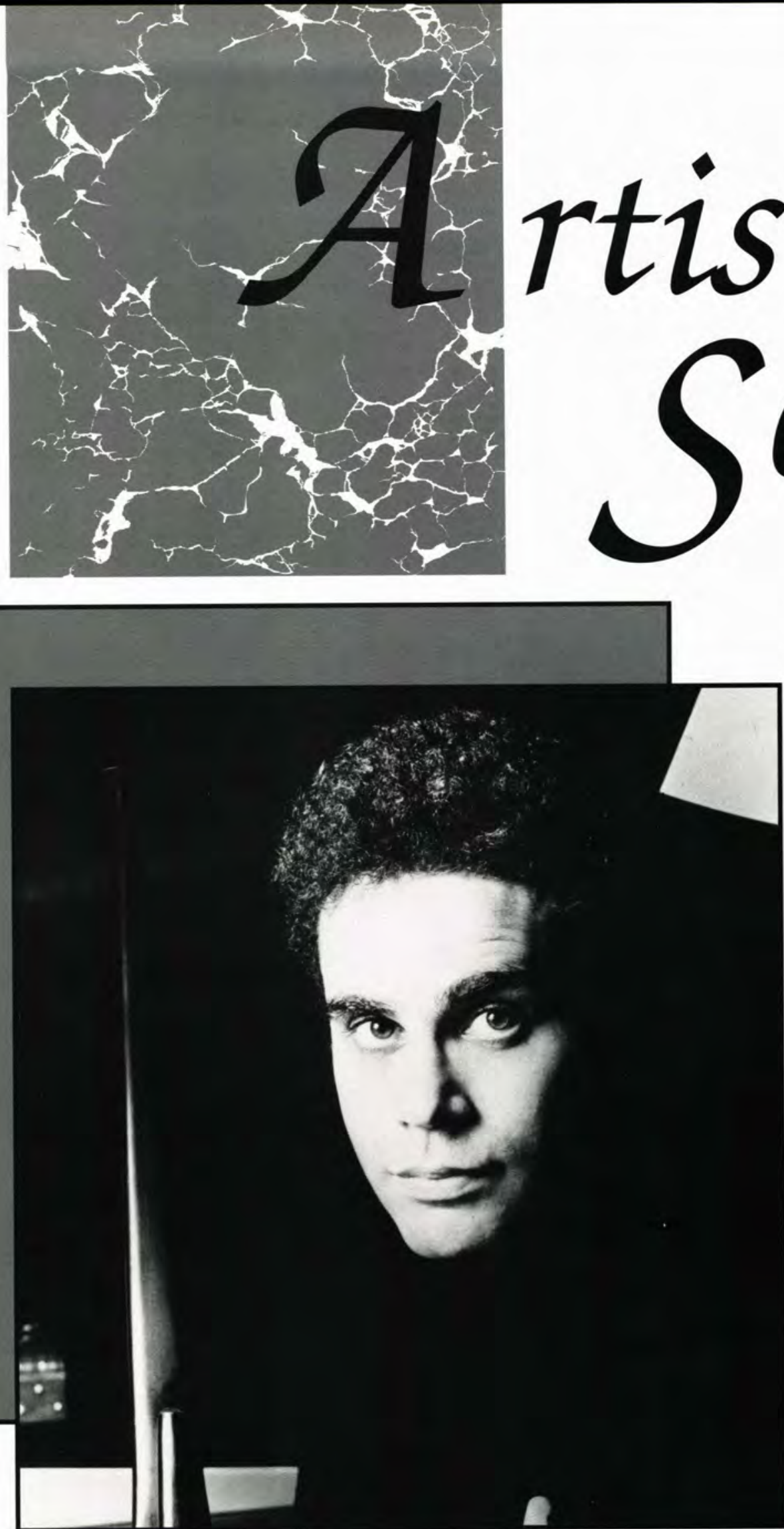
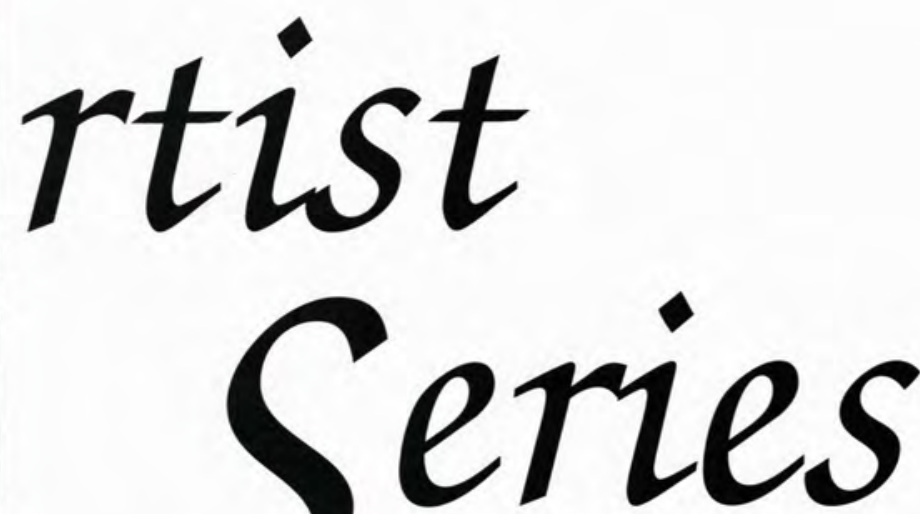

Mantovani Wishes Us

a Merry Christmas

Applause thundered through the James T. Jeremiah Chapel as the orchestra, chorus and the first violinist came up to the stage followed by the conductor. As suddenly as the applause began, the audience became silent. From this point forward, the evening was pure enjoyment. The songs were delightful cheery melodies that recalled memories of bygone years. They sparkled the imagination with thoughts of Santa's workshop, toys playing, hours dancing, and couples waltzing across the floor. All of the music was well played and well orchestrated. Too soon, the evening was over, but those present were left with minds full of the enjoyment of music.

- Jennifer Henry

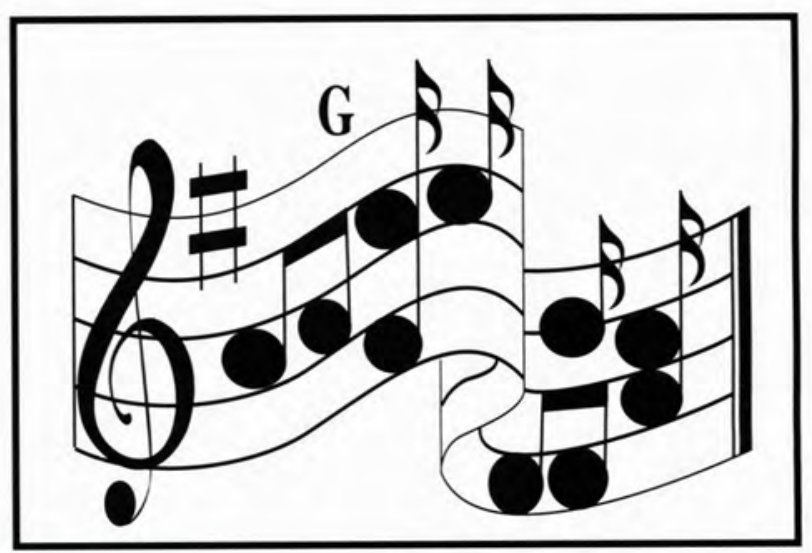

WITH GREAT MUSICAL ABILITY Jeffrey Siegel uses the piano to minister.

SHARING IN CHAPEL, the A.D. Players convey their message through drama. 


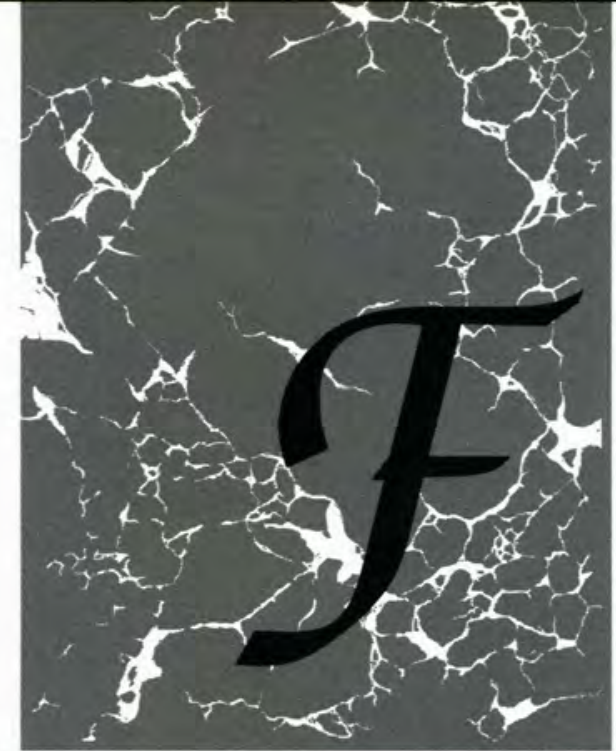

The Forensic Speech team competes with various colleges and universities; most are larger than Cedarville. This year the team won the State novice and varsity tournaments for the fourth consecutive year. Making this year unique was the fact that each member placed in an event at the state tournament. While no member of the team will say that the task was an easy one, none will deny the benefits which they have received. Each member demonstrated dedication and hard work. Through this dedication and determination of the coaches and students, the Lord blessed this team with a successful season.

- Becky Calvert

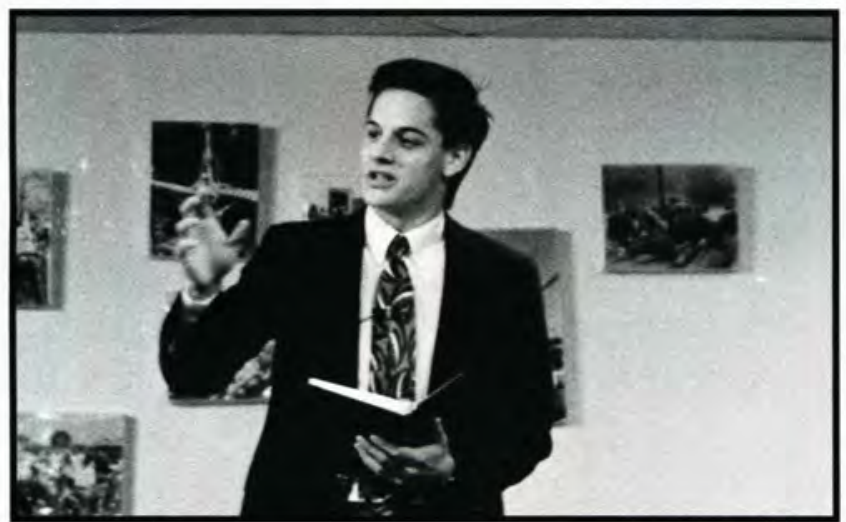

Photo by Andy Biddle

Top Right: DURING THE FORENSICS SHOWCASE

Aaron Newcomb and Ben Kalich share their abilities.

Top: WITH MUCH EMOTION Jeremy Grinnell makes his point.

Left: THE AUDIENCE IS QUIET as Scott Bowman gives a fluent speech.

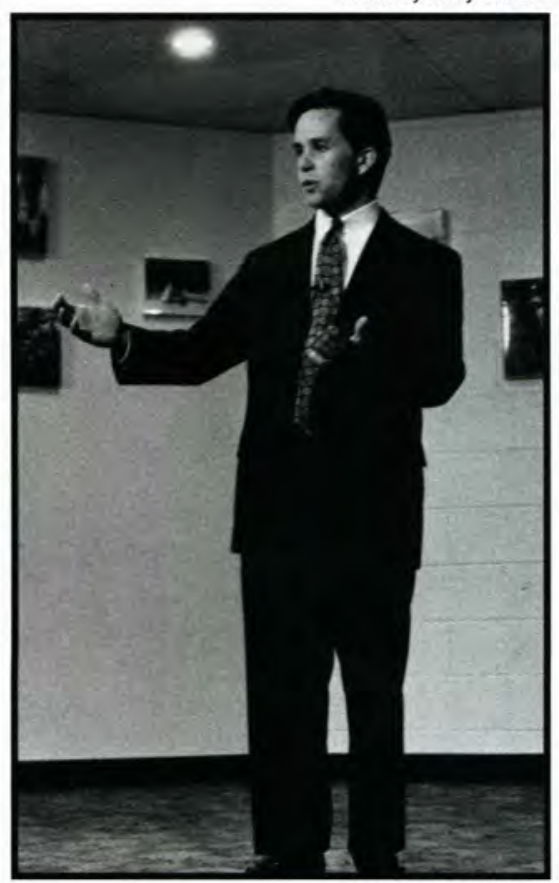

Photo by Andy Biddle

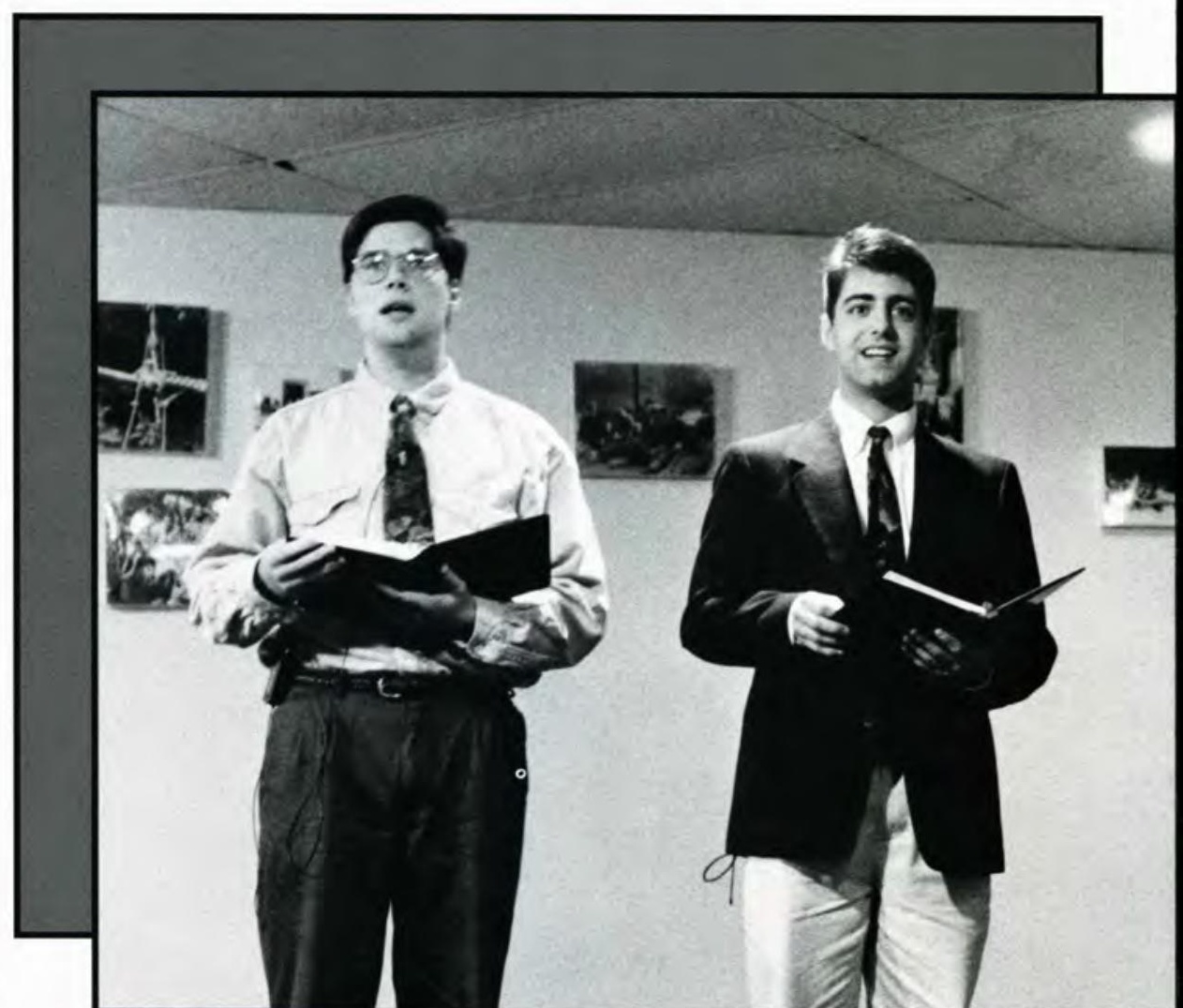

Photo by Andy Biddle

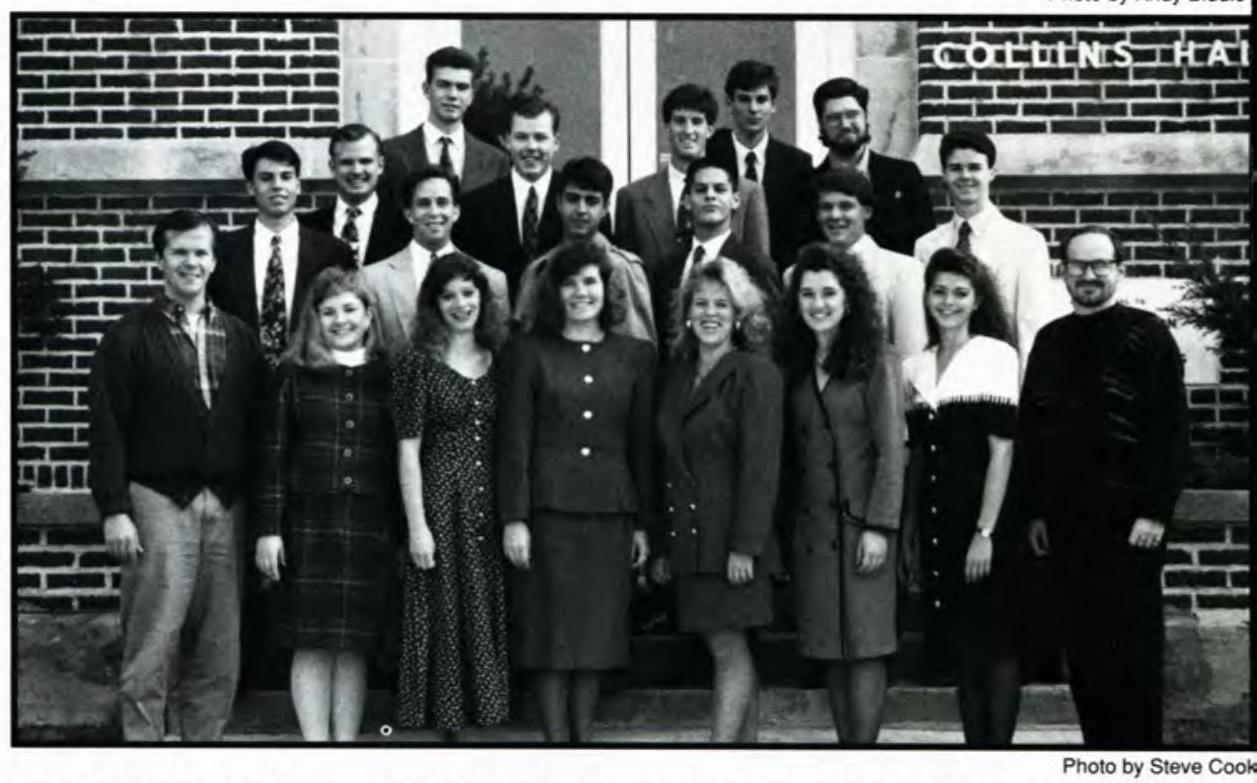

Front row: Dr. Robey, Jennifer Bartosiewicz, Mandie Secord, Becky Calvert, Jennifer Crawford, Shelley Fox, Lara Carlson, Mr. Gary Barker. Second row: Mark Totten, Scott Bowman, Ben Kalich, Jeremy Grinnell, Scott Blanton, Doug Moore. Third row: Chad Cornwell, Jonathan Edgerton, Erin Weaver, Aaron Newcomb. Back row: Jim Donahue, Justin Virant. 

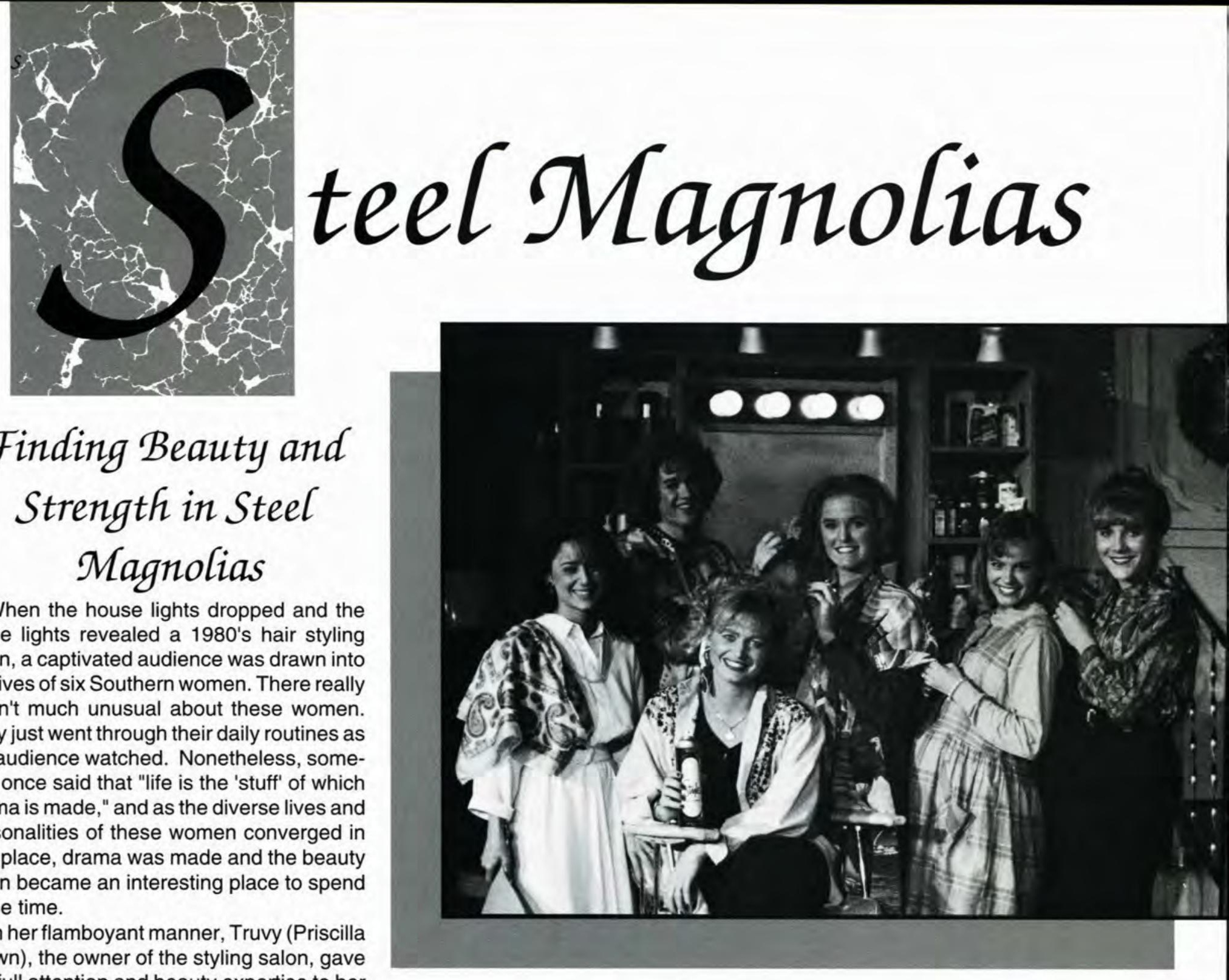

\section{Finding Beauty and}

\section{Strength in Steel Magnolias}

When the house lights dropped and the stage lights revealed a 1980's hair styling salon, a captivated audience was drawn into the lives of six Southern women. There really wasn't much unusual about these women. They just went through their daily routines as the audience watched. Nonetheless, someone once said that "life is the 'stuff' of which drama is made," and as the diverse lives and personalities of these women converged in one place, drama was made and the beauty salon became an interesting place to spend some time.

In her flamboyant manner, Truvy (Priscilla Brown), the owner of the styling salon, gave her full attention and beauty expertise to her willing customers, for she believed "There is no such thing as natural beauty." Truvy was always ready to share in the joys, sorrows, and latest local news of her regular Saturday customers. On the other hand, her new hairdresser, Annelle (Kari Beres) was nervous, shy and worried that she would make someone's hair too "poufy." The women of the salon were kind to her though and accepted her into their circle of friends. Even Ousier (Susanne Justice), a woman who claimed there was nothin' wrong with her spiritual condition --she had just been in a bad mood for 40 years-- found a warm spot in her heart for Annelle, who was truly concerned about Ousier's spiritual welfare. To the delight of the audience, the mayor's widowed wife, Claree (Shawna Smith), was adept at keeping her friend Ousier in her place. She confidently exclaimed, "If you don't have anything nice to say...come sit by me."

The play centers on Shelby's (April Hoover) life. When the audience first met her, she was preparing to become a blushing new bride. She and her mother, M'Lynn (Tracy Quinn), were in constant disagreement over the details of the wedding. After the wedding, how-

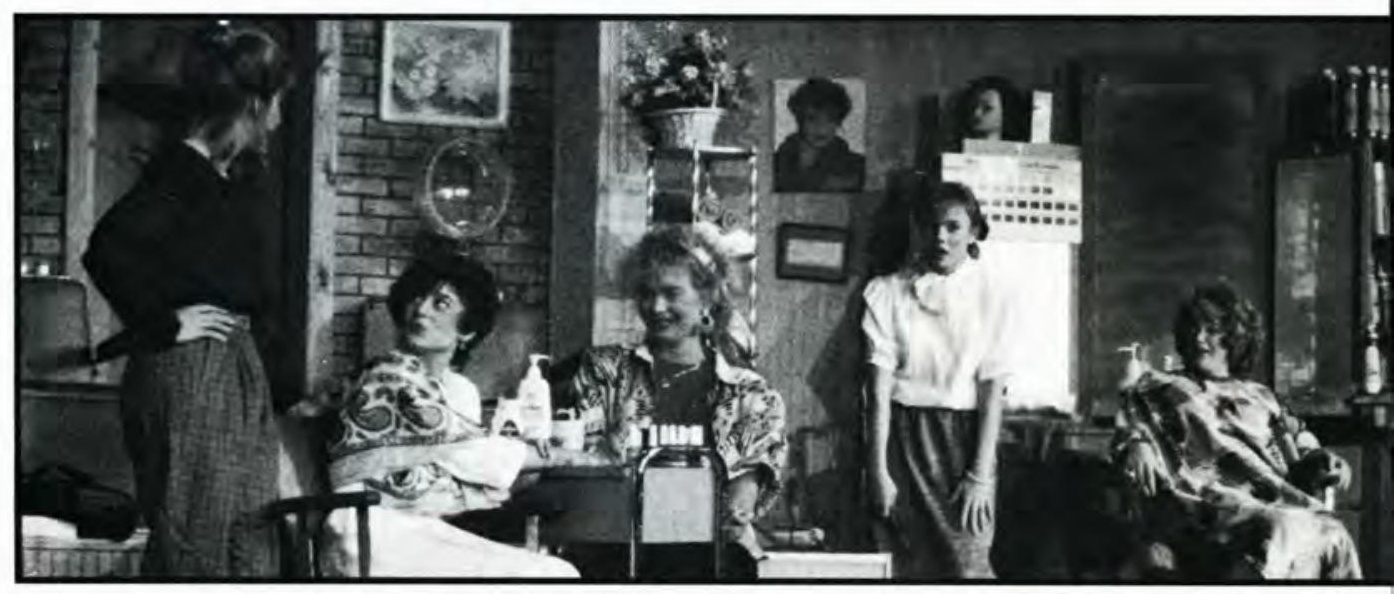

ever, they found another topic for controversy -- Shelby's pregnancy. Shelby was a diabetic, and giving birth could have cost her life. As the play progresses, the audience experiences the joy of the birth of Shelby's baby, as well as the sorrow of M'Lynn. M'Lynn sacrificed one of her own kidneys for Shelby; the transplant failed, and Shelby died. Amid their grief, the women in the salon found strength in their friendships with one another. They were strengthened to go on, strengthened like steel--Steel Magnolias.

\section{-Ruth Pfhaler}

"VALIUM" M'Lynn replies to Annelle's question of "what's the thirtieth wedding anniversary?"

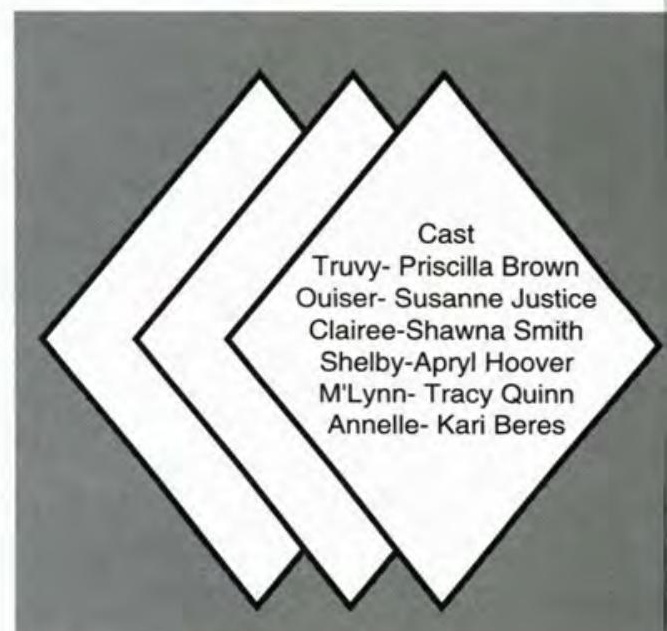




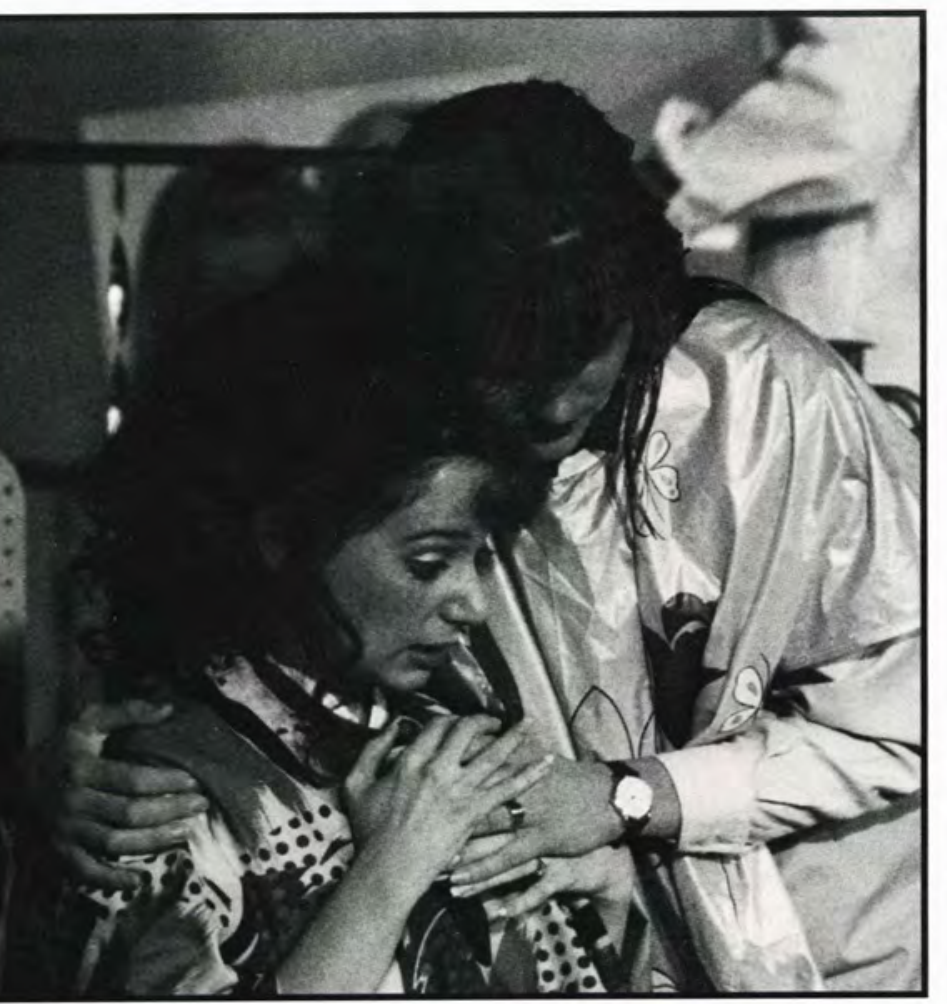

HONEY, DRINK THE JUICE! M'Lynn urges as she watches Shelby go into a diabetic seizure

"THANK YOU, LADIES, we'll all get through this just fine."
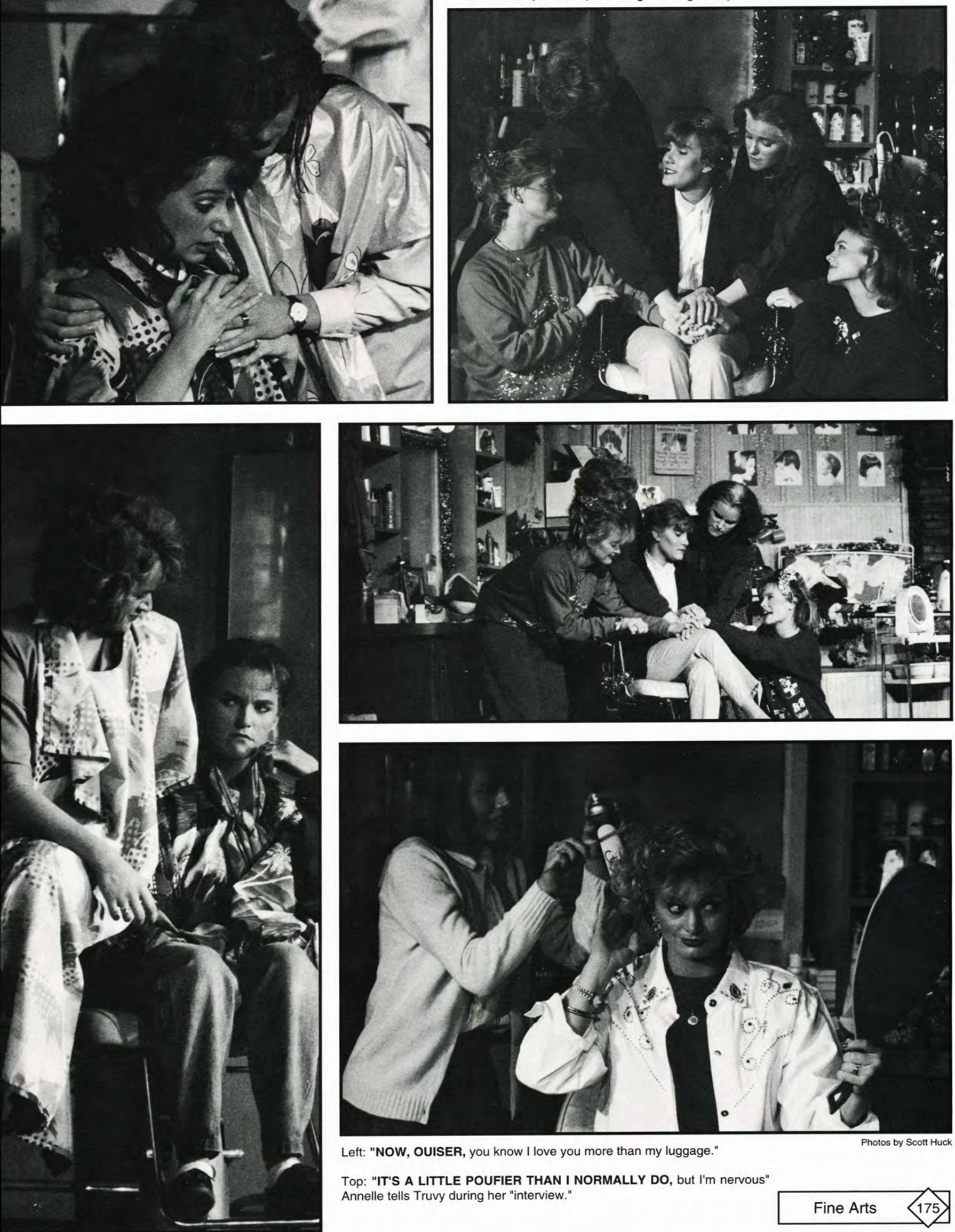

Left: "NOW, OUISER, you know I love you more than my luggage."

Top: "IT'S A LITTLE POUFIER THAN I NORMALLY DO, but I'm nervous" Annelle tells Truvy during her "interview." 


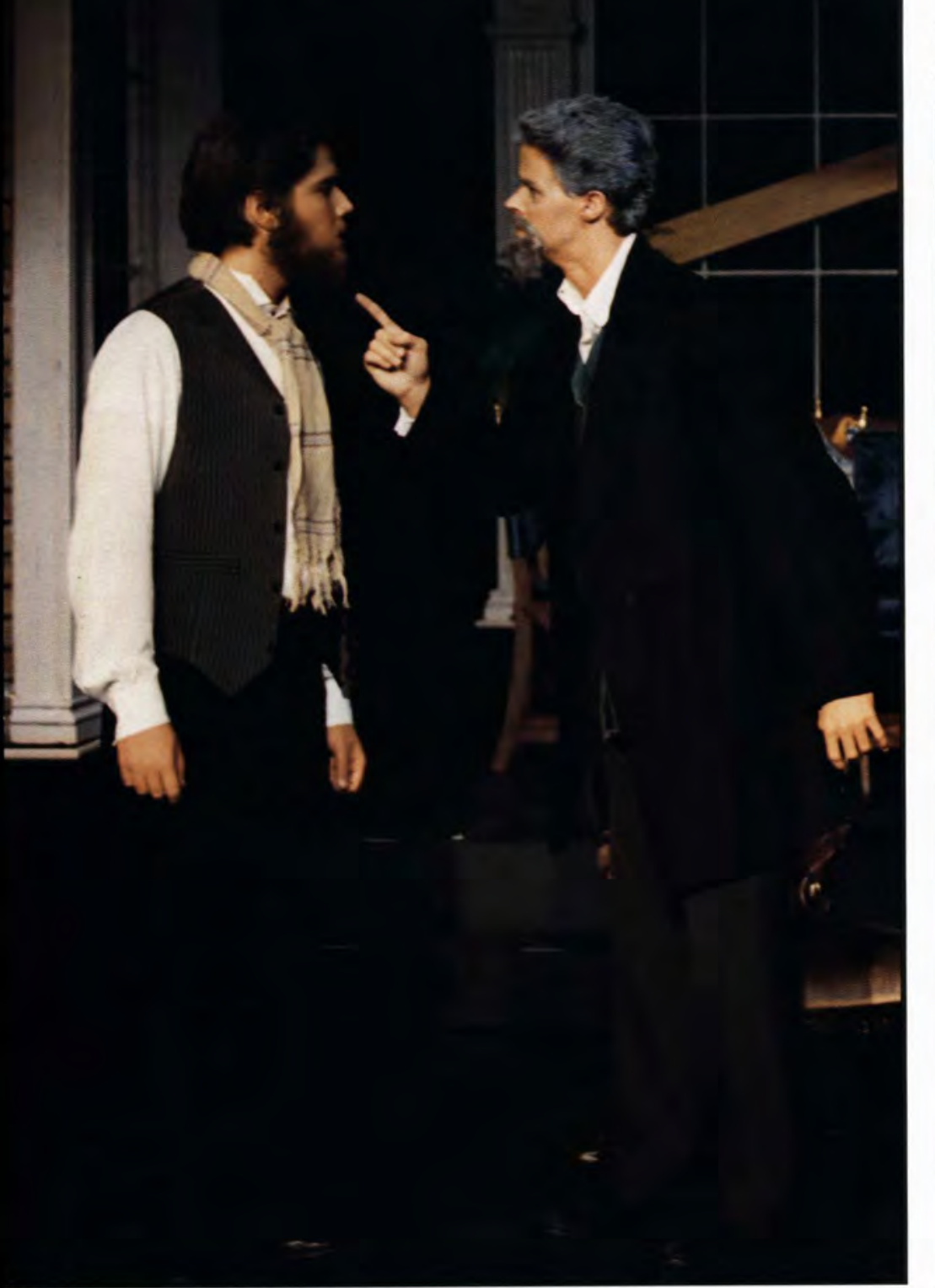

We the people must finally take him by the collar and declare, "You cannot say that!"

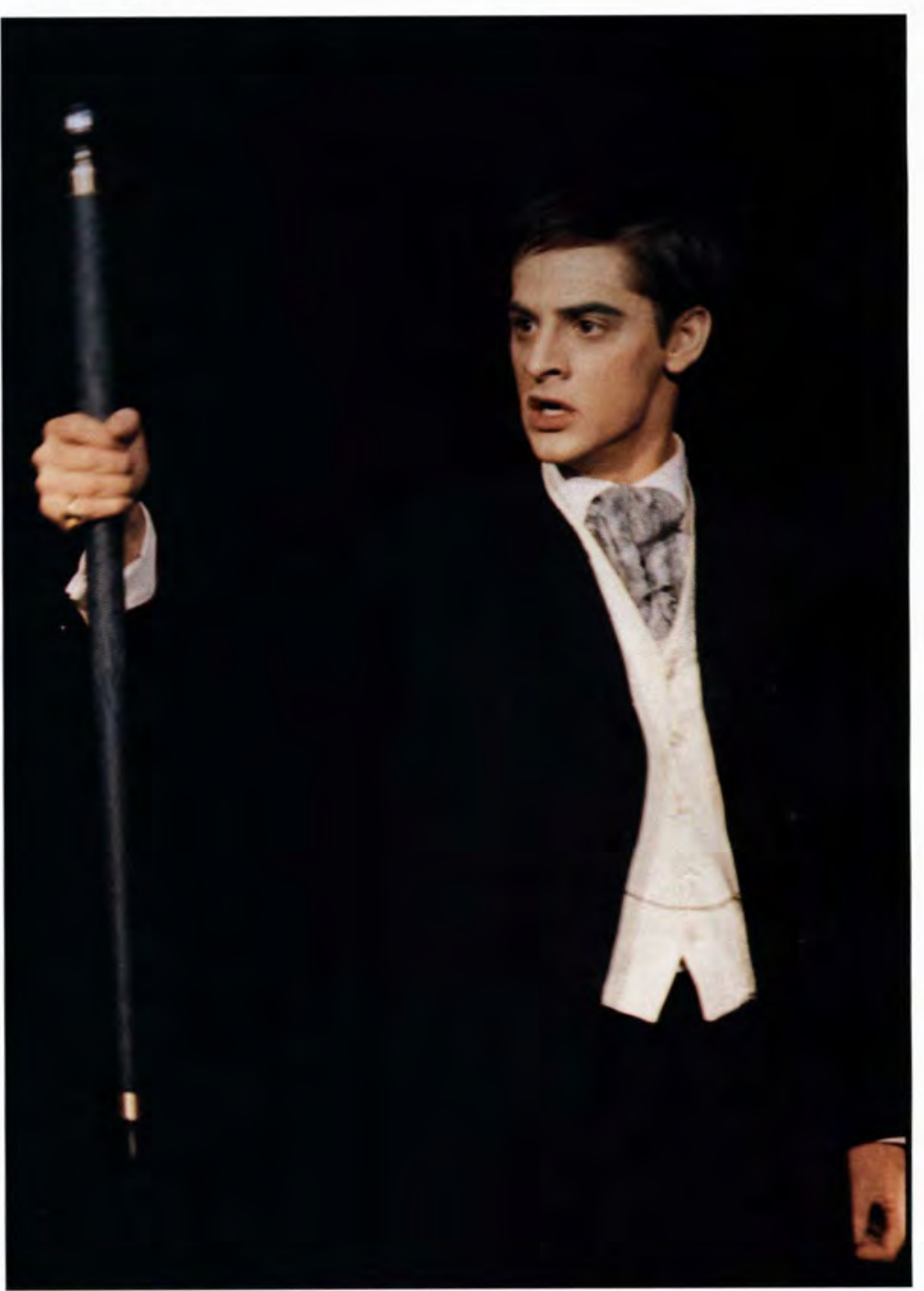

\section{Cast}

Morten Kill

Billing Catherine Stockmann Heather Rifenberick Mayor Peter Stockmann Jeremy Grinnell Hovstad

Dr. Stockmann

Captain Horster

Morten Stockmann

Petra Stockmann

Aslaksen

Townspeople
Ben Kalich

Aaron Newcomb Steve Brock

Jesse Leightenheimer Shelly Fox Chad Cornwell

Gary Childers Jennifer Crawford

Dustin Martin Kelly Navarre

Director: Mr. Gary Barker 


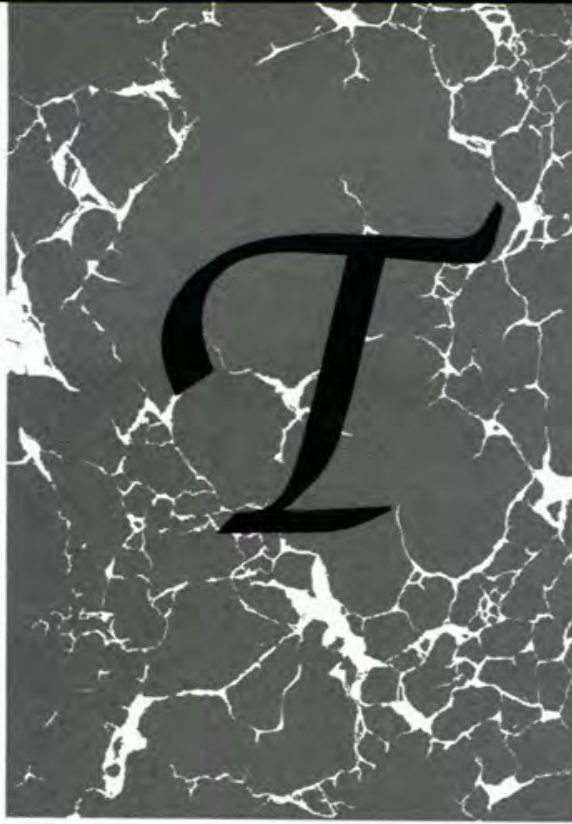

A lot of people who go to Shakespearean plays take with them the preconceived idea that, whether comedy or tragedy, Shakespeare is supposed to be boring and difficult to understand. Nothing could be farther from the truth, and the cast who presented the Comedy of Errors proved that misconceived notion to be false. People laughed. "They were surprised to find that Shakespeare could be funny, and that made it all the more enjoyable," said one leading cast member, David Mullins. "To make people laugh that hard at language not easily understood made the play a definite success," said
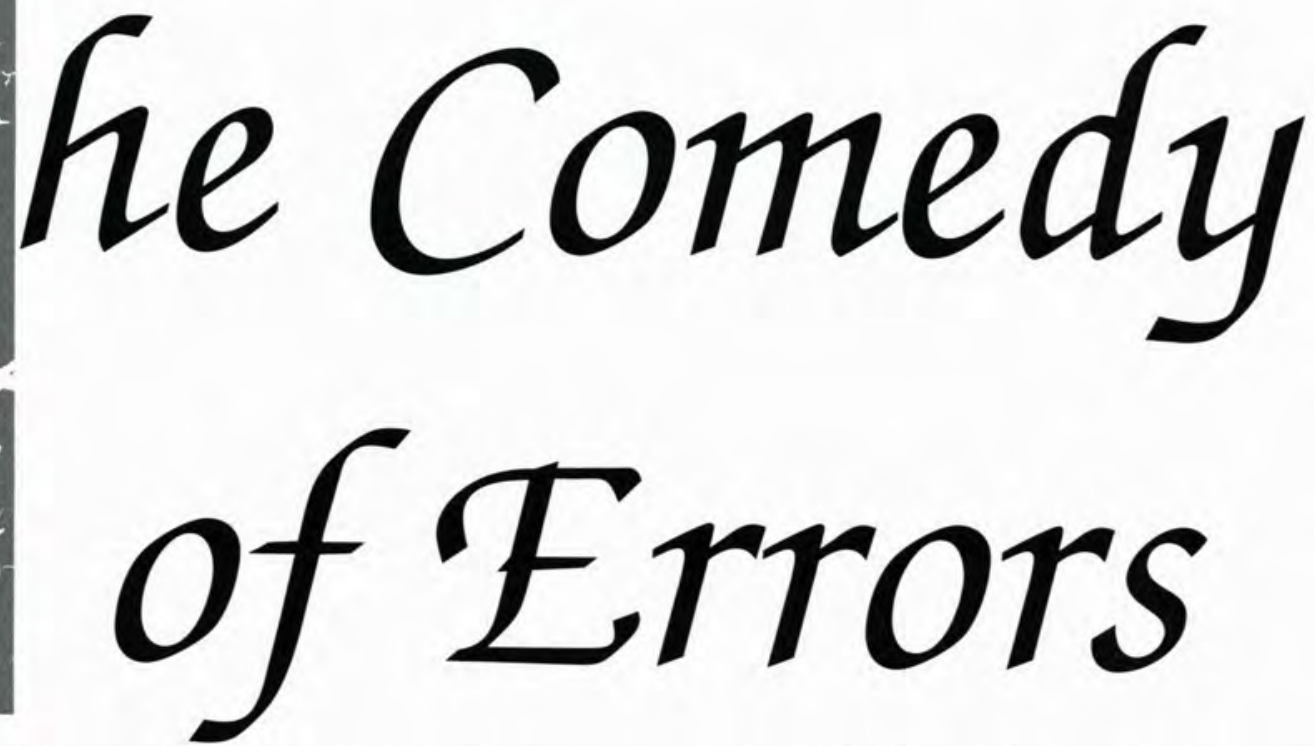

Heather Rifenberick who played Adriana, the wife of Antipholus of Ephesus. "Their facial expressions said everything," was the comment of one audience member. This superior acting was a result of long hours of practice and teamwork and the high standards of director, Dr. Robey, who insisted that every word be explained by actions on stage.

The story tells of two sets of twins born to a merchant and a servant on the same day on board a ship. Because of a storm on sea, both sets of twins were separated. One son and boy servant were raised by their father, the other son and boy servant by the mother. The action takes place when the two sets of identical twins unknowingly find themselves in the same city and are mistaken for one another. As one audience member put it, "The resulting mishaps were absolutely hysterical." The irony of the play was that, if they wanted to, the actors who played the Dromio twins could experience their own "Comedy of Errors" off stage. Although these men were not even related, as the finishing curtain fell, members of the audience could be heard saying, "Can you believe those twins? I still cannot tell them apart." -Ruth Pfahler

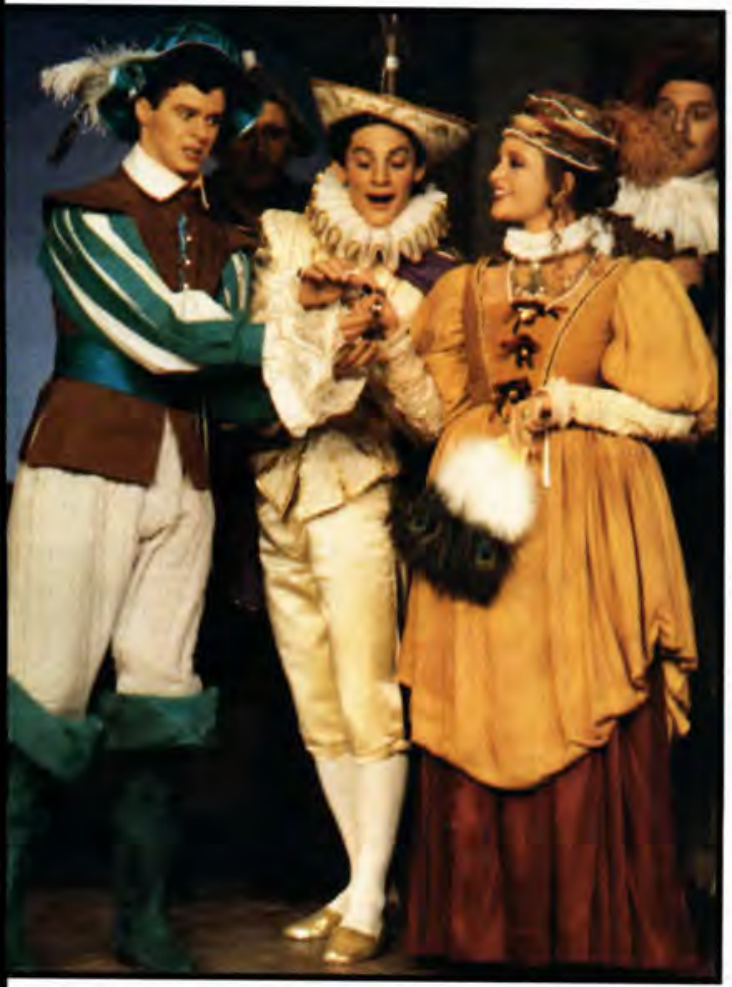

'Tis true, my liege, this ring I had of her.

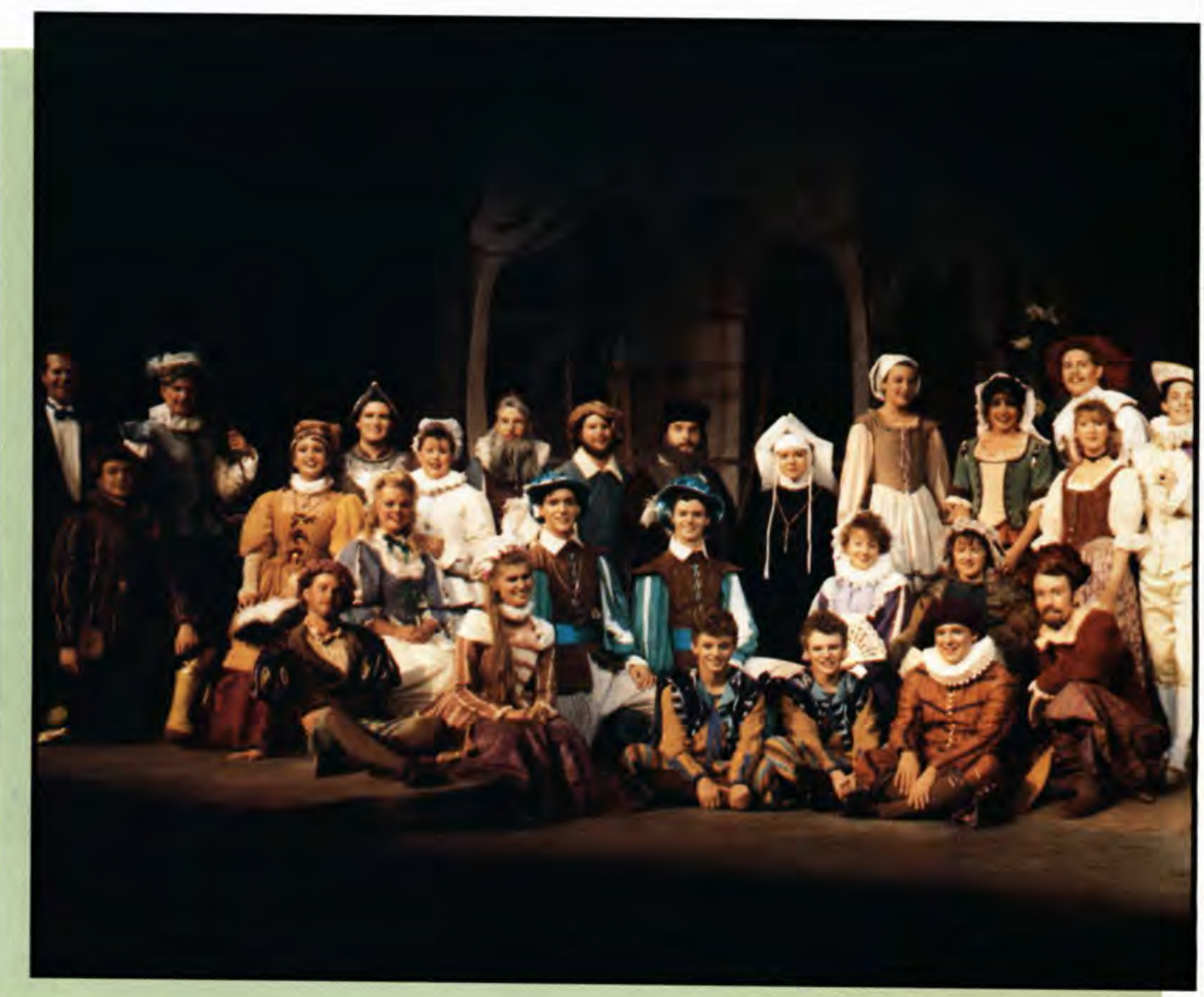




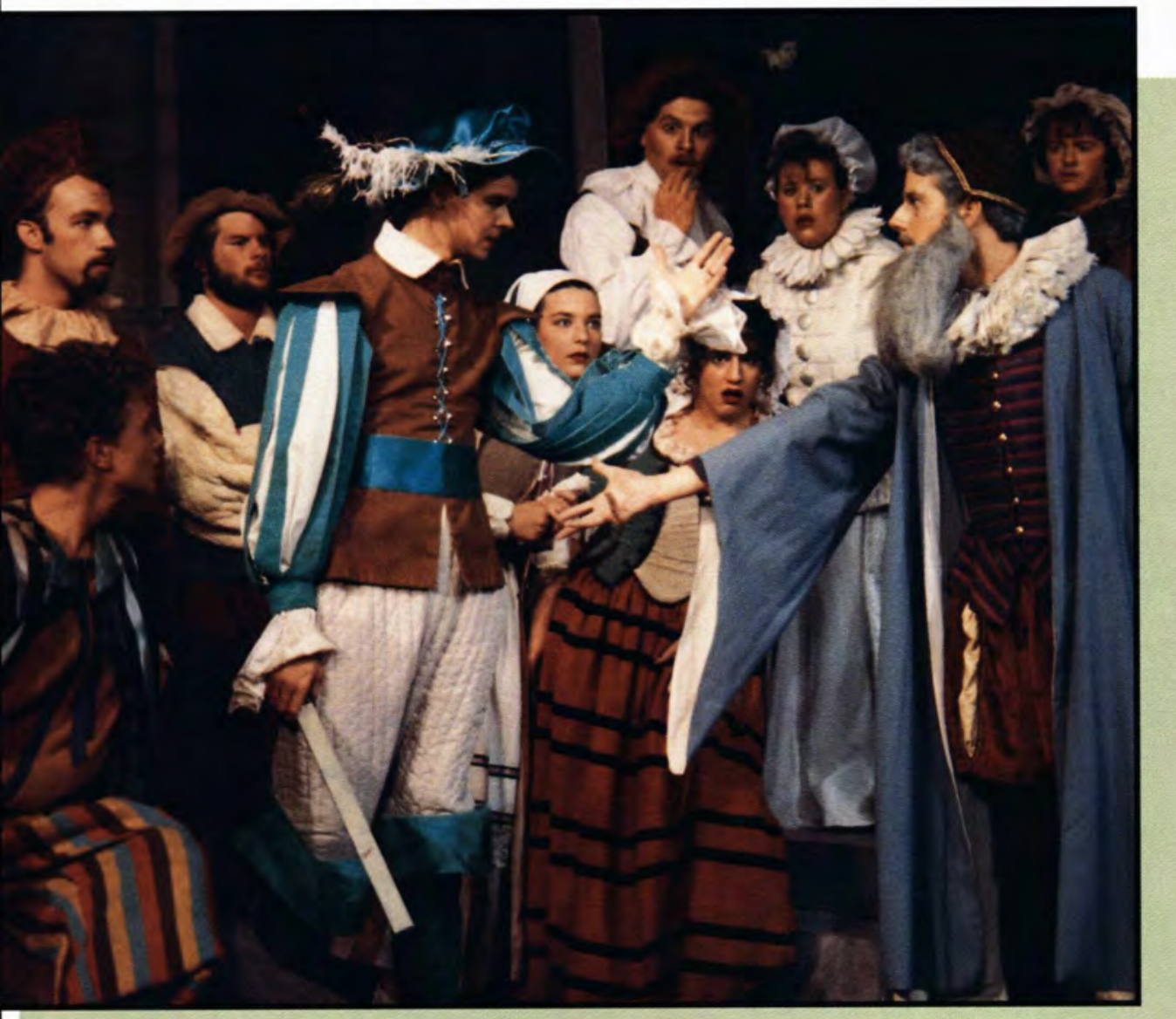

\section{Cast}

Duke

Aegeon

Antipholus of Syracuse Jeremy Haskell

Dromio of Ephesus Brent Apperson

Dromio of Syracuse David Mullins

Balthazer

Angelo

Merchant of Ephesus

Merchant

Pinch

Abbess at Ephesus

Adriana

Luciana

Luce

A Couresan

Jailer

Townspeople

Scott Blanton Sean Cottrill

Derran Reebel

Chad Cornwell David Moore

Stephanie Saville Heather Rifenberick Jill Ann Hunsberger Carol Lee Janna Ferner Dustin Martin Timothy Cowley Angel Dugan Wendy Herr Chris Jones

Bethann Mohn Michael Peck Christy Lyn Sarkisian Loretta Stephen

Directed by Dr. David Robey

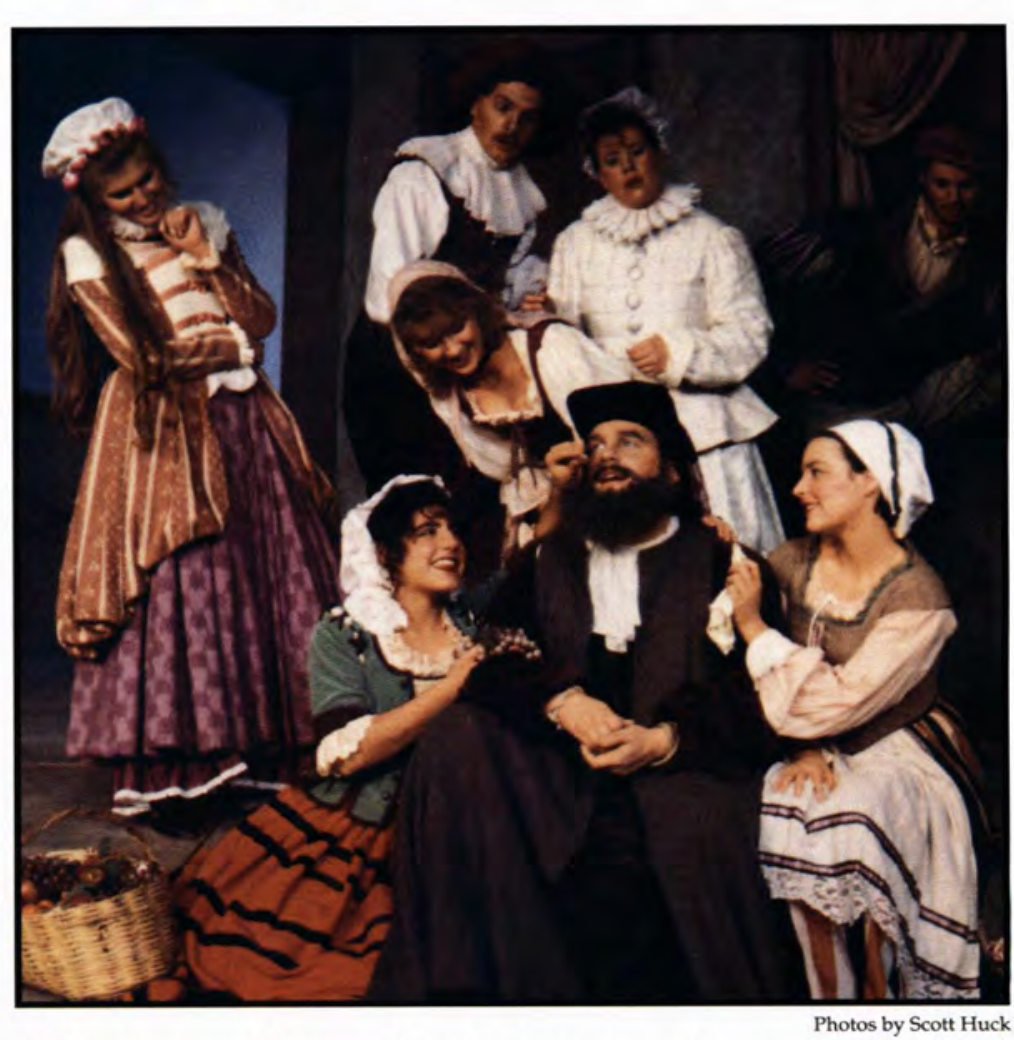

In Syracusa was I born, and wed unto a woman happy... 


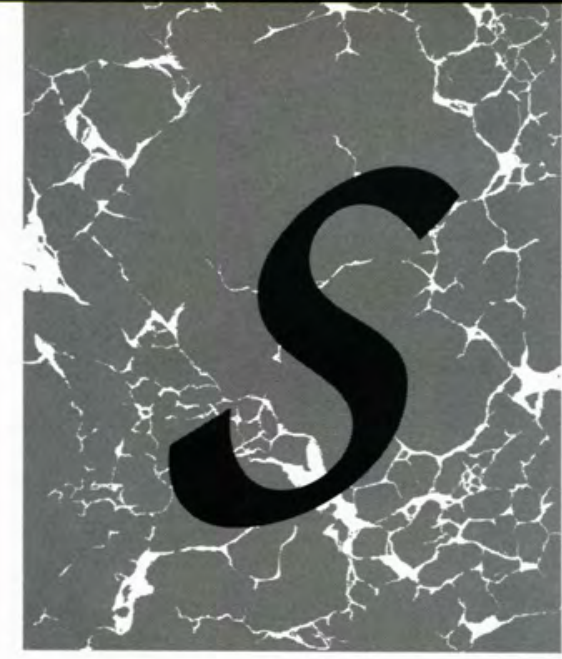

\section{Sonja Bartlett}

\section{Piano Recitalist}

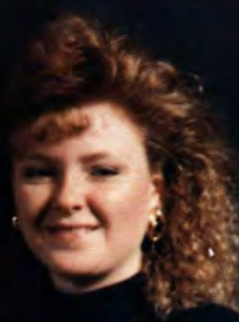

Sherilyn McPherson

Piano Recitalist
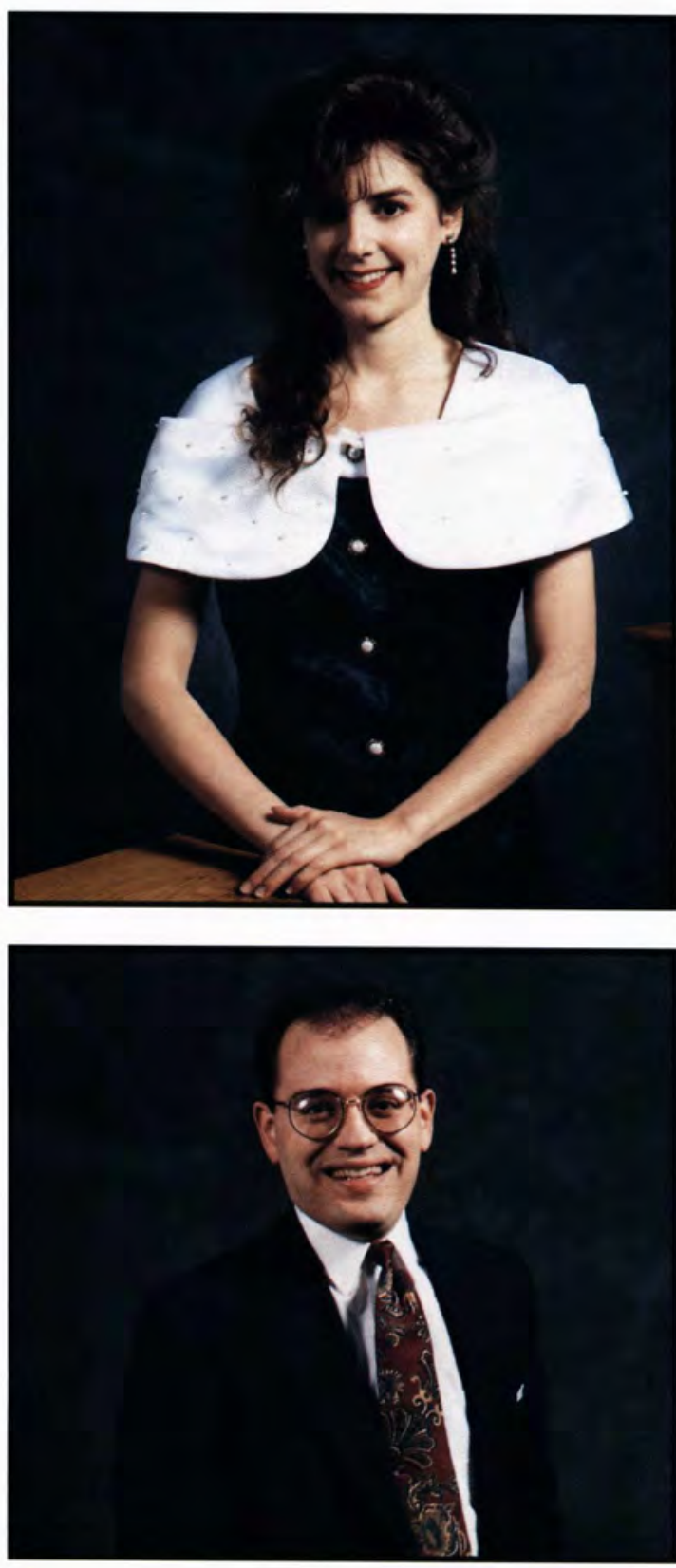

JackRooks

Vocal Recitalist
Sheryl Yankovich Piano Recitalist

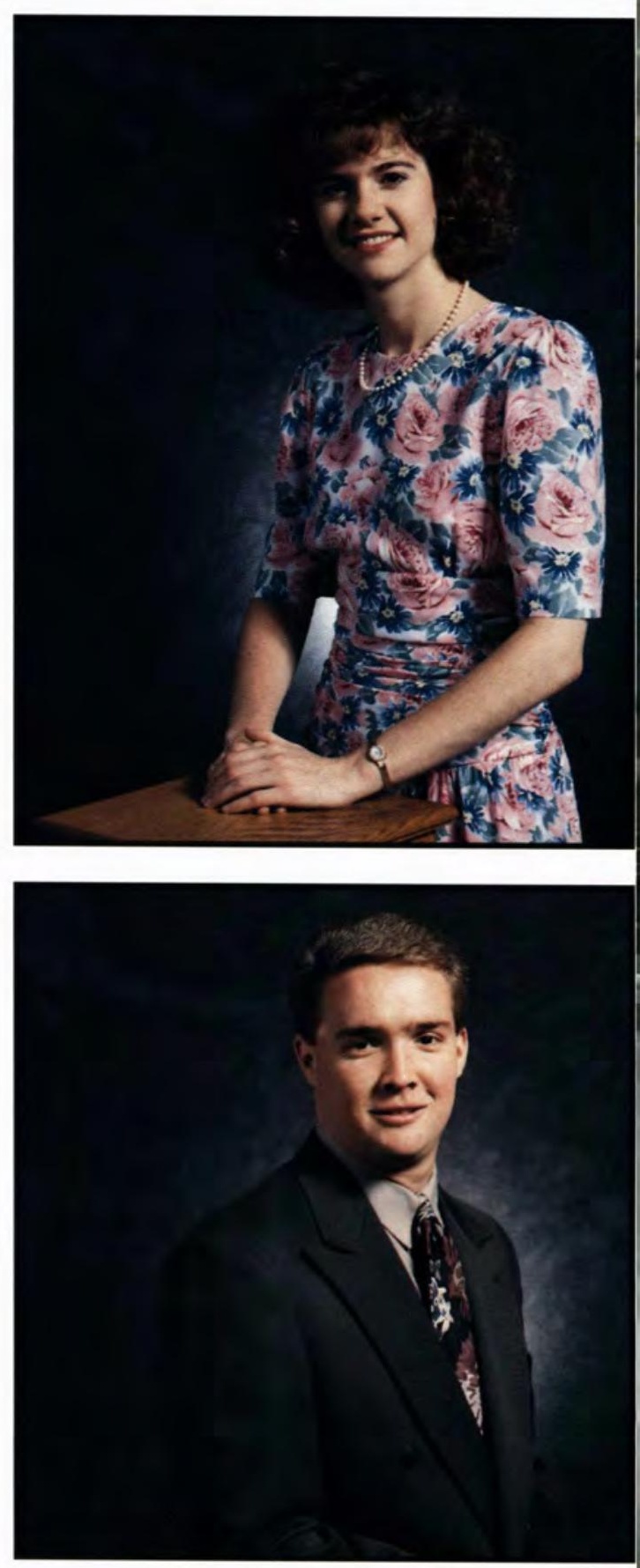

Steve Brock Speech Recitalist 
YOU NEED MORE

MONEY?
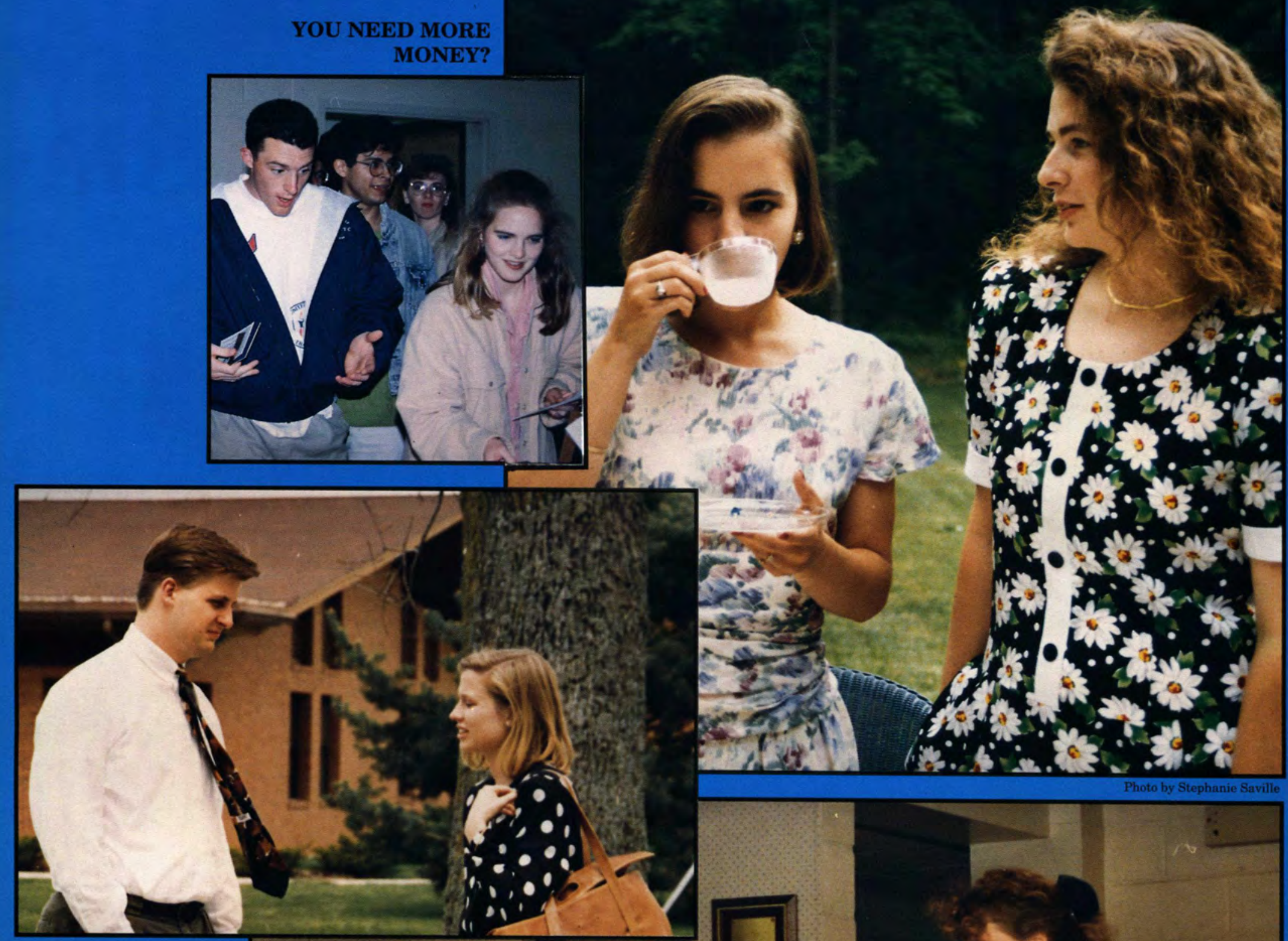
ave ith

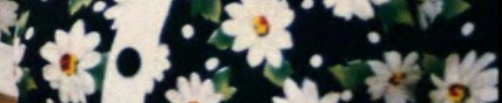

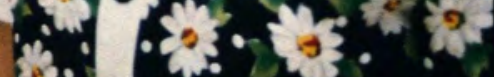

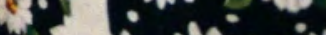

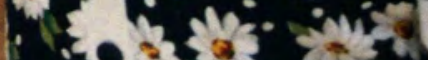

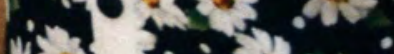
inting in the . Pewath Nongatis - villonise

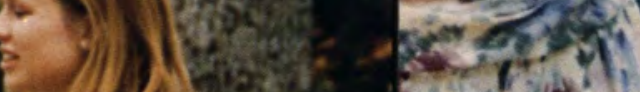

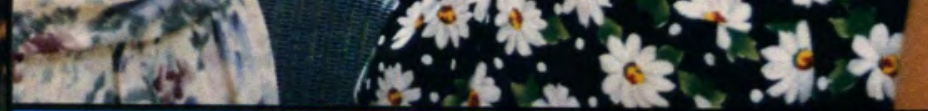

IN A DEEP CONVERSATION Matt Brown and Amy Riniker share the events of the day.

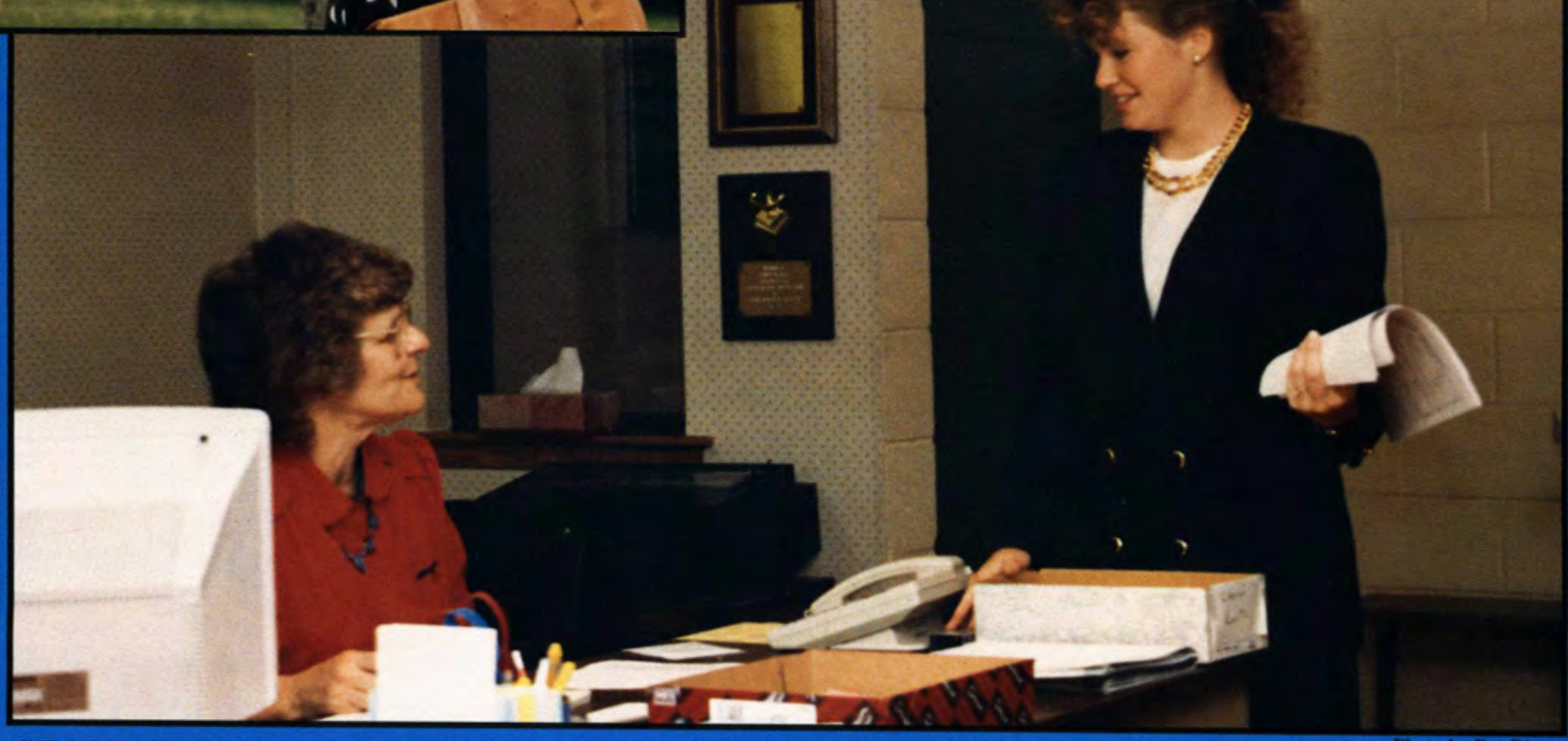

STOPPING FOR A CHAT, Julie Seaman finds Mrs. Knauff a good listener. 

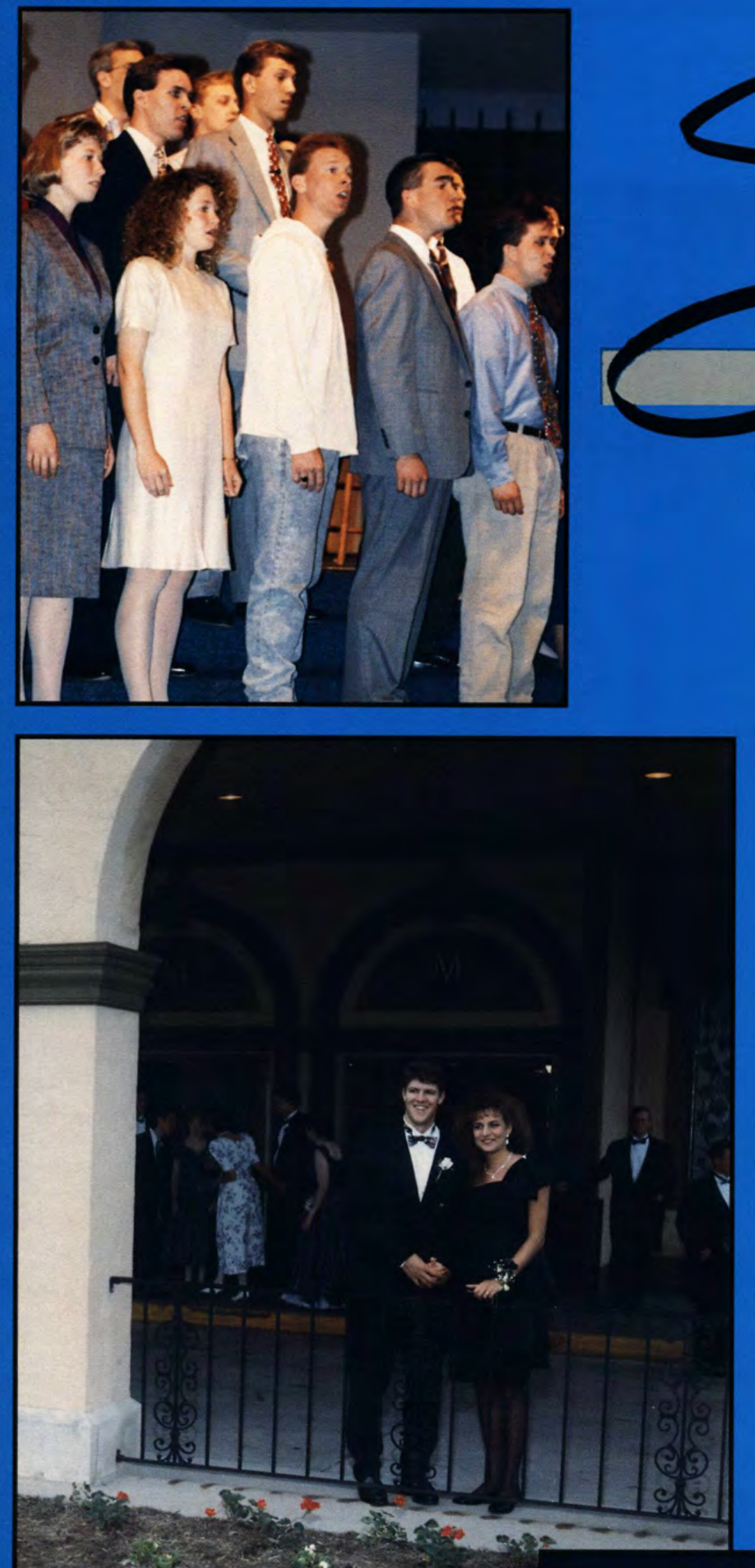

\section{in Seniors}

Who's Who

186-187

Senior Reception

188-189

J/S Banquet

190-191

Graduation

192-195

Senior Portraits

196-224

Remember when... $\quad 225-227$ 


\section{Leaving a \\ Precedence in}

\section{Academics}

\section{Who's Who 1993}

It is a national honor to be chosen as a member of Who's Who Among American College Students, and this year's faculty, staff and peers selected forty-nine students at Cedarville to receive this honor. The candidates, juniors and seniors, are selected on the basis of their academics, character and involvement in institutional organization and/ or cultural opportunities. The Who's Who chapel is a special chapel each year when the recipients of this honor are recognized and can share their appreciation with the student body. $\bullet$ Ruth Pfahler

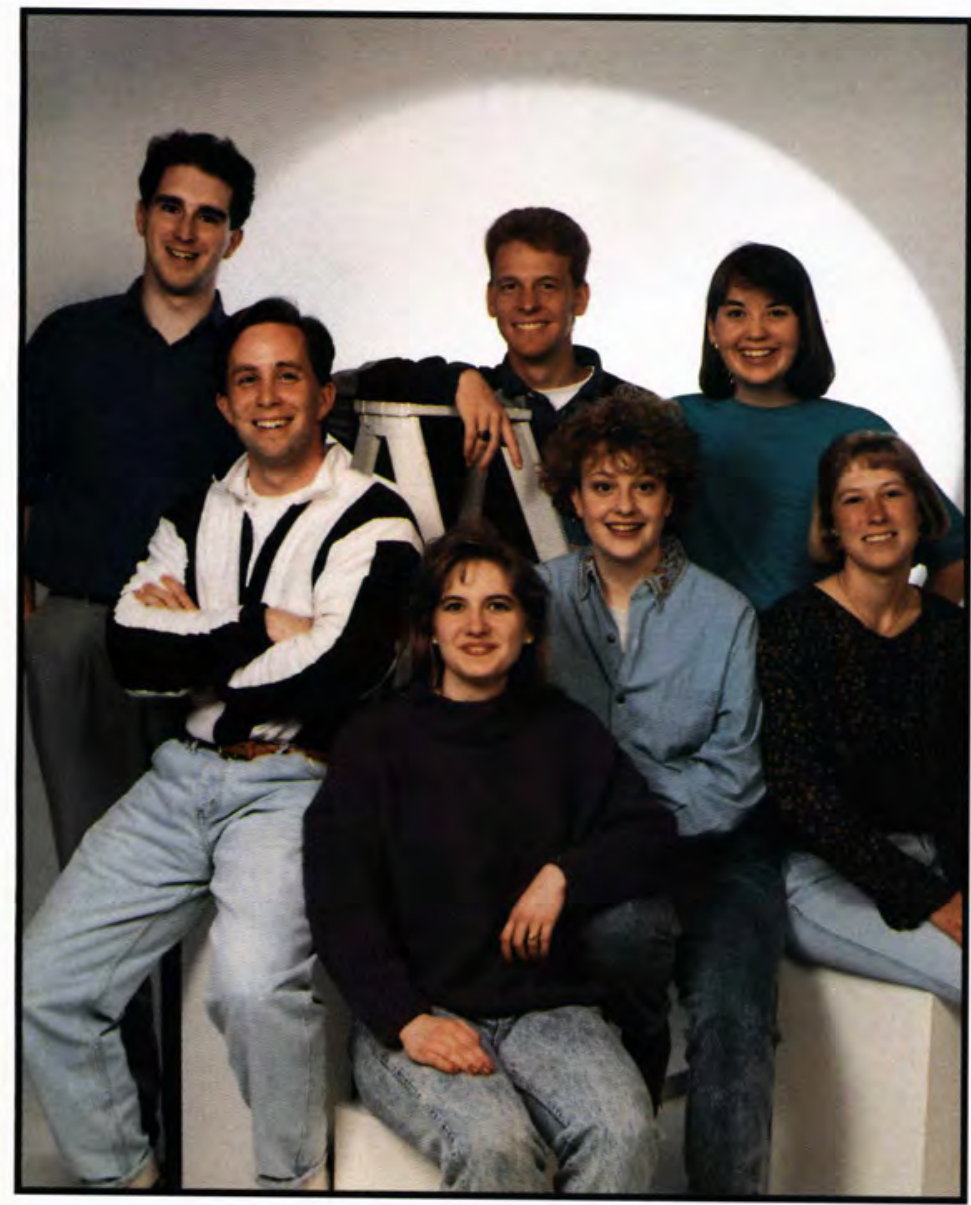

Bruce McKanna, William Montgomery, Lori Smith, Scott Bowman, Renee Eimers, Heather Rifenberick, Kari Davidson.

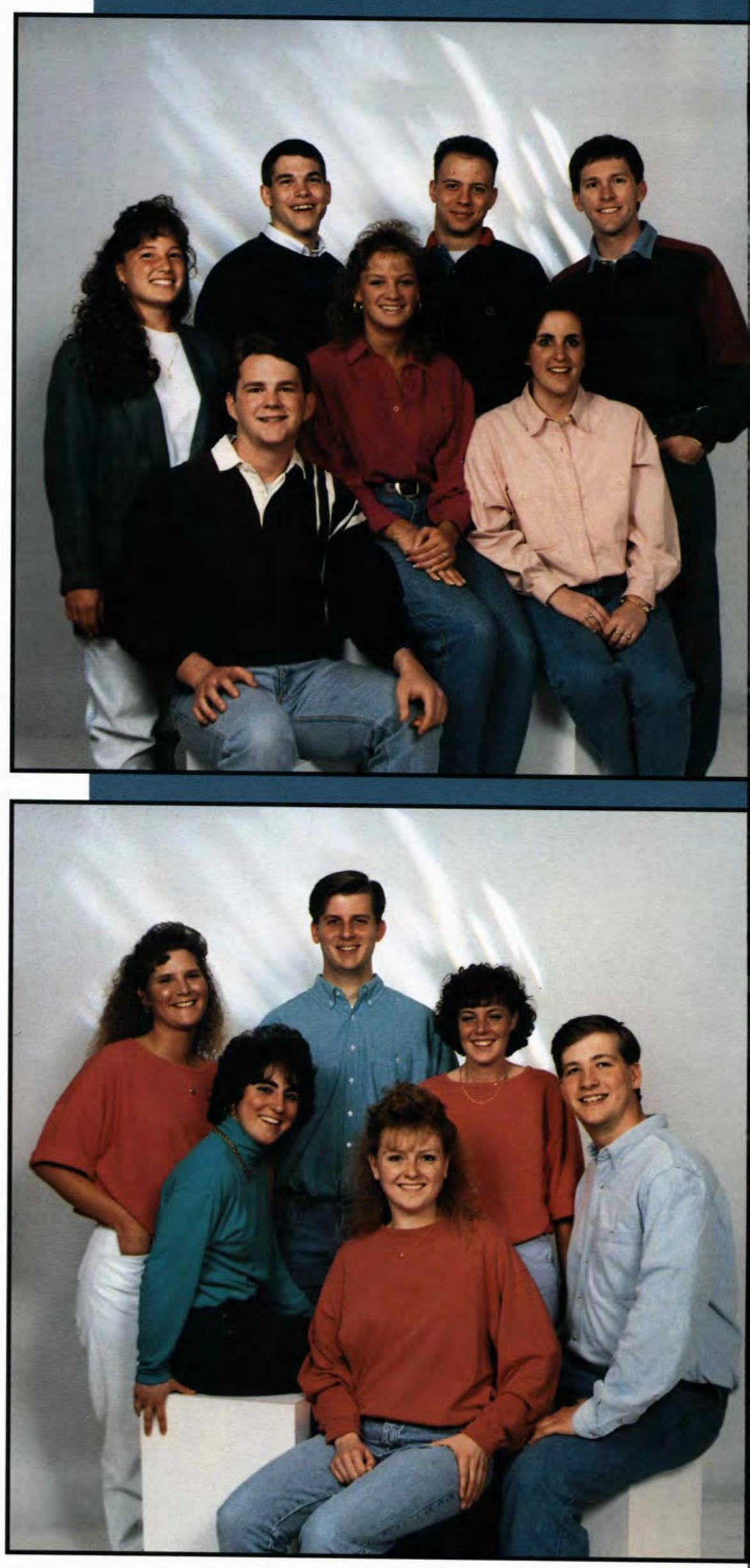

Stacy Oligee, Matt Brown, Sheri Leeds, Shelley Fiorito, Sonja Bartlett, Gary Childers. 


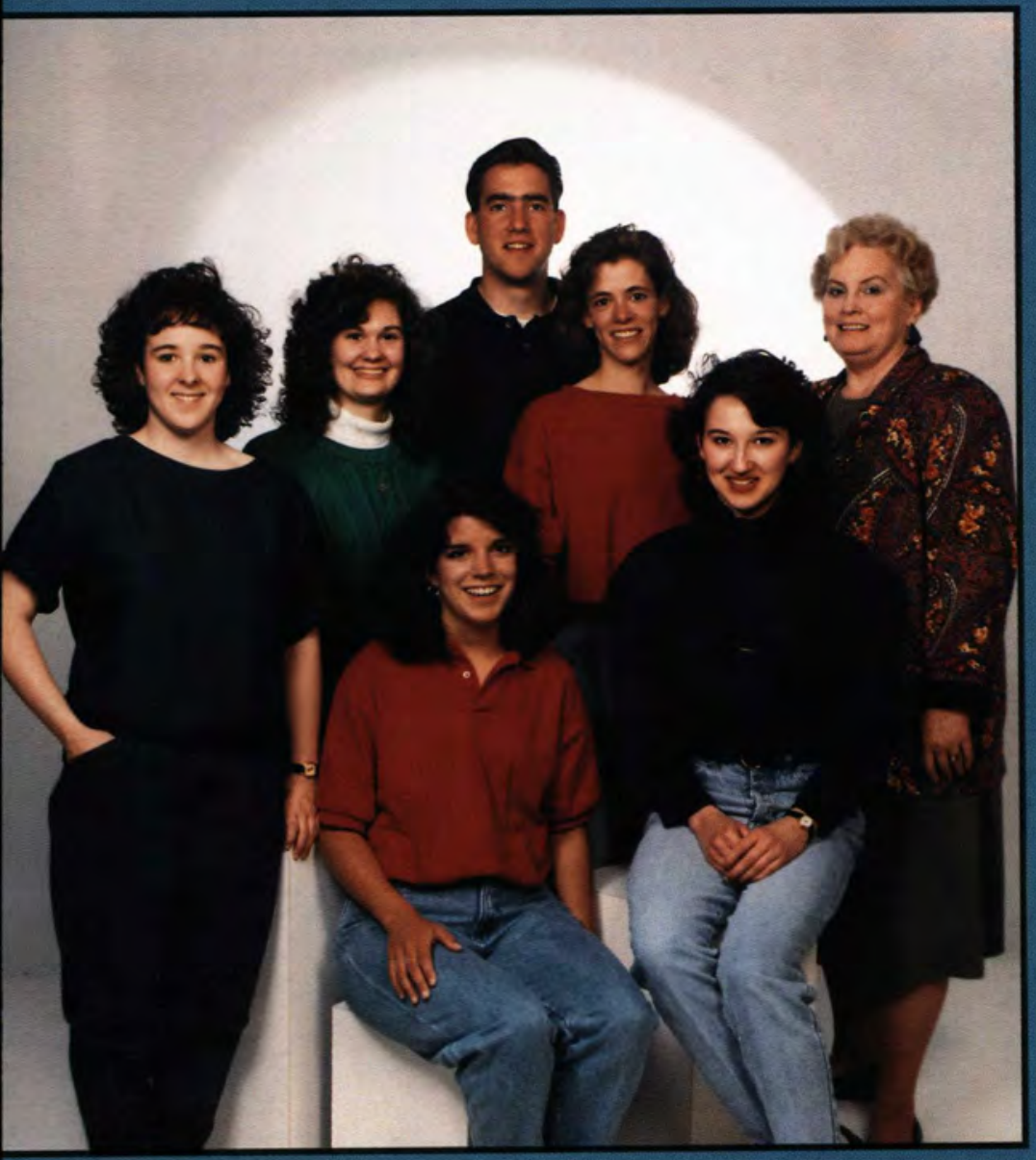

Dan Treier, Tim Vande Guchte, Ken Vanderwest, Michelle Plunkitt, Dan Ambrose, Sarah Good, Chad Coe

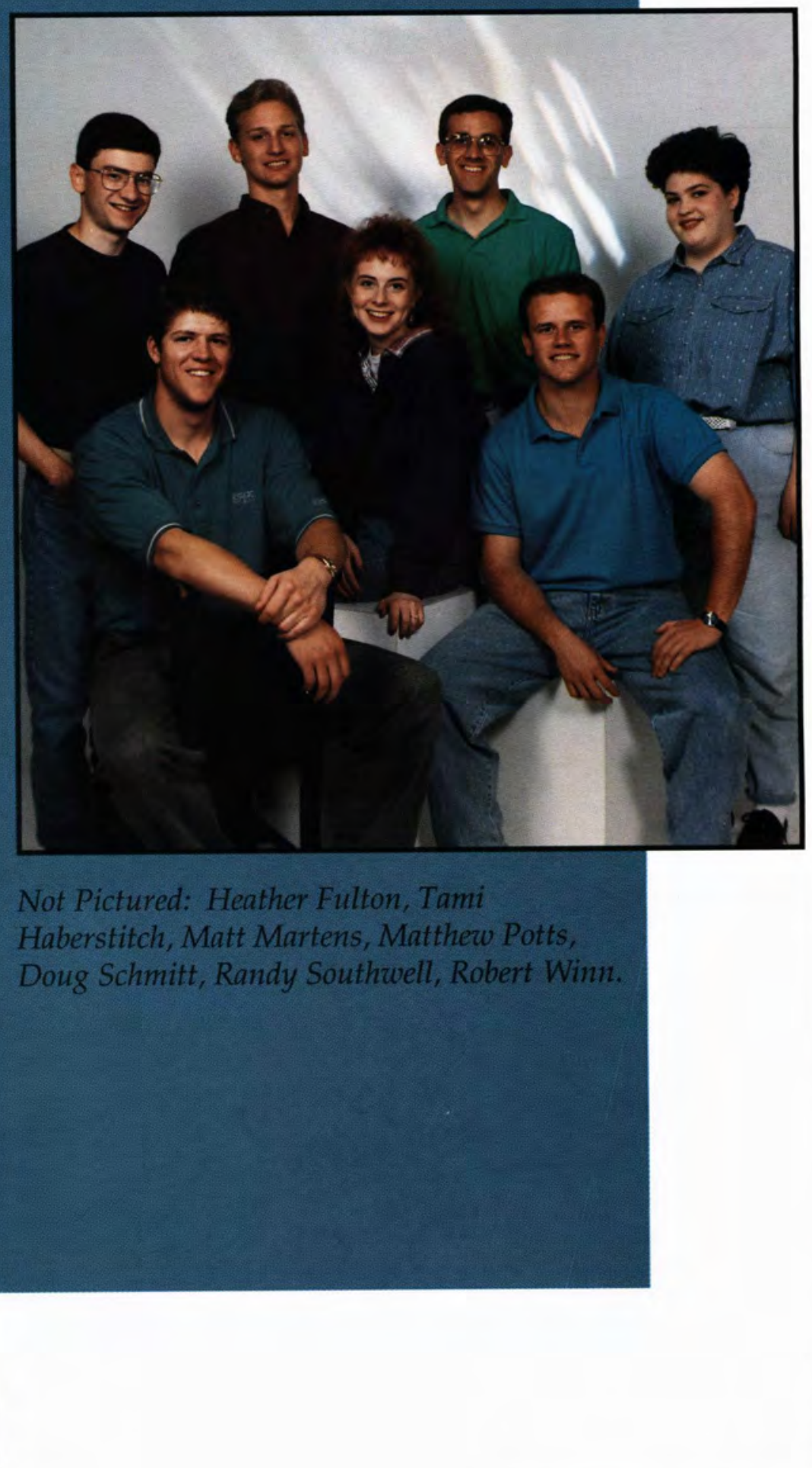

Julie Seaman, David Warren, Mark Vroegop, Ruth Bartholomew, Jeff Burr, Nathan Misirian, Cinnamon Brown, Cheryl Pinkerton. 


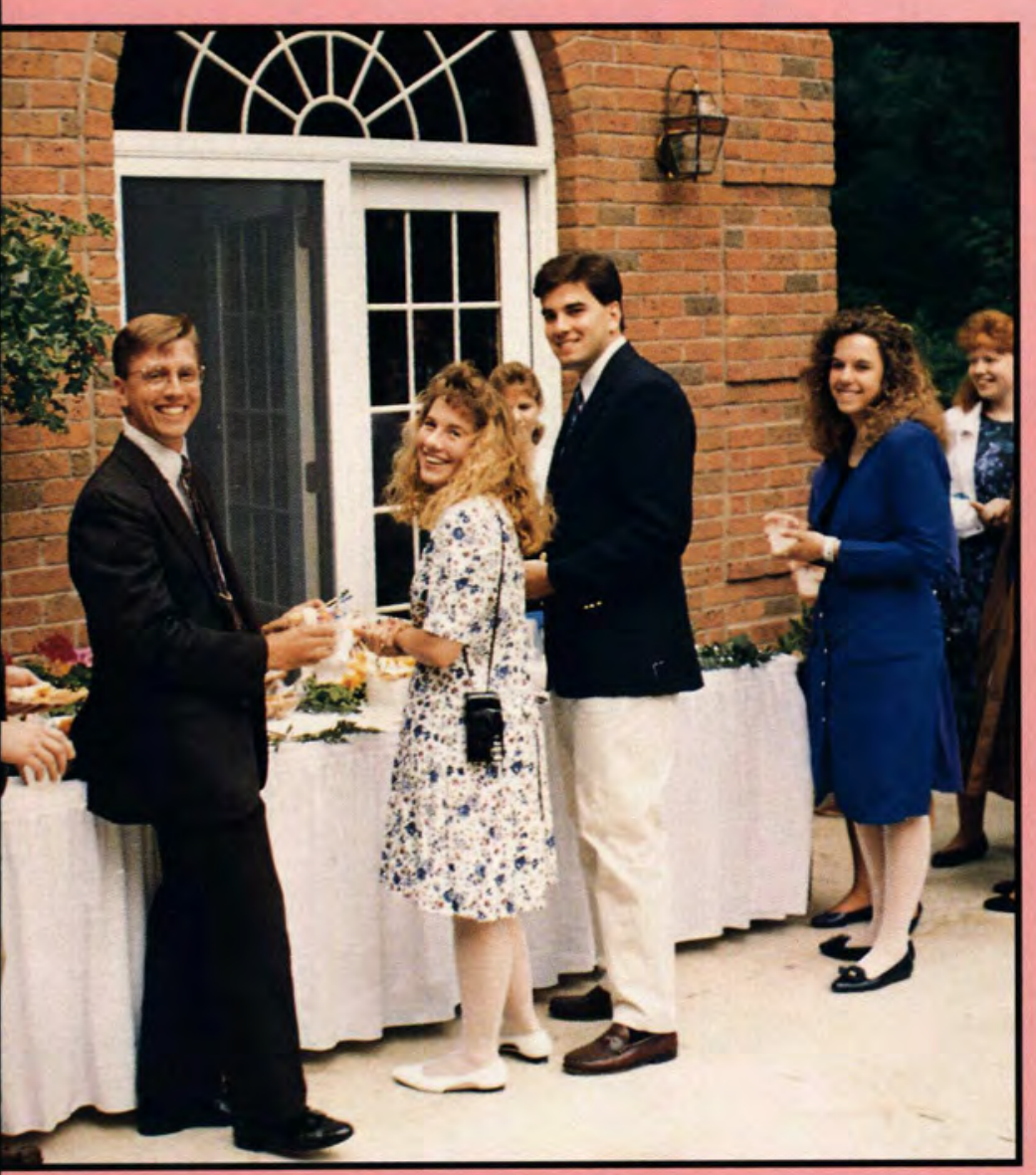

SMILE! THE FOOD HAS TO BE

BETTER THAN CHUCK'S!

IS THAT OFFICIAL COLLEGE BUSI-

NESS YOU ARE CALLING ABOUT

ON THE DIXONS' PHONE, DOUG?
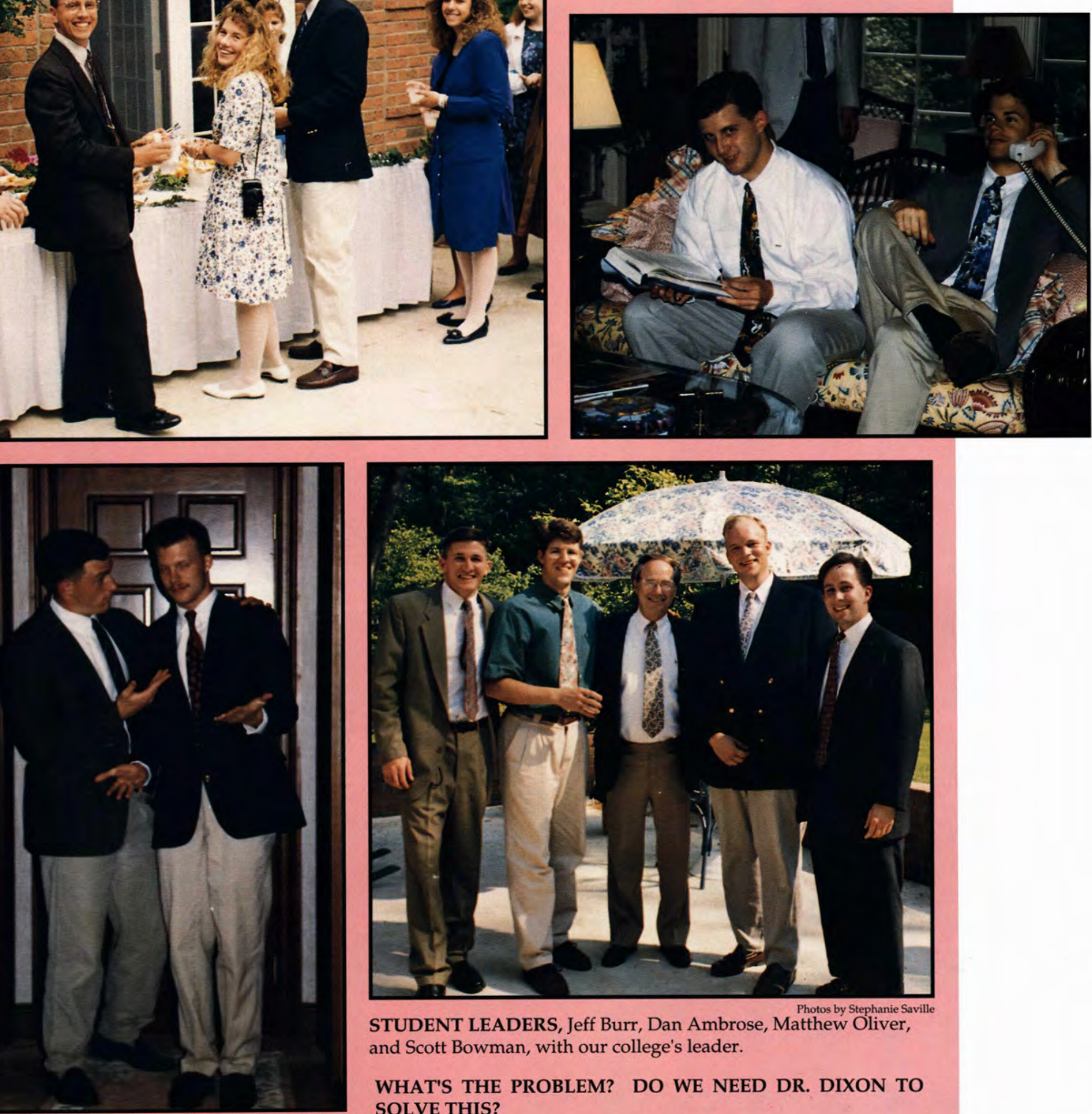

STUDENT LEADERS, Jeff Burr, Dan Ambrose, Matthew Oliver, and Scott Bowman, with our college's leader.

WHAT'S THE PROBLEM? DO WE NEED DR. DIXON TO SOLVE THIS? 


\section{Lasting Impressions}

\section{Made at the Junior-Senior Banquet}

Tonight is a special night leaving behind great impresfor all of us. A night to look sions on this campus with back on the memories of the friends, family, staff and facpast and to seal new ones in ulty. Each of you will leave ourheartsandminds. These your signature on this cammemories come from the pus, a lasting impression on impressions of people that those following behind you. have crossed our path, the During your college years places we have been, and you have been collecting the events that have taken memories of this part of your place. We all have memo- life. Professors, friends, roomrable moments from our mates, classes and chapels all childhood and through to- hold certain memories for night that have stamped a each of you. What you have pictureinourmindsforever. experienced as a part of the Our memories are formed Cedarville family will be one fromimpressions of thepast. of the most recent and "Last-

Not only are impressions ing Impressions" that you will left on us, but we leave im- takewith you when you leave. pressions on those all Marcy Johnson

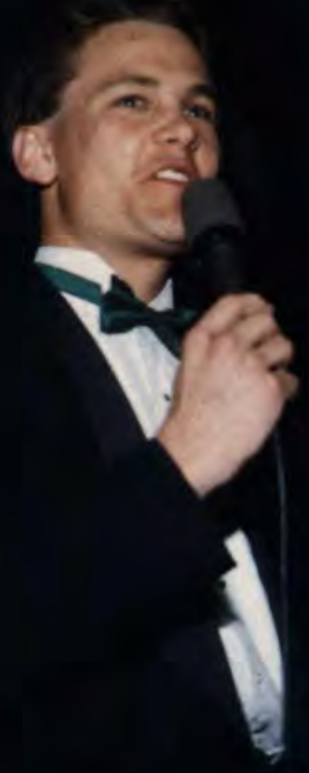
around us. Each senior is

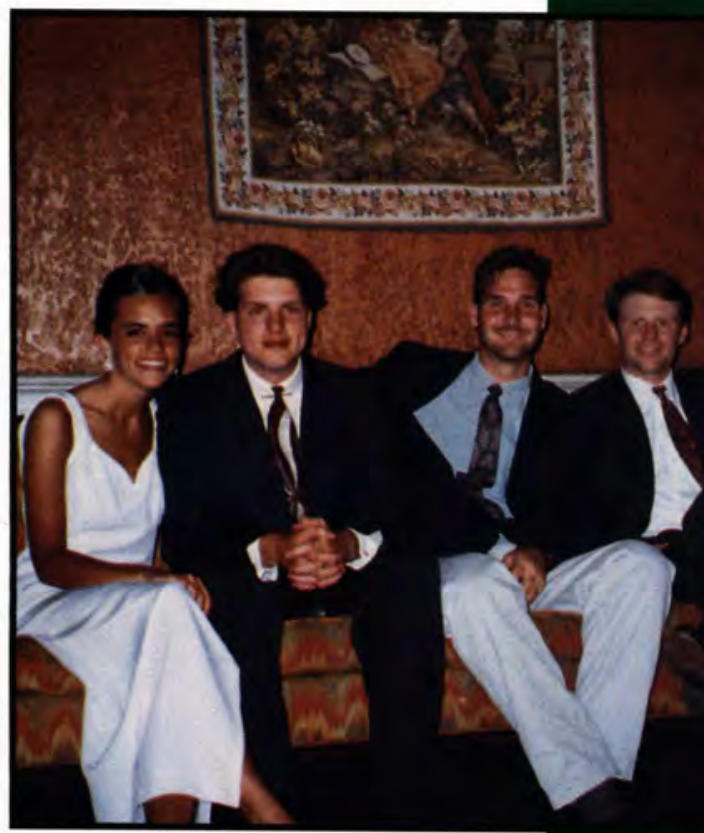

ANTICIPATING A RELAXING EVENING Claire Barnhart, Jim Hanssen, Steve Padgett, and Tom Kademus patiently wait for the banquet to begin.
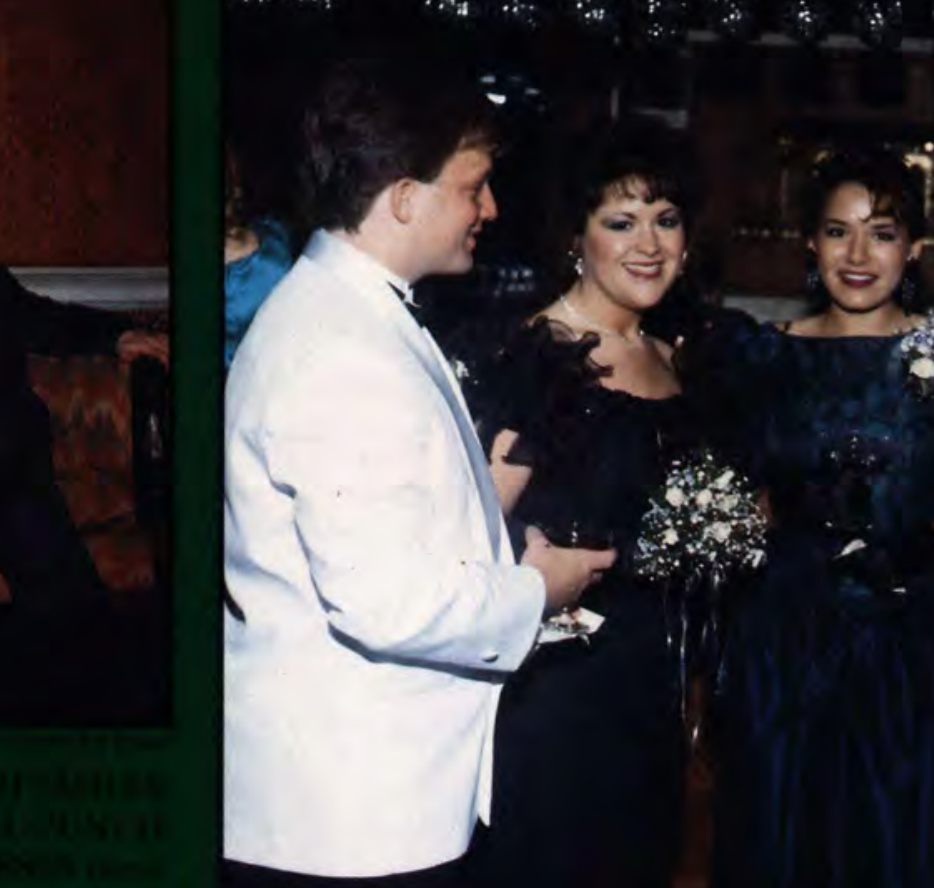

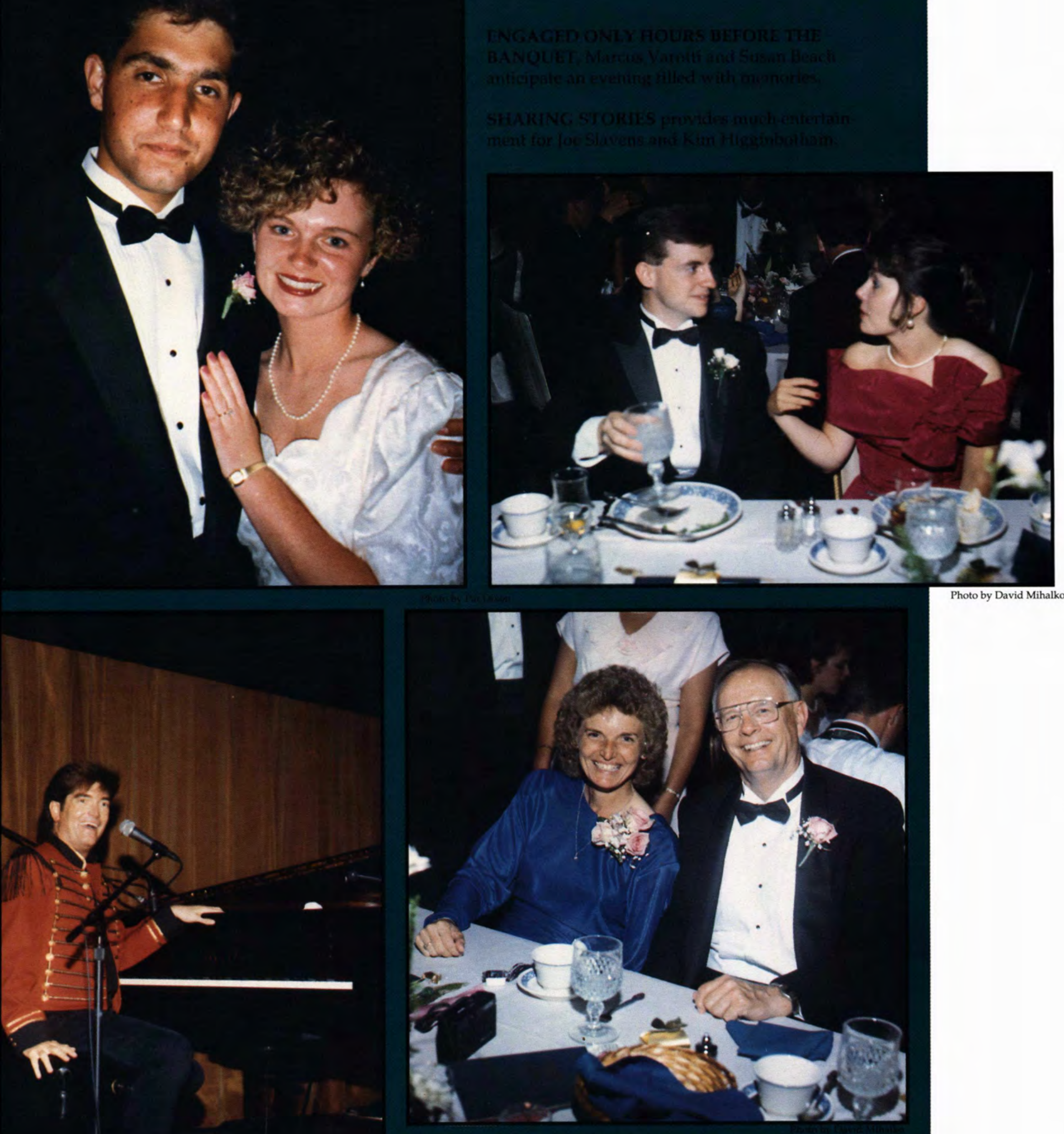

Photo by David Mihalko 


\section{Left,
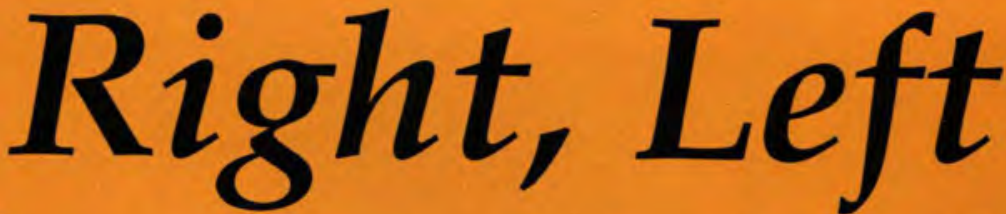 \\ Graduation \\ grea}

Announcements and re-

Do you get your left and right confused? Graduation can confuse even those who have never experienced this dilemma. The first challenge comes at rehearsal when you are handed a pink paper - a seating chart of sorts. (In truth, the paper is a technical writer's nightmare - one large graphic with no explanation.) You notice thirty-two rows of fourteen chairs with every row divided into two sets of seven. After killing a few gray cells, you realize each row is divided so that seven members of each row will enter from the left, the other seven from the right. Relief floods your soul as you find your seat - row 20 , seat 1 , right line. The worst should be over. minders fill the next thirty minutes. Dr. Matson and Dr. Wood explain the procedure for receiving your diploma. First, "Watch your hood lest it look like your arm should be in a sling." Second, remember "right hand over the left when you shake Dr. Dixon'shand and take your diploma." Or did he say, "left over right?" Ugh! Graduation must be the greatest exam of these four years: a test of whether you can follow directions and keep them straight under pressure.

Despite the pressure, come ten o'clock Saturday, all 459 seniors enter the gym in two parallel lines, reach their seats, and re- ceive their diplomas without any major baubles. (Except an unruly hood here and there.)

Family and friends are gathered - both tears and laughter marking the occasion. Commencement marks the exciting beginning of a new life, yet the good-byes that must be said choke up even the stereotypical, nonemotional male. Shakespeare summed up these emotions, "Parting is such sweet sorrow." Saying good-bye, however difficult, can be calmed by the reassurance that a reunion lies ahead, the greatest reunion being the one where we all join our Savior, Jesus Christ and our classmate, Diane Jones in heaven. Oh what a day that will be!

\section{-Marsha Olsen}

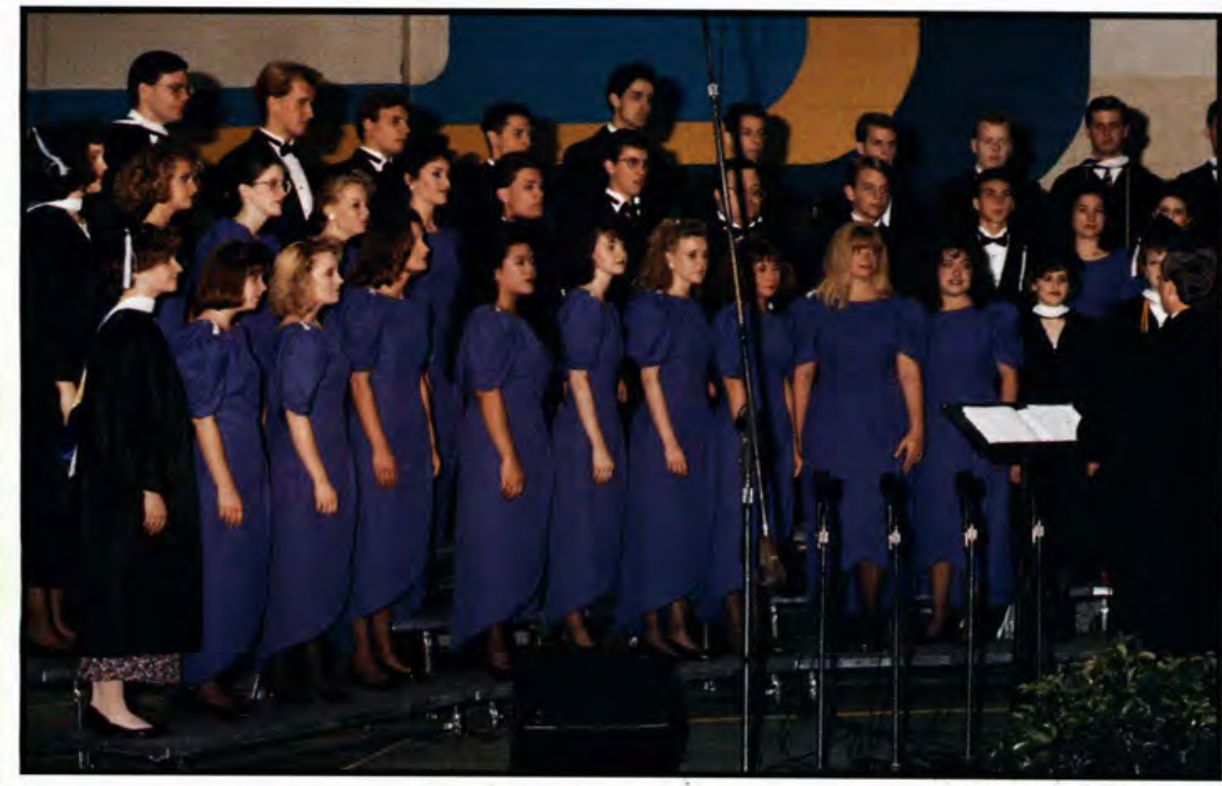

Photo by Ardvark Photography

THE CONCERT CHORALE MAKES THEIR LAST APPEARANCE TOGETHER AT GRADUATION. IN CHRIST ALONE, the song of the graduating class, is sung by the Class

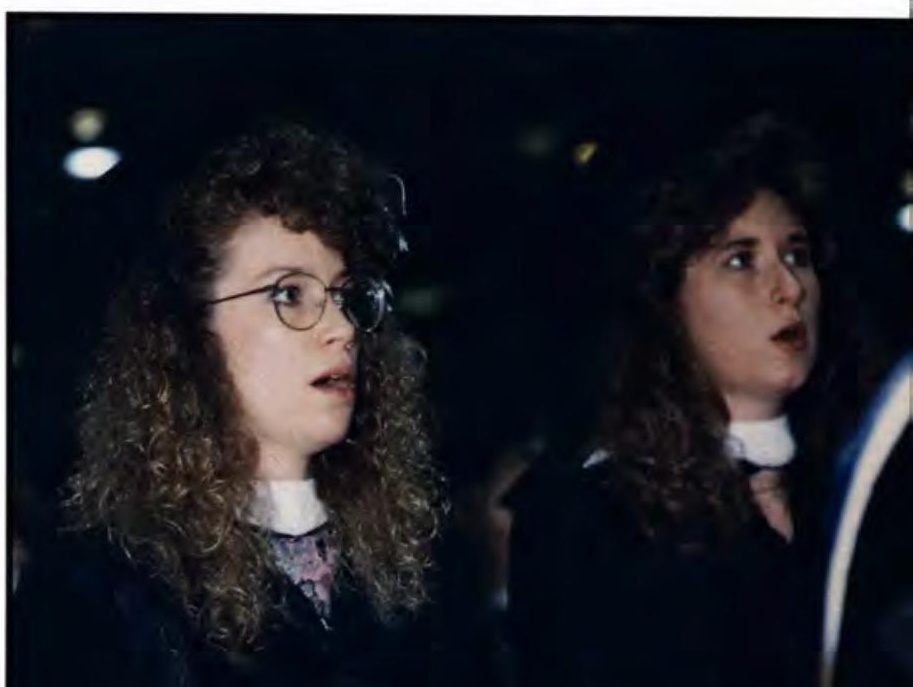




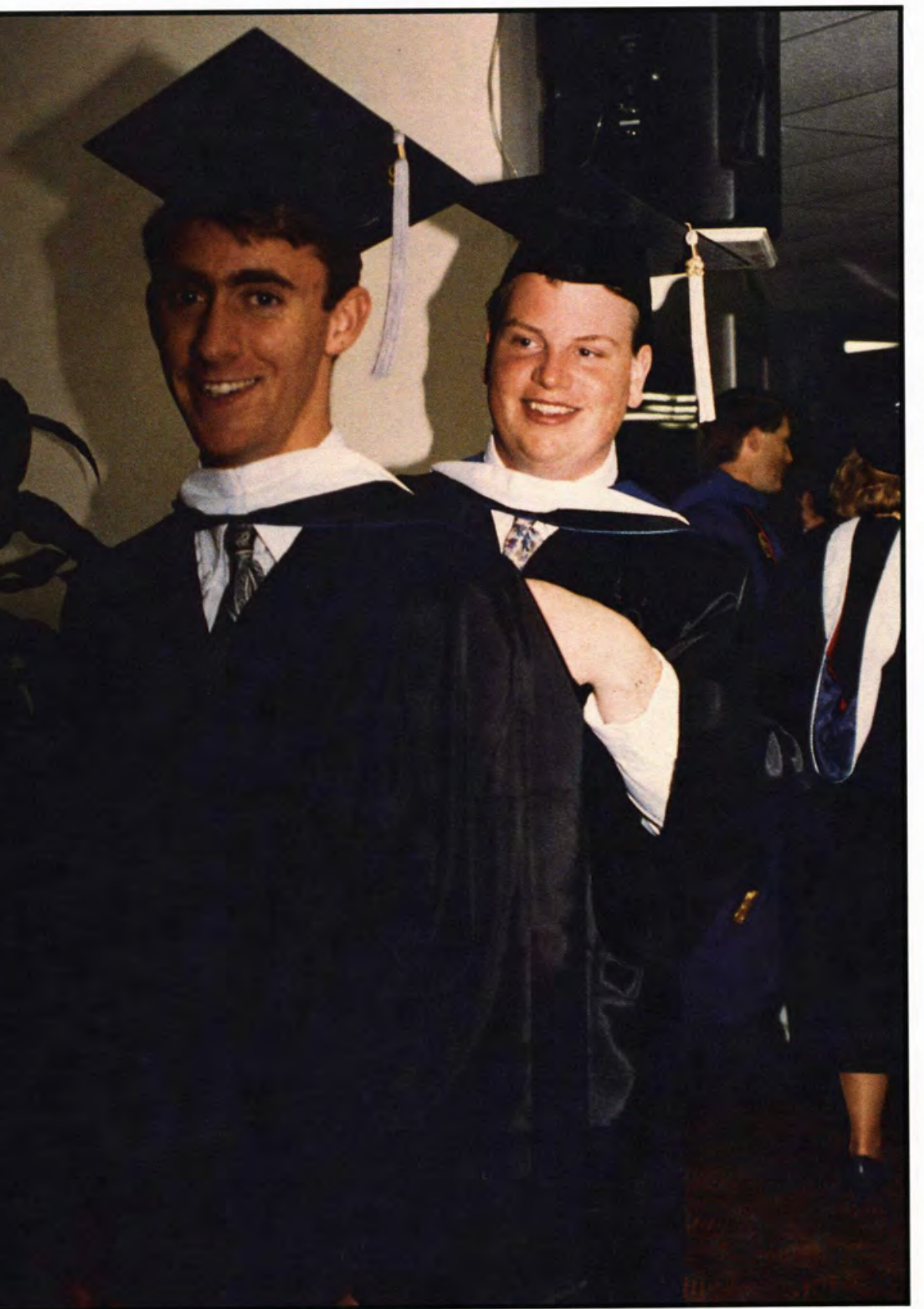

ALL DRESSED UP FOR THE BIG DAY, Steve Cook and Andy Eastman make last minute preparations for graduation.

DR. DIXON ADDRESSES THE GRADUATING CLASS OF 1993 FOR THE LAST TIME.
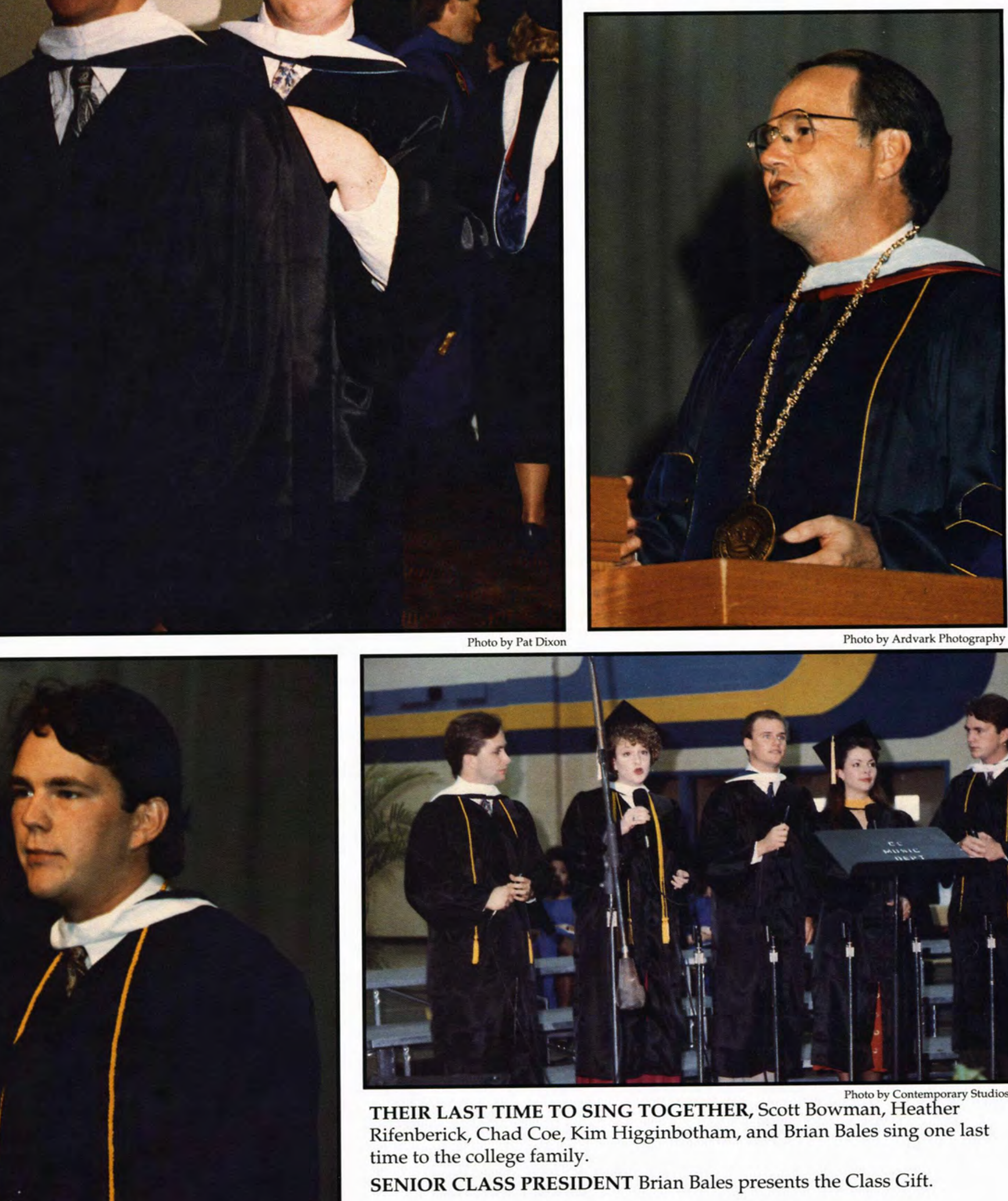


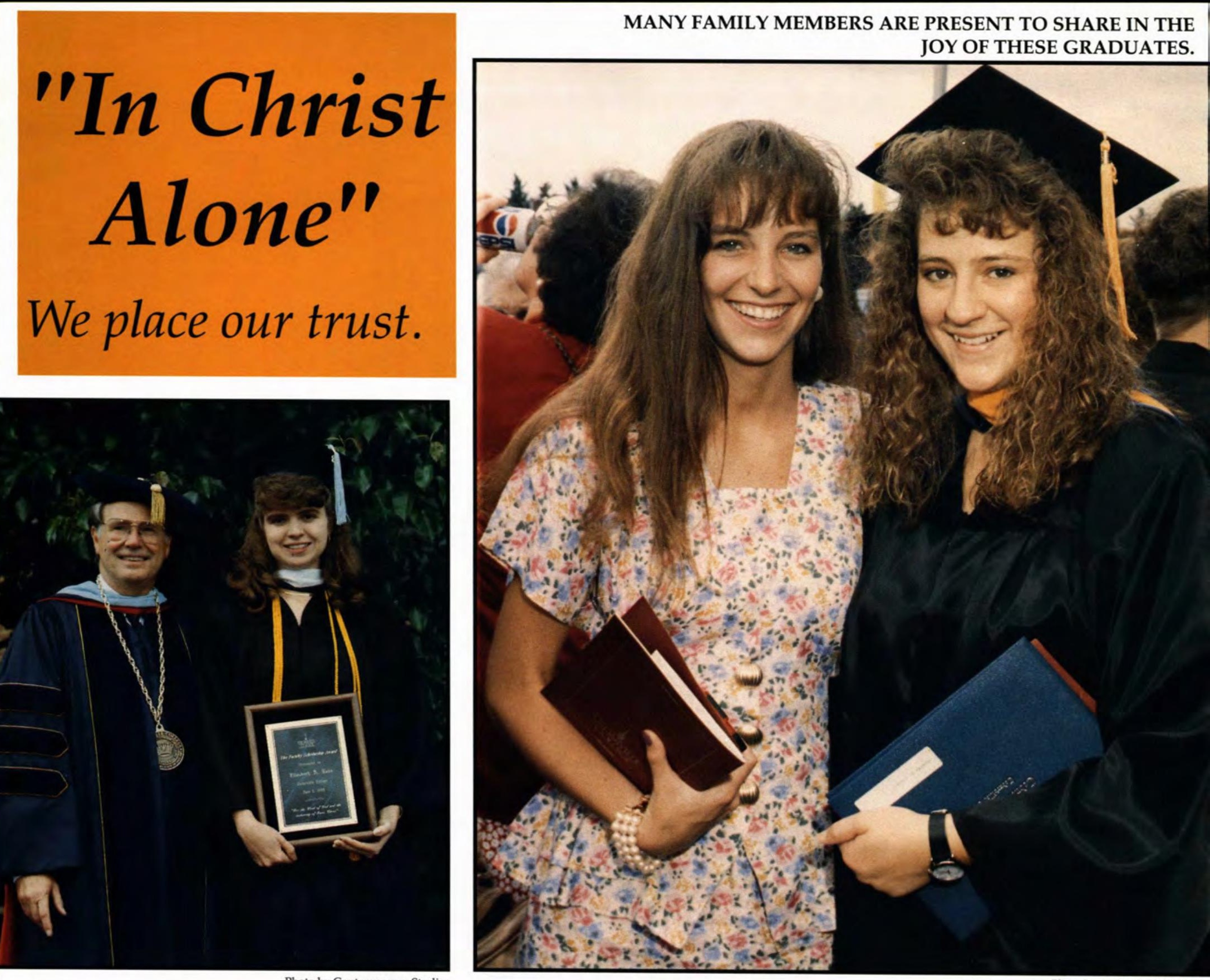

Photo by Contemporary Studios

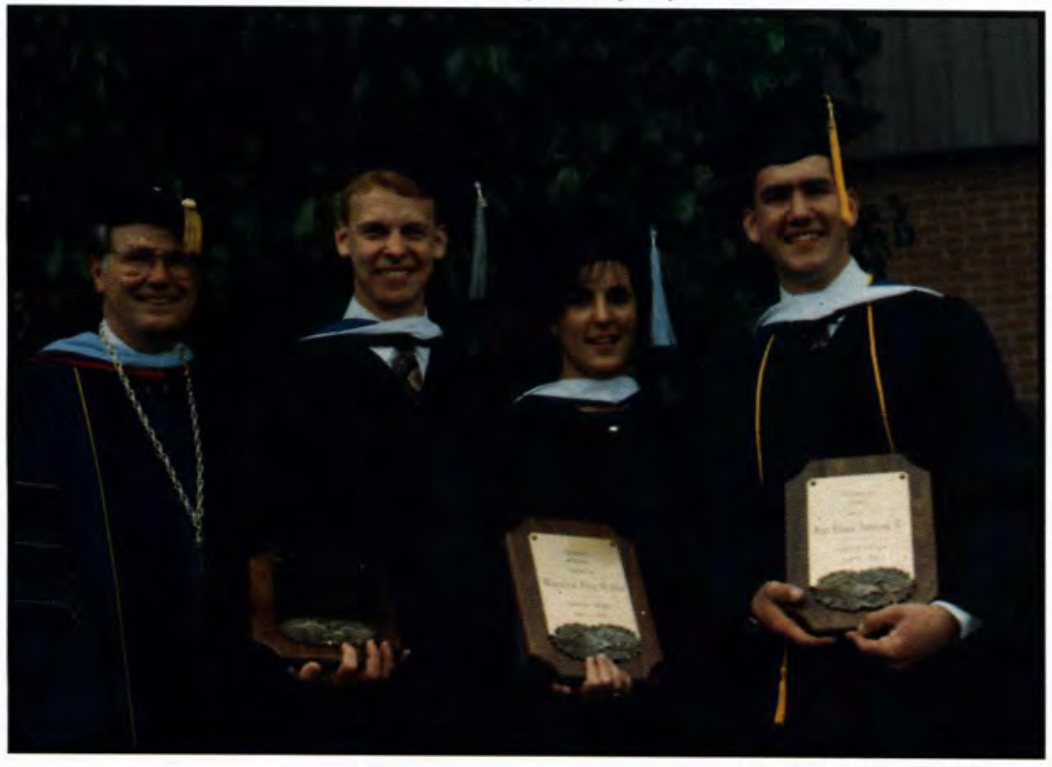

Photo by Contemporary Studios

Top: FACULTY SCHOLARSHIP AWARD WINNER, Elizabeth Lane, deserves her reward that was earned with much work.

PRESIDENT'S TROPHY WINNERS, Bill Montgomery, Kirsten Gibbs and Paul Anderson, invested many hours of service at the 194 Seniors college. 


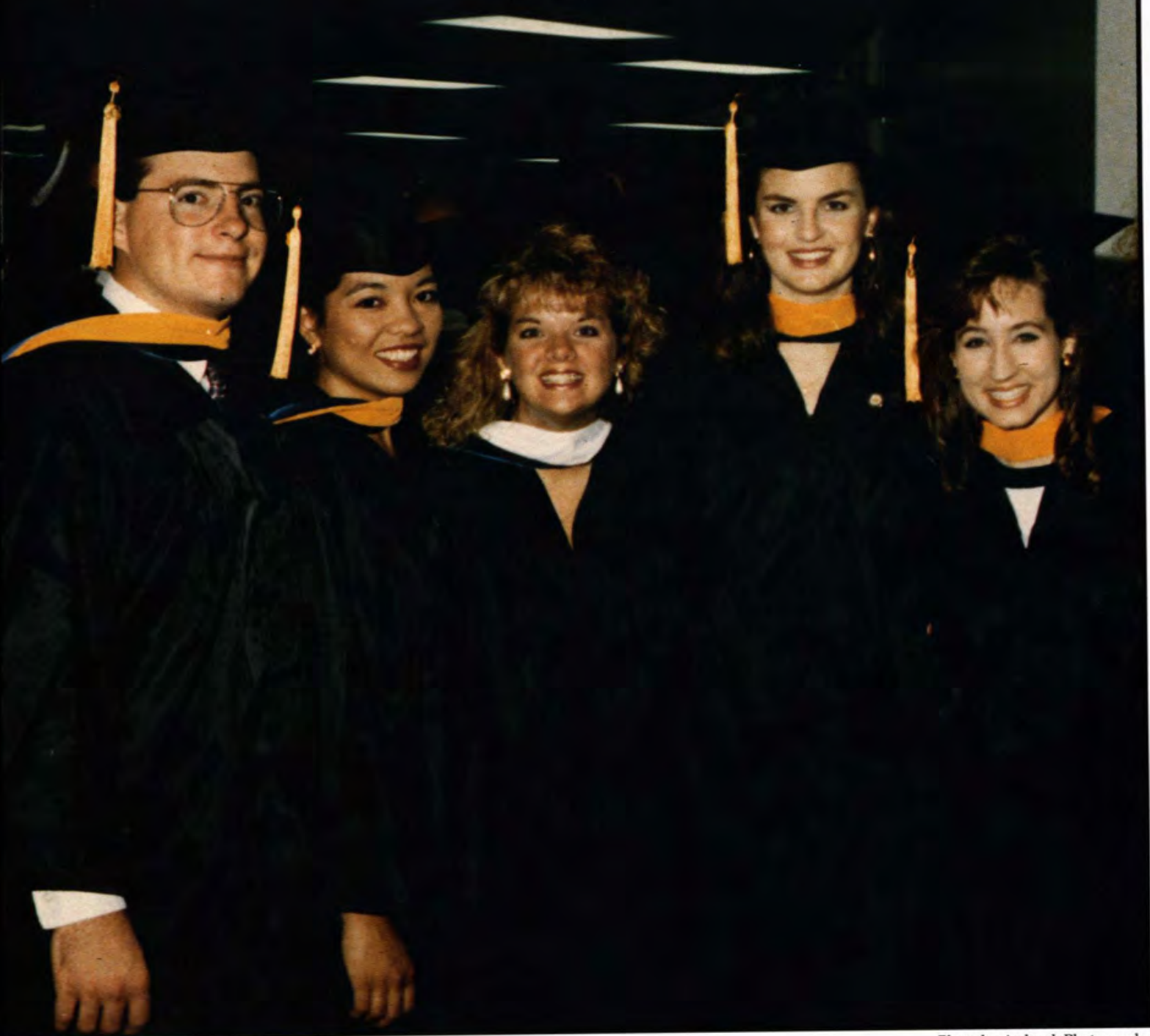

CEDARVILLE IS A GREAT

PLACE TO MAKE FRIENDS

FOR LIFE!

WITH HIS PEPSI Luman

Strong celebrates four years of

hard work and fun.

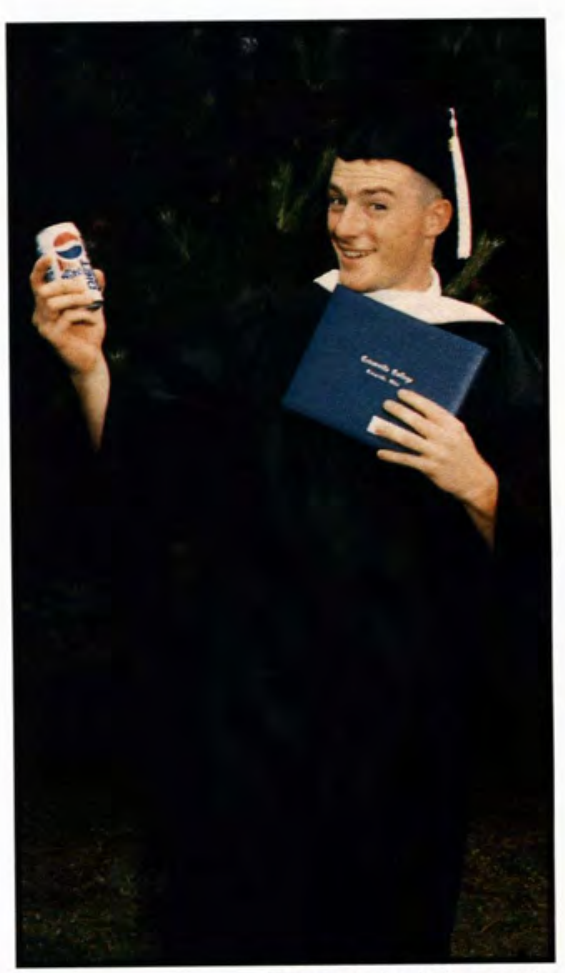

Photo by Ardvark Photography

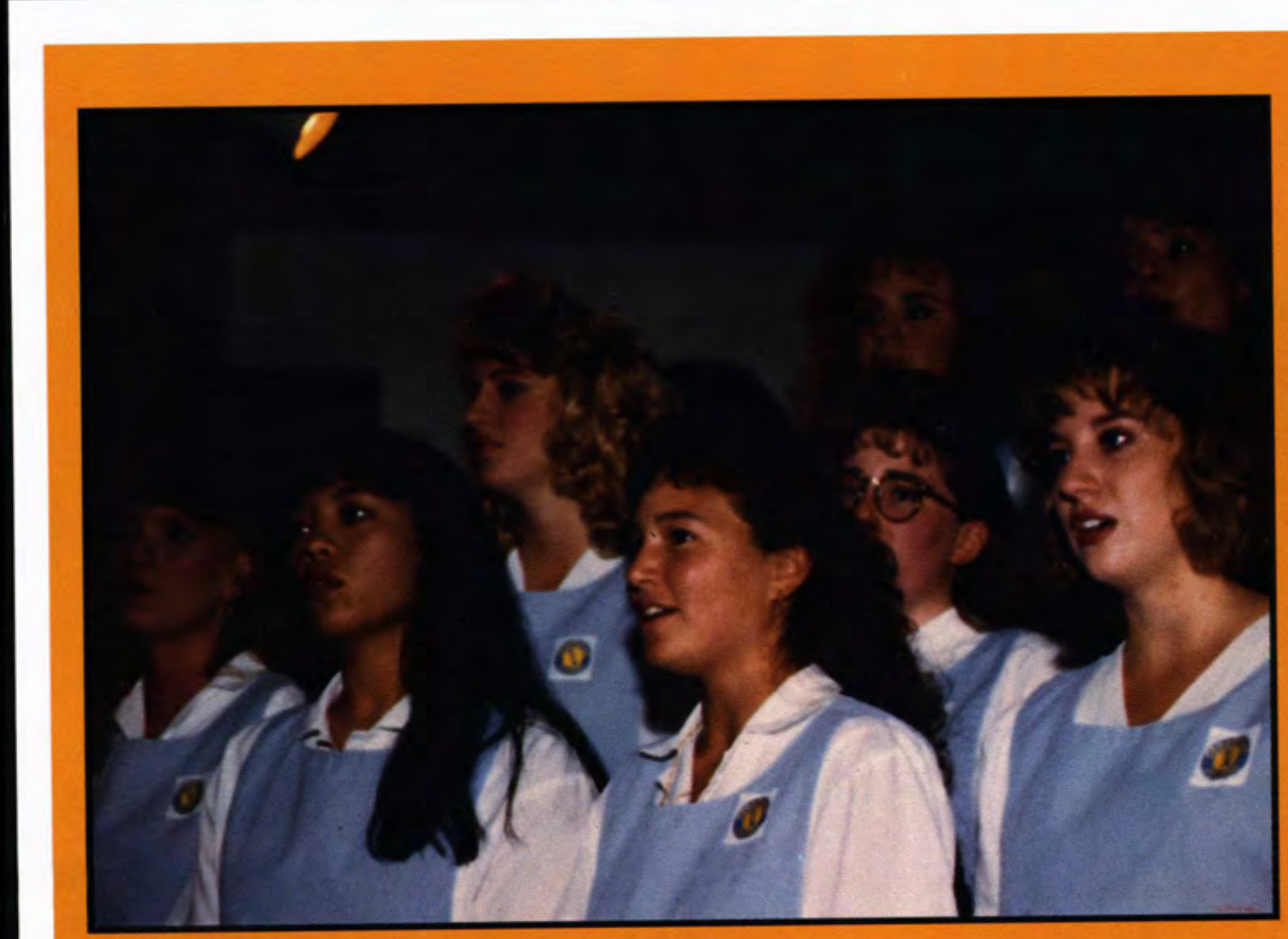

\section{Nurses' \\ Convocation}

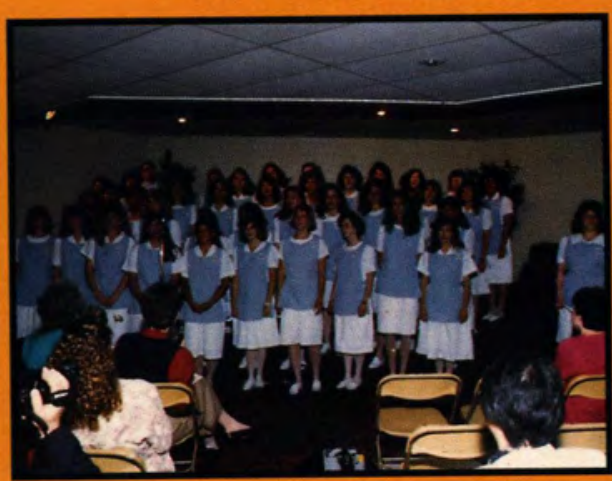

FORTY-FIVE NURSING MAJORS

received their pins from the Nursing

Department faculty.

USING THEIR MANY TALENTS,

the nursing students provided special music at the convocation. 


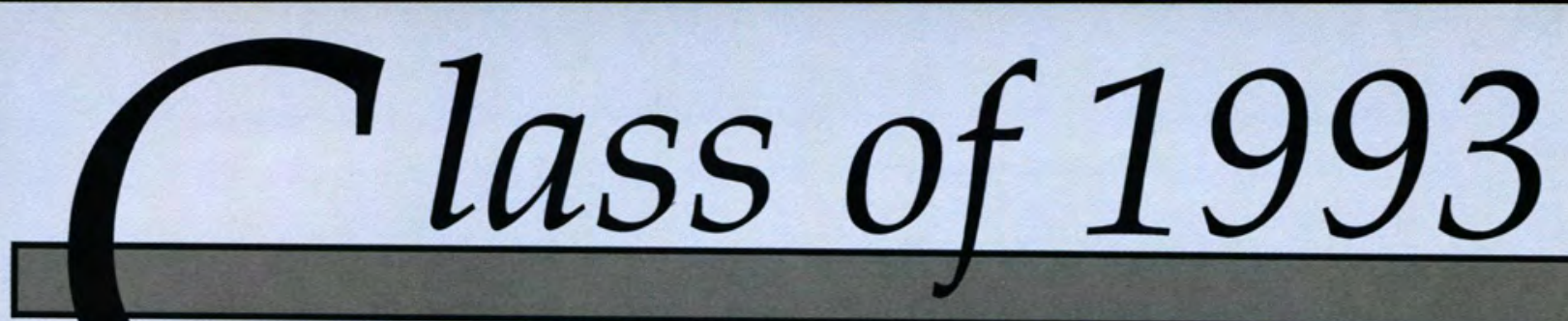

But be sure to fear the Lord and serve him faithfully with all your heart; consider what great things he has done for you. I Samuel 12:24

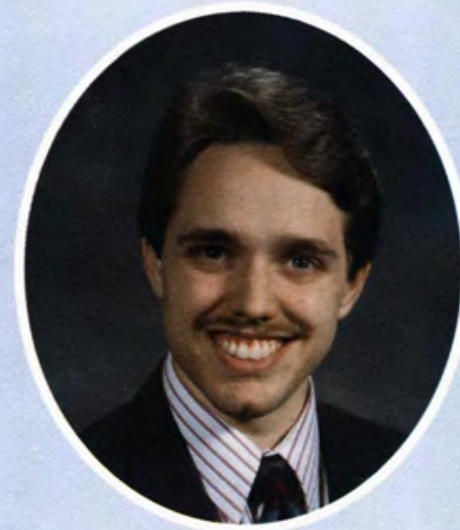

Laun Adams Accounting Akron, $\mathrm{OH}$

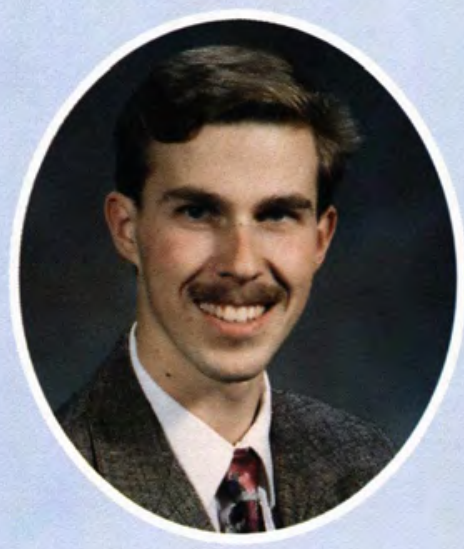

Timothy Alley History/Political Science Tacoma, WA

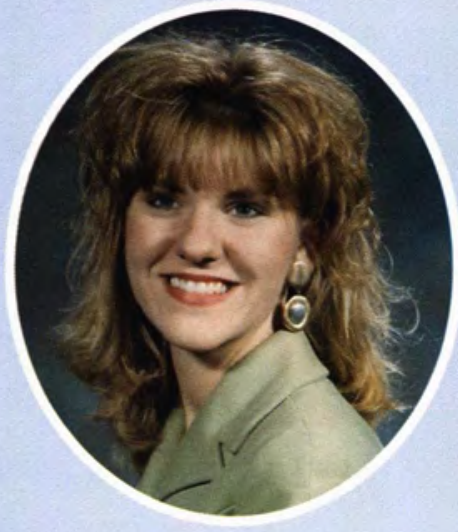

Dawn Ambrose Elementary Education Parma, $\mathrm{OH}$

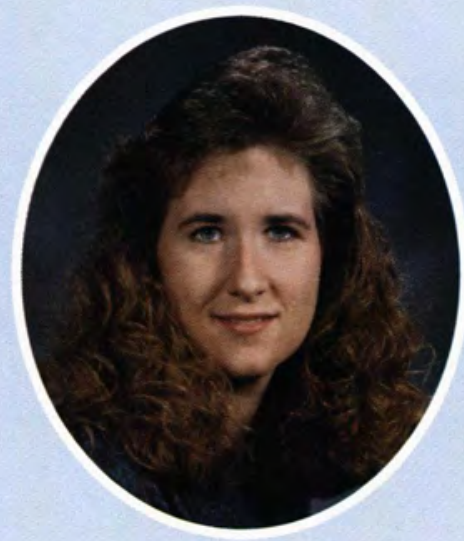

Donna Ademeit Elementary Education Indianola, IA

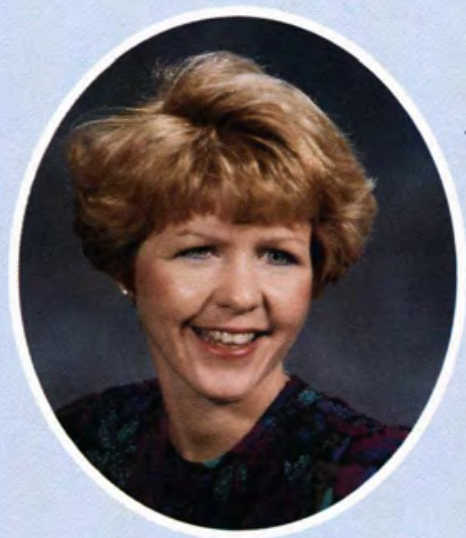

Crystal Allis Finance Rome, $P A$

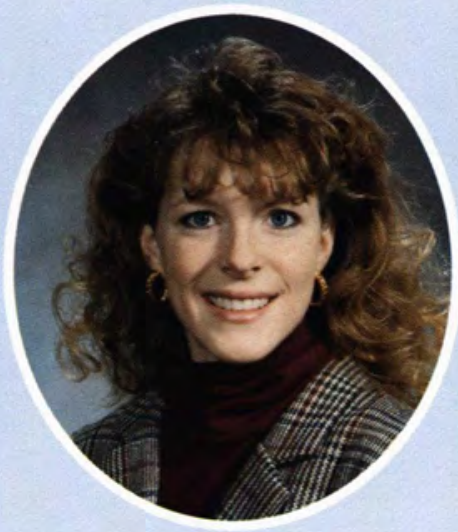

Dawn Anderson Elementary Education Cedarville, $\mathrm{OH}$

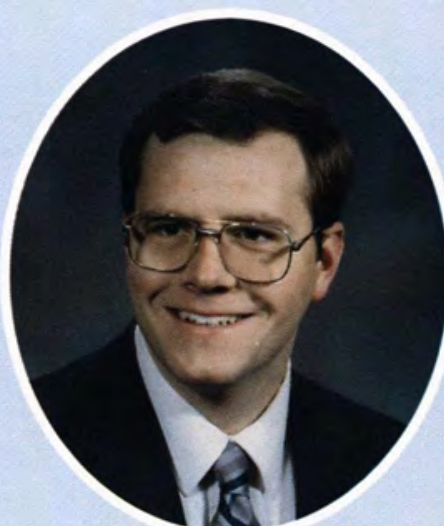

Nathan Adler Spanish Xenia, $\mathrm{OH}$

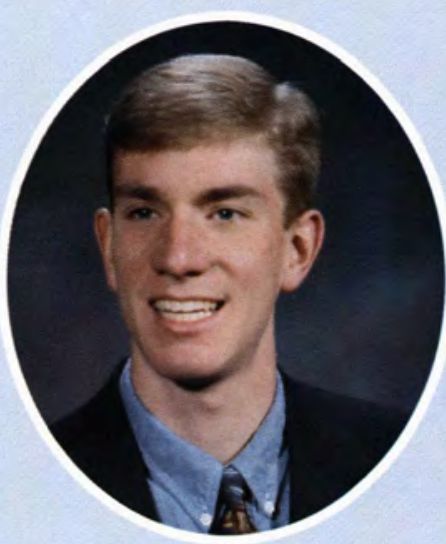

Jared Alsdorf Biology Spartansburg, PA

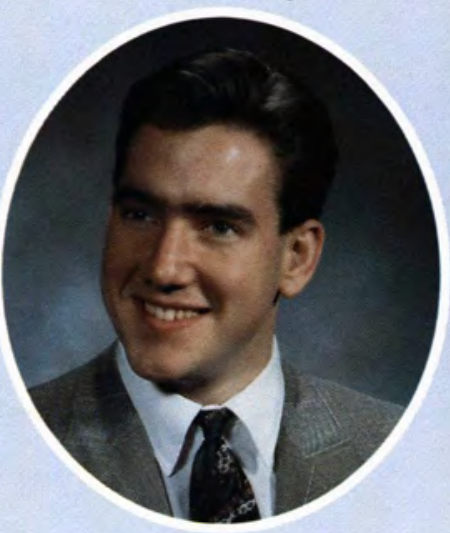

Paul Anderson, Jr. Mathematics Plymouth, MN

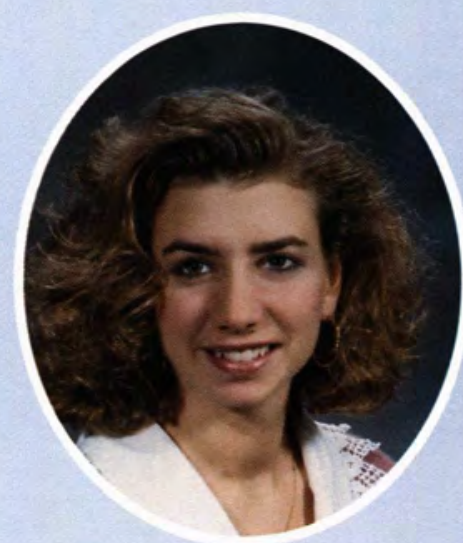

Tracy Allebach Accounting Telford, $P A$

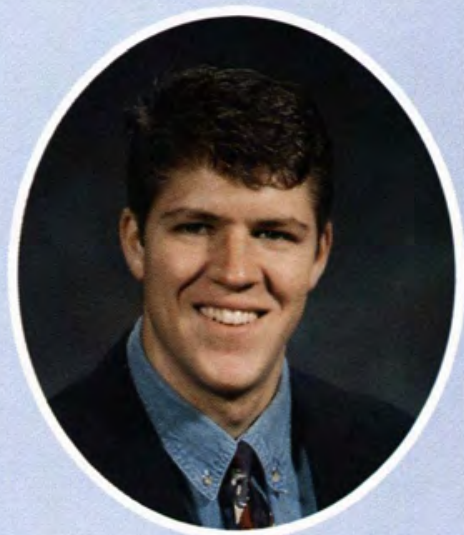

Dan Ambrose Social Science Parma, $\mathrm{OH}$

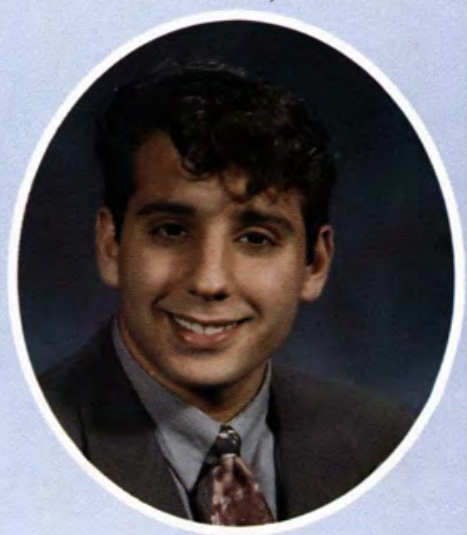

Michael Anthony History Fairborn, $\mathrm{OH}$ 


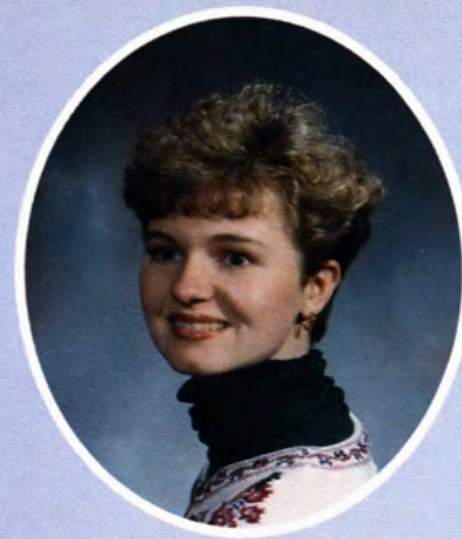

Susan Beach Elementary Education East Randolph, NY

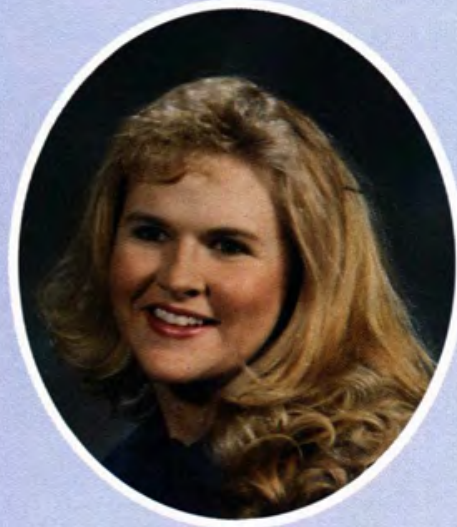

Jennifer Benefiel Elementary Education Mayfield, KY

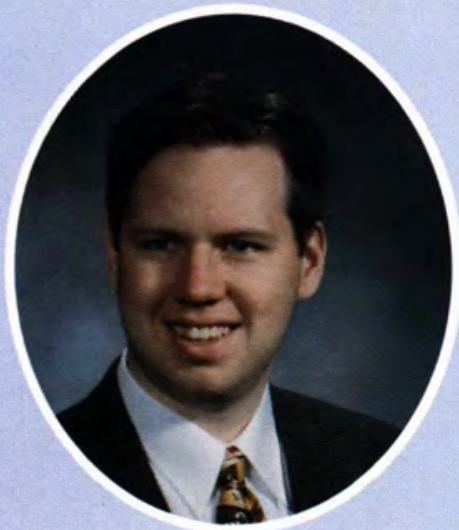

Brian Blackburn Marketing

Westerville, $\mathrm{OH}$

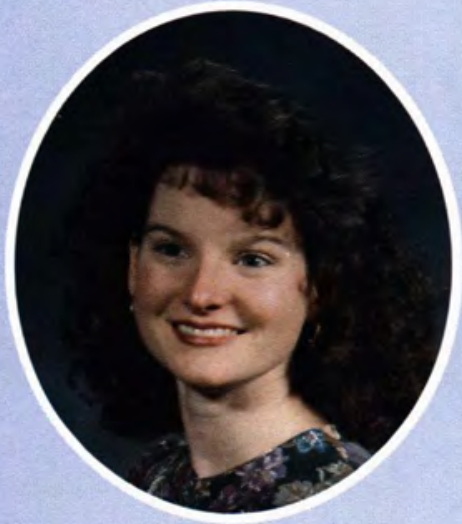

Jennifer Bond Nursing Norwalk, $\mathrm{OH}$

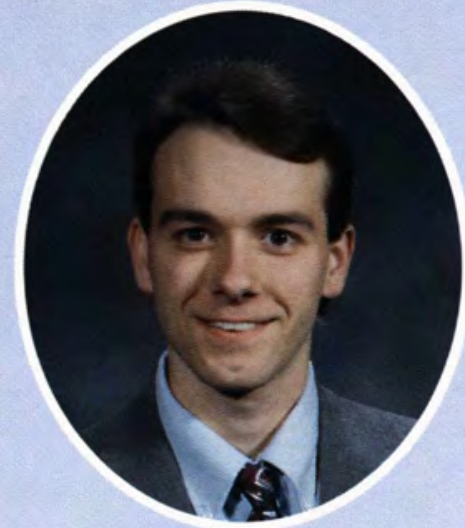

Kyle Beckelhymer Biology

Wallace, IN

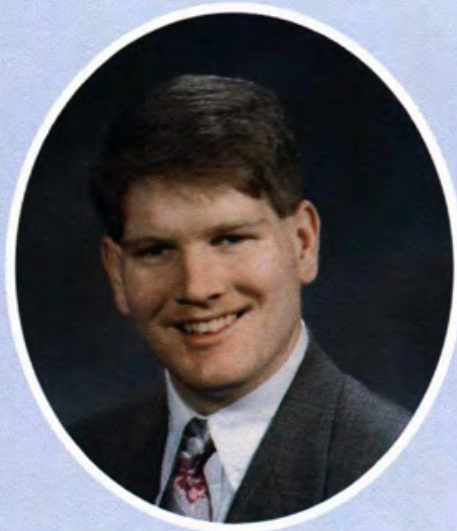

Erik Benson

Political Science/History Burt, MI

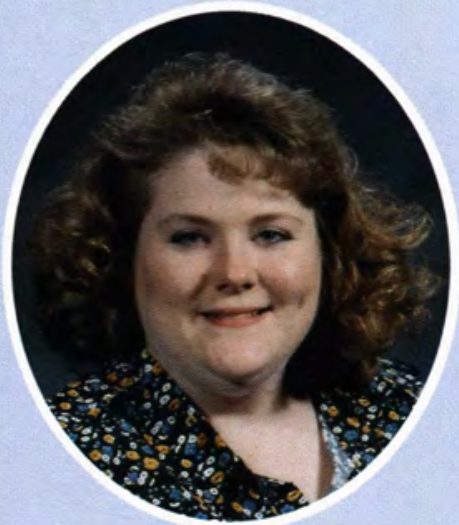

Sarah Blair

Elementary Education Mechanicsburg, $\mathrm{OH}$

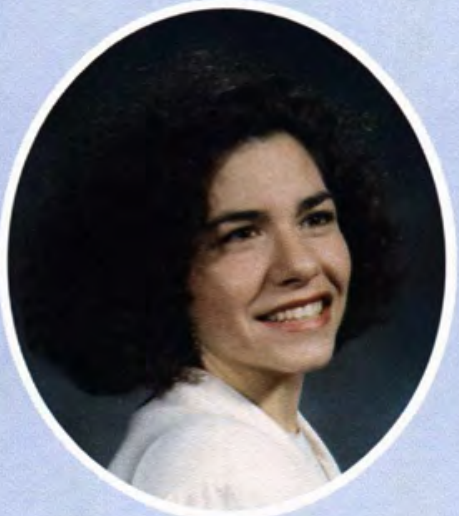

Nichole Bouchard Social Work Washington, MI

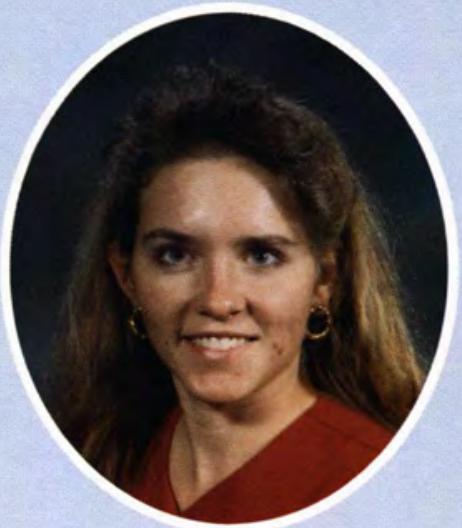

Gwendolyn Beebe

Social Work

Toledo, $\mathrm{OH}$

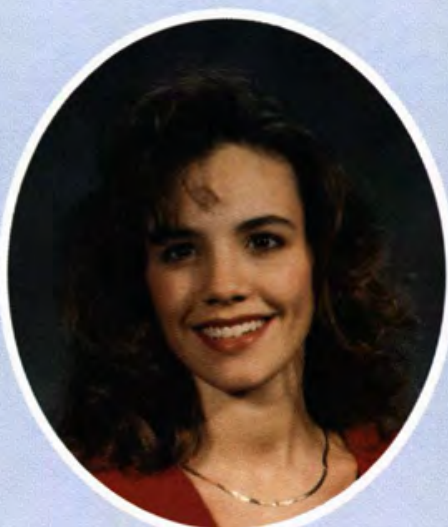

Danette Berry

Psychology

Baltimore, $M D$

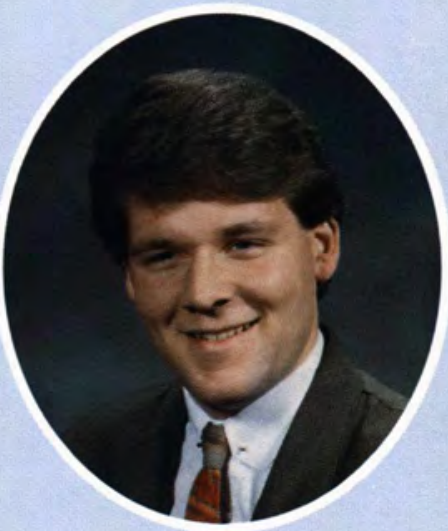

Steven Blanton

English Education

Urbana, $\mathrm{OH}$

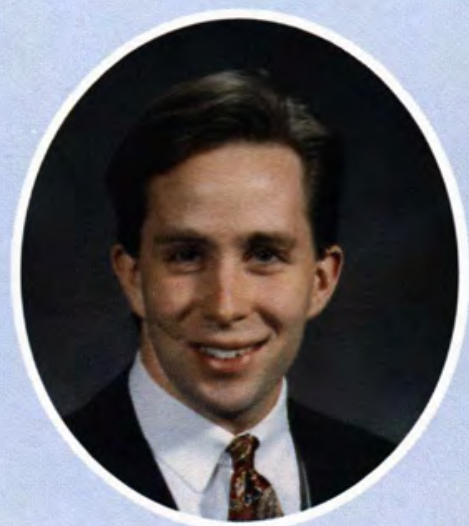

Scott Bowman

Marketing

Belmont, MI

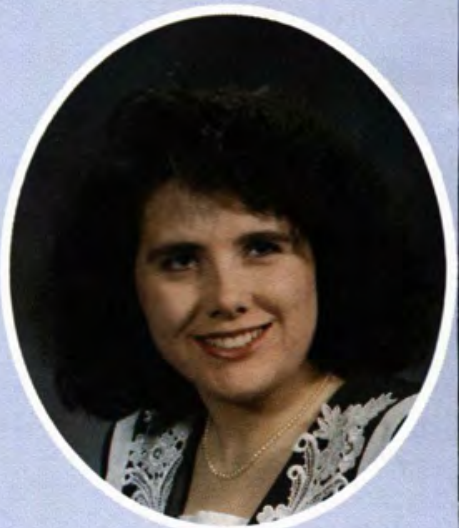

Lorynda Bender Behavioral Science Canandaigua, NY

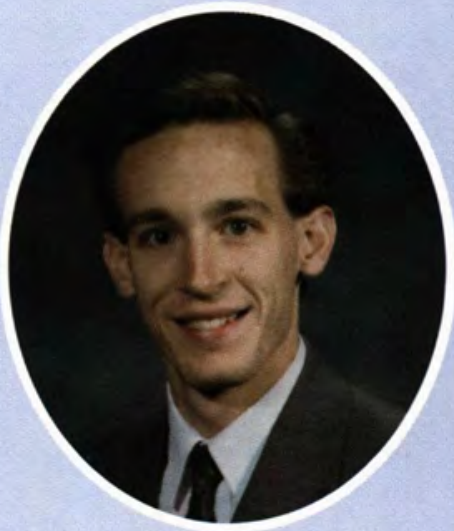

David Bishop

Computer Information Systems Aurora, CO

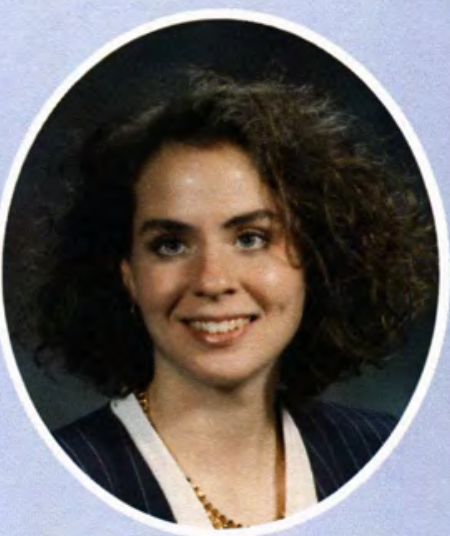

Sharon Bolender

Management/Marketing Cedarville, $\mathrm{OH}$

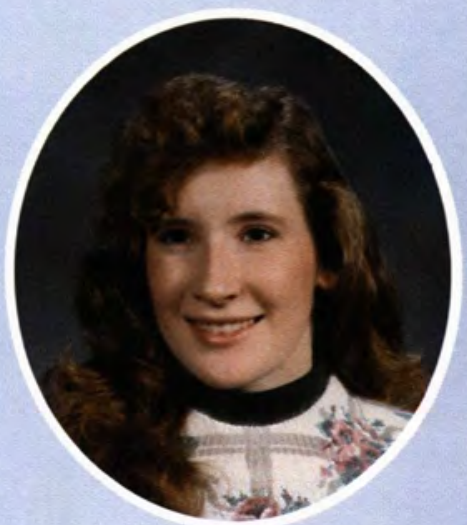

Julie Bracy

Elementary Education

Metamora, MI 


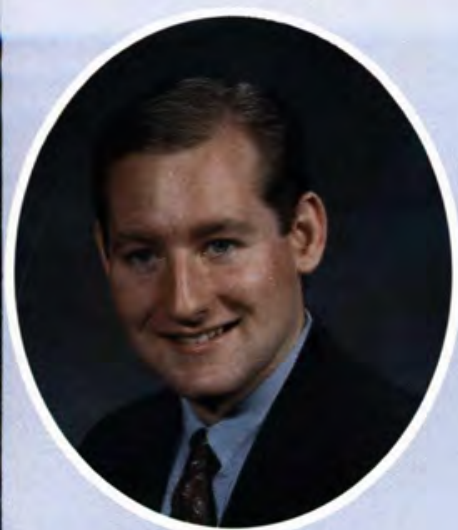

Matthew Brady Social Science/History

Lake Geneva, WI

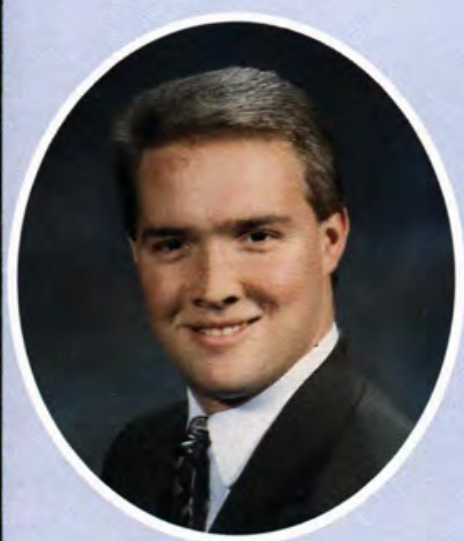

Stephen Brock

Communication Arts

Cedarville, $\mathrm{OH}$

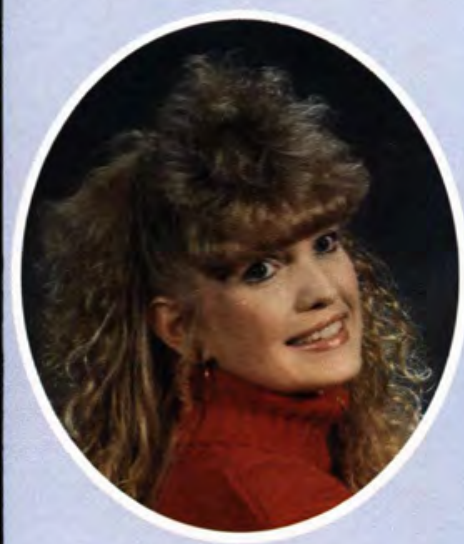

Kathy Brown

Nursing

Long Branch, WV

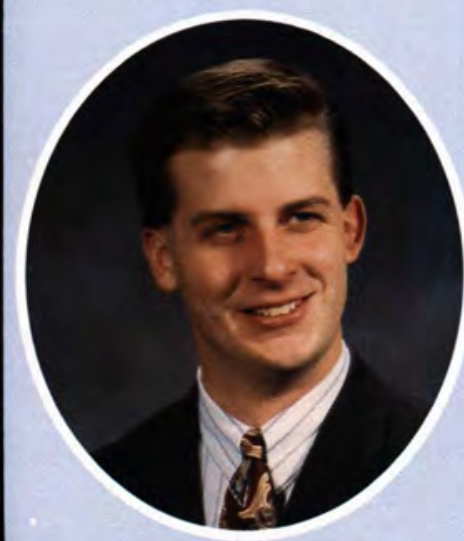

Matthew Brown

Psychology/Behavioral Science

Dayton, $\mathrm{OH}$

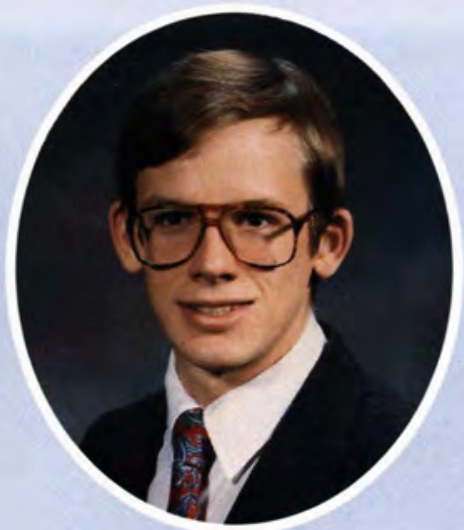

Jonathan Bretz

Elementary Education

Kettering, $\mathrm{OH}$

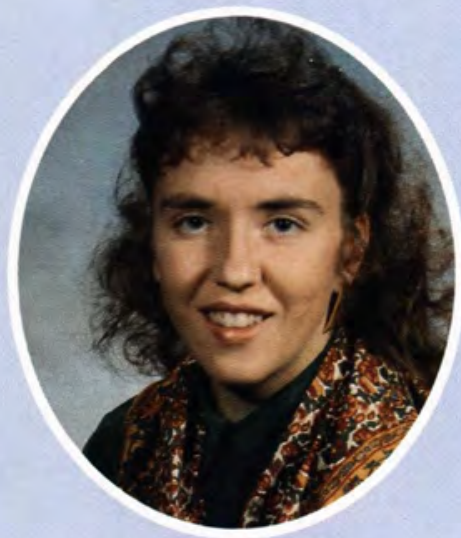

Cinnamon Brown

English

Fremont, IN

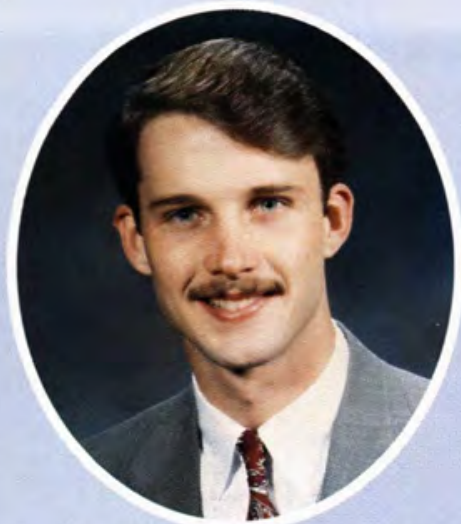

Brian Broaddus

English Education

Union Hall, VA

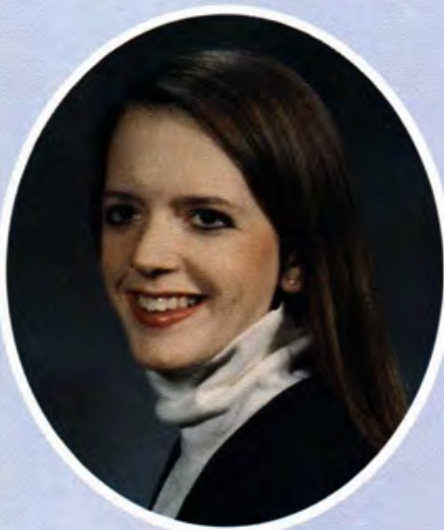

Darcey Brown

Management

Johnstown, $N Y$

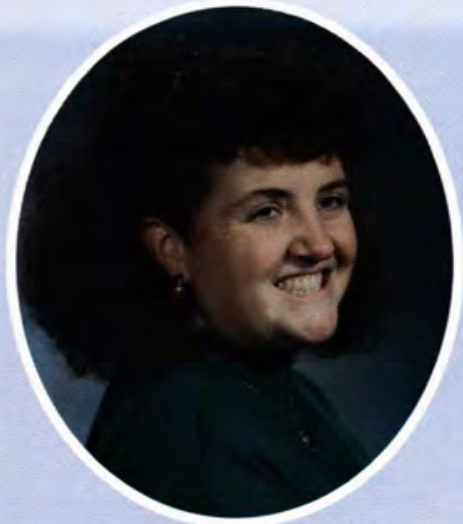

Allison Broadhead

Elementary Education

Mount Vernon, IN

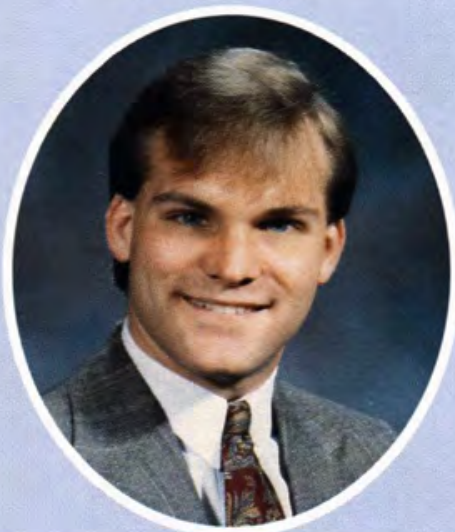

David Brown

Psychology/Behavioral Science

Sylvania, $\mathrm{OH}$

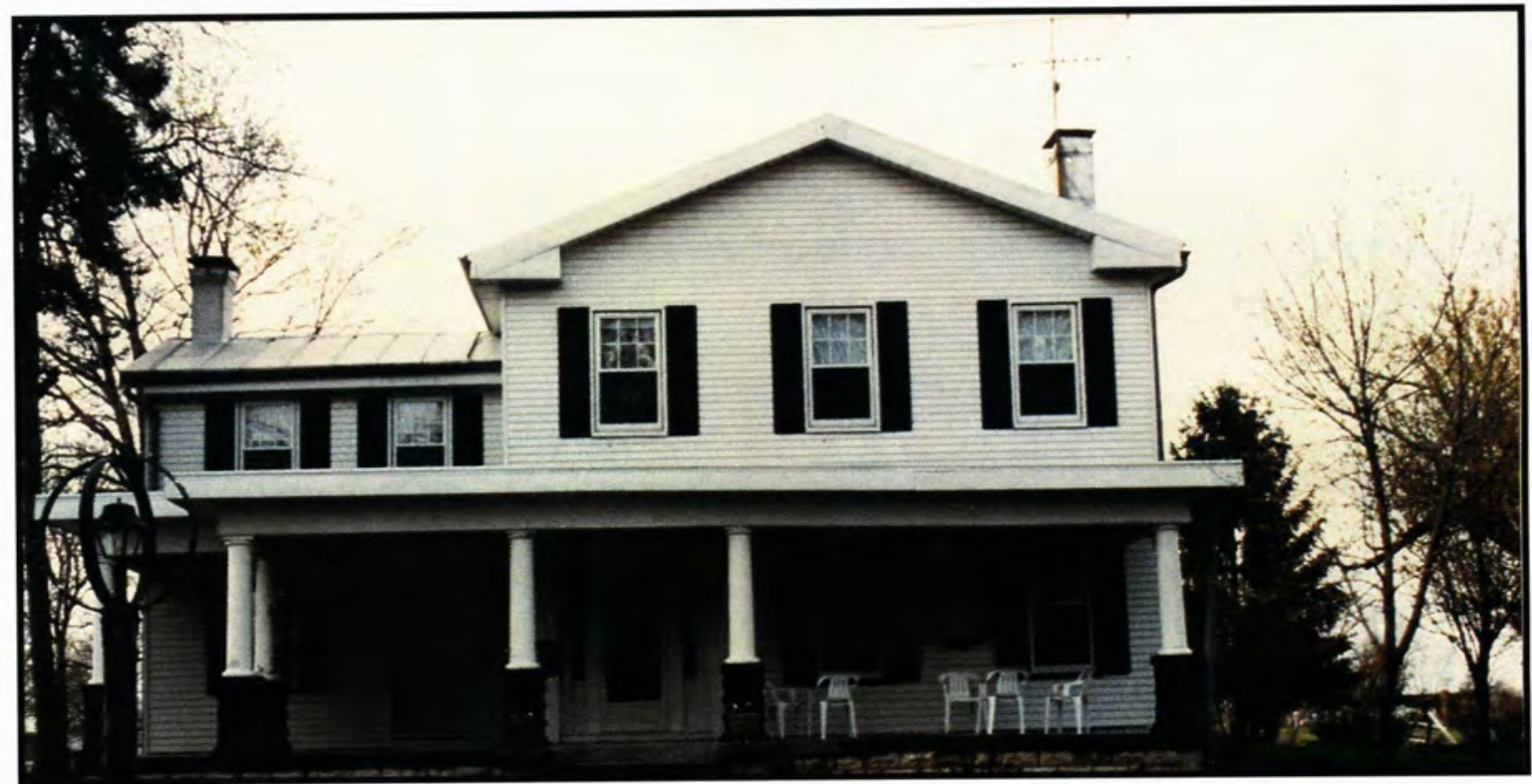

\section{Class of '93 Helps Restore Guest House}

For their "Barney's Week" project during the spring of 1992, the Class of '93 helped restore the house where the first group of Cedarville students met for classes when the college began. The Gibbs family moved to the village last year and bought the old house with plans to repair it and make it available as a place for parents and alumni to stay while visiting the college.

With the help of several students from the Senior class, the Gibbs were able to fix the house up so that they could open their now beautiful home to college visitors in September of 1992. The students enjoyed helping and were thankful for the opportunity to play a part in the restoration of the old house. Their services during the spring of 1992 now allows the Gibbs' Guest House to provide a continual ministry of hospitality to those who stay there.

-Kathleen Coy 


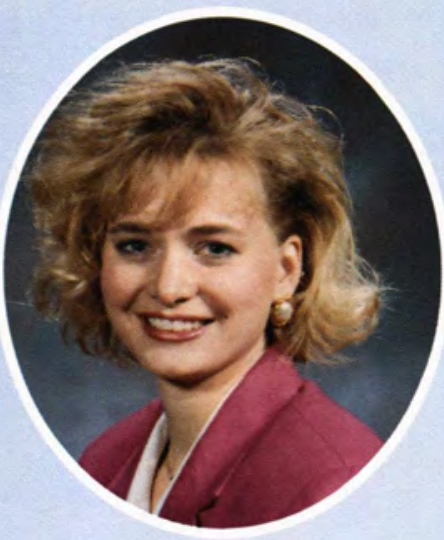

Priscilla Brown

Communication Arts

Edwardsburg, MI

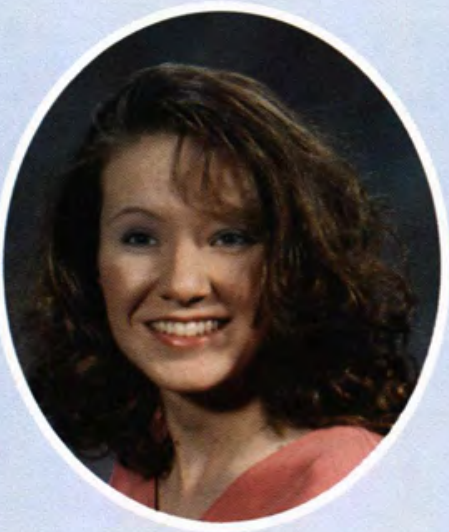

Julie Buckley

Applied Psychology

Aurora, IN

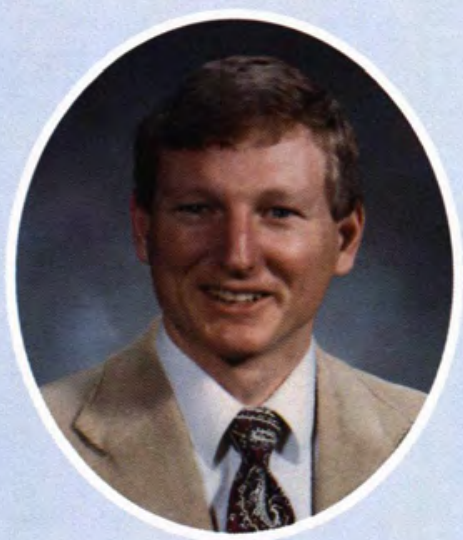

Randall Burton

Bible, Comprehensive

Dayton, $\mathrm{OH}$

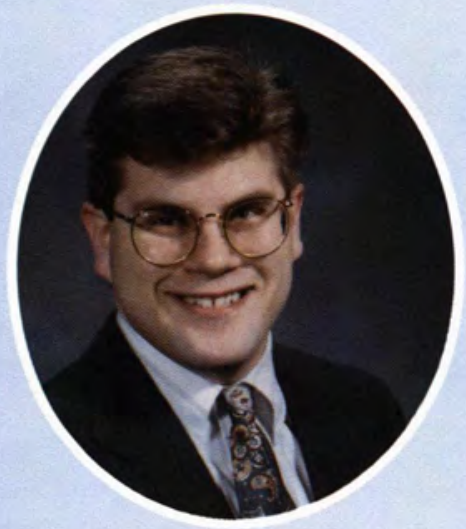

Nathan Cesal

Mathematics

Wisconsin Rapids, WI

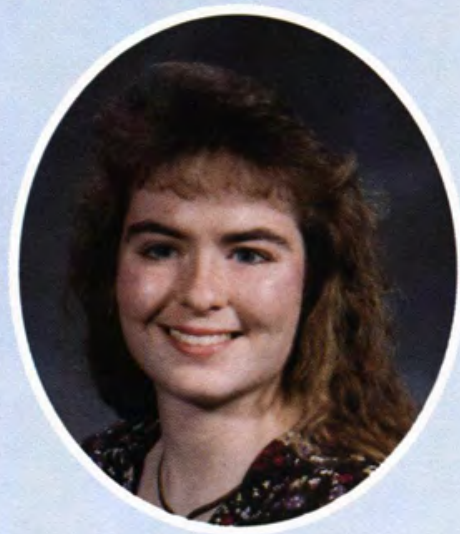

Stephanie Brown

Elementary Education

Easthampton, MA

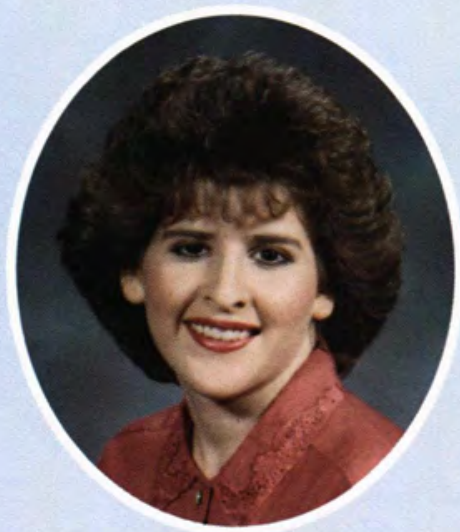

Julie Buentello

Communication Arts

Framingham, $M A$

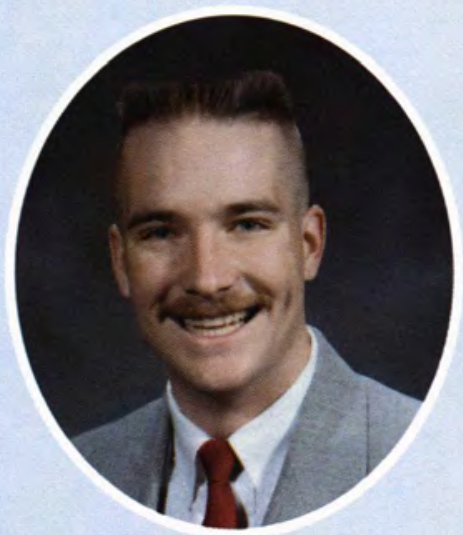

Jaden Callahan

Marketing

Lima, $\mathrm{OH}$

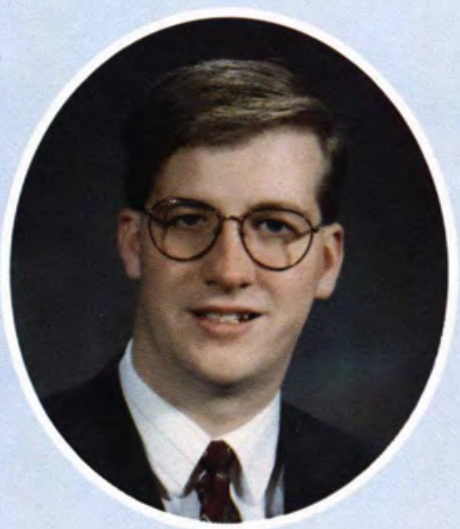

Gary Childers

Bible, Comprehensive

Jackson, $\mathrm{OH}$

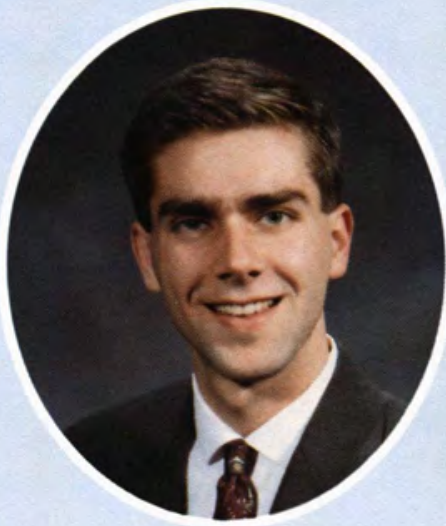

Matthew Bruckner

Marketing

Londonderry, $\mathrm{NH}$

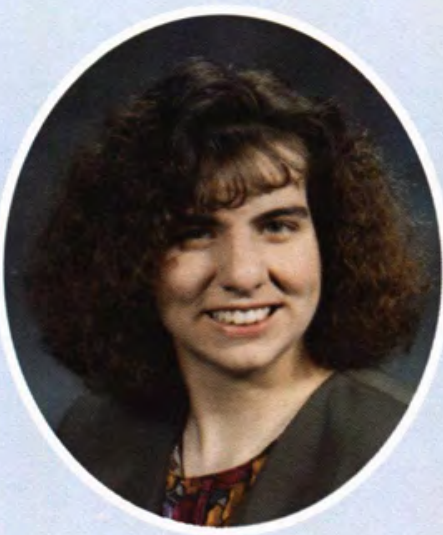

Tara Burns

Chemistry

East Rochester, $\mathrm{OH}$

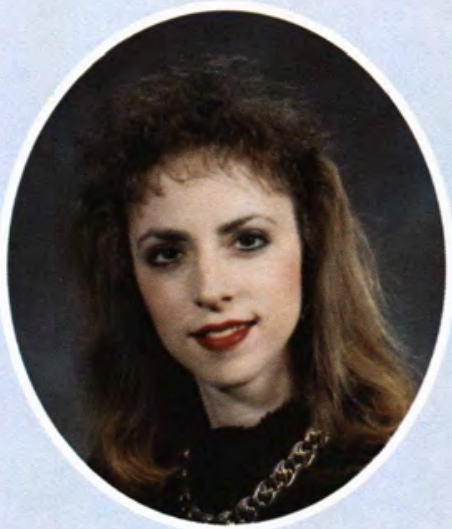

Michelle Canine

Elementary Education

Garland, TX

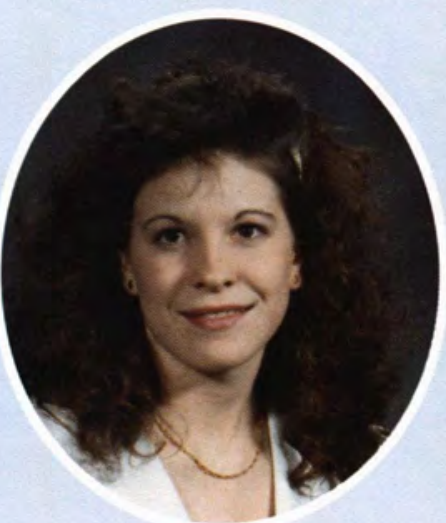

Melinda Clapper

Elementary Education

Lima, $\mathrm{OH}$

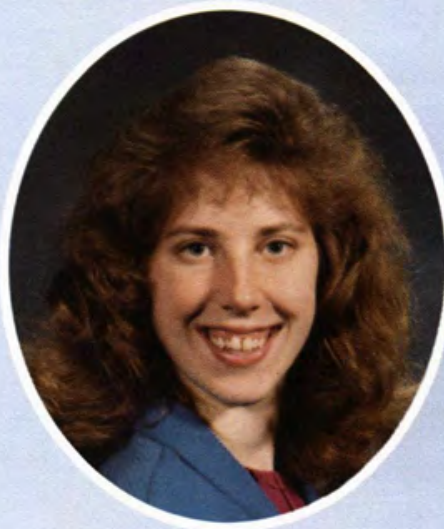

Susan Brunton

Mathematics

Clarksville, $\mathrm{OH}$

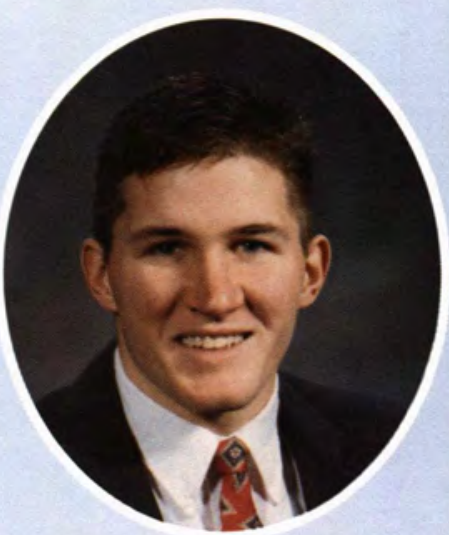

Jeffrey Burr

Bible, Comprehensive

Oxford, MI

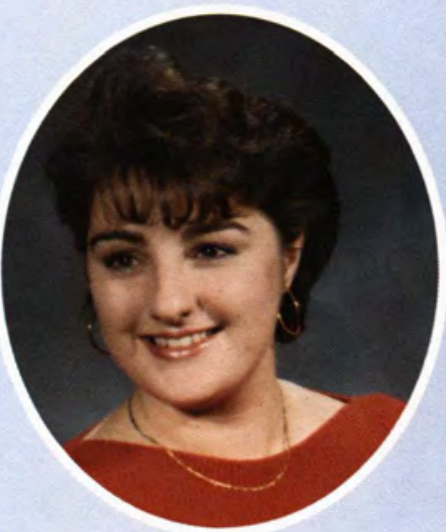

Angela Carson

Elementary Education

Centreville, NB

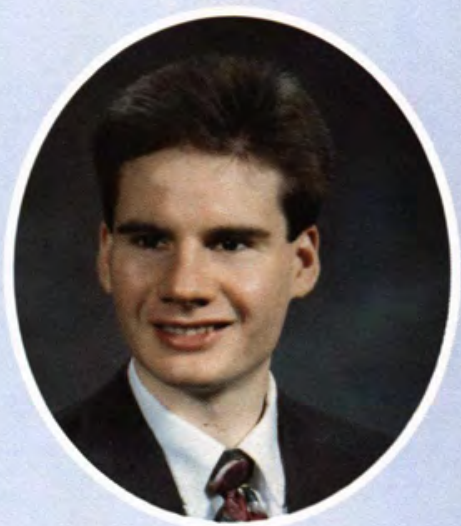

Alexander Clow

Criminal Justice

Springfield, $\mathrm{OH}$ 


\section{Not An Accident}

On the morning of Friday, October 30,1992, Diane Jones and Brian Smith ate breakfast and argued -- they argued about how sovereign God is. Diane maintained that because God is in complete control of all circumstances, there are no accidents. Brian disagreed, but in a letter to Dr. Dixon on Saturday, he admitted that through unusual means, Diane won the argument. On her way to work in Xenia, Friday afternoon, Diane was involved in a car accident that claimed her life.

Her death sent shock waves and grief through the student body as friends mourned and all were reminded of the brevity of life.

In a chapel memorial service, the Monday following her death, even students who did not know Diane were challenged by the testimony of her life. Diane's life exemplified a thankful spirit, a devotion to prayer, and a burden for the lost that compelled her to go out on Open Heirs every Friday. Her roommate, Jennifer Bond, said Diane had a huge cardboard box in the shape of a heart in her closet. Diane would write the names, dates, and prayer requests of people she talked to on $3 \times 5$ cards and place them in the heart.

Diane's goal in life was to live a life pleasing to God. A poem found in her room prayed, "Dear God, Help me be a good sport in this game of life." Diane left her life in God's hands desiring that the trial of her faith "result in praise, glory, and honor when Jesus Christ revealed" (I Peter 1:7, NIV). Diane was a good sport and no part of her life or death happened by accident.

Her death reminded the entire college family of the brevity of life. No one is guaranteed tomorrow. Thus, Dr. Dixon challenged all to sell out to God. Diane's prayer life and walk with God were not an accident. She decided to serve Him and she made a conscious effort to follow through on her decision. She dedicated Romans 12:11-12 to this year as a challenge to remain faithful: "Never be lacking in zeal, but keep your spiritual fervor, serving the Lord. Be joyful in hope, patient in affliction, faithful in prayer." Though the reasons why God called Diane home may never be evident, we know that "He Maketh No Mistake," and we rejoice that she now stands with her sovereign Lord who allows no accidents.

-Marsha Olsen
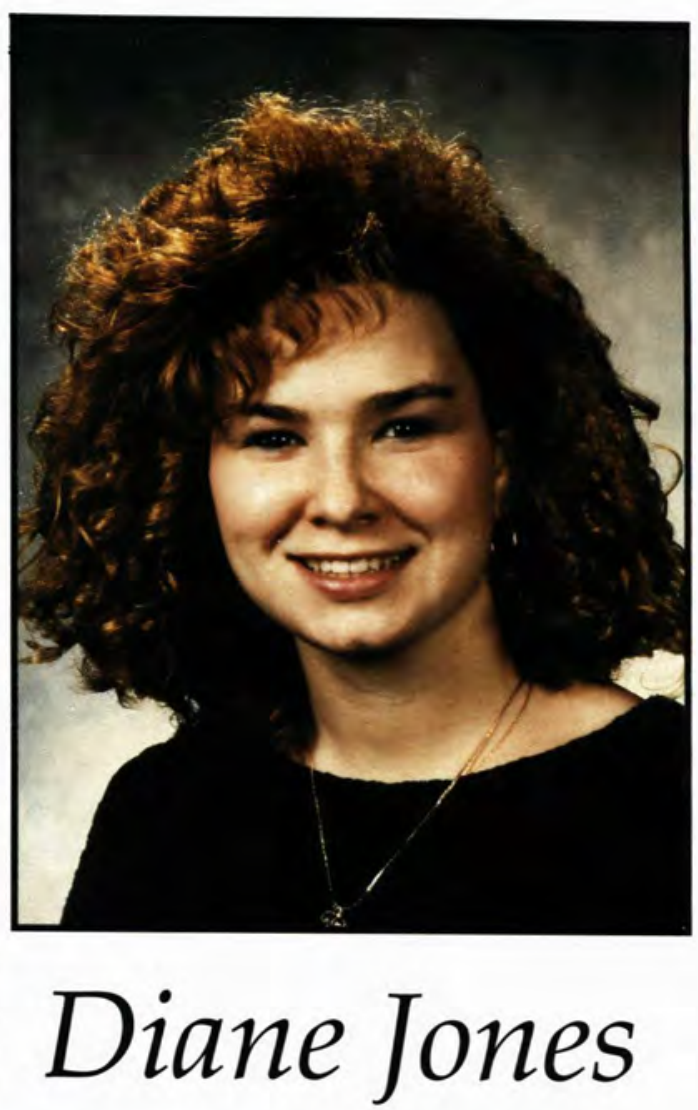

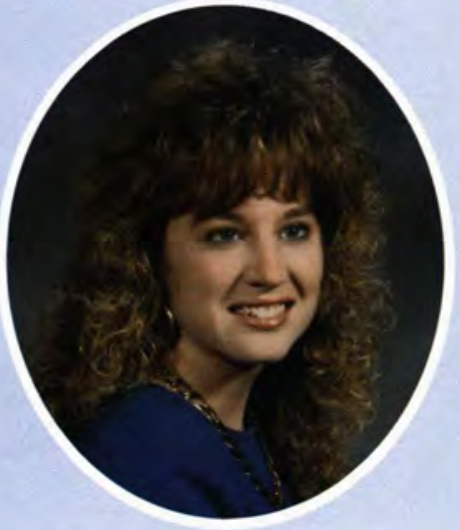

Julie Daugherty

Nursing

London, $\mathrm{OH}$

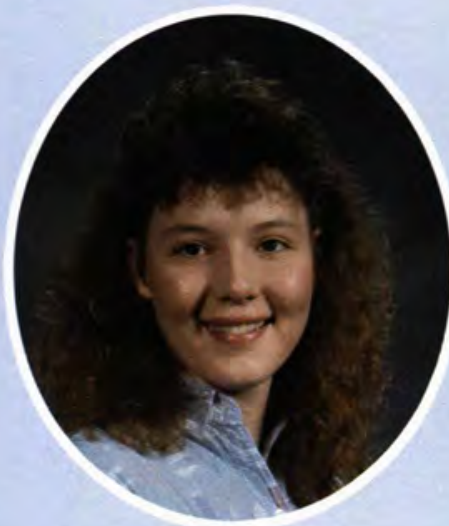

Susan Denlinger

Elementary Education

West Milton, $\mathrm{OH}$

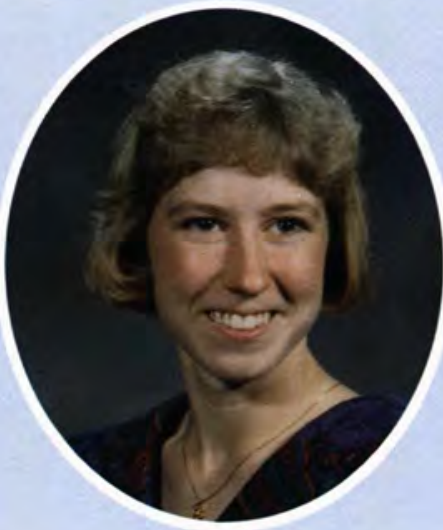

Kari Davidson

Nursing

Lebanon, $\mathrm{OH}$

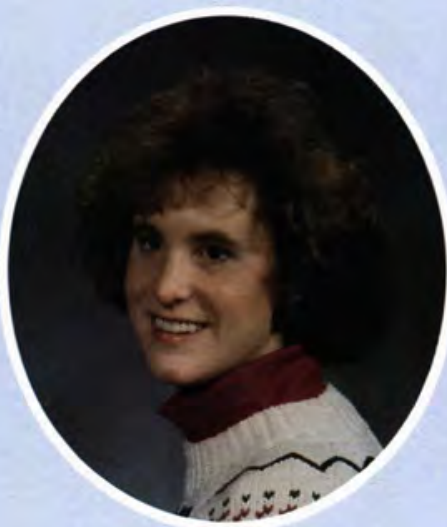

Melinda Derks

Nursing

Holland, MI

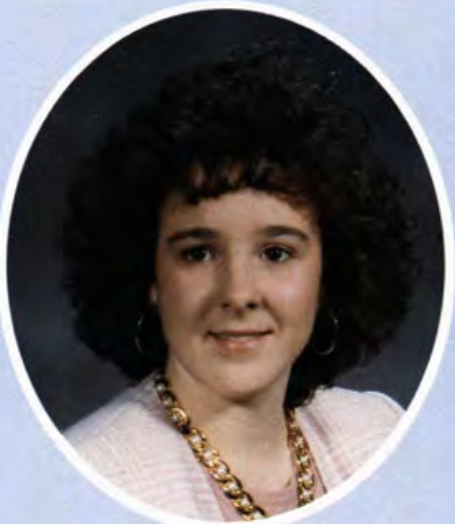

Cheryl Davis

English

East Machias, ME

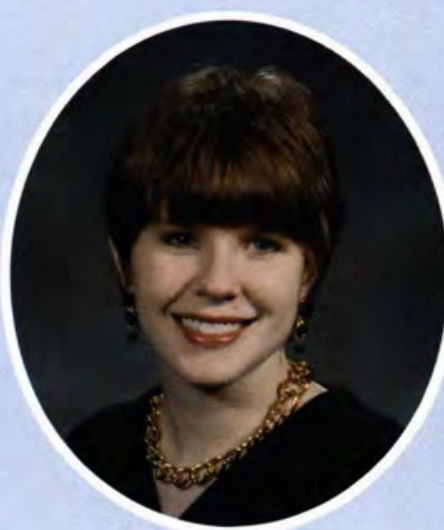

Karen Dieter

Marketing

Willowick, $\mathrm{OH}$

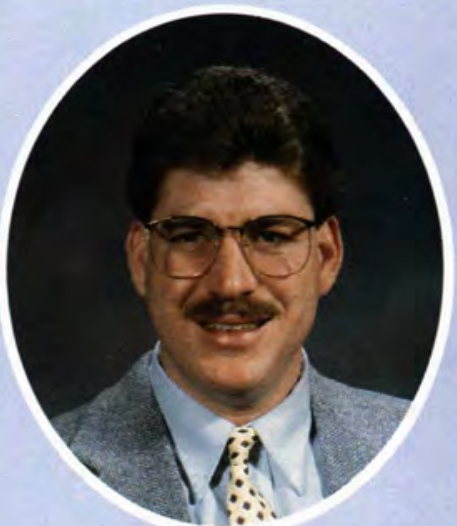

Dennis Davis Bible, Comprehensive Washington Court House, $\mathrm{OH}$

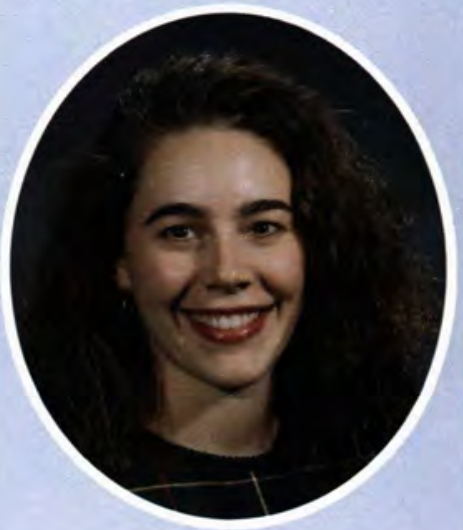

Amy Dirr Nursing Hamler, $\mathrm{OH}$ 


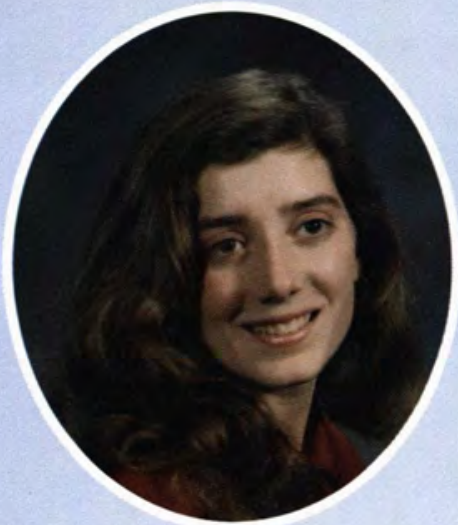

Michelle Ferrigno

Mathematics

Littleton, $\mathrm{CO}$

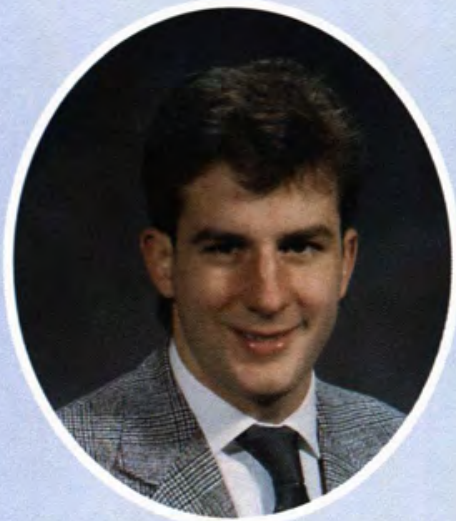

James Foster

English Education

Syracuse, NY

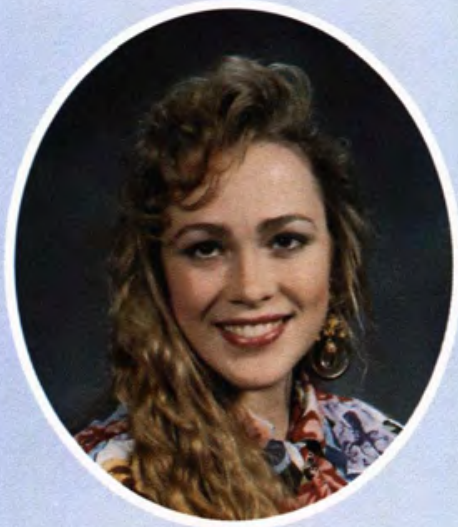

Heather Fulton

Physical Education

Newton Falls, $\mathrm{OH}$

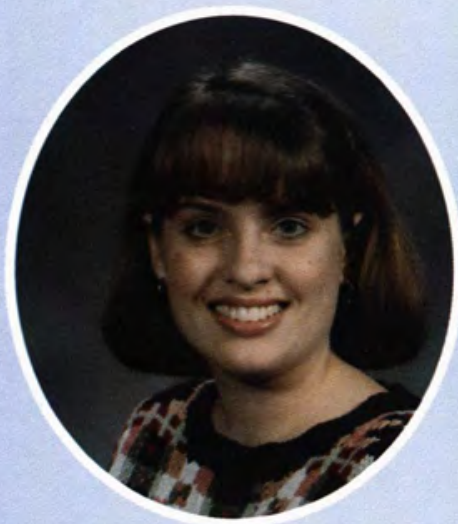

Amy Geiger

Nursing

New Carlisle, $\mathrm{OH}$

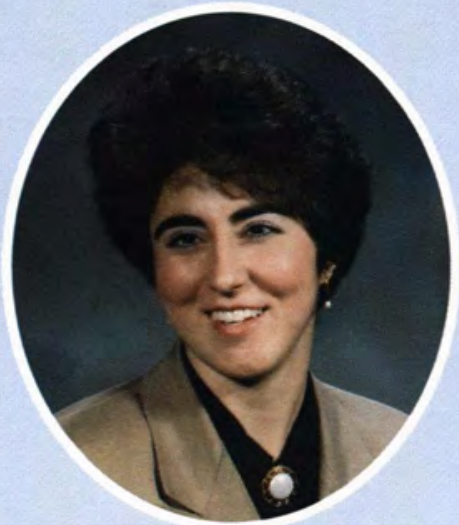

Shelley Fiorito Biology

Rochester, NY

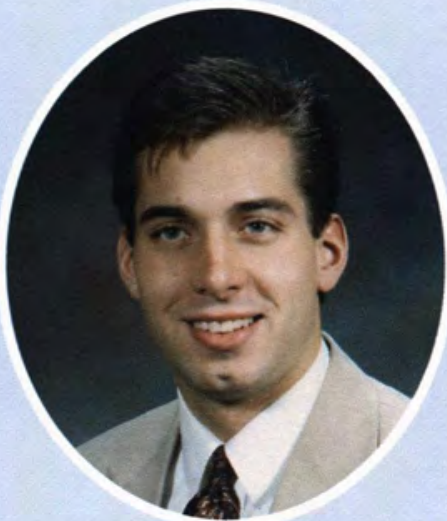

William Francis, Jr.

Pyschology

Henderson, $K Y$

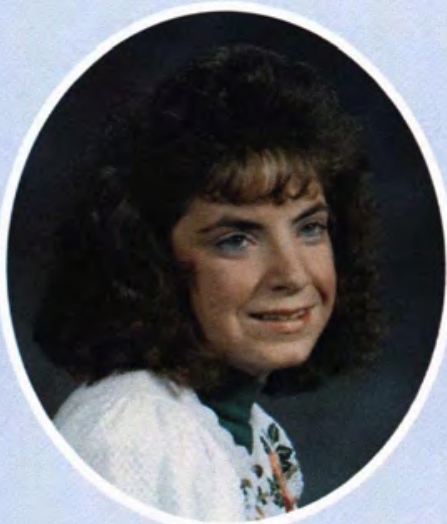

Brenda Furman

English Education

Binghamton, $N Y$

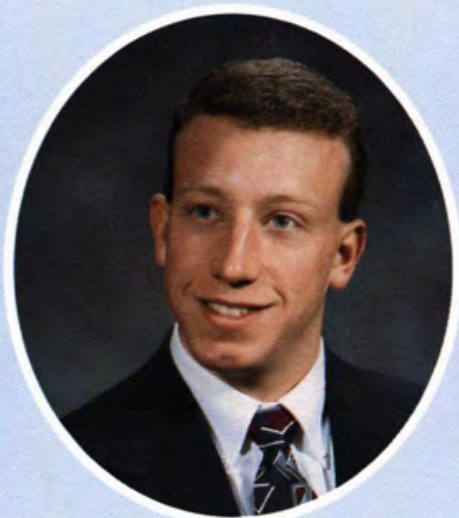

James Geise

Computer Information Systems Northumberland, PA

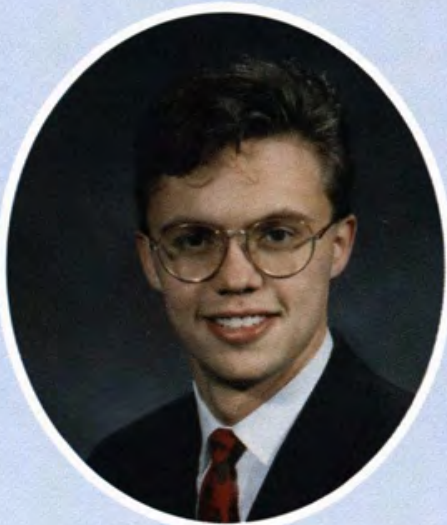

Randall Fleenor Accounting

Churubusco, IN

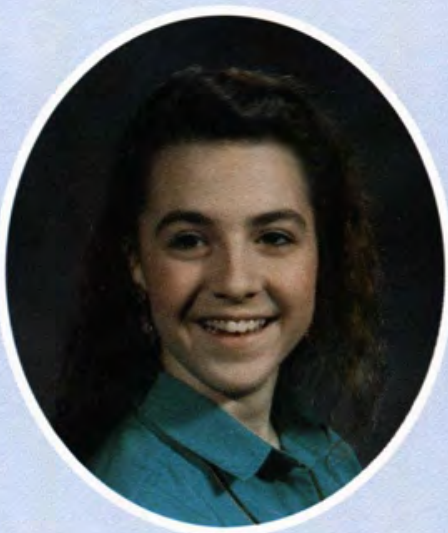

Kassandra Fry Nursing

Corss Lanes, WV

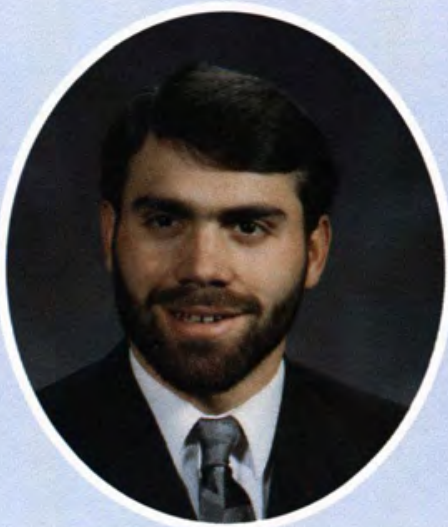

Dana Furman Biology

Lancaster, CA

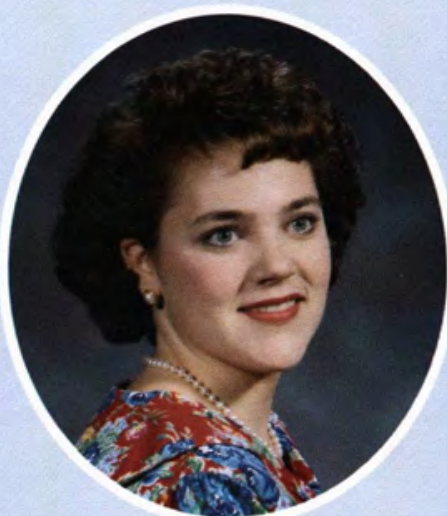

Gabrielle Gerber

Elementary Education

Winona Lake, IN

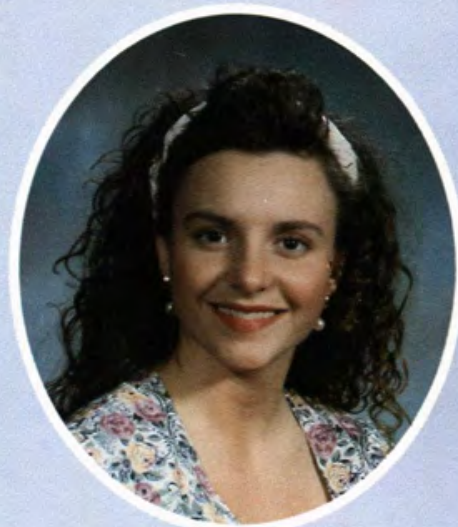

Elizabeth Foster Nursing

Baltimore, MD

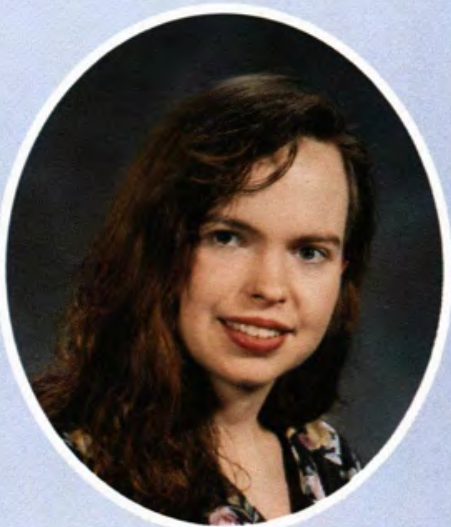

Elizabeth Fulton

Marketing

Troy, $\mathrm{OH}$

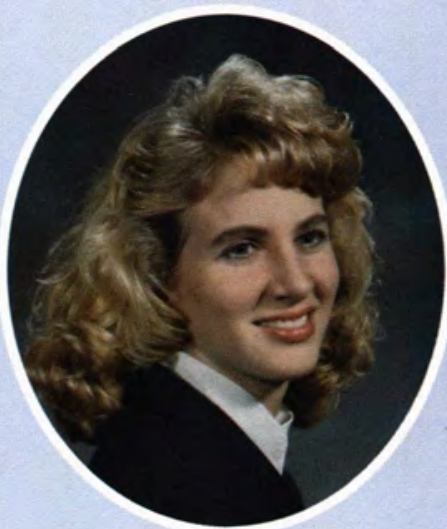

Kathleen Gasparro Nursing

Mt. Ephraim, NJ

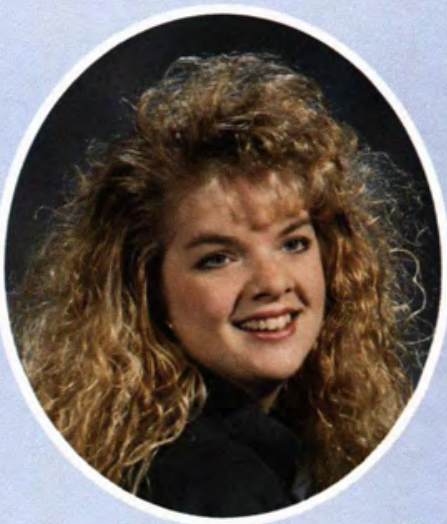

Kimberly Geremia Social Work Millville, NJ 


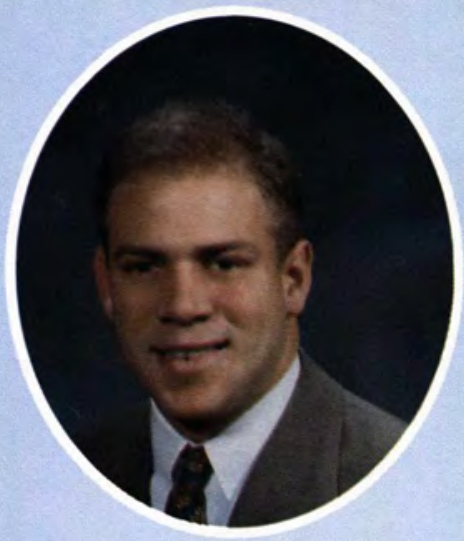

Stephen Hackenberry

Social Science

Cedarville, $\mathrm{OH}$

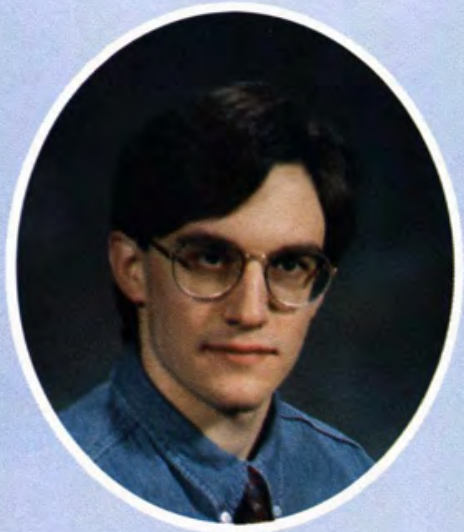

Tod Hamilton

English

Dayton, $\mathrm{OH}$

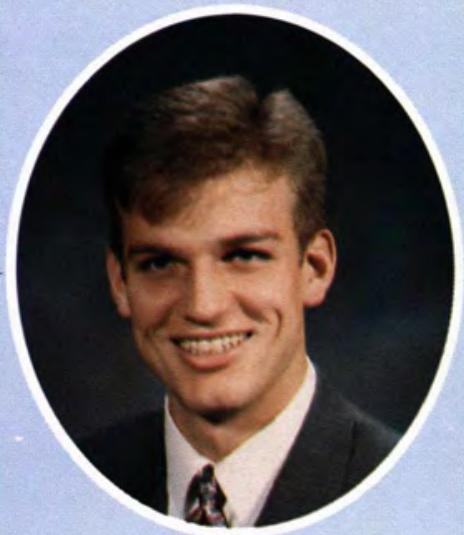

Kevin Hartman

Elementary Education

Lancaster, $N Y$

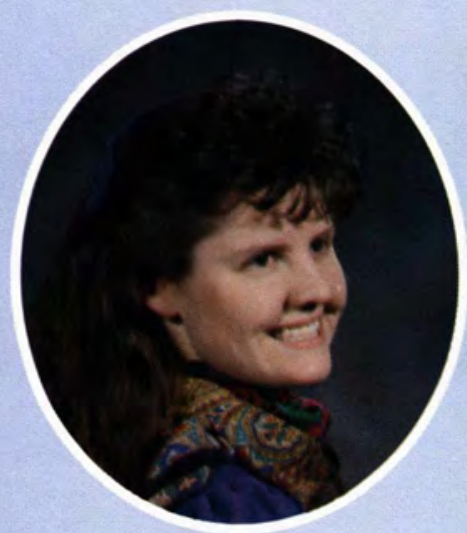

Christine Hayden

Nursing

Cedarville, $\mathrm{OH}$

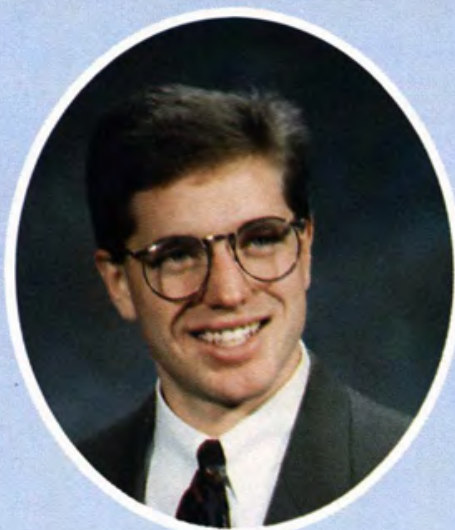

Thomas Halsted

Criminal Justice

Westphalia, MI

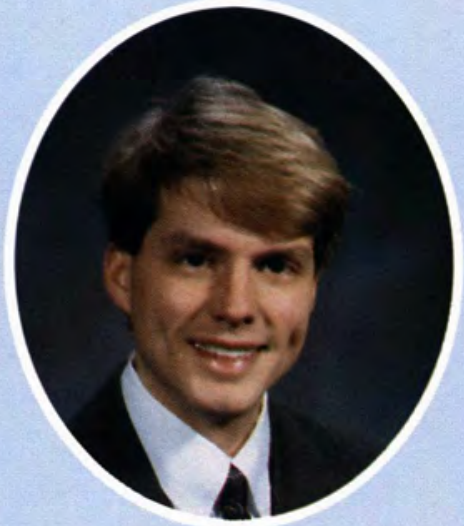

James Hanssen

Business Administration Ankeny, IA

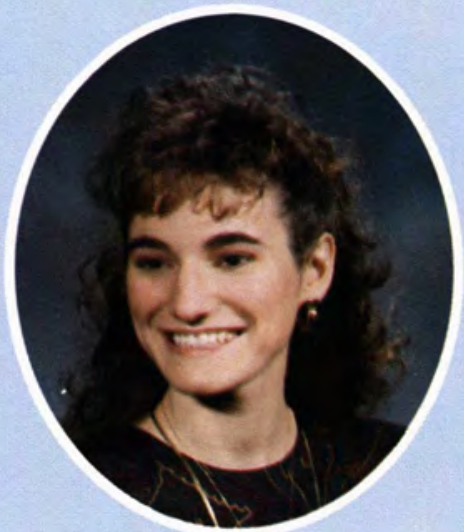

Deanne Hauser

Nursing

Gridley, IL

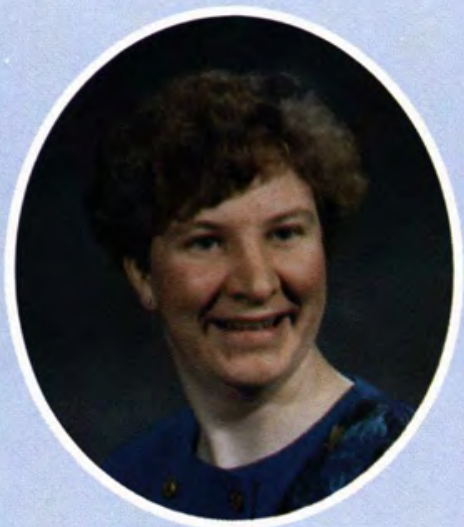

Denise Headdings

Elementary Education

Halifax, PA

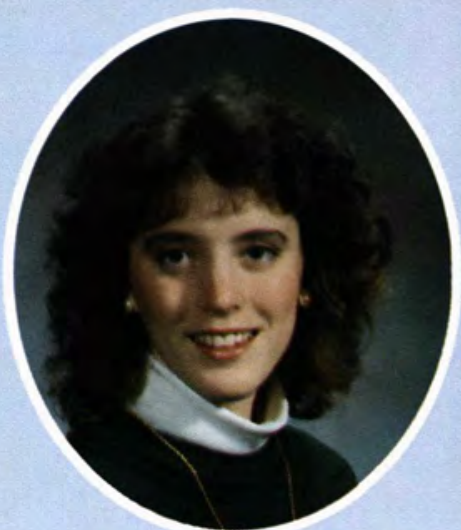

Elta Hamblen

Management

Kings Park, $N Y$

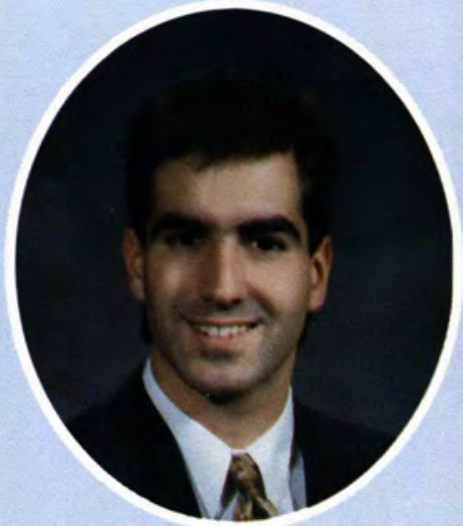

Richard Harrington Marketing

North Scituate, RI

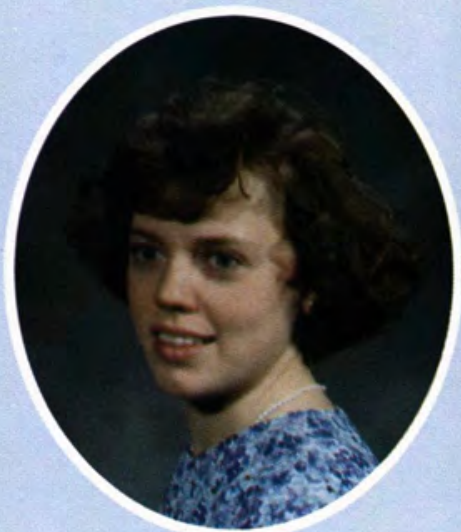

Shelley Hauter Nursing

Cedarville, $\mathrm{OH}$

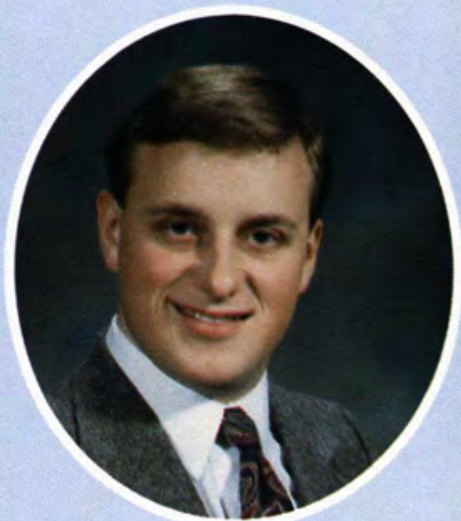

Stephen Heath

Computer Information Systems Milford, MI

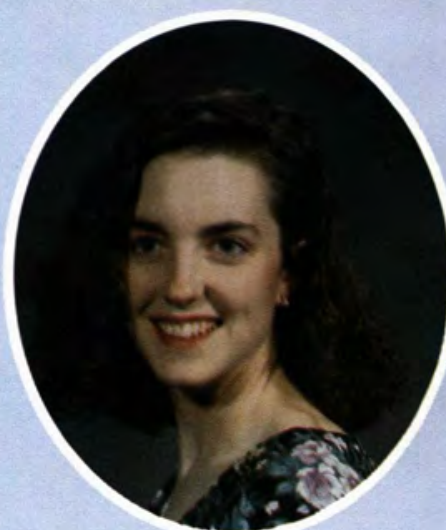

Julie Hamilton Biology

Dayton, $\mathrm{OH}$

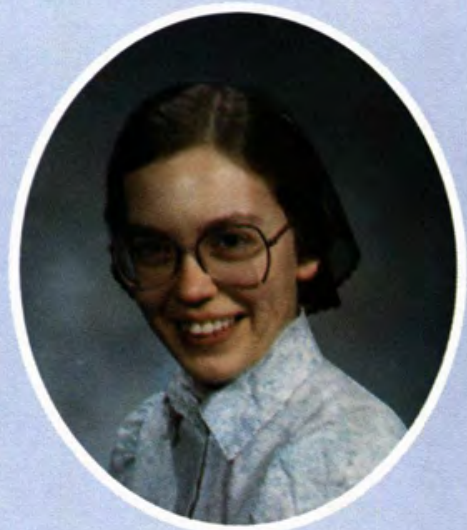

Cheryl Hartman

Nursing

Irwin, $\mathrm{OH}$

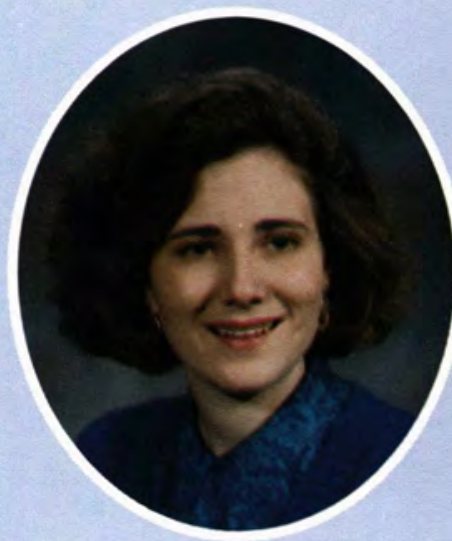

Joy Haworth English

Lexington, $K Y$

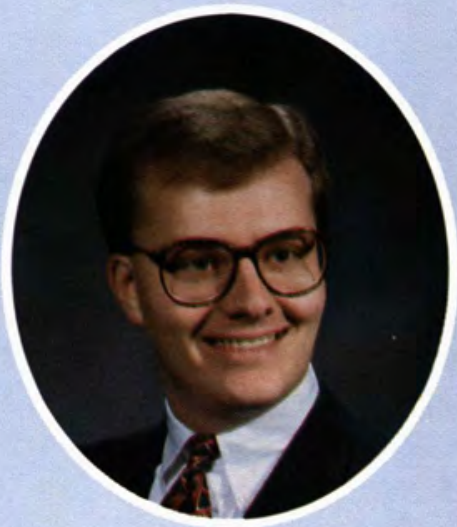

Joel Heckart

Accounting

Kettering, $\mathrm{OH}$ 


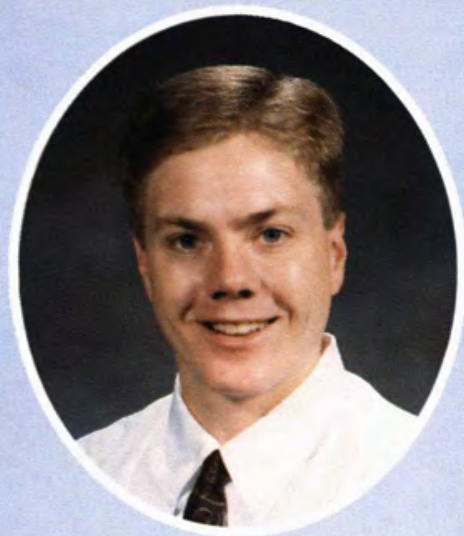

Steven Holden

Communication Arts

Piedmont, $\mathrm{OK}$

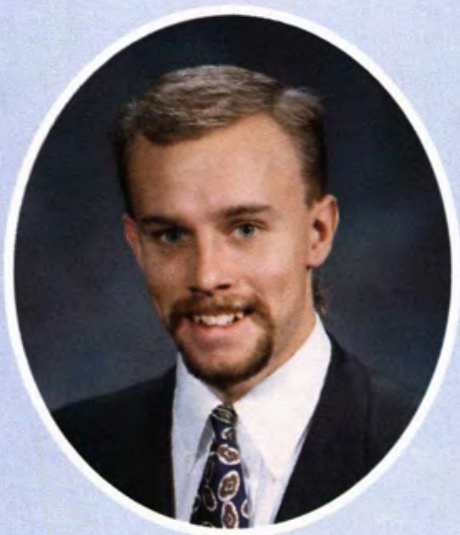

Steven Hornbuckle

Mathematics

St. Charles, IL

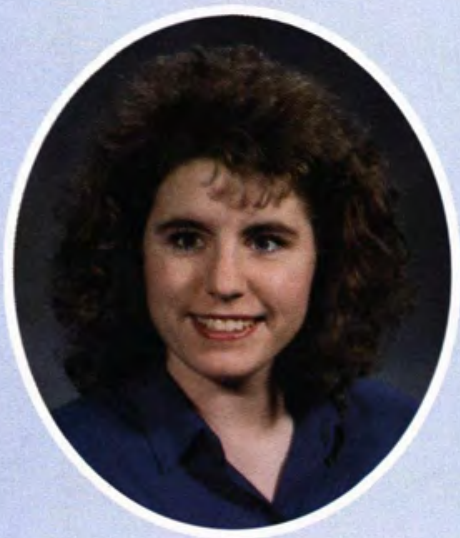

Kimberly Hubbard

Bible, Comprehensive

Elementary Education

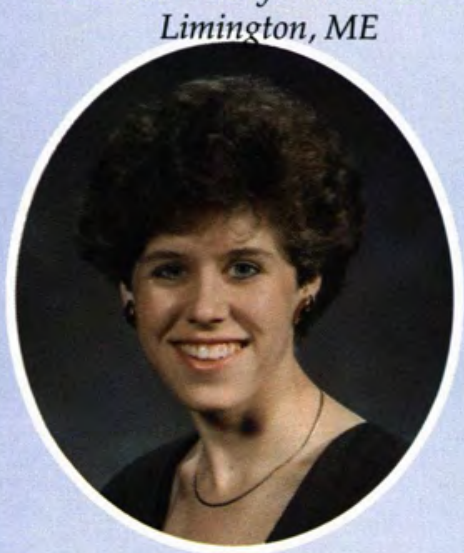

Jenine Hyten Nursing

Valparaiso, IN

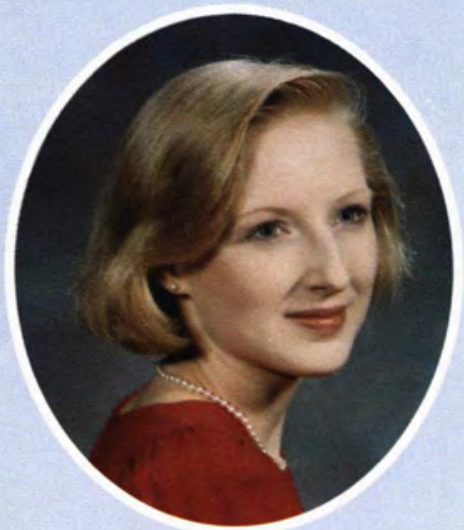

Mary Hollaway

Elementary Education

Columbus, $\mathrm{OH}$

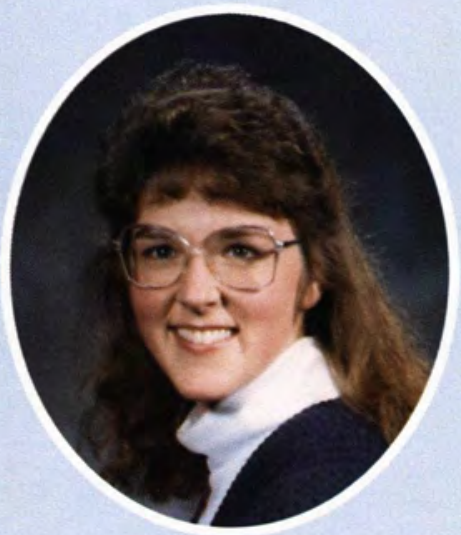

Vonda Horst

Elementary Education

Chambersburg, PA

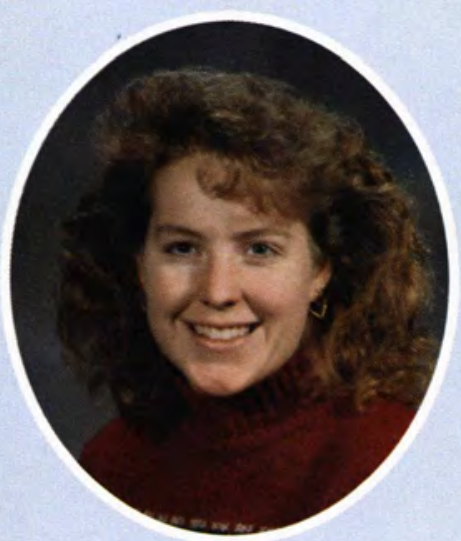

Melinda Hughes

Elementary Education Mc Minnville, $O R$

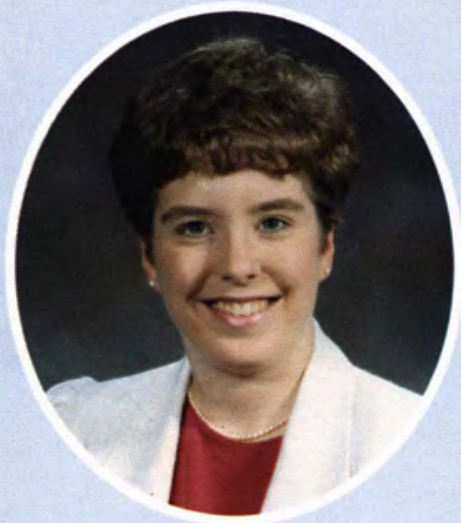

Kathleen Irish

Elementary Education

Rochester Hills, MI

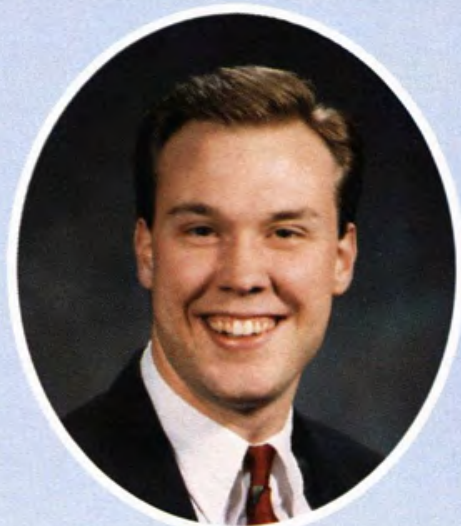

Mark Holsinger

Accounting

Dayton, $\mathrm{OH}$

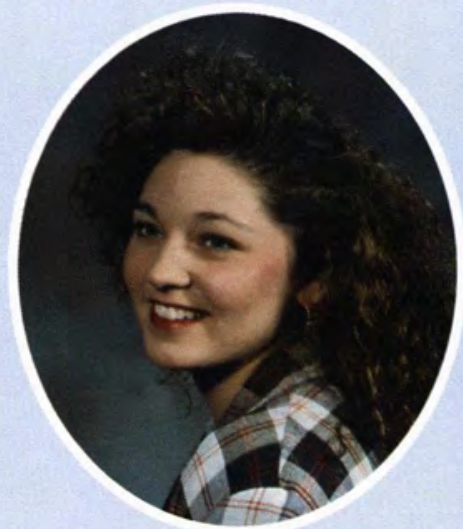

Kimberly Hosner

Broadcasting

St. Joseph, MI

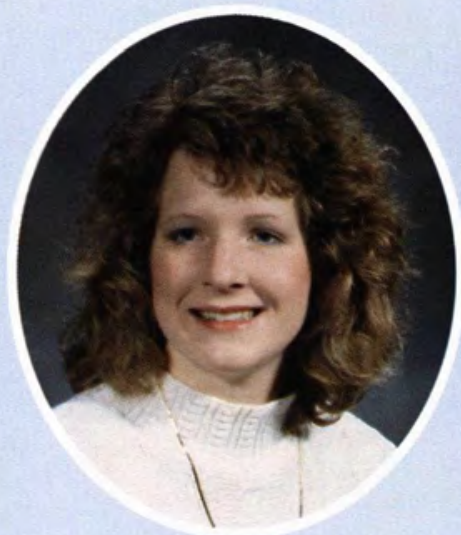

Melinda Humble

Pre-Law

Piketon, $\mathrm{OH}$

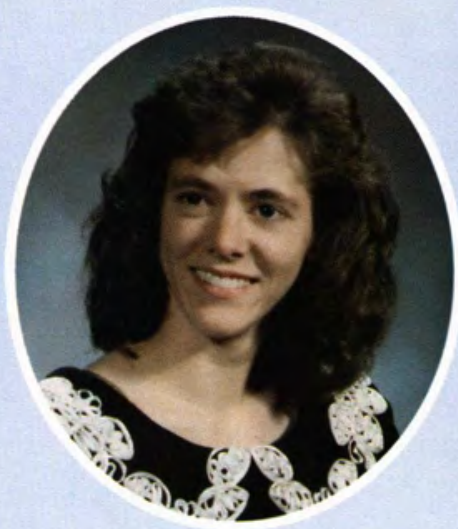

Elisabeth Irving

Biology

Littleton, $\mathrm{CO}$

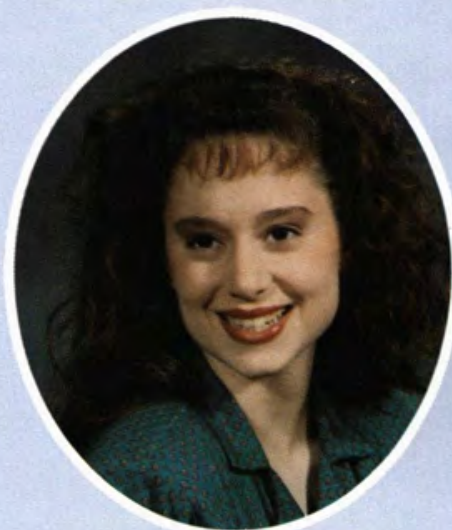

Apryl Hoover

Communication Arts

Elyria, $\mathrm{OH}$

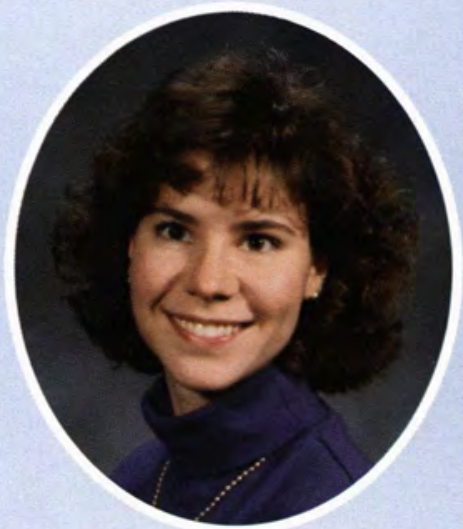

Patricia Howard

Elementary Education Capitan, NM

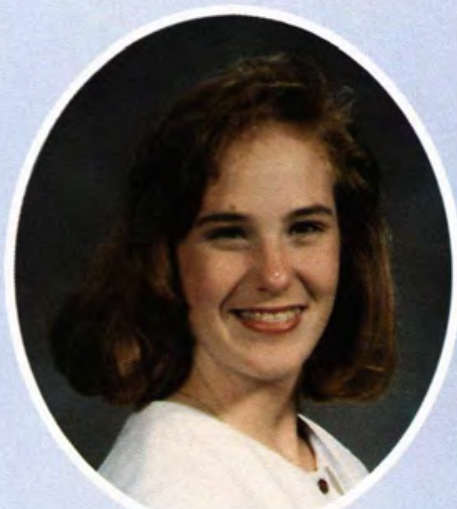

Carmen Hunt Elementary Education Virginia Beach, VA

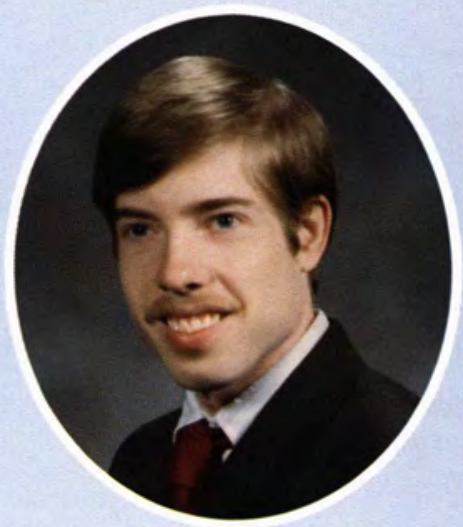

Robert Jackson Accounting

Monmouth Junction, NJ 


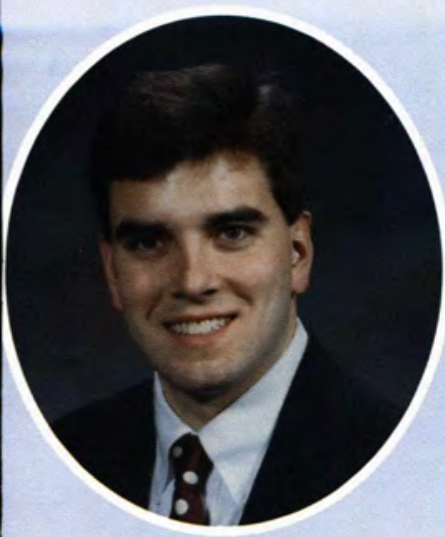

John Jacobson Accounting Augusta, MI

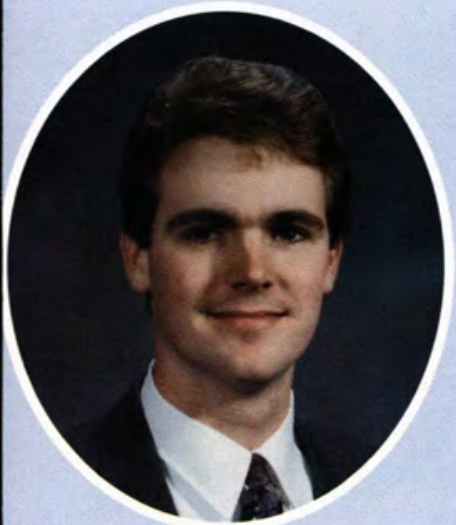

Jeffrey Johnson Accounting

Findlay, $\mathrm{OH}$

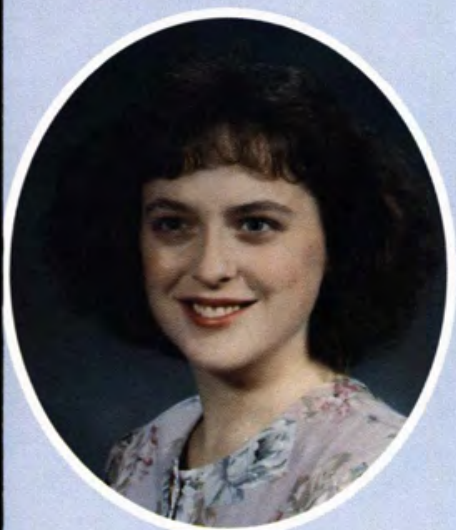

Lori Jones

Elementary Education Mount Vernon, $\mathrm{OH}$

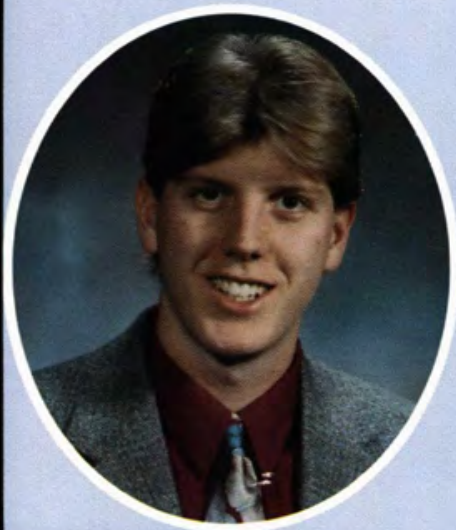

Edward Keefe, III Bible, Comprehensive Fayetteville, PA

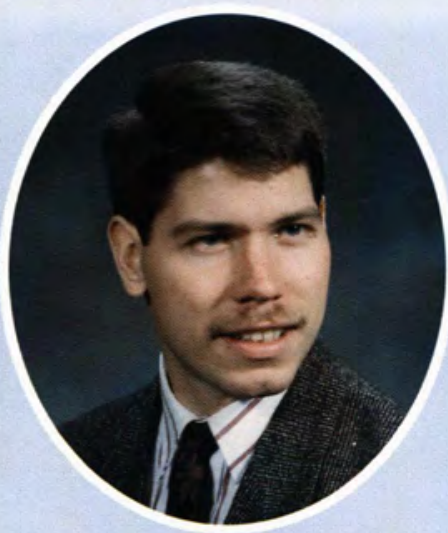

Andrew Jamieson Biology

Harrisville, MI

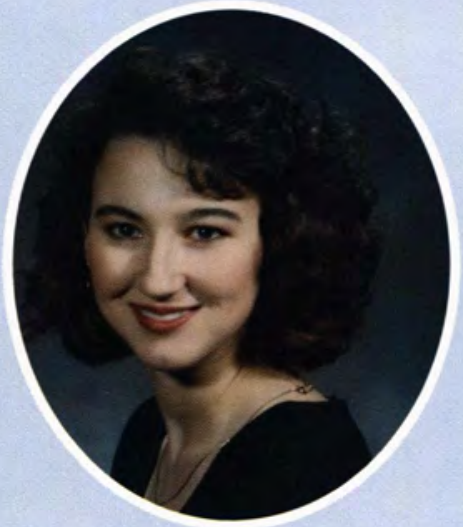

Victoria Johnson English

Lowell, MI

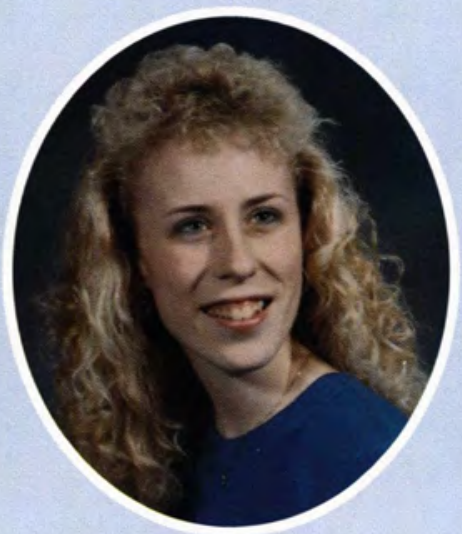

Tracy Justice

Elementary Education Sheboygan Falls, WI

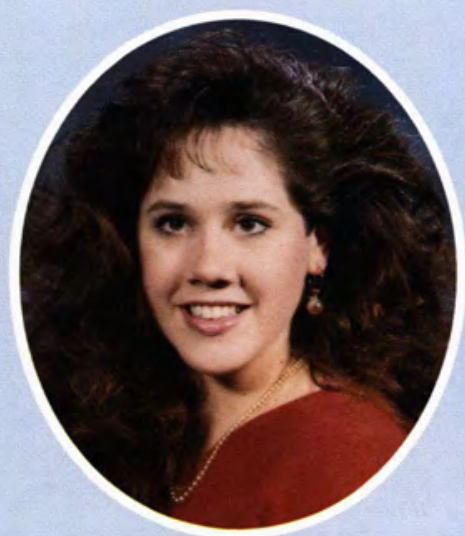

Heidi Keefer

Public Administration

Ypsilanti, MI

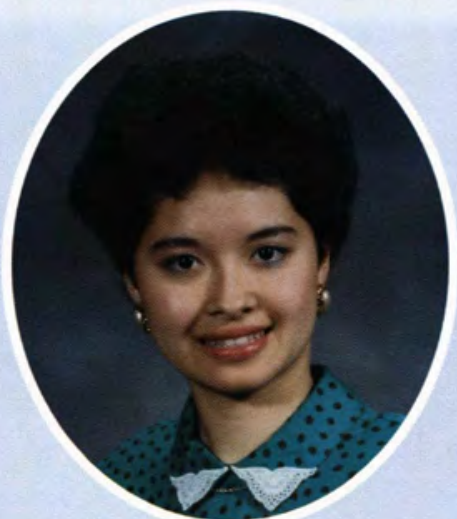

Gina Jamora

Nursing

Point Pleasant, WV

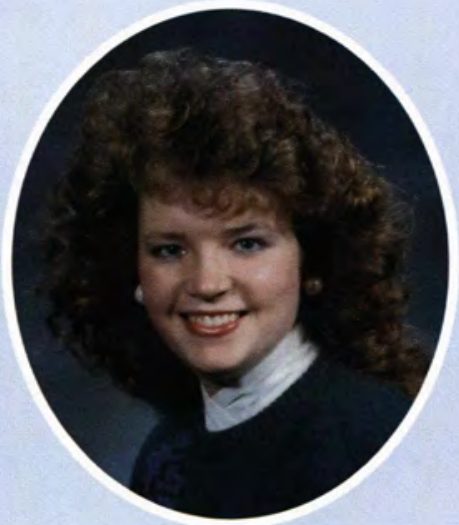

Faith Johnston

Mathematics

Creston, IA

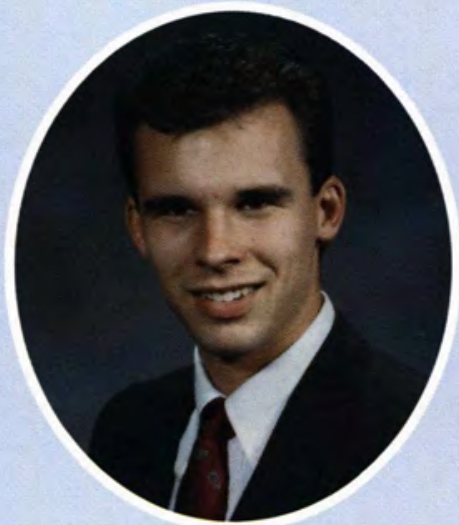

Mark Kakkuri

Communication Arts

Rochester Hills, MI

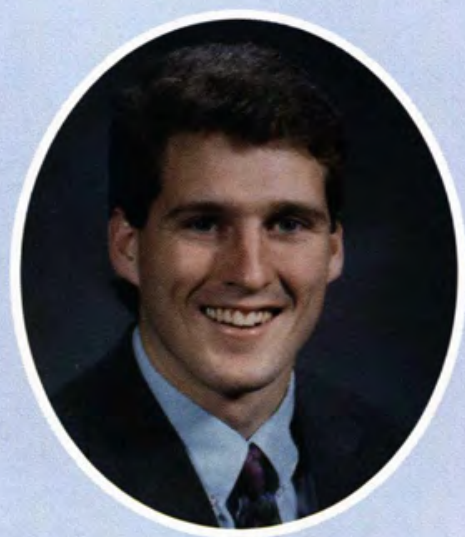

John Keenan

Accounting

Gallipolis, $\mathrm{OH}$

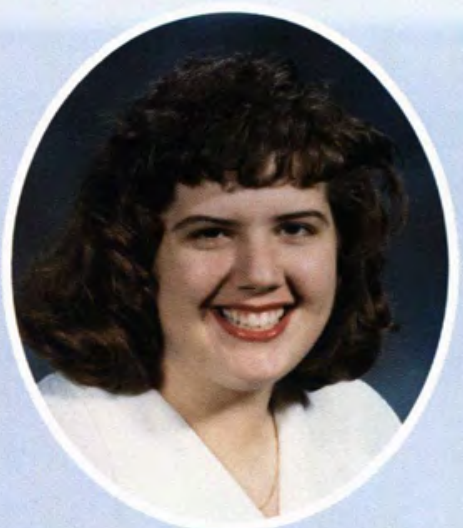

Carol Jariga

Social Science/History

Columbia Station, $\mathrm{OH}$

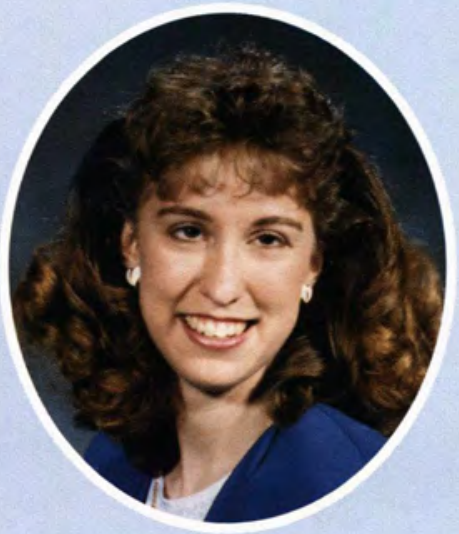

Christine Jones

Management

Ohlman, IL

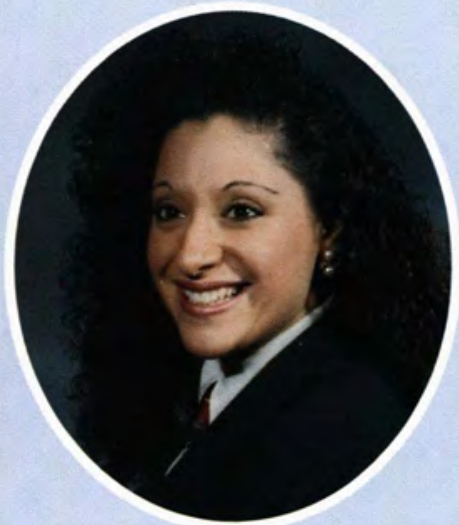

Andrea Katz

Psychology/Behavioral Science Reynoldsburg, $\mathrm{OH}$

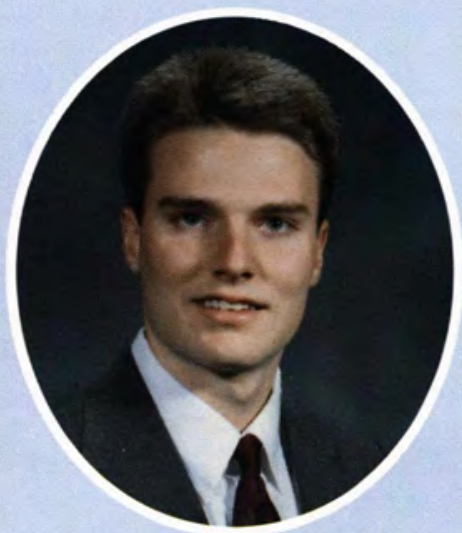

Kyle Kelley Marketing

Washington Court House, $\mathrm{OH}$ 


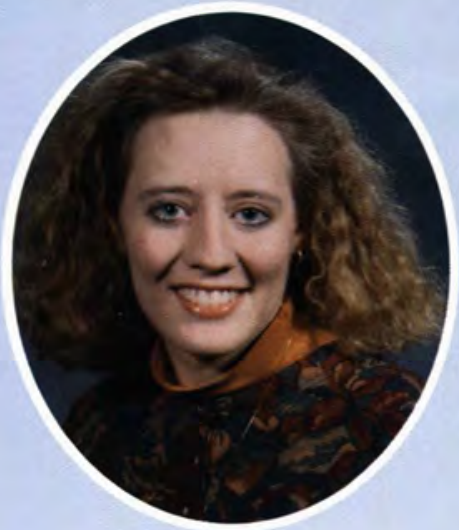

Gina Kendig

Elementary Education Solon, $\mathrm{OH}$

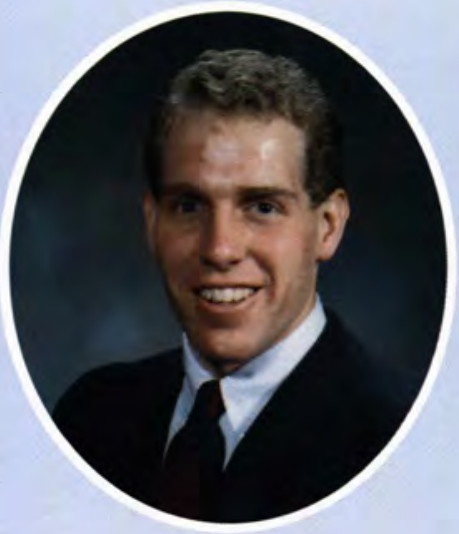

James King

Finance

Columbus, $\mathrm{OH}$

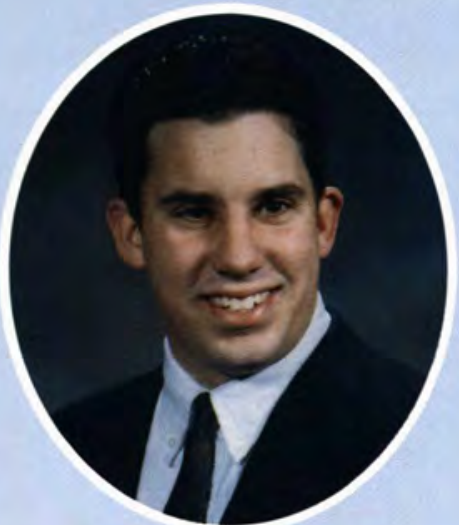

Matthew Kibble

Management

Columbus, $\mathrm{OH}$

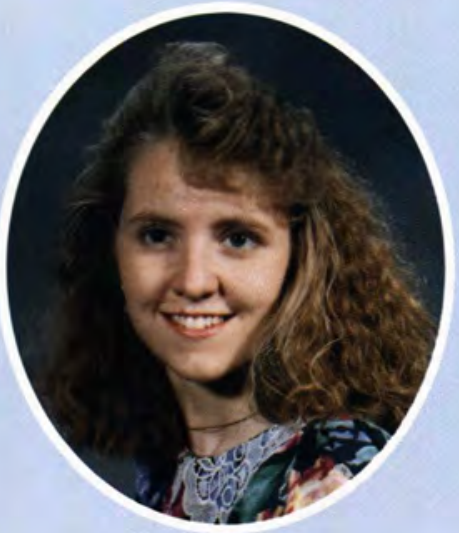

Melissa King

Nursing

Cable, $\mathrm{OH}$

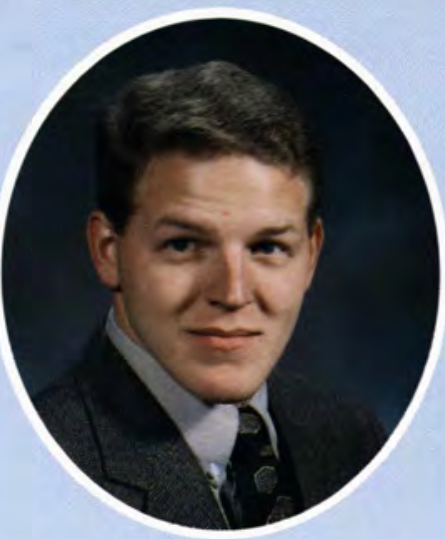

William Kigar

Management

Curtice, $\mathrm{OH}$

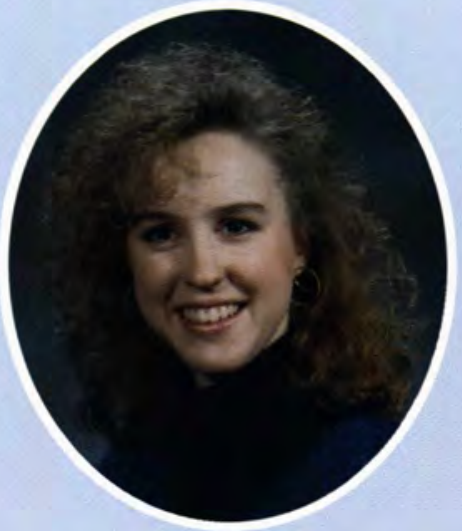

Allison Knowles

English Education

White Lake, MI

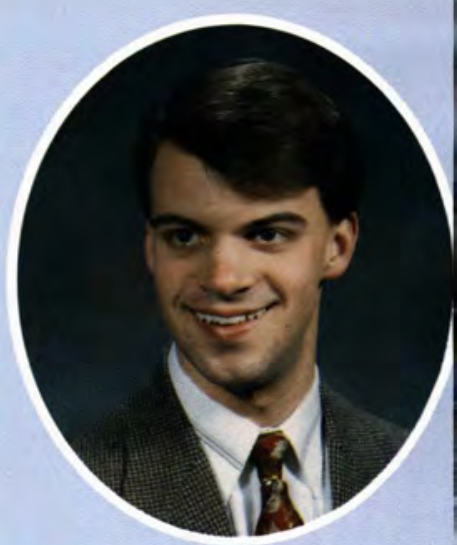

David Kimmel English

Cridersville, $\mathrm{OH}$

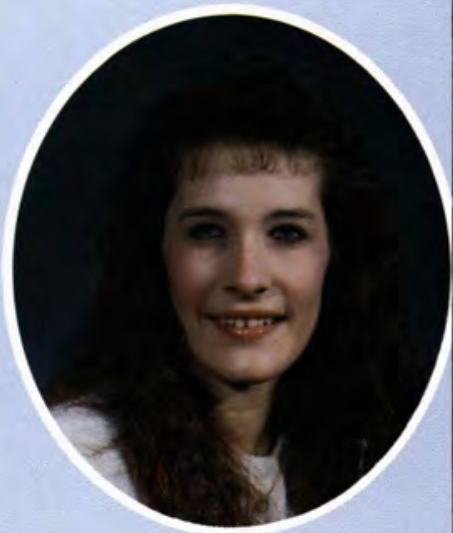

Tammy Koontz

Elementary Education

Lexington, NC

\section{"Senior"=Get a Job!}

Somehow, I never thought I'd have to choose between all the "dream careers" I had always envisioned. But now, I suddenly found I was a SENIOR. That word only meant one thing: GET A JOB. The thought of picking just one thing to do with the rest of my life seemed utterly depressing; I had simply avoided the idea for the last twenty years.

It wasn't that Cedarville College had not adequately armed me for this face-off. I did everything I was supposed to do. I took the career aptitude test--the counselor said I must have lied or something-the scores revealed no particular aptitude in any single area. Itook "Employment Strategies" to force myself to encapsulate my entire life on one sheet of paper. I switched my major from Pre-Med after a girl fainted on my feet during a recital and I stood up screaming. I regularly devoured articles like "The Top 25 Careers for the 90's," and worked one summer at an internship.

Nonetheless, I still don't know. In fact, I don't think I will ever know "What I Want To Be When I Grow Up." I startled myself at a recent interview when I realized that four years at Cedarville had taught me much more about people and the truly important things in life than it had about how to pour myself into a job.

God knows how I will use the skills He has given me. So Igo on, in hindsight seeing the road signs which prove $\mathrm{His}$ hand has guided me. What- ever career paths I choose are not as important as the motives behind my choice, the counsel in that decision, and the proper order of priorities in my life.

"To live a worthwhile life, one must know early what he wants on his tombstone." (Anonymous)

-Victoria Johnson

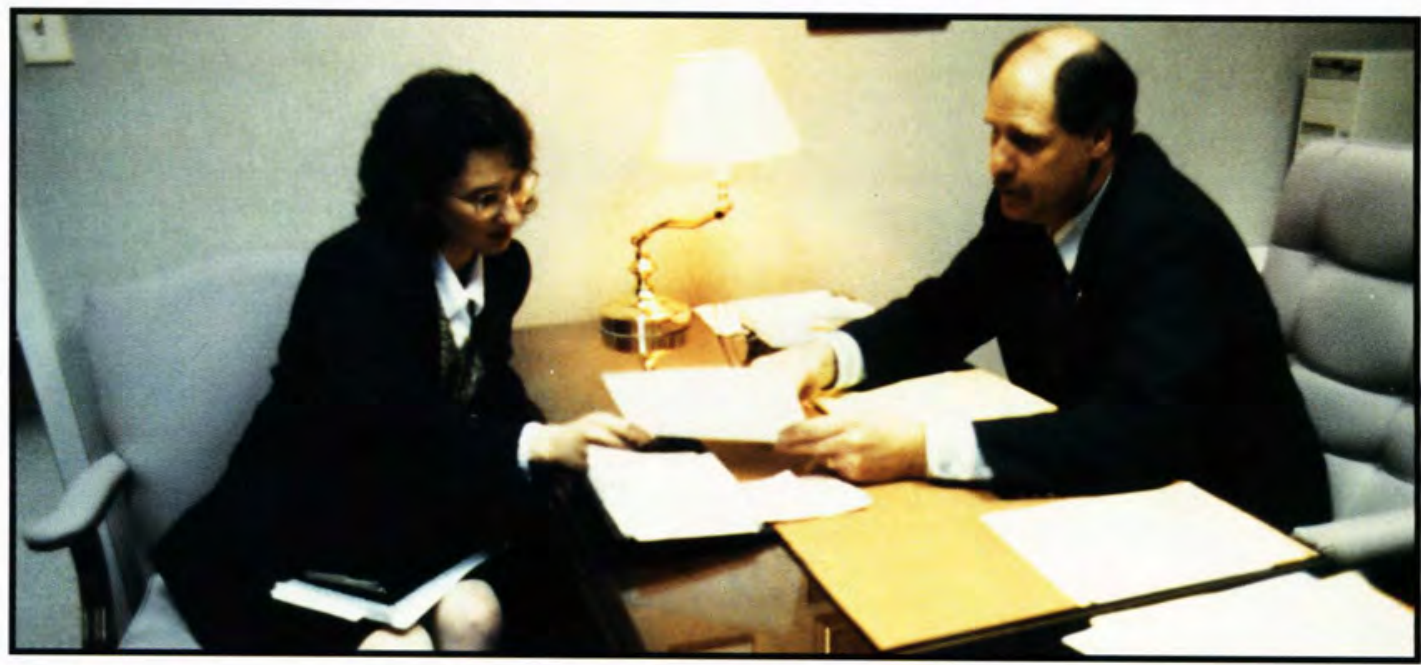




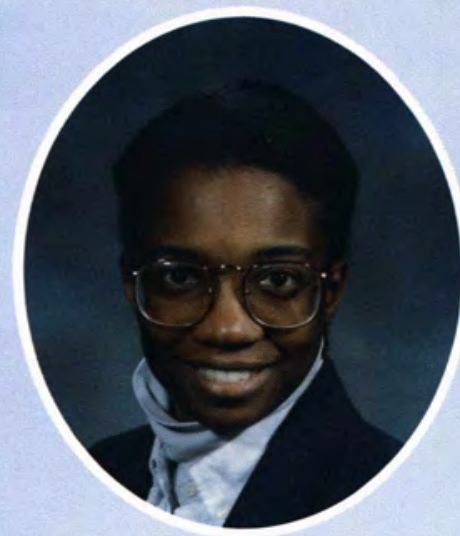

Giovanni Lynch Management Cedarville, $\mathrm{OH}$

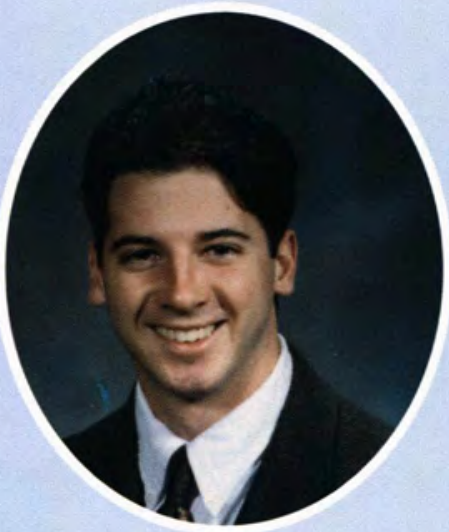

Dennis Marzano Elementary Education Scottdale, PA

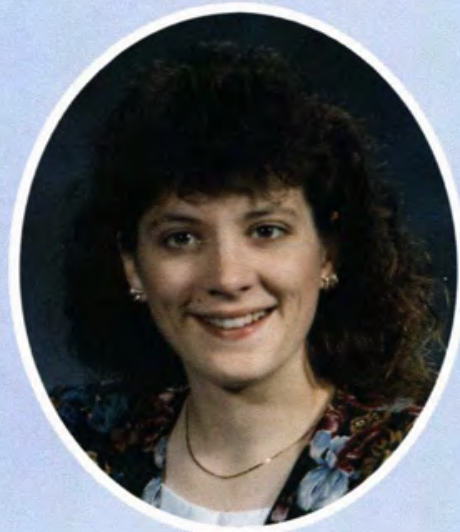

Kimberly McCoy Physical Education Carroll, $\mathrm{OH}$

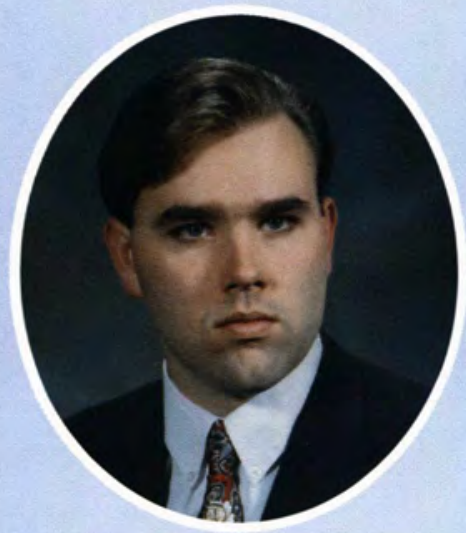

Paul McGrady, Jr. History/Political Science Lorain, $\mathrm{OH}$

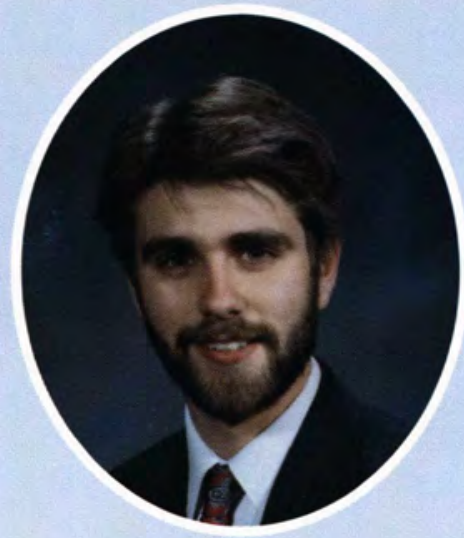

David Malone

Business Administration Buffalo Grove, IL

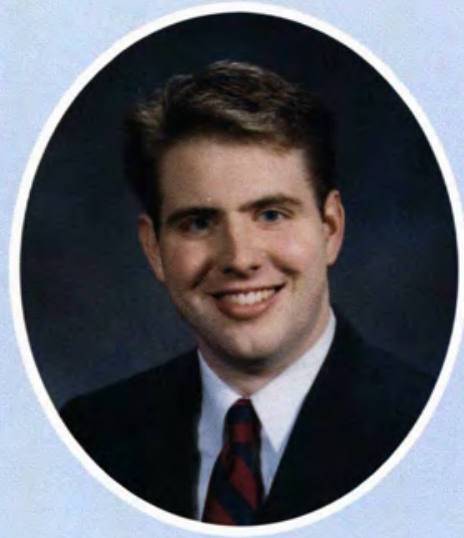

Thomas Mathisen Broadcasting Poplar Grove, IL

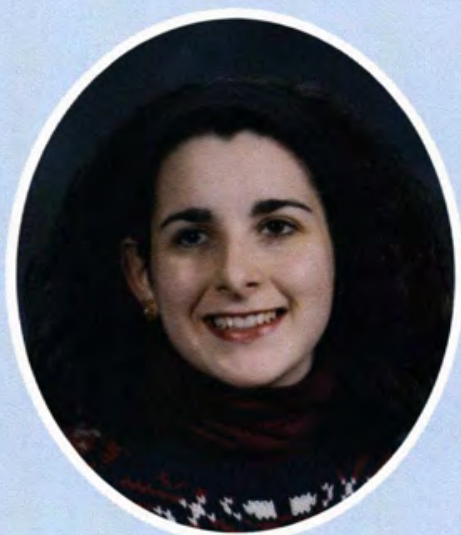

Molly McCoy

Elementary Education

Chester, $\mathrm{NH}$

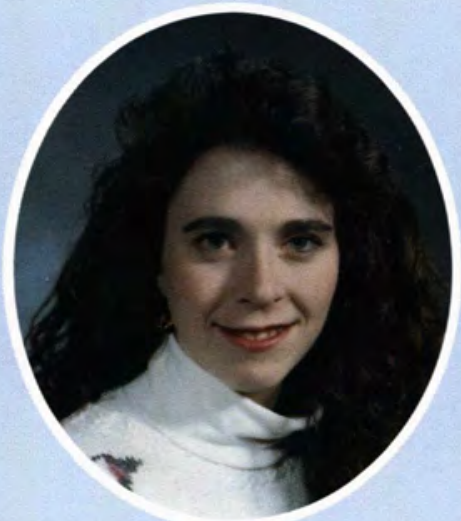

Christina McGuire

Elementary Education Petoskey, MI

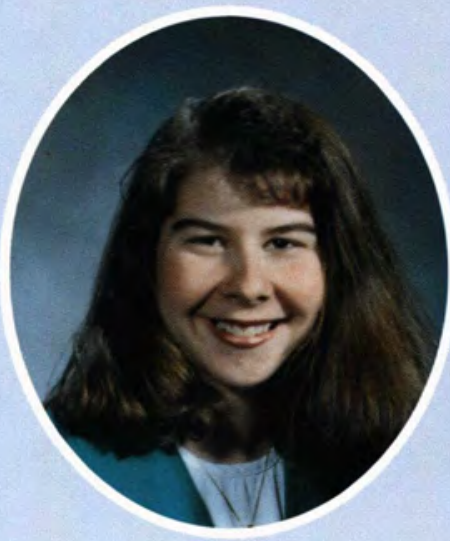

Laura Marshall Accounting

Schaumburg, IL

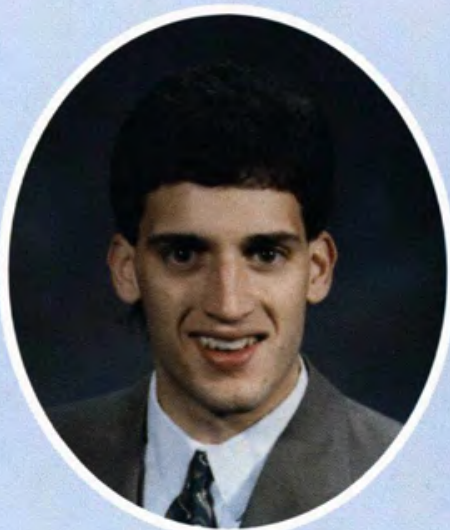

James McCallister Physical Education Rock Falls, IL

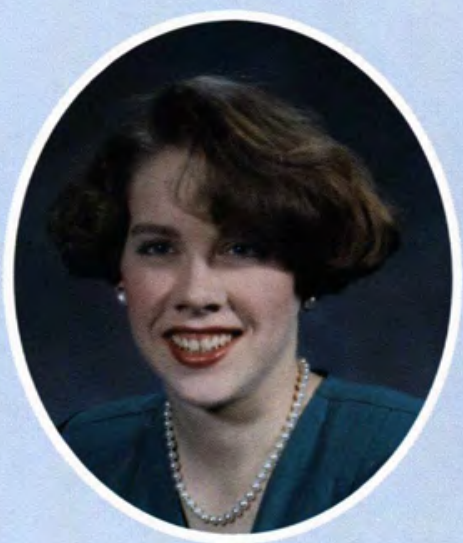

Rachel McDonald

English Education Radnor, $\mathrm{OH}$

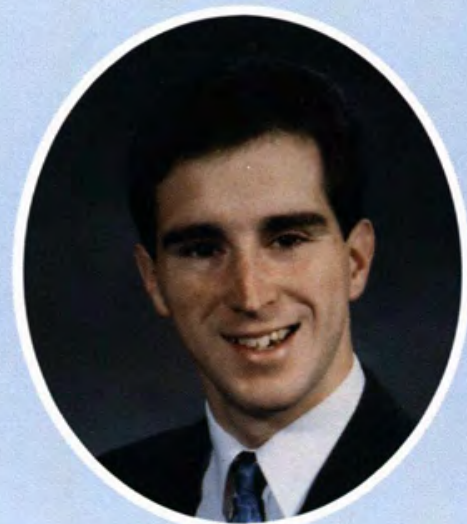

Bruce McKanna Social Science Copley, $\mathrm{OH}$

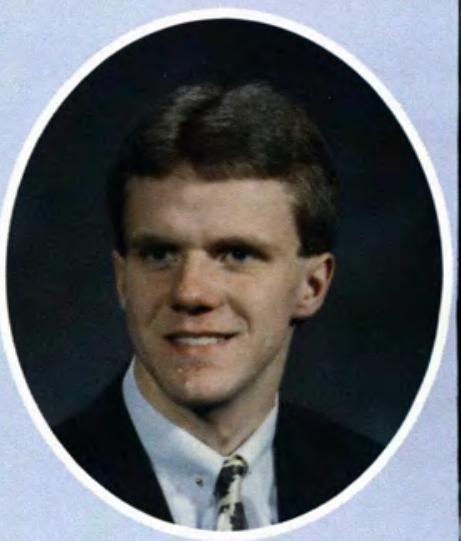

Matthew Martens Accounting Trenton, NJ

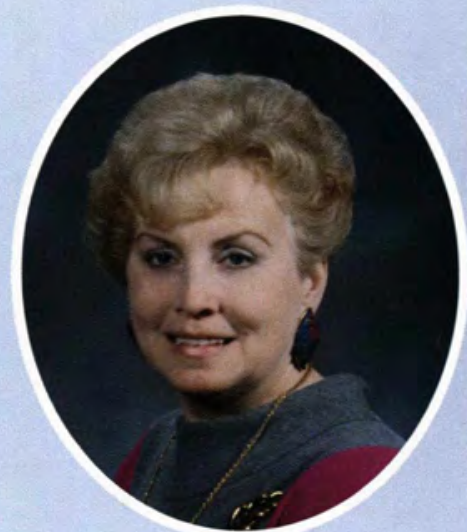

Beverly McComb-Davies Social Work

Cedarville, $\mathrm{OH}$

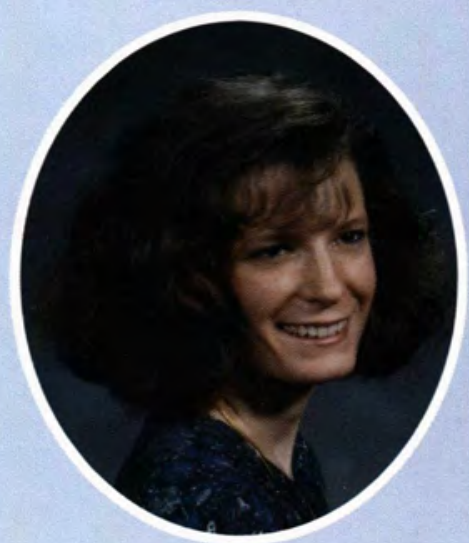

Beth McElroy

Psychology

Grandview, $\mathrm{OH}$

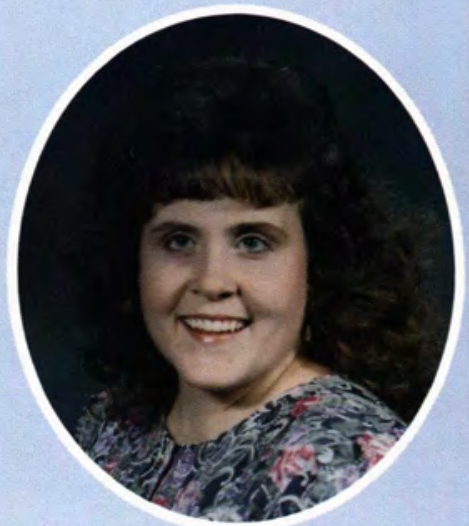

Amy McLaughlin

Elementary Education

Wheelersburg, $\mathrm{OH}$ 


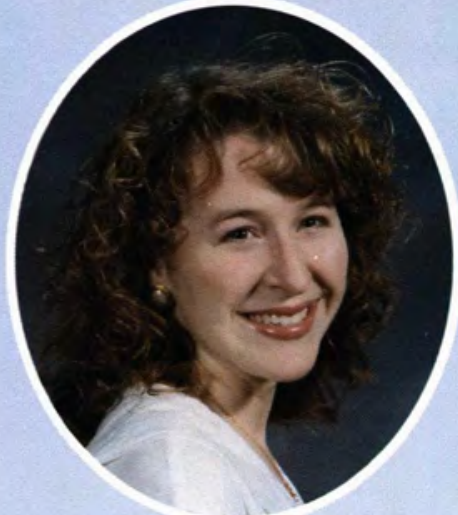

Julie Mulder

Elementary Education

Troy, $\mathrm{OH}$

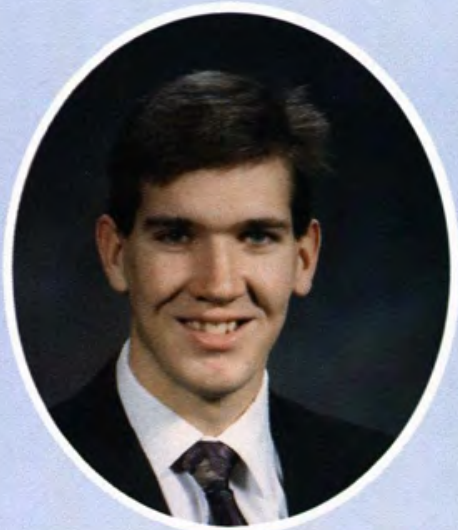

David Myers

Elementary Education

Dalton, $\mathrm{OH}$

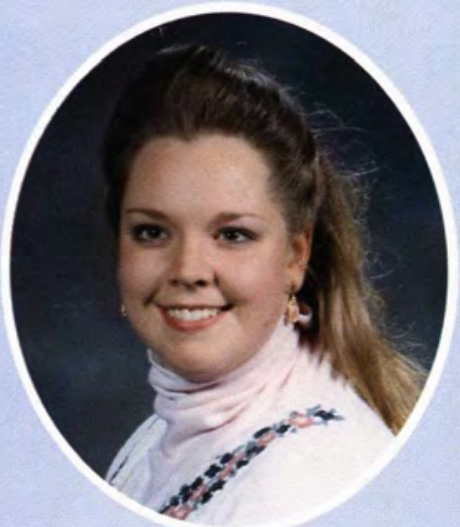

Christine O'Neal Elementary Education

Owings, $M D$

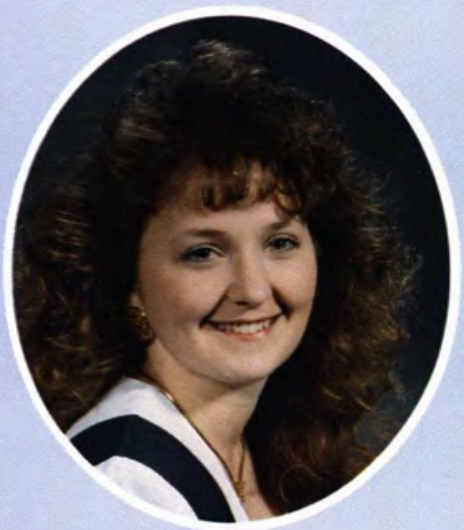

Lisa Olson

Elementary Education Conewango Valley, $\mathrm{NY}$

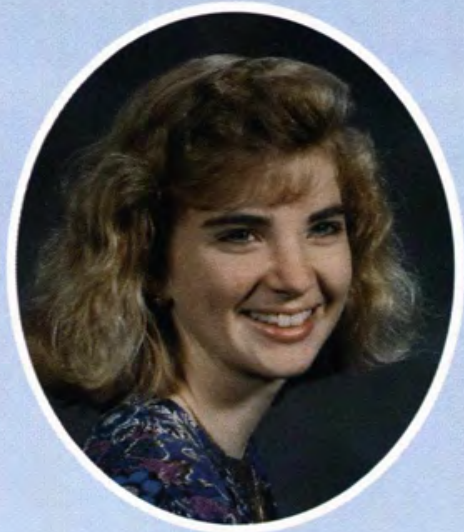

Julie Mummey

Elementary Education

Belle Center, $\mathrm{OH}$

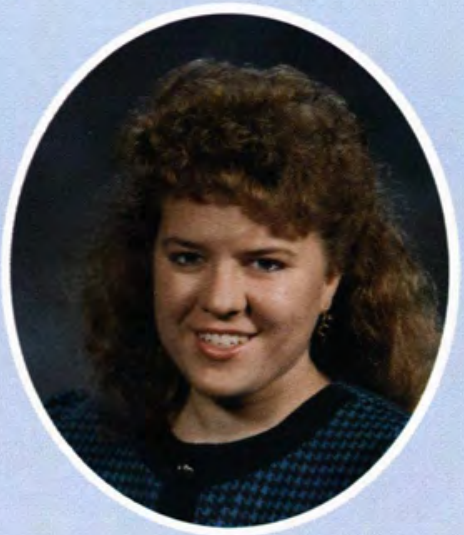

Michelle Nelson

Nursing

Lansing, MI

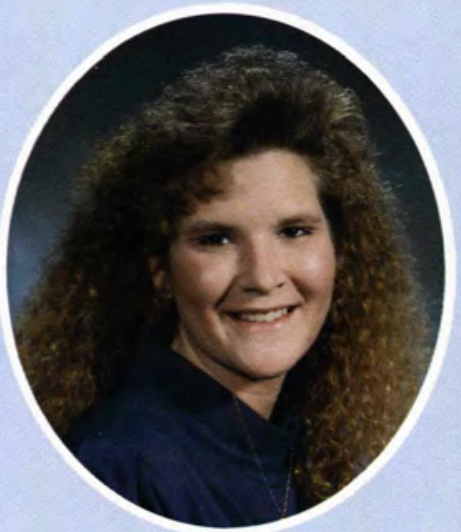

Stacy Oligee

Behavioral Psychology

West Alexandria, $\mathrm{OH}$

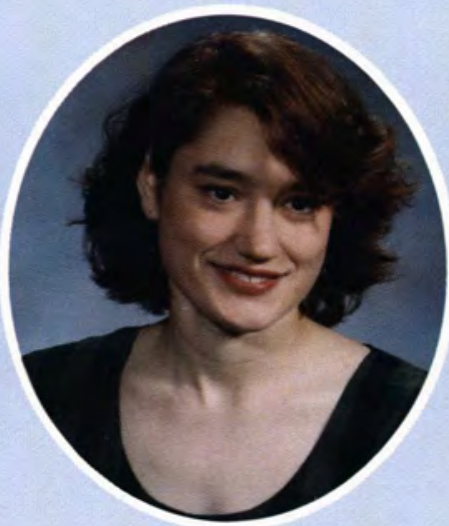

Julie Overmoyer

Social Science/History

Williamsport, $P A$

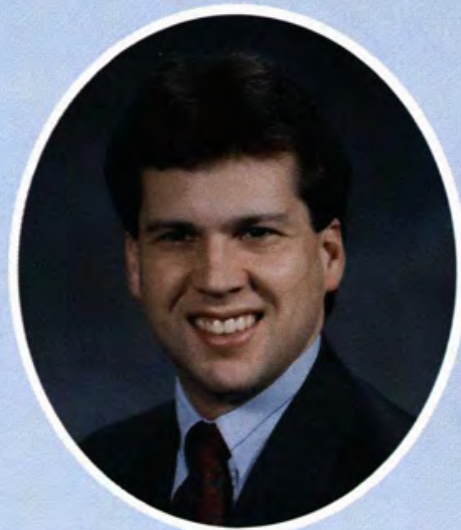

James Munk

Computer Information Systems Williamston, MI

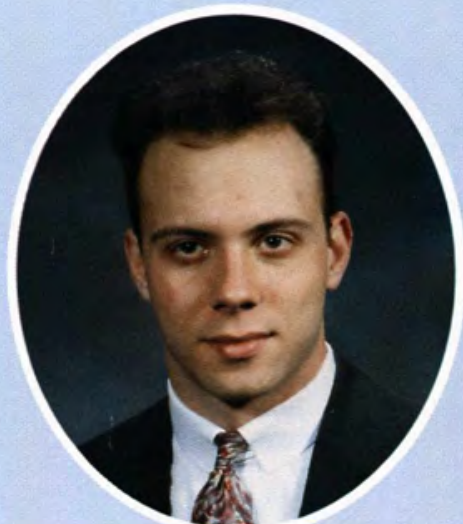

Brian Nettleingham Pre-Law

New Orleans, LA

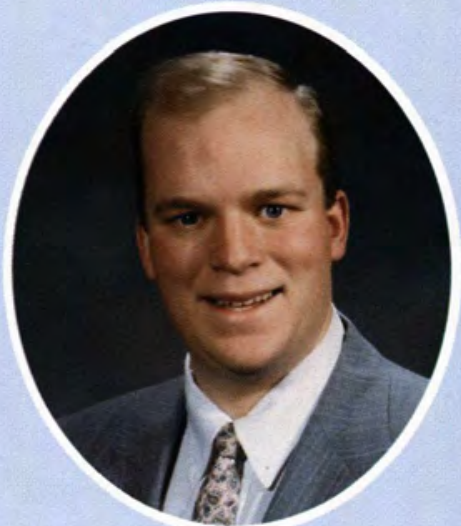

Matthew Oliver

Bible, Pre-Seminary

Blanchester, $\mathrm{OH}$

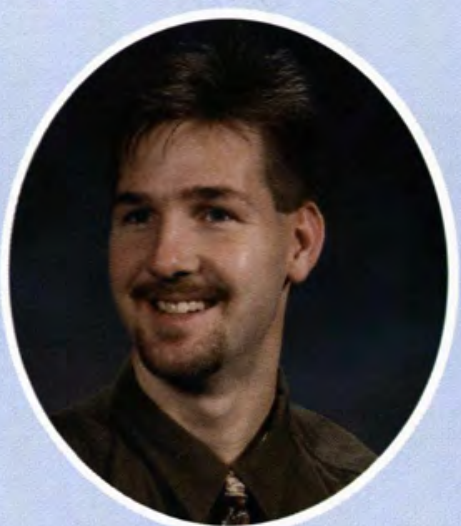

Steven Padgett

Physical Education

Tampa, FL

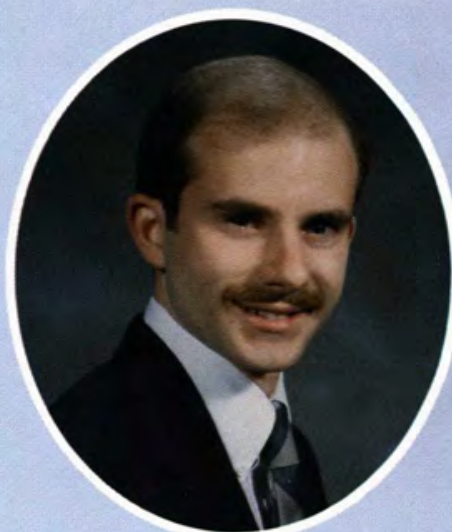

Kevin Murachanian American Studies Centerville, $\mathrm{OH}$

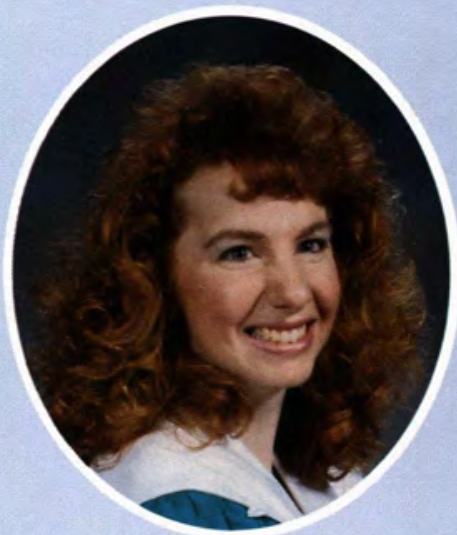

Kayley O'Keefe

Elementary Education Arlington Heights, IL

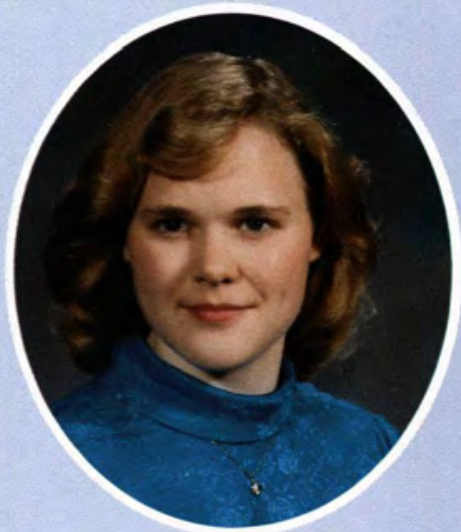

Marsha Olsen English

Rochester, MN

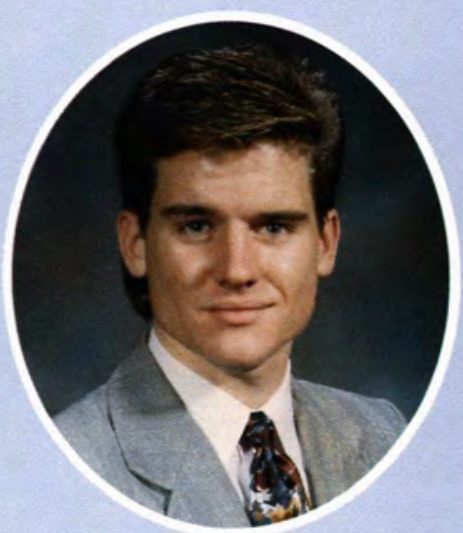

Kevin Parliament

Marketing

Milford, MI 


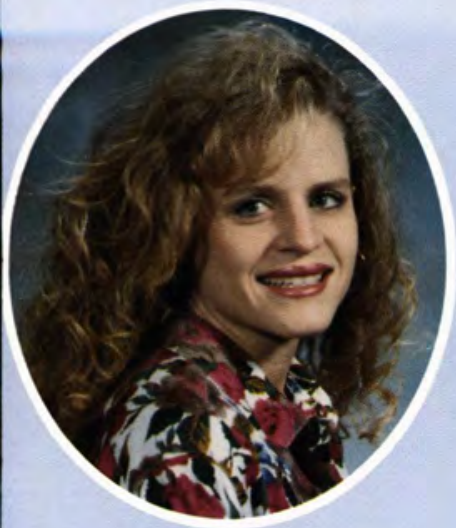

Mary Parlin

Biology

Astatula, FL

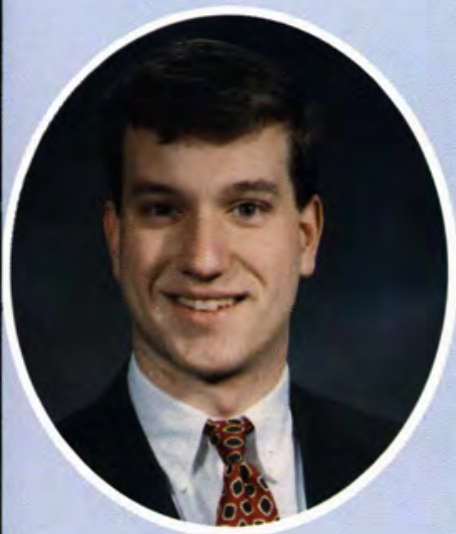

John Pereira

Finance/Management Knoxville,TN

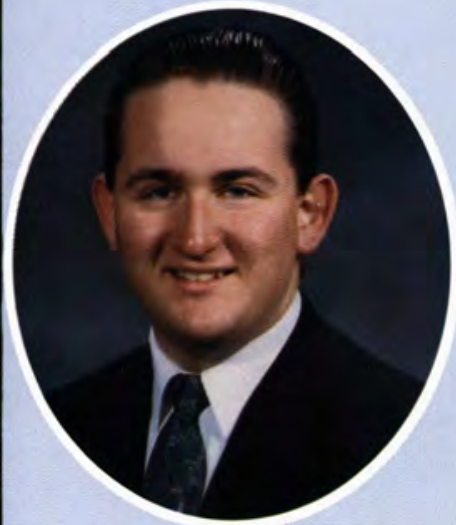

Chris Pincket

Broadcasting

Davie, FL

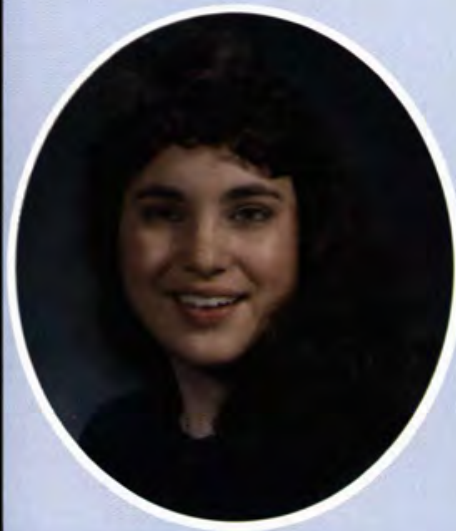

Cheryl Pinkerton

Nursing

Dugspur, VA

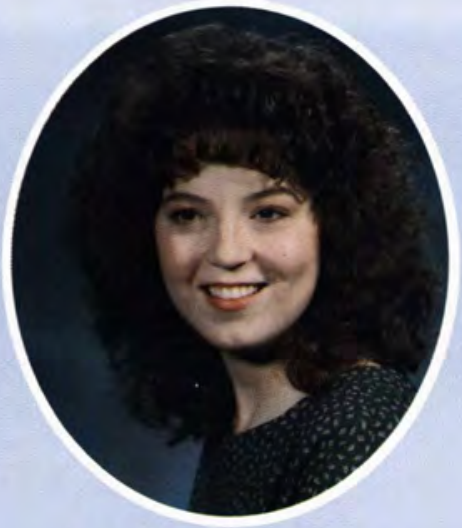

Janet Payne

English

Urbana, $\mathrm{OH}$

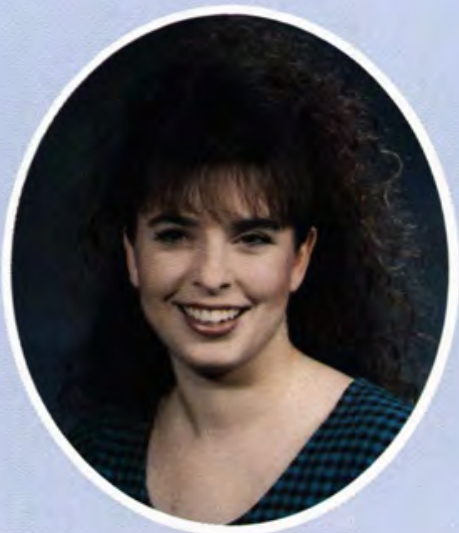

Amy Perkey

Elementary Education

Findlay, $\mathrm{OH}$

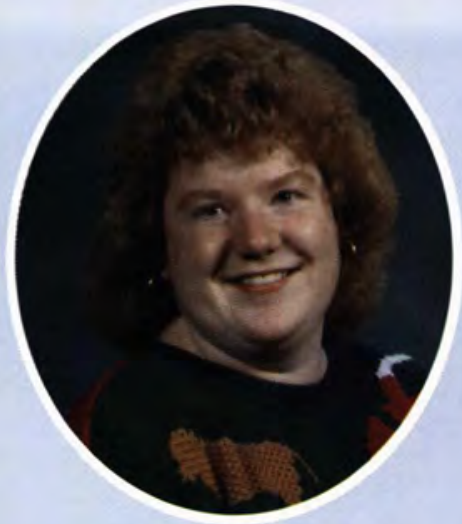

Jennifer Pearson

Elementary Education

Cherry Hill, NJ

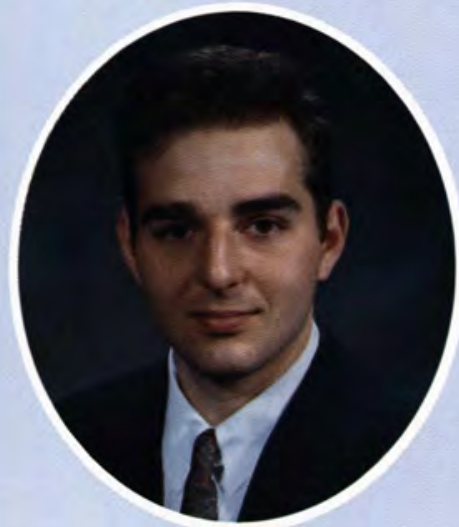

Greg Petek

Criminal Justice

Medina, $\mathrm{OH}$

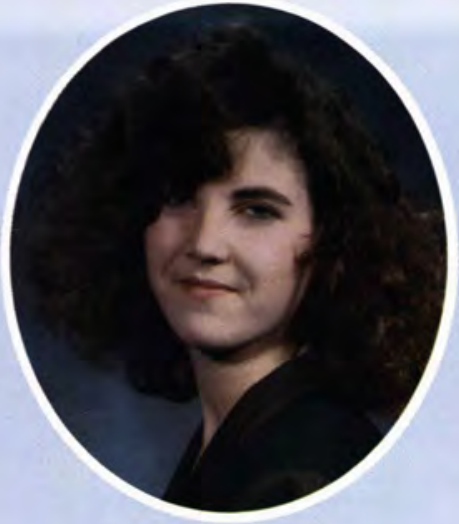

Terri Peet

Marketing

Nicholson, PA

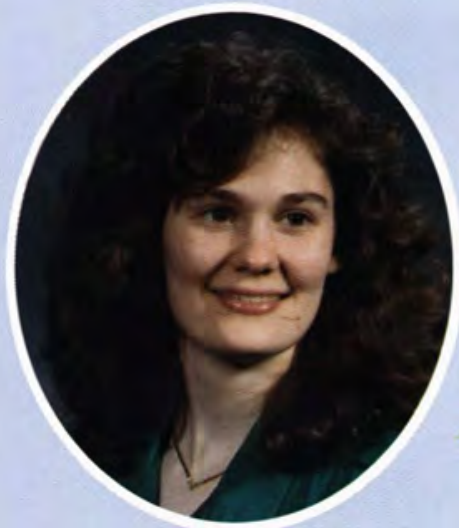

Ruth Pfahler

English Education

Bucyrus, $\mathrm{OH}$

\section{Senior Picture}

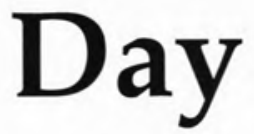

No one considers picture day to be a holiday or even a really special day, but it certainly is an unusual day at Cedarville College. What other day would anyone get "all dressed up with no place to go" - on purpose? Or is that "half dressed up?" If you've ever been to Cedarville picture day, you know nothing quite compares to the sight of a male student dressed from the waist up in his best Sunday suit coat, shirt and tie, and from the waist down in his oldest pair of faded Levi Jeans and Nike high tops.

Ah yes, picture day brings out a file of people all headed for the Athletic Center, heads tilted so the part in their hair faces the on coming wind. What other day is the weather forecast "guaranteed moisture to hang in the air with 35 mph winds" to make your hair flat and unruly? What other day do you spend so much time in front of the mirror primping and preening so you can sit for five minutes with the questions "serious or smile? Show teeth or not?" running through your head? When else do you sit with your head tilted to an unnatural angle in an attempt at poise and have a fake smile plastered on your face? Though picture day is not the most prominent memory students have of Cedarville College, it is an important part of the Cedarville culture. Even if no one else eagerly anticipates picture day, the nearest Wal-Mart surely must appreciate the yearly boost in hair spray sales.

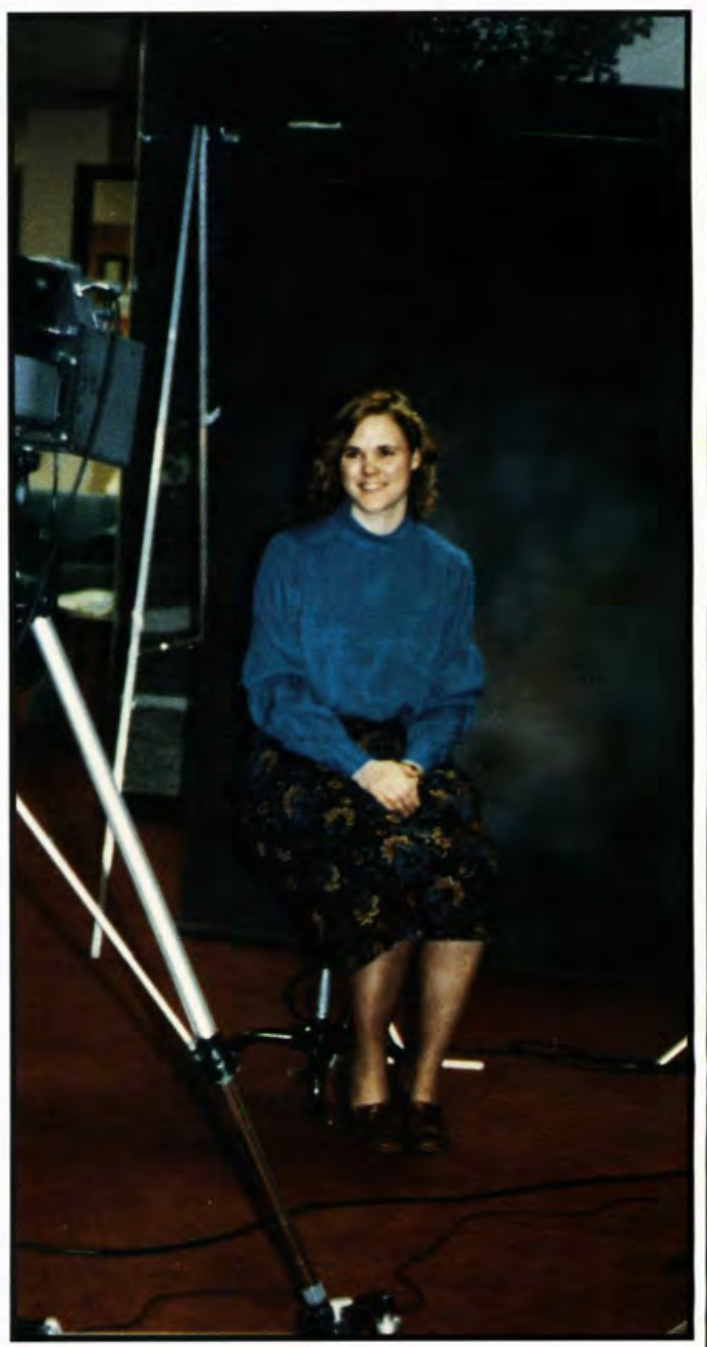




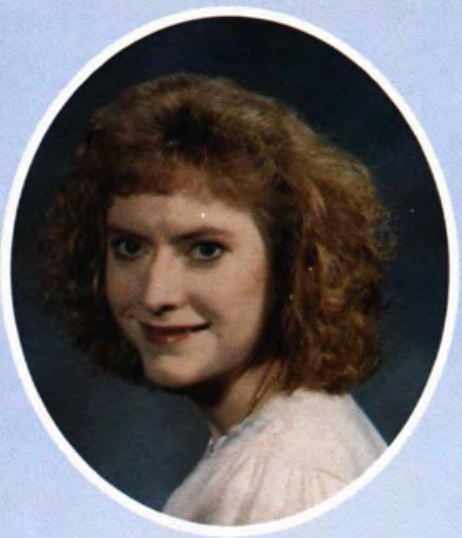

Rosemary Pletcher Nursing

Tacoma, WA

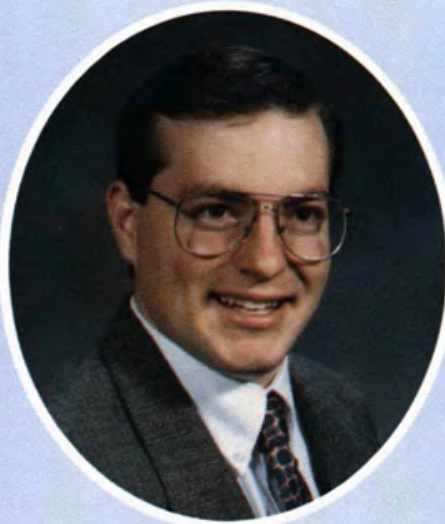

Kirk Powell

Nursing

Ravenna, MI

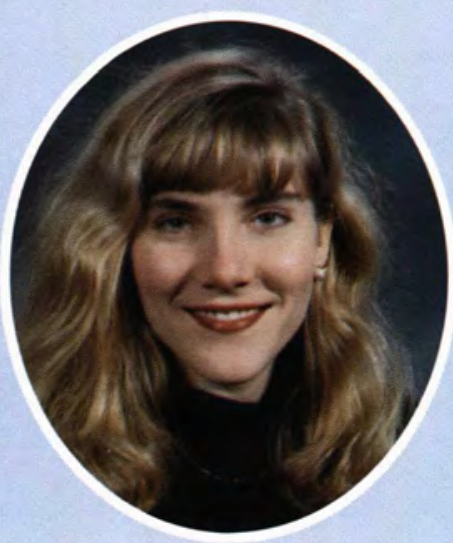

Tracy Quinn

Communication Arts/English Toledo, $\mathrm{OH}$

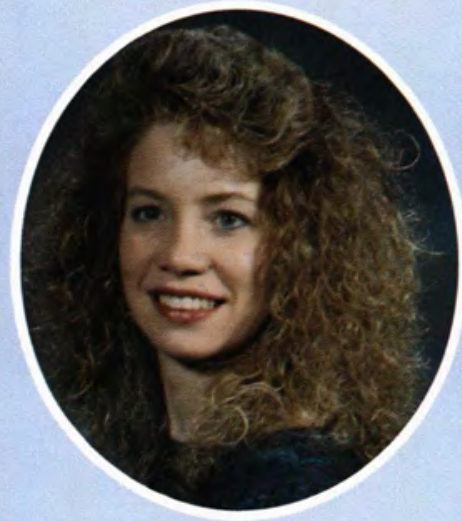

Kimberly Abbas Rich Elementary Education Cedarville, $\mathrm{OH}$

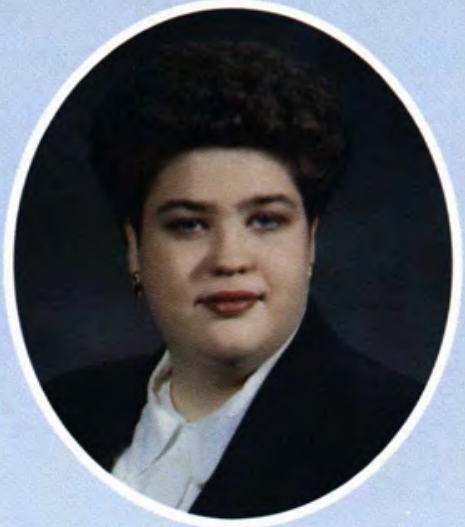

Michelle Plunkitt

Management

Xenia, $\mathrm{OH}$

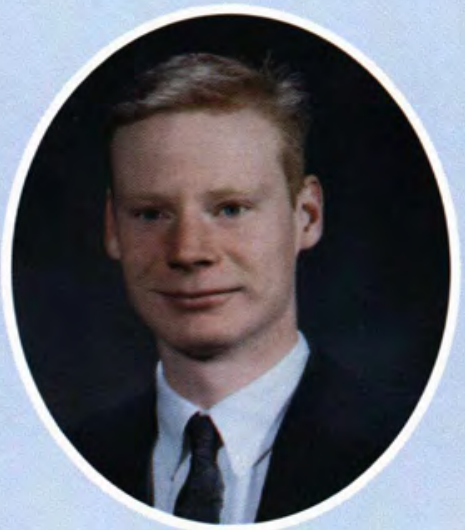

Michael Prall

Criminal Justice

Grass Valley, CA

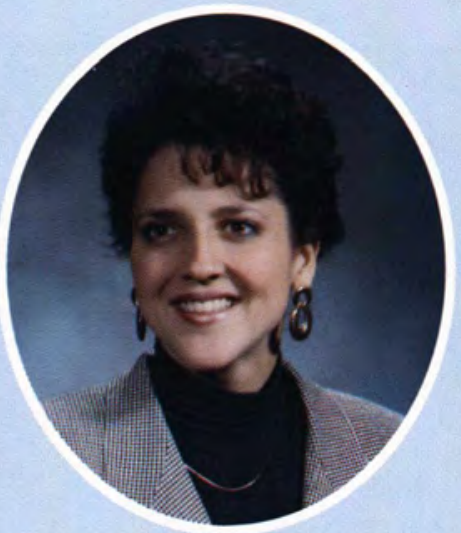

Tonya Ramey

English Education

Washington Court House, $\mathrm{OH}$

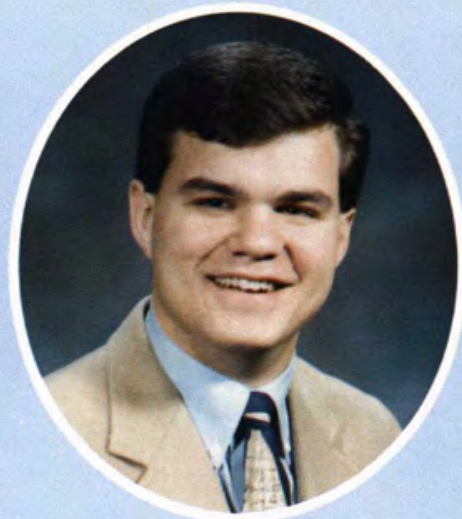

Matthew Rich

Elementary Education

Cedarville, $\mathrm{OH}$

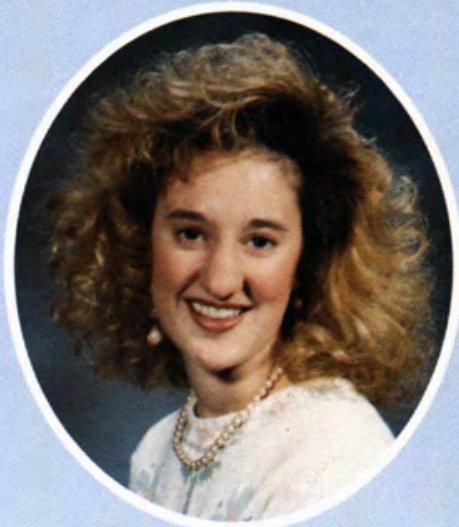

Monica Polish

Finance

Fraser, MI

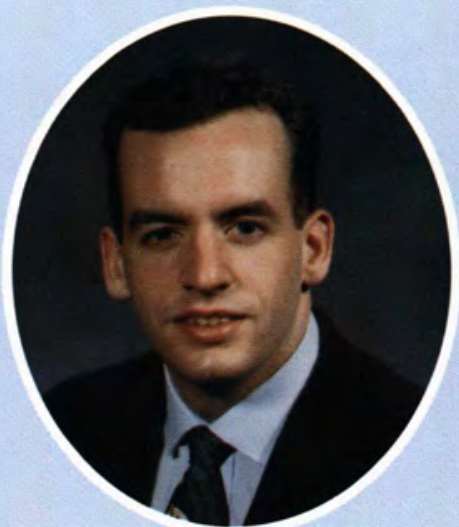

Todd Printz

Broadcasting

Urbana, $\mathrm{OH}$

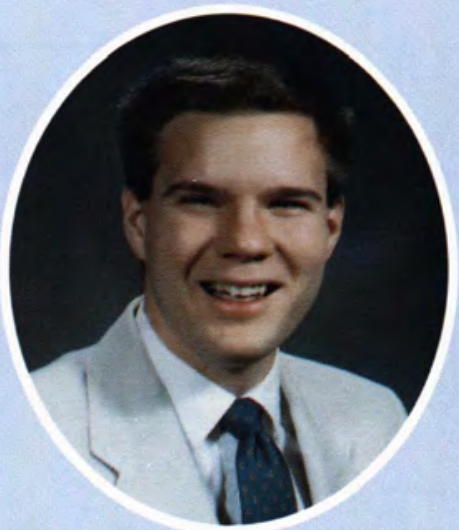

Robert Reed

Bible, Pre-Seminary

Tallmadge, $\mathrm{OH}$

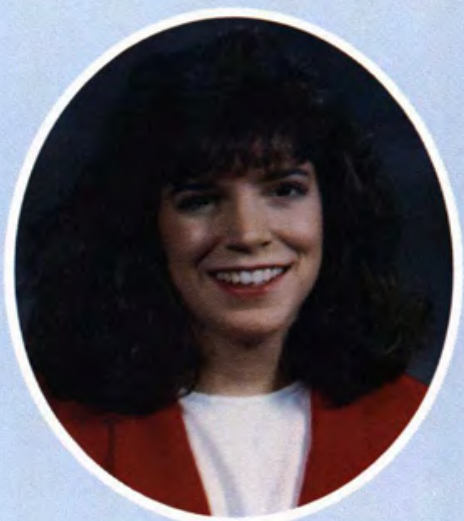

Deborah Richard Accounting/Finance

Havertown, PA

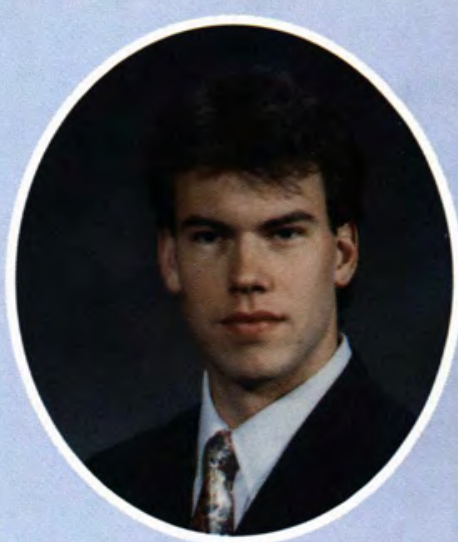

Matthew Potts

Behavioral Science

Oxford, MI

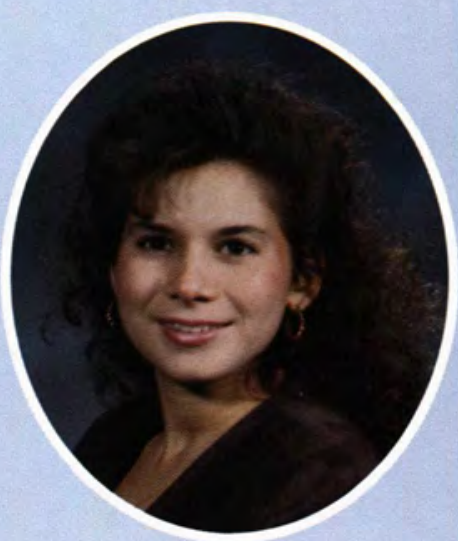

Krista Pritchard

Nursing

Seminole, FL

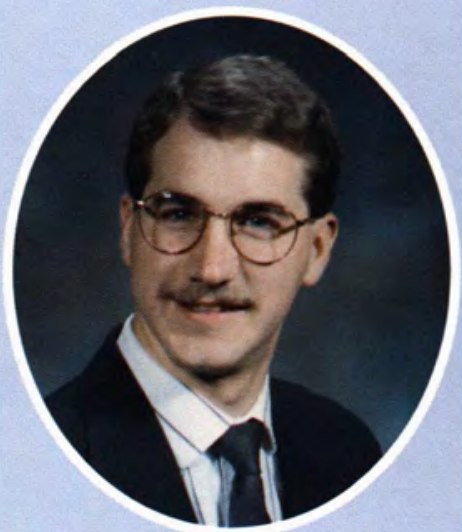

Donald Ressler

Accounting

Dalton, $\mathrm{OH}$

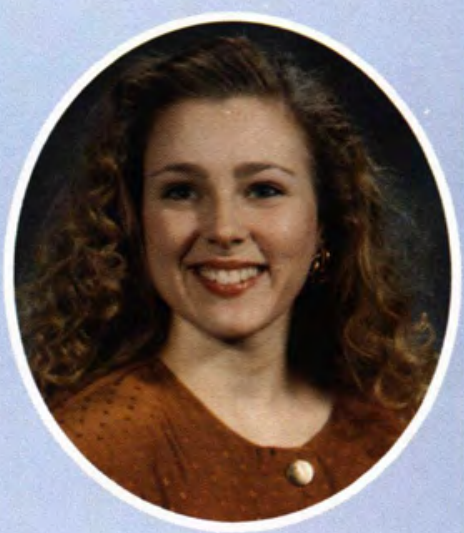

Karla Richardson

Nursing

Adrian, MI 


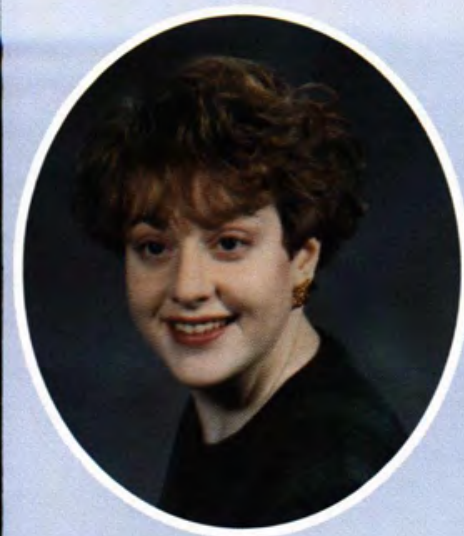

Heather Rifenberick English Joliet, IL

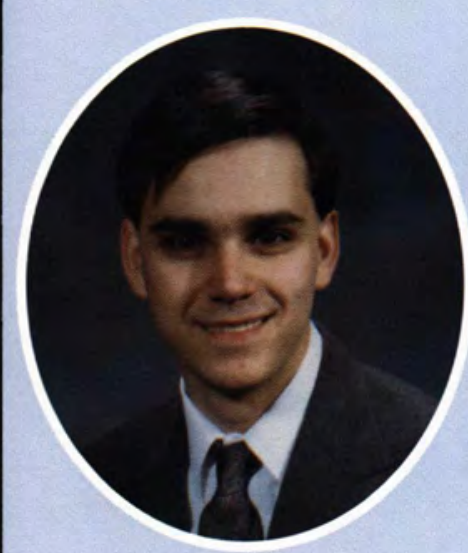

John Robertson Accounting

Cumberland, $M D$

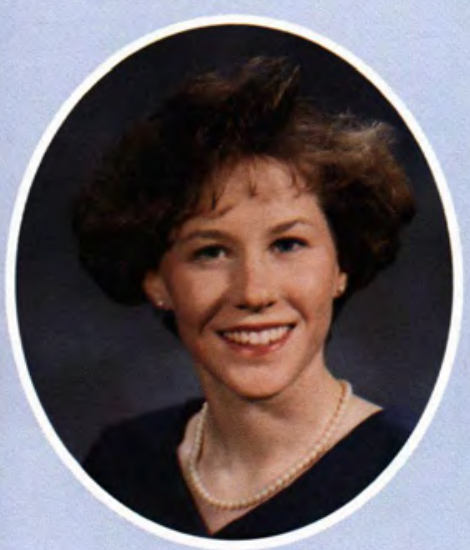

Jeanette Rome

Applied Psychology

Marysville, MI

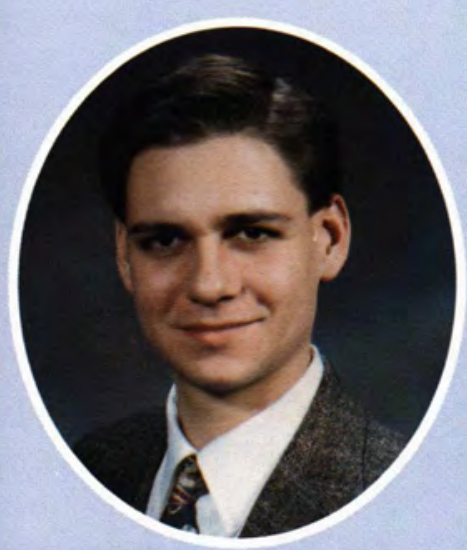

Jonathan Ross

Broadcasting

Chattanooga, TN

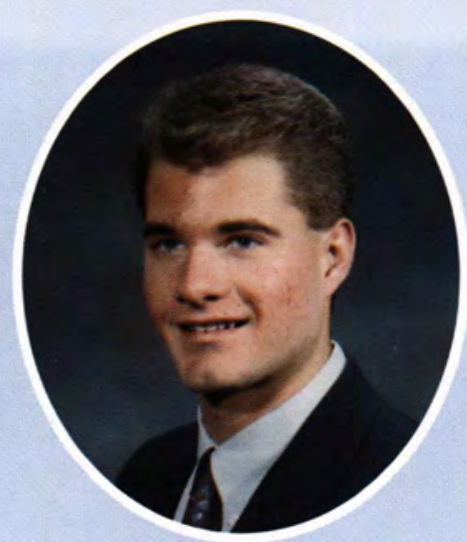

Jeffrey Rinehart Marketing

Delaware, $\mathrm{OH}$

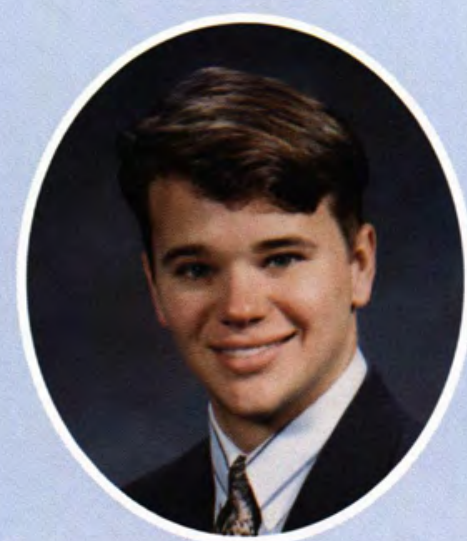

Jeffrey Robey

Communication Arts

Cedarville, $\mathrm{OH}$

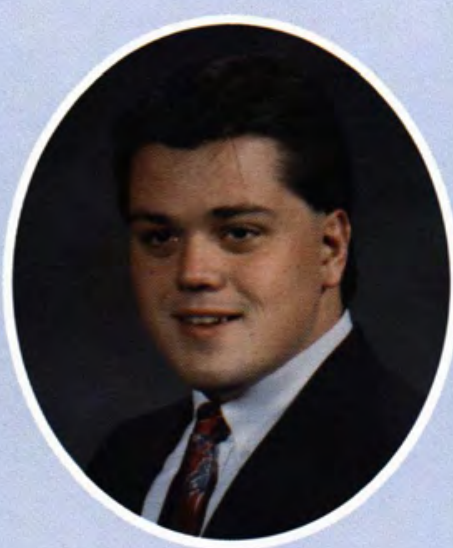

Timothy Roop

Criminal Justice

Cedarville, $\mathrm{OH}$

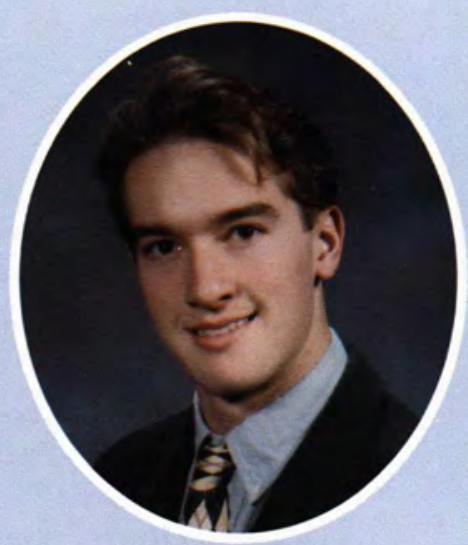

Henry Roy

Finance/Accounting

Portsmouth, RI

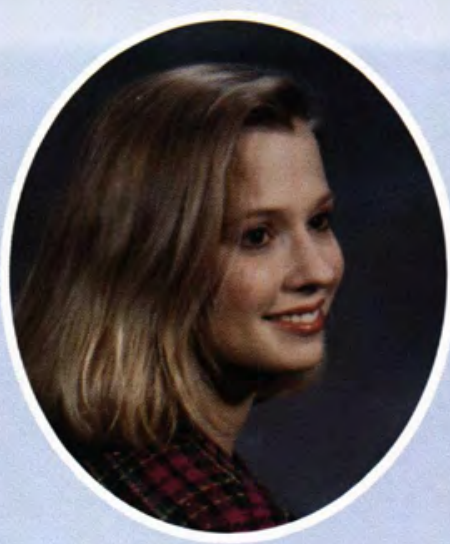

Amy Riniker

Psychology

Sellersville, PA

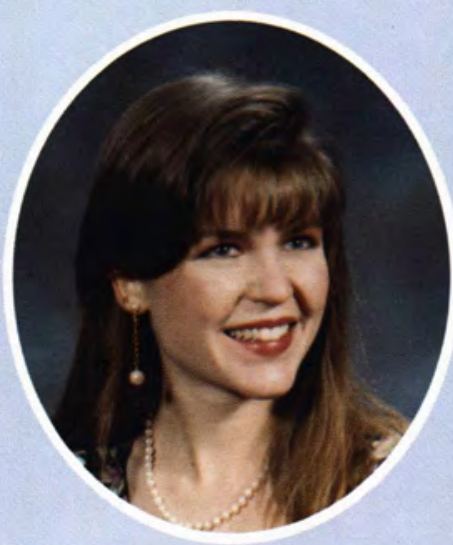

Theresa Rodgers

Communication Arts

Xenia, $\mathrm{OH}$

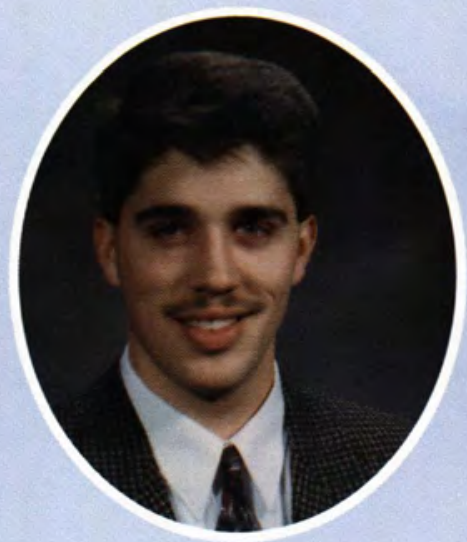

David Ross

Criminal Justice

Greenfield, IN

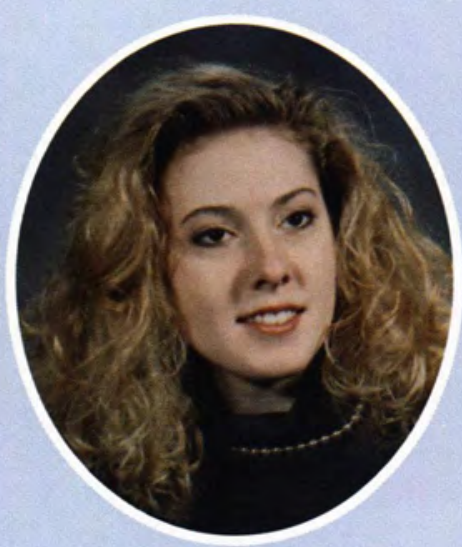

Karen Ruberg

Business Education

Rochester, IN

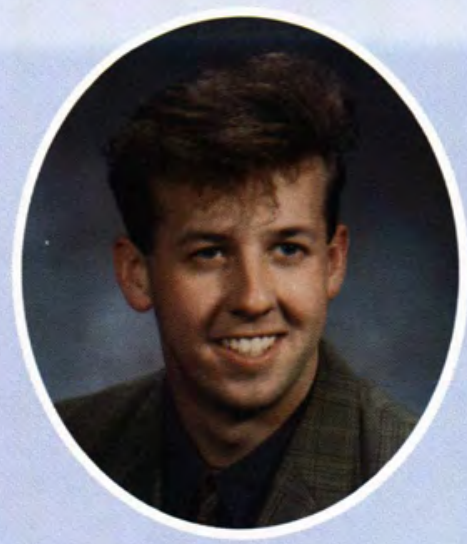

Dale Roberts

Marketing

Sykesville, $M D$

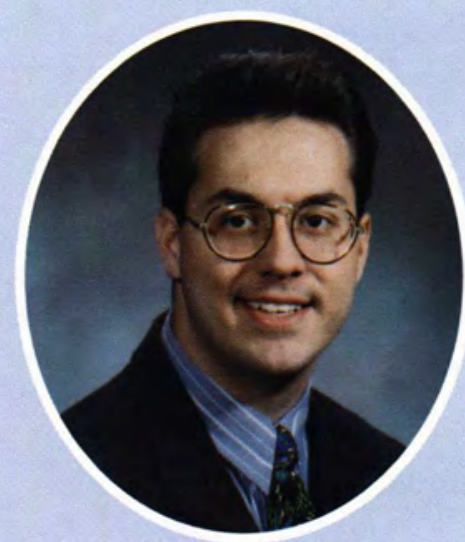

Mark Roeder

Communication Arts/Political Science Centerville, $\mathrm{OH}$

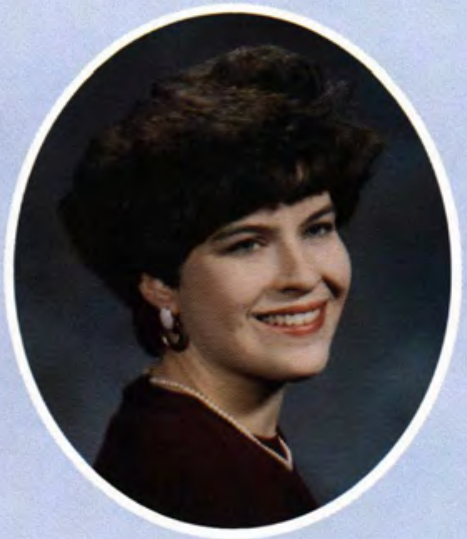

Jennifer Ross

Broadcasting

Cedarville, $\mathrm{OH}$

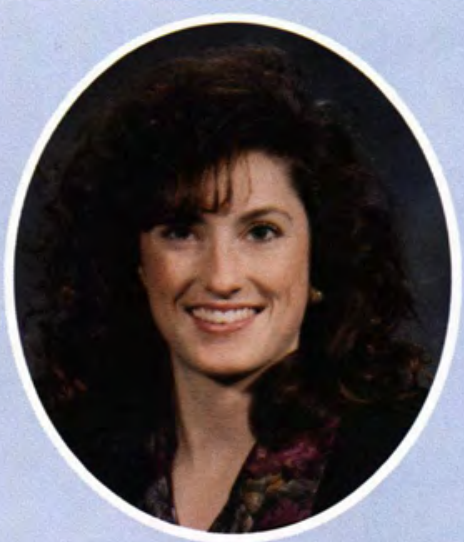

Jennifer Rudicil

Elementary Education

Westerville, $\mathrm{OH}$ 


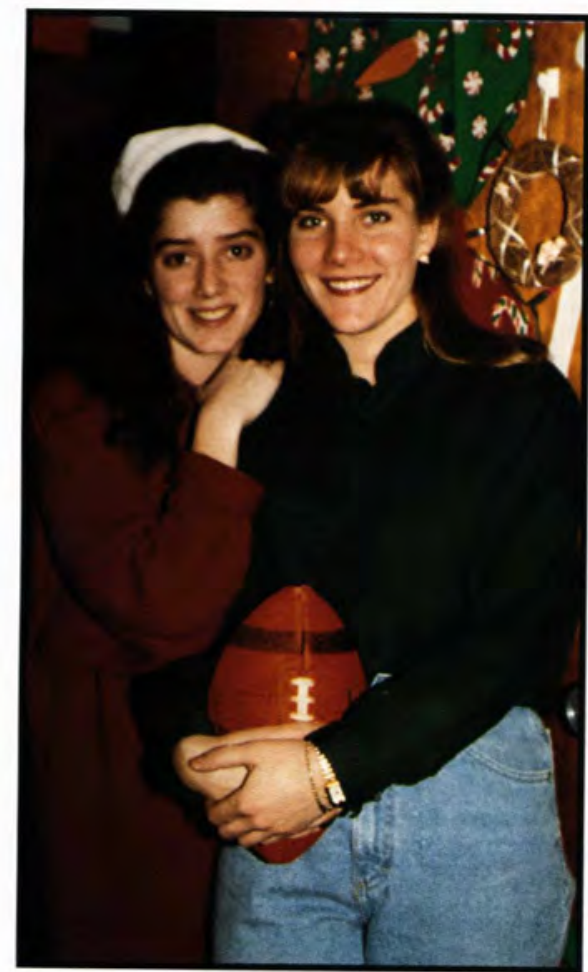

\section{Carpe Diem}

"So teach us to number our days..." Psalm 90:12. As students approach their senior year, they realize that they must make a number of decisions about what they want to do with their remaining college days. Everything they have "always wanted to do" floods their minds. They start thinking, "This is my last chance to join that organization, to ask someone to J/S or Homecoming, to go on MIS, to get engaged, to walk the beams in the ENS building without getting caught, and so on."

At the beginning of the year, each senior must set his/her priorities regarding involvement on campus, in ministry, and in academics. Throughout the year, they see their time getting shorter and shorter. Eventually, they all catch a severe case of "senioritis" desiring to spend more time with friends and less with their books.

These four years may be seen as a microcosm of life. May the brevity of time in college remind us that our lives are short and full of many opportunities that could be our "last chances." So as the Latin phrase challenges us, Carpe Diem!

- Marsha Olsen

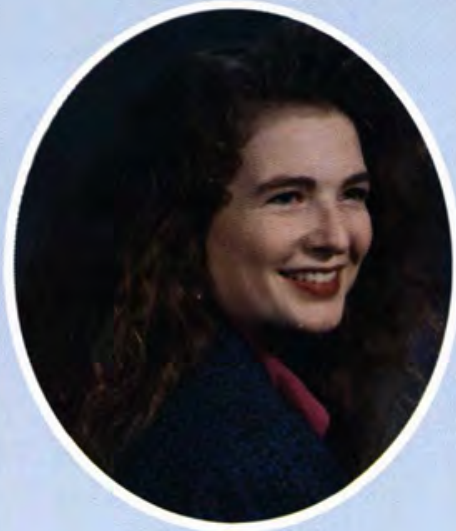

Julie Rutt

Accounting

Mount Joy, PA

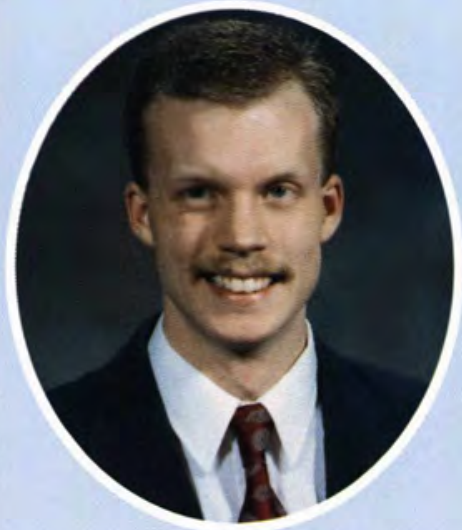

Brian Schaffer

Management

Cedarville, $\mathrm{OH}$

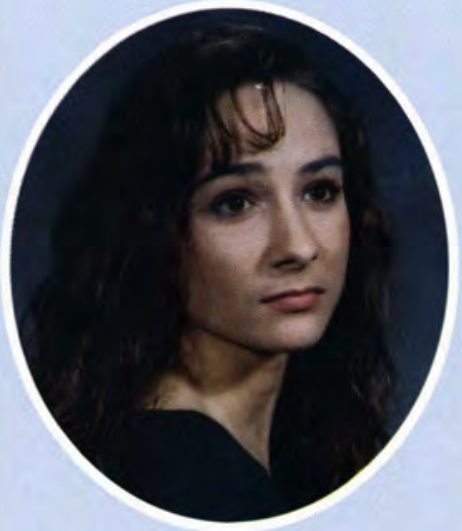

Gretchen Schwingle Behavioral Science/Psychology Naples, NY

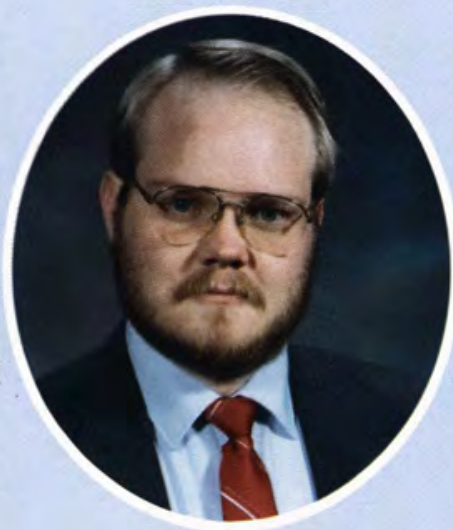

Donald Shade

Mathematics

New Port Richey, FL

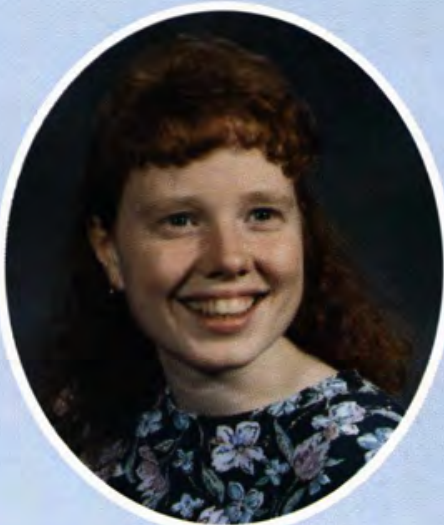

Lynann Salzman

Elementary Education

Leechburg, PA

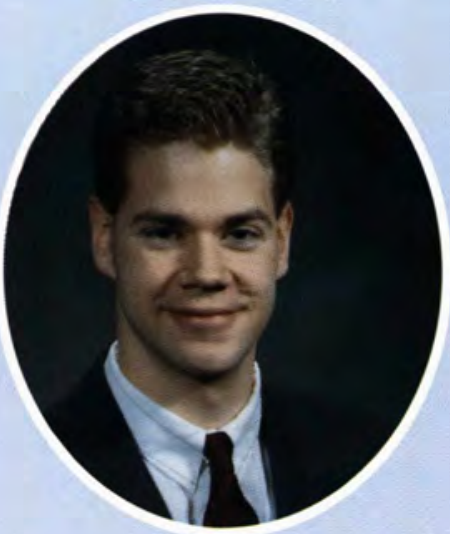

Douglas Schmitt

Finance

Wheaton, IL

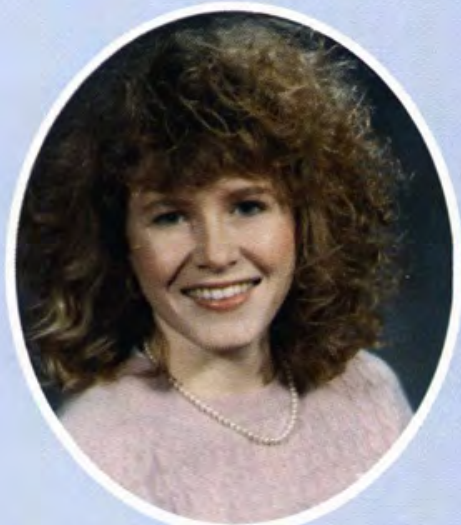

Julie Seaman

Elementary Education

Bellbrook, $\mathrm{OH}$

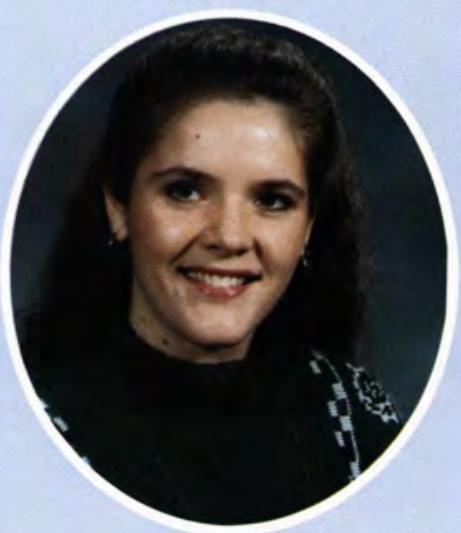

Lori Shaw

Social Work

Horseheads, NY

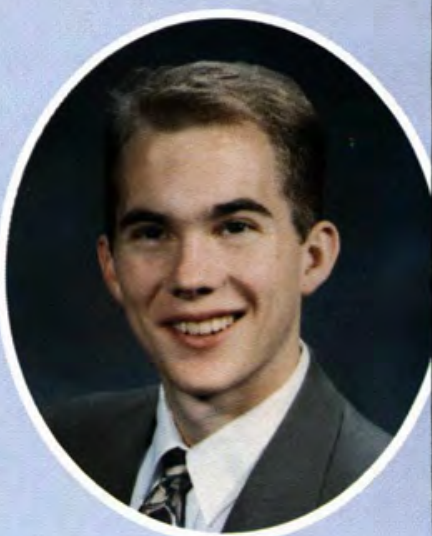

Warren Sayre Biology

Dayton, TN

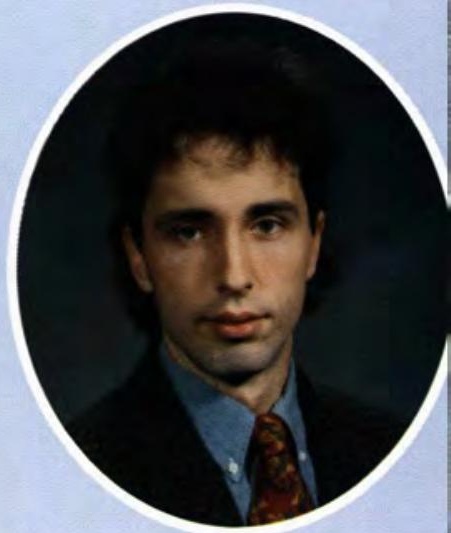

Michael Schmitt Marketing

Beavercreek, $\mathrm{OH}$

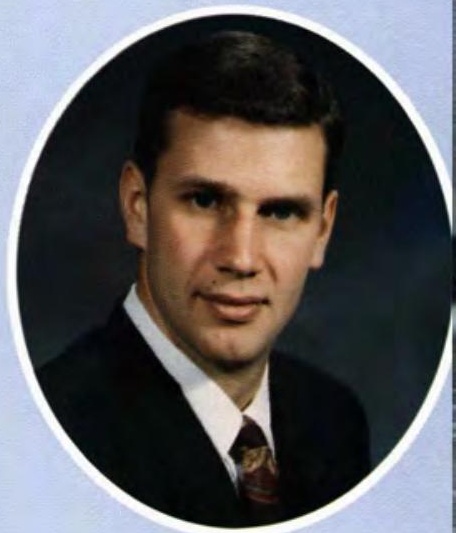

Kelly Seboe

Social Science

Auburndale, WI

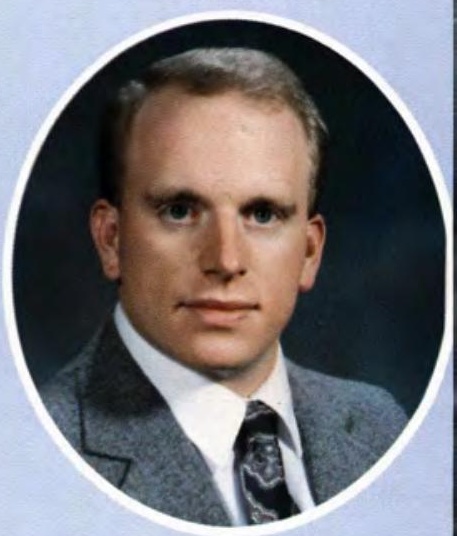

Timothy Shaw

Elementary Education Cedarville, $\mathrm{OH}$ 


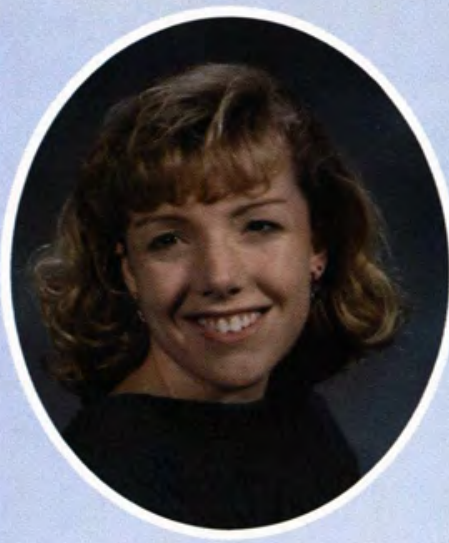

Nikki Starr

Social Work

Coldwater, MI

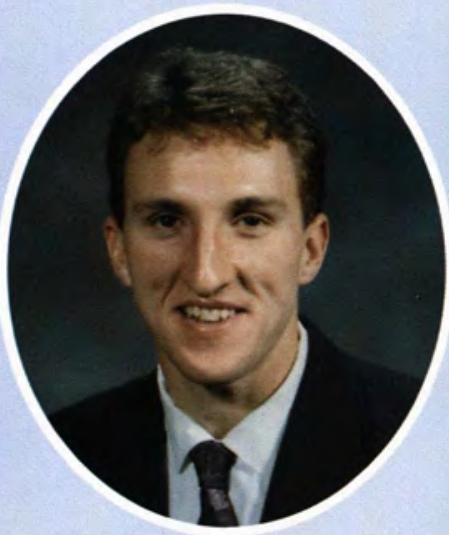

Ryan Stover

Social Science

Xenia, $\mathrm{OH}$

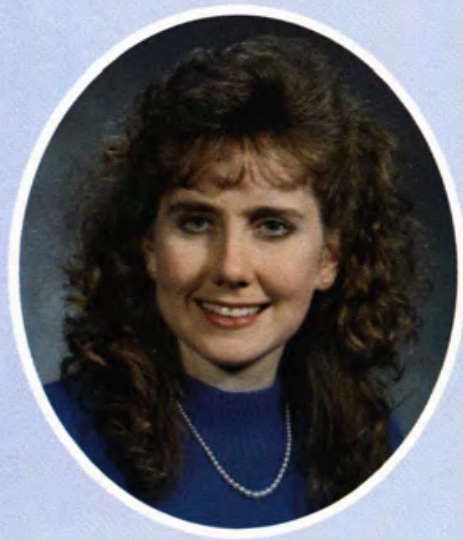

Shelly Sutton

Broadcasting

Lower Burrell, PA

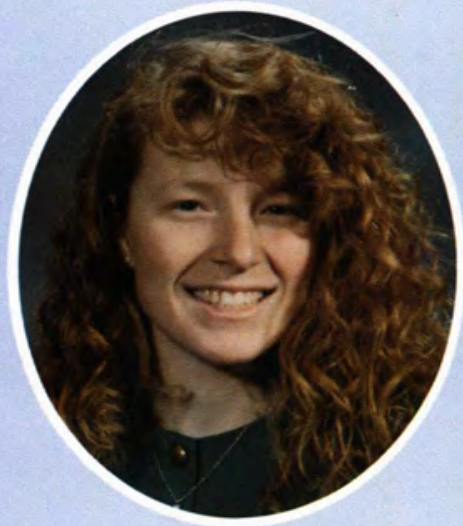

Kelly Taylor

Mathematics

Xenia, $\mathrm{OH}$

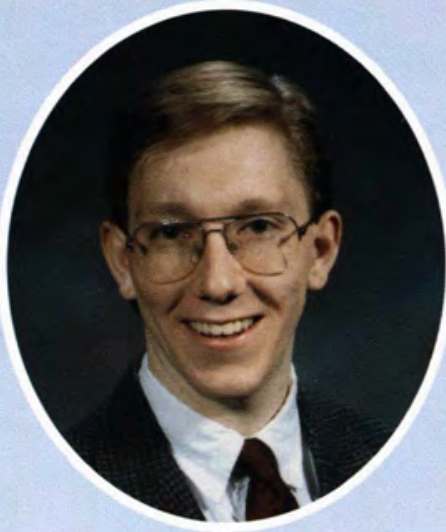

Martin Stephenson Biology

Tacoma, WA

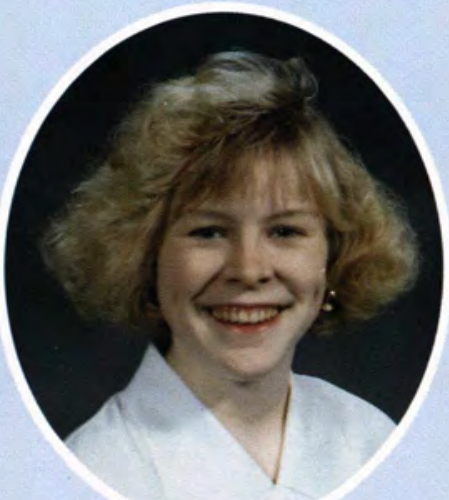

Shanda Strayer

Elementary Education

Ada, $\mathrm{OH}$

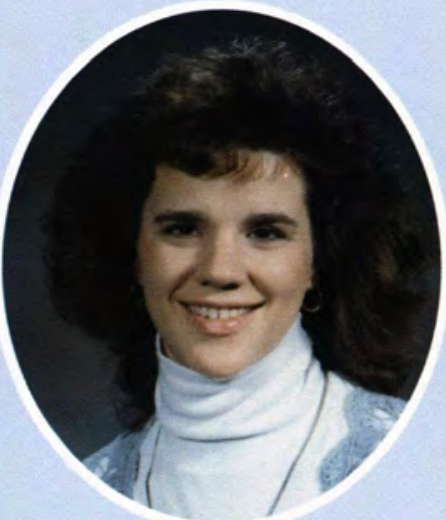

Rebecca Swinerton

Elementary Education

North Conway, $\mathrm{NH}$

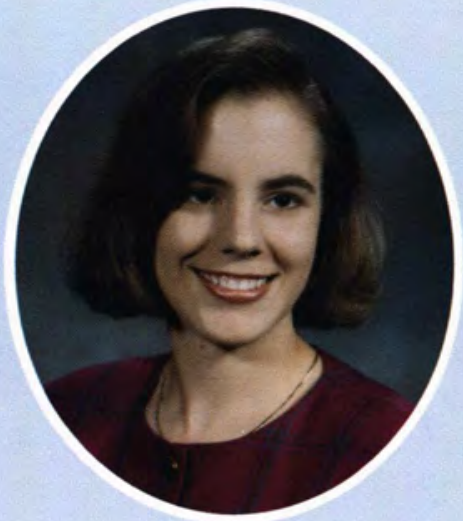

Tania Taylor

Marketing

Rossville, GA

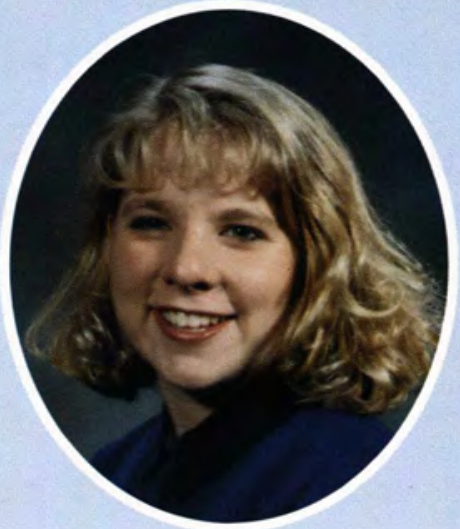

Virginia Stevenson

Elementary Education

Brockport, NY

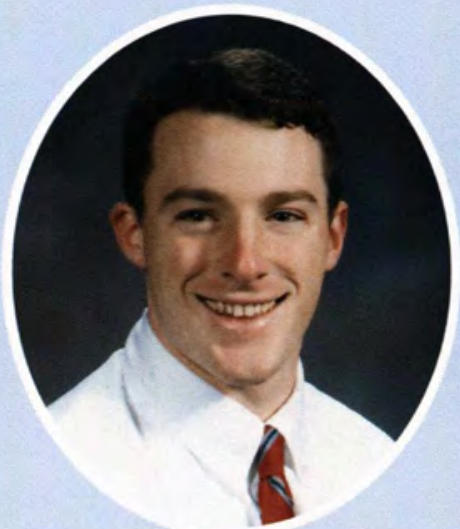

Luman Strong

Behavioral Psychology

Chelsea, MI

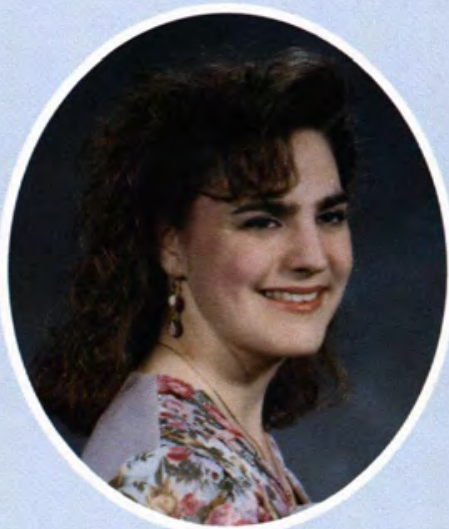

Elizabeth Tait

Elementary Education Elma, NY

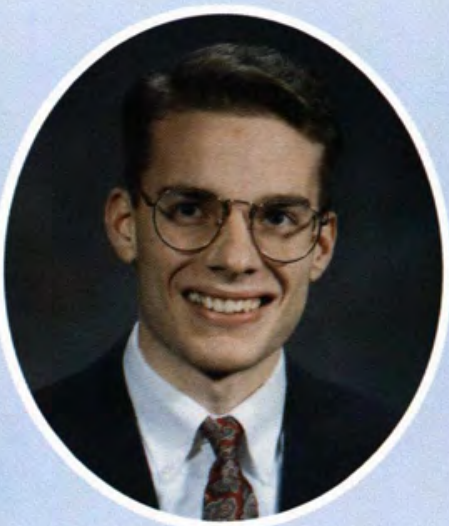

Joel Thomas

Criminal Justice

New Milford, $P A$

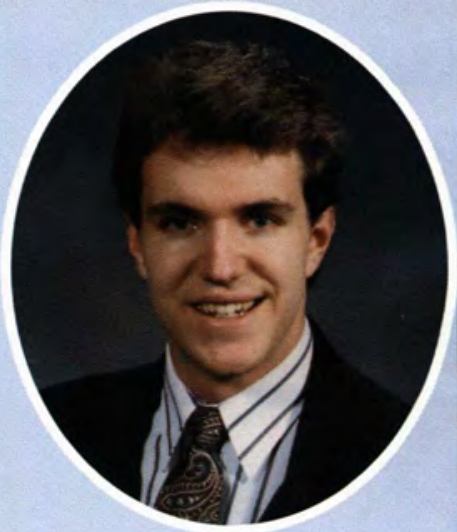

Hans Stonehouse International Business Cedarville, $\mathrm{OH}$

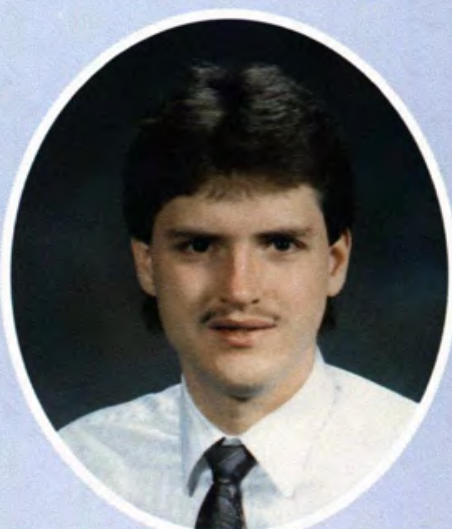

Gary Stumbo, Jr.

Political Science/History

Cedarville, $\mathrm{OH}$

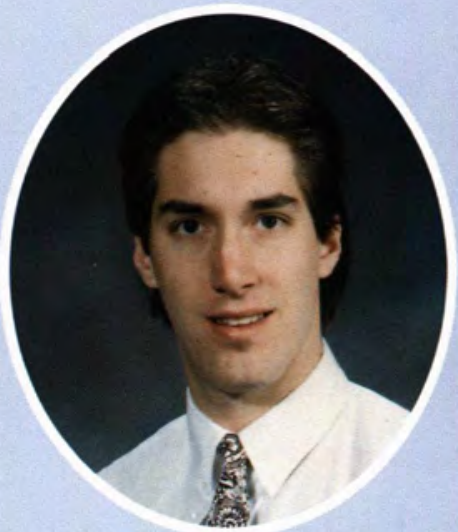

Douglas Taylor

Physical Education Xenia, $\mathrm{OH}$

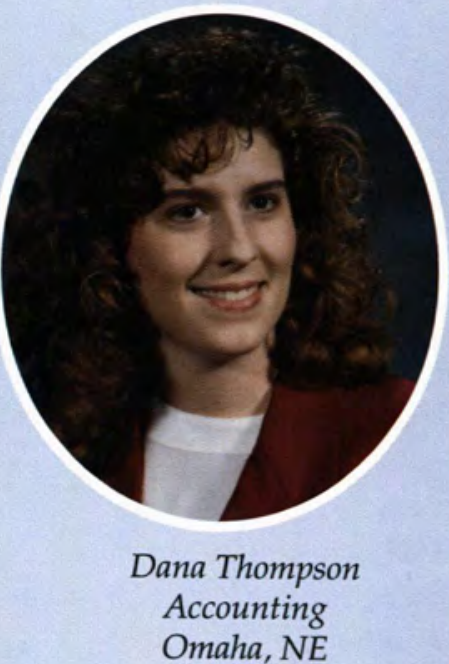




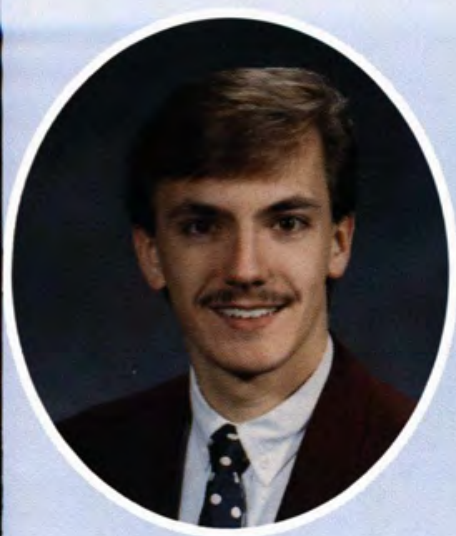

Charles Thorsen

Bible, Comprehensive

Cayuga, NY

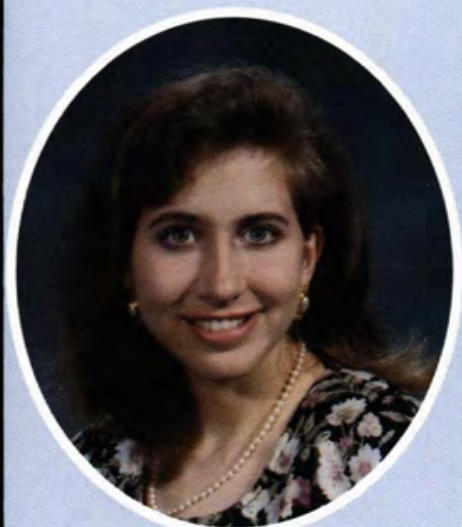

Gina Tschanz

Broadcasting

Holland, MI

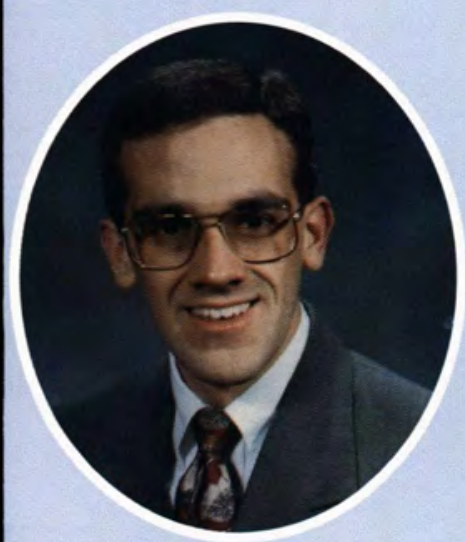

Kenneth Vanderwest

Communication Arts

Muskegon, MI

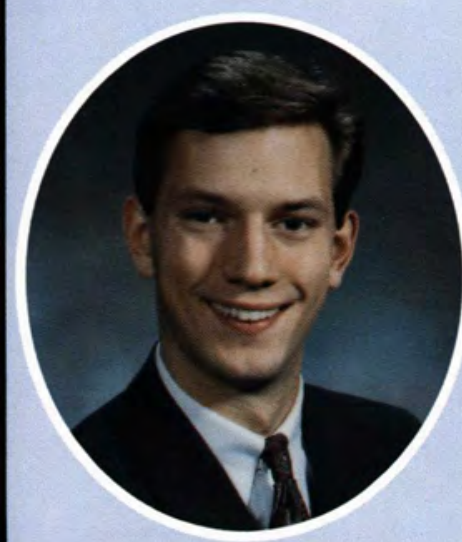

Mark Vroegop

Communication Arts

Schoolcraft, MI

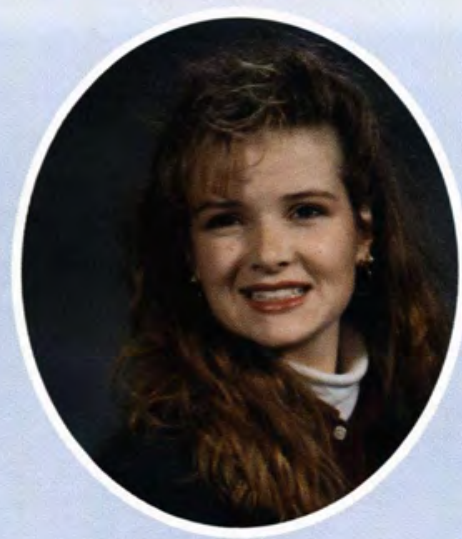

Sheryn Titus

Mathematics

West Mansfield, $\mathrm{OH}$

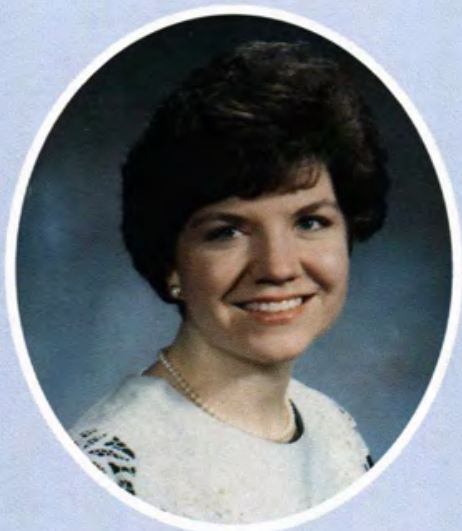

Denise Uhl

Elementary Education

Newfoundland, PA

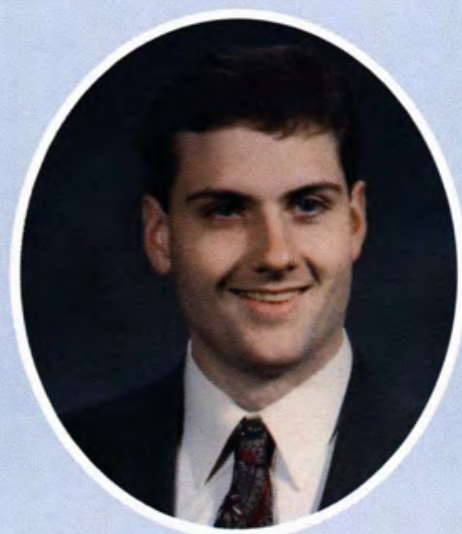

Stephen Vannest

Accounting

Gladwin, MI

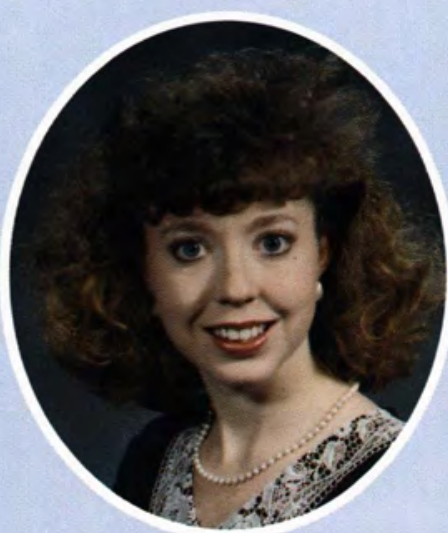

Sandra Waddell

Elementary Education

Ontario, Canada

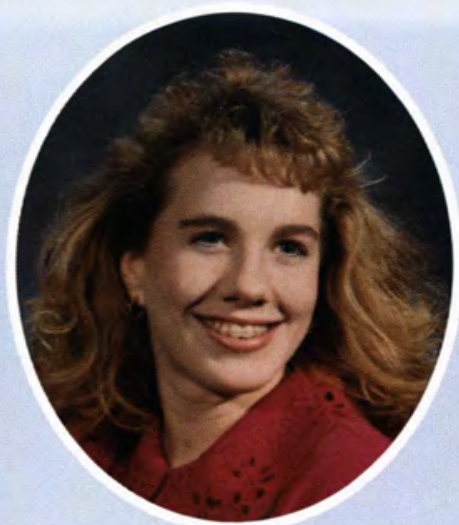

Mary Tramel

Elementary Education

Battle Creek, MI

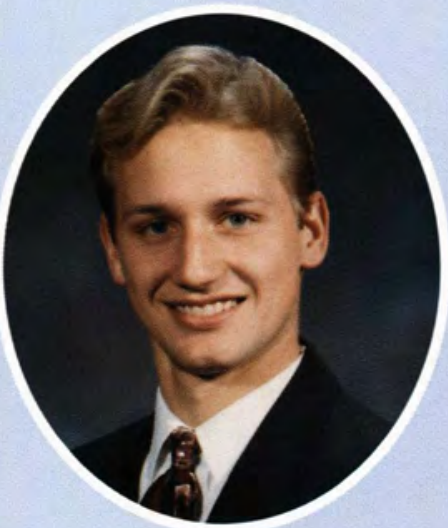

Timothy Vande Guchte

Bible, Comprehensive

Hudsonville, MI

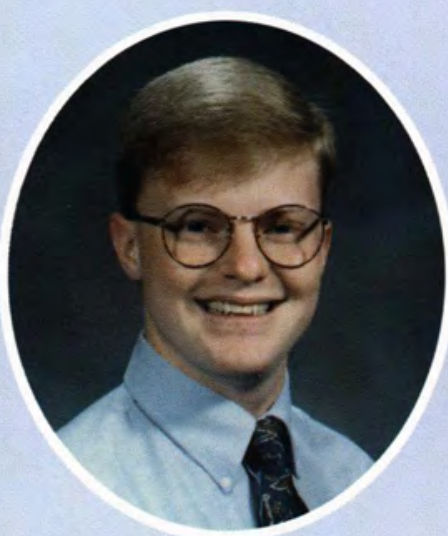

William Veelman

Elementary Education

Cedarville, $\mathrm{OH}$

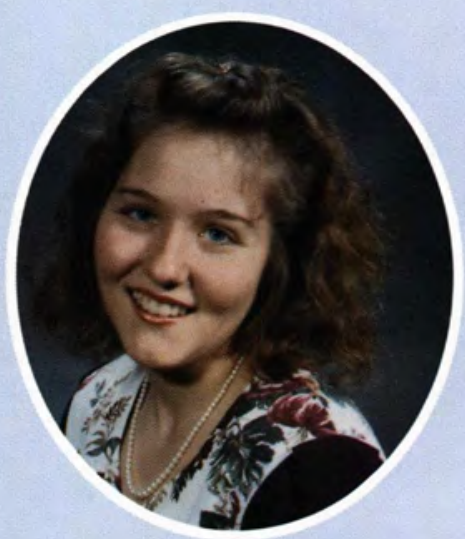

Melissa Wall

Elementary Education

Dayton, $\mathrm{OH}$

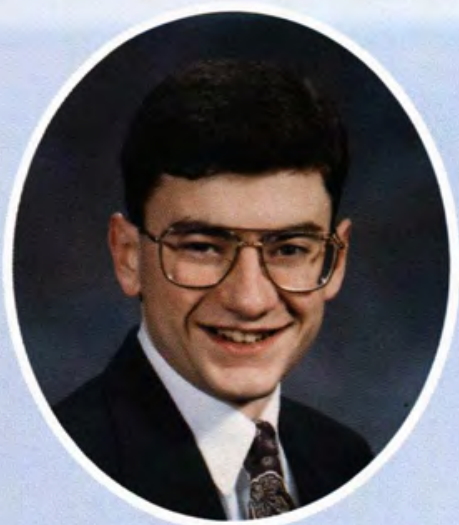

Daniel Treier

Computer Information Systems

Bloomdale, $\mathrm{OH}$

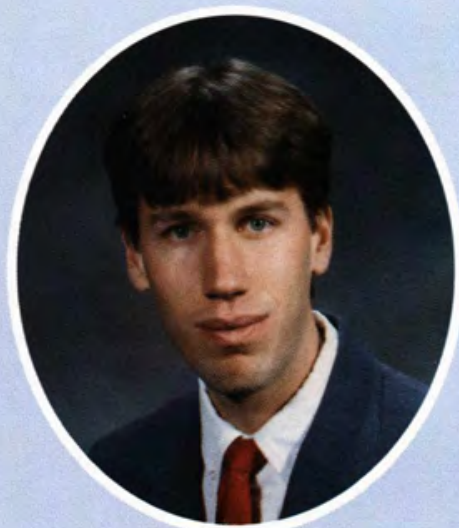

Timothy Vandenberg

Pre-Law

Zeeland, MI

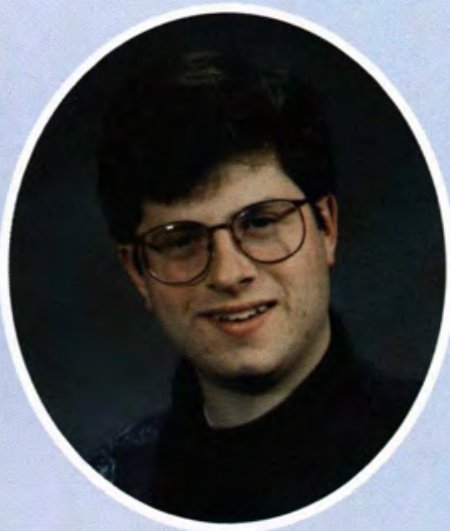

Michael Vrbanac

History

Newark, $\mathrm{OH}$

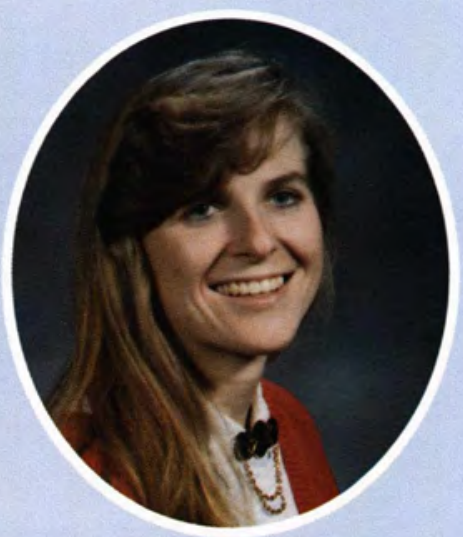

Lisa Waller

Nursing

Cedarville, $\mathrm{OH}$ 


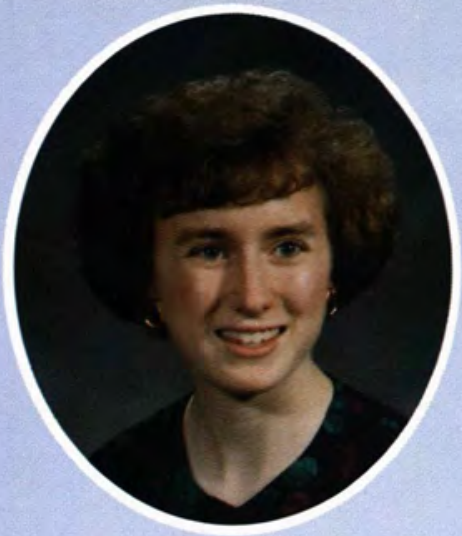

Karla Warnken

Elementary Education

Factoryoille, PA

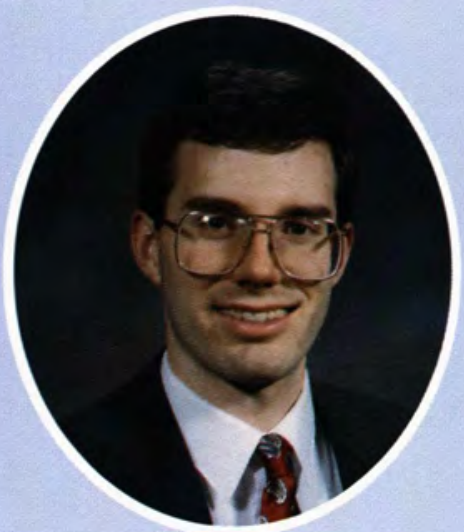

Bradley Weaver

Business Administration Eden, NY

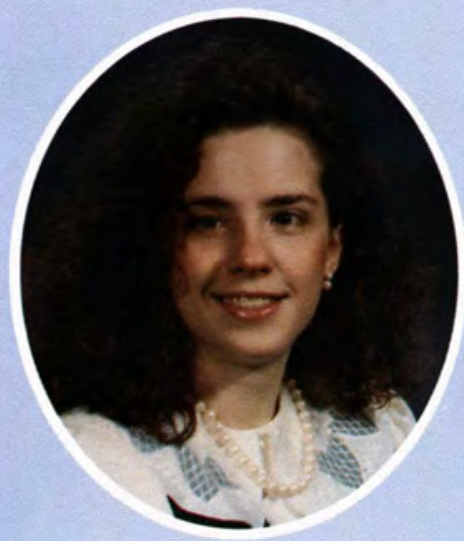

Angela White

History/Political Science Johnson City, TN

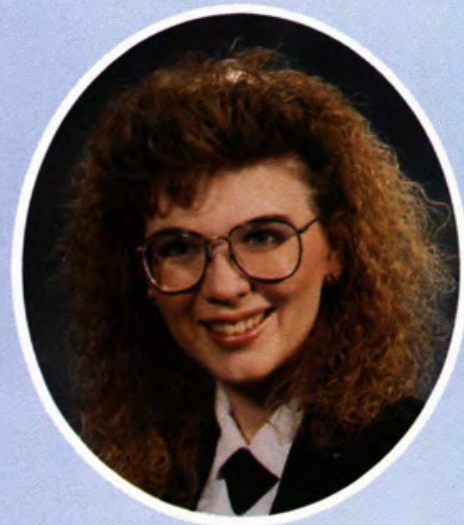

Jori Whittenberg Mathematics

North Branch, MI

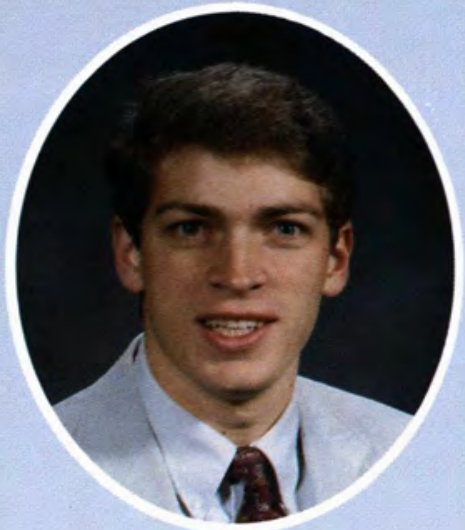

John Warnshuis

Bible, Pre-Seminary

Edinboro, PA

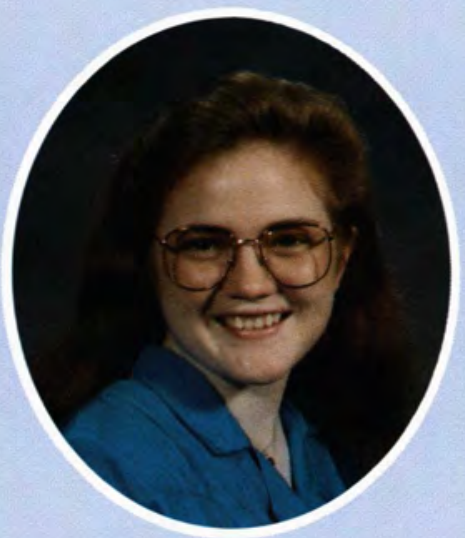

Doris Weaver

English Education

Denver, PA

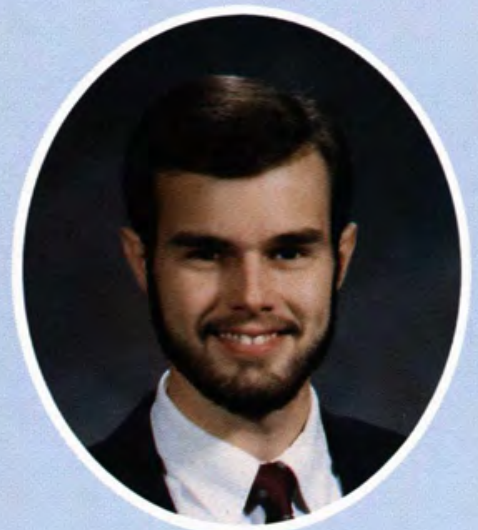

Shawn White

Biology

Sanford, FL

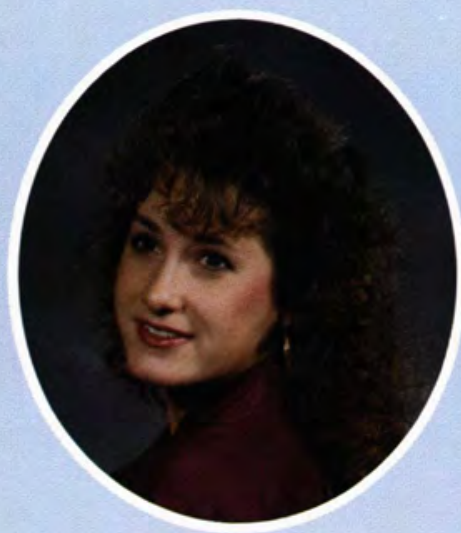

Corinna Williams

Nursing

Shawnee, KS

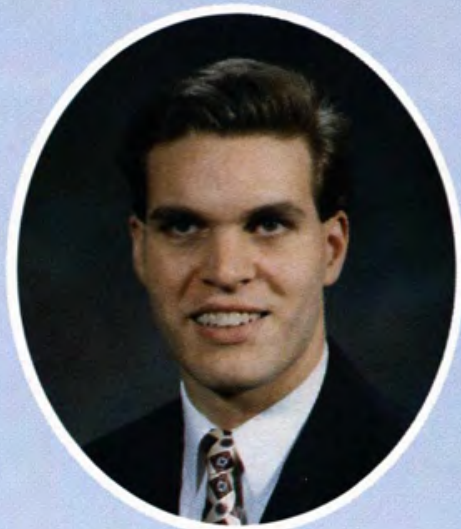

David Warren

Bible, Pre-Seminary

Cedarville, $\mathrm{OH}$

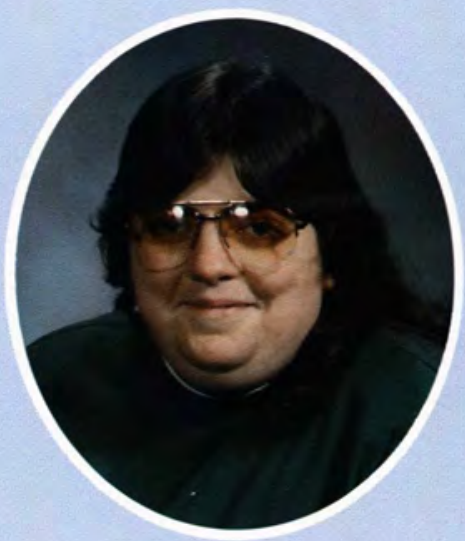

Zy Weber

Psychology

Irwin, $\mathrm{OH}$

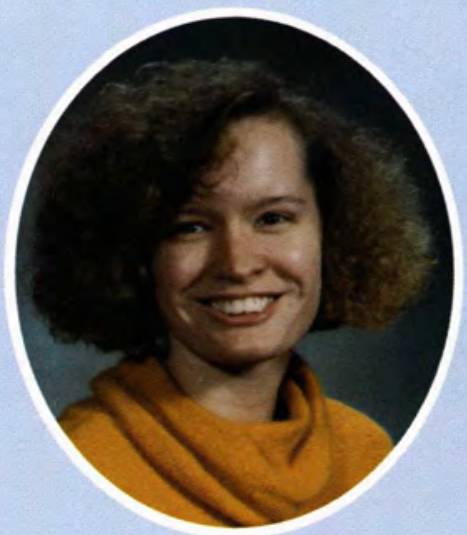

Amber Whited

Behavioral Science/Psychology Bowling Green, $\mathrm{OH}$

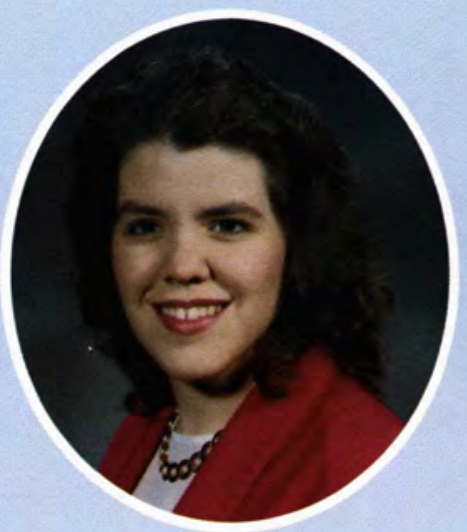

Connie Winch English

Maple Grove, MN

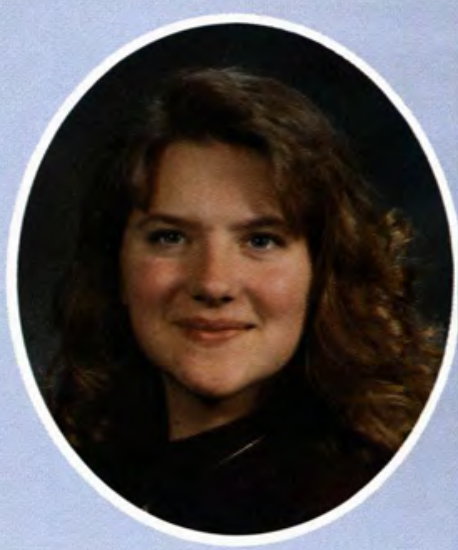

Cassandra Waters

Elementary Education Marion, $\mathrm{OH}$

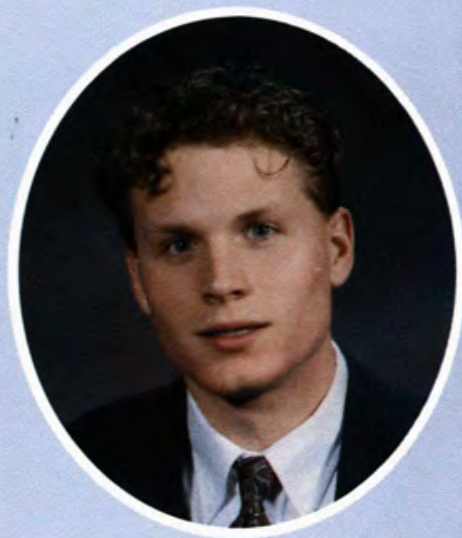

David Weigle

Elementary Education

Williamsport, PA

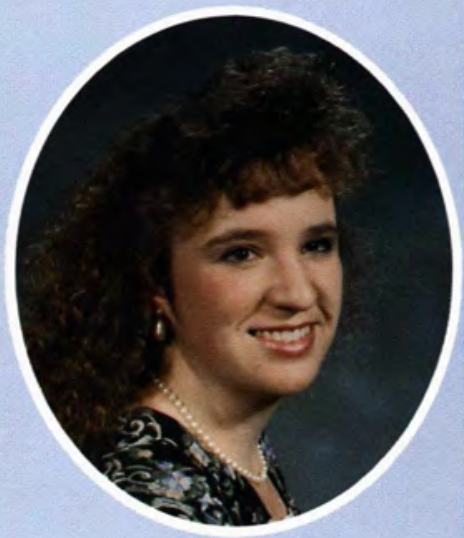

Molly Whitmer

Elementary Education

Bowling Green, $\mathrm{OH}$

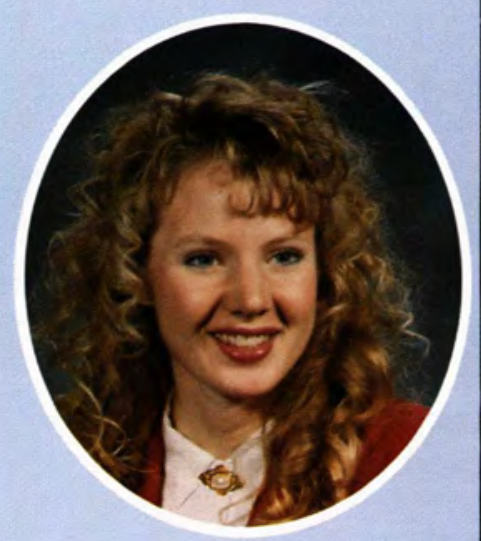

Stephanie Winchip Behavorial Psychology Medina, $\mathrm{OH}$ 


\section{Remember...}

One of the last college memories of a Cedarville Senior is the good-bye chapel when the memories of the past four years are reviewed, the class song is sung as a tear escapes an eye or two, and the class verse suddenly takes on a new meaning as you stand prepared to enter "THE WORLD."

ISamuel 12:24 - Only fear the Lord, and serve Him in truth with all your heart; for consider how great things He has done for you.

"Hmmm, only fear the Lord? That's all I have to do? I've been "fearing" a lot more than that lately. How am I going to find time to get all this last minute work done? What if my interview Thursday is a flop? How long will my parents allow a jobless, spouseless, college graduate to vegetate under their roof?"

"...and serve him in truth with all your heart;"

Yea, I've heard that a million times -- with all your heart, soul and mind. I know this sounds selfish, but how do I know I can serve Him with all my heart without losing out on what I want?"

"for consider how great things he has done for you."

"Oh, I get it! The great things God has done for me are proof that I should serve Him with all my heart. But what great things has God done for me? I can't think of...well, I guess He did provide the finances for me to attend here. Not only that, but he provided the support for my MIS trip last summer. He did send someone to encourage me last week when I was feeling depressed, and oh, I forgot to thank Him, He helped me through that presentation Monday that I was so nervous about. Now that I think of it, He even helped me pass Foundations with a C + my freshman year! I guess God has blessed me. He saved me. What could be greater than that? I really do serve a Great God, and He has done great things for me.. -Marsha Olsen

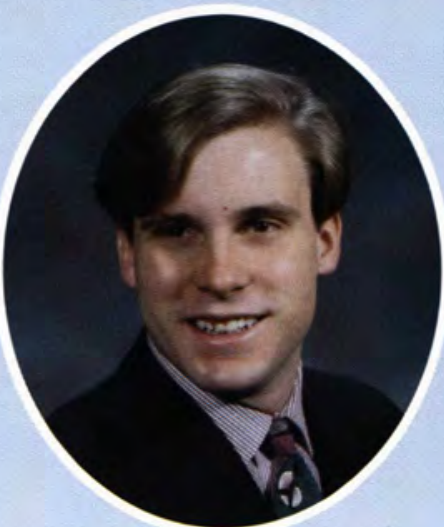

Craig Yoder

Bible, Comprehensive Berne, IN

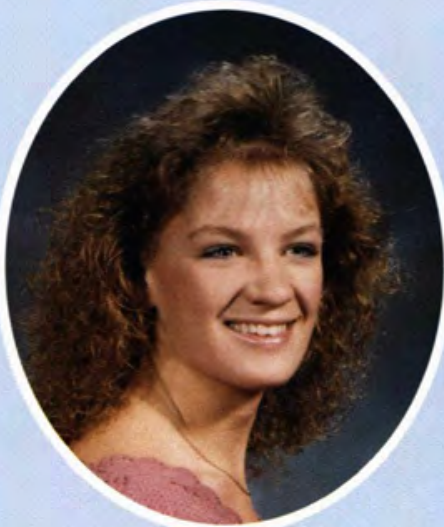

Amy Zehr

Elementary Education Fort Wayne, IN

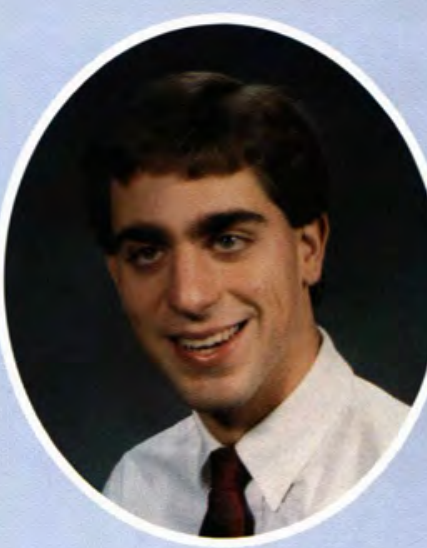

Nathan Yoder Social Science Irwin, $\mathrm{OH}$

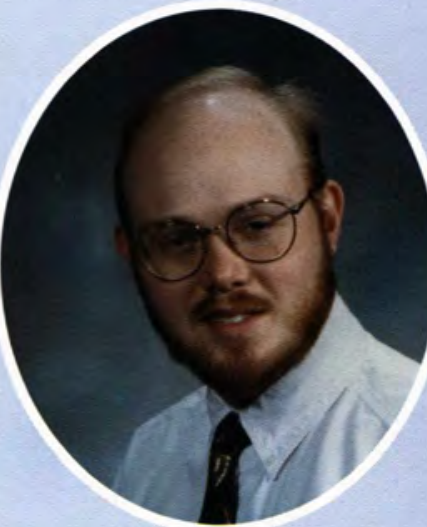

Jeffrey Zwart Biology

\section{OFFICE}

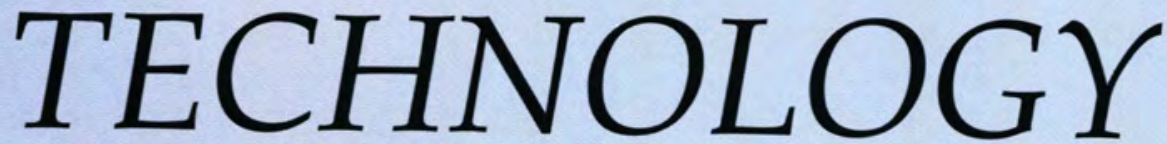

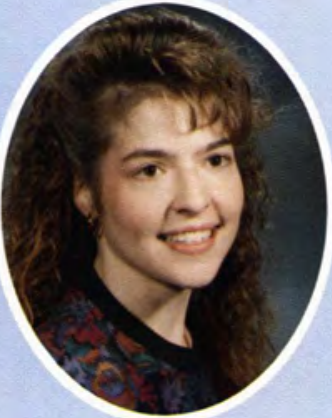

Leah Halsey

Brownsburg, IN

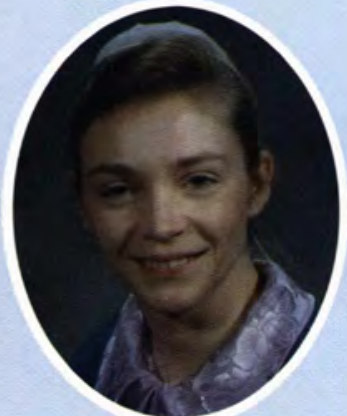

Dorothy Marner Arthur, IL

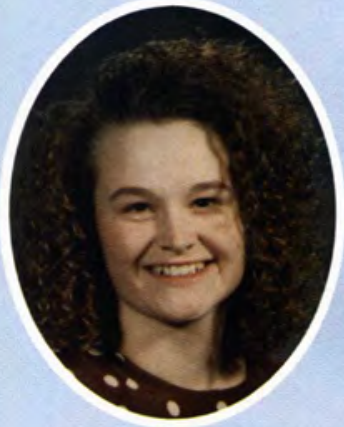

April Case

Greenwich, $\mathrm{OH}$

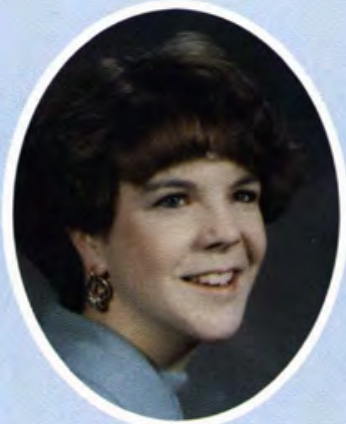

Deidre Moore

Rochester, MN

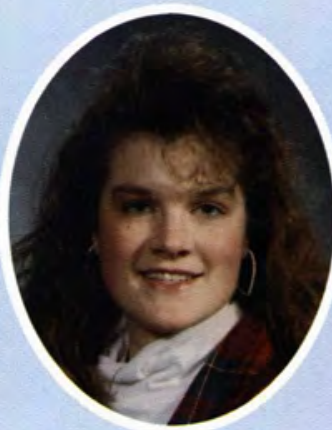

Ondrea Mullins

Ortonville, MI

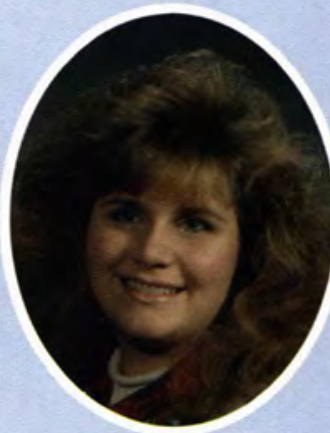

Cheryl Deinum Houston, TX

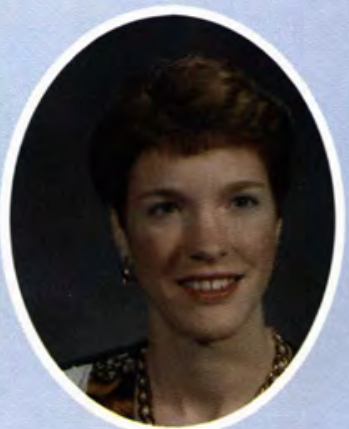

Jennifer Tyson Horseheads, NY 
AFTER A LONG WAIT, Tonya Ramey received her cap and gown.

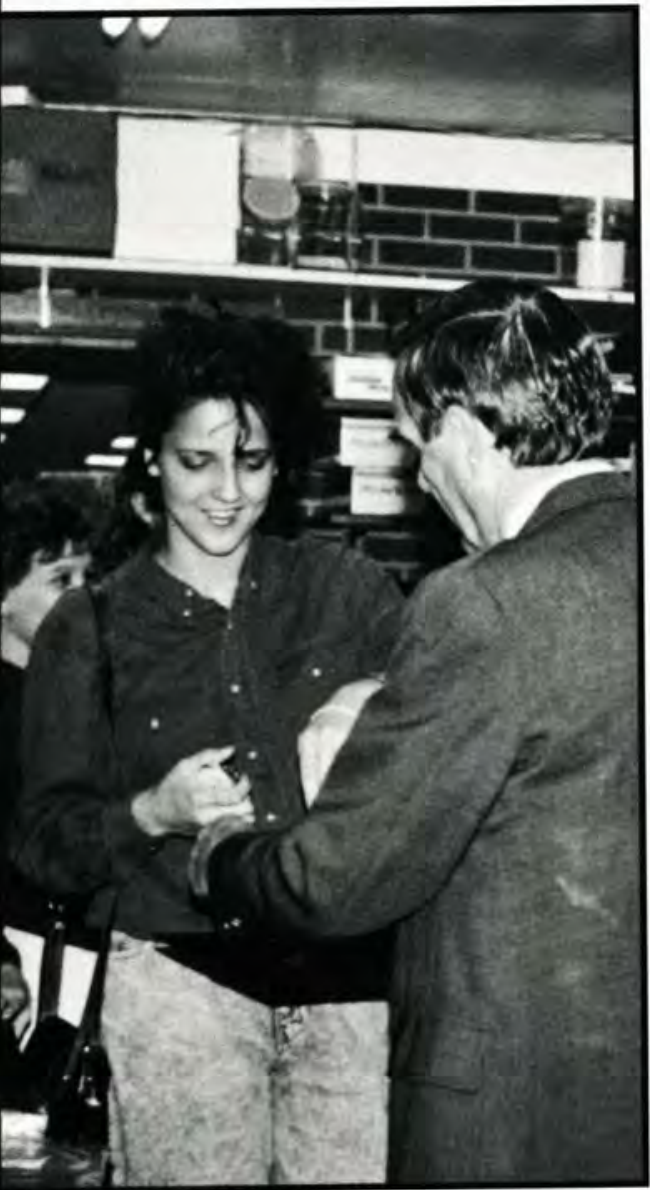

\section{Party in a}

\section{parking lot?}

If there is one thing that attacks seniors as the day of graduation creeps nearer, it is the itch to party, and there is no small quantity of parties provided to soothe this itch at Cedarville. There is the Ninety-three Days Party, the Senior Day, the Senior Night, the Senior Reception, the Parents' Night, the Junior/Senior Banquet, and the Senior Celebration. (It is a wonder there is even time for academic pursuits.) Yet amid this plethora of parties, there is one party that is unique - the Senior Parking Lot Party.

Now everyone knows that standing in line is generally not considered an occasion calling for a party. However, a senior with party itch will take any occasion as an excuse for a party.
So rather than stand in line for graduation tickets, tassel, cap, and gown while listening to the usual standingin-line-comments ("How much longer?", "I could have driven to Dayton and back by now!", Isn't there a faster way to do this?"), Cedarville seniors take this opportunity to fellowship with their friends. Of course, a party calls for music and food, so the loud speakers are brought in; and as the seniors fellowship in line in the bookstore parking lot, they enjoy hot dogs made with toppings to order and freshly squeezed lemonade. Food, drink, friends, fellowship and a couple of tunes - what more is needed for a party?

-Ruth Pfahler

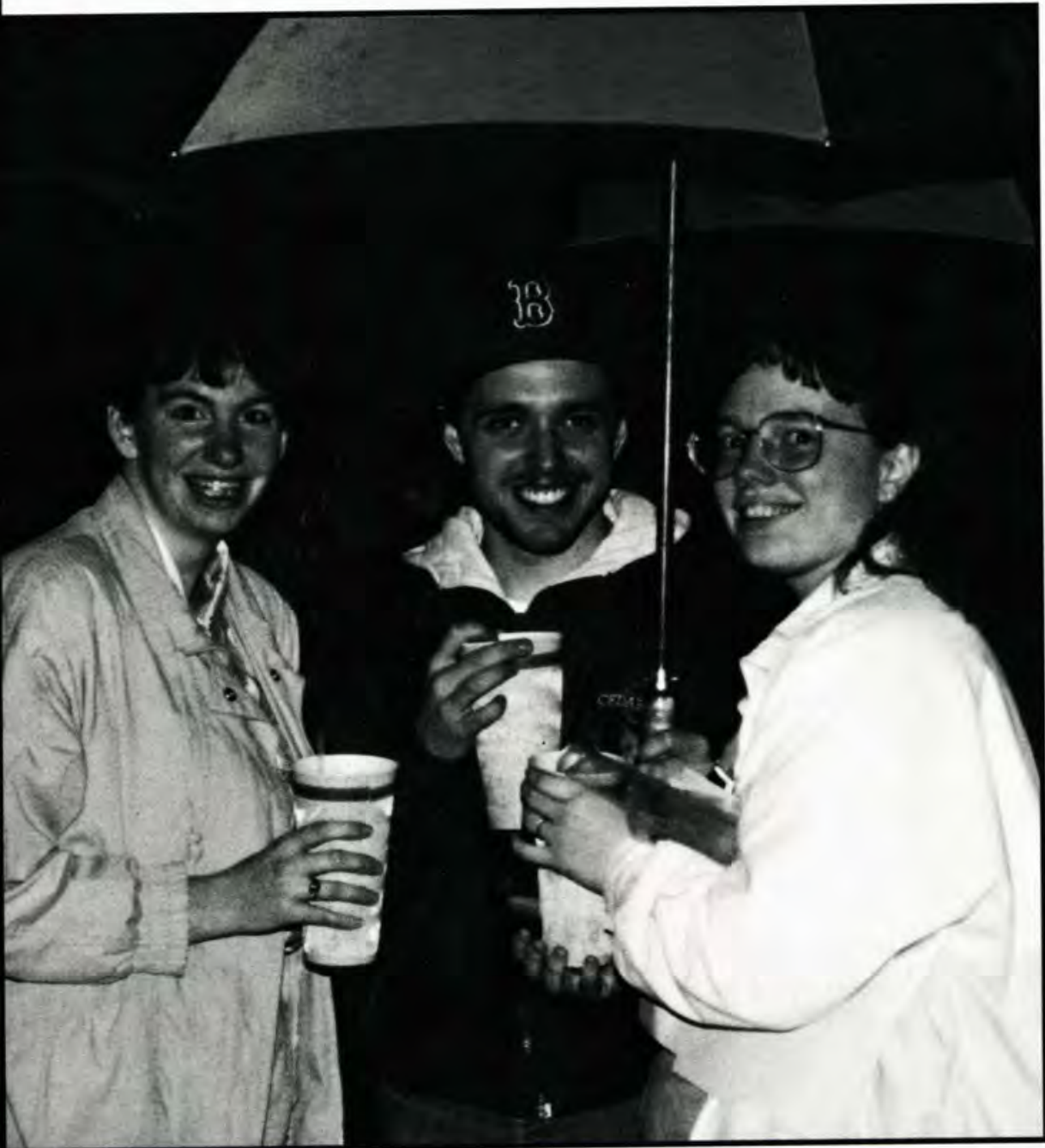

DESPITE THE RAIN these seniors still can smile.
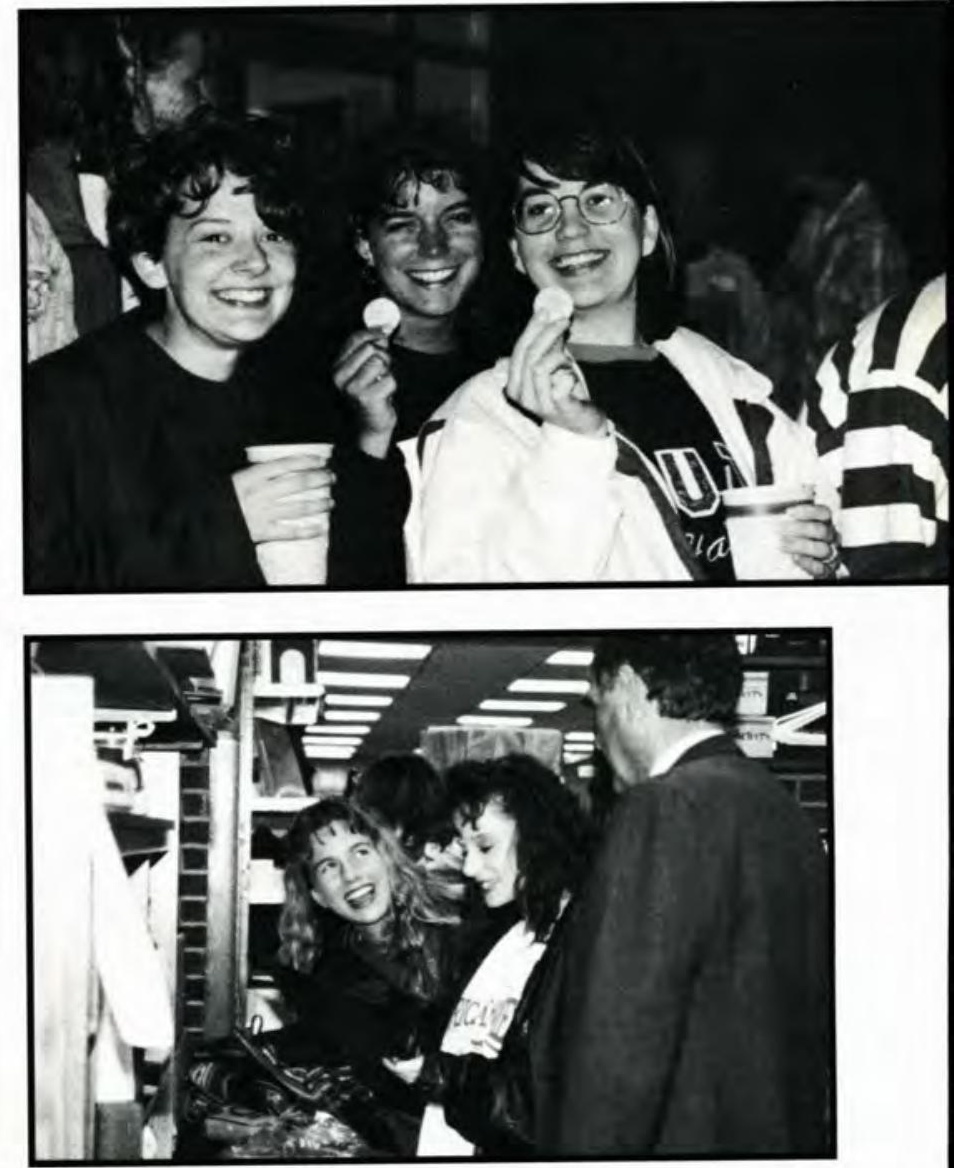

Top: FOUR HARD YEARS OF WORK ALL PAST, Jen Shriver, Debbie Richard and Lori Smith enjoy their last few days together.

WE DON'T HAVE TO PAY MORE MONEY, DO WE? 


\section{Some Lasting Memories}

IN DEEP THOUGHT Mark Vroegop reflects during his camping trip.

PIZZA is a favorite for all college students.
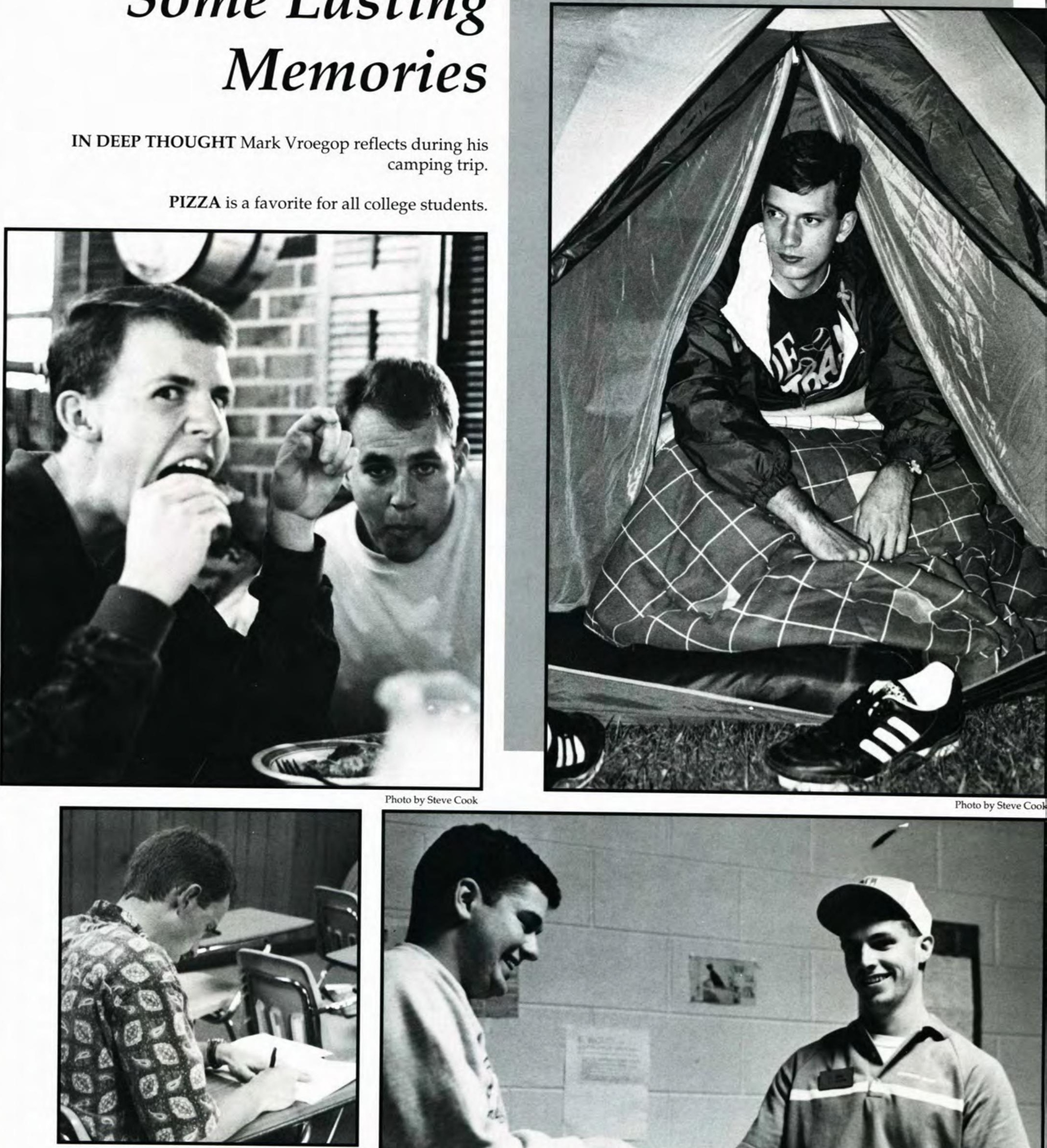

Photo by Steve Cook

hoto by Steve Cook

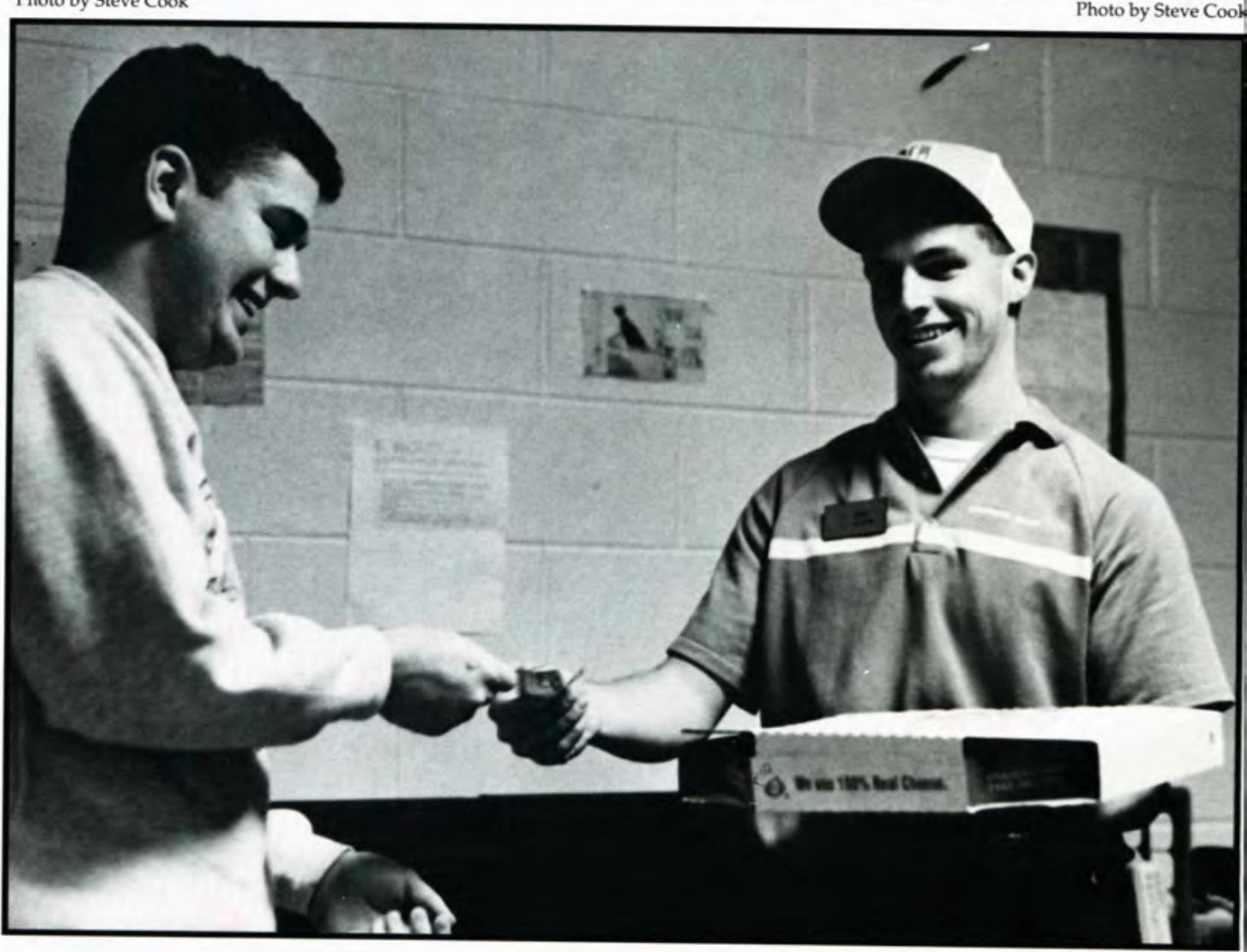

TAKING EXAMS is something all seniors, including Rich Doese, must endure.

THE DELIVERY BOY knows Sam Failor and his Brock friends well. 


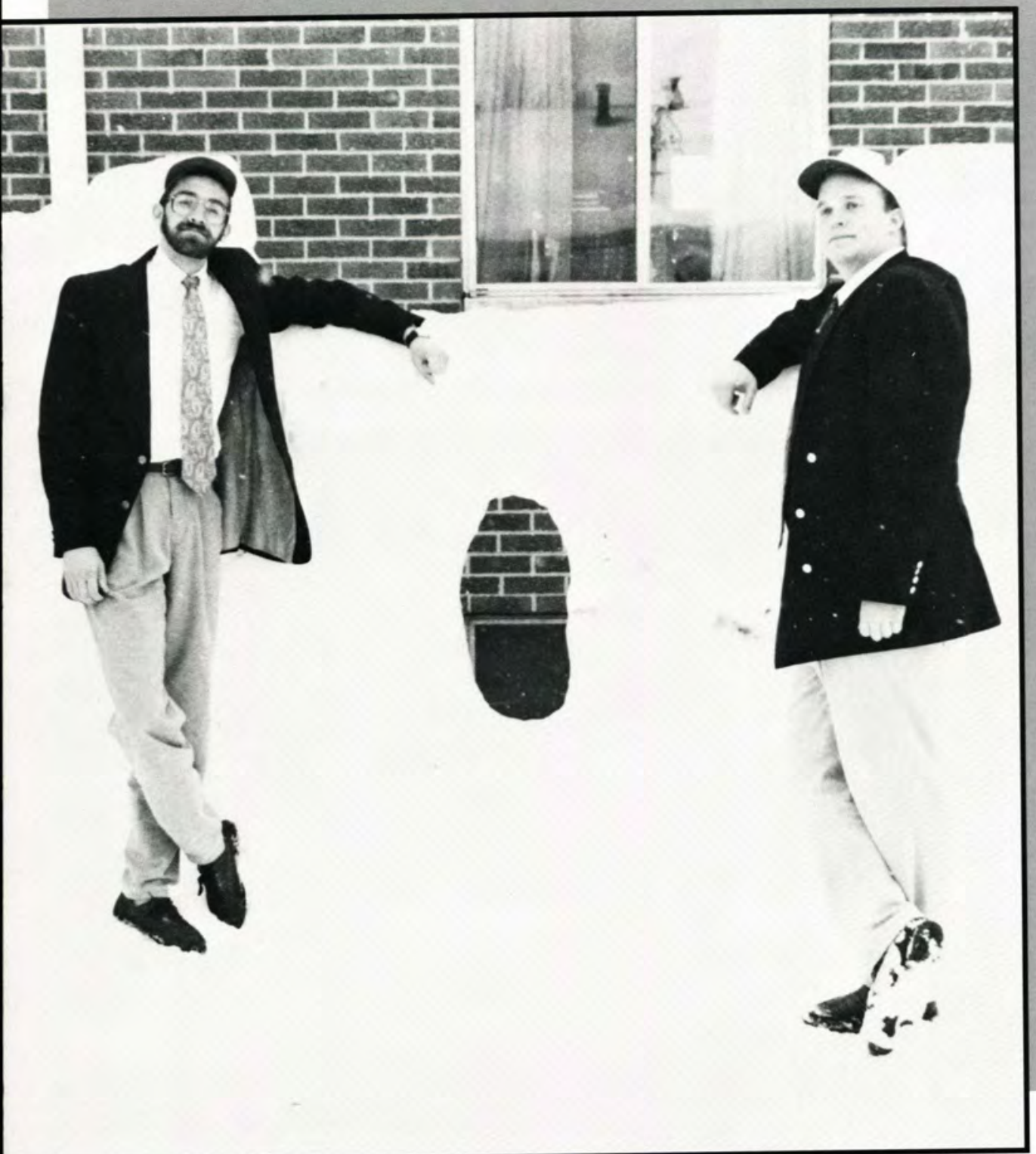

SCULPTORS, Ken Vanderwest and Matthew Oliver, proudly pose before their creation with their Alpha Chi hats on.

WILL YOU MARRY ME?

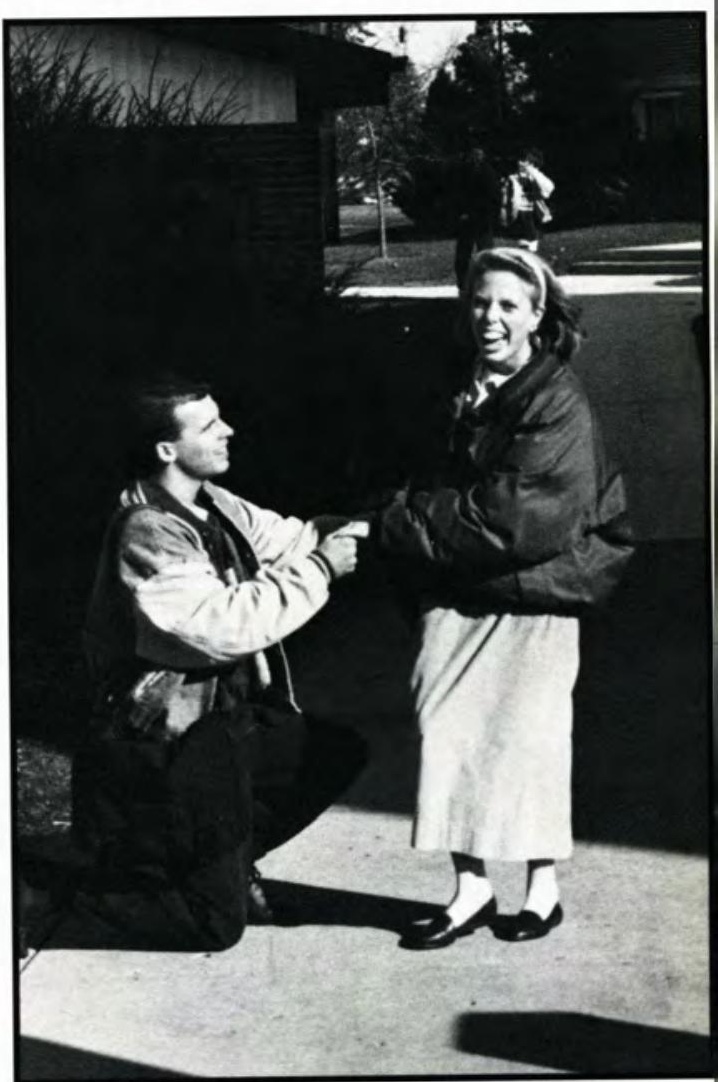

Photo by Todd Hill

Photo by Steve Cook

6

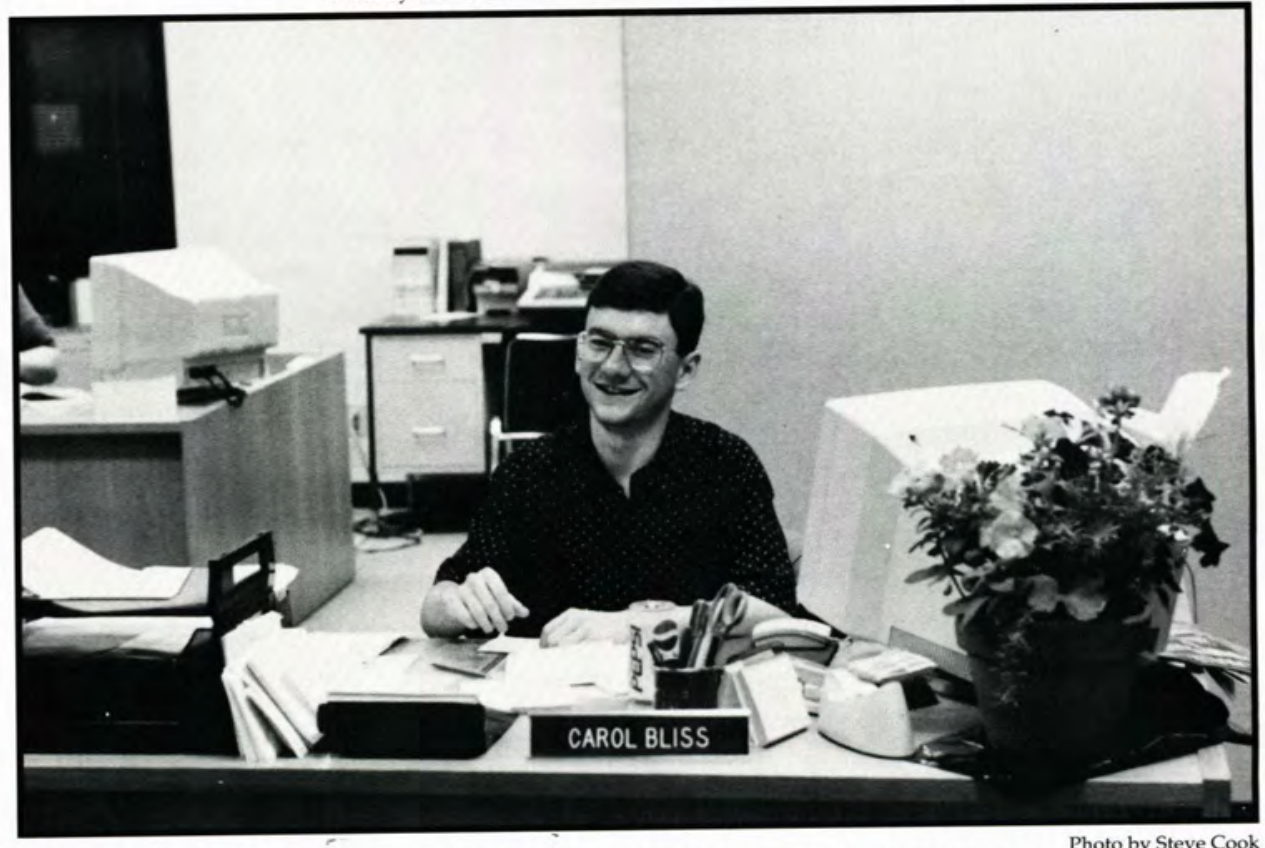

SECRETARY? Dan Treier, is that you, or is that Carol behind the desk?

FRIENDS, ONE OF THE BEST PARTS OF COLLEGE LIFE. 


\section{2-93}

\section{Barcelona}

Barcelona, Spain, hosted the SummerOlympics in 1992 and it proved to be a bonanza for the United States -- a total of 108 medals. A record 10,000 athletes, professional and amateur, from 183 countries gathered in this rapidly modernized metropolis nestled between the mountains and the Mediterranean Sea. Carl Lewis may not make it to the next Olympics -- he'll be 35 by then -- but he won two gold medals this time, one for long jump and one in the 400 meter relay. And in diving, Mary Ellen Clark won the bronze from the 10 meter platform.

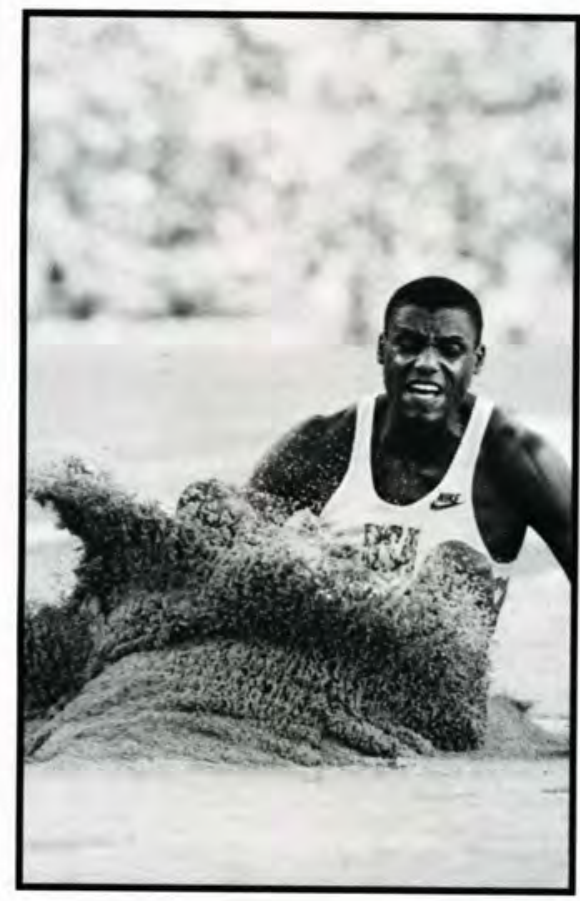

\section{Rioting in Los Angeles}

During the past two years, much has been said about the Rodney King beating and the LA riots in 1992. It all started when King was stopped by police, resisted and then was forcefully subdued while it was recorded on video tape. This tape was released to local television stations. This quickly received national attention, and four white officers were charged in the beating of King, who was black. The first jury found them innocent of any wrong-doing resulting in three days of rioting in Los Angeles. This resulted in 52 deaths, 2,383 people injured, 18,807 arrests, and property damage at about $\$ 785$ million.

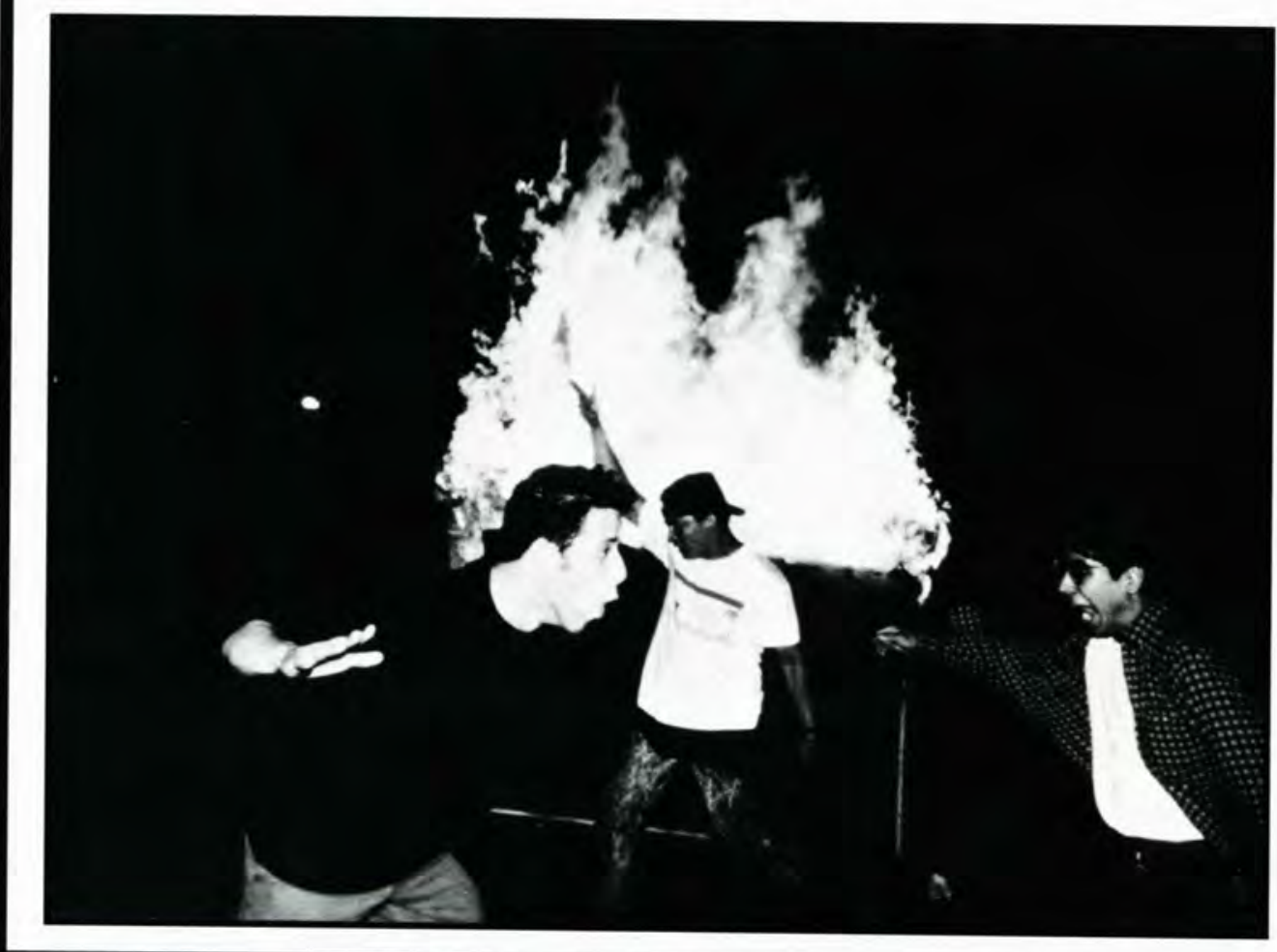

\section{Andrew, the Storm that \\ Shook Paradise}

Hurricane Andrew carved its way through the Bahamas and hit southern Florida with a powerhouse intensity before moving into Louisiana. The hurricane's 54-hour rampage, the most expensive natural disaster ever to hit this country, left an estimated 180,000 homeless in Florida alone. It was a harrowing time, as tens of thousands of people tried to evacuate the Miami area and thousands more rode out the storm in shelters and boarded-up homes. At least 51 deaths were directly attributed to the storm -- 41 in Florida and 10 in Louisiana. The amount of damage was estimated at \$20 billion in Florida and nearly $\$ 2$ billion in Louisiana.

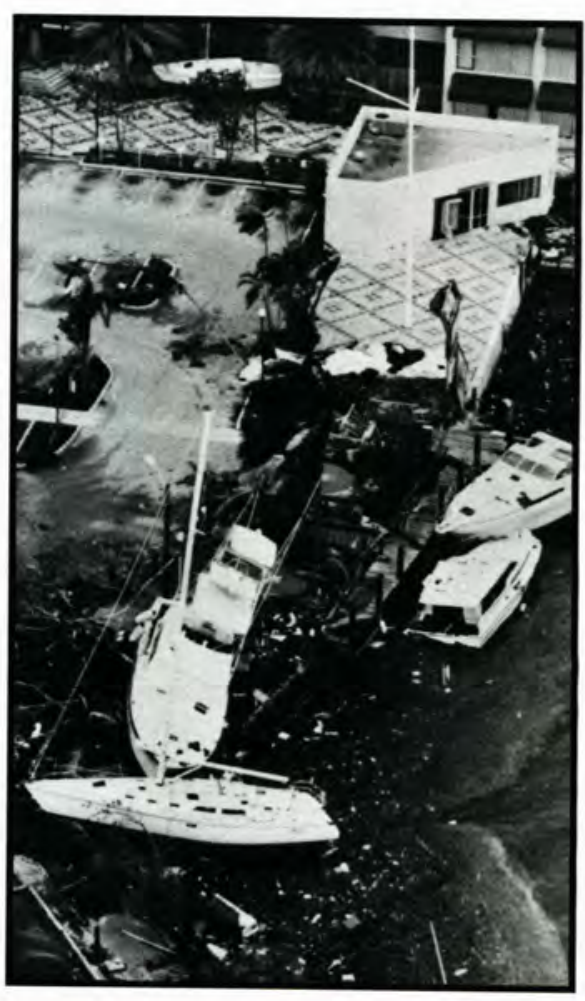




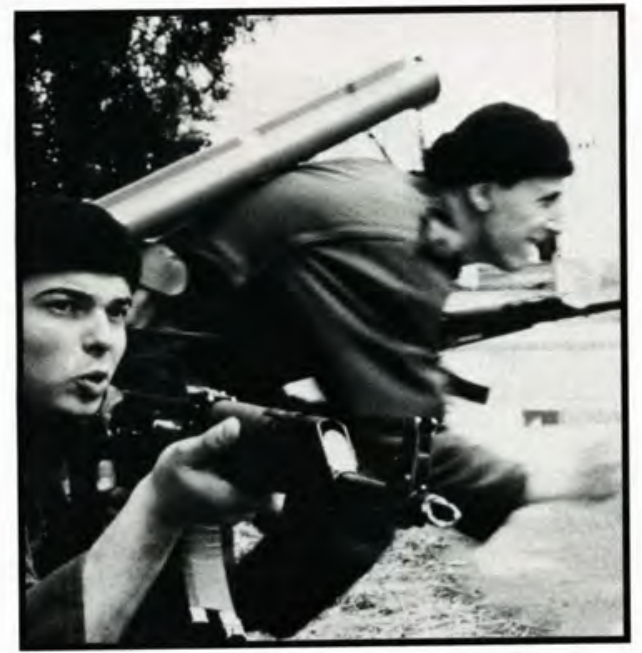

\section{Serbian Soldiers} in Bosnia

Civil war spread across Yugoslavia, a nation of six republics and two provinces that had been plagued for centuries by historic, ethnic, religious and economic differences. Nationalist, anticommunist parties won elections in 1991 in all republics except Serbia, the largest, and Montenegro, the smallest.
Then Croatia and its neighbor Slovenia declared their independence. Traditional rivalries were strongest between the 9 million Serbs, who belong to the Orthodox church, and the 5 million Croats, who are Roman Catholic. Tens of thousands of people became refugees and the killing continued.

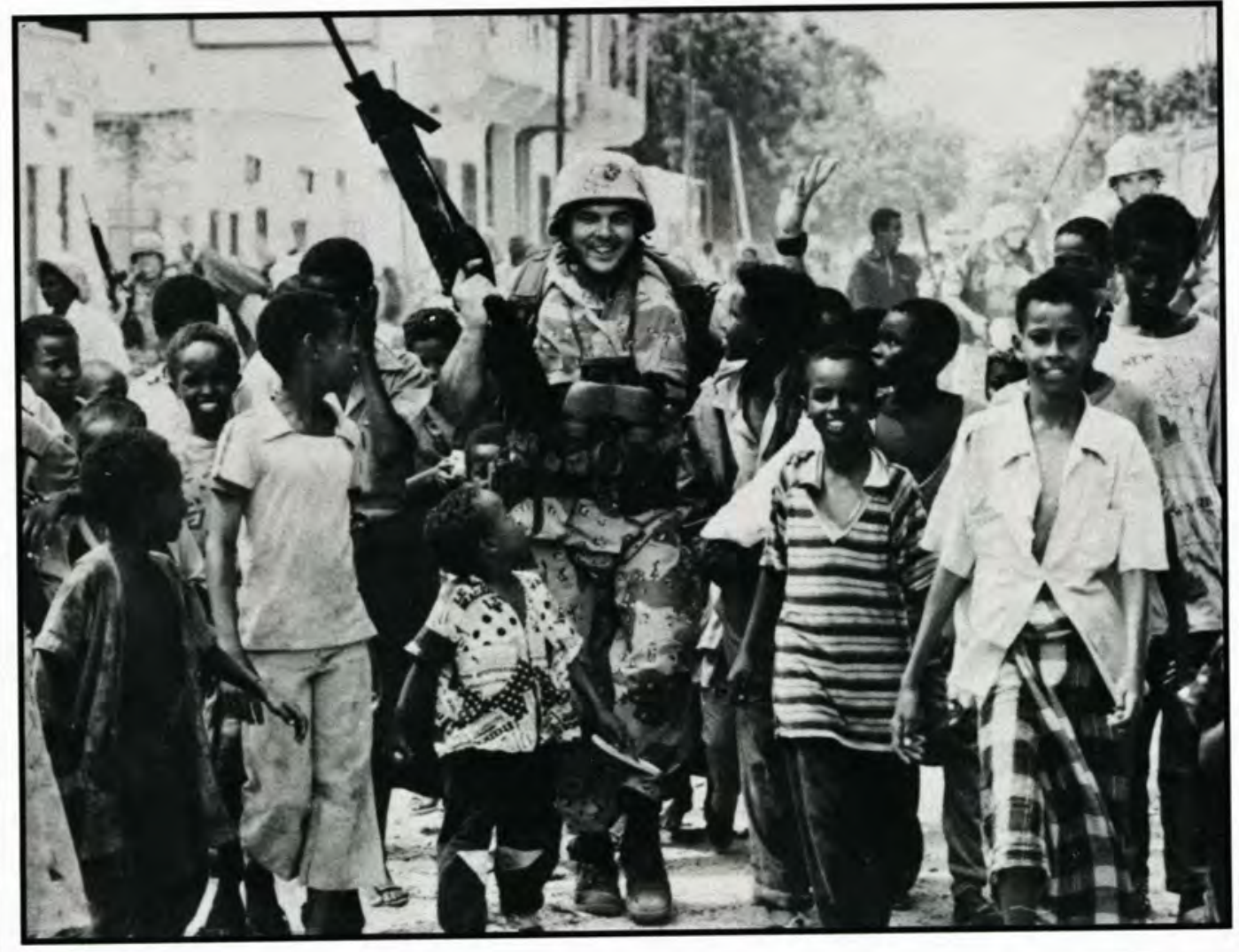

\section{Food for}

\section{Somalia}

The U.S. Marines arrived in Somalia on December 9,1992. The starving African country was ravaged by famine and widespread looting of food from international relief agencies. The Marines offered a security force to insure safe food distribution.

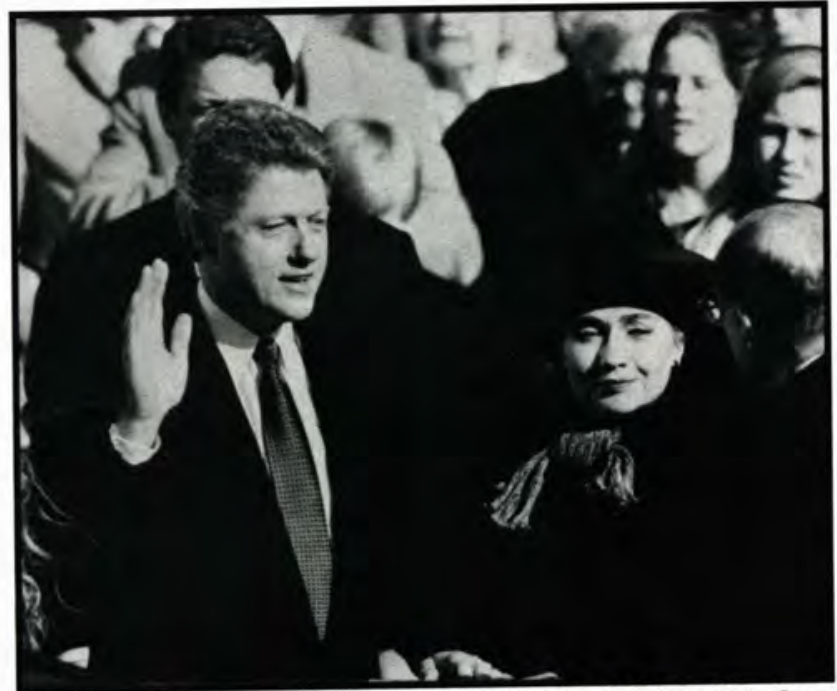

\section{Taking the Oath}

At noon on January 20, William Jefferson Clinton took the oath of office and became the $42 \mathrm{nd}$ president of the United States. As cannons thundered in salute, George Herbert Walker Bush surrendered power and stepped into history. $\quad$ All copy provided by RM Photo Service Inc. 


\section{Parent Patrons}

The 1993 Miracle staff offers a special thank you to all of those parents an churches who through their generous gifts made this Miracle possible. Withou their help many special elements of this yearbook such as extra color pages photography or design elements would be greatly reduced or eliminated. Thank you!

Rev. \& Mrs. Leigh Adams Berea, $\mathrm{OH}$

Mr. \& Mrs. Eugene Armour Rochester, NY

Mr. \& Mrs. Abraham Awabdy Clifton Park, NY

J. J. Bey

Greenville, $\mathrm{OH}$

Mr. \& Mrs. James Blevins Bidwell, OH

Mr. \& Mrs. Russell Blew Windsor, PA

Mr. \& Mrs. Wayne Blind Columbus, $\mathrm{OH}$

Dr. \& Mrs. Randy Bork Lapeer, MI

Mr. \& Mrs. Dale Borkholder Palatine, IL

Mr. \& Mrs. Fred Boyer Coloma, MI

Mr. \& Mrs. Mark A. Brandon Mansfield, $\mathrm{OH}$

Mr. \& Mrs. Kenneth Broadhead Mt. Vernon, IN

Mrs. Beatrice Brown Johnstown, NY
Mr. \& Mrs. David Brown

Easthampton, MA

Mr. \& Mrs. David H. Brown Sylvania, $\mathrm{OH}$

Mr. \& Mrs. Vernon L. Brown Dayton, $\mathrm{OH}$

Ms. Deanna R. Buckingham Milford, $\mathrm{OH}$

Mr. \& Mrs. Richard Burns

East Rochester, $\mathrm{OH}$

Mr. \& Mrs. John Burton

Boca Raton, FL

Mr. \& Mrs. John Calvert

Ooltewah, TN

Mr. \& Mrs. John Check

Ontario, NY

Mr. \& Mrs. James Cochran

Deerfield Beach, FL

Mr. \& Mrs. Gary Coe

Wyoming, MI

Mr. \& Mrs. Moises Cruz, Jr. Coudersport, PA

Mr. \& Mrs. Samuel De Man Grand Rapids, MI

Mr. \& Mrs. Wally Decker Fort Morgan, CO
Mr. \& Mrs. Daryle Doden Auburn, IN

Mr. \& Mrs. John Donahue Missoula, MT

Dr. \& Mrs. Marvin Eastlund Ft. Wayne, IN

Mr. \& Mrs. Robert Eckart Harleysville, PA

Mr. \& Mrs. Russell Edwards Sleepy Hollow, IL

Mr. \& Mrs. David K. Fath Annville, PA

Mr. \& Mrs. Edward Fay Waldorf, MD

Mr. \& Mrs. Ron Ferner Folsom, CA

Mr. \& Mrs. Dean Fox Pekin, IL

Mr. \& Mrs. William Fulton Troy, $\mathrm{OH}$

Mr. \& Mrs. Thomas Gerendas Wayland, MA

Mr. \& Mrs. Eddie Gill Newark, $\mathrm{OH}$

Mr. \& Mrs. Donald Gilson Marion, $\mathrm{OH}$ 
Mr. \& Mrs. E. David Gordon Carmel, IN

Mr. \& Mrs. Randal Gosser ndianapolis, IN

Mr. \& Mrs. Larry Green

Whiteland, IN

Mr. \& Mrs. G. Riley Griffiths ranklin, $\mathrm{OH}$

Mr. \& Mrs. Peter Gurry

Nestfield, NJ

Mr. \& Mrs. Lewis J. Guyn

Anaheim, CA

Mr. \& Mrs. Gary L. Habegger Jniontown, $\mathrm{OH}$

Mr. \& Mrs. Hans Hahnenstein

Painted Post, NY

Mr. \& Mrs. Fred Haigh

fort Wayne, IN

Mr. \& Mrs. Donald Harju

Hudsonville, MI

Mr. \& Mrs. Allen Hewson Freeiton, ON

Mr. \& Mrs. Dennis Higley

Troy, $\mathrm{OH}$

Mr. \& Mrs. Bill D. Hillman

Morton, IL

Mr. \& Mrs. David Hoadley

Epsom, NH

Mr. \& Mrs. Gerry Horton

Mattituck, NY
Mr. \& Mrs. Daniel Irving

Littleton, CO

Mr. \& Mrs. Thomas Jagger

Corning, NY

Dr. \& Mrs. Ismael Jamora

Point Pleasant, WV

Dr. \& Mrs. Frank Jenista

U.S. Embassy, Manila

Mr. \& Mrs. David Johnson

Enfield, CT

Mr. \& Mrs. Marvin Jones

East China, MI

Mr. \& Mrs. David F. Jordan Schaumburg, IL

Dr. \& Mrs. Richard Judkins Perrysburg, $\mathrm{OH}$

Mr. \& Mrs. Edward Keefe

Fayetteville, PA

Mr. \& Mrs. R. B. Keefer

Ypsilanti, MI

Mr. \& Mrs. Kenneth Kelley

Washington C. H., OH

Mr. \& Mrs. Sidney A. Kihle Columbia Station, $\mathrm{OH}$

Mr. \& Mrs. Stephen Kirchoff Bedford, NH

Mr. \& Mrs. Earle Knowles

White Lake, MI

Mr. \& Mrs. Ralph Kuivinen

Fairview Park, $\mathrm{OH}$
Mr. \& Mrs. Rene Landwehr Howards Grove, WI

Mr. \& Mrs. Phillip Lawrence Shelbyville, MI

Mr. \& Mrs. John Le Blanc Frankfort, IN

Mr. \& Mrs. Richard Linak Sylvania, $\mathrm{OH}$

Mr. \& Mrs. John Linnehan Ellsworth, ME

Mr. \& Mrs. John Longshaw Shamong, NJ

Ms. Eden E. Lynch

Johnson City, NY

Mr. \& Mrs. Roger Marland Plattsburgh, NY

Mr. \& Mrs. Clifford Marr

Windham, ME

Mr. \& Mrs. Michael McDermott Reno, NV

Mr. \& Mrs. John McQueen

West Liberty, OH

Mr. \& Mrs. Clair Miller

Zion, IL

Mr. \& Mrs. Joel Miller

Freeport, IL

Mr. \& Mrs. Richard P. Moore Rochester, MN

Mr. \& Mrs. LeRoy E. Myers

Clear Spring, MD 


\section{Parent Patrons}

Mr. \& Mrs. Earl Nickelson

St. Charles, IL

Mr. \& Mrs. Lee Nicodemus

Riverside, CA

Mr. \& Mrs. Jawad Nunes

Wilmington, $\mathrm{OH}$

Mr. \& Mrs. Richard Olsen

Rochester, MN

Mr. \& Mrs. George Osuch

Sandy Hook, CT

Mr. \& Mrs. William Otto

St. Petersburg, FL

Mr. \& Mrs. Jay Pearson

Cherry Hill, NJ

Mr. \& Mrs. Joseph Perkins

Poland, $\mathrm{OH}$

Mr. \& Mrs. Ronald Peterson

Strongsville, $\mathrm{OH}$

Mr. \& Mrs. Samuel Pierce

Dublin, $\mathrm{OH}$

Mr. \& Mrs. Albert Polish

Fraser, MI

Mr. \& Mrs. Gerald Reynolds

Norwood, $\mathrm{OH}$

Mrs. Francoise Rich

Sylvania, $\mathrm{OH}$

Mr \& Mrs. Philip L. Rohrer

Dayton, $\mathrm{OH}$
Mr. \& Mrs. M. Val Roloff

St. Charles, MO

Mr. \& Mrs. James C. Rooks Butler, PA

Mr. \& Mrs. Jerry Rotramel

Elkhart, IN

Mr. \& Mrs. Gary Rutledge

Rochester Hills, MI

Mr. \& Mrs. J. Richard Rutt

Mount Joy, PA

Mr. \& Mrs. Gary Schmitt

Wheaton, IL

Mr. \& Mrs. Roger Schoolar

Strongsville, $\mathrm{OH}$

Mr. \& Mrs. William Sharp

Harvard, IL

Mr. \& Mrs. Edward Siert

Delavan, WI

Mr. \& Mrs. Alvin Smith

Lambertville, MI

Mr. \& Mrs. Dennis A. Smith Herndon, VA

Dr. \& Mrs. Palmer Smith

Centerville, $\mathrm{OH}$

Mr. \& Mrs. Joseph Sprankle

Chesapeake, VA

Mr. \& Mrs. William Stanley

Herndon, VA
Mr. \& Mrs. Gerald Stanton

Defiance, $\mathrm{OH}$

Mr. \& Mrs. Leroy Stephenson Tacoma, WA

Mr. \& Mrs. Robert Stevens Charleston, WV

Dr. \& Mrs. Fred Tasker Huron, $\mathrm{OH}$

Ms. June Thompson Iowa Falls, IA

Mr. \& Mrs. Dean Treier Bloomdale, $\mathrm{OH}$

Mr. \& Mrs. Dennis Ulery Ballston Spa, NY

Mr. \& Mrs. Douglas

Vande Guchte

Hudsonville, MI

Mr. \& Mrs. Jack Weaver

Walla Walla, WA

Dr. \& Mrs. James Weiss

Dayton, $\mathrm{OH}$

Mr. \& Mrs. Donald Wingert

Mechanicsburg, PA

Mr. \& Mrs. David Wong Caldwell, ID

Mr. \& Mrs. Joseph Zehr Fort Wayne, IN 


\section{Church Patrons}

Calvary Baptist Church Youth Group Covington, $\mathrm{KY}$

Calvary Baptist Church

Connersville, IN

Calvary Bible Church

Derry, NH

Cedarville United Methodist Church Cedarville, $\mathrm{OH}$

Center Street Baptist Church Marshalltown, IA

Ellsworth Baptist Temple

Ellsworth, ME

Emmanuel Baptist Church

Dayton, $\mathrm{OH}$

Faith Baptist Church

St. Marys, PA

First Baptist Church of Willowick Willowick, $\mathrm{OH}$

First Baptist Church

Gallipolis, $\mathrm{OH}$

First Baptist Church of Univ. Place Tacoma, WA

Foothills Baptist Church

Hardy, AR
Grace Bible Church

Dunmore, PA

Hagerstown Bible Church Hagerstown, MD

Harpursville Baptist Church Harpursville, NY

Heritage Baptist Church Clarks Summit, PA

Independent Baptist Church Keeseville, NY

Patterson Park Church

Beavercreek, $\mathrm{OH}$

Regular Baptist Church

Loup City, NE

South Norfolk Congregation

Christian Church

Chesapeake, VA

South Paris Baptist Church South Paris, ME

Temple Baptist Church

Portsmouth, $\mathrm{OH}$

Village Baptist Church Missions Buffalo Grove, IL

Wheelersburg Baptist Church Wheelersburg, $\mathrm{OH}$ 
A

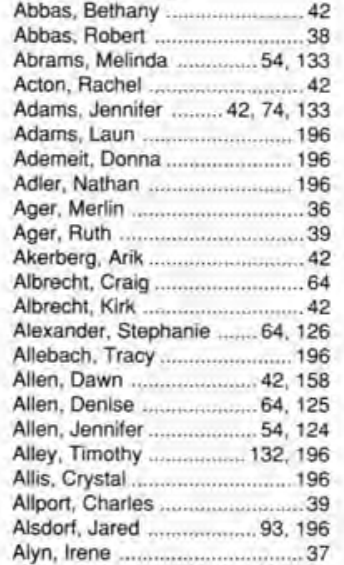

Alyn, Irene .......
Ambrose, Dan $\quad 93,97,99,130$ 150, 187, 189, 196

Ambrose, Dawn ………90, 196 Ames, Sandra ...............54, 130

Amour, Angela
Amundson, Elizabeth

Anderson, Christopher ….........42 42

Anderson, Dawn ............... 196
Anderson, Eric ........42, 166, 167 Anderson, Keri . $\quad 167$
Anderson, Kerry
An

Anderson, Lyle … 37, 166, 167 Anderson, Paul ... 14, 96, 99, 113 187, 194

Anderson, Rachelle .54
.. .71

Anderson, Susan ....

Anderson. Jr., Pau

Andresen, Danie
Andrews, Amy

Andrews, Amy
Andrews, Fran

Anglea, John
Annoni, Scott

Anthony. Michaet - $\quad 157,8$

Apperson, Brent _.....89, 179, 197

Arjani, Kimli .

Armour, Paul

$64,78,79$

Armstrong, Carre …........117, 197 Armstrong, Rebecca $\ldots 64,93,127$ Armstrong, Sarah ...............42, 74 Artman, April

Ashbaugh, Leslie

Ashbaugh, Sarah

Ashby, Patricia $\quad 197$

Ashcratt, Eric ……..... 64, 81, 122 Ashley, Douglas …........ 42, 150

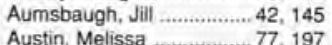
Awabdy. Amy

Awabdy, Nicholas 64, 78, 122, 141

Awbrey, Jeremy ……....... 42

\section{B}

Bader, Ronald ……..... 39

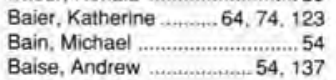

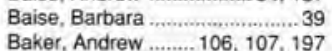

Baker, Angela

Baker, David

Baker, James

Baker, Kathy

Baker, Lols.

Baker, Michae

Baker, Mike

Baker, Sue.........

Baldwin, David.

Baldwin, Richard 2 . 36 Bales, Brich

Ballard, Stanley

Bandy, Larry …….............54, 123

Bannerman, Shannon …_...... 197

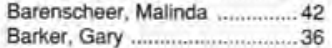

Barker, Gar,
Barker. Mr.

Barlock. Charlotte

Barnard, Heather
Barnes, Amy

Bames, Amy

Barnes, Brian -..............5 5

Barnes, David ............134, 146, 14

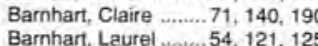

arnitz, Lisa

Barnum, Robert .64, 85, 119, 167 Barrett, Janie _...........54, 77 Bartholomew. Ruth ...74, 187, 197 Bartlett, Carolyn ............
Bartlet, Sonja $\ldots 2 . . .187$

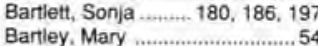
Barnley. Mary

Barton, Jeremy .............64, 78, 16 Bartosiewicz, Jerniter 20, 54, 165 , 172
Bass, Marla _........64.78, 112

Bassett. W.

36,90

Bates, Amy _..... 20, 33, 74, 81, 86

$93,110,119,166,167,197$

Battin, Phil

Baver, Erik........

Bauer, Michael .

Baughman, Melissa .................64, 167

Baumann, Donald ..................... 38

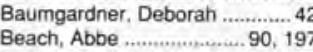

Beach, Susan _....85, 93, 191, 198

Beasley, Rebecca …........42, 166

Brady, Matthew _...17, 30, 90, 199

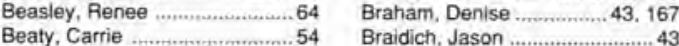

Beaulieu, Andrea …...........71 Braithwaite, Edwin ..................38

$\begin{array}{lll}\text { Beck, Karen } & 54,74,89 & \text { Braley, Christina } \\ \text { Beck. Kristine } & 43,118,119\end{array}$ Beck, Kristine $\ldots \ldots \ldots . . . . .64$
Beckelhymer, Kyle $\ldots . . . . . . .198$

Beckham. Sharon ..................64 64

Beebe, Wesley - 54, 81, 166. 167 Breneman, Mathew . 43, 119, 122 Breneman, Todd _...64, 85, 123 Bresnahan, Stephanie ......54, 131

Beheler, Tiffany ......... 54, 90, 127

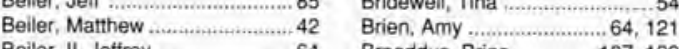

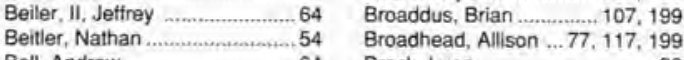

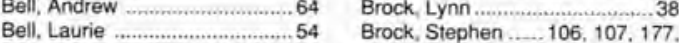

Belmont, Kevin ..64, 93, 136, 137

Benaman, Matt.

Benefiel, Jennifer

Benim, Shari.

Bennett, Alicia

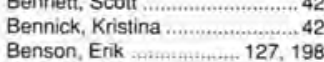

Benson, Erik
Beres, Kari .............................. 42,174

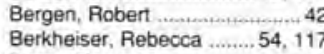

Berry, Danette …................... 198 Brown, Katthew. 86, 93, 113, 166,

Berry, Devon ………...54, $119 \quad 184,186,199$

Beshaw, Harold ...............64, 115

Brown, Priscilla $\quad 174,200$

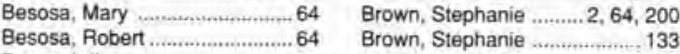

Beste, Jeff .

Bickel, Nathan

Biddle, Agnes $\ldots . . . . . .1$.
Biddle. Andrew ...........42, 95,120

Biddle, Benjamin ....... $\quad .54,167$

Brunner, Debora ….........54, 128
Brunton, Susan …..119, 133, 200

Bigam, Jeffrey ……................54 Bryant, Jenny

Biggers, Kristie

Biggs. Maria

54,122

Bingham, Jettrey …..........54, 78

Bird, Ben ...

Bird, Melissa

Bishop, Aaron

Bishop, David

Blackburn, Jeftrey

Blair, Eric, Sarah

Blane, John

Blanon, Steven .

Blansette, Shane

54,78
.$\ldots .64$

Brown, Stephen

Brubaker, Amy
Brubaker, Nicole

4... 38

Bruckner, Matthew $\ldots . . . . . . . \quad 81,200$

Bryant, Jenny …....119, 133, 200

Buckingham, Jettrey $\ldots . . . . . .64 .125$

Bucklew, Tammy …….............55

Buckley, Joyce $\quad-\quad 43$
Buckley, Julie

Buehner, Amy ………......5, 128

Buehner, Noah
Buentello, Julie ...86, 93, 166, 200

Butfington, Shandis ............ 115

$\begin{array}{ll}\text { Bulanow, Greg } & 116,142 \\ \text { Bunn, Stephanie } & . . . . . . . .15\end{array}$

Burdette, Steven ….....43, 81, 123
Burkett, Jennifer
Bur.

Burkett, Jennifer
Burkhard. Sara..................... 55,122

Burkholder, Jacqueline …..........43

Burkholder, John ....................64
Burkley, Deborah ........... 55, 127

Blenis, Darcey $64,78,93,129$

Blevins, Elizabeth ……...42, 74, 78

Blind, Brian …….... 64, 81, 89

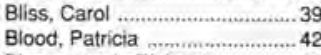

Blumenstock, Richard ............36

Bockmann, Thomas $\ldots . .3,64,81$
Boetm. Matthew …....42, 74, 12

Bolender, Jeff ....................155

Bolender, Sharon :-140, 155, 198
Bolger, Brian ......................64, 81

Bolhuis, Nathan …..........42

Bolsem, S

Bond, Jenniter

Bond, Kathryn ................................5

Bondorti, Jacqueline ................54

Bonga, Janet ..............54, 89, 120

$\begin{array}{ll}\text { Boone, Abby ……... } & 98,117,167 \\ \text { Boothe, Laura } & 42,140,155\end{array}$

Borgman, Darlene …..........42, 130

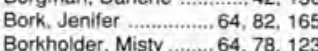

Borkholder, Misty ……64, 78,123
Borling, Scott …........ 42,74
Bonton, Jason

Bosling. Tonya

Bosma, Janice

Bossley. Heather

Bossley, Heidi

..+ .54
.$\quad .77$
...-+38

Bouchard, Jenae ..............64, 153

Bouchard, Nicho

Bowen. Heidi

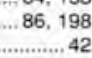

Burnet, Sara

Burns, April ......... 55
Burns, Bob
Burns, Brian ........55, 72, 115, 240

Burns, JulleLynn .55, 90, 123, 166

Burns, Michele

Burns, Robert

$\quad \quad .74,200$ 200

Uurrichter, Margare

Burton, Randal

Bussa, Evelyn

Butler, Jennifer ….......55, 59, 120

Button, Mark ............................ 95
Butts, William .................5, 127

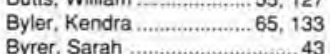

Cook, Steven . 100, 101, 130, 169 ,

193, 201

Cooley, John

Cadwell, Spring …....55, 77, 120

Caidwell, Clifford

Calhoun, Scott

Call, Jacqueline

Call, Jennifer ….........65,90,123

Callahan, Bradley ......... 55

Callan, Donald ...............6, 37, 146

Calvert, Becky ……......74, 78, 172

Calvert, Philip .... 55
Camerer, Timothy _.... 43, 166, 167

Campbell, Laura ….........65, 129

Canine, Michelle

Canton, Steve

Cardosi, Carlene ….................. 167,127

Carlson, Carolyn ............................ 37

Carlson, Dawn ............131

Carison, Paul

Carnahan, Brian

65,122

Carnahan, Jeremy

43,117

Carroll. Michael

Carroll, Tracy

Carson, Angela

Carsten, Laura

Carter, Olivia

Cary, Jr., Daniel

Case, Eric

Casselman, Brent

Cassidy, John .

Cato, Jim ....

Caton, Steven

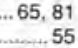

Cesal, Nathan.

..124, 200

Chance, Gregory

$55,77,133$

.....55, 166, 167

Chasnov, Robert ......................37

Check, Johath

Cheek. Devin

$71,78,81$
-43

Chezik, Janet ..........65, 121, 127

Childers, Rebecca ……....55, 167

Childress, Bethany

Christie, Heather

Christman, Robert

43
.. .71
.55

Clair, Ida

Clapper. Melinda

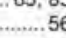

Clark. Cherish

4. 78,129

Clark, Martin

Clark, Susan ………….......... 167

Clark, Tammy -65, 74, 85, 89, 93.

Clark, Timothy

Clavin, Clifford......

Clement, Steven

Clevenger, Charles .......32, 35, 37

Cline, Kelly

Clow. Alexander ................................200

Clow, Andrew _............. 201
Coakley, Jenna

Cobb, Robert ........ 43

Cody, Paul ..................... 43

oe, Lisa

Coffait, Joy

Coffin. Shelly

128

Colbert, Bruce

Colemar, Melissa _..............56

Colman, Dr. ........................ 32

Colman. James .......32, 34, 35, 37
Combs, Mark........... 127, 146

Comegys, Miriam .......65, 89, 118

Comers, Heidi

Comrie, Matt

Cone, Jett

Cone, Julie

... 127

Conkel, Kevin 65, 85, 93, 122, 141

Conkey, Tracy

Conley, Bobb

Conner, Kimberly

56, 127

............................. 37 Cook, Elise ............. 56, 93, 123
65,

56, 89 
Filson, John _...................
Finnity. Jenniter Fiorito, Julie ......... 45, 118
Fiorito. Shelley $90,186,204$ Fissel, Nancy ............... 39 Fiveland, Peter : 45, 95, 115, 119
Flanigan, Rachelle ..........45, 155 Flanigan, Rachelle Fleenor. Randall Flentge, Dennis .....................
Fleshman, Jr., Royce …........ 48 Fogg, Robert

Foley. Bret

Ford, Laura

Fortner. Jennifer

Fortune, Annette

Foster, Elizabeth
Foster, James26, 72, 86, 100, 20 Foster, Regan.

Fought, Christophe
Fourman, Brian

Fourman, Briar
Fouts. Jami

Fowler, Gary.

Fox, Sean

Fox, Shelley 13, 57, 167, 169, 172

Fraley, Melanie

Francis, Connie

Francis, Keith

Francis, William

Frank, Dwayne ....

Freeman, Melissa

Freeman, Michelle ................4

Freese, Kathy _....... 37, 149, 153
French, Jamie ................ 45

Friemel, Valerie
Fry, Kassandra

Fuller, Jil

Fulton. Elizabeth

Fulton, Heather.

Fulton, Heather.

Fulton, Peter.

Funston, Jerry

Furman, Brend
Furman. Dana

45,149
57,122

38,74

.37
.204
+.37
+.37

66
45
153
45
119

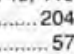

187,20

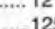

... 125

\section{... 45}

04 Guyn. Kimberly ……..........46, 121

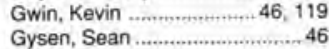

\section{$\mathrm{H}$}

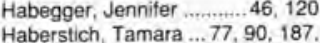
205

Hack, Leslie . ......................57

Hackenberry, Stephen, David ............................... 46

Hadley, Jonathon .......................5 57
Hadley, Melissa

Haffey, Deborah …n........36, 36

Hagerman, Catherine ..............5, 56

Hahnenstein, Christine . 26, 66, 93

Haines, George ............... 57, 127

Haley, Jennifer

Halk. Marsha

Hall, Mitch

Halsey, Joseph

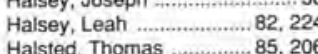

Hamblen, Elta …................120, 206

Hamblen, Elta ................120, 86,119

Hamel, Lindsay ...........57, 86,
Hamer, Keith $\ldots 2,123$

Hamer, Keith

Hamilton, April ..
Hamilton, Craig

Hamilton, Julie

Hamilton, Tod

Hamilton, Troy ...

Hammock, Darry

82,123
57

George, Andrea ..........57, 81, 204

Geremia, Kimberly ... 86, 127, 204 Gess, Shawn

Gess, Shaw

$+.205$

Gbbs, Kirsten ... 86, 99, 186, 194.

Han, Nathan
Hand, Jamie ……................. 46,157

Handel, Christopher ..57, 77, 112

124

Hannah, Heather

Hanson. Angela

Hanson. Angela ................. 46

Hansen, James ........90, 190, 206

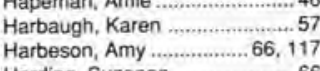

Harding. Suzanne ….............66

Harju, Bryan ….........46, 166, 167

Harmon, Marie .................. 57

Harner, Amy Melissa 46, 82, 116, 118

167
Harner, Sandra ...........................

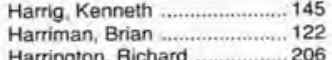

Harrington, Fichard $165,166,167$
Harris, Jacob $57,165,166,19$ Harrison, Donna
Hartenstein, Jennifer .. 46, 82, 115

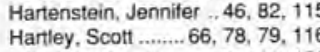
Hartman. Angela _.. 66, 138, 158
Hartman, Karyn .................57, 77 Hartman, Melissa .... 46, 138, 149 , 158,159

Harty, James

46
66
46,179
57

Haskell, Jeremy

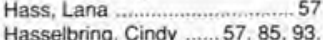

140. 155

Hassell, lan ...

Hassenzahl, Timothy

57
57
57

Hastings, Jonathan ......... 57

Hatcher, Karen

Hauser, Deanne 93, 138, 139, 206

Hauter, Shelley

Hawkins, Charles.

Hawkins, Christopher ..................46

Haworth, Joy ..................206
Hayden, Christine ............ 28, 206

Hayes, Woodrow .................57 57

Hazekamp. Kimberly 46, 121, 133

Hazen, Marinus ….................36

Headdings, Denise ........149, 206
Heale, Elissa .............46, 82, 165

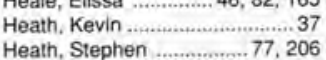

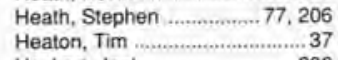

Heckart, Joel
Heckman, Ruth ….........46, 98, 129

Hedlund, Ginger ….............57, 119

Heffiner, Roger

Hegna, Harwood

207
37

Heidorn, Cynthia

.57, 117

Heim, Carla ..................58, 128

Heim, David 46, $74,119,121,166$
Heinold, Mistalina .....................58

Heldreth. Michelle .. 66, 86, 89, 90,

173

Heller Alyson 66 Huli, Dana _..........66, 90, 98, 127

Hellwig, Evan
Helmick, Larry …............................38, 74

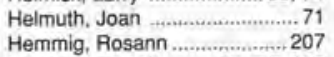

Henderson, Gail ..........71, 77, 133

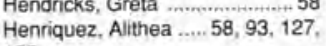

Henry, Debra …........ 86, 138, 207

Henry, Debra $\ldots . . . . . . . .86,138,207$
Henry, Jennifer $\quad 58,77,82,100$ Henry. Kara _........66, 93, 133

Hermansky, Nicole .........................167

Hermansky, Nicole $\ldots . . . . . . . . . . . .167$
Hernandez, Nicole ............. 46, 77

Herr. Gwendolyn .......................66
Herr. Wendy .............82, 165, 179

Herrick, John …..........66, 78, 119

Herring, Christian ............. 71, 128

Herschberger, Linford 58, 77, 123.

166,167

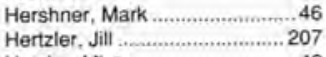

Hetzler. Misty ..........................46
Heubner, Ryan

Heubner, Ryan .....................167
Hewson, Ryan $\ldots 6,93,98$

Heyd, Ruth ....................66, 78

Hezlitt, Rebecca ....................58
Hickman, Georgia ...... 66, 74, 121

Hickox, Sandra ................ 58, 117

Hicks, Heather ...........46, 129

Hiebert, Aaron .................66, 85

Higginbotham, Kimberly .... 12, 99 ,

$166,191,193,207$

Higley, Ann

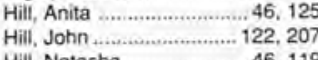

Hill. Natasha

122,207
46,119

Hiil, Thom

Hill, Todd

Hiller, Janelle

Hillman. Christina

Himes, Jenny

Hines, Heather

Hinshaw. Jessica

Hintz, Marcy

Hitz, Christop
Ho, Nathan

Ho, Nathan ….................58, 74

Hoadley, Kristine $\ldots . . . . . .46,119$

Hodson, Carolyn ...........................39.

Hoewing, Rodney ...............58, 122

Hoewing, Step

Hoffman, Randall ......................... 46

Hoftman, Terri ……..........46, 155

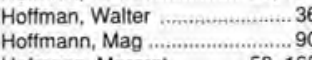

Hotmann, Margret …..........58, 165

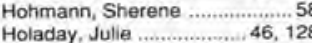

Holcomb, Michelle _.......66, 12

Holden, Steven ... 11, 99, 173, 208

Hollaway, Mary

Holley, Rachel

Holloway, Camille
Holloway, Thile

66,126

Huebner, Ryan _...33, 58, 82, 166

Johnson, Marcy $\quad 67,101,130$
Jones, Lori

Jones, Natalie

166,209

Holsinger, Mark _...... 86, 125, 20

Homan. Richard .r...r. 58

Honeywell, Melissa ...........58, 120
Hook. Adam

Hooley, Darren ...............146. 150

Hoop, Amy _...........46, 125

Hoover, Heidi ....58, 124, 167, 169

Horine, Benjamin ..........................66 66

$\begin{array}{lll}\text { Hornbuckle, Steven …..............208 } \\ \text { Home, Jennifer } & 47,123\end{array}$

Horne, Jennifer $\ldots$. Vonda .................... 77, 208

Horton, Jennifer

Horton, John

Hoskins. Jonathan

77,66
166,167

Hosner, Kimberly …..................... 208

Houston, Rhonda .66, 89, 93, 118

Howard, Patricia

Howard, Tricia

66,149

Howe, Kara

Howell, Tiftany .........66, 117, 167

Hoy, Bowe .......

Hoy. Timothy

Hu, Nathan

Hubbard, Kimberly

Huber, Pearl

Huber, Trish

Huttman. Nathaniel ........47, 146

Huggler, Laura ..........47. 125, 138

Hughes, Melinda .............
Hull, Dana $208,90,98,127$ Humphreys, Donald ..................37

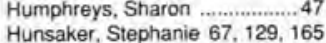
Hunsberger, Angela _.........58, 85 Hunsberger. Jill5, 15, 58, 166, 179 Hunt, Carmen

Hunt, Jeffrey

...... 58

Hurt, Keith

67,90

Hutchins, Sally

Hyback, Cheryl
Hyten, Jenine

58,116

I

lamaio, John

ilijes, Kristine .......

Ingalls, Marg
Intosh, Paul

Irelan, Timothy

Irish, Kathleen ...................77, 208

Irving. Elisabeth ......187, 188, 208

Irving, Mark ........................ 87,114
Izard, Ray

Jackson, Janelle _...............58, 117

77,208
138

lacobs, Carrie

Jacobson. John

47.161

Jagger, Emily 58, 77, 86, 90, 119

James, Robert $\ldots . .58$

Jamieson, Andrew .......... 121, 209
Jamora, Gina $\ldots 6,209$

Jarig Carol

166,209
11,209

Jariga, William

Jefteries, Bryan

Jeflries, Clark

67,78
47

$\begin{array}{rr}\text { Jenks, Stephen ......r.r.r. } & 58,115 \\ \text { Jensen, Naomi .......... } & 58\end{array}$

Jeremiah, Amanda .......................47
Jeremiah, Dr.

Jex, Aaron .

Joers, Shawn ..

47,128
. .133

John Heflick, Jr. ......................57

Johnson, Clifford r.r. 38, 191

Johnson, Derek ........ 47, 119, 122
Johnson, Eric ......... 24, 58, 165

Johnson, Janell

.......... 68

Johnson, Jeffrey

Johnson, Judy

Johnson, Martha ........................., 36

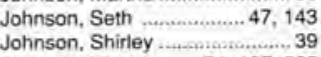

Johnson, Victoria _...74, 187, 209

167

Johnston, Faith ......................... 209

Joiner, Randy .............. 67, 85, 130

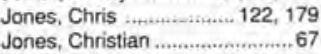

Jones, Philip

Jones. Susan

$+\ldots$

Jones, Tanya

$67,117.165$ 


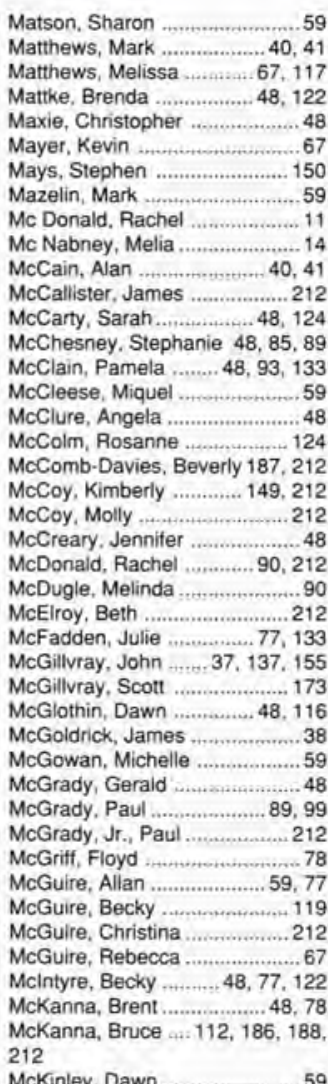

McLaughlin, Amy .....................212

McMahon, Amy …......59, 77, 125

McMillen, Matt _.

McMurtry, David …............48, 46

McNabney, Melia 88, 93, 125, 21

McNamara, Matthew …................48
McNamee, Jenn .................... 121

McNamee, Jenniter ............
McNiece, Amy ........................... 48

McPherson, Mindy59, 82, 90, 124

McPherson, Sherilyn ......180, 213 McQueen, Abby .. 48, 82, 118, 140

McQueen, Todd ...................... 213

McVey, Diana ...................... 5

McVey, Joy . ........................117

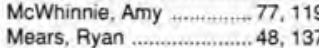

Meeder, Jon .......................67, 89

Megilligan. Brian .67, 82, 113, 165

Meigs, Stephen ...............85, 213

Melbin, Paul .

Melkonian, Christopher ............ 48

Melvin, Paul ..............90, 15

Menendez, Anthony .................213

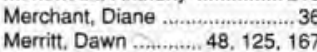

Merritt. Dawn ............ 48, 125, 167

Messer, Jason ..........................5

Meyer, Jennette ..........................59

Meyer, Julie ................48

Michael, Lynda …............67, 113

Michael, Scott ...

Milentis, Gregory

Milentis, Kristin

Miley, Sam .

Millen, Mark …………...............7 7

Miller, Aimee _.............59, 126, 138

Miller, Amy ..................................

Miller, Annette ...................67 67

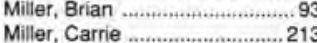

Miller, Carrie

138

Miller, Clint ...................150

Miller, DiAnn ……......59, 93, 153

Miller, Douglas ................38, 40,41

Miller, Elizabeth …..............77, 138

Miller, Elizabeth ...........77, Eric ........ $67,74,78,123$

Miller, Jettrey $59,67,89,117,155$

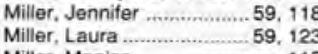

Miller, Monica

Miller, Regina

Miller, Regina

Miller, Rhonda

Miller, Ron ......... Ronald

Miller, Susan

Milligan. William

Mills, Jared

Mills, Robin ........

Milner, Kristin

59,123

Misere, Jonathan ........68, 82, 165 Misirian, Jonathan ..................99 Mitchell, Matthew ….............71, 78 Mitchell, Micah ..............141, 213 Moffett, Susan _._.........59, 123 Mohn, Bethann .. 48, 74, 128, 167 ,

Moles, Dennis ...................59, 120 Monroe, Beverly Montgomery, W

$186,194,213$

Moodie, Cynthia ..............59

Moon, Elizabeth .........59, 116, 165

Moor, Holly

98.213

Moore, David ..............98, 117, 179

Moore, Deidre …..............118, 224

Moore, Douglas . 33, 48, 122, 172 .

177, 179

Moore, MaryAnn .......................213

Moraes, Simone .........................71 71

Moraes, Vivian _...................213

Morales, Michael ........................ 59
Moreland, Kurt

Moreland, Kurt _.............. 36,86
Morgan, Jeffrey

Morgan, Kristine …................68, 74

Morris, Dee .

Morse, Hope .

Mosby, Jennifer

158
68

Mosby, Jenny

Moseley, Sarah .........59, 133, 165

Mosley, Jr., Donald ,..................., 68 Most, Aaron ......................59, 123

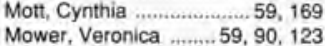
Mower, Veronica ........59, 90, 123 Mulanax, Tina ...................68, 93

16,214
$1 . .119$
.132

Mullins, Andrea ................. B2

Mullins, David 48, 81, 89, 129, 179

Mullins, Ondrea …............118, 224

Mumney, Julie ............................ 214

Munk, James .....................214

Murachanian, Kevin ........165, 214

Murdoch, Murray …........... 38, 157
Murphy, James …...........68, 142

Murphy, Jay ................................. 127
Murphy, Jim ................... 87

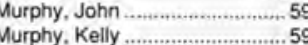

Myers, David

Myers, Jennifer

142,214

Myers, Lora

Myles, Melind

\section{$\mathrm{N}$}

Nader, Fred ........................ 48 Naess, Brian .............48, 119, 122

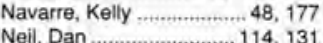

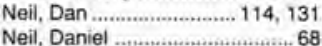
(2) 126
48.119 Nelles, Daniel ......................48, 119 Nelson، Brian Nelson, Karen .................59, 124
Nelson, Michelle ......74, 118, 214 Nettleingham, Angela ........48,90 Nettleingham, Brian .98, 173, 186 . 214

Neudeck, Jennifer ............. 68, 113 Neufeld, Michael ................48, 167 Newcomb, Aaron $14,68,172,177$
Newkirk, Charity ...... 48, 115, 166 Newton, Lorraine ................68, 8 Nichols, Kenneth .........60, 99, 133 Nicholson, Tanya
Nickel, Christopher Nickel, Christopher ….........60, 141
Nicklas, Timothy …........48, 117 Nicodemus, Andrea .....................48 48 Niemotka, Kara ...

Nnoromele, Patrick .......................36 Noble, Cathy …..................48, 90 Noller, Kendal ..................... 48 Noneman, Kristin .............. 48, 122
Nordaas, Kristi .................60, 119

$\mathrm{O}$

O'Brien, Eric O

O'Keefe, Kayley

O'Keefe, Patrick

, 77,214

ONeal, Christine _....... 93, 214

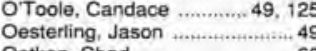

Oetken, Chad ………..............60

Oligee, Stacy .................. 186, 214

Oliver, Matthew ... 33, 81, 97, 130

$189,214,227$

Olsen, Marsha $, 74,101,123,214$

Olson, Christy

Olson, Lisa

Orcutt, Monty

Orme, Betty
Orme, Matthew

Ormsbee, David

Orser, William.

Osuch, Dean

Otto, Mark

Otto, Matthias

Overcash. Rebeka

vermoyer, Julie

Owens, Amy

\section{$\mathrm{P}$}

Padgett, Steven

...... 190,214

Pagnard, Charles .1.. 37

Palmer, Bradley .........68, 85, 113

Palmer, Thomas ........................60 60

Pangburn, Dawn ................... 86, 119

Pantana, Krista ...........68, 93, 127

Pappar, Zakk ..................... 116

Parliament, Kevin .....89, 113, 214

Parlin, Katrina ....................77.81

Parlin, Mary ……..................215

Parrow, Chad ....................68, 85

Parsell, Ali ..................60, 113
Parsons, Elizabeth

Pasquale, Michael 60, 89, 99, 133

Passineau, Michael ..........60, 117

Patonyak, Melissa .......... 60, 149

Patterson, Rory ……...................6

Patterson, Stephen .................... 49

Paul, Angela

Payne, Janet ....

Pearson, Jennifer

Pearson, Kevin

Peart, Bob

Peart, Robert

Peck, Michael

Peet, Terri...

Pelton, Ryan ........

Perdue, Cariene

Pereira, John
Perkey, Amy

Perkey, Amy ………..............215

Perkins, Deborah ..68, 86, 90, 129

Perkins, Marla .....49, 74, 77, 131

Perry, Heather ....60, 93, 158, 240

Perry, Michelle

Persons, Chadwick

Persons, Penny....$+\ldots . .+\ldots . . .+60$

Petek. Greg ......................123, 215

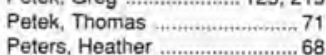

Peters, Heather ......................6 68
Peterson, Amy ......... 60, 115, 166

Peterson, Doralee ......68, 82, 165

Peterson, Kyle

Peura, Sandra

Plahler, David .......................49

Pthaler, Ruth

Phelps, Aimee $\ldots \ldots \ldots \ldots . . .19$
Phillips, Cheryl ........... 68, 98,173

Phillips, Edmond …………...40, 41

Phillips, Eric ................68, 117

Phillips, Marianne

Phipps, James

Phipps, Lori .

Pickell, Beth

Pickens, Jonathan _............ 40,118

Plerce, Alex.

Pierce, Doug...

Pierce, Stewart ..................... 68

Pincket, Chris ..........69, 123, 239

Pinkerton, Cheryl ................187, 215

Piovesan, Nathan ....49, 119, 125 . 127

Piper, haron ............61, 86, 123
Pletcher, Kimberly _..........49, 125 Pletcher, Kimberly _...........49, 125
Pletcher, Rosemary ....... 130, 216 Pletcher, Rosemary ........ 130, 216
Plikerd, Stephanie .............. 49

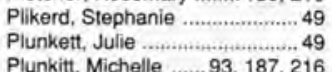
Plunkitt, Michelle ......93, 187, 216 Plush, Jonathan ........................ 69 Poiesz, Mildred ......................69, 129 Polish, Monica ………….....93, 216 Pontius, Bob …..................78, 716 Pontius, Bob .............................. 61 Pool, Tamara .

Pope, Melissa

Popp, Brett .....

Popp, Pamela ……........................ 61 Porter, Erica .............49, 123, 155 Porter, Jennifer …..............61, 61 81
Porter, John

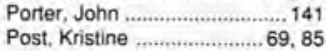
Potter, Jaimee ...61, 82, 119, 123 , 165 Potts, Janet _............. 49, 125, 166
Potts, Matthew ............... 187, 216 ..... 187,216 Powell, Kirk.

Powers, Laura

187,216
.$+\ldots 9$

Powley, Amy

Powley, John

..49, 125

Prall, Michae

Pratt. Sandy

216
$. \ldots . . .19,123$

Prentis, Tara _.........61, 118

Preston, David ............61, 78, 116
Printz, Todd

Printz, Todd
Pritchard, Krista 93, 140, 155, 216

Prosser, Chad …................49, 98

Proudfoot, Denise an............. 49, 149

Prusinowski. Maureen

.- .69
.. .61
61

Purciful, Aaron

Purple, Donna

Purple, Jon

32. 61

Pursell, Hera

\section{Q}

Qualls, Scott

Quinn, Matthew
Quinn, Tracy $\ldots . . .14,90,174,216$

Quint, Cynthia ............................. 49

\section{R}

Radcliff, Dale 
Snyder, Holly ........51, 82, 95, 127

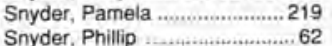
Somenille, Cherith ....62, 77, 120 167

Sorensen, Eric $\quad 93,219$ Sorg, Elizabeth ..................62, 74

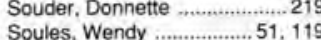
Soules, Wendy ….............51, 119 Southwell, Christina .............69, 85 Southwell, Randy .. 130, 137, 187 . 219

Southworth, Michelle ……..51,7 Souza, Shelly ………....... 85, 219 Spencer, Brian .......51, 82, 95, 13 Spencer, Dorothy ……un... 41 Spencer, Edward 37 Spieth, Jeremy ...62, 81, 123, 165 , 183

Sprankle, Brenda ......69, 123, 149 Sroute, Julle 153 Stacey, Bob ….......................... 119 Stach, Todd …...................69, 95 Stafford, Julie …..............51, 125 Stairs, Jennifer …..................51 Stanton, Kendra Stanton, Kristen ...........................51 Staples, Jennifer ...........................62 62 Staples, Joanna .............................. 220

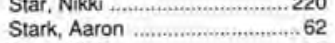
Starr, Nikki ....................................77 Stautfer, James 41 Stauffer, James ................... 62,165 Steininger, Gretchen ...................70 Stephen, Loretta ............. 62, 179
Stephenson, Martin Stephenson, Martin ….......74, 220 Stern, Suzanne Stevens, Jason _...............51, 74 Stevenson, Virginia ...........93, 220 Stewart, Andrew ..............62, 137 Stickley, Gary …................70, 125 Stickley, Gary ....................70, 70,149 Stitzel, Kimberly ............................. 62 Stockham, Matthew ............ 95, 179 Stockham, Matthew ............ 95, 122 Sioll, William

Stone, Deana ...............................71 Stone, Stephen …...................... 70 Stone, William ........................ 51 Stonehouse, Hans …r............ 220 Stover, Ryan ........................137, 220 Strayer, Shanda ….........77, 220 Streetman, Paul .................. 51 Streicker, Kathleen .....62, 77, 118
Streit, Sandra Streit, Sandra
Strobl, Aandall

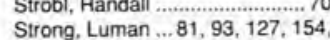
Strong, L
195,220 Strong, Lynette ........................ 51 Strong, Tamara ….................... 51
Stull, Katherine............. .78 Stumbo, Jr., Gary …................. 220 Sturrock, Rebecca .............70, 117 Stutes, Christin , th......................62 Stutes, Patty ……………….... 41 Stutzman, Yvonne ............62, 121
Suko, Rebecca ..............51, 82 Suko, Rebecca ................ 51, 82
Sutherland, Robert ................. 70 Sutherland, Robert ......................
Sutter. Cindy

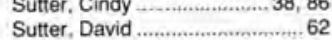
Sutter, David ..............................62 Sutton, Shelley ............. 95 Sutton, Shelly …............. 82, 220 Swackhamer, Tracy _....... 70, 129 Swanson, Kevin …...............51, 78 Swanson, Sharon ……............... 70 Swartzentruber, Rita .............70, 86 Sweetland, Mary ...............
Swigart, James ...62, 78, 119, 121
Swinerton, Becky .......................77 Swinerton, Becky .................... 220

\section{T}

Tait. Elizabeth ..........................220 Tang, Then

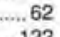
Tang. Tom $\ldots . . . \ldots \ldots \ldots . . . . . .122$ Tapp, Amy.

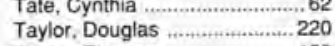
Taylor, Douglas …................... 158

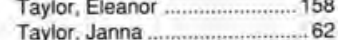
Taylor, Janna ...........................62 Taylor, Jason ....................51, 141
Taylor, Kelly ........................... 220 Taylor, Kelly _.............................. $\begin{array}{lr}\text { Taylor. Sara } & 70,118 \\ \text { Taylor, Tania } & 184,220\end{array}$ Taylor, Tania ................. 184, 220 Taylor. Virginia ….................. 131 Terkelsen, Sandra ............................ Terkelsen, Susan .................41
Terpstra, Jon ........ 70, 114, 167 Terrill, Sheri ..............................62
Terry, Chris _...............62, 120 Tew, Jennifer ................................ 5 Tharp, Catherine …...................62 Thigpen, David $\ldots \ldots \ldots \ldots . .62,9$
Thomas, Christy …..........70,118 Thomas, Joel ……................... 220 Thomas, Robert .......... 85, 93, 220 Thompson, Jason …..........51, 74 Thompson, Jason $\quad . \quad 51,74$
Thompson, Jill Thompson, Tyler …..................... 70 Thomson، Jacqueline ......62, 116 Thorsen, Charles ....106, 107. 221 Thorsen, Kristine 62, 82, 118, 165 Threlfall, Christine

Thunder, Veronica ......................5 Timmer, Christine ........51, 74,119 Titus, Sheryn …......... 85, 145, 221 Tolosa, April Tonelli, Robert ......................70, 85 Totten. Mark ….............98, 17 Tramel, Mary _................... 221 Traucht, Andra .... 9...........70, 86 Trimble, Titfany ......................62 62 Triplett, Paula $\quad \ldots . . . .62,158$

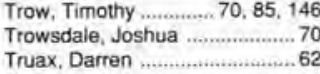
Tschanz, Gina _..................221 Tuinstra, Timothy ..........52, 74,78 Turner, Cooley Tweedy. Cynthia $\ldots . . . .52,124$ Tweedy, Cynthia $\ldots . . . . .52,124$
Tyson, Jennifer ...............115, 224

\section{U}

Uhl, Denise ……...............86. 22 Ulery, Adam …....70, 74, 78, 122 Usita, Lemuel …….......... 62, 115
Utz, Mark

\section{V}

Valentine, Stephen : 128 VandeGuchte, Timothy ....89, 187 221

Vandenberg, Timothy ..... 173, 221 Vanderbilt, Jenniter ........128, 167
Vanderwest, Kenneth $81,99,106$, $107,187,221,227$

VanDeusen, Ryan _..... 150 VanDuesan, Ryan …………...151 15 VanDyke, Kristi ....70, 86, 98, 132 , 133

VanEaton, Justín ............95, 167 Vannest, Stephen ..................221
VanSteenbergh, Mindy .....52, 122 VanTil, Holly

Varner, Amy ….....................52 Varotti, Marcus …......52, 157, 191 Vaughn, Kevin ….....62, 81, 117 Veelman, William,

Vine, Allan

. Vitarelli, Chad ....89, 99, 113, 166 ,

Volante, Judy
Vrbanac, Michael _........... 117,221 Vrbanac, Michael ..........117, 221
Vroegop, Mark . 86, 187, 221, 226

\section{W}

Waddell, Sandra .......90, 116, 221 Wagenaar, Tara .......63, 129, 165 Wahlen, Steve .......................119 119
Wainwright, Kathleen $\ldots . . . .52,120$ Wainwright, Kathleen …...52, 120
Walborn, Josette ...................... 70 Walborn, Josette …..................... 70
Walker, Amy

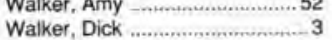
Walker, Dick ............. 3
Walker, Julie ... 13, 70, 78, 98, 126 Walker, Kristi $\quad 63$ Walker, Ronald ........................ 36 Walker, Tricia ……….... 52 Wallace, Heather

Wallenbeck, Kevin ........................63 Waller, Lisa

Wallis, Joel ……............. 63 Walsh, Elizabeth …..................70
Walter, Lynn _. Walter, Lynn _.......70, 90, 119
Walter, Melanie ..........63, 78, 118 Walter, Melanie ..........63, 63,118
Walters, Wendy Waltz, Brandon

Wambold, John ...................63, 12 Wandell, Brenda ….......... 119, 131 Ward, Erin
Ward, Kara
Ward, Moly Ward, Molly …....70, 78, 121, 173 Warnken, Karla ............... 123, 22 Warnken, Sarah …......................5 Warnshuis, James ............63, 165
Warnshuis, John .... 106, 107, 165. 222 Warren, David ... 29, 36, 165, 187 , 222 Warriner, Jennifer ..............52, 120

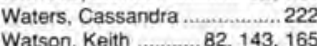
Wawro, Erin ...............63, 121, 165 Weaver, Bradley ….... $63,121,162$ Weaver, Doris ........................ 222
Weaver, Erin ............. 19, 63, 172 Weaver, Erin .............. 19, 63, 172

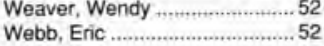
Webb, Eric ................................. 52

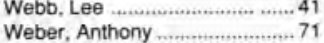
Weber, Zy ..............................222 Weigle, David ……..............222 Weise, Ann .....................63, 119 Weiss, Jamie ….............52, 166
Weiss, Malia
70,130 Wenger, Ruth ......................63,90 Wenger. Shannon ..............70, 153 Wenzel, Leslie ...................52, 123 Wenzel, Lesile …...............52. 123 Wert, Sonja .................................52

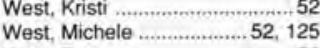

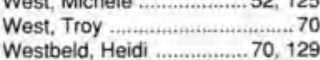
Westbeld, Heidi …............70, 129 Wetzel, Daniel ............................ 38
Wetzel, Phyllis ...................... 41 Weyand, Wendy ....................70, 77 Weyhe, Jill .........70,93

Wheeler, Bert

Whisman, David

.... 36

White, Angela ........... 89, 173, 222

White, Laurel ........................ 70,77

White, Shawn ............. 17, 74, 222

Whited Amber .................... 222

Whitehead, Amy …….....52, 165

Whitmer, Amanda ...............52, 169
Whitmer, Molly

Whitmer, Molly $\ldots \ldots \ldots . .165,222$
Whitmore, Jamie …........145, 169

Whitmore, John ….................... 38

Whitney, Beth ……........52, 52

Whittaker, Keila …............ 63, 81, 121

Whitten, Scolt ....

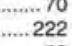

Wiedemann, Jody _.................63

Wiersma, Todd …….................... 154

Wiggins, Robert ..................... 38,85
Wikstrom, Steven .................. 52

Wikstrom, Steven

Wilcox, Lisa
Wilcox, Ray

Wilcox, Rry ............................ R1

Wildasin, Stephen …...........63, 74, 126

Wiley, Cheri ............................. 52
Wiltert, Jennifer 130

.... 145

Wilhelm, Butch .....t.

Wilkerson, Michael ..... 70, 81, 142

Wilkes, Lisa ………............ 70

Wilkinson, Stacey ….......................63

Willent, Charles ........................... 63

Willett, Chuck …......................... 128

Williams, Corinna
Williams, Joy

Williams, Joy ...................41, 149
Williams, Julie ......52, 70, 81, 122

Williams, Julie,......52, $70,81,122$
Williams, Kristen …….63, 121

Williams, Phonda ...................... 52

Williams, Tim _....... 98

Willisienson, Jenn

..... 63

Wilson, Adam …...............63, 117

Wilson, Carrie ….....................63

Wilson. Christopher $\quad 21,63,117$
Wilson, David ............70, 166, 167

Wilson, Janit ...

Wilson, Michael
Wilson, Shannon

Wilson, Shannon .........................5

Wilson, Stephanie $63,120,167$

Wilson, Jr., Michael .............. 70
Witt, Kenneth ....................

Winch, Connie 129, 133, 167, 222 Winchip, Stephanie .78, 123, 166 222

Wine, Rebecca ... 52, 120

Wingate, Tina .........................70 Wingert, Chad ... 63, 93, 124, 133 165

Wingert, Kelly ........................ 223 Winn, Lisa ...............................
Winn, Robert Winn, Robert ................. 187, 223
Winship, Jill Winship, Jill .............................223 Winter, Mary …......................... 223 Winters, Jena
Winters, Jenniter ...........................63 Wintle, Stephen …........70, 82, 165 Wireman, Matt ……… 146
Wires, Stacey Wires, Stacey ……...........52, 129 Witt, Amy
Witters, Ryan ............................... 52,78 Wittkamper, Tammy .........70, 10 Wolt, John

Wolfanger, Paige _....63, 86 Wolfanger, Paige …t.........74, 718 Wolters, Heidi ...........52, 74, 120 Womack, Glenda ...........................4 41
Womack, Mark …..................... 41 Womack, Mark ......................41 41

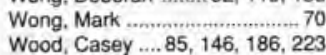

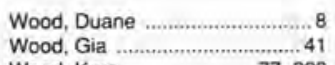
Wood, Kara r.77, 223 


\section{Following the example}

ENJOYING THE SUNNY

DAY, these students look

forward to the Day of

Prayer.

AT THE ELECTION

PARTY Lauren Fields

watches the screen for the

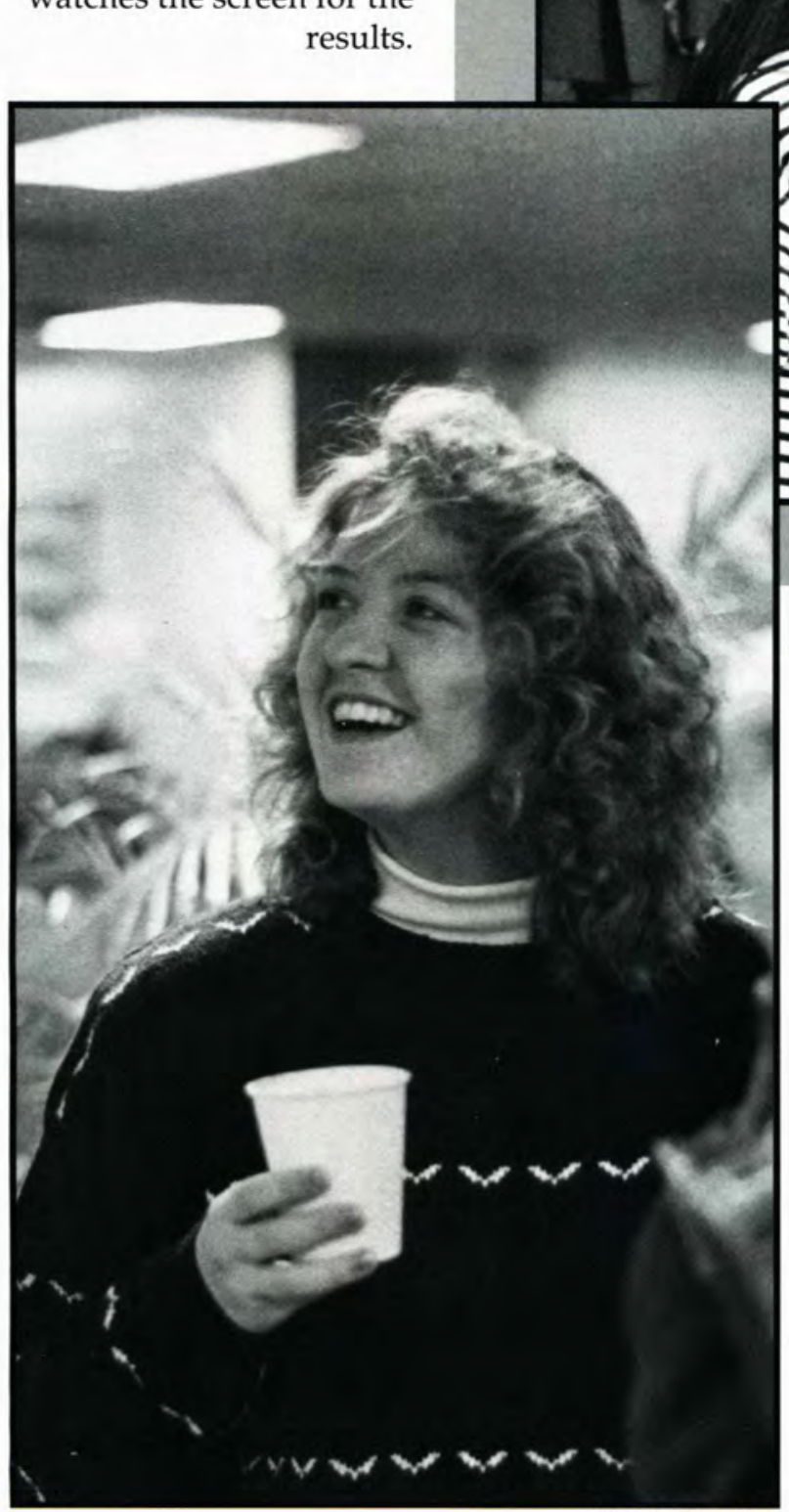

Photo by Steve Cook

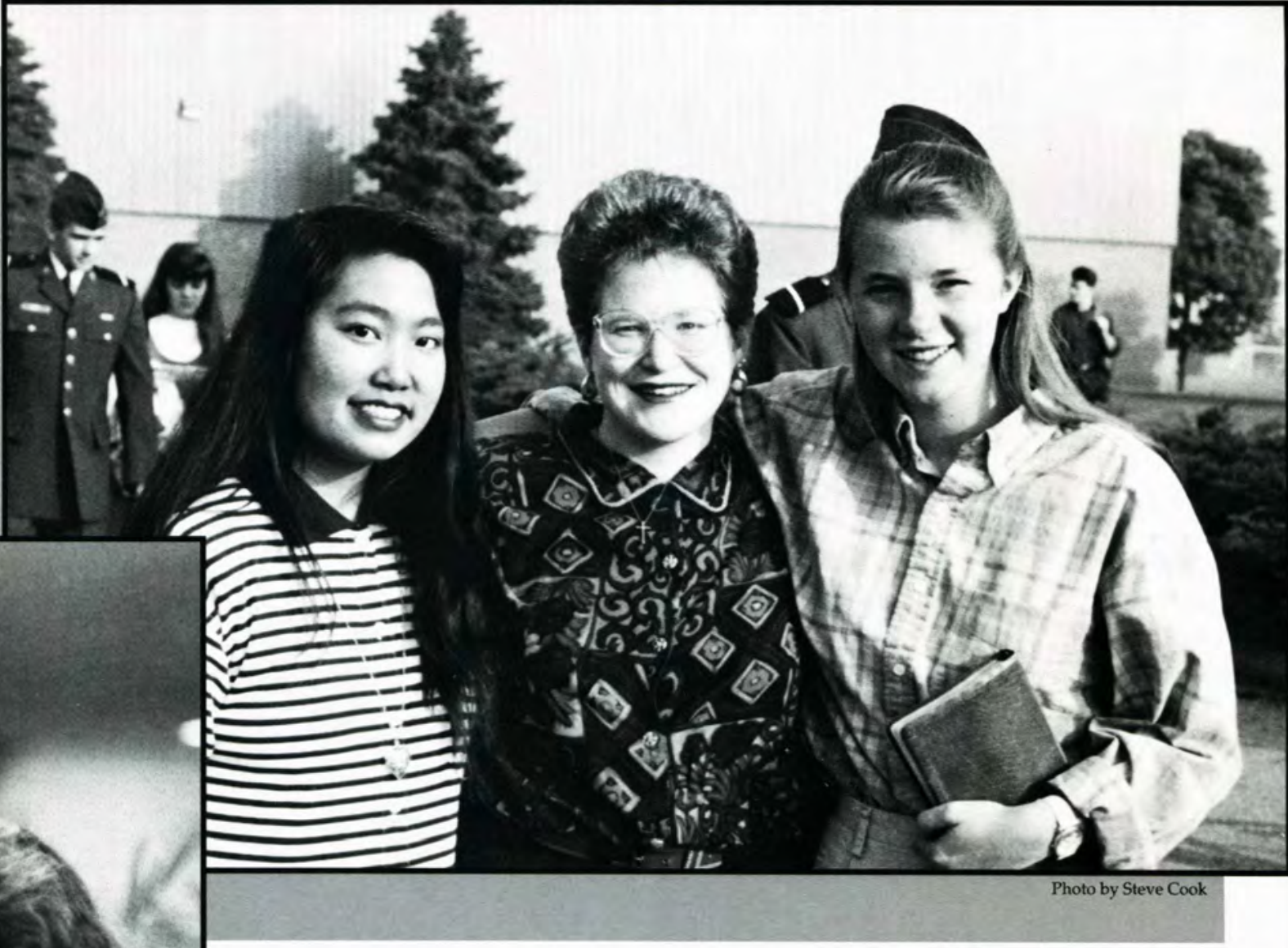

of our Lord...

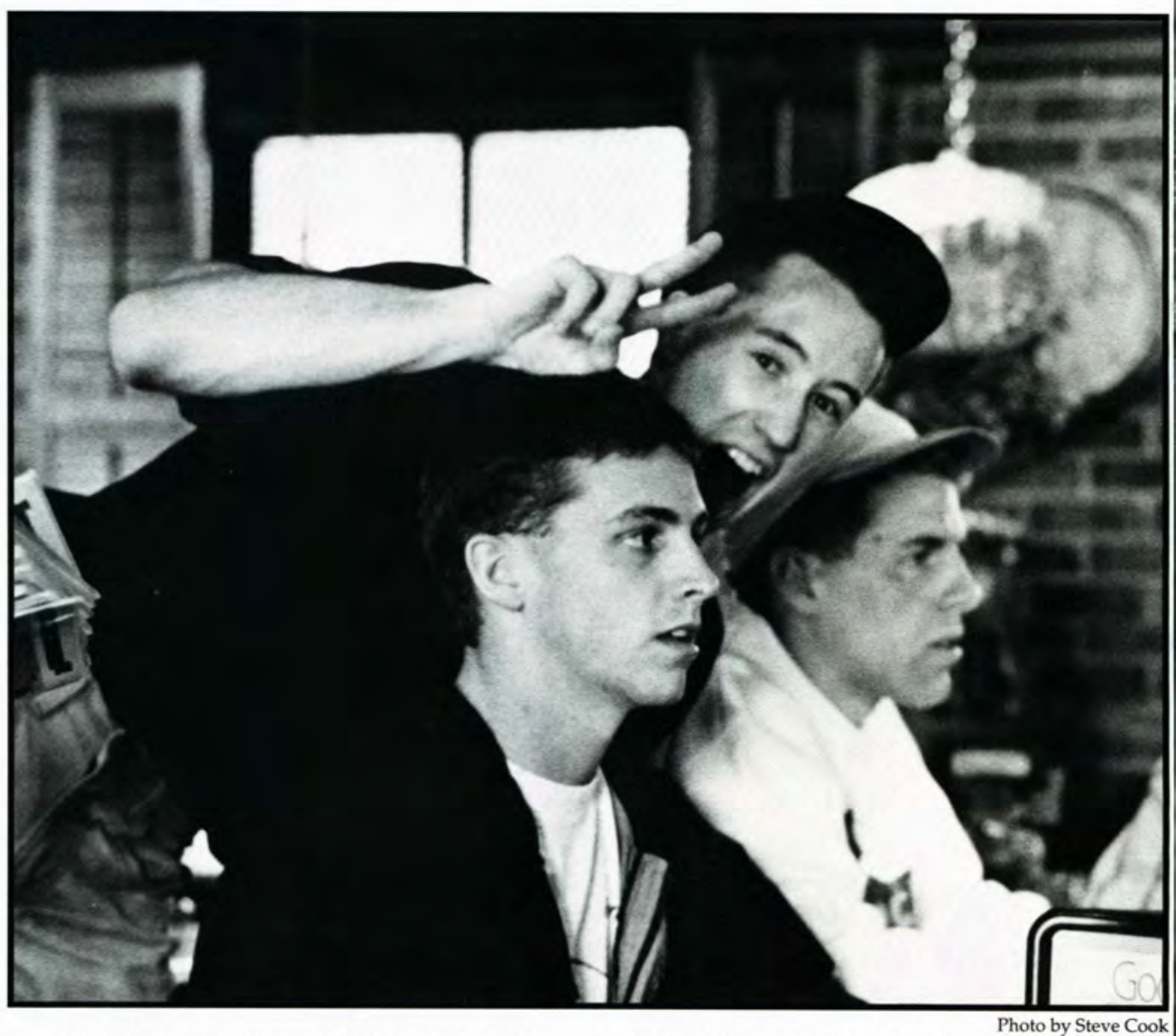

YOU ONLY WANT TWO PIZZAS? CAN'T YOU EAT MORE THAN THAT? 


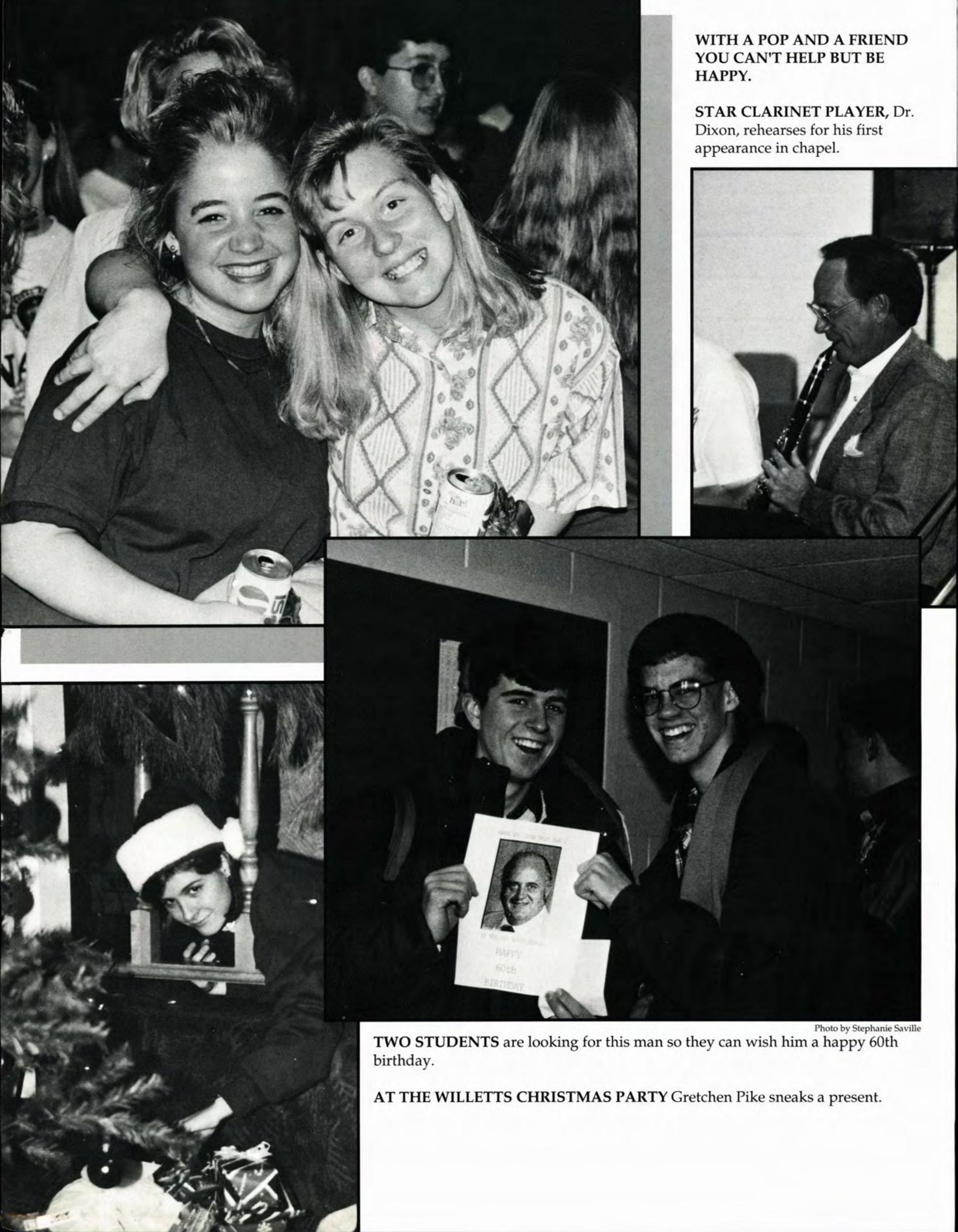



